UNIVERSIDADE DE SÃO PAULO

FACULDADE DE ECONOMIA, ADMINISTRAÇÃO E CONTABILIDADE DEPARTAMENTO DE ADMINISTRAÇÃO PROGRAMA DE PÓS-GRADUAÇÃO EM ADMINISTRAÇÃo

PROSPECÇÃO DO FUTURO NAS EMPRESAS: UMA PROPOSTA DE MODELO PARA INTEGRAÇÃO ENTRE O ESTUDO DO FUTURO E A ESTRATÉGIA EMPRESARIAL

Nelson Daishiro Yoshida

Orientador: Prof. Dr. James Terence Coulter Wright

SÃO PAULO

2016 
Prof. Dr. Marco Antonio Zago

Reitor da Universidade de São Paulo

Prof. Dr. Adalberto Américo Fischmann

Diretor da Faculdade de Economia, Administração e Contabilidade

Prof. Dr. Roberto Sbragia

Chefe do Departamento de Administração

Prof. Dr. Moacir de Miranda Oliveira Junior

Coordenador do Programa de Pós-Graduação em Administração 
NELSON DAISHIRO YOSHIDA

\title{
PROSPECÇÃO DO FUTURO NAS EMPRESAS: UMA PROPOSTA DE MODELO \\ PARA INTEGRAÇÃO ENTRE O ESTUDO DO FUTURO E A ESTRATÉGIA EMPRESARIAL
}

\begin{abstract}
Tese apresentada ao Programa de PósGraduação em Administração do Departamento de Administração da Faculdade de Economia, Administração e Contabilidade da Universidade de São Paulo, como requisito parcial para a obtenção do título de Doutor em Ciências.
\end{abstract}

Orientador: Prof. Dr. James Terence Coulter Wright

\section{VERSÃO CORRIGIDA}

(versão original disponível na Faculdade de Economia, Administração e Contabilidade)

\section{São Paulo}


FICHA CATALOGRÁFICA

Elaborada pela Seção de Processamento Técnico do SBD/FEA/USP

Yoshida, Nelson Daishiro

Prospecção do futuro nas empresas: uma proposta de modelo para integração entre o estudo do futuro e a estratégia empresarial / Nelson Daishiro Yoshida. - São Paulo, 2016.

$300 \mathrm{p}$.

Tese (Doutorado) - Universidade de São Paulo, 2016.

Orientador: James Terence Coulter Wright.

1. Administração executiva 2. Estratégia organizacional 3. Estudos do futuro 4. Tomada de decisão I. Universidade de São Paulo. Faculdade de Economia, Administração e Contabilidade. II. Título. 
A todos que se dedicam à formação e ao exercício da integridade. 


\section{AGRADECIMENTOS}

Agradeço ao meu orientador Prof. Dr. James Terence Coulter Wright pelo estímulo e incentivo ao tema da pesquisa, pela experiência e conhecimento compartilhados e especialmente pelas reflexões que muito contribuíram para o desenvolvimento desta tese. Obrigado pela sabedoria em direcionar meu interesse acadêmico e pela disposição em orientar-me ao longo do projeto.

Aos professores Drs. Martinho Isnard Ribeiro de Almeida e Renata Giovinazzo Spers, pelas relevantes contribuições recebidas por ocasião do exame de qualificação.

Aos professores Drs. Adalberto Américo Fischmann, Silvio Aparecido dos Santos, Geraldo Luciano Toledo, Paulo Roberto Feldman, Roy Martelanc, Adriana Backx Noronha Viana, Maria Aparecida Gouvea, Washington Franco Mathias, Daniel Estima de Carvalho, Leandro José Morilhas, Carlos Honorato Teixeira, Rodolfo Olivo, Luis Fernando Ascenção Guedes e Márcio Shoiti Kuniyoshi pelas contribuições e reflexões sobre o processo de pesquisa e pela troca de experiências durante o curso.

À equipe de Coordenação do Programa de Estudos do Futuro (PROFUTURO) da Fundação Instituto de Administração (FIA) pelo apoio na fase de coleta de dados.

À Reni Berezin, pelo apoio na condução e revisão das análises estatísticas.

Aos participantes respondentes da survey, e também aos das entrevistas, que gentilmente doaram seu tempo e experiência para contribuir com o desenvolvimento desta tese.

Aos professores, colegas de curso e amigos que, durante o período de desenvolvimento desta tese, atuaram no papel fundamental de me fazer enxergar claramente como as pesquisas geram valor, como elas são desenvolvidas por meio da coletividade de pesquisadores e, finalmente, como elas expandem as fronteiras do conhecimento pela dedicação, rigor e método.

Finalmente, um agradecimento profundo à minha família, que além do incentivo e do apoio para que eu pudesse trilhar a jornada da pesquisa, compreende de forma inequívoca o valor da busca pelo aprimoramento.

A todos, muito obrigado! Sem eles, estas palavras jamais estariam sendo escritas, e elas representam um valor imensurável. 
“...se não há uma direção para o futuro, então o presente é vazio em significado".

Michel Godet 


\section{RESUMO}

Esta tese buscou estudar a integração entre a prospecção do futuro e projetos dentro do escopo da estratégia. Decisões envolvendo projetos no âmbito da estratégia das organizações são para horizontes de tempo de médio ou longo prazo. Nessa situação, gestores precisam lidar com incertezas de futuro, e para isso podem recorrer às metodologias de prospecção do futuro. $\mathrm{O}$ estudo do futuro é atividade complexa, pela abrangência de temas a serem considerados, contudo, é provável que gestores pratiquem essa atividade devido à responsabilidade assumida por suas decisões. A prática de metodologia prospectiva gera resultados, e estes podem contribuir nas decisões em projetos estratégicos. A literatura de estudos do futuro contém recomendações sobre como praticar metodologia prospectiva, porém aborda menos a utilização dos resultados de estudos prospectivos e a sua contribuição para a estratégia empresarial. Ela se concentra mais nos processos de desenvolvimento dos projetos de prospecção para se chegar aos resultados. Dessa forma, esta tese visou ao estudo da utilização dos resultados da prospecção nas decisões de projetos no âmbito da estratégia empresarial. Os fenômenos estudados envolvem a transição entre a prática da prospecção do futuro, a consequente disponibilidade de seus resultados e a contribuição dos mesmos nos processos de análise prospectiva para suporte a decisões. O objetivo geral da tese é a proposta de um modelo que contribua nessa transição. A metodologia utilizada foi mista - quantitativa e qualitativa - desenvolvida por meio de survey e entrevistas, e a abordagem utilizada foi exploratória e descritiva. Os resultados indicam haver limitações na integração entre prospecção do futuro e estratégia empresarial. Foi identificado que a prospecção do futuro é considerada importante pelos gestores participantes da pesquisa. Em contraste, a transição para a sua prática, passando pela disponibilidade de seus resultados, e a posterior utilização deles em processos de suporte à tomada de decisões em projetos estratégicos, apresenta limitações. Os resultados indicam que, apesar da importância da atividade de prospecção, gestores avaliam que ela é praticada em um nível mais baixo, e ao final a contribuição de seus resultados é avaliada em nível ainda mais baixo. Isso é mais evidente nas empresas de menor quantidade de funcionários, menor faturamento, de capital fechado ou limitado, sendo que nessas empresas a prospecção é para horizonte de tempo mais curto. Já gestores de empresas com maior quantidade de funcionários, maior faturamento e de capital aberto lidam melhor com a prospecção do futuro, sendo que estudam seus projetos estratégicos em horizonte de tempo mais longo. Observou-se que as principais limitações identificadas estão relacionadas com o conhecimento das metodologias de prospecção do futuro, e isso limita principalmente a identificação de temas importantes a serem estudados e monitorados acerca do futuro, configurando-se como lacunas de análise prospectiva ou pontos cegos. Por decorrência disso, a contribuição da prospecção na estratégia empresarial sofre limitações. Conclui-se, portanto, que a integração entre prospecção do futuro e a estratégia empresarial poderia ser facilitada por meio do uso de um modelo de suporte, voltado para: (1) reduzir a possibilidade de lacunas de análise prospectiva; e (2) suportar a avaliação: da prática da prospecção do futuro, do uso dos seus resultados nas decisões, e finalmente da aplicação da expertise sobre prospecção do futuro na empresa. Os resultados confirmam que o modelo proposto contribuiria na integração da prospecção do futuro com a estratégia empresarial. 


\begin{abstract}
This doctoral dissertation aimed to study the integration between futures studies and projects within the scope of strategy. Decision-making in projects related to the strategy of organizations involve medium to long term horizon. In such context, managers have to deal with uncertainties of future, and then they may apply futures studies methodologies. Studying the future is a complex activity, due to the broadness of topics involved; however, it is likely that managers do it because they take responsibility for their decisions. The practice of futures studies methodologies leads to results, and these results may be useful to support decisions in strategic projects. The research literature about futures studies shows recommendations on how to practice prospective methodology, but it barely touches the use of the results of futures studies methodologies and their contribution to strategy. It focuses on the development processes of studying the future through the application of methods. Thus, this doctoral dissertation is aimed to study the use of futures studies results in decisions of projects within the scope of corporate strategy. The phenomena studied involve the transition from the practice of futures studies methods, the consequent availability of results and their contribution in the prospective analysis processes for decision support. The overall objective of the research is the proposal of a model that would help in this transition. The research methodology was through mixed method - quantitative and qualitative - developed through survey and interviews, and the approach was exploratory and descriptive. The results indicate that there are limitations in the integration between futures studies and strategy. It was identified that futures studies are considered very important by the participants of the research. In contrast, the transition to its practice, passing through the availability of its results, and to later use of the results to support processes in decision-making has limitations. The results indicate that despite managers consider important to study the future, they assess the practice of futures studies in their companies at lower level, and the contribution of its results is also assessed at further lower level. This is most evident in companies with small number of employees, low revenues, limited companies, in which the strategic projects are analyzed to shorter time horizon. In contrast, managers of companies with high number of employees, high revenues and publicly traded companies are able to practice futures studies methodologies, and their strategic projects analyses are for longer time horizon. The main constraints identified are related to the knowledge of the methodologies of futures studies, and this is mostly because of the limitation in identifying important issues to be analyzed and monitored about the future, which becomes, then, a gap of prospective analysis or a blind spot in the vision of the future. The consequence is that futures studies methodologies and its contributions for strategy has constraints. Therefore, the integration of futures studies and corporate strategy could benefit from applying a model to support it in two ways: (1) reducing the possibility of blind spots on relevant strategic issues about the future, and (2) supporting the assessment of: the practice of futures studies methods, the use of its results in decision-making and also the futures studies expertise application in the organization. The results confirm that the proposed model would help in the integration of futures studies and corporate strategy.
\end{abstract}




\section{SUMÁRIO}

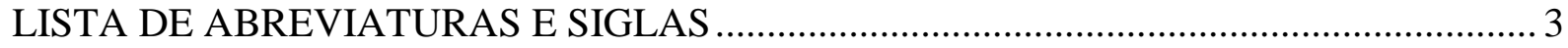

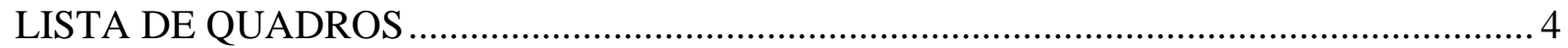

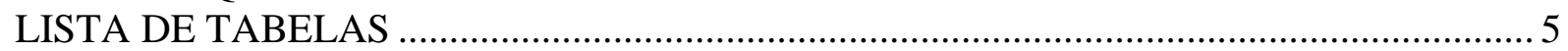

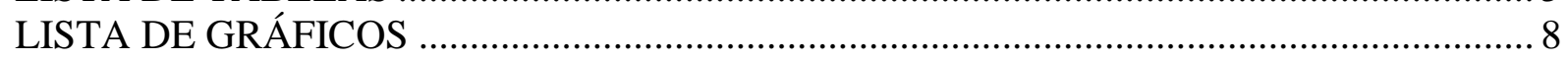

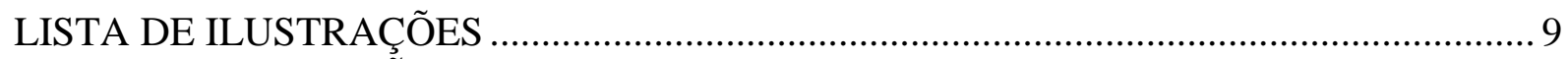

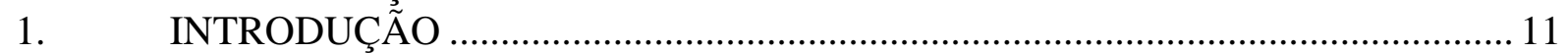

2. O DESAFIO DE INTEGRAR PROSPECÇÃO E ESTRATÉGIA.......................... 15

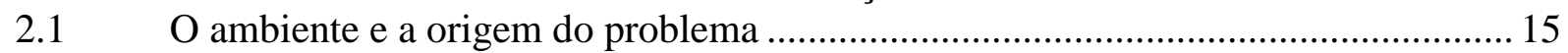

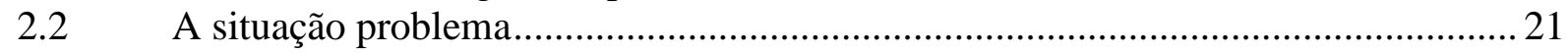

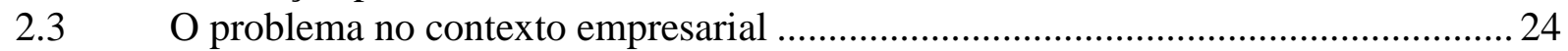

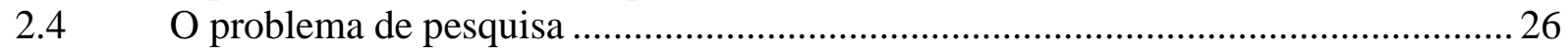

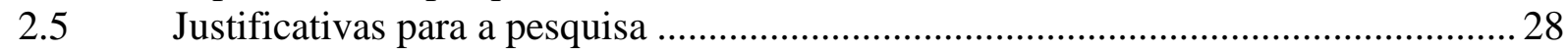

2.6 Questões associadas com a situação problema .......................................................29

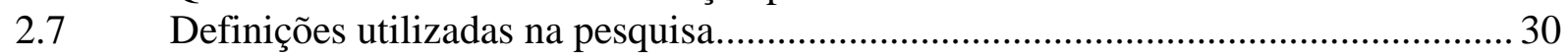

2.7.1 Alguns aspectos de terminologia aplicada na tese ............................................... 33

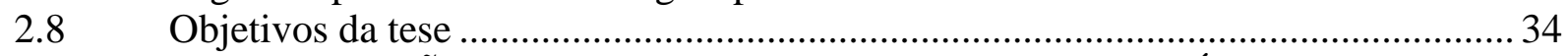

3. A PROSPECÇÃO DO FUTURO E OS PROJETOS ESTRATÉGICOS: UMA

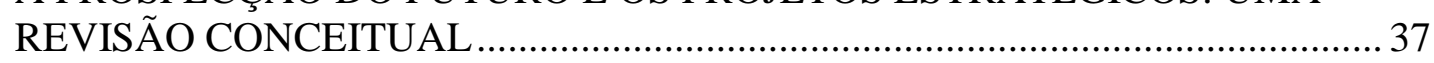

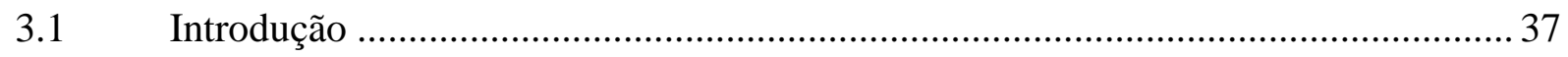

3.2 Prospecção do futuro: Levantamento da produção acadêmica .................................. 38

3.2.1 Produção acadêmica na administração: contendo termos da prospecção .................. 39

3.2.2 Produção acadêmica na administração: foco específico na prospecção do futuro.... 46

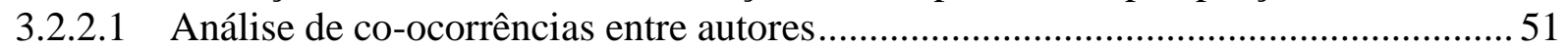

3.2.3 Prospecção do futuro como suporte à pesquisa acadêmica...................................... 63

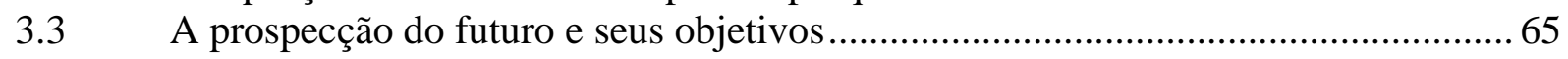

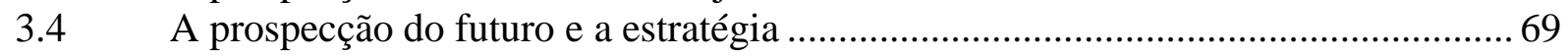

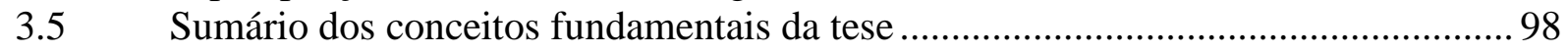

3.6 Fundamentação conceitual para operacionalizar a pesquisa .................................. 100

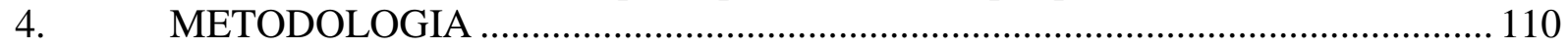

4.1 Escopo da metodologia: Estudo exploratório e descritivo ..................................... 110

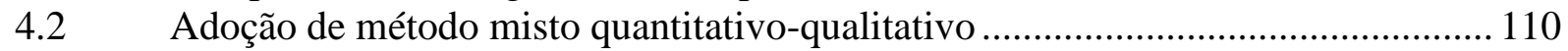

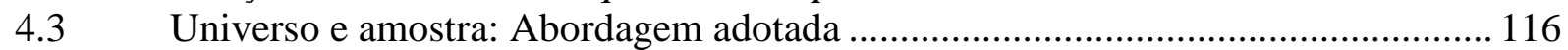

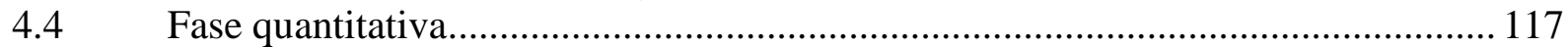

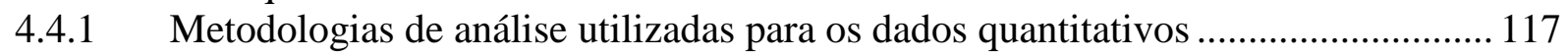

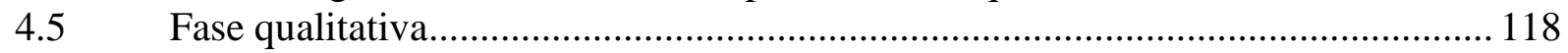

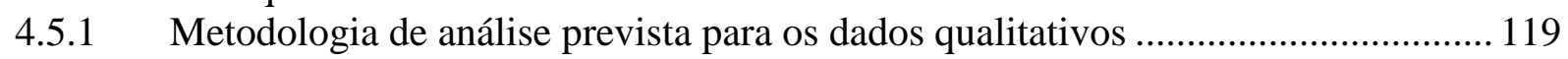

4.6 Modelo Conceitual Teórico da Pesquisa e sua integração com a metodologia ....... 120

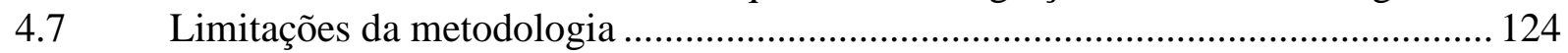

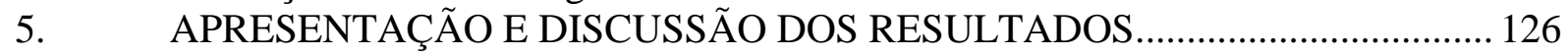

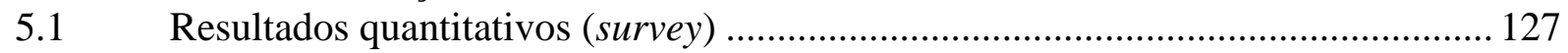

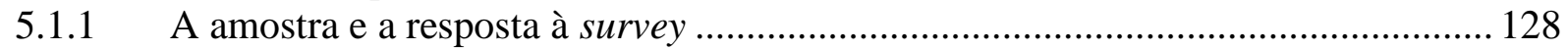

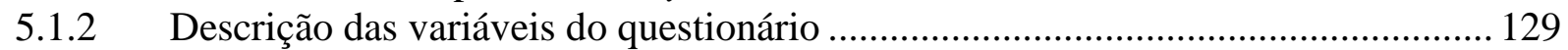

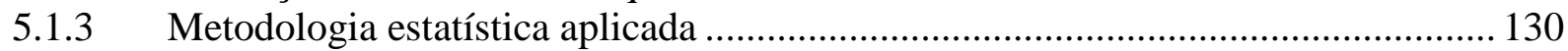

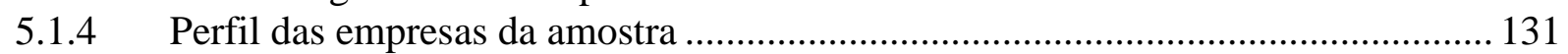

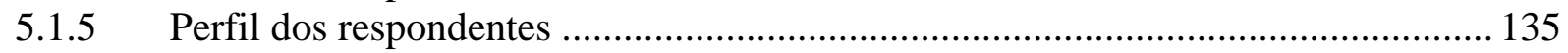

5.1.6 Sobre a prática da prospecção do futuro .............................................................. 139

5.1.7 A Importância, a prática e a contribuição ............................................................. 142

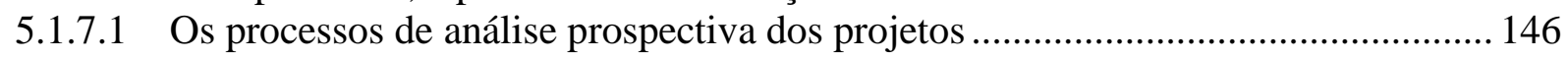

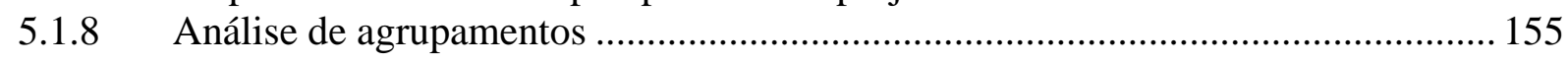




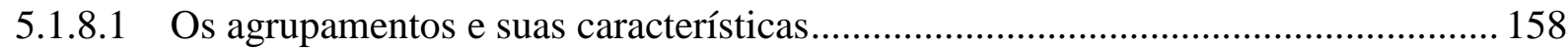

5.1.8.2 Os agrupamentos e a satisfação com a prospecção ............................................. 163

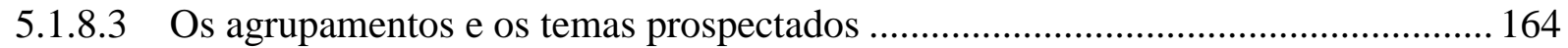

5.1.8.4 Os agrupamentos e processos de análise prospectiva ........................................... 170

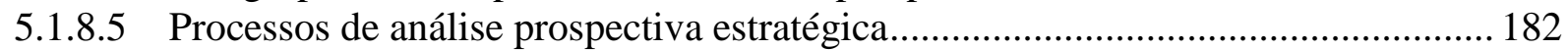

5.1.8.6 Avaliação da atividade de prospecção do futuro................................................... 189

5.1.9 Empresas EXPLORADORAS ESTRUTURADAS e EXPLORADORAS

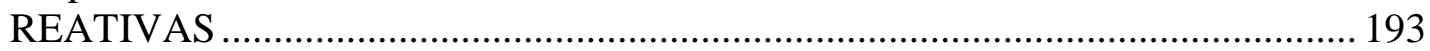

5.1.9.1 Importância e prática da prospecção nos grupos EE e ER ..................................... 195

5.1.9.2 Importância e contribuição da prospecção nos grupos EE e ER .............................. 203

5.1.9.3 Prática e contribuição nos grupos EE e ER para os diferentes temas ..................... 212

5.1.9.4 Prática e contribuição de processos de análise prospectiva nos grupos EE e ER ... 213

5.1.10 Variáveis relevantes que influenciam as diferenças entre os grupos de empresas .215

5.1.11 Abordagem fundamental na análise dos dados quantitativos: A segmentação da

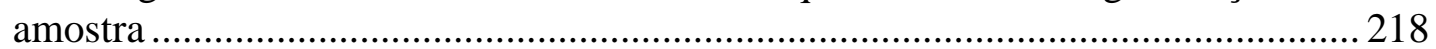

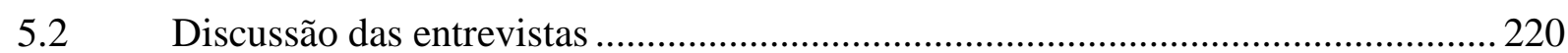

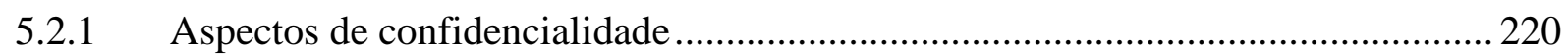

5.2.2 Entrevistas prévias à coleta de dados quantitativa ............................................... 222

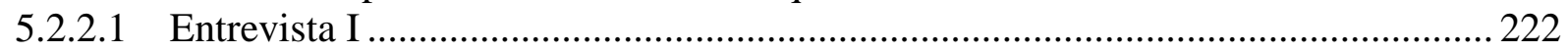

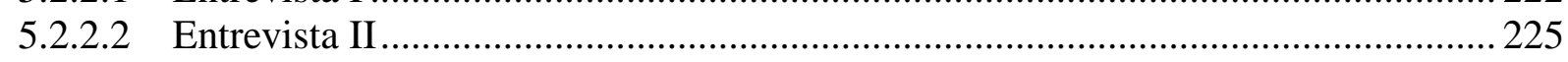

5.2.3 Entrevistas posteriores à coleta de dados quantitativa ......................................... 229

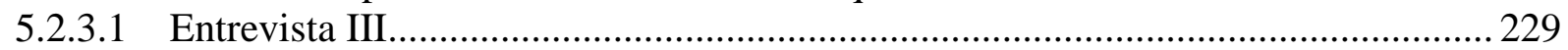

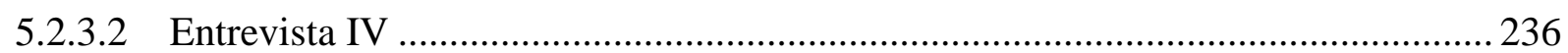

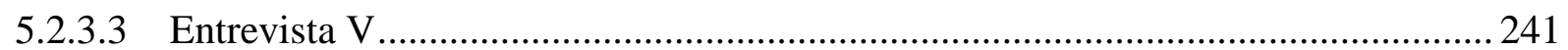

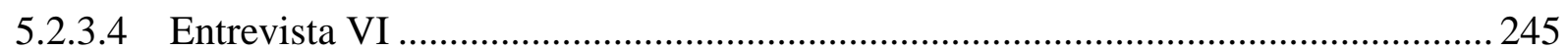

5.2.4 Sumário dos principais temas das entrevistas realizadas ......................................... 248

6. CONCLUSÕES, RECOMENDAÇÕES E COMENTÁRIOS ................................ 250

6.1 Sobre a questão geral que inspirou o problema de pesquisa ................................. 250

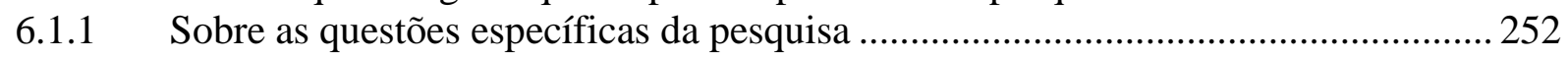

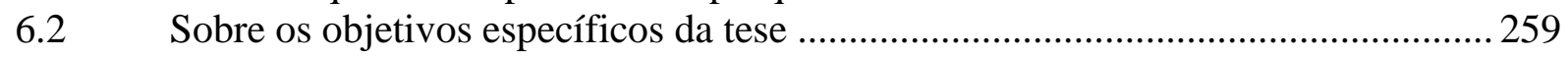

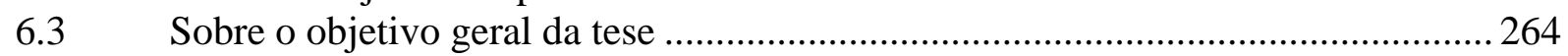

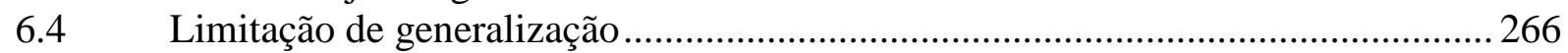

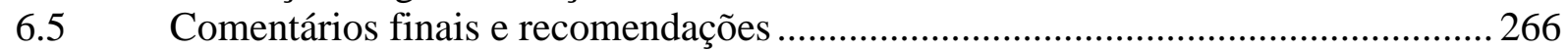

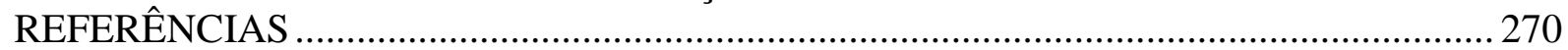

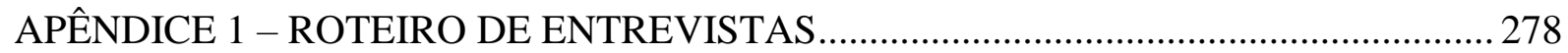

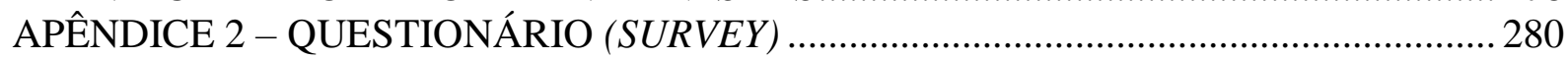




\section{LISTA DE ABREVIATURAS E SIGLAS}

B2B

CHAID

CEO

FEA

FIA

FMM

HCI

HR

ISI

MBA

NDA

OSCIP

PESTEL

PIB

PPGA

PROFUTURO

RIS

SCI

STEEP

TIA

USP

WFS

WFSF
Business to Business

Chi-Squared Automatic Interaction Detection

Chief Executive Officer

Faculdade de Economia, Administração e Contabilidade da USP

Fundação Instituto de Administração

Foresight Maturity Model

Human Computer Interaction

History Research

Institute for Scientific Information

Master in Business Administration

Non Disclosure Agreement

Organização da Sociedade Civil de Interesse Público

Política (P), Economia (E), Sociedade (S), Tecnologia (T), Meio Ambiente (E) e Legal (L) - acrônimo do original em inglês: PESTEL Analysis

Produto Interno Bruto

Programa de Pós-Graduação em Administração

Programa de Estudos do Futuro da Fundação Instituto de Administração

Research Information Systems

Science Citation Index

Social (S), Tecnologia (T), Economia (E), Meio-Ambiente (E), Política (P) acrônimo do original em inglês STEEP Analysis

Trend Impact Analysis

Universidade de São Paulo

World Future Society

World Futures Studies Federation 


\section{LISTA DE QUADROS}

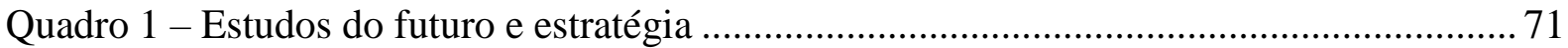

Quadro 2 - Disciplinas do modelo de maturidade ............................................................ 92

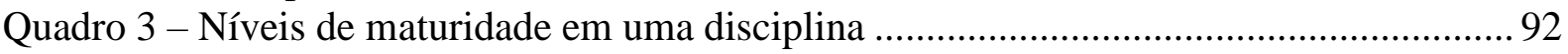

Quadro 4 - Descrição dos níveis de maturidade ................................................................. 94

Quadro 5 - Avaliação da maturidade por disciplina e os objetivos de aprimoramento........... 95

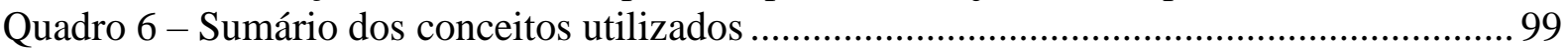

Quadro 7 - Processos de análise prospectiva nos projetos ................................................ 100

Quadro 8 - Contribuição da prospecção na análise prospectiva estratégica ........................... 101

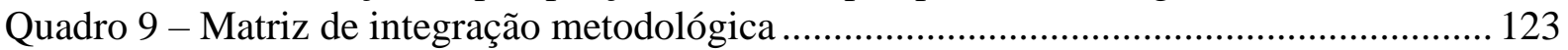

Quadro 10 - Legenda: Processos de análise prospectiva dos projetos .................................. 148

Quadro 11 - Afirmações para avaliar a prospecção......................................................... 153

Quadro 12 - Legenda de temas portadores de incertezas de futuro...................................... 164

Quadro 13 - Legendas de temas portadores de incertezas de futuro .................................... 196

Quadro 14 - Legendas de temas portadores de incertezas de futuro .................................... 203

Quadro 15 - Legendas de processos de análise prospectiva .............................................. 214 


\section{LISTA DE TABELAS}

Tabela 1 - Journals e suas respectivas quantidades de documentos publicados (contendo termos sobre prospecção)

Tabela 2 - Quantidade de documentos publicados por país

Tabela 3 - Journals e suas respectivas quantidades de documentos publicados (sobre prospecção do futuro)

Tabela 4 - Quantidade de documentos por país (os primeiros 30 países) …............................50

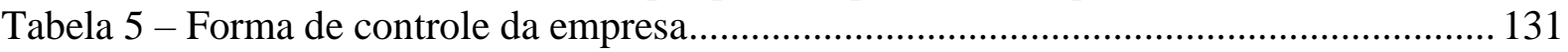

Tabela 6 - Predominância da origem de capital da empresa .............................................. 132

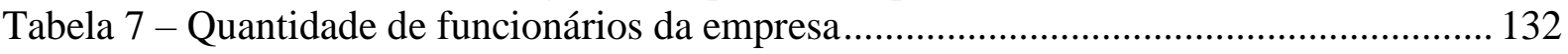

Tabela 8 - Quantidade de funcionários - por porte agregado............................................. 133

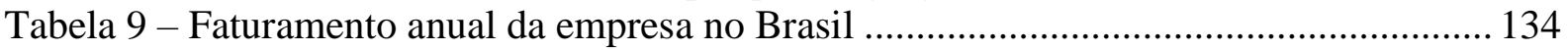

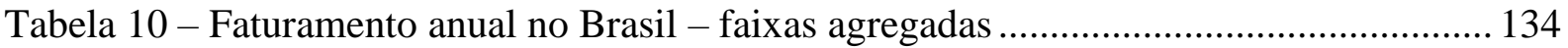

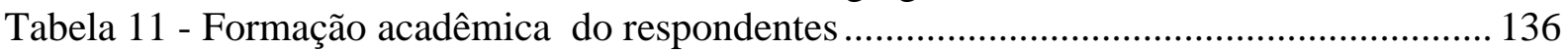

Tabela 12 - Tempo de experiência profissional do respondente ........................................... 137

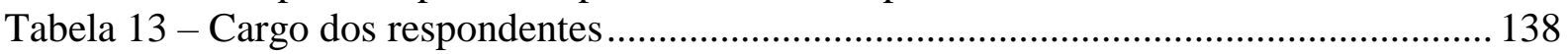

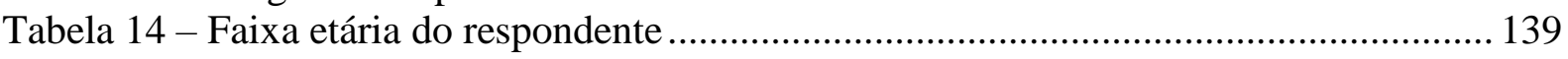

Tabela 15 - Os Temas por ordem decrescente de Importância........................................... 142

Tabela 16 - Os processos de suporte à análise prospectiva ................................................ 147

Tabela 17 - Contribuição da prospecção do futuro nos processos de análise......................... 149

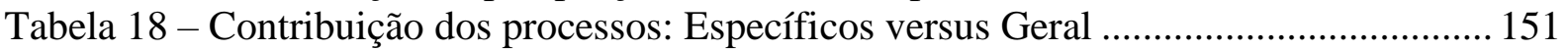

Tabela 19 - Teste de agrupamento de respondentes por duas abordagens ........................... 156

Tabela 20 - Forma de controle da empresa: Nos dois agrupamentos ................................... 158

Tabela 21 - Quantidade de funcionários da empresa: Nos dois agrupamentos ..................... 159

Tabela 22 - Faturamento da empresa: Nos dois agrupamentos ............................................. 160

Tabela 23 - Horizonte de tempo da prospecção no último projeto estratégico: Nos dois

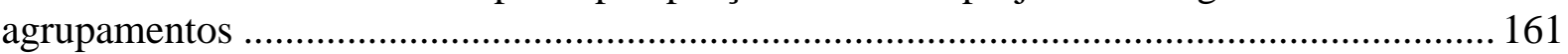

Tabela 24 - Setores de atuação agregados: Nos dois agrupamentos .................................... 162

Tabela 25 - Origem do capital predominante da empresa: Nos dois agrupamentos ............. 162

Tabela 26 - Satisfação com a prospecção: Nos dois agrupamentos .................................... 163

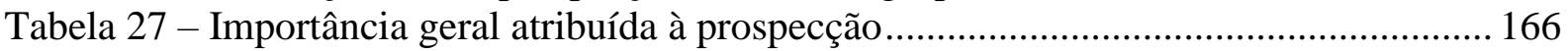

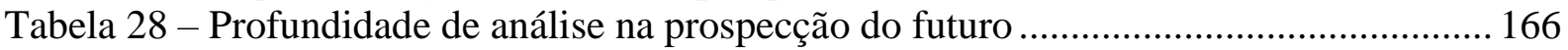

Tabela 29 - Quanto a prospecção contribui na tomada de decisão........................................ 168

Tabela 30 - Análise dos contextos futuros dos negócios envolvidos no projeto .................... 171

Tabela 31 - Análise do alinhamento do projeto com a estratégia da organização................. 171

Tabela 32 - Calibração de premissas utilizadas no projeto .................................................. 172

Tabela 33 - Definição de sinais ou indicadores que sirvam para monitorar o futuro acontecendo....

Tabela 34 - Análise do quanto o projeto pode influenciar os resultados futuros da organização

Tabela 35 - Simulação - Colocar pessoas para analisarem a organização dentro do contexto

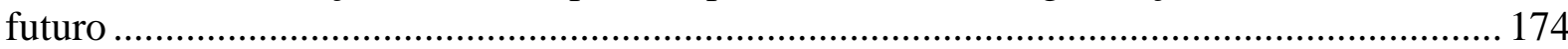

Tabela 36 - Estudo de mudanças necessárias na organização em função do projeto ............. 174

Tabela 37 - Identificar necessidade de aprimoramento de competências ............................ 175

Tabela 38 - Exame de incertezas estratégicas envolvidas no projeto ................................... 176

Tabela 39 - Contribuição da prospecção para a análise de contextos futuros dos negócios . 177 Tabela 40 - Contribuição da prospecção para a análise do alinhamento do projeto estratégico com a estratégia da organização. 
Tabela 41 - Contribuição da prospecção para a análise de calibração de premissas utilizadas

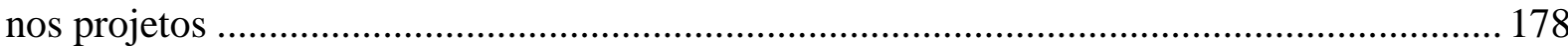

Tabela 42 - Contribuição da prospecção para a análise das forças relevantes do futuro que influenciem o projeto

Tabela 43- Contribuição da prospecção para definir os sinais ou indicadores que sirvam para monitorar o futuro acontecendo

Tabela 44 - Contribuição da prospecção para análise do quanto o projeto pode influenciar os resultados futuros da organização .

Tabela 45 - Contribuição da prospecção para simulação - analisar a organização no contexto futuro

Tabela 46 - Contribuição da prospecção para o estudo de mudanças necessárias na organização.

Tabela 47 - Contribuição da prospecção para a identificação das necessidades de aprimoramento de competências .

Tabela 48 - Contribuição da prospecção para o exame das incertezas estratégicas envolvidas

no projeto.

Tabela 49 - Contribuição da prospecção na identificação de lacunas estratégicas

Tabela 50 - Contribuição da prospecção para aprimorar a tomada de decisão em projetos estratégicos

Tabela 51 - Contribuição da prospecção para a identificação de temas estratégicos a serem monitorados.

Tabela 52 - Contribuição da prospecção na identificação de tendências e eventos do ambiente

Tabela 53 - Contribuição da prospecção para análise das consequências de alternativas de decisão estratégica.....

Tabela 54 - Contribuição geral da prospecção do futuro nos processos de análise prospectiva dos projetos

Tabela 55 - Grau de concordância: No projeto foi avaliado se havia pontos cegos nas análises

Tabela 56 - Grau de concordância: As análises e conclusões da prospecção foram utilizadas na tomada de decisões

Tabela 57 - Grau de concordância: O conhecimento sobre prospecção do futuro estava adequado para os desafios do projeto

Tabela 58 - Grau de concordância: A prospecção do futuro foi adequadamente praticada no projeto.

Tabela 59 - Avaliação da importância menos (-) avaliação da prática da prospecção ........... 195

Tabela 60 - Avaliação da importância menos (-) avaliação da prática da prospecção: Tema

Política e Governo.....

Tabela 61 - Avaliação da importância menos (-) avaliação da prática da prospecção: Tema

Economia

Tabela 62 - Avaliação da importância menos (-) avaliação da prática da prospecção: Tema

Sociedade

Tabela 63 - Avaliação da importância menos (-) avaliação da prática da prospecção: Tema

Mercado e Demanda

Tabela 64 - Avaliação da importância menos (-) avaliação da prática da prospecção: Tema Insumos e Recursos

Tabela 65 - Avaliação da importância menos (-) avaliação da prática da prospecção: Tema

Competidores

Tabela 66 - Avaliação da importância menos (-) avaliação da contribuição da prospecção.. 203 
Tabela 67 - Avaliação da importância menos (-) avaliação da contribuição da prospecção:

Tema Política e Governo

Tabela 68 - Avaliação da importância menos (-) avaliação da contribuição da prospecção:

Tema Economia.

Tabela 69 - Avaliação da importância menos (-) avaliação da contribuição da prospecção:

Tema Sociedade 206

Tabela 70 - Avaliação da importância menos (-) avaliação da contribuição da prospecção:

Tema Meio Ambiente e Sustentabilidade 207

Tabela 71 - Avaliação da importância menos (-) avaliação da contribuição da prospecção:

Tema Legislação e Regulação Setorial 208

Tabela 72 - Avaliação da importância menos (-) avaliação da contribuição da prospecção:

Tema Mercado e Demanda 210

Tabela 73 - Avaliação da importância menos (-) avaliação da contribuição da prospecção:

Tema Insumos e Recursos.

211

Tabela 74 - Avaliação da prática menos (-) avaliação da contribuição da prospecção.......... 212

Tabela 75 - Avaliação da prática menos (-) avaliação da contribuição da prospecção 


\section{LISTA DE GRÁFICOS}

Gráfico 1 - Quantidade de documentos com os termos relacionados à prospecção 40

Gráfico 2 - Journals que mais publicaram documentos com os termos da prospecção do futuro.....

Gráfico 3 - Países que mais publicaram documentos com os termos da prospecção .............. 43

Gráfico 4 - Tipo de documento publicado.......................................................................... 45

Gráfico 5 - Quantidade de documentos com foco específico na prospecção do futuro ........... 46

Gráfico 6 - Journals que mais publicaram sobre prospecção do futuro................................... 47

Gráfico 7 - Os 30 primeiros países (pela quantidade de documentos sobre prospecção) ....... 49

Gráfico 8 - Documentos publicados por tipo: Com foco em prospecção do futuro.................. 51

Gráfico 9 - Distribuição das empresas pela quantidade de funcionários .............................. 133

Gráfico 10 - Distribuição das empresas (faturamento anual Brasil) ...................................... 135

Gráfico 11 - Distribuição da amostra pelo tempo de experiência profissional ...................... 136

Gráfico 12 - Distribuição dos respondentes pelo cargo na empresa (qtde) .......................... 138

Gráfico 13 - Distribuição dos respondentes por faixa etária (\%) ........................................ 139

Gráfico 14 - Grau de satisfação com os objetivos atingidos pela prospecção do futuro (\%) 140

Gráfico 15 - Distribuição (\%) do horizonte de tempo do último projeto estratégico (\%)..... 141

Gráfico 16 - Importância, Prática e Contribuição: Por Temas portadores de incertezas de

futuro.

Gráfico 17 - Prática e contribuição de processos de análise prospectiva ............................. 147

Gráfico 18 - Contribuição da prospecção do futuro nos processos de análise (\%) ................. 150

Gráfico 19 - Grau de concordância com as afirmações sobre o domínio da prática de

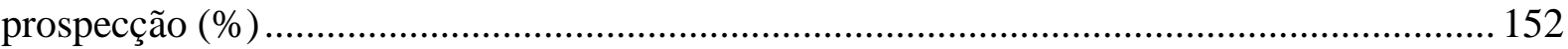

Gráfico 20 - Importância atribuída à prospecção do futuro - Empresas do Cluster 1 .......... 165

Gráfico 21 - Importância atribuída à prospecção do futuro - Empresas do Cluster 2 .......... 165

Gráfico 22 - Profundidade da prática da prospecção (por tema): Cluster 1 ........................... 167

Gráfico 23 - Profundidade da prática da prospecção (por tema): Cluster 2 ........................... 168

Gráfico 24 - Contribuição da análise da prospecção nas decisões: Cluster 1 ........................ 169

Gráfico 25 - Contribuição da análise da prospecção nas decisões: Cluster 2 ........................ 169

Gráfico 26 - Avaliação da importância menos (-) avaliação da contribuição da prospecção:

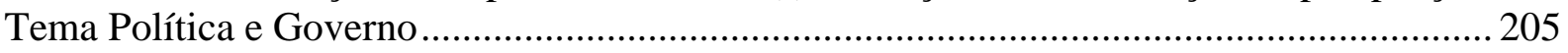

Gráfico 27 - Avaliação da importância menos (-) avaliação da contribuição da prospecção:

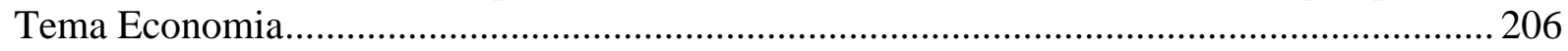

Gráfico 28 - Avaliação da importância menos (-) avaliação da contribuição da prospecção:

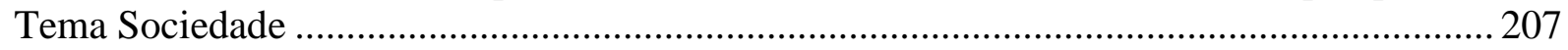

Gráfico 29 - Avaliação da importância menos (-) avaliação da contribuição da prospecção:

Tema Meio Ambiente e Sustentabilidade ............................................................................. 208

Gráfico 30 - Avaliação da importância menos (-) avaliação da contribuição da prospecção:

Tema Legislação e regulação setorial ................................................................................. 209

Gráfico 31 - Avaliação da importância menos (-) avaliação da contribuição da prospecção:

Tema Mercado e Demanda

Gráfico 32 - Avaliação da importância menos (-) avaliação da contribuição da prospecção:

Tema Insumos e Recursos. 


\section{LISTA DE ILUSTRAÇÕES}

Ilustração 1 - Mapa de autores pelas co-ocorrências (relevância >4) …….............................. 53

Ilustração 2 - Mapa de autores pelas co-ocorrências (relevância >6) …...................................5 54

Ilustração 3 - Mapa de autores pelas co-ocorrências (relevância >8) ...................................... 56

Ilustração 4 - Mapa de autores pelas co-ocorrências (relevância >10) ..................................... 58

Ilustração 5 - Mapa de conexões de Michel Godet com outros autores ..................................61

Ilustração 6 - Mapa de conexões de Peter Schwartz com outros autores ...............................62 62

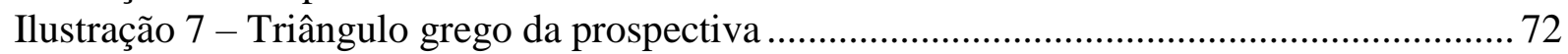

Ilustração 8 - Integração entre a prospectiva e a estratégia ...................................................... 72

Ilustração 9 - Análise de Tendências Impactadas...................................................................... 77

Ilustração 10 - Mudanças ao longo do tempo como consequências de ações e eventos ..........81

Ilustração 11 - Estrutura geral para administração estratégica relacionando passados,

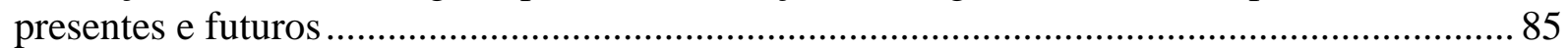

Ilustração 12 - Modelo de avaliação de maturidade ........................................................... 96

Ilustração 13 - Modelo conceitual preliminar para subsidiar o modelo conceitual teórico... 103

Ilustração 14 - Modelo Conceitual Teórico da pesquisa ...................................................... 104

Ilustração 15 - Modelo de suporte à integração entre prospecção do futuro e tomada de

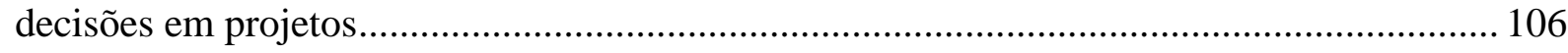

Ilustração 16 - Modelo Conceitual Teórico da pesquisa ......................................................... 120

Ilustração 17 - Fases para o desenvolvimento da pesquisa .................................................... 121

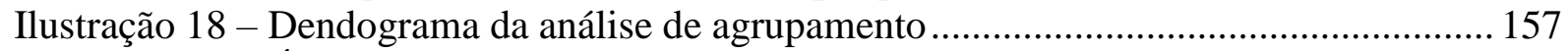

Ilustração 19 - Árvore de relevância de variáveis para os grupos ......................................... 216

Ilustração 20 - Pressupostos conceituais para subsídio à proposta de modelo conceitual teórico

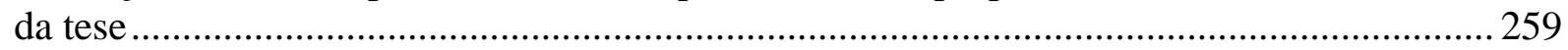

Ilustração 21 - Modelo de suporte à integração entre prospecção do futuro e tomada de

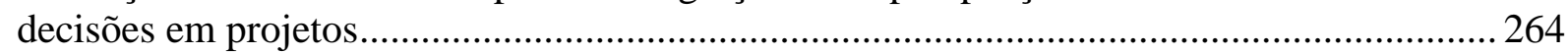




\section{INTRODUÇÃO}

Ao se mobilizar para analisar projetos estratégicos para suas organizações, gestores se defrontam com incertezas sobre o futuro. Questões sobre o que pode vir a acontecer limitam a possibilidade de proceder com as decisões, induzindo ao aprofundamento das análises e à avaliação de premissas dos projetos. Por decorrência, espera-se que o estudo do futuro (ou a prospecção do futuro) seja uma atividade praticada pelos administradores, caracterizando-se como uma forma de lidar com incertezas sobre o que pode vir a acontecer, ou para se avaliar as consequências de alternativas de decisão a serem tomadas.

Milliken (1987) já tinha observado que as incertezas são um grande desafio para administradores. Lidar com elas é complexo, pois elas sempre estão associadas com o futuro, o qual apresenta complexidade e volatilidade.

Recorrer a métodos que possam contribuir para a análise do que pode vir a acontecer é um passo natural, especialmente em projetos que apresentem incertezas de futuro, como são tipicamente os projetos estratégicos - eles comprometem recursos significativos da organização (recursos humanos, físicos, financeiros), são de horizonte de tempo além do curto prazo, visam aos objetivos e metas da organização em linha com a estratégia, e seus resultados geram valor. Dessa forma, se poderia supor que nessas condições haja nas organizações uma mobilização para a prospecção do futuro.

O escopo do que pode ser incluído num estudo prospectivo aumenta conforme o horizonte de tempo aumenta, segundo Stacey (1991, p. 190) argumenta, ao mencionar que a dinâmica de negócios pode ser caótica no longo prazo, e que também haja muitos futuros possíveis. Hines e Bishop (2013, cap. 3, ebook) argumentam que quanto mais longo é o horizonte de tempo, maiores as chances de mudanças ocorrerem. Por consequência, a complexidade de estudos de horizontes de tempo mais longo aumenta consideravelmente. Tal condição ocorre especialmente quando se lida com projetos estratégicos.

Schwartz (2003) compara a atividade de lidar com o futuro com a de uma embarcação à vela navegando por um mar turbulento. Ele questiona se é sensato, para as pessoas, deixar o barco ser atingido pelas ondas sem nada fazer. Ou elas deveriam tentar navegar com uma visão de futuro (SCHWARTZ, 2003, cap. 9, ebook). Linstone (2002) apontou áreas de 
desenvolvimento tecnológico cujos impactos poderiam ser enormes para o futuro, indicando ser prudente analisar antecipadamente esses impactos.

Portanto, em situação de análises em horizontes de tempo mais longo, possivelmente gestores recorram à prospecção do futuro. Seja ela praticada de forma estruturada, seguindo metodologias recomendadas e com abordagem mais prescritiva, ou mesmo de forma não estruturada, e talvez sem seguir prescrições a partir de conhecimento sobre as técnicas que possam contribuir no processo. A prospecção do futuro pode proporcionar análises e conclusões sobre o que poderá vir a acontecer, o que pode contribuir para engajar os gestores em um processo disciplinado, cooperativo e criativo de pensar o futuro, culminando em ações resultantes nos projetos estratégicos (KAHANE, ebook, 2012).

Uma vez considerando que gestores recorram ao estudo do futuro, e que isso ocorra dentro do processo de análise de projetos estratégicos, os resultados dos estudos prospectivos podem ser utilizados pelos gestores. O uso dos resultados de estudos prospectivos, nas decisões em projetos estratégicos, seria um próximo passo natural para os gestores. Esta tese procura demonstrar como a atividade de prospecção, estruturada e integrada ao processo de planejamento e gestão estratégica, pode contribuir para o sucesso das iniciativas estratégicas das organizações.

Aprender a como perceber um contexto externo, completo com suas incertezas futuras, é uma importante habilidade no mundo atual (CHERMACK, 2011, ebook, prefácio), e a orientação para a prática da prospecção do futuro poderia evitar o despreparo para lidar com surpresas inevitáveis, sendo esta uma atividade crítica para decisões tomadas no presente (SCHWARTZ, 2003, cap. 1, ebook).

Godet (1994, p. 29) argumenta que a prospectiva não é previsão ou futurologia, sendo mais uma forma de pensar em prol da ação contra o fatalismo. $\mathrm{O}$ autor propõe atuação para controlar o futuro, mesmo ele podendo ter múltiplas configurações e sendo incerto. O futuro, segundo ele, está para ser construído, não está escrito em lugar nenhum, ele não pode ser previsto, em outras palavras. Mas, segundo o autor, o futuro é a razão de ser do presente, quando as opções precisam ser analisadas com vistas a buscar futuros possíveis. Boas previsões, segundo Godet, não trazem objetivo de acertar previsões, mas sim avaliar possíveis 
ações que permitam evitar os riscos que possam nos impedir de chegar ao futuro desejado (GODET, 1994, p. 29).

Lidar com o futuro significa reconhecer o ritmo das mudanças, não negar suas influências, buscando desenvolver respostas a elas antes que estejam ocorrendo (SCHWARTZ, 2003, cap. 1, ebook). Isso possivelmente gera uma importância percebida para a prospecção do futuro.

Schwartz (2003) também argumenta que o mundo não vai tomar as decisões pelas pessoas, portanto elas devem se mobilizar para que as decisões possam ser tomadas. As pessoas devem buscar o controle sobre seu destino. Lembrando-se da analogia que o autor fez, sobre navegar sobre mar turbulento, ser atingido por ondas em sucessão pode não ser bom, melhor seria ter uma direção, uma visão de futuro, e saber reagir às ondas que certamente irão atingir o barco e as pessoas nele embarcadas (SCHWARTZ, 2003, cap. 9, ebook). Essa mobilização para suporte à decisão gera resultados, e esses resultados podem representar uma contribuição da prospecção do futuro para o processo de tomada de decisão.

Esta tese foi, portanto, desenvolvida com foco na transição entre a importância atribuída à prospecção, sua decorrente prática com a respectiva obtenção de resultados, e finalmente chega à contribuição proporcionada por ela no processo de tomada de decisão.

A estrutura desta tese é composta de seis (6) capítulos. O conteúdo dos capítulos é descrito a seguir.

Este presente capítulo (Cap. 1) visa a descrever inicialmente os fenômenos estudados na tese, bem como servir como orientação preliminar sobre os conteúdos dos capítulos subsequentes.

No Cap. 2 se encontra a apresentação do problema de pesquisa, com o contexto dos fenômenos descrito de forma mais aprofundada, as justificativas para a pesquisa proposta, e a própria definição do problema de pesquisa desta tese. Esta última é aprofundada ainda mais, trazendo a origem do problema, a situação que caracteriza o problema, as questões associadas e a descrição do problema de pesquisa. Também estão apresentadas as definições importantes utilizadas nesta tese, bem como alguns aspectos relevantes relacionados ao uso da terminologia. Finalmente são apresentados os objetivos da tese, refletidos a partir das questões relacionadas com o problema de pesquisa. 
No Cap.3 se encontra uma revisão de conceitos sobre prospecção do futuro. Os conceitos da teoria são apresentados e utilizados para fundamentar o desenvolvimento da pesquisa proposta nesta tese.

A metodologia de pesquisa aplicada nesta tese está descrita no Cap. 4. Ela é apresentada de forma detalhada, visando a esclarecer os passos aplicados e oferecer informações sobre o desenvolvimento dos mesmos. Também estão apontadas as limitações relacionadas com a metodologia utilizada nesta pesquisa.

Os resultados da tese estão apresentados e discutidos no Cap. 5. As análises dos dados obtidos pelos dois métodos aplicados nesta tese, quantitativo e qualitativo, estão descritas nesse capítulo. Os passos aplicados para cada uma das abordagens podem ser encontrados em nesse capítulo.

No Cap. 6 estão apresentadas as conclusões, comentários e recomendações finais sobre os achados da presente tese, suas implicações para a academia e para os gestores, e as possíveis abordagens em estudos futuros sobre o tema.

As referências bibliográficas utilizadas estão apresentadas no final.

Os apêndices à tese trazem o roteiro de entrevistas e o questionário aplicado nas etapas qualitativa e quantitativa, respectivamente. 


\section{O DESAFIO DE INTEGRAR PROSPECÇÃO E ESTRATÉGIA}

\subsection{O ambiente e a origem do problema}

Em 1995 Georgantzas e Acar já mencionavam que o ambiente de negócios estava cada vez mais complexo, descontínuo e turbulento. Em situações como essa, de rápidas e inesperadas mudanças, formular o pensamento estratégico apenas usando modelos mentais se torna insuficiente, fazendo com que o planejamento orientado a cenários se torne relevante instrumento de suporte à tomada de decisão. A visão alternativa de diferentes mundos, com novas perspectivas a serem agregadas pelo tomador de decisões permitem outras percepções de realidade que podem enriquecer o processo decisório (GEORGANTZAS e ACAR, 1995, p.41).

O desenvolvimento tecnológico estava gerando novos contextos à época de 2002, quando Linstone argumentou que algumas das rotas tomadas pela tecnologia trariam desafios éticos enormes, a exemplo da genética ou a do software genético (tradução literal de genetic software) - que foi descrito por Linstone como capaz de gerar suas próprias análises de aprimoramentos em produtos e processos, sem a intervenção humana. Em outras palavras, ultrapassando uma fronteira tecnológica que tornaria o ambiente cada vez mais complexo e dinâmico (LINSTONE, 2002).

Thomas Chermack (2011, ebook, cap. 1) enfatiza que a presença de incertezas não é novidade, contudo o grau em que elas ocorrem e os seus impactos não têm precedentes na história. Já Peter Schwartz (2003) apontou que o mundo estaria entrando em um período de grandes mudanças na civilização, nos vinte anos à frente (a partir de 2003), e que talvez elas ocorressem em proporções similares às duas grandes transformações ocorridas na história - a transição da era dos caçadores coletores para a era da agricultura, e a revolução industrial da transição entre os séculos 19 e 20 (SCHWARTZ, 2003, cap. 9, ebook).

Há forças muito poderosas surgindo em um ritmo cada vez mais rápido, como por exemplo, a urbanização, mudanças climáticas, envelhecimento demográfico, para citar apenas algumas delas (RAMIREZ et al, 2010, p. 303). Já Chermack (2011) afirma que o mundo está mudando mais rápido do que nunca, e ainda assim tomadores de decisão se comportam de forma contrária ao que sabem ser a verdade. Eles continuam a buscar a resposta, como se existisse 
apenas uma correta, e ainda pior, como se a responsabilidade deles fosse encontrá-la (CHERMACK, 2011, ebook, Part One).

A complexidade está aumentando no mundo, temas como globalização, fragmentação, regionalização, tensões entre diferentes culturas e religiões estão com seu potencial de influenciar mudanças em processo de aceleração. Mais do que nunca, o mundo hoje é marcado pela turbulência, quebras de tendências e possíveis impactos sobre os negócios, sendo recomendável dar atenção consciente sobre novas tendências (HINES; BISHOP, 2013, ebook, cap. 3).

Em síntese, as turbulências nos mercados se encontram em processo de aceleração, fruto de maior interdependência e integração entre países e blocos de países. Somam-se a esse fenômeno os avanços na tecnologia que possibilitaram o aumento sem precedentes da interconectividade e disseminação de informações, seja no âmbito entre países, instituições de estado e entre mercados, setores da economia, cadeias produtivas e chegando ao nível das pessoas e, cada vez mais, interligando máquinas e equipamentos antes isolados e desconectados.

As transformações decorrentes da disponibilidade de diversas tecnologias estão presentes no dia a dia, e elas influenciam as perspectivas futuras, uma vez que fenômenos decorrentes do uso de novas tecnologias são acompanhados por efeitos de ordem superior que dificilmente podem ser estimados, em detalhe, quando da adoção das mesmas. As consequências da presença de novas tecnologias na sociedade podem trazer benefícios, por certo, mas também trazem incertezas em diversos temas de âmbito institucional, corporativo e pessoal. Dessa forma, ampliam-se os desafios a enfrentar quando se necessita avaliar projetos, especialmente os que envolvam horizonte de tempo mais longo. Some-se a isso a aceleração das mudanças, o que induz ainda mais a necessidade das empresas se orientarem para o futuro, ou seja, de aumentarem a propensão à prática de metodologias prospectivas que possam contribuir para melhor lidarem com incertezas de futuro.

A preocupação com o alcance das transformações tem mobilizado profissionais para analisarem temas relevantes sobre o futuro. No mundo há organizações dedicadas aos temas globais de futuro, como a World Future Society (WFS) ou a World Futures Studies Federation (WFSF). A WFS foi fundada em 1966, e desde então tem ativamente promovido a 
discussão sobre temas relevantes de futuro, contribuindo para o aprimoramento da tomada de decisões orientadas para o futuro, por meio da disseminação de conhecimento e do incentivo à maior conexão entre pessoas que praticam metodologias de prospecção. A instituição congrega 5.800 membros no mundo (WFS, 2016).

A literatura acadêmica apresenta diferentes abordagens sobre como lidar com incertezas de futuro. Isso é resultado da mobilização de pesquisadores que, instigados pela necessidade recorrente de se estudar o futuro e contribuir na tomada de decisões, desenvolveram estudos sobre métodos de prospecção do futuro. Esses métodos se encontram dentro do que se denominam estudos do futuro, numa tradução literal do termo em inglês futures studies. As pesquisas sobre estudos do futuro ganharam impulso na década de 1960, e há significativa produção sobre o tema nesses pouco mais de 50 anos (GIDLEY, 2013).

A autora ainda menciona que apesar das pesquisas desenvolvidas sobre estudos do futuro, ainda há controvérsia na academia sobre esta área do conhecimento. De um lado, segundo ela, há os que a veem como tendo foco em previsão ou predição. De outro lado, há os que argumentam que, pelo fato do futuro ser desconhecido, a área de estudos do futuro não passa de "especulação infundada" ${ }^{1}$. Gidley propõe possíveis explicações sobre o porquê da área de estudos do futuro, apesar de ter produção científica razoável no período, ainda ter a sua literatura pouco enfatizada ou sem a visibilidade merecida. A primeira explicação seria que (1) há pouca visibilidade da produção na área por ela ser transdisciplinar, o que não a localiza especificamente em uma disciplina. A segunda hipótese é que (2) há certa tendência, de praticantes de estudos do futuro, em ideologizar os conceitos e métodos da área como a próxima área da teoria que salvará o mundo, o que cria uma imagem de arrogância e elitismo. Em terceiro vem a hipótese de que (3) os journals da área, talvez até por causa desse suposto elitismo e da interdisciplinaridade, acabam também se distanciando de outras áreas da academia. Por fim, e talvez a principal explicação, (4) se a área se mostra efetivamente isolada das demais áreas do conhecimento, possivelmente haja desafios para integrar a prospecção com as outras áreas da academia (GIDLEY, 2013).

Sobre essa questão, de integrar a área da prospecção com as outras áreas do conhecimento, que Gidley (2013) menciona, Slaughter (2001) teve uma intuição semelhante, quando

\footnotetext{
${ }^{1}$ Tradução do original em inglês: "ungrounded speculation"
} 
argumentou que a aproximação de estudos do futuro e a então chamada "agenda integral" poderia se tornar uma boa abordagem para lidar com importantes desafios de alcance global.

Já segundo Dator (2002a, p. 21) os estudos do futuro não deveriam ficar limitados a uma disciplina acadêmica somente, uma vez que um dos problemas da academia hoje é a sua segmentação, que pode estar contribuindo para o desaparecimento da moderna universidade, por causa da sua inabilidade em lidar com a natureza transdisciplinar dos problemas do mundo.

Essa discussão sobre a área de estudos do futuro pode trazer, também, uma reflexão sobre como a prática de estudos prospectivos ocorre nas organizações. A quantidade de temas a serem analisados é grande devido ao aumento da complexidade, e o contexto atual mostra que as mudanças podem estar em processo de aceleração cada vez maior. Então possivelmente os tomadores de decisão se encontrem pressionados a prospectar, num ambiente cada vez mais complexo, multidisciplinar e com mudanças rápidas. Trata-se de um desafio significativo para quem precisa tomar decisões que apresentem incertezas de futuro, mas ainda assim, desafio que precisa ser enfrentado.

Nehme et al (2012) enfatizam que a comunicação tem papel importante em processos de estudos prospectivos. Os autores também corroboram sobre a multidisciplinariedade, e argumentam adicionalmente que pesquisadores acadêmicos tendem a apresentar dificuldade de pensar além de suas disciplinas. Esta longa tradição disciplinar da pesquisa e docência influencia o processo de pensar prospectivamente sobre novas possibilidades na academia, quando se analisam aspectos sobre inovações que poderiam ser adotadas na academia.

O futuro emerge a partir da interação entre eventos, tendências, imagens e ações. Imagens são visões que as pessoas têm acerca de futuros possíveis, e as ações estão relacionadas, em parte, com coisas feitas para que essas visões de futuro aconteçam. Então a área de futures studies busca contribuir no processo de examinar as imagens de futuro que as pessoas tenham, para que elas possam aprimorar suas decisões (DATOR, 2002b).

Godet (1994, p. 38) argumenta que uma das utilidades que dá credibilidade à análise prospectiva é que ela serve como um direcionador de estratégia. Ela proporciona uma guia para ações (em um plano) que consideram possíveis futuros desejados. Ela também contribui 
para analisar futuros plausíveis, e dessa forma identificar a partir de uma lista de eventos atuais, aqueles que apontam para o futuro, e que possam ter consequências relevantes no futuro.

Dessa forma, o interesse em estudar o futuro está, em grande parte das vezes, associado à formulação da estratégia da organização e aos respectivos projetos decorrentes. A estratégia é um dos indutores dos estudos do futuro, ou da prospecção do futuro. Estratégia tem associação com decisões, com escolhas, portanto tem associação com coisas que serão ou não serão feitas, e isso em função do que se estima que virá a acontecer. Há, dessa forma, a necessidade de se decidir como os recursos da organização deverão ser utilizados, e em quais alternativas de projetos eles serão aplicados. Por decorrência, a prospecção do futuro pode contribuir no suporte a decisões estratégicas.

Segundo Drucker (2010, p.188), a construção do futuro começa hoje, numa referência ao entendimento de que decisões têm, na maioria das vezes, relações com o futuro. O autor propõe que o objetivo de se trabalhar na construção do futuro é decidir o que deve ser feito hoje, para que se possa ter um amanhã. Em outras palavras, construir o futuro não é decidir o que deve ser feito no futuro, mas o que deve ser feito hoje.

Mintzberg et al (1976) argumentaram que uma decisão apresenta compromisso com ações, e quase toda decisão leva o futuro em consideração.

Decisões em projetos estratégicos envolvem a análise de temas relacionados com o futuro, alguns deles podendo atingir horizontes de tempo mais longos. Nessa condição, a diversidade de temas envolvidos também pode ser grande (HINES; BISHOP, 2013, cap. 3, ebook). Isto pode levar gestores a utilizar metodologia, estruturada ou não, para avaliar e estudar o futuro. Essa mobilização para estudar o futuro reflete uma responsabilidade assumida pelos gestores com os resultados das decisões tomadas, como consequência, pode ocorrer uma propensão para a prática da prospecção do futuro.

No processo de análise de projetos estratégicos, podem surgir diferentes temas que são portadores de incertezas de futuro. Alguns desses temas são comuns nas análises de projetos, como por exemplo, a economia, a tecnologia e o meio ambiente, para citar alguns exemplos. O estudo desses temas por meio de prospecção do futuro gera análises, conclusões acerca do 
que pode vir a acontecer, que por sua vez possam ou devam contribuir no processo de análise dos projetos estratégicos.

A prospecção exige investimentos de recursos humanos, econômicos e de tempo. Os gestores devem, portanto, considerar a possível contribuição dos resultados obtidos a partir de estudos prospectivos. Contudo, dada a permanência de incertezas sobre o futuro e a alta complexidade de se lidar com muitos temas, é possível ocorrer limitações na aplicação de recursos, e também no uso efetivo dos resultados de estudos prospectivos nas análises sobre projetos estratégicos nas organizações.

A contribuição da prospecção do futuro no processo de pensar, analisar, planejar, implantar e controlar a execução de planos de projetos estratégicos pode ocorrer em diferentes graus. $\mathrm{O}$ contexto do projeto em análise define a complexidade do estudo, e dessa forma, influencia a abrangência de temas a serem analisados, assim como o horizonte de tempo para o qual se estuda o futuro. Estabelecer os objetivos do estudo de prospecção também deve considerar alinhamento com os objetivos do projeto.

O uso de diferentes métodos para estudar o futuro pode ser uma das atividades desempenhadas por executivos nas organizações. Entretanto, a forma com que essa atividade é desempenhada pode variar bastante, tendo como possíveis extremos opostos: (1) de um lado o pressuposto de que seja possível prever o futuro, e no outro extremo a (2) total abdicação da prospecção do futuro, sendo esta última uma opção que pode ser inclusive conscientemente tomada.

É possível que gestores em organizações recorram à prospecção, no mínimo por necessidade de prestar contas pelas suas decisões aos stakeholders mais diretos. Dessa forma, é pouco provável que haja a total abdicação da prospecção do futuro, e dessa forma ocorra de fato uma atitude orientada para a prática do estudo do futuro.

Uma vez que a estratégia envolva questões pertinentes ao futuro, as opções de decisão em projetos estratégicos recebem a influência dos resultados de estudos prospectivos, sendo estes obtidos por meio de metodologia estruturada ou não. Os temas portadores de incertezas de futuro podem influenciar as decisões estratégicas, e a contribuição da prospecção provavelmente poderá se dar em diferentes graus. 
A presente tese envolve, portanto, os fenômenos compreendidos entre a orientação (propensão) de gestores da empresa para a prática da prospecção do futuro, passando pela importância dada à mesma, a consequente prática de metodologia prospectiva, e finalmente a contribuição dos resultados da prospecção em decisões sobre projetos estratégicos.

Havendo a constatação de limitações nesse processo, esta tese busca explorar recomendações, eventualmente culminando em um modelo preliminar para suporte à integração entre prospecção do futuro e estratégia empresarial.

\subsection{A situação problema}

Lidar com incertezas sobre o futuro faz parte do conjunto de responsabilidades de gestores em organizações. O futuro apresenta incertezas, e não se pode deixar de analisá-las por causa de dificuldades ou limitações. Executivos de cargos mais elevados sabem bem disso, e eles têm a quem se reportar, o que os mobiliza a manter atenção quanto ao futuro, por mais incerto que ele seja. Para Drucker (2010, p.200), “praticamente toda decisão de administração básica é uma decisão de longo prazo". Executivos precisam ter a capacidade de tomar decisões de longo prazo, que se caracterizam por comprometer investimentos de recursos que poderão levar anos para gerar retornos. Dessa forma, eles não têm como fugir do dever de estudar e analisar o futuro, se "amoldar a ele" e balancear objetivos de curto prazo com os de longo prazo. Como antecipado pelo autor, prever o futuro é tarefa inútil, mas o que se espera de gestores é que não fujam dessa responsabilidade, não se descuidem nem sejam negligentes com ela. Há, portanto, uma propensão, indução ou orientação para a prática de prospecção do futuro.

Pesquisadores como Godet (1994), Schoemaker (1995), Hines (2002), Schwartz (2003) e Chermack (2011), dentre outros, têm se dedicado a estudar e aplicar metodologia de estudo do futuro. As pesquisas apontam importantes recomendações a serem seguidas. Elas são, dentre outras, analisar as principais incertezas estratégicas, identificar e calibrar as premissas necessárias, reconhecer o risco de se ignorar pontos cegos na análise, identificar o que precisa ser acompanhado para monitorar o futuro acontecendo e saber lidar com a abrangência de temas que devam entrar no estudo prospectivo. Outro aspecto importante é o conhecimento sobre métodos de estudo do futuro, e como aplicá-los. 
Essas recomendações na utilização de metodologias prospectivas dão origem a importantes questões, especialmente quando se mobilizam recursos da organização para a prática de métodos de estudo do futuro. A necessidade de se prospectar pode ser induzida por um processo de tomada de decisão. Contudo, quando se tem problemas complexos, podem ocorrer limitações nas análises devido à ambiguidade e incertezas presentes, dificultando a busca por respostas mais claras. Ainda assim, gestores são compelidos a fazerem o melhor (CHERMACK, 2011, ebook, cap. 2). Essas limitações podem ocorrer durante a aplicação da metodologia de prospecção do futuro.

Hamel e Prahalad (1996, ebook, cap. 5) argumentaram que o uso da imaginação pode contribuir para a formação de uma visão das tendências de um setor, e assim identificar quais fatores influenciam no processo, e assim possibilitar seguir uma rota que leve a organização ao futuro. Contudo, ainda resta certo grau de incerteza residual ${ }^{2}$. Os autores apontaram que esta incerteza residual se mostra muito acima do desejado, devido à falta de um pensamento profundo e sustentado sobre o futuro. Lembrando Hines e Bishop (2013), a diversidade de temas envolvidos quando se estuda o futuro é muito elevada (HINES; BISHOP, 2013, cap. 3, ebook).

Analisar estratégia demanda imaginação, ou criatividade, como argumentado por Almeida (2010) ao lembrar que na análise do ambiente organizacional, dentro de um processo de planejamento estratégico, é necessário utilizar a criatividade. O horizonte de tempo considerado no processo de análise do ambiente organizacional é de futuro, demandando forma de pensar criativa, ideias e estudo de projetos de mudanças (ALMEIDA, Martinho, 2010, p. 19-20). Chermack também valoriza o uso da criatividade no desenvolvimento de cenários de futuro (CHERMACK, 2006). Kahane (2012) corrobora com o tema, ao propor que o estudo do futuro leva a um processo disciplinado, cooperativo e criativo de pensar o futuro, culminando em ações resultantes em projetos estratégicos (KAHANE, ebook, 2012). List (2006) é outro autor que advoga pela ênfase na criatividade.

A conexão entre estratégia e prospecção do futuro pode se manifestar de muitas formas, e a criatividade é possivelmente umas dessas formas. Ela tem papel importante na interpretação das informações para identificar movimentos de ruptura do ambiente corrente. Em outras palavras, há possibilidade de identificar sinais fracos que possam servir para analisar e

\footnotetext{
${ }^{2}$ Tradução do original em inglês "residual uncertainty".
} 
formular cenários de futuros alternativos. O desafio é a interpretação do que os sinais possam ter de significado, ou seja, como utilizar a criatividade para que essa formulação de cenários possa contribuir de forma efetiva (ALMEIDA, Fernando et al 2007).

Esse ambiente de incertezas de futuro, mais complexo quando se está estudando o futuro em horizonte de tempo mais longo e no qual se precisa recorrer à imaginação e criatividade, pode ser um contexto propício para o surgimento de dificuldades para os gestores.

Dessa forma, o fenômeno de interesse desta tese está relacionado com algumas indagações preliminares:

- Se gestores em organizações têm propensão à prática de prospecção do futuro, e isto sendo realidade, então será que a mobilização deles ocorre na proporção em que eles consideram importante a atividade? E os respectivos resultados da prospecção do futuro, será que eles contribuem na tomada de decisões em projetos estratégicos? Se gestores são diligentes para praticar a prospecção, então talvez eles o façam seguindo recomendações ou prescrições, contudo, esta premissa estaria correta?

$\mathrm{Na}$ literatura encontram-se estudos que buscam analisar a integração entre prospecção do futuro e problemas de decisão estratégica, como os de Eisenhardt e Zbaracki (1992), Chermack (2004), Wright e Goodwin (2009) e Ericson (2010), para citar alguns. Geralmente esses estudos apresentam foco no contexto do problema de decisão, ou seja, uma aplicação de como proceder para prospectar sobre um determinado problema de decisão. $\mathrm{Na}$ área do conhecimento da prospecção do futuro, encontram-se diferentes métodos com diversas recomendações sobre sua aplicação, porém, a transição entre os resultados da prospecção e a decisão propriamente dita é tomada como certa, ou seja, admite-se que a prospecção foi bem desenvolvida e foi focada no problema de decisão, então a transição flui naturalmente.

Essa premissa pode não ser verdadeira. A propensão para a prática da prospecção do futuro deveria levar a uma transição clara e produtiva entre a prospecção do futuro e as decisões estratégicas, contudo, isso pode não ser uma realidade entre os gestores.

Dessa forma, nesta tese, a abordagem adotada foi de estudar a importância dada à atividade de estudos do futuro, a decorrente mobilização para a prática da prospecção e finalmente a 
contribuição dos resultados obtidos nas decisões sobre projetos estratégicos. Em outras palavras, concentra-se na transição entre (1) importância dada à atividade, (2) sua prática nas organizações, gerando resultados, e finalmente a (3) contribuição dos resultados da prospecção nas decisões em projetos estratégicos.

Se essa transição descrita ocorre isenta de limitações, então a integração entre a prospecção do futuro e a decisão estratégica seria ideal. Contudo, isso pode não ser realidade, e dessa forma, uma importante contribuição para a administração seria a de aprimorar a integração dos processos de estudos do futuro à tomada de decisões em projetos do âmbito da estratégia.

\subsection{O problema no contexto empresarial}

Desafios da dinâmica dos mercados, dos impactos de novas tecnologias e da maior integração entre atores aumentaram a complexidade ambiental em que organizações e gestores se encontram. Na academia são encontradas áreas de pesquisa que buscam desenvolver estudos relacionados aos fenômenos decorrentes dessa maior complexidade. Uma dessas áreas de pesquisa, a dos estudos do futuro, busca contribuir para que as incertezas de futuro possam ser estudadas, analisadas e eventualmente seja possível estimar possíveis desdobramentos ao longo do tempo.

Há setores caracterizados por mudanças rápidas e significativas, tipicamente originadas pelo avanço da tecnologia, a exemplo do setor de internet. Para setores que apresentam tais características, pode ser recomendável a prudência com relação ao futuro sem que, no entanto, isso promova omissão em relação às transformações do ambiente. Segundo Stacey (1991) "O futuro é uma combinação de situações de mudança", sendo importante avaliar quando elas podem ocorrer, a magnitude das consequências geradas por elas e o grau de previsibilidade das mudanças e de suas consequências (STACEY, 1991 p. 27).

Gestores envolvidos em projetos estratégicos são confrontados com temas que portam incertezas sobre o futuro. Esse contexto requer análises sobre o futuro, sobre o que pode acontecer, e muitas vezes com horizonte de tempo que pode avançar por anos à frente. A amplitude de temas envolvidos em tais condições é grande, podendo incluir questões de ambiente externo amplo, de baixa possibilidade de controle por parte dos gestores da organização. 
As metodologias de estudos do futuro não almejam acertar a previsão, mas potencializar a criatividade para a formulação de contextos claros, e ao mesmo tempo em nível de detalhes relevantes sobre os cenários futuros (LIST, 2006). O autor ainda argumenta que avaliar a atividade de prospecção do futuro é muito difícil, porque nela não se busca acertar a previsão, mas estimular a criatividade para formar visões claras e relevantes sobre cenários para o futuro. De certa forma, o autor orienta que avaliar a prospecção do futuro, pela comparação entre o que aconteceu de fato com o que foi analisado ser possível de acontecer, seria uma abordagem equivocada. Ainda assim, resta a pergunta sobre o que deveria ser uma abordagem adequada para avaliar a atividade de prospecção do futuro.

Dentre os métodos para prospectar o futuro está o de cenários, que tem como objetivo agregar mais informações ao processo de prospecção, melhorar as informações e assim compreender as decisões envolvidas. Isso permite que elas sejam tomadas observando o que foi prospectado, e assim almejar objetivos relacionados ao futuro (WRIGHT; SPERS, 2006).

Ao se depararem com esse contexto, gestores podem recorrer a metodologias para estudar o futuro, analisar o que pode vir a acontecer, e assim poder considerar as consequências que possam se originar a partir de alternativas de decisão. Como consequência, obtêm-se resultados da prática da prospecção, e estes resultados podem contribuir no processo de tomada de decisão em projetos estratégicos.

Em síntese, essa contribuição da prática da prospecção do futuro pode ocorrer em diferentes graus, tanto pode ser positiva e de fato apoiar as decisões, quanto pode ser limitada e servir apenas minimamente nas decisões. Os processos recomendados para a prática da prospecção, e a utilização de seus resultados podem apresentar limitações que prejudiquem o apoio às decisões. O ambiente do problema de pesquisa se localiza em uma possível lacuna, localizada na transição entre a propensão para a prática da prospecção, a sua prática propriamente dita, e finalmente a contribuição que ela pode gerar no apoio à decisão. 


\subsection{0 problema de pesquisa}

O futuro é imprevisível, e mesmo assim se observa dedicação por parte dos gestores para se estudar o que pode vir a ocorrer, visando ao suporte à tomada de decisões. Então se poderia concluir que o suporte à tomada de decisão tem um peso significativo sobre gestores, o que os compele a prospectar o futuro, ainda que ele seja tido como imprevisível.

Esse paradoxo pode gerar certa perplexidade, mas ao mesmo tempo indica que se existe a dedicação para a prospecção, então de alguma forma é assumido que ela possa contribuir na tomada de decisões. Contudo, pode ser possível que essa contribuição não seja totalmente eficaz, e que haja limitações na integração dos seus resultados no processo de tomada de decisões.

Desde os anos 1960, observou-se aumento nos esforços para pesquisar e aplicar metodologias de estudos do futuro (GIDLEY, 2013). Ao longo do tempo vem sendo propostas recomendações sobre como praticar os métodos evitando os riscos inerentes, visto que se trata de atividade multidisciplinar e complexa. O estudo do futuro é complexo, por envolver problemas que ainda estão pouco explicados e entendidos. Ela é atividade acompanhada de algum ceticismo, pois dada a complexidade dos problemas e a diversidade dos temas envolvidos, o estudo do futuro não busca a certeza, uma vez que ela não pode ser alcançada (SARDAR, 2010). Roney (2010) também corrobora que a área de estudos do futuro é uma das mais multidisciplinares.

Ainda assim, apesar de não ser possível prever o futuro, é necessário estudar o mesmo para apoiar decisões e ações decorrentes delas, visando a objetivos que se projetam para o futuro. Drucker (2010, p.188) argumentou que decisões têm, na maioria das vezes, relações com o futuro, e o objetivo de se trabalhar na construção do futuro é decidir o que deve ser feito hoje, para que se possa ter um amanhã. Assim como Sardar (2010), Drucker também argumenta que o futuro é imprevisível, mas que apesar disso ele prega a responsabilidade de gestores pelas decisões que precisam ser tomadas no presente, e o fato de que eles têm que considerar consequências futuras das decisões. (DRUCKER, 2010, p.188).

Uma decisão apresenta compromisso com ações, e quase toda decisão leva o futuro em consideração, segundo argumentaram Mintzberg et al (1976). 
Então assim se configura o desafio para os gestores, lidar com incertezas de futuro, imprevisíveis por natureza, e ainda assim ter que se mobilizar para suportar suas decisões baseadas em alguma forma de estudar o futuro. Um desafio que é enfrentado constantemente por gestores em organizações, sendo pertinente perguntar se eles o fazem com tranquilidade, ou se defrontam com limitações nesse processo.

Como mitigar os efeitos dessas limitações? Haveria uma forma de contribuir para que a prospecção do futuro possa apoiar as decisões em projetos estratégicos? Se a prospecção gera resultados de sua prática, então a utilização dos mesmos e a consequente transição para a decisão ocorrem sem problemas?

O problema de pesquisa proposto na presente tese é decorrente de uma indagação geral:

\section{Um modelo de apoio à integração de resultados de estudos prospectivos com a estratégia empresarial pode contribuir para apoiar decisões em projetos estratégicos?}

Esta tese foi desenvolvida, portanto, para estudar se há mesmo esse estímulo, por parte dos gestores, em estudar o futuro quando estão envolvidos em decisões em projetos estratégicos. Este estímulo é aqui chamado de "orientação para a prática de prospecção do futuro".

Algumas premissas adotadas nesta tese precisam ser apresentadas.

Em primeiro lugar, por hipótese, considera-se que a prospecção seja praticada nas organizações. Como descrito anteriormente, é reconhecido que gestores assumam a frente do processo de lidar com incertezas de futuro, mesmo sabendo que se trata de uma tarefa árdua.

Em segundo lugar, como uma derivação da primeira premissa, parte-se do pressuposto de que entre a identificação do estímulo para a prática da prospecção do futuro, e sua consequente contribuição para apoiar decisões, podem ocorrer fenômenos que causem limitações à contribuição. Se a complexidade de estudar o futuro é elevada, seria esperado que sua prática, e respectiva contribuição, possam sofrer limitações. 


\subsection{Justificativas para a pesquisa}

Embora seja esperado que gestores tenham como reponsabilidade lidar com incertezas de futuro, a prática da prospecção do futuro pode não ocorrer de forma a efetivamente contribuir no processo de tomada de decisão.

Devido à dificuldade de se lidar com as incertezas de futuro, é possível que a prática de estudos prospectivos nas organizações apresente limitações. Estas podem se manifestar de diferentes formas, entre dois extremos, sendo de um lado o ceticismo em relação à capacidade de se prever o futuro, e chegando até ao outro lado, que é o da ilusão de controle, no qual se acredita em poder prevê-lo (MAKRIDAKIS et al, 2009).

Nesse contexto, seria compreensível que gestores pudessem sentir-se compelidos a não prospectar o futuro. Há, contudo, o fato deles deverem prestação de contas a stakeholders diretos, sejam eles acionistas proprietários, seja o poder público, clientes, colaboradores ou mesmo a sociedade. Sempre é bom lembrar que executivos devem, aos seus acionistas ou proprietários, o comprometimento de estarem sempre à frente dos riscos estratégicos, para que possam informá-los se os riscos não têm solução (GILAD, 2004, p.22). Isso deve fazer com que eles recorram à prospecção do futuro.

Uma situação na qual é comum a necessidade de se estudar o que pode acontecer no futuro é a análise de projetos no âmbito da estratégia, que comprometam recursos significativos, podendo ser econômicos, humanos e de tempo, e cuja aplicação nos projetos é de difícil reversão quando iniciada. Em outras palavras, projetos estratégicos, que induzam a decisões estratégicas pela importância das ações envolvidas ou dos recursos comprometidos (EISENHARDT; ZBARACKI, 1992).

Esses mesmo autores argumentaram que o fator político tem grande influência na tomada de decisão, chegando a discutir se ele é um fenômeno gerado por conflitos, ou se é um processo criado deliberadamente pelo jogo de poder para controlar ou direcionar a decisão. O controle da informação (ou a sua falta) tem influência na decisão (EISENHARDT; ZBARACKI, 1992).

Esses projetos também apresentam horizonte de tempo que pode se estender por período de médio ou longo prazo. Nesta situação é necessário adotar premissas, o que induz à prospecção 
do futuro. A prospecção nessas condições envolve grande diversidade de temas a serem estudados (HINES; BISHOP, 2013, cap. 3, ebook).

Os temas portadores de incertezas de futuro podem ser muitos, incluindo política, economia, tecnologia e sociedade, para citar alguns. Gestores podem ter dificuldades de estruturar o processo de análise, e dessa forma se configura uma situação na qual a contribuição da prospecção, por consequência, pode variar.

Sendo importante prospectar o futuro, então a prospecção provavelmente é praticada e gera resultados. Estes, por sua vez, podem contribuir nas análises de projetos estratégicos.

Esse processo descrito no parágrafo anterior parece lógico, sob o ponto de vista de operacionalizar a prospecção do futuro em organizações. Dessa forma, considerando que haja o reconhecimento da necessidade de estudar o futuro, é possível que a sua prática seja efetivada na organização, ou seja, que ocorra uma orientação para a prática de prospecção do futuro, como explicada na seção anterior. Contudo, nem sempre as coisas ocorrem como o desejado, podendo haver limitações no processo que causem uma transformação no fenômeno como ele é desejado que ocorresse, e ao fim ele ocorre de forma diferente da desejada.

Assim se justifica a pesquisa proposta nesta tese. Essa transição entre importância atribuída à atividade de prospecção do futuro, a sua prática decorrente e a consequente contribuição da prospecção nas decisões possivelmente apresenta limitações, as quais poderiam ser tratadas pelo uso de um modelo de suporte à integração entre prospecção e gestão estratégica.

\subsection{Questões associadas com a situação problema}

Para elucidar o problema de pesquisa desta tese, o desenvolvimento da pesquisa almejou respostas para uma questão geral de pesquisa, que indaga se um modelo de apoio à integração de resultados de estudos prospectivos pode contribuir para apoiar decisões em projetos estratégicos. Associados a esta questão geral, estão os questionamentos específicos a seguir: 
Q1. Se gestores em organizações têm orientação para a prática da prospecção do futuro, então será que a mobilização deles ocorre na proporção adequada à importância que caracteriza esta orientação?

Q2. E, se a prospecção é praticada nas organizações, os seus respectivos resultados contribuem para a tomada de decisões em projetos estratégicos?

Q3. Quais os temas portadores de incertezas de futuro considerados mais importantes pelos gestores?

Q4. Em quais dos temas se dedica mais a prospecção?

Q5. Quais os temas cujos resultados prospectados contribuem mais na análise de projetos estratégicos?

Q6. Que processos recomendados na prospecção são mais praticados ao se analisar projetos estratégicos?

Q7. Os resultados da prospecção do futuro contribuem nos processos de apoio à tomada de decisões em projetos?

Q8. Os resultados obtidos, a partir da prospecção bem-sucedida e focada no problema de decisão, fluem naturalmente para apoiar a decisão?

Essas questões orientaram o desenvolvimento da tese. Para deixar bem especificado aos participantes da pesquisa, foi solicitado que suas respostas se referissem ao último projeto estratégico implantado na organização, do qual tenha participado das análises ou das decisões.

\subsection{Definições utilizadas na pesquisa}

As definições a seguir foram utilizadas nesta tese para desenvolver a pesquisa.

Prospecção do futuro: É a atividade de estudar o futuro, analisar as incertezas relacionadas, as tendências que podem se consolidar, as mudanças que podem vir a ocorrer, bem como os 
cenários que podem ser possíveis no futuro, e assim apoiar decisões. Adaptado a partir de Schwartz (2003), Dator (2002b), Godet (1994).

Orientação para a prática da prospecção do futuro: É a propensão a praticar prospecção, estimulada pelo reconhecimento da importância de estudar o futuro para lidar com incertezas nos projetos estratégicos.

Projeto Estratégico: Projetos de médio e longo prazo, em diferentes áreas da organização, que envolvem muitos recursos físicos, humanos e econômicos, e que tipicamente são de difícil reversão após o início de sua implantação. Exemplos (não se restringindo a estes):

- Projetos de desenvolvimento e lançamento de novos produtos/serviços;

- Projetos de localização de novos pontos de presença para operação ou produção;

- Projetos de aquisição de novas plataformas tecnológicas para a produção ou suporte às operações da organização;

- Projetos sobre mudanças no portfólio de produtos/serviços;

- Projetos sobre mudanças nos modelos de negócios da organização.

Adaptado das definições de projeto a seguir:

[...] processo único, consistindo de atividades coordenadas e controladas, com datas de início e de fim, executadas para se atingir objetivos em conformidade com requisitos específicos, considerando restrições de tempo, orçamento e recursos (LESTER, 2014, p. 1).

E de Callahan e Brooks (2004) no qual Strategic Project Management é:

[...] uso apropriado do conhecimento, habilidades, ferramentas e técnicas de gerenciamento de projetos no contexto dos objetivos e metas da organização, para que os resultados dos projetos agreguem valor para a organização de forma mensurável (CALLAHAN; BROOKS, 2004, p. 23).

Além disso, os autores também argumentam que projetos são temporários, únicos e têm um escopo bem definido (CALLAHAN; BROOKS, 2004, p. 20). Esses projetos são considerados como sendo do âmbito da estratégia das organizações.

Tema portador de incertezas de futuro: É o assunto (matéria, tópico) cujo futuro não pode ser descrito sem correr o risco de estar errado, uma vez que haja muitos fatores relacionados a ele que são de difícil previsibilidade. 
Exemplos de temas: política, economia, tecnologia.

Adaptado a partir de Perminova et al (2008), que definiram incertezas em projetos como “[...] incerteza é um evento ou situação que não era esperada que pudesse acontecer, independente do fato de que ela pudesse ter sido considerada de forma antecipada" (PERMINOVA et al, $2008)^{3}$.

Nesta definição, nota-se que os autores se referem ao evento ou à situação no tempo verbal passado, o que parece contra intuitivo para os propósitos de estudar o futuro para suporte à decisão. Os autores usam a retórica no passado para enfatizar o problema da falta de visão de futuro. Posto de outra forma, o problema decorre da fase de gerenciamento de riscos dos projetos, quando se analisa o que pode ocorrer no projeto antecipadamente, visando preparar medidas para mitiga-los. Os autores argumentam sobre a relevância de tentar antecipar os riscos do projeto nas análises, para que no futuro aquilo que era um risco ou uma oportunidade não considerada (também uma incerteza) não venha a surpreender a organização.

Dessa forma, nesta tese utiliza-se a definição de incerteza de forma que ela signifique, no momento presente, o desconhecimento quanto ao que poderá ocorrer no futuro, considerando o assunto, matéria ou tópico em estudo.

Horizonte de tempo da prospecção: Trata-se do alcance de tempo para o futuro, ou o período de tempo para o qual é estudado o futuro, contado a partir da data em que se está fazendo a prospecção.

Adaptado de Chermack (2011, ebook, cap. 5) - Horizonte de tempo na literatura de cenários é o quanto distante para o futuro se analisam os cenários.

Frequência (percentual) da prática de prospecção: É o percentual dos casos de projetos estratégicos no qual a prospecção é praticada, por exemplo, se ela foi praticada em 5 projetos dentre 10 , então a frequência seria de $50 \%$.

\footnotetext{
${ }^{3}$ Original em inglês: [...] is an event or a situation, which was not expected to happen, regardless of whether it could have been possible to consider it in advance"
} 


\subsubsection{Alguns aspectos de terminologia aplicada na tese}

A terminologia utilizada ao longo desta tese pode gerar alguma confusão ao leitor, razão pela qual esta seção busca antecipar algumas informações para evitar isso.

É importante mencionar que, nesta tese, o termo "prospecção do futuro" é utilizado de forma intercambiada com o termo "estudos do futuro", indicando o foco da pesquisa nas metodologias que tratam do estudo do futuro. A ênfase da pesquisa aqui desenvolvida é nos processos que fazem parte de recomendações nas metodologias de prospecção do futuro. Eventualmente se encontrará o termo "prospecção" de forma isolada, e seu sentido deve ser considerado o mesmo que "prospecção do futuro".

Também se utilizam no texto "estudos prospectivos", significando o conjunto de processos aplicados na metodologia de estudos do futuro. Em outras palavras, estudos prospectivos podem ser entendidos como "análises desenvolvidas por meio da prática de métodos de prospecção do futuro".

Dessa forma, o termo "prática da prospecção" significa execução de processos de estudar o futuro. E não meramente uma projeção quantitativa de um indicador ou uma premissa sobre um dado futuro específico de interesse da organização.

Por "resultados" da prospecção entende-se como sendo o produto que foi gerado a partir da prática da prospecção, ou seja, a partir das análises realizadas por meio da execução de processos de estudar o futuro.

Nesta tese, ao se mencionar a frase "orientação para a prática da prospecção do futuro", ela deve ser entendida como a decisão de prospectar, com a consequente mobilização para prospectar, resultando em estar orientado para o futuro ao ponto de agir para se lidar com as incertezas de futuro. Uma empresa orientada para a prática da prospecção do futuro seria aquela na qual seus gestores reconheçam a importância da atividade, pratiquem a mesma na proporção de sua relevância e finalmente obtenham resultados que contribuam, ou sejam considerados na tomada de decisões. 


\subsection{Objetivos da tese}

Para elucidar as questões relacionadas ao problema de pesquisa apresentadas no capítulo anterior, esta tese foi desenvolvida buscando atender a um objetivo geral, que é:

O1: Elaborar um modelo preliminar que apoie a integração da prospecção do futuro à gestão estratégica.

Como mencionado no capítulo anterior, os gestores têm importante papel em relação a decisões que contenham incertezas de futuro. Mesmo reconhecendo a dificuldade de se prever o futuro, ao ponto em que autores argumentam que ele é imprevisível, os gestores são pressionados a fazerem o melhor nessa situação (CHERMACK, 2011, ebook, cap. 2). Gestores não tem como fugir do dever de ter que antever o futuro, segundo Drucker (2010, p. 200).

Sendo necessário estudar o futuro para apoiar a tomada de decisões, e sabendo-se que se trata de um desafio significativo por ser difícil de prever, então é bem possível que esse processo não seja isento de limitações. Essas limitações podem reduzir o potencial de contribuição da prospecção do futuro nas decisões. Se isso for realidade, então a proposição de um modelo que apoie a integração entre prospecção e tomada de decisões, em projetos do âmbito da estratégia, se torna a principal contribuição desta tese.

Esse modelo talvez possa proporcionar uma forma preliminar de avaliar o quanto os gestores nas organizações estão preparados para lidar com incertezas de futuro. Adicionalmente, a sua aplicação poderia contribuir para que gestores e tomadores de decisão possam adotar uma maior orientação para o futuro, se isso for necessário em suas organizações.

Outros objetivos são derivados a partir do objetivo principal. Nesta tese, parte-se do pressuposto que a prática da prospecção é realizada de forma frequente nas organizações, pelo fato de que gestores que se envolvam com projetos estratégicos sejam desafiados por questões que apresentem incertezas de futuro. $\mathrm{O}$ modelo e sua estrutura proposta estão apresentados ao final do capítulo 3, que é focado na revisão conceitual.

Dessa forma, é pressuposto que a atividade de prospectar o futuro seja considerada importante, e assim se pratique prospecção nas organizações, e finalmente se chegue a 
resultados da prospecção que possam contribuir nas decisões em projetos. Portanto, os fenômenos relacionados à orientação para a prática da prospecção do futuro, como definida nesta tese, envolvem três etapas: (1) a motivação pela sua prática, que basicamente decorre da importância atribuída à atividade; (2) a prática da prospecção, por meio de alguma forma de prospecção, estruturada ou não; e (3) finalmente a contribuição dos seus resultados no processo de tomada de decisão em projetos estratégicos.

Para se atingir o objetivo principal proposto nesta tese, propõem-se os objetivos específicos descritos a seguir:

O2: Identificar quais temas portadores de incertezas de futuro são considerados mais importantes em projetos estratégicos.

O3: Identificar quais temas portadores de incertezas de futuro mobilizam mais os gestores para a prática da prospecção.

O4: Identificar quais temas obtém maior contribuição da prospecção na tomada de decisões em projetos estratégicos, e qual a contribuição geral da prospecção na análise dos temas portadores de incertezas de futuro.

O5: Identificar quais processos recomendados nas análises de prospecção do futuro são praticados nas organizações.

O6: Avaliar quanto os resultados da prospecção do futuro contribuíram para os processos de suporte à tomada de decisões em projetos estratégicos.

O7. Estudar o estado da prospecção do futuro nas organizações, avaliando em que grau os gestores percebem que a atividade está bem desenvolvida em suas organizações.

O desenvolvimento da pesquisa buscando atingir esses objetivos apresentados serviu de guia para responder às questões de pesquisa. A abordagem da metodologia de pesquisa é predominantemente exploratória, como mostrado no capítulo de metodologia mais adiante. 


\section{A PROSPECÇÃO DO FUTURO E OS PROJETOS ESTRATÉGICOS: UMA REVISÃO CONCEITUAL}

\subsection{Introdução}

Neste capítulo são apresentados os conceitos relacionados com a prospecção do futuro, os quais são relevantes para o desenvolvimento desta tese. Algumas relações entre prospecção e estratégia empresarial também são abordadas, sob a ótica do que é recomendado pelos autores da prospecção.

O capítulo é dividido em seções, contendo:

(1) Esta seção de introdução, para apresentar a estrutura das divisões do capítulo;

(2) Uma seção contendo dois levantamentos de produção acadêmica sobre prospecção do futuro. O primeiro levantamento apresenta a bibliometria da produção contendo termos relacionados à prospecção do futuro, com escopo geral na área de administração, negócios e contabilidade, portanto, sem necessariamente ser sobre prospecção do futuro (futures studies). O segundo levantamento é com escopo mais concentrado na produção sobre a prospecção do futuro dentro da área de administração, negócios e contabilidade.

(3) Aprofundamento dos conceitos relacionados mais fortemente com a prospecção e, especialmente com seus objetivos, representando os temas abordados nesta tese.

(4) Conceitos relacionados com a prospecção do futuro e a estratégia.

(5) Um sumário integrando os principais fundamentos utilizados nesta tese.

(6) Finalmente, uma síntese com fundamentos que suportam o modelo conceitual teórico seguido no desenvolvimento desta tese. 


\subsection{Prospecção do futuro: Levantamento da produção acadêmica}

Esta seção e suas respectivas subseções são dedicadas à produção acadêmica sobre prospecção do futuro. O objetivo é ilustrar o que se tem realizado na academia sobre o tema, tendo sido utilizada inicialmente para atualizar referências teóricas mais recentes, quando aplicáveis.

Caso o leitor esteja mais interessado no que foi utilizado na fundamentação, talvez seja recomendável ir direto à seção 3.3, e dali adiante.

No banco de dados da SCOPUS (www.scopus.com) foi realizado um levantamento da produção acadêmica sobre prospecção do futuro (em 31/12/2015).

A escolha deste banco é devido a alguns fatores:

(1) Ela é multidisciplinar, o que favorece o levantamento, uma vez que o tema aqui pesquisado também tem características de ser multidisciplinar.

(2) Esta base de dados permite exportar arquivos de registros bem completos, em formato RIS (Research Information Systems), que é um formato possível de ser manipulado com ferramentas de análise bibliométrica como BIBEXCEL e PAJEK, utilizados para o desenvolvimento desta tese.

(3) Em termos de quantidades de documentos contidos na base SCOPUS (da Elsevier), ela apresenta praticamente os mesmos resultados da base Web Of Science (da Thomson Reuters), que foi durante um bom tempo uma boa referência para a produção científica. Segundo Archambault et al (2009), os resultados mostram que a correlação entre as duas bases é muito elevada $(0,99)$.

(4) A montagem de um mapa visual de autores baseada em co-ocorrências (cooccurrences) é possível a partir de um arquivo em formato RIS utilizando-se o BIBEXCEL e o PAJEK. No caso da base SCOPUS, ela permite considerar todos os autores citados, enquanto que a base Web of Science permite montar mapa considerando o primeiro autor de cada artigo citado, o que limita um pouco o estudo bibliométrico de co-ocorrências. 


\subsubsection{Produção acadêmica na administração: contendo termos da prospecção}

Ao se buscar os documentos relacionados com prospecção, foi utilizado o seguinte conjunto de palavras a seguir, como chave de busca na base SCOPUS (em 31/12/2015):

( TITLE-ABS-KEY ("futures studies" OR forecasting OR backcasting OR future OR futurology OR "futures studies" OR "futures research" OR "emerging patterns" OR prediction OR anticipation OR prospective OR foresight OR roadmap OR vision)) AND ( LIMIT-TO ( SUBJAREA , "BUSI" ) )

Esses termos são comumente encontrados como referência à prospecção do futuro (BOURGEOIS, 2014). A quantidade de termos do autor é bem maior do que a chave de busca, contudo, foram escolhidos os termos mais abrangentes que, ainda preservem relação com processos de prospecção.

Alguns dos termos de Bourgeois (2014) são mais específicos de métodos e ferramentas, então foram desconsiderados para não gerar viés na busca (e.g. scenario, delphi). Já outros são também encontrados comumente em outras áreas do conhecimento (e.g. proactive, normative, system, model), então foram desconsiderados para não acrescentar documentos que não tenham relação com o tema de pesquisa.

O foco da busca foi apenas nos termos da chave de busca, portanto, ela resultou em toda a produção acadêmica que continha os termos, independentemente se o documento se tratava especificamente sobre prospecção do futuro (futures studies). Então os resultados incluem outras áreas do conhecimento da administração. Na próxima seção estão mostrados os resultados com foco na área de prospecção do futuro especificamente. O leitor poderá ir direto a ela caso não deseje ver os resultados desta seção, que foi incluída na tese para ilustrar a multidisciplinariedade da área de prospecção do futuro dentro da administração.

Na busca com o foco na área de administração, negócios e contabilidade, não foi utilizado o termo chave "futures studies" com o conector AND associado aos termos da chave de busca, porque o objetivo inicial do levantamento foi capturar tudo relacionado com os termos, mesmo sabendo que isso poderia gerar algum ruído no levantamento. 
O total de documentos atingiu 96.069. A evolução histórica da quantidade de documentos encontrados nessa busca geral está mostrada no gráfico a seguir.

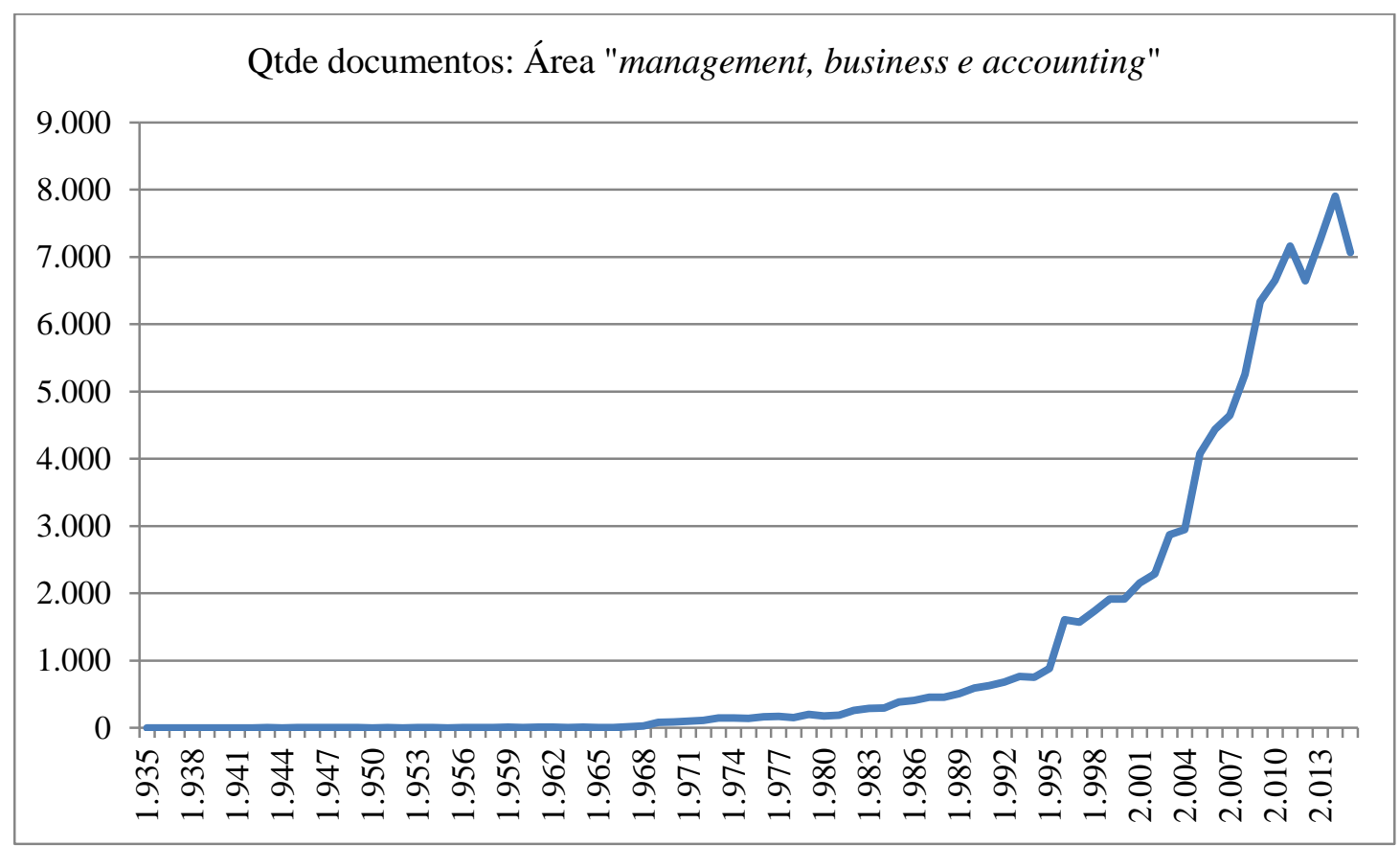

Gráfico 1 - Quantidade de documentos com os termos relacionados à prospecção Fonte: Base de dados SCOPUS (em 31/12/2015)

Nota-se que a produção acadêmica é crescente, sendo que a aceleração da produção ocorre a partir de meados de 1995. Isso pode ter relação com a maior integração econômica e o maior uso de novas tecnologias, gerando maior complexidade nas análises sobre o futuro, conforme discutido no capítulo 2.

Os journals que mais publicaram artigos e demais documentos da produção acadêmica podem ser vistos no gráfico a seguir (20 maiores publicadores). 


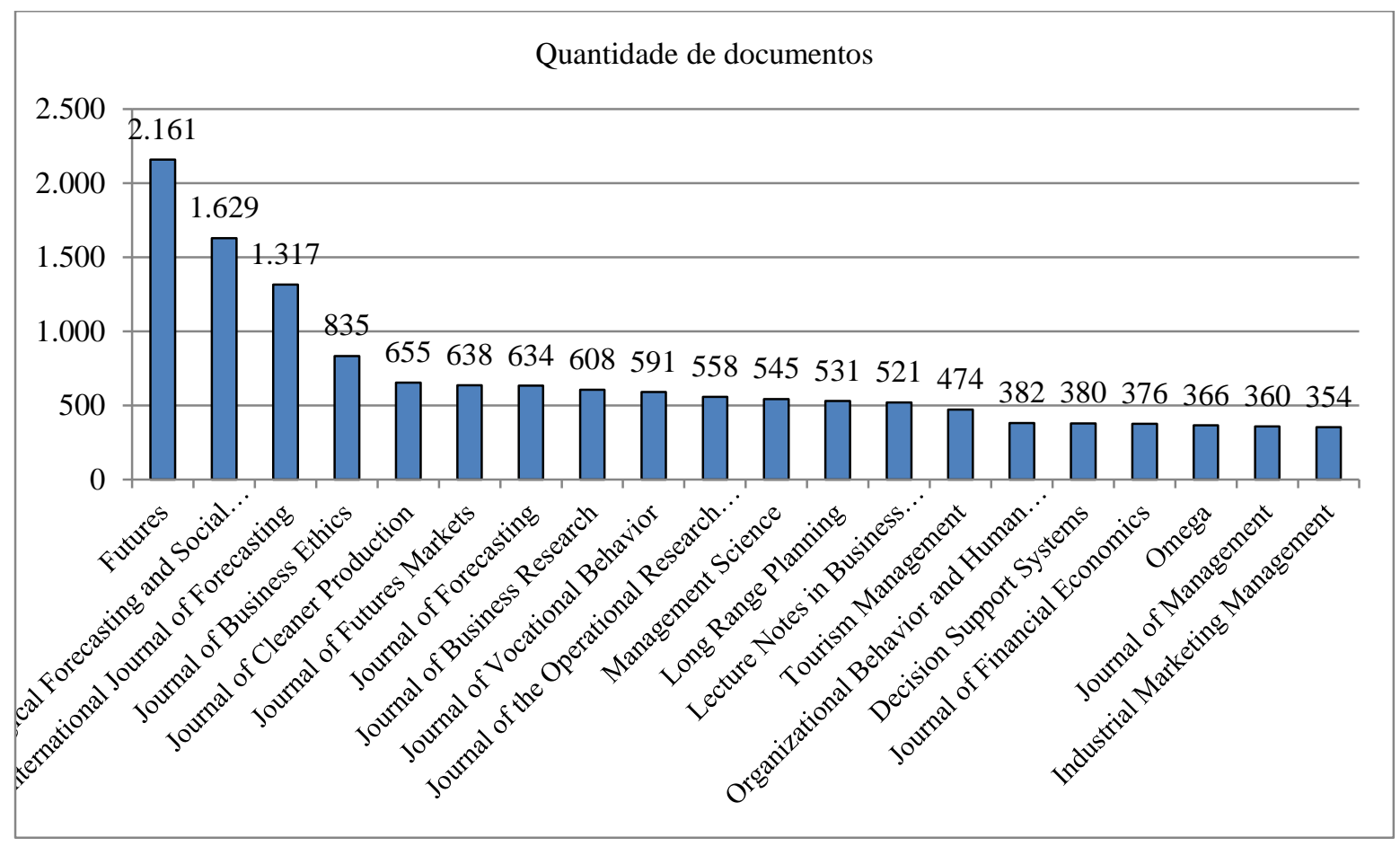

Gráfico 2 - Journals que mais publicaram documentos com os termos da prospecção do futuro Fonte: Base de dados SCOPUS (em 31/12/2015)

Importante mencionar que os quatro journals mais focados em estudos do futuro - Futures, Technological Forecasting and Social Change, International Journal of Forecasting $e$ Journal of Forecasting - são editados desde antes de 1995. Este fato ilustra que o crescimento da quantidade de publicações, a partir de 1995, pode ser oriundo também do aumento das publicações que contenham os termos tipicamente encontrados nos estudos sobre o futuro, e isso em quaisquer outros journals, não necessariamente focados em prospecção do futuro. Esse resultado talvez ilustre o que disseram Chermack (2011) e Hines e Bishop (2013), sobre a aceleração das mudanças presenciadas no passado recente, o que possivelmente esteja induzindo pesquisadores a considerarem cada vez mais, em seus estudos, aspectos relacionados ao futuro.

A tabela de origem dos dados do gráfico anterior é mostrada a seguir, para facilitar a identificação dos journals. 
Tabela 1 - Journals e suas respectivas quantidades de documentos publicados (contendo termos sobre prospecção)

\begin{tabular}{|l|r|}
\hline \multicolumn{1}{|c|}{ Journal } & $\begin{array}{c}\text { Quantidade } \\
\text { de } \\
\text { documentos }\end{array}$ \\
\hline Futures & 2.161 \\
\hline Technological Forecasting and Social Change & 1.629 \\
\hline International Journal of Forecasting & 1.317 \\
\hline Journal of Business Ethics & 835 \\
\hline Journal of Cleaner Production & 655 \\
\hline Journal of Futures Markets & 638 \\
\hline Journal of Forecasting & 634 \\
\hline Journal of Business Research & 608 \\
\hline Journal of Vocational Behavior & 591 \\
\hline Journal of the Operational Research Society & 558 \\
\hline Management Science & 545 \\
\hline Long Range Planning & 531 \\
\hline Lecture Notes in Business Information Processing & 521 \\
\hline Tourism Management & 474 \\
\hline Organizational Behavior and Human Decision Processes & 382 \\
\hline Decision Support Systems & 380 \\
\hline Journal of Financial Economics & 376 \\
\hline Omega & 366 \\
\hline Journal of Management & 360 \\
\hline Industrial Marketing Management & 354 \\
\hline
\end{tabular}

Fonte: Fonte: Base de dados SCOPUS (em 31/12/2015)

Os trinta países que mais publicaram documentos estão mostrados no gráfico a seguir. 


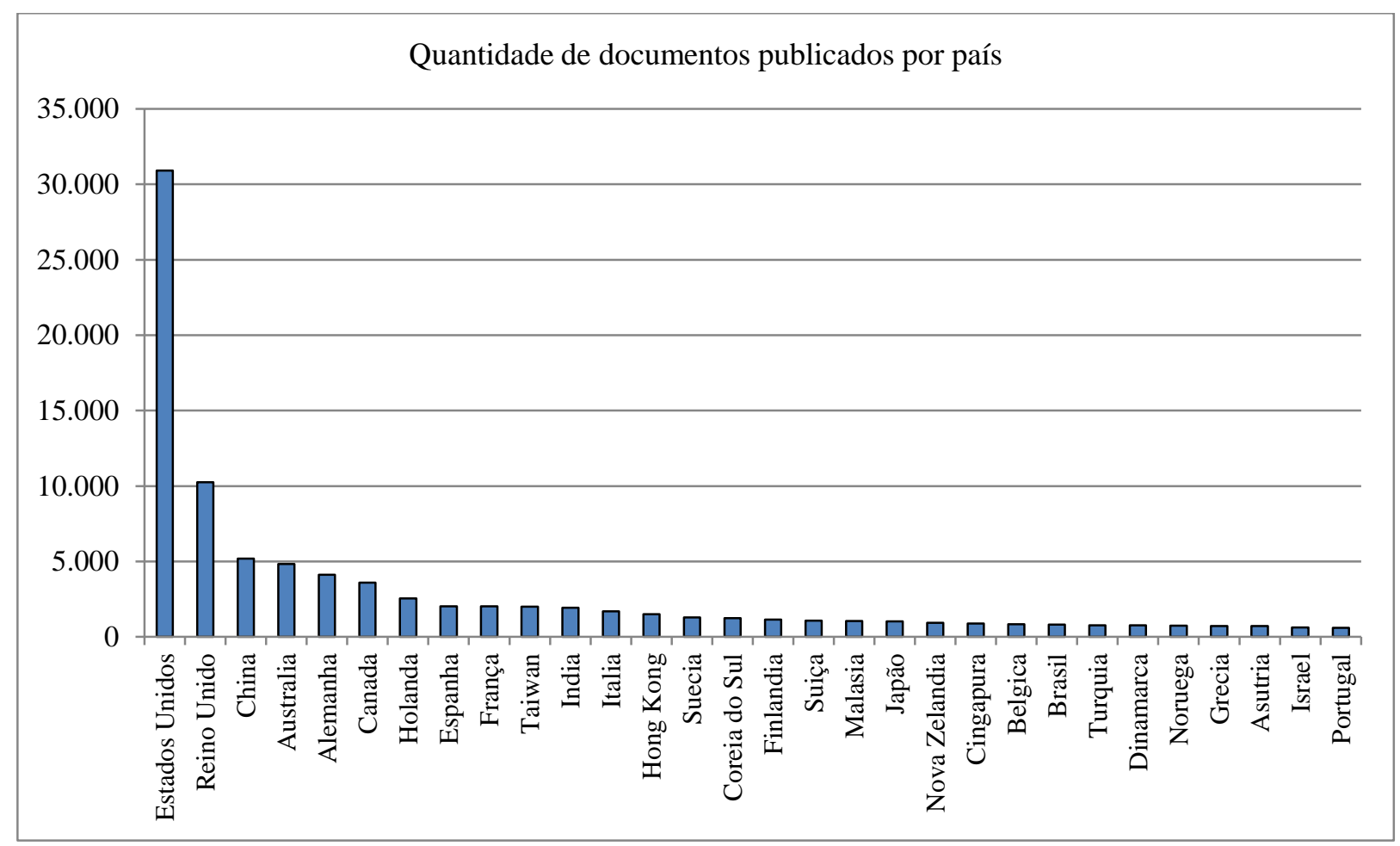

Gráfico 3 - Países que mais publicaram documentos com os termos da prospecção Fonte: Base de dados SCOPUS (em 31/12/2015)

A tabela do gráfico está mostrada a seguir. 
Tabela 2 - Quantidade de documentos publicados por país Fonte: Base de dados SCOPUS (em 31/12/2015)

\begin{tabular}{|c|c|c|}
\hline País & Quantidade de documentos & $\%$ \\
\hline Estados Unidos & 30.902 & $32,2 \%$ \\
\hline Reino Unido & 10.259 & $10,7 \%$ \\
\hline China & 5.205 & $5,4 \%$ \\
\hline Austrália & 4.832 & $5,0 \%$ \\
\hline Alemanha & 4.122 & $4,3 \%$ \\
\hline Canadá & 3.599 & $3,7 \%$ \\
\hline Holanda & 2.545 & $2,6 \%$ \\
\hline Espanha & 2.038 & $2,1 \%$ \\
\hline França & 2.033 & $2,1 \%$ \\
\hline Taiwan & 2.013 & $2,1 \%$ \\
\hline Índia & 1.935 & $2,0 \%$ \\
\hline Itália & 1.711 & $1,8 \%$ \\
\hline Hong Kong & 1.518 & $1,6 \%$ \\
\hline Suécia & 1.291 & $1,3 \%$ \\
\hline Coréia do Sul & 1.248 & $1,3 \%$ \\
\hline Finlândia & 1.143 & $1,2 \%$ \\
\hline Suíça & 1.075 & $1,1 \%$ \\
\hline Malásia & 1.066 & $1,1 \%$ \\
\hline Japão & 1.028 & $1,1 \%$ \\
\hline Nova Zelândia & 946 & $1,0 \%$ \\
\hline Cingapura & 897 & $0,9 \%$ \\
\hline Bélgica & 843 & $0,9 \%$ \\
\hline Brasil & 813 & $0,8 \%$ \\
\hline Turquia & 777 & $0,8 \%$ \\
\hline Dinamarca & 766 & $0,8 \%$ \\
\hline Noruega & 737 & $0,8 \%$ \\
\hline Grécia & 729 & $0,8 \%$ \\
\hline Áustria & 714 & $0,7 \%$ \\
\hline Israel & 637 & $0,7 \%$ \\
\hline Portugal & 598 & $0,6 \%$ \\
\hline Demais países & 8.049 & $8,4 \%$ \\
\hline
\end{tabular}

O Brasil se encontra em $23^{\circ}$ lugar na quantidade de publicações que não sejam especificamente sobre prospecção do futuro, mas que contenham termos comumente encontrados em documentos sobre prospecção do futuro.

O tipo de documento publicado pode ser visualizado no gráfico a seguir. 


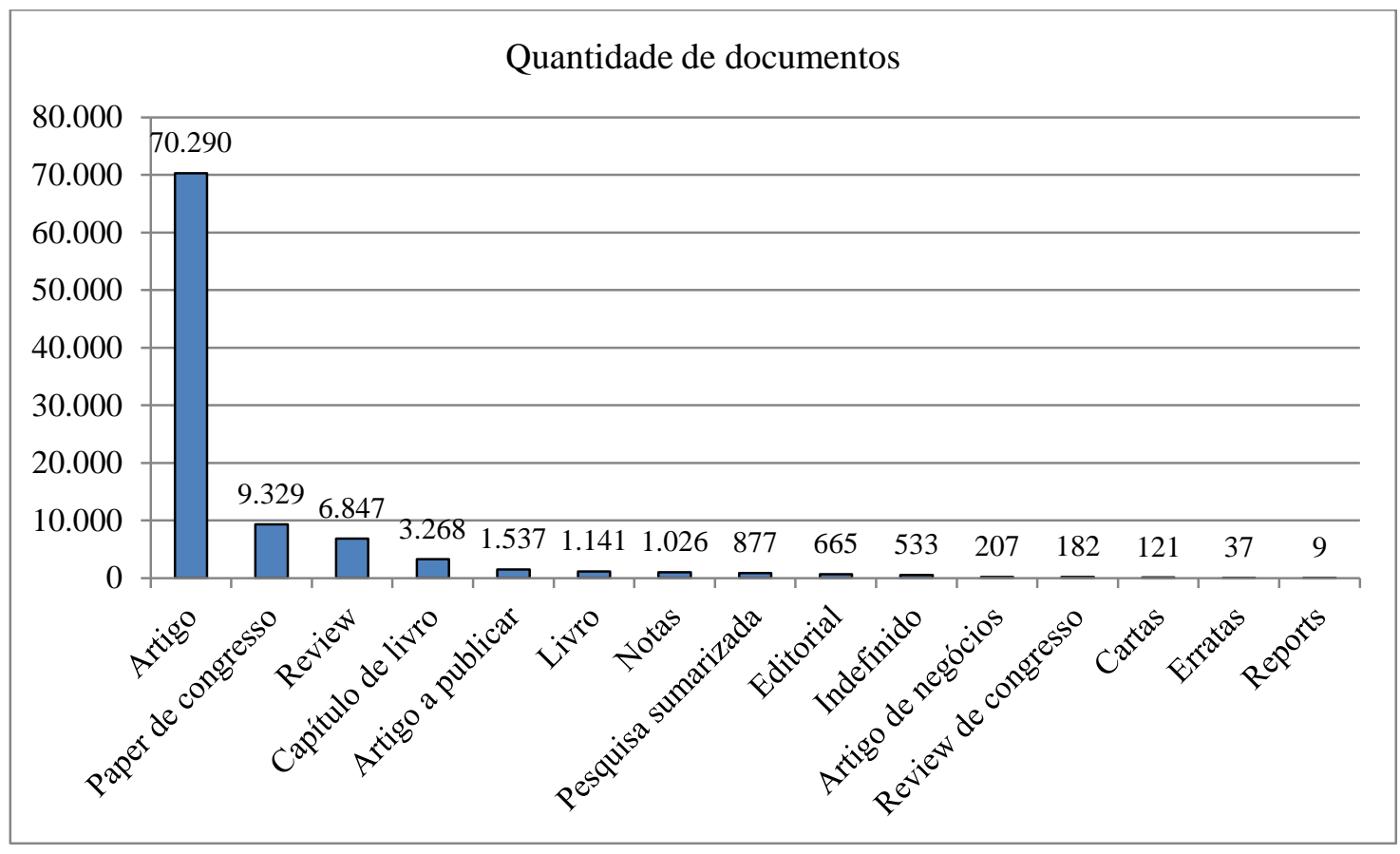

Gráfico 4 - Tipo de documento publicado

Fonte: Base de dados SCOPUS (em 31/12/2015)

O total da área de administração, negócios e contabilidade é de 96.069 documentos. Se não for restrito a essas áreas, o total de documentos sobe para 196.958, e as áreas de administração, negócios e contabilidade representam quase $49 \%$ do total, ficando em primeiro lugar. Em segundo lugar aparecem as áreas de economia, econometria e finanças, com 10\% e em terceiro lugar as ciências sociais com $9 \%$. Na sequência vem engenharia $(8 \%)$, ciências da decisão $(6 \%)$, psicologia (4\%), ciências da computação $(4 \%)$, ciências dos materiais $(2 \%)$ e ciências do ambiente (2\%) em nono lugar (Fonte: base de dados SCOPUS em 31/12/2105).

Este levantamento geral mostra que os termos relacionados com o futuro são encontrados na produção acadêmica e, em especial, a produção acelerou nos últimos vinte anos. Devido à grande quantidade de documentos, não é possível fazer um detalhamento maior, pois o banco de dados da SCOPUS não permite exportar mais de 2.000 registros com todos os campos bibliográficos. Essa limitação impede fazer um mapa de autores, por exemplo.

$\mathrm{Na}$ próxima seção é mostrado um detalhamento maior, com foco específico no tema pesquisado nesta tese - a prospecção do futuro. 


\subsubsection{Produção acadêmica na administração: foco específico na prospecção do futuro}

Para se identificar a produção acadêmica que se concentra em prospecção do futuro, foi utilizado na chave de busca utilizada na seção anterior, o conjunto de termos "futures studies" conectado pelo operador $A N D$ para filtrar a produção com foco em estudos do futuro. Esse termo é largamente utilizado nos artigos sobre a área do conhecimento de estudos do futuro.

A chave de busca utilizada, portanto, foi:

(TITLE-ABS-KEY("futures studies") AND TITLE-ABS-KEY(forecasting OR backcasting OR future OR futurology OR "futures studies" OR "futures research" OR "emerging patterns" OR prediction OR anticipation OR prospective OR futurology OR foresight $O R$ "driving forces" OR roadmap OR vision)) AND ( LIMIT-TO(SUBJAREA, "BUSI" ))

O total de documentos atingiu 2.265, representando 2,36\% do total de documentos obtido na busca anterior. A evolução histórica da quantidade de documentos encontrados nessa busca específica na produção sobre futures studies está mostrada no gráfico a seguir.

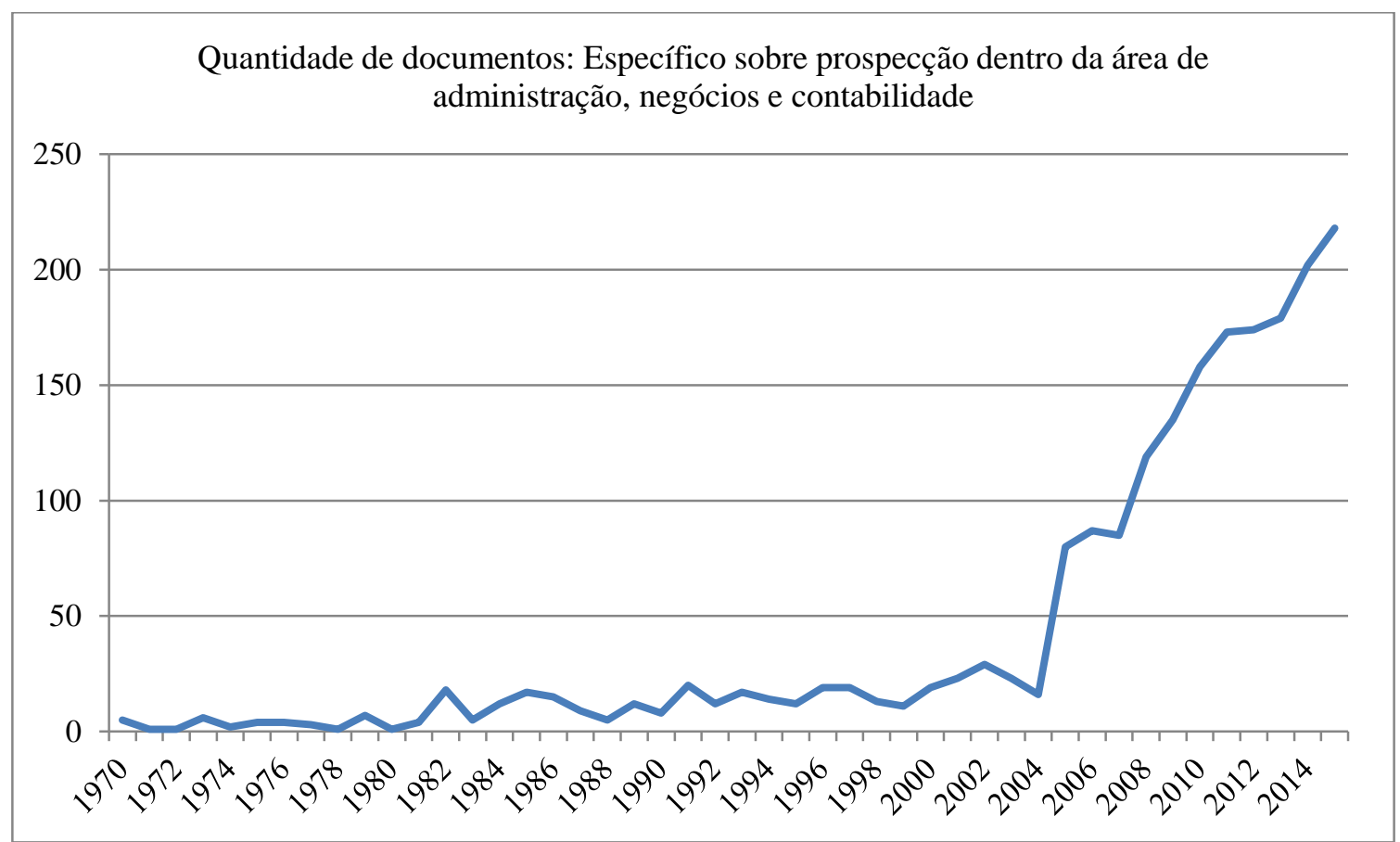

Gráfico 5 - Quantidade de documentos com foco específico na prospecção do futuro Fonte: Base de dados SCOPUS (em 07/01/2016) 
Com o foco mais estreito, pela adição da chave futures studies conectada pelo conector $A N D$, observa-se que a quantidade de documentos também apresenta perfil crescente, com a diferença de que a aceleração da produção com foco específico em futures studies ocorreu dez anos depois daquela observada para a produção geral sem discriminar foco em futures studies.

Os journals que mais publicaram artigos e documentos, com foco específico sobre prospecção do futuro, podem ser vistos no gráfico a seguir (os 20 maiores publicadores).

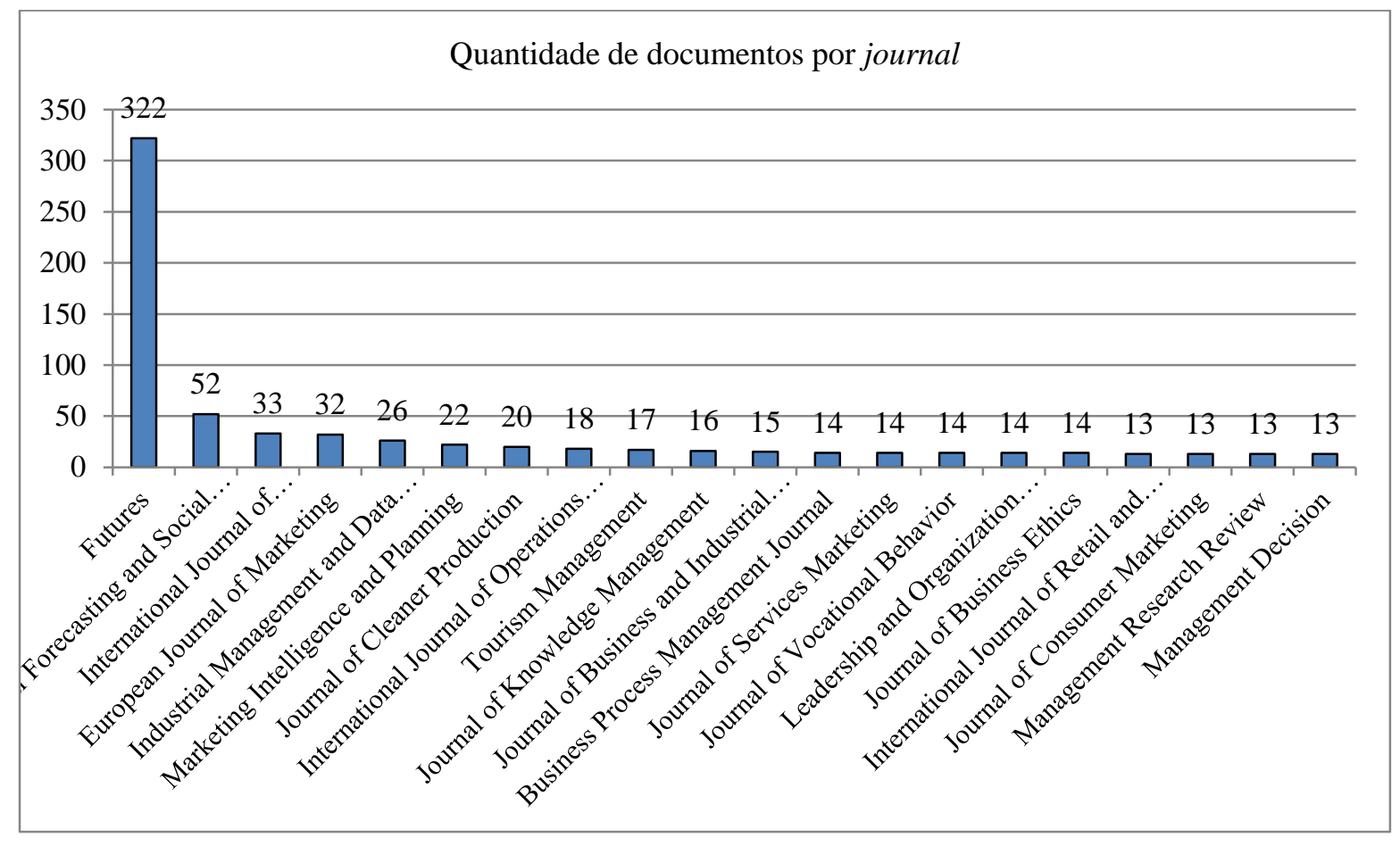

Gráfico 6 - Journals que mais publicaram sobre prospecção do futuro Fonte: Base de dados SCOPUS (em 07/01/2016)

O percentual de participação de artigos do journal Futures, sobre o total de documentos publicados aumenta para 14,2\% nesta busca específica sobre prospecção do futuro. Na busca anterior, o percentual para este journal foi de pouco mais de 2,2\%. No caso do Technological Forecasting and Social Change, o percentual de documentos nesta busca foi de 2,3\%, enquanto que na anterior havia de sido de $1,7 \%$. A explicação para isso se deve ao fato do Futures se concentrar especificamente no estudo das metodologias de prospecção, enquanto que os outros são de prospecção do futuro de forma geral. O efeito disso é que os outros journals publicam artigos que são sobre a aplicação das metodologias, visando apresentar resultados da utilização delas. Por decorrência disso, os artigos desses journals não trazem necessariamente a chave futures studies no seu conteúdo, o que explica porque o 
Technological Forecasting and Social Change tenha somente 52 artigos nesta busca aqui realizada.

A tabela de origem dos dados do gráfico anterior é mostrada a seguir, para facilitar a identificação dos journals.

Tabela 3 - Journals e suas respectivas quantidades de documentos publicados (sobre prospecção do futuro)

\begin{tabular}{|l|r|}
\hline \multicolumn{1}{|c|}{ Journal } & $\begin{array}{c}\text { Qtde de } \\
\text { documentos } \\
\text { por journal }\end{array}$ \\
\hline Futures & 322 \\
\hline Technological Forecasting and Social Change & 52 \\
\hline International Journal of Contemporary Hospitality Management & 33 \\
\hline European Journal of Marketing & 32 \\
\hline Industrial Management and Data Systems & 26 \\
\hline Marketing Intelligence and Planning & 22 \\
\hline Journal of Cleaner Production & 20 \\
\hline International Journal of Operations and Production Management & 18 \\
\hline Tourism Management & 17 \\
\hline Journal of Knowledge Management & 16 \\
\hline Journal of Business and Industrial Marketing & 15 \\
\hline Business Process Management Journal & 14 \\
\hline Journal of Services Marketing & 14 \\
\hline Journal of Vocational Behavior & 14 \\
\hline Leadership and Organization Development Journal & 14 \\
\hline Journal of Business Ethics & 14 \\
\hline International Journal of Retail and Distribution Management & 13 \\
\hline Journal of Consumer Marketing & 13 \\
\hline Management Research Review & 13 \\
\hline Management Decision & 13 \\
\hline
\end{tabular}

Fonte: Base de dados SCOPUS (em 07/01/2016)

Os trinta países que mais publicaram documentos sobre prospecção do futuro estão mostrados no gráfico a seguir. 


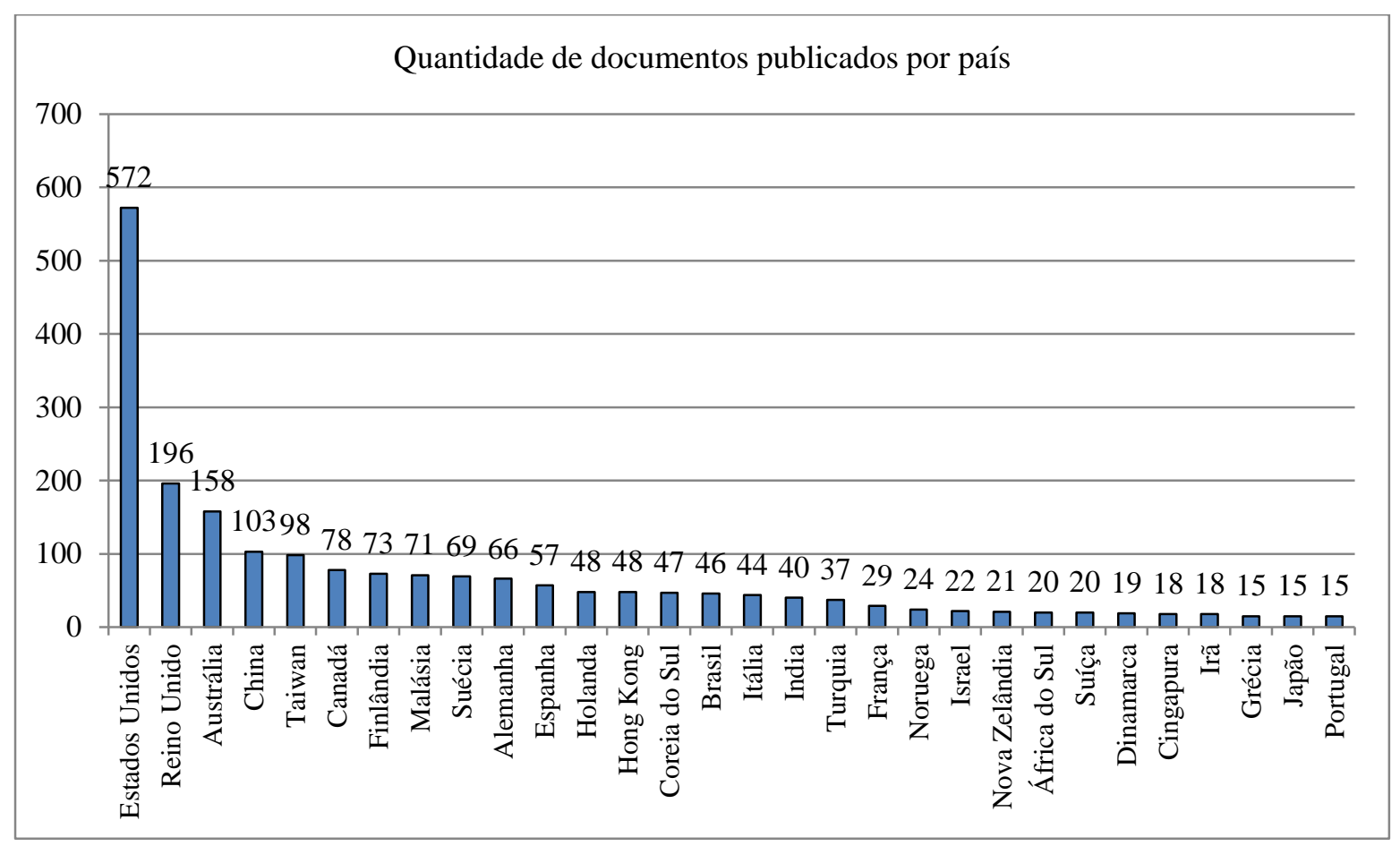

Gráfico 7 - Os 30 primeiros países (pela quantidade de documentos sobre prospecção) Fonte: Base de dados SCOPUS (em 07/01/2016)

Nessa lista o Brasil está em $15^{\circ}$ lugar. Esta melhora na posição do país tem relação, possivelmente, com o fato de que o Brasil pesquise mais sobre prospecção dentro da área de administração, negócios e contabilidade. Isso se comparado com os demais países, que talvez pesquisem relativamente mais em outras áreas do conhecimento também (com foco geral na produção contendo termos da prospecção nas publicações). O Brasil produziu 2,0\% das publicações sobre prospecção do futuro (com foco específico em futures studies), enquanto que esse percentual cai para $0,8 \%$ se forem consideradas as publicações gerais que contenham termos sobre prospecção (não necessariamente sobre futures studies).

A tabela de países pode ser vista a seguir. 
Tabela 4 - Quantidade de documentos por país (os primeiros 30 países)

\begin{tabular}{|c|c|}
\hline País & Quantidade de documentos \\
\hline Estados Unidos & 572 \\
\hline Reino Unido & 196 \\
\hline Austrália & 158 \\
\hline China & 103 \\
\hline Taiwan & 98 \\
\hline Canadá & 78 \\
\hline Finlândia & 73 \\
\hline Malásia & 71 \\
\hline Suécia & 69 \\
\hline Alemanha & 66 \\
\hline Espanha & 57 \\
\hline Holanda & 48 \\
\hline Hong Kong & 48 \\
\hline Coreia do Sul & 47 \\
\hline Brasil & 46 \\
\hline Itália & 44 \\
\hline Índia & 40 \\
\hline Turquia & 37 \\
\hline França & 29 \\
\hline Noruega & 24 \\
\hline Israel & 22 \\
\hline Nova Zelândia & 21 \\
\hline África do Sul & 20 \\
\hline Suíça & 20 \\
\hline Dinamarca & 19 \\
\hline Cingapura & 18 \\
\hline Irã & 18 \\
\hline Grécia & 15 \\
\hline Japão & 15 \\
\hline Portugal & 15 \\
\hline Demais países & 178 \\
\hline
\end{tabular}

Fonte: Base de dados SCOPUS (em 07/01/2016)

As publicações pelo seu tipo de documento publicado podem ser vistas no gráfico a seguir. 


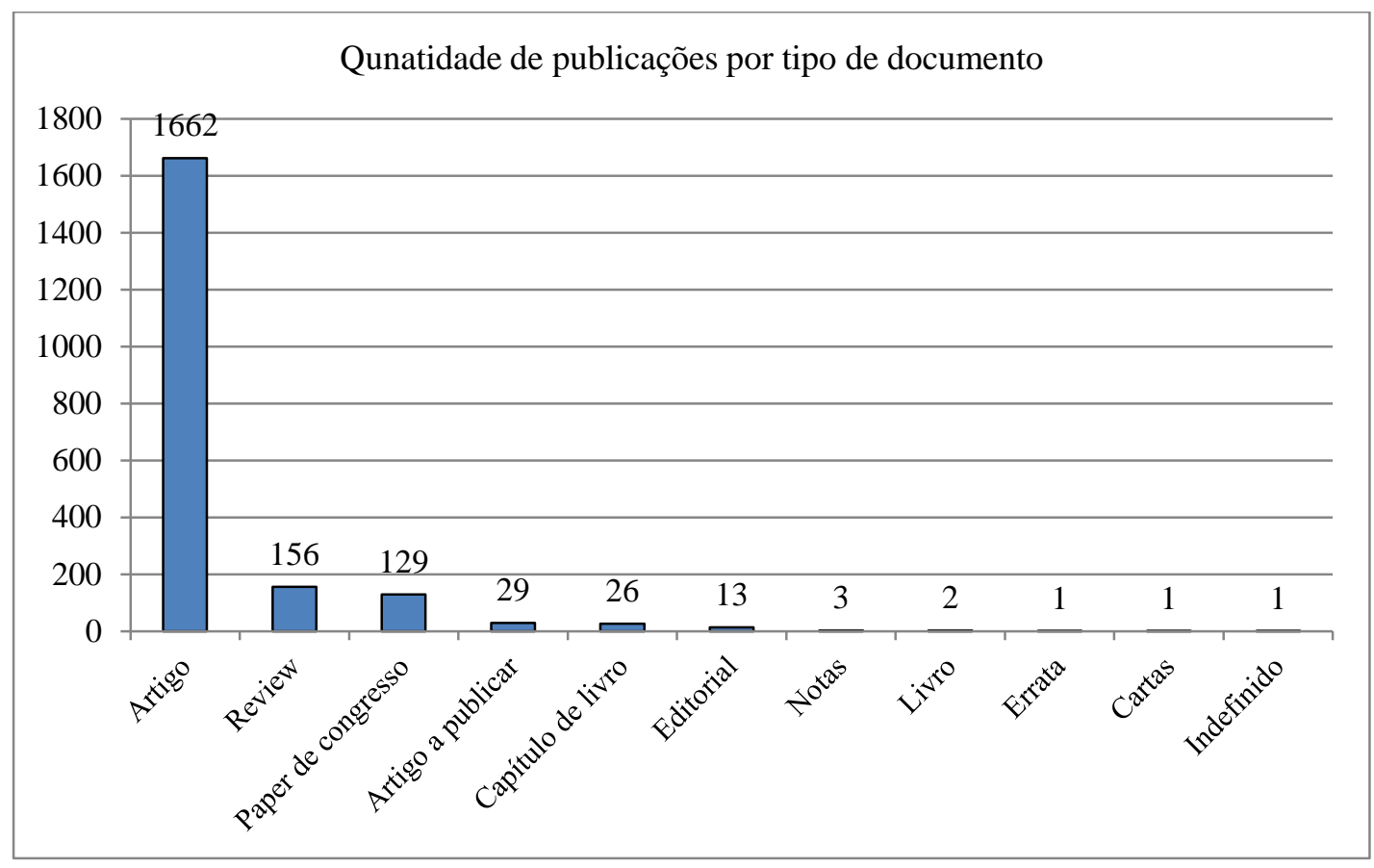

Gráfico 8 - Documentos publicados por tipo: Com foco em prospecção do futuro Fonte: Base de dados SCOPUS (em 07/01/2016)

Em síntese, o total das áreas de administração, negócios e contabilidade especificamente sobre prospecção do futuro é de 2.265 documentos. (Fonte: base de dados SCOPUS em 07/01/2106). Este levantamento com foco específico em futures studies mostra que a produção acadêmica acelerou nos dez últimos anos.

\subsubsection{Análise de co-ocorrências entre autores}

Como a quantidade de artigos dessa busca específica na área de estudos do futuro resultou em quantidade próxima de dois mil artigos, foi possível realizar uma análise de co-ocorrências entre autores. A SCOPUS permite que se exporte arquivo com até dois mil itens, contendo todos os dados bibliográficos dos documentos, e isso em formato RIS (Research Information System). Conforme mencionado anteriormente, este formato pode ser manipulado por softwares de análise bibliométrica, como o BIBEXCEL, que é o que foi utilizado para analisar as co-ocorrências para formar o mapa de autores. Este, por sua vez, foi montado utilizando o arquivo de redes gerado pelo BIBEXCEL, o qual pode ser manipulado pelo software de montagem de mapas PAJEK.

Como a quantidade de artigos é muito grande (2.000 artigos na base exportada), um mapa de autores que inclua todas as co-ocorrências (formação de pares de autores): Pares estes, formados entre os autores citados nos artigos versus uma lista de autores que aparecem com 
frequência maior que 30 vezes nesta mesma base. Esse processo de formar pares de autores gera um mapa completamente poluído, pois a quantidade de conexões (pares de autores) a partir de um banco de 2.000 artigos é enorme. Este mapa não está incluído aqui, pois é inviável qualquer tipo de visualização de redes de co-ocorrências de autores com a quantidade de conexões geradas a partir de 2.000 artigos.

Autores como Leydesdorff e Vaughan (2006) apontam limitações no processo de utilizar coocorrências entre autores. Aqui nesta tese, contudo, utilizou-se esta análise apenas para visualizar que autores da área de prospecção se conectam com quais autores das demais áreas, e quais seriam essas áreas.

Por meio de um método bibliométrico visual, é possível se notar que a produção acadêmica da prospecção se conecta com as demais áreas da academia, e mais diretamente com a de estratégia e a de teoria da decisão. Esse fato não é surpresa, pois seria para suporte a decisões estratégicas que a prospecção do futuro tem como principal aplicação.

Para visualizar melhor as conexões entre os pares de autores, é possível eliminar as conexões por meio de relevância crescente. Em outras palavras, removem-se as conexões gradativamente aumentando a relevância das conexões a cada iteração. Os resultados desse processo estão apresentados nos gráficos mais adiante.

Lembrando novamente dos termos de busca utilizados:

(TITLE-ABS-KEY("futures studies") AND TITLE-ABS-KEY(forecasting OR backcasting OR future OR futurology OR "futures studies" OR "futures research" OR "emerging patterns" OR prediction OR anticipation OR prospective OR futurology OR foresight OR "driving forces" OR roadmap OR vision)) AND ( LIMIT-TO(SUBJAREA, "BUSI" ) )

Os anos de publicação vão de 1970 (inclusive) até o presente momento (JAN/2016, no caso).

Na primeira iteração, foram removidas as conexões entre autores com relevância menor que 4, o que resultou em um mapa ainda de difícil visualização, mas já trazendo alguma possibilidade de enxergar conexões entre autores da área de estudos do futuro. Os autores que se destacam à direita são alguns da área de prospecção do futuro. 


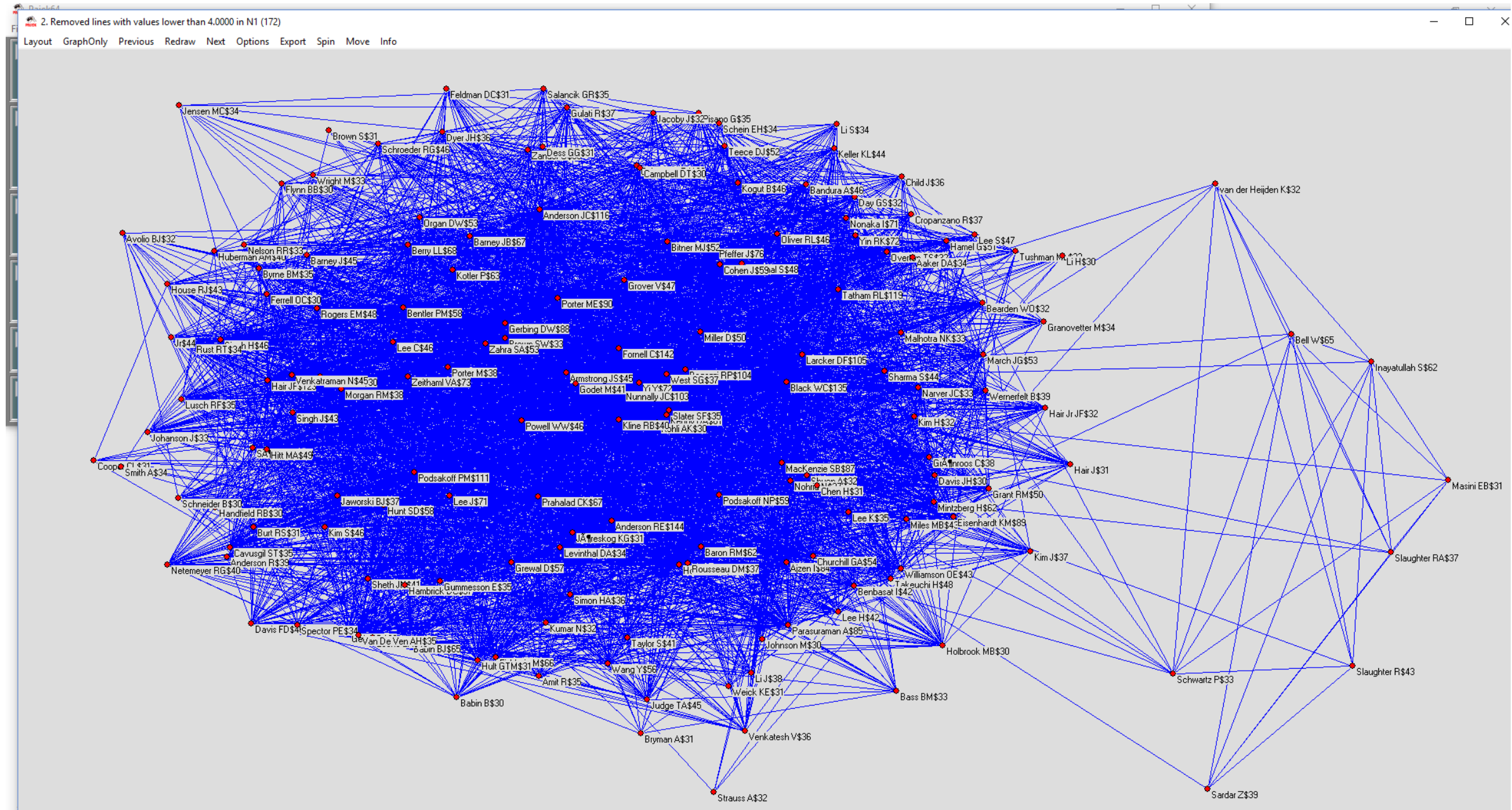

IH

Ilustração 1 - Mapa de autores pelas co-ocorrências (relevância >4)

Fonte: Análise do autor (baseada no banco de dados SCOPUS)

A próxima iteração removeu as conexões com relevância menor que 6. Os resultados estão a seguir. 


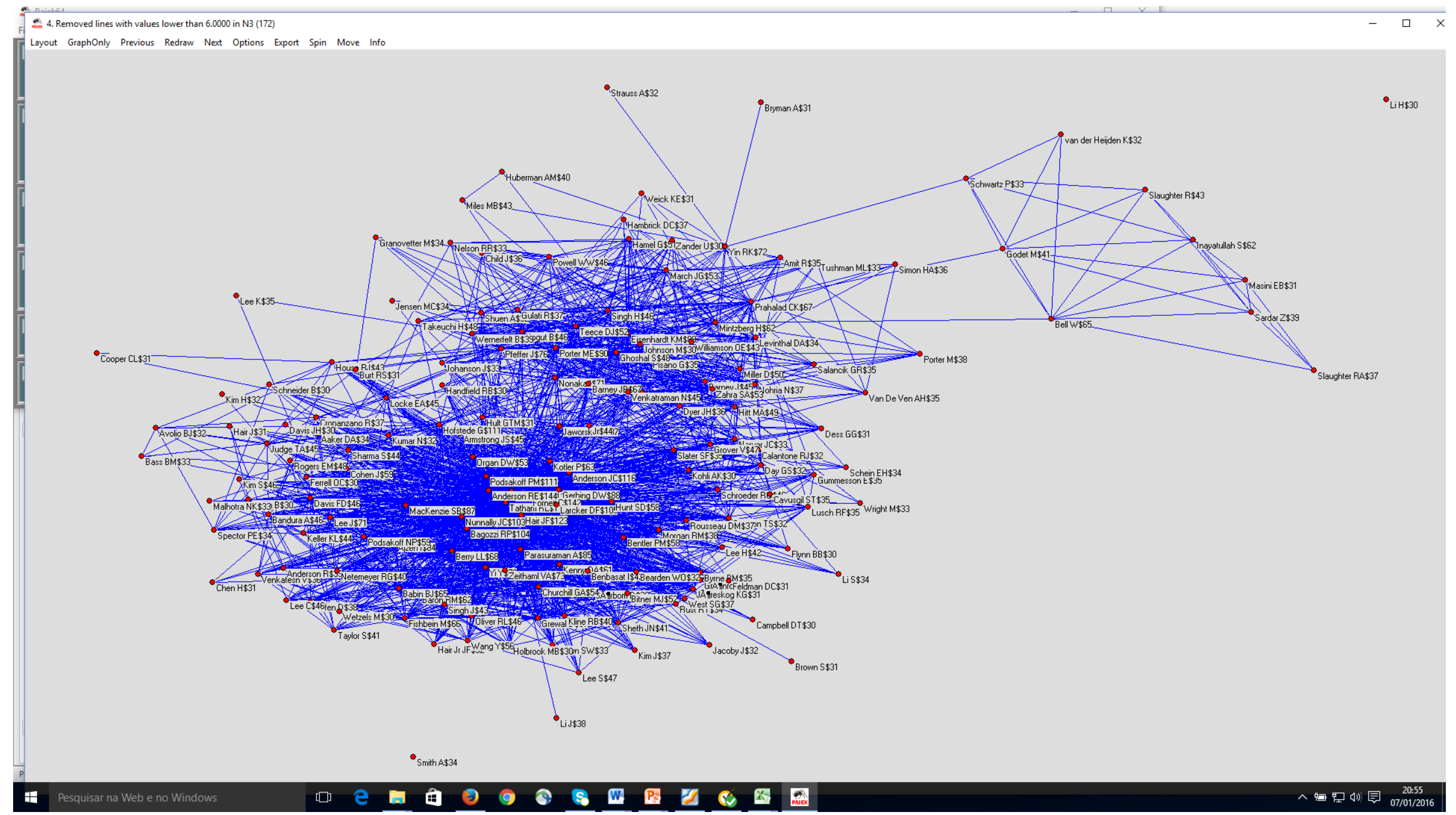

Ilustração 2 - Mapa de autores pelas co-ocorrências (relevância >6)

Fonte: Análise do autor (baseada no banco de dados SCOPUS) 
Nesse mapa, observa-se que à direita se forma um agrupamento de autores que são os que publicaram mais sobre prospecção, como Wendell Bell, Sohail Innayatullah, Michel Godet, Ziauddin Sardar, Richard Slaughter, Eleonora Masini, Peter Schwartz e Kees Van Der Heijden.

Executando mais um passo iterativo, agora retirando as conexões com relevância menor que 8 , temos o seguinte mapa na próxima página. 


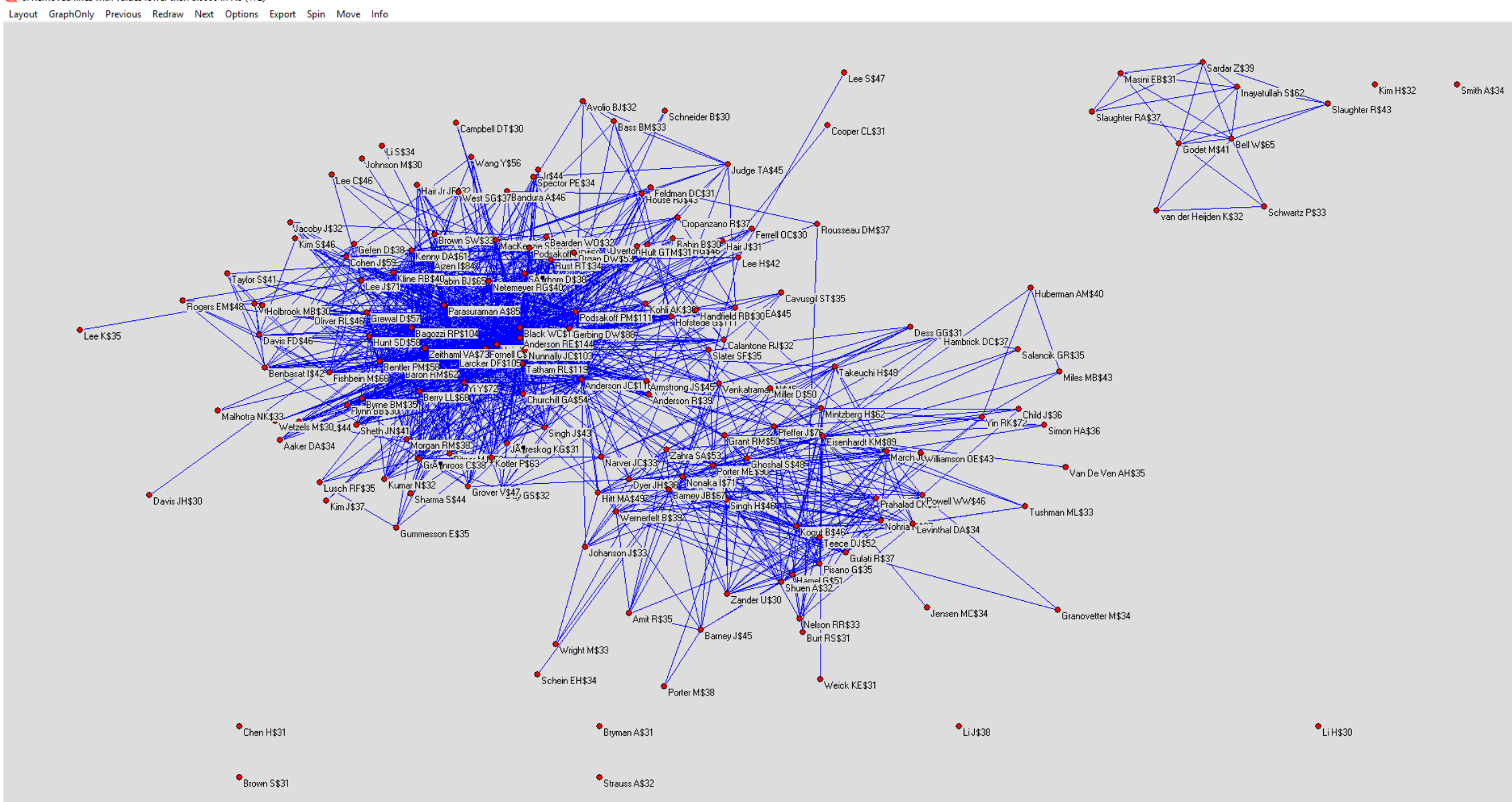

Ilustração 3 - Mapa de autores pelas co-ocorrências (relevância >8)

Fonte: Análise do autor (baseada no banco de dados SCOPUS) 
No mapa acima se observa que os autores mais frequentes na área de prospecção do futuro já formam um cluster, e pode-se observar também que os autores mais frequentes na área de estratégia também começam a formar outro cluster mais ao centro da figura. Ali estão autores como Prahalad, M. Porter, H. Mintzberg, K. Eisenhardt, M. Hitt, G. Hamel. Também se observa que autores da área da teoria da decisão são encontrados nesse cluster, como $\mathrm{H}$. Simon, J. March e a própria K. Eisenhardt.

Ao se retirar conexões com relevância menor que 10, temos o seguinte mapa na próxima página. 


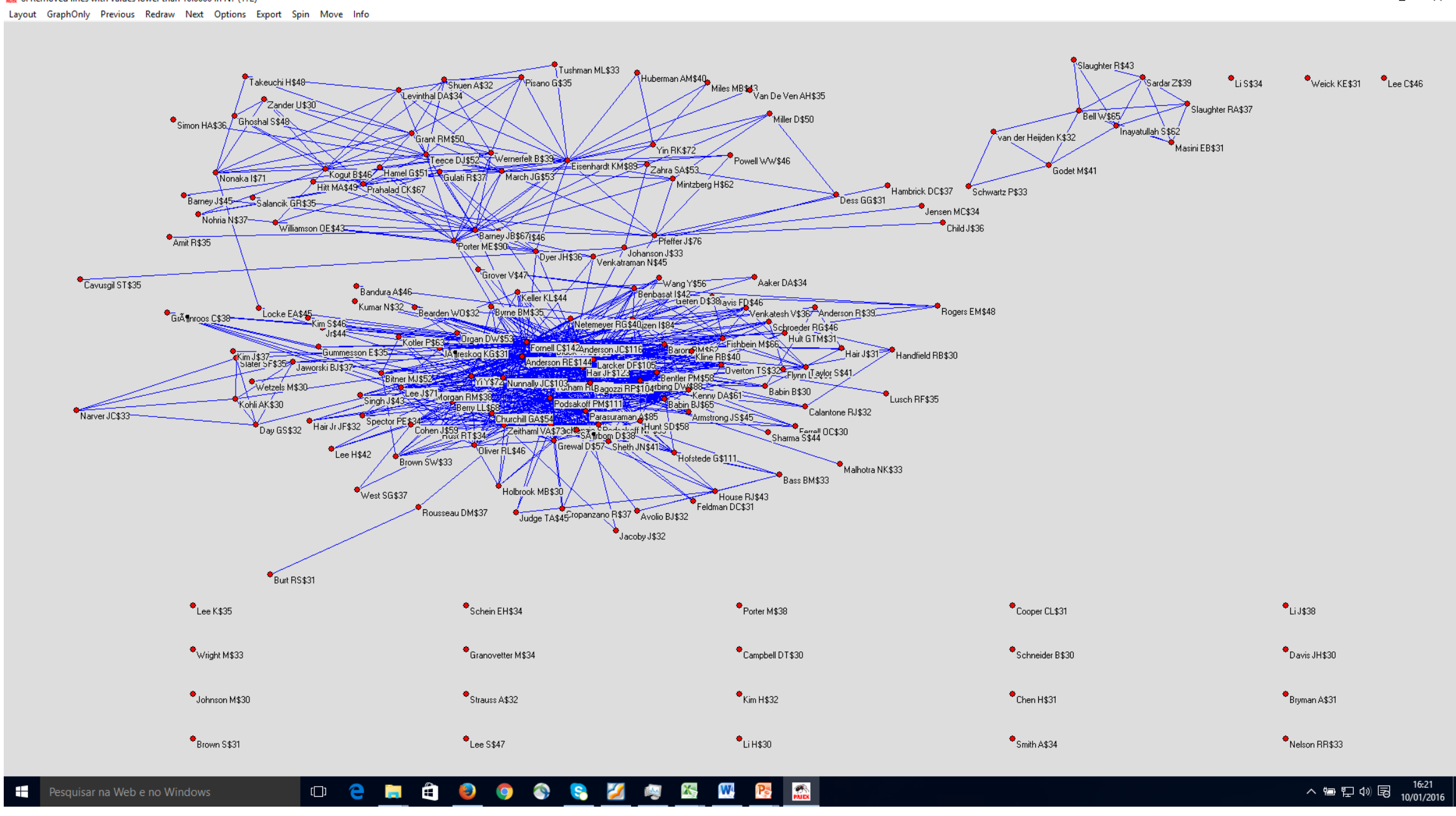

Ilustração 4 - Mapa de autores pelas co-ocorrências (relevância >10) Fonte: Análise do autor (baseada no banco de dados SCOPUS) 
Vai ficando evidente a formação de clusters de autores por sua co-ocorrência de citações.

Uma informação importante para o leitor, na formação desses mapas não foram retiradas as iniciais de nomes intermediários de autores, visando a evitar que homônimos de sobrenome e primeira inicial fossem considerados como o mesmo autor. Ainda que se corresse o risco de haver a discriminação de um autor com sua primeira inicial apenas, ou com todas as inicias, e.g. PORTER, M. e PORTER, M.E., foi decidido que esse problema seria menor do que considerar dois autores diferentes como sendo o mesmo. A consequência dessa decisão, numa análise de co-ocorrência de autores, é acontecer o que se observa no mapa anterior, o de se ter PORTER, M. e PORTER, M.E, sendo este último ainda conectado ao mapa de conexões. Infelizmente não há como contornar esse problema, porque as revistas acadêmicas catalogaram artigos com o nome dos autores com apenas a primeira inicial, ou com todas as iniciais, ou pior ainda, com variações entre esses dois extremos quando havia mais de três nomes.

Em síntese, a análise da produção acadêmica na área de prospecção do futuro serviu para dois objetivos: (1) atualizar a literatura acerca dos temas tratados nesta tese, e (2) enxergar como a produção acadêmica da prospecção do futuro se conecta com as demais áreas da administração.

Para ilustrar as conexões entre os autores da área da prospecção com as das demais áreas, retorna-se para o mapa de autores integral, sem retirar conexões de menor relevância, e utiliza-se o recurso do software PAJEK.

Conforme mencionado, o software PAJEK serve para montar mapas visuais de conexões entre elementos, no caso nós de uma rede que representam autores (os nós). Ele permite que se movimentem os autores dinamicamente utilizando o cursor clicado sobre cada um, e arrastando-o para se visualizar as conexões entre os nós (autores), mesmo sendo o mapa carregado de conexões, essa operação permite visualizar com quais autores um determinado autor se conecta. Fazendo esse processo sobre esse mapa inicial, sem retirar conexões de menor relevância, é possível observar algumas relações interessantes. Não se podem reproduzir todos os passos que podem ser executados para visualizar, dinamicamente, as conexões entre os autores aqui neste documento impresso. Contudo, é possível fazer os processos para alguns autores, para relatar que as conexões entre os autores da prospecção do 
futuro se dão, especialmente, com autores da área de estratégia como H. Mintzberg, C.K. Prahalad, M. Porter, K. Eisenhardt, G. Hamel, M. Hitt e J. Barney. Há também conexões com autores da área da teoria da decisão, como J. March, H. Simon e a própria K. Eisenhardt.

Um dos autores que é relevante quando se trata de prospecção é Michel Godet. Este autor apresenta conexões com C.K.Prahalad, G. Hamel, M. Porter, J. Barney e H. Mintzberg que têm produção na área de estratégia. $\mathrm{Na}$ área de teoria da decisão, as conexões são com J. March, H. Simon e K. Eisenhardt, sendo esta última também da área de estratégia.

Há, de certo, conexões com os demais autores da área de estudos do futuro, como Peter Schwartz, Z. Sardar, W. Bell, R. Slaughter e K. Van Der Heijden.

A ilustração da próxima página mostra essas conexões. 


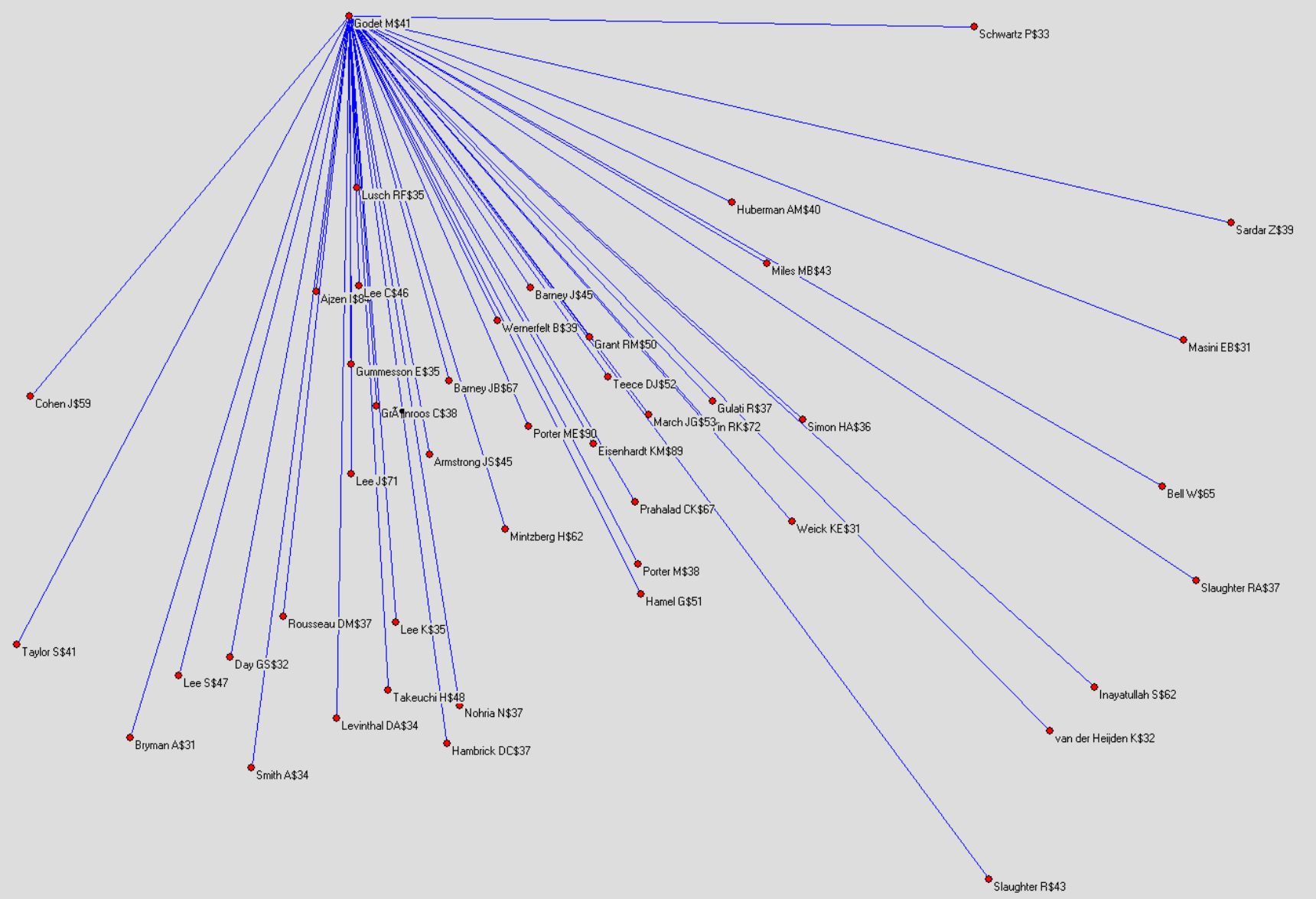


Para Peter Schwartz, o mapa revela que este autor se conecta também com autores das áreas de estratégia e teoria da decisão.

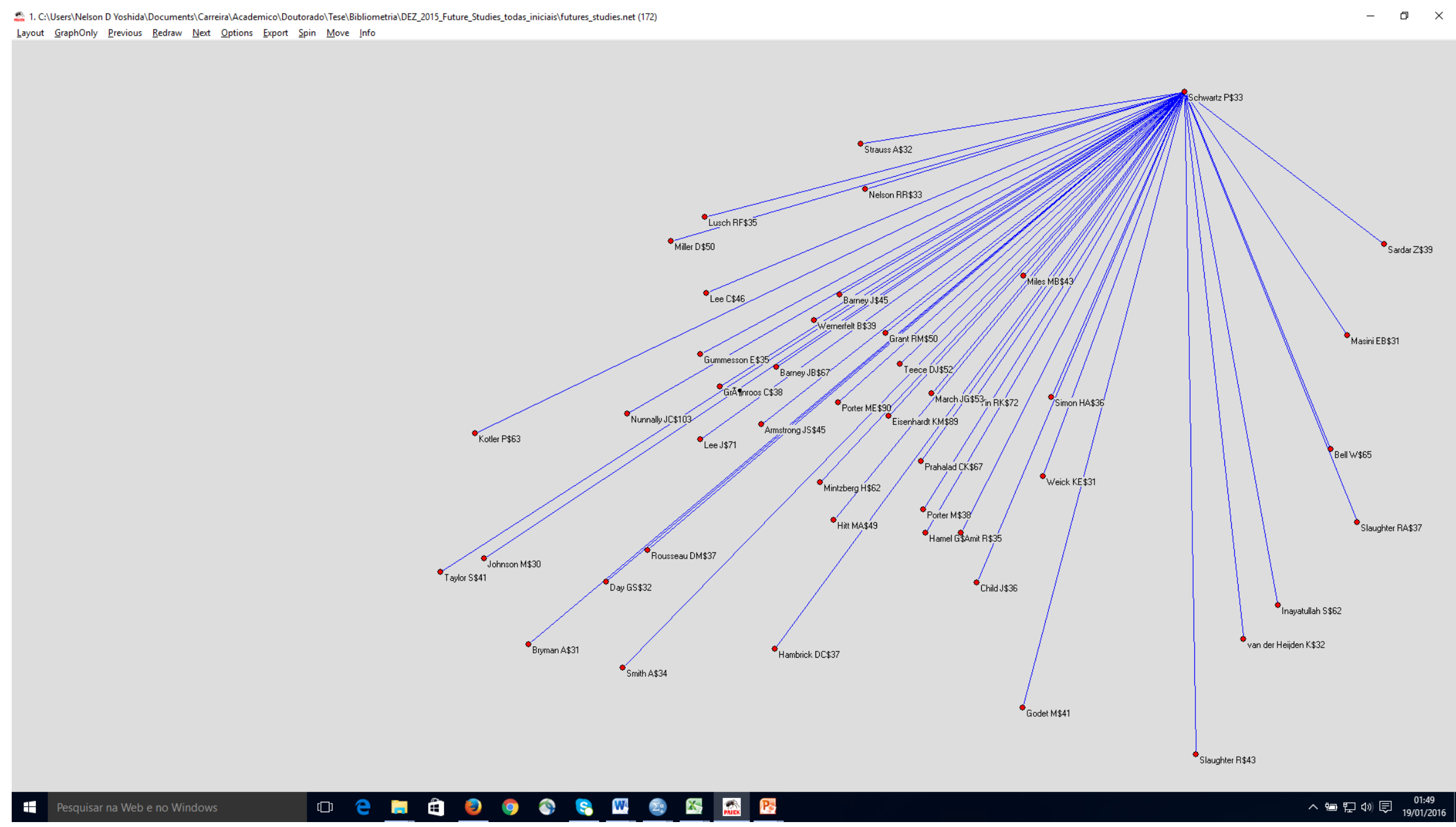

Ilustração 6 - Mapa de conexões de Peter Schwartz com outros autores 
Há conexões com outros autores, de áreas como, por exemplo, inovação, marketing e inteligência competitiva. Isso é esperado, uma vez que são áreas que têm relação com a área de estudos prospectivos.

\subsubsection{Prospecção do futuro como suporte à pesquisa acadêmica}

Estudar o futuro também tem suas contribuições na pesquisa acadêmica. Okoli e Pawlowski (2004), por exemplo, verificaram a aplicabilidade do método Delphi para suporte a diferentes processos de pesquisa acadêmica. Dentre esses processos, os autores mencionam: (1) seleção e definição de questões de pesquisa, (2) identificação das variáveis de interesse e geração de proposições acerca delas, (3) reforço das conclusões do estudo sob a ótica da contribuição da teoria resultante, devido à consulta a especialistas sobre os temas em estudos, (4) aumentar o potencial de entender as relações causais entre fatores envolvidos na pesquisa e (5) validação de constructos. Esses processos apresentam benefícios oriundos do uso da técnica Delphi porque há a integração da experiência e expertise de muitos especialistas. Portanto, seria uma forma de construção de conhecimento coletivo sobre o tema a ser pesquisado, o que aumenta o potencial de realizar uma pesquisa que contribua para expandir as fronteiras do conhecimento (OKOLI; PAWLOWSKI, 2004).

Mankoff et al (2013) também corroboram essa visão, ao proporem que as pesquisas sobre o desenvolvimento da tecnologia de interação humano-computador $(\mathrm{HCI})^{4}$, com seus impactos ainda não entendidos, podem ser direcionadas pelo uso de metodologia prospectiva, no caso o Delphi. O argumento dos autores é que, ao se analisar horizonte de tempo mais longo por meio de metodologia de estudos do futuro, é possível analisar que desdobramentos as novas tecnologias poderiam provocar, inclusive em áreas que não são consideradas como possivelmente impactáveis pelas novas tecnologias em pesquisa. Uma visão de horizonte mais curto, que segundo os autores é uma tendência do ser humano, limita a análise e pode criar pontos cegos sobre impactos indesejados, ou por outro lado pode deixar de vislumbrar oportunidades ainda impensadas. Metodologia prospectiva, portanto, contribui para orientar novas pesquisas sobre tecnologias emergentes (MANKOFF et al, 2013).

Van Der Duin et al (2014) argumentam que o processo de identificação de inovações futuras, por meio de redes de inovação, tem na atividade de prospecção importante contribuição.

\footnotetext{
${ }^{4} \mathrm{HCI}:$ Human-Computer Interaction
} 
Segundo os autores, as pesquisas que poderão ser desenvolvidas no futuro, sobre tendências de inovação, poderão ter nos estudos prospectivos um importante ponto de apoio. E esses estudos prospectivos serão do tipo em rede, o que eles chamam de prospecção em rede ${ }^{5}$, porque a área de conhecimento da gestão da inovação tem muita similaridade com a da prospecção do futuro, e também porque há conexão próxima entre a área da prospecção do futuro com as de inovação colaborativa e inovação aberta. Em síntese, as áreas de prospecção do futuro e redes de inovação estão relacionadas, e a construção do conhecimento nessas duas áreas pode ter influências mútuas desse relacionamento (VAN DER DUIN et al, 2014).

Zhu e Alan Porter (2002) também corroboram que a prospecção do futuro contribui para pesquisas na área de desenvolvimento de tecnologias emergentes. O monitoramento propiciado por análises prospectivas, realizado sobre bases de dados disponíveis, pode contribuir para identificar rotas de desenvolvimento tecnológico. Essas rotas, por sua vez, podem contribuir para pesquisadores e gestores de tecnologia no processo de identificar os seus próximos passos de desenvolvimento (ZHU; PORTER, Alan, 2002).

A abordagem de Zhu e Porter (2002) usa a bibliometria como método de análise de dados em grande quantidade, e esse método é largamente utilizado na prospecção do futuro, especialmente para construir visões de desenvolvimento de tecnologias, conforme também fizeram Daim et al (2006) e Woon e Madnick (2009). Como se trata de método que rastreia a produção científica, que atualmente está bem disponível por meio de journals e outros meios de comunicação, a prospecção do futuro por meio de bibliometria é importante etapa para se avaliar a produção acadêmica. Ela tanto pode ser utilizada para avaliar a produção acumulada até o momento (estudo retrospectivo), como também para analisar tendências futuras das pesquisas acadêmicas e do desenvolvimento tecnológico.

Em síntese, a prospecção do futuro, com seus métodos e técnicas, tem potencial real de apoiar a pesquisa acadêmica em diferentes áreas do conhecimento. Como o futuro é múltiplo, multidisciplinar e incerto (SARDAR, 2010; DRUCKER, 2010), é compreensível o argumento de Mankoff et al (2013), Van Der Duin et al (2014) e Zhu e Porter (2002) de que metodologias de prospecção do futuro possam apoiar as pesquisas acadêmicas.

\footnotetext{
5 Tradução livre a partir do termo em inglês networked foresight.
} 
Esse argumento também é corroborado pelo fato da produção científica, que inclui termos comuns da área de prospecção do futuro, ter acelerado a partir de 1995.

Conforme mencionado por Chermack (2011), Hines e Bishop (2013) e Vecchiato (2012), a história recente indica aceleração crescente das turbulências e isso se reflete na necessidade de pesquisar os impactos em diferentes áreas do conhecimento.

\subsection{A prospecção do futuro e seus objetivos}

\section{Objetivos da prospecção do futuro}

A produção acadêmica na área da prospecção agora é analisada de forma focada nos temas desta tese.

James Dator, professor da Universidade do Havaí, e membro do Hawaii Research Center for Futures Studies, baseia-se nos conceitos de Wendell Bell (1997), e também em suas próprias análises (DATOR, 2015) para declarar que o futuro não pode ser previsto. Então a atividade de estudar o futuro ("futures studies") não deve ser realizada para se tentar prever o futuro. Ela deve, sim, ter foco em estudar imagens sobre o futuro, e estas imagens, apesar de diferentes entre as pessoas, devem servir de suporte para ações que possam ser implantadas no presente. Em grandes linhas:

- O futuro não pode ser previsto, mas alternativas de futuro podem e devem ser analisadas, para identificar quais as principais, e quando poderão se consolidar.

- O futuro não pode ser previsto, mas futuros preferíveis podem e devem ser analisados. O principal objetivo de estudos do futuro (futures studies) é facilitar para as pessoas a atividade de formular, revisar, analisar continuamente e implantar os futuros preferíveis.

- Para ser útil, a atividade de estudar o futuro deve ser precedente ao planejamento, à estratégia, e assim servir de suporte a decisões orientadas pela estratégia.

O autor enfatiza que a atividade de prospectar o futuro deve ser contínua, ela não se conclui em uma "solução final". Ela deve propiciar uma visão não estática do futuro, que deve ser continuamente analisada à luz das mudanças e das novas informações. Isso é reforçado por Van Der Heijden (2004) quando ele argumenta que a estratégia desenvolvida pelo 
aprendizado focado no ganho de controle sobre a estratégia leva ao uso da racionalidade, enquanto aquela desenvolvida pelo aprendizado focado na participação leva a processo contínuo de ações baseadas em aprendizado organizacional. O método de cenários aplicado isoladamente para se chegar à definição de uma boa estratégia, geralmente não gera bom resultado (VAN DER HEIJDEN, 2004).

A utilidade dos estudos do futuro pode ser potencializada ao se reexaminar as análises a seguir, sobre como aprofundar os processos para (GORDON et al, 2005):

- Integrar novas tecnologias com metodologia de estudos do futuro;

- Reduzir o domínio do desconhecido;

- Lidar com incertezas do futuro;

- Facilitar o planejamento e a administração de sistemas não lineares operando em ambiente caótico;

- Aprimorar o entendimento dos fatores psicológicos que levam a decisões irracionais;

- Adequar os níveis de agregação nos estudos de prospecção

- Aproveitar o potencial das novas fontes de informações sociais.

Em relação ao caos e complexidade, Coates et al (2001) apontaram o crescimento da complexidade para os praticantes de prospecção, e os métodos que lidam com formação de contextos foram considerados os que mais poderiam ganhar adeptos. No processo de prospecção é menos importante a familiaridade com a atividade, e mais importante a determinação do que é que o analista precisa descobrir sobre o futuro, e como ele pretende que isso seja realizado (COATES et al, 2001). Este ensinamento leva à reflexão de que os objetivos de um projeto de prospecção são fundamentais, e o processo de como desenvolver tal projeto precisa ser bem fundamentado. Em outras palavras, é preciso clareza de objetivos e saber dar a devida comunicação aos processos a serem desenvolvidos.

A comunicação tem papel importante na prospecção do futuro, pois ela é um dos suportes para a confiança e credibilidade no processo, especialmente quando se envolvem múltiplos atores, de instituições diversas. Processos relacionados a estudos prospectivos dependem de 
os participantes efetivamente se engajarem no processo, e isso pressupõe bons processos de comunicação (NEHME et al, 2012).

Estrada e Almeida (2007) propõem que o objetivo da gestão estratégica é atingir a visão de futuro desejada. O planejamento deve ser realizado com o foco na visão de futuro, sendo importante que ela esteja refletida na estratégia a ser seguida, no plano de ações, na execução e controle do plano e nas inovações que a organização deverá avaliar e implantar para se atingir a visão de futuro. A formulação da estratégia pressupõe a análise de uma visão do futuro, conectando a visão prospectiva no planejamento estratégico.

Para Fischmann e Almeida (1991) a administração estratégica envolve integrar decisões administrativas, operacionais e estratégicas, ao mesmo tempo em que se busca aumentar eficiência e eficácia na organização. A decisão estratégica, por sua vez, envolve o futuro, como argumentam Eisenhardt e Zbaracki (1992), Chermack (2004), Wright e Goodwin (2009) e Ericson (2010). A conexão entre prospecção do futuro e a estratégia se dá, em grande parte, pelo processo de tomada de decisões.

Para Hitt et al (2005, p. 6), o processo de administração estratégica envolve o conjunto de compromissos, decisões e ações que conduzam a organização para a competitividade estratégica, que pode levar a retornos acima da média. Relembrando Drucker (2010, p. 188) que diz ser necessário estudar o futuro para apoiar decisões e ações decorrentes delas, visando a objetivos que se projetam para o futuro; pode se argumentar que administração estratégica inclui, dessa forma, análise de questões sobre o futuro. A prospecção do futuro deve, dessa forma, ser conectada com a gestão estratégica empresarial.

A estratégia forte e adequadamente formulada foi o principal ponto mencionado por presidentes de empresas (CEOs), quando questionados sobre o que pode transformar empresas ao ponto de serem as mais respeitas no futuro (HITT et al, 2005, p. 9).

Uma das finalidades do estudo do futuro está, em especial, na avaliação da evolução tecnológica. Nesse contexto de tecnologia em evolução, decisões precisam ser tomadas, e elas vão definir como a organização poderá fazer uso dela, obtendo resultados futuros (FIDLER, 2011). Dessa forma, a prospecção do futuro tem papel na estratégica tecnológica, sendo um exemplo da integração entre prospecção e estratégia empresarial. 
Ainda dentro do contexto de se avaliar tecnologia, a prospecção pode ser utilizada para se analisar não somente uma tecnologia completa, mas também seus componentes necessários para que o total dela possa efetivamente se realizar. Utilizando o roadmap tecnológico é possível desenhar um mapa de etapas ao longo do tempo, conectando os componentes tecnológicos na linha do tempo com suas relações de antecedência. Ao final, o que se obtém é uma visualização de viabilidade da tecnologia se consolidar, e quanto tempo levaria para que isso ocorresse (LEE; PARK, 2005).

Como mencionado anteriormente, a prospecção do futuro serve para se estimar o que precisa ser feito para se atingir futuros preferíveis. E uma forma de fazer isso é utilizar o backcasting, que numa tradução aproximada seria a atividade de fazer uma projeção para o passado, a partir de um futuro desejado (WRIGHT; GOODWIN, 2009). Essa abordagem é mais normativa, sendo que a prospecção neste caso seria utilizada com objetivo de se desenhar passos a cumprir para se atingir um futuro aspirado.

Armstrong (1985) argumentou que estudar o futuro deve anteceder o planejamento, porque neste último serão necessárias informações e análises para subsidiar alternativas de planos. Hogarth e Makridakis (1981) também já haviam ensinado que a preparação para o futuro é realizada por um planejamento estabelecido por decisões orientadas para o futuro. A característica comum, entre as atividades de estudar o futuro e a de planejamento, é que a orientação para o futuro traz a necessidade de julgamento humano, o qual é influenciado por vieses ou heurísticas.

A prática da prospecção do futuro é avaliada mais em relação às previsões resultantes (WINKLHOFFER et al, 1996). Pouco se estudou sobre o uso das informações obtidas na tomada de decisão. Para os autores, a utilização dos resultados pode se dar de duas grandes formas: (1) a instrumental, onde a prospecção é aplicada como meio para subsidiar a decisão; e (2) a simbólica, onde ela é usada para justificar uma decisão que, por outro meio qualquer, já estaria tomada (WINKLHOFER et al, 1996). Em qualquer das formas, os autores enfatizam que no final há decisões a serem tomadas, e esse seria o objetivo da prospecção.

Em 1995, Schoemaker tinha argumentado que a prospecção também contribui com os seguintes objetivos. Primeiro, para lidar com situações de incertezas elevadas, quando os gestores se sentem sobrepujados na sua capacidade de avaliar o que poderá vir a acontecer. 
Segundo, nos casos em que a organização passou por surpresas de grande impacto no passado, indicando que seus gestores possam ter limitações para avaliar as possibilidades desse tipo de evento ocorrer. Terceiro, quando se percebe que os gestores da organização não percebem ou não são capazes de gerar novas oportunidades. Quarto e último, quando a qualidade do pensamento estratégico na organização é considerada baixa (SCHOEMAKER, 1995).

Estudar a evolução futura de produtos e serviços também está dentro dos objetivos da prospecção. Walsh (2005) concentrou-se nisso, no fato que um produto (ou serviço) tem diferentes atributos e utiliza diversos componentes tecnológicos, então é recomendável analisar como esses atributos ou componentes tecnológicos deverão ser aplicados nos produtos, e quando. É importante pensar na inovação, e como ela deve ser integrada no portfólio de produtos da organização (WALSH, 2005).

Por final, a questão sobre objetivos da prospecção do futuro leva a uma pergunta recorrente: A metodologia de estudos do futuro tem uma competência central? A resposta para esta pergunta seria, talvez, que estudos do futuro são eminentemente multidisciplinares e integrativos - o que implica que a disciplina de estudos do futuro não tem uma competência central. A prospecção do futuro tem, certamente, uma combinação singular de métodos, e é justamente essa combinação singular que pode, sem dúvida, dar à metodologia de estudos do futuro a sua competência central. Mas então vem outra pergunta pertinente: A área de estudos do futuro é um campo legítimo para a pesquisa acadêmica? Roney (2010) provoca esses questionamentos, e estimula o debate, o que parece mostrar que ele gostaria que ele ocorresse.

\subsection{A prospecção do futuro e a estratégia}

\section{Prospecção e estratégia}

Existe uma conexão entre foresight (prospectiva) e gestão estratégica. Segundo Fidler (2011) o pensamento e análise prospectiva contribuem no processo de tomada de decisão sobre tecnologia. A conexão entre essas áreas é robusta, ela proporciona melhor processamento de informações nas organizações, e apoia bem o contraste entre os grandes problemas de longo prazo com as visões de curto prazo dos administradores (FIDLER, 2011). 
Alan Porter et al (1991, p. 47) argumentam que a gestão estratégica da tecnologia induz ao estudo do futuro. E que essa atividade está mais presente do que se pode perceber nas organizações que lidam com tecnologia, pois mesmo quando se decide, conscientemente, não preparar a organização para mudanças, também nesta situação foi realizado um exercício prospectivo. Esta decisão reflete a estimativa de que as mudanças do ambiente não afetam a organização no futuro, o que representa um resultado da análise prospectiva (PORTER, Alan et al, 1991 p. 48).

Fischmann e Almeida (1991) propuseram que administração estratégica envolve integrar decisões, desde administrativas, passando por operacionais e chegando às estratégicas, buscando também incrementar eficiência e eficácia na organização. As decisões estratégicas, necessariamente, envolvem o futuro e suas múltiplas dimensões, como argumentam Eisenhardt e Zbaracki (1992), Chermack (2004), Wright e Goodwin (2009) e Ericson (2010). Dessa forma, há uma conexão entre prospecção do futuro e estratégia, e ela ocorre, em grande parte, por meio do processo de tomada de decisões.

Roney (2010) também apontou que há uma convergência entre gestão estratégica e prospecção do futuro. A prospecção usa as ciências físicas e sociais para resolver problemas de planejamento estratégico. Algumas das aplicações da prospecção envolvem: (a) identificar mudanças no ambiente externo (economia, mercado, setores) da organização, (b) analisar os impactos das novas tecnologias sobre as competências da organização, (c) selecionar caminhos para se atingir objetivos estratégicos, (d) analisar mudanças nos padrões que resultam em sucesso, (e) selecionar entre alternativas estratégicas (RONEY, 2010).

Roney (2010) ainda argumenta que há oito abordagens metodológicas de estudos do futuro utilizadas no planejamento estratégico, elas podem ser vistas no quadro a seguir. 
Quadro 1 - Estudos do futuro e estratégia

\begin{tabular}{|c|c|c|c|c|c|c|c|c|}
\hline \multirow{2}{*}{$\begin{array}{c}\text { Escopo de } \\
\text { metodologias de } \\
\text { Estudos do } \\
\text { Futuro } \\
\downarrow\end{array}$} & \multirow[b]{2}{*}{$\begin{array}{l}\text { Visão e } \\
\text { Missão }\end{array}$} & \multicolumn{3}{|c|}{ Análise de Ambiente } & \multirow{2}{*}{$\begin{array}{l}\text { Análise de } \\
\text { competência } \\
\text { s internas }\end{array}$} & \multicolumn{2}{|c|}{ Decisões } & \multirow[b]{2}{*}{ Implementação } \\
\hline & & $\begin{array}{l}\text { Economi } \\
\text { a }\end{array}$ & Mercado & $\begin{array}{l}\text { Setore } \\
\text { s }\end{array}$ & & Objetivos & Estratégia & \\
\hline $\begin{array}{l}\text { Analogia } \\
\text { Histórica }\end{array}$ & $\mathrm{F}$ & & & M_F & M_F & & $\mathrm{F}$ & \\
\hline $\begin{array}{l}\text { Análise } \\
\text { Sistêmica }\end{array}$ & & M_F & M_F & M_F & M_F & & & \\
\hline Previsão & & $\mathrm{F}$ & $\mathrm{F}$ & $\mathrm{F}$ & & M_F & & \\
\hline Simulação & & M_F & M_F & M_F & $\mathrm{F}$ & $\mathrm{F}$ & M_F & $\mathrm{F}$ \\
\hline $\begin{array}{l}\text { Cenários - } \\
\text { Formação }\end{array}$ & & M_F & M_F & M_F & M_F & M_F & $\mathrm{F}$ & M_F \\
\hline $\begin{array}{l}\text { Análise de } \\
\text { Impactos }\end{array}$ & & M_F & M_F & M_F & M_F & & M_F & M_F \\
\hline $\begin{array}{l}\text { Tomada de } \\
\text { Decisão }\end{array}$ & & & & & & & $\mathrm{F}$ & \\
\hline $\begin{array}{l}\text { Monitoramento } \\
\text { e Rastreamento }\end{array}$ & & $\mathrm{F}$ & $\mathrm{F}$ & $\mathrm{F}$ & & & & $\mathrm{F}$ \\
\hline
\end{tabular}

Legenda: F = Frequente / M_F = Muito Frequente

Fonte: adaptado de Roney (2010)

O debate sobre que processos são de qual das áreas não parece ter conclusão clara, porque por um lado pode-se perguntar se projetos de "estudos do futuro" não são projetos de "estudos de planejamento" desenvolvidos por praticantes de prospecção do futuro. Por outro lado, pode-se também perguntar se as metodologias de planejamento estratégico não seriam um subconjunto de metodologias de estudos do futuro. Um debate argumentativo sobre esse tema seria interessante (RONEY, 2010). O autor ainda adiciona que, a despeito dessa discussão, parece certo que os defensores de cada uma das áreas se beneficiam, de fato, da existência da outra área.

Godet (1994) argumentou que a transição entre antecipação e ação é uma importante responsabilidade dos administradores. Contudo, não é uma coisa simples de fazer, sendo importante que para isso ocorra com maior fluidez a apropriação dos resultados do processo de prospectar o futuro (GODET, 1994, p. 3). O modelo do triângulo grego é a inspiração para Godet, conforme mostrado na figura a seguir. 


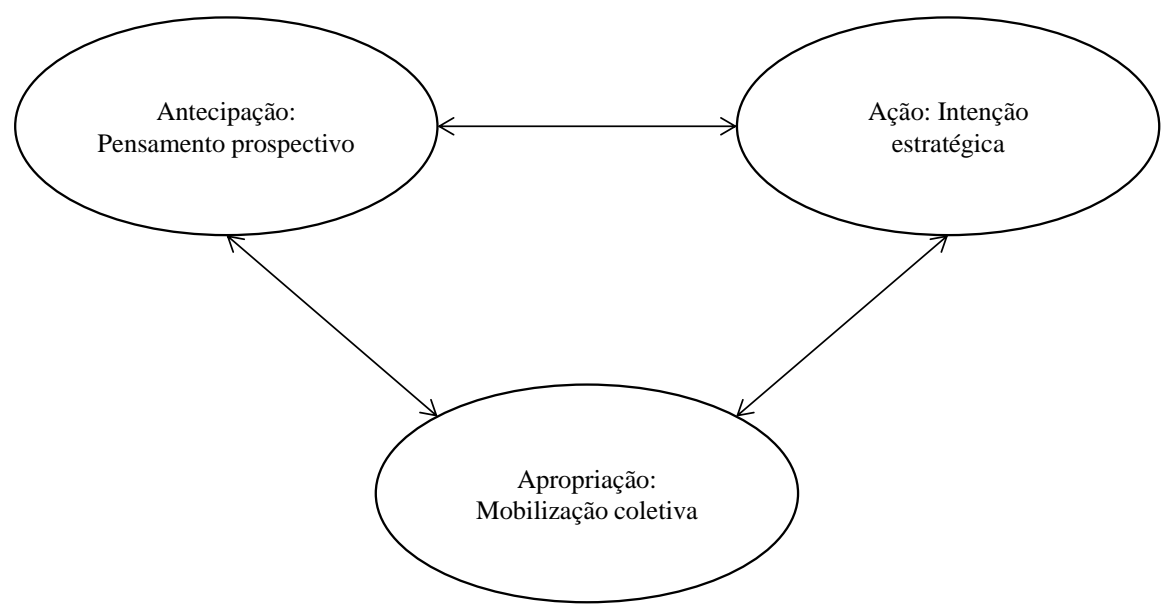

Ilustração 7 - Triângulo grego da prospectiva

Fonte: Godet, 1994, p.4

O autor elabora uma integração entre a prospectiva e a estratégia. Ela pode ser visualizada na figura a seguir.

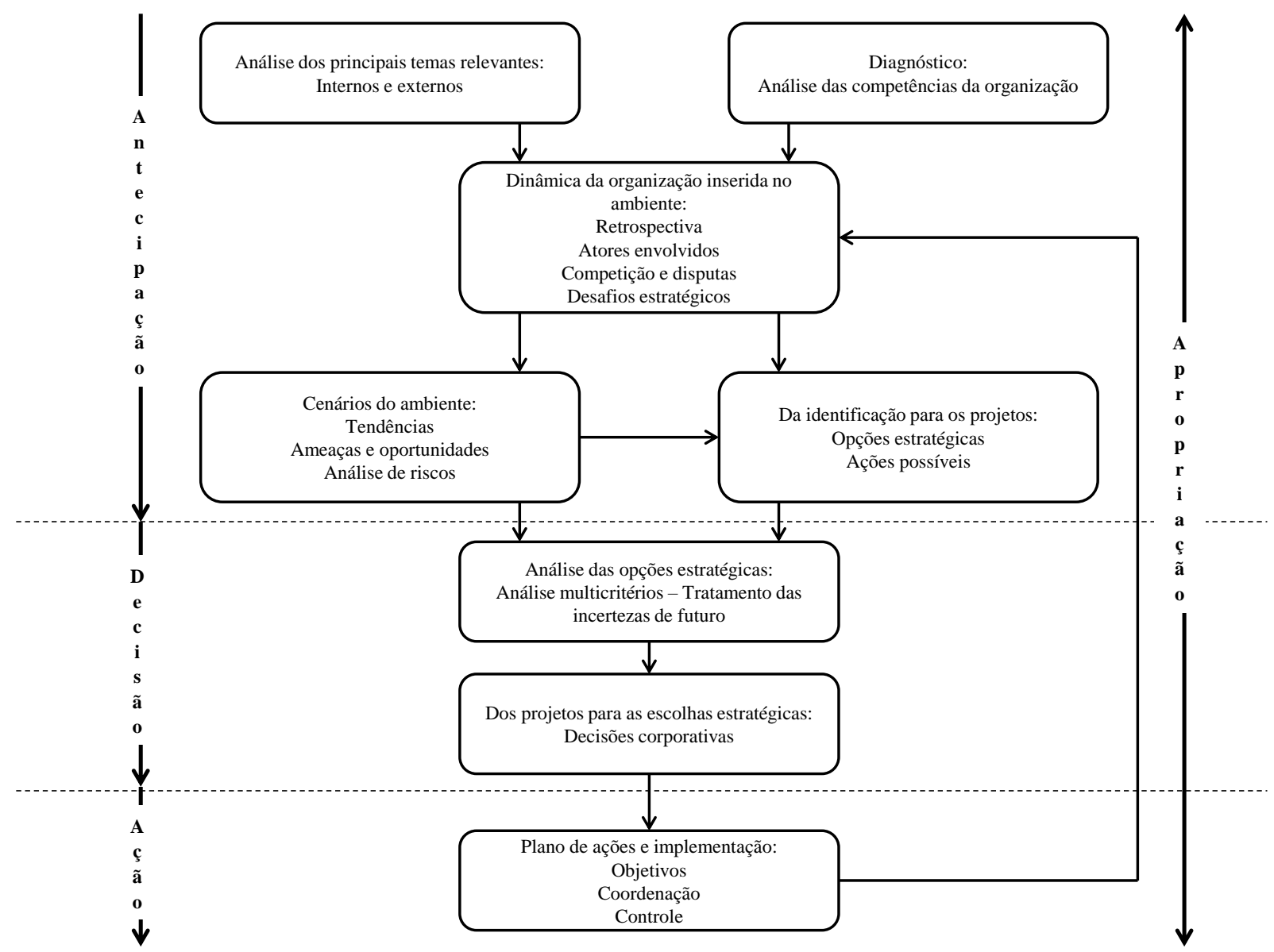

Ilustração 8 - Integração entre a prospectiva e a estratégia

Fonte: Adaptado de Godet (1994, p. 228) 
Nesse modelo, Godet (1994) enfatiza que em todo o processo executado para antecipar, decidir e agir, a apropriação permeia a todos. E isso é recomendado pelo autor porque ao final, pessoas integradas e organizações que lhes permitam gerar essa integração é que fazem a diferença (GODET, 1994, p. 229).

Godet e Roubelat (1996) sinalizaram que não se deve dar muita atenção a essa discussão sobre conflito entre racionalidade e intuição - ambos são necessários. Para eles, em algum momento alguém vai precisar tomar decisões, e esta, para acontecer, vai depender de julgamento sobre as análises prospectivas. Se ocorrer a apropriação dos resultados das análises, pelos tomadores de decisão, a transição para a ação vai ser mais fácil. Posto de outra forma, a estratégia da organização depende não somente da visão e análise prospectiva, mas também do quanto os tomadores de decisão se apropriam da visão de futuro. Então seria recomendável que os tomadores de decisão participem das análises prospectivas (GODET; ROUBELAT, 1996).

Simon (1997) apontou que o ser humano apresenta racionalidade condicionada, e que aspectos da cognição influenciam a tomada de decisões. O ser humano, segundo ele, não consegue analisar todas as alternativas de ações plausíveis em uma decisão, não é capaz de coletar e processar todas as informações e analisar as consequências das alternativas, e também não consegue calcular o valor dessas consequências (SIMON, 1997).

Wilson (2000) argumenta que o maior desafio é integrar cenários prospectados com ações estratégicas. Para ele, cenários não são um fim em si, eles devem suportar a tomada de decisões. A dificuldade é que "todo o conhecimento que se tem disponível é sobre o passado, mas todas as decisões são sobre o futuro". Dessa forma, interpretando o que o autor recomenda, a prospecção do futuro é um meio, uma metodologia, e ela precisa ser motivada por algum fator, que segundo ele é o suporte à tomada de decisões, e estas últimas sempre terão incertezas de futuro.

A tendência das pessoas que analisam o futuro é tentar apoiar decisões, e nesse processo elas podem buscar bases do presente e do passado, para projetar o que pode vir a acontecer. Isso pode funcionar se o contexto da análise não necessita considerar o ambiente externo amplo. A complexidade do ambiente pode limitar essa abordagem de projeção, de tentar prever o futuro. Quando as incertezas são muitas e as análises são complexas, é recomendado utilizar o 
método de cenários. Seguir a abordagem de projetar um ponto singular no futuro (uma previsão) ignora outras possibilidades e, sempre importante lembrar, um ponto singular no futuro pode ser comparado a uma gota em um mar de probabilidades (RINGLAND, 2006, p. 33-34).

Ringland (2006, p. 4) também menciona a conexão entre estratégia e prospecção, no caso por cenários. O objetivo da prospecção é subsidiar o planejamento na parte relacionada com o tratamento das incertezas do futuro.

Schoemaker (1995) argumentou que ocorrem três vieses quando se exercita o estudo do futuro: (1) excesso de confiança, (2) falta ou excesso de análise prospectiva e (3) tendência a querer encontrar evidências para corroborar uma visão estabelecida e desejada. Esta última, segundo ele, representa o pior dos vieses.

Tversky e Kahneman (1974) contribuíram com sua pesquisa sobre os vieses cognitivos, e como estes influenciam a forma com que as pessoas julgam as incertezas. O processo é caracterizado, segundo os autores, pela presença de heurísticas e vieses que acabam por limitar a possibilidade de analisar racionalmente as incertezas.

Fahey e Prusak (1998) argumentaram que um dos grandes pecados da gestão do conhecimento é o foco no passado e no presente, e não no futuro. $\mathrm{O}$ argumento deles é que apesar do futuro ser imprevisível, toda estratégia, decisão ou ação tem, por definição, premissas sobre o futuro. Três causas são apontadas como explicação para esse pecado: (1) as pessoas sentem-se mais confortáveis quando têm dados em mãos, e isso somente pode ser feito em relação ao passado ou ao presente. Isso gera tendência de convergir para o que está ocorrendo ou o que ocorreu, porque as pessoas não querem se indispor politicamente ao defender que o futuro pode mudar, se outras pessoas dizem que não. A segunda causa (2) um completo mal-entendido entre conhecimento e futuro - o objetivo de estudar o futuro não é prevê-lo, mas sim analisar o que as visões sobre o mesmo podem informar aos tomadores de decisão, para que estes possam avaliar suas estratégias e ações. A terceira causa é (3) a falha em reconhecer que as visões alternativas de futuros contribuem para iluminar o entendimento sobre o presente (FAHEY, PRUSAK, 1998). 
Hirsch et al (2013) defendem que o método de cenários deve prever a quantificação, embora eles reconheçam que a abordagem apenas qualitativa também tenha sua utilidade. Os autores argumentam que a conexão entre cenários e estratégia pressupõe quantificação, pois embora a linguagem de cenários seja narrativa, declare possibilidades dentro de uma descrição de contexto, a linguagem corporativa utiliza mais fatos, o que significa números. É por isso que se defende que cenários sejam quantificados (HIRSCH et al 2013).

Outra forma de conectar cenários com estratégia, por meio de quantificação, é utilizar o método de opções reais (MILLER; WALLER, 2003). Os autores propõem que o método de opções reais pode contribuir mais no processo decisório, se for incluído o método de cenários como metodologia em uma estrutura integrada de gestão de riscos, que teria: Cenários, identificação de exposição a riscos decorrentes de cenários, formulação de respostas aos riscos, e finalmente passos de implementação. O benefício dessa estrutura é que ela agrega uma visão qualitativa ao mundo excessivamente quantitativo das opções reais.

Dentre as responsabilidades de executivos de organizações, está a de estar atento para novas oportunidades de negócios. Heger e Rohrbeck (2012) mostram que novas áreas de negócios, não inclusas no portfólio corrente da organização, podem representar importantes oportunidades, ou mesmo ameaças. Contudo, relatam os autores, uma pesquisa na literatura revela que ainda faltam estudos que tratam de como as atividades de prospecção podem ser aplicadas no contexto corporativo e estratégico de empresas. E no caso da avaliação de novas áreas de negócios, as limitações podem vir de quatro desafios: (1) integrar múltiplas perspectivas na análise, (2) lidar com alto nível de incertezas, (3) analisar as diversas interdependências entre os temas que estão presentes nas análises, e (4) conseguir envolver e engajar um grande número de experts externos e tomadores de decisão internos (HEGER; ROHRBECK, 2012).

Quando se trata de avaliar a conexão entre o estudo de incertezas de futuro e a estratégia, dois temas parecem ganhar mais relevância recentemente. Um deles está relacionado com problemas de meio ambiente e sustentabilidade, e outro vem da questão regulatória. $\mathrm{O}$ primeiro tem estado no campo de atenção há muito tempo, pois houve vários casos de impactos ambientais significativos a corporações. O segundo é um tema que ganhou força pela pressão oriunda das mudanças climáticas, o que expandiu o escopo da regulamentação para o mundo todo, e não somente na extensão geográfica local ou regional. Lidar com a 
integração entre prospecção e estratégia, nesses dois temas, ganhou relevância. Engau e Hoffman (2011) ilustram esse fenômeno, e argumentam que os processos que estão sendo praticados nas empresas abrangem escopo até maior do que a literatura produzida até então propôs. E que apesar de uma percepção de que as organizações possam estar passivas, mais defensivas em relação aos temas de sustentabilidade e regulação, os dados obtidos por eles demonstram que de fato elas possam estar mais proativas e agressivas em relação a eles, o que cria uma oportunidade para aprofundar pesquisas sobre esses temas na prospecção e sua utilização na estratégia (ENGAU; HOFFMAN, 2011).

É importante mencionar que a pessoa que estuda o futuro deve esperar que suas ideias sejam ridicularizadas. Afinal, o futuro pode trazer mudanças, então as ideias geradas em um processo de prospecção do futuro devem parecer não convencionais, chocantes, ofensivas ou mesmo ridículas (DATOR, 2002a). Em outras palavras, na gestão estratégica, se o futuro vai repetir o passado, então não é necessário estudá-lo, contudo esta atitude seria prudente?

Por talvez não ser prudente essa atitude, a área tem tido contribuições crescentes ao longo do tempo. Kuosa (2011) faz uma análise sobre a evolução da área de estudos do futuro, e nessa análise ele indica que, em sua opinião, há dois paradigmas consolidados sobre a área, e mais um terceiro que pode estar emergindo: (1) o primeiro é o tradicional modelo mais determinista, que pretende prever o futuro e, dessa forma, passa perto do que pode ser considerado místico. O segundo (2) é o modelo que cresceu nos Estados Unidos após a Segunda Guerra Mundial, no qual se admitem futuros alternativos, usam-se probabilidades, buscam-se controle e planejamento, adota-se o pensamento sistêmico e se analisa o ambiente externo com muita ênfase. Já o novo paradigma (3) é aquele que vai tentando se libertar desta visão ocidental americana, e para isso ele se baseia em forma de pensar mais dialética, ele admite as variações internas e os paradoxos (KUOSA, 2011).

Kuosa (2011) argumenta ainda que há diferentes atores no mundo dos estudos do futuro. Há os que não são profissionais e não dominam os conceitos e métodos de estudar o futuro; há os profissionais, que são aqueles que dominam os métodos e conceitos e podem desenvolver visões consistentes de futuro; e finalmente há os chamados gatekeepers, guardiões numa tradução livre, que são aqueles responsáveis pela qualidade dos demais praticantes (dos futuristas), sendo que eles inclusive podem desenvolver os métodos ou propor novos. Mas 
ainda há muita coisa para fazer em relação à qualidade dos praticantes de prospecção, chamado de futuristas pelo autor (KUOSA, 2011).

Gordon (1994) apresenta uma abordagem de lidar com eventos que alteram tendências de estabilidade. Trata-se da Análise de Tendências Impactadas (TIA - Trend Impact Analysis), uma forma de projetar os impactos futuros de eventos que mudam a tendência de estabilidade assumida. Uma ilustração serve para mostrar melhor como isso é realizado.

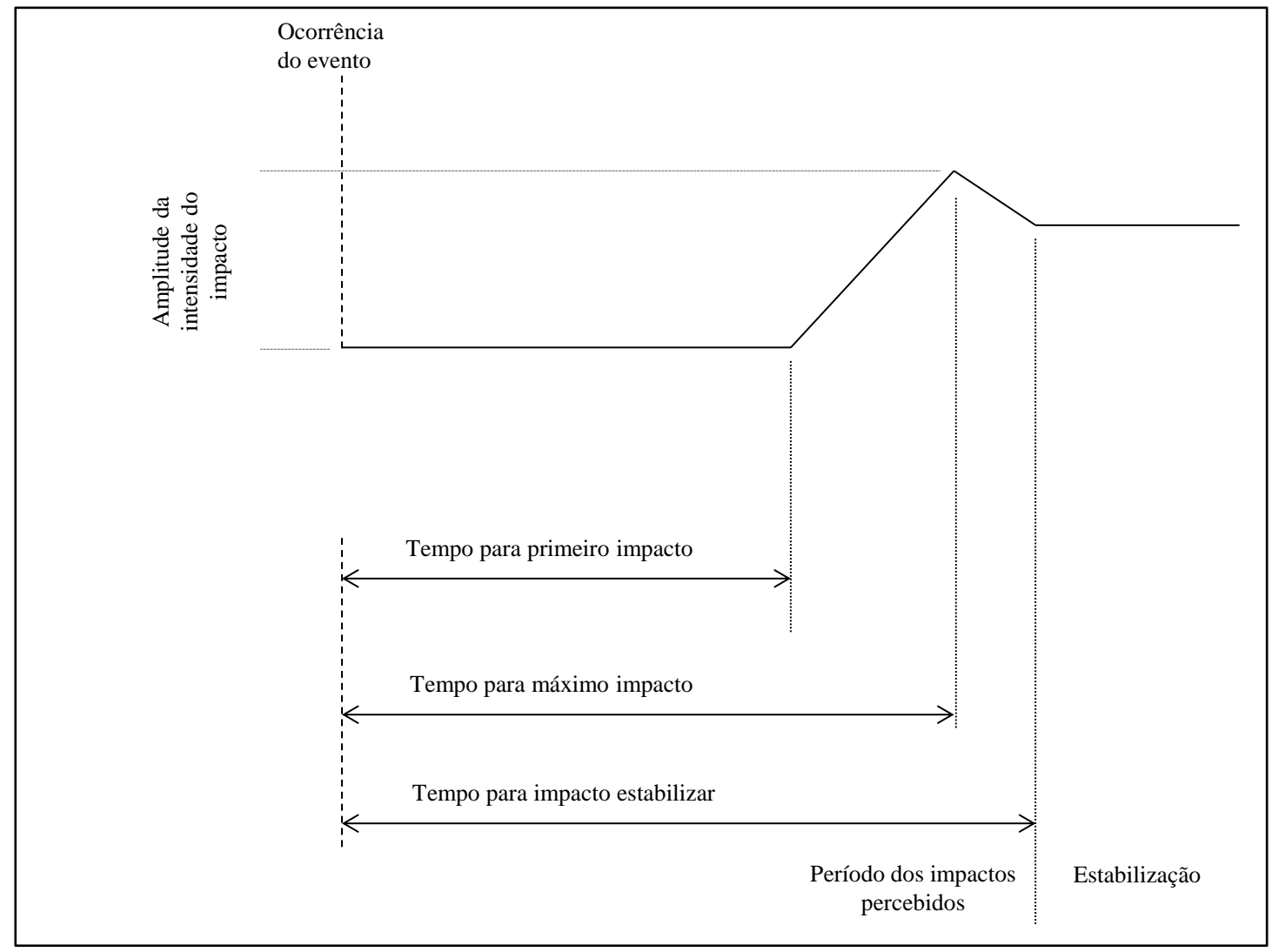

Ilustração 9 - Análise de Tendências Impactadas

Fonte: Adaptado de Gordon (1994)

Para realizar uma análise como a proposta, é preciso estimar alguns parâmetros (GORDON, 1994):

- Quando o evento ocorre;

- Quando o impacto do evento se manifesta sobre os objetos em estudo (e.g. volume de vendas);

- Qual a amplitude do impacto; 
- Quando o impacto se estabiliza, e em qual patamar estará o objeto em estudo (e.g. volume de vendas).

O que Gordon (1994) propõe é uma forma de simulação, de estimação do que pode ocorrer caso um ou mais eventos possam impactar a tendência de estabilidade. Em outras palavras, se mudanças são possíveis de ocorrer, é importante tentar avaliar o que elas vão provocar nos resultados.

Burt (2007) argumenta que descontinuidades são comumente antecedidas por sinais, mas estes geralmente são percebidos tarde demais para que gestores possam tomar ações a tempo de lidar com suas consequências. Dessa forma, estudar o futuro, seja por qual metodologia, deve possibilitar a análise desses antecedentes, dando condições para que rupturas ou descontinuidades possam ser percebidas a tempo de agir. A combinação do método de cenários com análise de sistemas e as condições indutoras para rupturas de Clayton Christensen contribui para que isso seja possível (BURT, 2007).

Rossel (2012) adiciona a esse tema, ao propor que o dinamismo dos tipos de mudanças precisa ser avaliado. Não basta apenas montar uma visão bidimensional colocando os sinais fracos em termos de níveis de incertezas versus impactos potenciais. É preciso também avaliar os sinais fracos pela sua forma, escala e profundidade de mudanças que possam provocar. Isso esclarece melhor como as mudanças poderão ocorrer (ROSSEL, 2012).

Ilmola e Kuusi (2006) propuseram que um dos papeis importantes dos praticantes de estudos do futuro é saber filtrar os sinais fracos. Excesso de filtragem cria pontos cegos na análise, pouca filtragem provoca avalanche de temas que podem não ser relevantes. Calibrar o quanto se seleciona os sinais fracos é fundamental para suportar a tomada de decisões. Então há risco

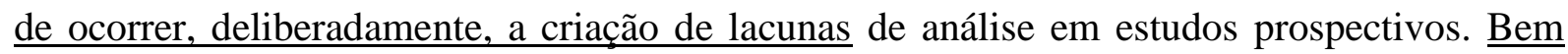
como elas podem surgir a partir do desconhecimento ou da ignorância sobre alguns dos temas.

O efeito do que está na periferia, fora do foco de concentração dos gestores, pode ser significativo para o futuro da organização. Ter foco muito concentrado a temas admitidos como mais relevantes pode levar a resultados limitados, conduzindo para riscos ignorados que podem impactar a organização (DAY; SCHOEMAKER, 2004). 
A visão periférica contribui para perceber indícios de sucesso (ou fracasso) nas organizações. É preciso ter vigilância sobre eventos futuros que podem impactar o futuro da organização. Esse estado de alerta contribui para formar visão de antecipação e, dessa forma pode subsidiar a preparação da organização para dar resposta aos eventos, e assim mitigar efeitos negativos ou, talvez melhor, aproveitar oportunidades (DAY; SCHOEMAKER, 2007).

Um dos grandes desafios da prospecção do futuro é a aplicação dos métodos nas empresas, os gestores não sentem falta de métodos para prospecção, mas demonstram dificuldade em executar seus processos conforme recomendações (SCHWARZ, 2008). Dessa forma, a prospecção do futuro é atividade que possivelmente seja praticada nas organizações, mas é grande a possibilidade de haver limitações nesse processo.

Há questionamentos sobre a eficácia e a contribuição que os estudos do futuro (e cenários) possam gerar para organizações (BURT; VAN DER HEIJDEN, 2008). A causa, segundo os autores, é que muitas vezes falta um enquadramento que possibilite entender o objetivo de um projeto de estudo do futuro, seja que métodos estejam sendo utilizados para prospectar o futuro. É preciso lidar melhor com os objetivos de projetos de estudos do futuro, saber identificar potenciais lacunas em organizações, e assim estimular a prática do estudo do futuro (BURT; VAN DER HEIJDEN, 2008).

O entendimento incorreto sobre o que é possível se obter com a atividade de prospectar o futuro é outro problema. Armstrong (1985) ensina que ocorre uma confusão entre forecasting e planejamento. Em muitos casos onde o executivo principal de uma organização diz necessitar de um forecasting, ele está de fato se referindo a um planejamento. Armstrong diz que forecasting é um processo que busca estimar como o futuro poderá ser, enquanto planejamento é um processo que visa determinar como o futuro deverá ser (ARMSTRONG, 1985, p. 6). Planejamento define os objetivos, dessa forma, proporciona a direção para se chegar ao futuro como deverá ser.

Para Armstrong existe uma relação entre forecasting e planejamento, sendo esses termos distintos em significado. O planejamento tem foco na análise de informações, na definição e avaliação de estratégias, no estabelecimento de objetivos, indicadores e metas, e finalmente na monitoração dos resultados. Forecasting é um processo que antecede o planejamento, visando subsidiar este último com análises e informações (ARMSTRONG, 1985, p. 6). 
Segundo Drucker (2010, p.188) as decisões tomadas hoje têm objetivo de contribuir para a construção do futuro. E como elas têm relação, na maioria das vezes, com o futuro, então a prospecção tem objetivo de contribuir nas decisões que poderão moldar como o futuro será construído.

Estudar o futuro tem como foco se preparar para atingir objetivos ou se prevenir e se preparar para situações inesperadas. A preparação para o futuro é realizada por um processo de planejamento para suporte a decisões orientadas para o futuro (HOGARTH; MAKRIDAKIS, 1981).

O estudo do futuro visa, tanto analisar alternativas de futuro quanto estimar o estado das variáveis e do ambiente da organização nessas alternativas, e também monitorar o andamento ao longo do tempo (HOGARTH; MAKRIDAKIS, 1981).

Amara (1991) propunha que estudos do futuro focassem na detecção e descrição de mudanças estruturais, portanto, de descontinuidades ou rupturas por vir.

"O futuro é uma combinação de situações de mudança", argumenta Stacey (1991, p. 27). O autor ainda ensina que uma situação geral de mudança no ambiente, para estar bem descrita, precisa apresentar as seguintes especificações:

(1) o tempo para a mudança, ou seja, quando ela ocorre, quanto tempo leva para que ocorram as consequências da mudança;

(2) a magnitude das consequências da mudança;

(3) o grau de previsibilidade da mudança e das suas consequências.

Segundo essas especificações, é quase certo que em algum momento no futuro haverá mudanças, e uma variável importante quando se analisa futuro é o horizonte de tempo (STACEY, 1991, p. 27). O autor ilustra isso por meio da figura a seguir. 


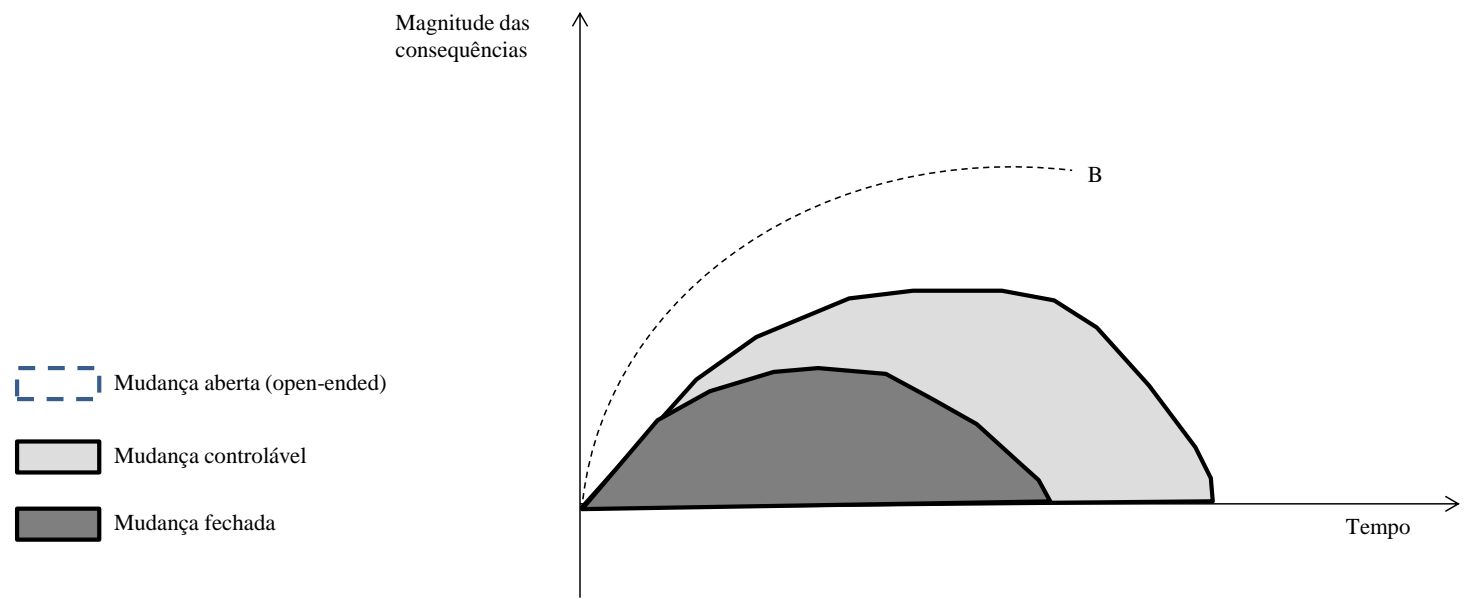

Ilustração 10 - Mudanças ao longo do tempo como consequências de ações e eventos Fonte: Stacey, 1991, p. 28

Considerando a variação da influência dos fatores externos e o quanto se pode controlar as consequências desses fatores, as mudanças podem apresentar três formas de se manifestar ao longo do tempo. A fechada pressupõe controle sobre os fatores, e por isso tem horizonte de tempo curto, a controlável apresenta fatores menos controláveis, mas por ações dos gestores se pressupõe que suas consequências possam ser ainda controláveis, e finalmente a aberta é aquela na qual os fatores externos são incontroláveis ou mesmo inesperados, portanto suas consequências não podem ser antecipadas (STACEY, 1991).

Planejadores tendem a adotar horizontes de tempo para estabelecer seus planos a serem implantados. Praticantes de prospecção do futuro também, com a característica de que estes últimos tendem a adotar horizontes mais longos que os primeiros (RONEY, 2010).

Godet (1994) defende que estudos do futuro devam ser aplicados para evitar o fatalismo. Posto de outra forma, o autor argumenta que é recomendável sondar o futuro em suas perspectivas e alternativas, visando à preparação para o que pode vir a acontecer, ou mesmo se possível influenciar para o que venha a acontecer. Pode se depreender disso que, para ele os objetivos da prospecção do futuro não incluem acertar previsões, mas sim avaliar possíveis ações que possam evitar os riscos na jornada para chegar aos futuros desejados (GODET, 1994, p. 29).

Godet (1994) ainda argumenta que há diferentes abordagens em relação ao futuro. A que o autor propõe, chamada de "prospectiva" (La Prospective) é a e abordagem da (1) Conjectura, na qual se consideram hipóteses possíveis e abrangentes de natureza qualitativa e quantitativa, 
com múltiplos cenários analisados. A segunda é a da (2) Projeção, que pressupõe que o futuro poderá repetir o passado, então as tendências vigentes são projetadas para se estimar como afetará o futuro, de forma quantitativa. A terceira é a da (3) Previsão, que busca estimar os eventos antes que eles aconteçam, sendo baseada em futurologia segundo o autor, e inclui todos os aspectos sobre pesquisa sobre o futuro (uma abordagem anglo-saxã). A quarta abordagem é a da (4) Profecia, baseada em inspiração por vezes considerada divina, contudo, se aplicada com premissas coerentes pode consolidar visões plausíveis de futuros (método de cenários). A quinta e última é a do (5) Planejamento, na qual se analisa um futuro desejado e se implantam ações para se atingi-lo, sendo esta definição baseada em Ackoff (1969), segundo o autor (GODET, 1994, p. 33).

Schwartz (2003) faz uma comparação da organização com um barco navegando num mar turbulento. As ondas vão atingir o barco, é inevitável. É melhor, segundo ele, tentar antecipar a forma com que elas vão atingi-lo, e não deixar o barco à deriva (SCHWARTZ, 2003, cap. 9, ebook). Essa analogia é pertinente na situação de incertezas de futuro presentes em processos de decisão, pois é mais prudente analisar as consequências e os impactos das alternativas em análise. Ao final, alguém vai perguntar o que foi feito para se preparar para o futuro, e a quem cabe responsabilidade pelas decisões, as respostas devem estar disponíveis.

Uma interpretação sobre o que diz Schwartz (2003) sobre organizações navegarem em mar turbulento seria que: As ondas que estão à vista podem ser monitoradas e gerenciadas, se a organização estiver preparada para os riscos já visíveis, elas representam o curto prazo. Contudo, aquelas que estão além da visibilidade podem ser mais fortes ou mais fracas, e representam as incertezas do longo prazo. Se a estratégia de longo prazo dá a direção a ser tomada, seria recomendável saber como serão as ondas lá. Para isso serviria a atividade de prospecção do futuro.

Em outra obra de Schwartz, de 1996, o autor enfatiza que prospecção via método de cenários é mais arte do que ciência, mas os passos básicos são os mesmos, na sua visão. E isso vale, seja para pequenas empresas, indivíduos ou mesmo grandes corporações. Em qualquer delas pessoas vão se encontrar várias vezes em processo de revisar e refinar decisões, realizar mais pesquisas na busca de mais elementos ou informações, testar novos contextos de futuro, e analisar as implicações de tudo isso recorrentemente. A ênfase de Schwartz é no exercício de 
ensaiar as implicações (nas palavras dele), o que significa simular os contextos imaginados nos cenários (SCHWARTZ, 1996, p. 28-29).

Kahane (2012) propõe que estudos do futuro gerem análises e conclusões que possam contribuir para engajar os gestores em um processo disciplinado, cooperativo e criativo de pensar o futuro, culminando em ações resultantes nos projetos estratégicos (KAHANE, ebook, 2012). Dessa forma, suporte a decisões é um dos principais objetivos da prospecção do futuro. Isso é corroborado por Chermack (2011), quando ele argumenta que aprender a como perceber um contexto, completo com suas incertezas pertinentes, é uma importante habilidade no mundo atual (CHERMACK, 2011, ebook, prefácio).

O processo de suporte a decisões é uma atividade crítica para decisões tomadas no presente. Chega a ser desconcertante que houvesse percepção de eventos cujos sinais estavam presentes no ambiente, indicando a real possibilidade de eles virem a acontecer, e quando aconteceram muitas pessoas se mostraram surpresas com o fato consumado. Isso se chama "surpresas inevitáveis" (SCHWARTZ, 2003, cap. 1, ebook). Para o autor, o estudo do futuro serve também para preparar-se para o inevitável, ou seja, aquilo que era possível de ser percebido antecipadamente.

Estudar o futuro significa reconhecer o ritmo das mudanças, $\underline{\text { não negar esse fato e desenvolver }}$ respostas a elas antes que elas aconteçam, o que pode dar a percepção de importância para a prospecção do futuro (SCHWARTZ, 2003, cap. 1, ebook). Schwartz também argumenta que o mundo não vai tomar as decisões pelas pessoas, portanto elas devem se mobilizar para que as decisões possam ser tomadas, com a responsabilidade assumida. As pessoas devem buscar o controle sobre seu destino (SCHWARTZ, 2003, cap. 9, ebook). Seria natural, dessa forma, a mobilização para suporte à decisão, gerando resultados que possam representar o papel de contribuição da prospecção do futuro no processo de tomada de decisão estratégica.

Corroborando o que Schwartz (2003) argumenta sobre surpresas inevitáveis, Bazerman e Watkins (2005) também avaliaram que o ser humano pode ignorar eventos previsíveis. Eles usam o termo "surpresas previsíveis" como sendo um evento ou um conjunto de eventos que surpreendem gestores nas organizações, mesmo tendo havido disponibilidade de informações que permitiriam avaliar a possibilidade de ocorrência desses eventos. Portanto, estimar a ocorrência de eventos futuros pode evitar consequências negativas para a organização ou 
mesmo para a sociedade, e se houver metodologia que possa dar suporte a isso, então cabe utilizá-la para evitar problemas (BAZERMAN; WATKINS, 2005).

Em contraste com eventos que possam ser inesperados, há alguns que se manifestam lentamente e podem ser monitorados. A urbanização, as discussões sobre mudanças climáticas, o envelhecimento demográfico, para citar apenas alguns dos temas em pauta atualmente estão cada vez mais atuantes e presentes nos processos de análise e de decisão (RAMIREZ et al, 2010, p. 303). Para Chermack (2011) o mundo está mudando mais rápido do que nunca, e paradoxalmente alguns tomadores de decisão se comportam como se isso não fosse tão impactante. $\mathrm{O}$ autor argumenta que esses tomadores de decisão continuam a buscar uma resposta, como se existisse apenas uma correta, e ainda pior, como se a responsabilidade deles fosse encontrá-la (CHERMACK, 2011, ebook, Part One). Interpretando Chermack, pior do que buscar uma resposta singular, o que já seria arriscado, é pensar que a sua responsabilidade é esta, como que assumindo um princípio de determinismo que é uma ilusão de controle, conforme descreveram Makridakis et al (2009).

Temas como globalização, fragmentação, regionalização, tensões entre diferentes culturas e religiões estão com seu potencial de influenciar mudanças em processo de aceleração. A complexidade está aumentando muito, e cada vez mais é preciso dar atenção sobre novas tendências, mudanças e eventos futuros potencialmente impactantes (HINES; BISHOP, 2013, ebook, cap. 3).

A prospecção deve dar suporte à visão de futuros múltiplos, porém plausíveis. Então futures studies deve facilitar a prática de examinar as imagens de futuro, para que tomadores de decisão possam aprimorar suas decisões (DATOR, 2002b).

$\mathrm{O}$ entendimento do passado e os conceitos sobre o futuro, ou os futuros, formatam o comportamento e as atitudes das pessoas no presente. A tendência é de que as impressões sobre o futuro vão influenciar muito o desenvolvimento de estratégia, o que pode enfatizar o valor de estudar o futuro considerando aspectos como intuição, intenção e idealismo (CUMMINGS; DAELLENBACH, 2009). A conexão entre prospecção e estratégia será reforçada, segundo os autores. 
Futuro e passado têm conexão com o presente, e talvez as áreas de estudo da pesquisa histórica (HR - history research) e a dos estudos do futuro (futures studies) possam se complementar e levar a benefícios mútuos para o conhecimento. Kaivo-Oja et al (2004) apontam para essa possibilidade, ao argumentar que ocorre uma certa descontinuidade entre o presente, o passado recente e o futuro próximo. Essa descontinuidade teria origem no fato de que a área de pesquisa histórica (HR) seja mais tradicional, o que possivelmente prejudica a análise dos efeitos das decisões estratégicas no passado recente. Enquanto que a área de estudos do futuro tende a se concentrar mais na visão estratégica de horizonte mais longo, o que pode negligenciar o horizonte operacional do futuro próximo (KAIVO-OJA et al, 2004). O modelo que os autores propuseram está mostrado na ilustração a seguir.

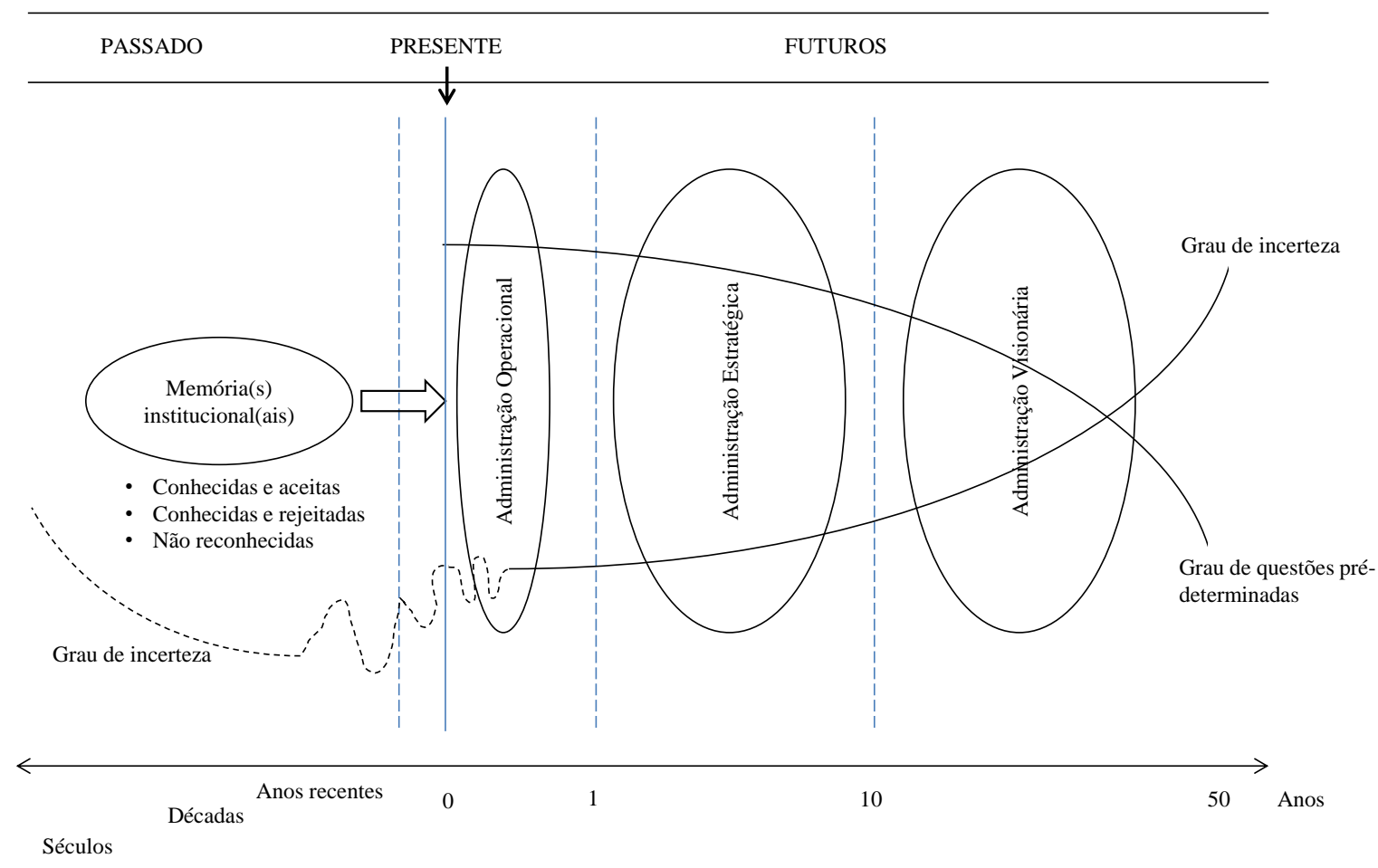

\footnotetext{
Ilustração 11 - Estrutura geral para administração estratégica relacionando passados, presentes e futuros

Fonte: Kaivo-Oja et al (2004)
}

Esse modelo que Kaivo-Oja et al (2004) adaptaram, a partir de propostas de outros autores, ilustra que no passado recente e no futuro de curto prazo há uma descontinuidade, um ruído no grau de incertezas em relação a análises e explicações sobre os efeitos das decisões estratégicas sobre o passado recente. E o modelo também mostra que o futuro de curto prazo tem ruído no grau de incerteza, porque talvez os praticantes de estudos do futuro não estejam atentos ao curto prazo (KAIVO-OJA et al, 2004). Ou, numa hipótese complementar, talvez isso seja também devido à dificuldade de analisar os efeitos das decisões do passado mais 
distante sobre o passado mais recente. E isso poderia talvez gerar limitações no processo de avaliar as decisões e as suas consequências, quando as decisões estão para ser tomadas e possam gerar consequências no futuro próximo.

Descontinuidades (disruptions) são fenômenos chamados de STEEP Surprises, por Markley (2011). O autor argumenta ser muito importante analisar o futuro para rastrear a possibilidade de ocorrência de descontinuidades, especialmente as de impacto na estratégia. Aquelas, particularmente, que apresentem baixa probabilidade de ocorrência, mas impactos potencialmente elevados, chamadas por ele de STEEP Surprises do Tipo II. Muitas razões levam este tipo de evento a ter pouca credibilidade, e a mais forte é a falta de consciência sobre eles, chamada pelo autor de "descrença passiva". O autor defende ação coletiva para aumentar o potencial de detecção deste tipo de evento (MARKLEY, 2011).

Alguns benefícios de prospectar o futuro de forma interativa, participativa e adaptativa são (ERIKSSON; WEBER, 2008):

- Aumentar o potencial de tomada de decisão mais racional;

- Tornar as análises mais próximas da realidade percebida em conjunto, permitindo que elas sejam desenvolvidas com visão mais dependente do caminho (adaptadas às opções de caminhos de desenvolvimento);

- Enxergar a influência do ambiente externo para além da visão de poucas pessoas, e ao mesmo tempo manter as opções abertas para que possam ser aplicadas conforme o a necessidade, ou descartadas se for o caso;

- Combinar a visão coletiva e a individual, aumentando o poder do pensamento prospectivo;

- Finalmente, gerar mais poder de análise de opções e alternativas, a partir do aumento do pensamento estratégico.

Eriksson e Weber (2008) defendem, portanto, que futuro e estratégia têm conexão que necessita de pessoas para analisarem como ela deve ocorrer. Ainda mais, mantendo o objetivo de suporte à tomada de decisão. Kaivo-Oja et al (2004) também enfatizam que a rede de contatos e conexões (stakeholders) é muito importante para suporte ao desenvolvimento de 
uma visão robusta de futuro, pois ao final, o objetivo é possibilitar que tomadores de decisão possam defender suas decisões.

Lempert e Groves (2010) mencionam que o modelo mais comum de processo de tomada de decisão, que considere aspectos ambientais, tem como estrutura o ciclo "preveja-entãodecida". Isso pressupõe estimar probabilidades de ocorrência de eventos, o que complica muito o processo de análise, pois as incertezas típicas de problemas de decisão envolvendo o meio ambiente são muito grandes. Eles defendem a utilização de modelos adaptativos, com suporte computacional, para simular inúmeros cenários futuros. Em outras palavras, prospecte o futuro e suporte a tomada de decisão, fazendo isso em processo interativo e adaptativo simulando muitos cenários.

As incertezas que afetam a gestão estratégica podem ser classificadas em diferentes categorias (GEORGANTZAS e ACAR, 1995, p. 59):

\section{U1: de ambiente, relacionadas a eventos e tendências \\ U2: de movimentos de competidores \\ U3: de decisões da empresa e sua capacidade de se mobilizar \\ U4: de alinhamento tático e capacidade para implementação}

Georgantzas e Acar (1995, p. 58) argumentam que o planejamento orientado a cenários pode contribuir para lidar as incertezas U1, U2 e U3 diretamente. A abordagem proposta pelos autores não prevê diretamente o tratamento de incertezas da categoria U4, uma vez que esta última tem mais relação com a implementação da estratégia, enquanto os autores se concentram mais no design (análise e formulação) da estratégia.

Milliken (1987) contribuiu com o tema da dificuldade de tratar incertezas, sendo que ele indicou três formas de incertezas. A primeira forma, (1) a incerteza de estado, reflete a limitação em entender o ambiente conforme ele se encontra no presente, por decorrência como ele poderá ser no futuro, pois não se consegue perceber os fatores de mudanças vigentes no ambiente. A segunda forma é (2) a incerteza de efeito, que significa que as pessoas têm limitações na análise sobre os efeitos que o ambiente futuro poderá ter sobre a organização. Finalmente, a terceira forma de incerteza é a da (3) resposta, a qual é associada com a 
limitação em analisar que alternativas de respostas a organização pode adotar, ou que consequências essas alternativas de respostas poderão gerar no futuro (MILLIKEN, 1987). O autor apontou que a volatilidade e a complexidade do ambiente externo limitam a capacidade de as pessoas enxergarem essas diferenças entre os tipos de incertezas.

A prospecção do futuro é geralmente praticada quando em situação de complexidade do problema em análise. A presença de incertezas no processo de tomada de decisão é comum nessa situação. Stacey (1991, p. 6-7) argumenta que as pessoas, quando confrontadas com algum problema mais complexo, tendem a juntar informações acerca do problema, processálas e depois proceder a análises sobre escolhas de ações para lidar com o problema. Nesse processo, as pessoas sofrem as suas respectivas limitações, e podem ignorar a realidade em sua volta pelo foco em suas crenças pessoais. Isso nada mais é, segundo o autor, que um processo de criar um modelo, o qual é desenvolvido a partir das próprias experiências anteriores das pessoas. Portanto, o autor argumenta que os atos de pensar, analisar e definir um conjunto de ações são inerentemente influenciados pelo que as pessoas aprenderam no passado, nos modelos que elas desenvolveram no passado por meio de experiências e aprendizado. Dessa forma, o que as pessoas fazem ao se confrontar com novos desafios é recorrer a esses modelos do passado.

O que Stacey (1991) alerta é que a complexidade não pode ser analisada com o radar baseado em modelos de passado. Os problemas complexos precisam ter respostas, alternativas que possam dar suporte ao que gestores vão utilizar como ações para lidar com eles. Em outras palavras, é preciso ter orientação para mudanças, estar aberto para novas situações e contextos. Ele defende que o futuro é imprevisível, ao mesmo tempo em que argumenta que o passado, em algumas situações, não ajuda em nada. A proposta para resolver este paradoxo, segundo ele, seria adotar alguns passos importantes para que gestores em empresas possam lidar com decisões estratégicas (STACEY, 1991, p. 10-11):

- Estabelecer objetivos, avaliar declarações de missões, articular visões, sonhos ou intenções. Dessa forma, saber onde a empresa está e onde ela pretende chegar em momento futuro.

- Inspirar pessoas no sentido de acreditar na visão futura. Alinhar as pessoas em torno da visão para se direcionar o consenso e comprometimento com a visão. 
- Administrar estrategicamente requer ações. Um plano geral e flexível, com passos determinados ao longo do tempo e objetivos a serem atingidos pelas ações para se realizar a visão da empresa.

Schwarz defende que a simulação é um importante meio para que pessoas possam calibrar seus modelos mentais no sentido do pensamento estratégico e da orientação para o futuro em ambientes dinâmicos e complexos. Na pesquisa desenvolvida pelo autor, utilizou-se um jogo de guerras em negócios, e foi observado que o fato de os alunos terem que assumir o papel e as reponsabilidades pelas decisões contribuiu para eles conectarem suas ações/decisões com o conhecimento (SCHWARZ, 2013).

Johnston (2013) diz haver quatro impactos possíveis de obter a partir da prática de prospecção do tipo adaptativa (adaptative foresight), aquela que não busca visões transformadoras ou de descontinuidades:

- Incremento da consciência: No sentido de aumento da percepção das pessoas acerca das necessidades, valores, abordagens e métodos de prospecção para o entendimento dos desafios do futuro e a consequente preparação para lidar com ele.

- Melhorando a apropriação das informações: Por meio de oferta de conceitos e dados empíricos que levam à maior capacidade de planejar e tomar decisões.

- Ativação efetiva da análise de incertezas: Por meio do aprimoramento da capacidade de analisar de forma eficaz as incertezas de futuro presentes na prospecção.

- Disseminando influência: Um impacto relacionado com a capacidade de influenciar agentes, tomadores de decisão e formadores de opinião para a reflexão, o pensamento sobre alternativas e suas consequências, e isso sobre assuntos relevantes de diferentes naturezas, como políticas públicas, negócios, estratégia, investimentos, produtos e serviços, leis/regulamentos, insumos.

Esses quatro impactos podem ser considerados como objetivos da prospecção do futuro, ou seja, ela seria praticada para se chegar à possibilidade de vivenciar os impactos acima.

Rohrbeck e Bade (2012) estudaram inúmeros artigos (114) publicados entre 1980 e 2011 sobre monitoramento do ambiente, estudos do futuro, visão periférica e foresight estratégico / 
corporativo. Os autores propõem um redirecionamento na abordagem de lidar com prospecção do futuro - sair de uma abordagem orientada à previsão para outra orientada a múltiplos futuros. Isso seria positivo para dar flexibilidade, agilidade e robustez à estratégia.

Nos anos 1980 o foco dos estudos estava mais voltado nos aspectos da "razão de ser" dos estudos do futuro. Algo com objetivo de enfatizar as razões pelas quais se deveriam desenvolver pesquisas sobre o tema. Nos anos 1990 o foco se voltou para métodos e processos de praticar prospecção do futuro. Também foi ampliado o escopo do que era recomendado ser incluído em prospecção, dando maior valor para o ambiente externo, devido ao aumento da complexidade. Talvez por esta mesma razão, a teoria da complexidade tenha entrado em evidência e continuado presente nos estudos até o presente. Agora, a conexão entre os estudos do futuro e as demais funções gerenciais ainda se encontra com poucas contribuições, segundo os autores (ROHRBECK; BADE, 2012).

Rohrbeck e Bade (2012) ainda contribuem para recomendar que gestores tomem a frente da adaptação organizacional, da construção da robustez organizacional diante das mudanças. Enfim, gestores devem construir a orientação para o futuro da organização.

Sobre avaliação da prática dos métodos de prospecção e a respectiva satisfação com os resultados, Mentzler e Kahn (1995) argumentaram que a familiaridade com os métodos e a satisfação com os resultados têm relação entre si. Ao longo de dez anos (1985 a 1995), houve um aumento no uso de métodos quantitativos em relação aos qualitativos. O horizonte de tempo era bem variado no início do período, já ao final houve maior recorrência a horizontes de tempo mais curto, de três meses a dois anos. Os métodos mais praticados foram identificados: (1) opinião de executivos, (2) pesquisas de mercado, (3) regressão e (4) linhas de tendência, segundo a categorização adotada pelos autores. No horizonte de tempo mais curto, o método de opinião de executivos teve maior satisfação no início do período, mas ao final do período a satisfação média com ele foi menor do que com os outros três métodos. Embora a pesquisa dos autores tenha sido com métodos aplicados a horizontes mais curtos, ela traz a informação de que a satisfação com a prospecção é uma questão complexa (MENTZLER; KAHN, 1995). 
Greiner et al (2014) apontaram que uma das grandes dificuldades em se lidar com projetos de cenários é a validação dos resultados, o que pode limitar bastante a utilização dos mesmos, ou mesmo a avaliação da atividade de estudar o futuro.

Nesse tema contribuíram Boaventura e Fischmann (2008), ao proporem um modelo para testar a consistência da visão de futuro. Os autores recomendam testar a visão de futuro pela sua consistência, pois em algum momento decisões estratégicas serão tomadas, e elas levam em consideração a visão de futuro da organização. Se esta última for consistente, aumentam as chances de melhores decisões.

WRIGHT et al (2008) estudaram um caso no qual identificaram que é importante analisar a receptividade do corpo executivo, de promover uma intervenção na estratégia corrente da empresa, após receberem os resultados de um exercício de cenários. Os autores apontam que se essa receptividade for baixa ou nula, talvez não devesse ser desenvolvido o exercício. Fatores psicológicos interferem no processo, os executivos podem estar em inércia estratégica, o que atenua a percepção das ameaças externas e os leva a aderirem sem receios à estratégia corrente da empresa. Se o exercício de cenários for realizado e os resultados indicarem ameaças, os fatores psicológicos vão fazer os executivos atenuarem a percepção de impactos. Se por outro lado o exercício de cenários não apontar ameaças significativas, então os mecanismos psicológicos vão reforçar a inércia estratégica vigente (WRIGHT et al, 2008).

Grim (2009) propôs um modelo de avaliação da maturidade para a prática de foresight nas organizações. Trata-se de um modelo com três partes: (1) Disciplinas, (2) Níveis de Maturidade e (3) Indicadores de Maturidade.

O autor apresenta três estruturas para aplicar o modelo. Apresentadas nos quadros a seguir. 
Quadro 2 - Disciplinas do modelo de maturidade

\begin{tabular}{|l|l|}
\hline \multicolumn{1}{|c|}{ Disciplina } & \multicolumn{1}{c|}{ Descrição } \\
\hline Liderança & $\begin{array}{l}\text { Proporcionar a transição da prospecção para ações, } \\
\text { de forma continuamente praticada }\end{array}$ \\
\hline Estruturação & $\begin{array}{l}\text { Proporcionar a identificação dos problemas corretos, } \\
\text { e o entendimento claro do que como eles são }\end{array}$ \\
\hline Monitoramento & $\begin{array}{l}\text { Identificar o que ocorre na organização, e seu } \\
\text { ambiente externo próximo e amplo }\end{array}$ \\
\hline Prospecção & Prospectar o futuro, e suas múltiplas possibilidades \\
\hline Visão & Definir o que a organização deve se tornar no futuro \\
\hline Planejamento & $\begin{array}{l}\text { Desenvolver planos, pessoas, competências e } \\
\text { processos para suportar a visão de futuro }\end{array}$ \\
\hline
\end{tabular}

Fonte: Adaptado de Grimm (2009)

Grim (2009) propõe que essas seis disciplinas sejam avaliadas na organização, e o composto delas poderia ser uma forma de avaliar a maturidade de uma empresa para a prospecção do futuro. Cada disciplina seria formada por práticas, e estas seriam avaliadas para compor o grau de maturidade da disciplina.

As práticas de cada disciplina seriam medidas segundo cinco níveis, os quais estão ilustrados abaixo.

\begin{tabular}{|c|c|c|c|c|c|}
\multicolumn{5}{c|}{ Quadro 3 - Níveis de maturidade em uma disciplina } \\
\hline \multirow{3}{*}{ Disciplina } & \multicolumn{5}{|c|}{ Nível de maturidade para prospecção } \\
\cline { 2 - 7 } & 1 & 2 & 3 & 4 & 5 \\
\cline { 2 - 7 } & Adhoc & Aware & Capable & Mature & World-class \\
\hline Prática 1 & & & & & \\
\hline Prática 2 & & & & & \\
\hline Prática 3 & & & & & \\
\hline ... & & & & & \\
\hline Prática N & & & & & \\
\hline
\end{tabular}

O nível Adhoc é o reativo, segundo a demanda e a necessidade, sem representar comportamento proativo. 
O $\underline{\text { Aware }}$ é o nível da consciência, do reconhecimento de que o futuro pode representar potenciais riscos ou oportunidades para a organização, e os gestores podem aplicar conhecimento prospectivo básico, sem maior profundidade.

O $\underline{\text { Capable }}$ representa um pouco mais além do reconhecimento, ele significa razoável domínio de habilidades para lidar com incertezas de futuro.

O nível Mature representa estágio avançado de competências para prospecção do futuro, significando potencial de executar todos os passos necessários para um exercício prospectivo consistente.

O World-class é o estágio máximo de maturidade, que significa que os gestores da organização podem inclusive contribuir para a proposição de novos métodos e modelos de suporte à prospecção, e também estariam expandindo a fronteira do conhecimento sobre a área de conhecimento, por meio de publicações (GRIM, 2009).

A forma de suporte para avaliar rotas de aprimoramento é proposta pelos dois quadros a seguir. 
Quadro 4 - Descrição dos níveis de maturidade

\begin{tabular}{|c|c|c|c|c|}
\hline Ad hoc & Aware & Capable & Mature & World-class \\
\hline \multicolumn{5}{|l|}{$\begin{array}{l}\text { Prospecção sob } \\
\text { demanda }\end{array}$} \\
\hline & $\begin{array}{l}\text { Educação } \\
\text { prospectiva básica } \\
\text { Melhores práticas } \\
\text { Lições aprendidas }\end{array}$ & & & \\
\hline & & $\begin{array}{l}\text { Maior } \\
\text { profundidade } \\
\text { educacional } \\
\text { Capacidade de } \\
\text { operar bem um } \\
\text { grupo de trabalho } \\
\text { Compartilhamento } \\
\text { dentro do grupo }\end{array}$ & & \\
\hline & & & $\begin{array}{l}\text { Compartilhamento } \\
\text { de conhecimento } \\
\text { Informações } \\
\text { documentadas e } \\
\text { referenciáveis } \\
\text { Planos para } \\
\text { aprimorar } \\
\text { educação } \\
\text { prospectiva } \\
\text { Avaliação de } \\
\text { consistência e } \\
\text { qualidade }\end{array}$ & \\
\hline & & & & $\begin{array}{l}\text { Capacidade de } \\
\text { criar novos } \\
\text { métodos } \\
\text { Publicação } \\
\text { Feedbacks } \\
\text { recorrentes } \\
\text { praticados }\end{array}$ \\
\hline
\end{tabular}

Fonte: Adaptado de Grim (2009) 
Quadro 5 - Avaliação da maturidade por disciplina e os objetivos de aprimoramento

\begin{tabular}{|l|c|c|c|c|c|}
\hline \multirow{3}{*}{ Disicplina } & \multicolumn{5}{|c|}{ Níveis de Maturidade } \\
\cline { 2 - 7 } & 1 & 2 & 3 & 4 & 5 \\
\cline { 2 - 7 } & Ad hoc & Aware & Capable & Mature & World-class \\
\hline Liderança & & & & $\rightarrow$ & \\
\hline Estruturação & & & & & \\
\hline Monitoramento & & & & & \\
\hline Prospecção & & & & & \\
\hline Visão & & & & & \\
\hline Planejamento & & & & & \\
\hline
\end{tabular}

Fonte: Adaptado de Grim (2009)

O modelo proposto por Grim (2009) é bastante completo e permite adotar adaptações para calibrar cada indicador em termos de profundidade.

Outro modelo de avaliação da maturidade para a prática de prospecção do futuro em organizações foi inspirado no que propuseram Rohrbeck e Gemünden (2008). Nesta abordagem, que mais tarde foi sistematizada por Rohrbeck (2011), os autores utilizaram descrições obtidas de estudos de múltiplos casos, com entrevistas realizadas com gestores de 15 empresas europeias. A estrutura do modelo é composta por 5 dimensões, as quais representam constructos a serem avaliados na organização, considerando fatores relacionados a capacidades e competências. Essas dimensões, propostas por Rohrbeck, estão mostradas na ilustração a seguir. 


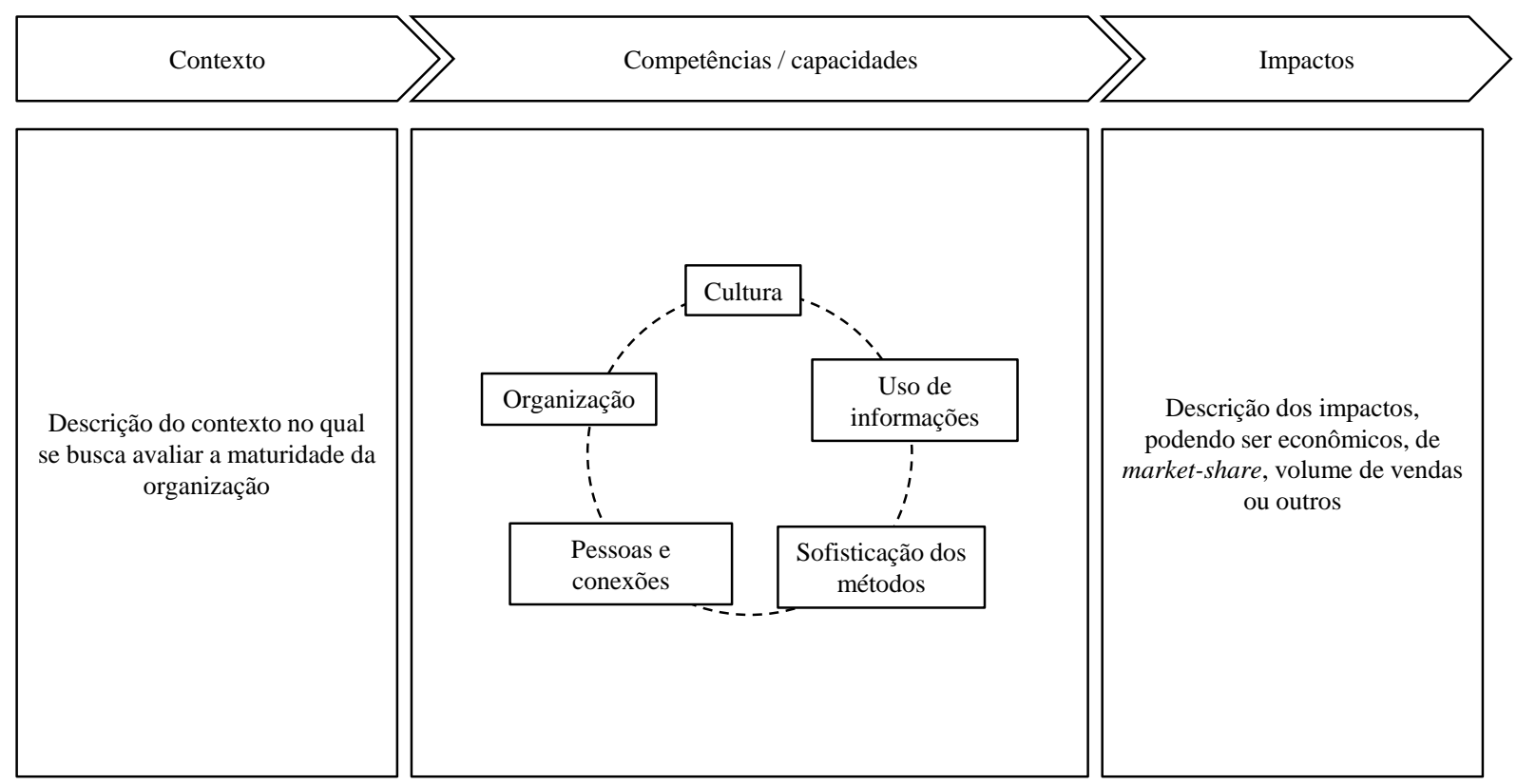

Ilustração 12 - Modelo de avaliação de maturidade

Fonte: adaptado de Rohrbeck (2011, p. 72)

Na intuição de Rohrbeck (2011), que foi baseada em seu trabalho anterior com Gemünden em 2008, as dimensões propostas, se analisadas pelo grau em que são tratadas na organização, podem representar uma forma de medir a maturidade da mesma em relação à prospecção. A dimensão - Uso de Informações - avalia como gestores extraem significados a partir de dados e informações disponíveis, ou mesmo pesquisadas, e adicionalmente como esse significado é estruturado de forma a gerar utilidade para os gestores da organização. Neste processo, pode contribuir bastante o grau de Sofisticação dos Métodos, outra dimensão que pode representar quanto capacitada estaria a organização para dar suporte às análises necessárias. Rohrbeck propõe esse modelo com foco na prospecção do futuro, mas ele poderia ser aplicado para outras atividades também.

No modelo de Rohrbeck (2011), a dimensão Pessoas e conexões envolve avaliar como as pessoas se conectam entre si na organização, ou mesmo fora dela, e dessa forma como elas geram ideias, compartilham percepções e opiniões, resultando em um ambiente rico para o pensamento prospectivo e suas relações com estratégia. Em se tratando da dimensão Cultura, sua interpretação está no estímulo ou propensão a permitir fluidez de compartilhamento, de troca de informações, ideias, por meio de atitudes encorajadoras. Uma organização sem isso tenderia a bloquear criatividade, opiniões divergentes ou contraditórias que poderiam servir de gatilho para um pensamento prospectivo mais aprofundado. Finalmente, a dimensão Organização está relacionada à estrutura organizacional e à integração entre as áreas. Ela 
também tem relação com aspectos de governança e sua influência no processo de tomada de decisões, o que tem influência no processo de prospecção do futuro.

Rohrbeck (2011) propõe um modelo bem abrangente, com elevado grau de possibilidade de detalhar a sua aplicação nas organizações, a exemplo do que faz Grim (2009). Suas propostas ainda não foram desdobradas em pesquisas que contribuíssem para o aprofundamento de cada uma das dimensões ou disciplinas. Esta tese tem o foco em contribuir nessa linha.

Vecchiato (2012) também corrobora a opinião de que a complexidade e a dinâmica do ambiente de negócios estão mais aceleradas. Em seu estudo, o autor conclui que os benefícios da prospecção não estão no produto, na previsão ou na predição, mas no processo de prospectar, que ao final leva os gestores a se prepararem para o futuro, baseados no aprendizado obtido nas discussões prospectivas, não necessariamente nos resultados das discussões. A prática da prospecção, segundo o autor, gera três benefícios, os quais podem também ser entendidos como objetivos: (1) percepção de potenciais mudanças no ambiente, (2) analisar formas de aproveitar as mudanças e (3) reconfigurar os ativos, tangíveis e intangíveis, visando manter alinhamento com o ambiente externo.

Pela literatura que envolve o método de cenários, os processos praticados são mais focados no desenvolvimento de cenários, ou seja, mais em como se chegar ao produto final, que é a descrição de cenários plausíveis de futuro. Os estudos abordam pouco como utilizar cenários, ou seja, como seus resultados podem ser utilizados para subsidiar decisões. Já em relação à avaliação dos projetos de desenvolvimento de cenários, a literatura praticamente não apresenta estudos sobre este tema (CHERMACK, 2011, ebook, part two).

Cabe mencionar que, em níveis gerais, estudos do futuro têm sido abordados de forma mais distante de formalismos metodológicos, sem buscar uma solução ótima. As metodologias passaram, dessa forma, a ficar menos evidentes e os estudos do futuro mais orientados aos problemas prospectivos, o que é mais efetivo (AMARA, 1991). Isso também foi corroborado por Stacey (1991), Fahey e Prusak (1998), List (2006), Wright e Spers (2006), Drucker (2010) e Chermack (2011).

Em síntese, retomando o que Rohrbeck e Bade (2012) apontaram sobre a literatura de estudos do futuro, houve períodos de concentração de escopo das pesquisas desenvolvidas. Já houve 
período com maior foco em demonstrar porque a prática da prospecção seria prescritiva, ou seja, necessária e, portanto, deveria ser praticada e traria benefícios. Posteriormente houve esforço da academia para pesquisar sobre como aprimorar os métodos, buscando desenvolver recomendações e prescrições que suportassem a prática da prospecção. Atualmente o foco proposto pelos autores está em desenvolver estudos que proponham formas de avaliar a contribuição da prospecção na estratégia, no suporte à tomada de decisões. Em outras palavras, a conexão entre a prospecção e as demais funções gerenciais das organizações é o foco atual, segundo os autores (ROHRBECK; BADE, 2012).

Em linha com esse pensamento, observa-se que ele tem uma razão de ser proposto, porque os estudos que mencionam esse tema como um passo importante são, de fato, mais recentes, a exemplo de Burt e Van Der Heijden (2008), Rohrbeck e Gemünden (2008), Roney (2010), Chermack (2011), Rohrbeck (2011), Heger e Rohrbeck (2012), Grim (2009), Greiner et al (2014).

\subsection{Sumário dos conceitos fundamentais da tese}

Nesta tese os conceitos fundamentais utilizados podem ser visualizados no quadro geral da próxima página

Os conceitos utilizados nesta tese foram colocados dentro dos temas estudados, e a aplicação deles para suporte ao desenvolvimento da pesquisa foi explicada. Os autores que apresentam contribuições para esse suporte estão mostrados no quadro também. 
Quadro 6- Sumário dos conceitos utilizados

\begin{tabular}{|c|c|c|}
\hline Tema & Aplicação para esta pesquisa & Autores \\
\hline Avaliação da prospecção & $\begin{array}{l}\text { Formas de avaliar os resultados dos estudos prospectivos } \\
\text { Propostas de modelos de avaliação da atividade de prospecção } \\
\text { Contribuições para estimular o desenvolvimento de modelos de avaliação da } \\
\text { prospecção }\end{array}$ & $\begin{array}{l}\text { Burt e Van Der Heijden (2008), Chermack (2011), Greiner et al (2014), Grim (2009), Heger e Rohrbeck } \\
\text { (2012), Rohrbeck e Gemünden (2008), Rohrbeck (2011), Roney (2010), Winklhoffer } \text { et al (1996) }\end{array}$ \\
\hline Contribuição da prospecção & $\begin{array}{l}\text { Aspectos relacionados com as formas de contribuição da prospecção para a } \\
\text { estratégia e para a tomada de decisões }\end{array}$ & $\begin{array}{l}\text { Chermack (2011), Greiner et al (2014), Grim (2009), Hirsch et al (2013), Kahane (2012), Miller e Waller } \\
\text { (2013), Rohrbeck e Bade (2013), Rohrbeck (2011), Roney (2010) }\end{array}$ \\
\hline $\begin{array}{l}\text { Integração entre prospecção e } \\
\text { estratégia }\end{array}$ & $\begin{array}{l}\text { Integração entre prospecção e estratégia } \\
\text { Recomendações sobre alinhamento de objetivos } \\
\text { Formas de tratramento de incertezas de futuro na análise de estratégia } \\
\text { Desafios estratégicos e abordagens prescritivas utilizando prospecção }\end{array}$ & $\begin{array}{l}\text { Almeida (2010), Armstrong (1985), Boaventura e Fischmann (2008), Cummings; Daellenbach (2009), Day } \\
\text { e Schoemaker (2007), Drucker (2010), Eriksson e Weber (2008), Estrada e Almeida (2007), Engau e } \\
\text { Hoffman (2011), Fidler (2011), Fischmann e Almeida (1991), Godet (1994), Gordon (1994), Heger e } \\
\text { Rohrbeck (2012), Hines e Bishop (2013), Hogarth e Makridakis (1981), Kaivo-Oja et al (2004), Ringland } \\
\text { (2006), Rohrbeck e Bade (2013), Roney (2010), Schoemaker (1995), Visser e Chermack (2009), Wilson } \\
\text { (2000), Wright e Spers (2006), Wright et al (2008) }\end{array}$ \\
\hline Limitações à prática da prospecção & $\begin{array}{l}\text { Aspectos que limitam a prática da prospecção } \\
\text { Problemas que dificultam os processos prospectivos } \\
\text { Geram insegurança comos resultados dos estudos } \\
\text { Podem dificultar a utilização dos resultados } \\
\text { Podem reduzir a orientação à pràtica da prospecção }\end{array}$ & $\begin{array}{l}\text { Chermack (2011), Day e Schoemaker (2004), Fahey e Prusak (1998), Hogarth e Makridakis (1981), Kaivo- } \\
\text { Oja et al (2004), Makridakis et al (2009), Ringland (2006), Roney (2010), Sardar (2010), Schwarz, (2008), } \\
\text { Schwartz (2003), Simon (1997), Schoemaker (1995), Stacey (1991), Tversky e Kahneman (1974), Wright } \\
\text { et al (2008) }\end{array}$ \\
\hline Objetivos da prospecção & $\begin{array}{l}\text { Razões para recomendar a prática da prospecção } \\
\text { Benefícios potenciais a partir do pensamento e da prática prospectiva } \\
\text { Processos aplicáveis para suporte à integração da prospeç̧ão com estratégia } \\
\text { Abordagens prescritíveis para alinhar objetivos da prospecção coma } \\
\text { estratégia }\end{array}$ & $\begin{array}{l}\text { Amara (1991), Armstrong (1985), Bazerman e Watkins (2005), Burt e Van Der Heijden (2008), Chermack } \\
\text { (2011), Chermack (2003), Dator (2002a e 2002b), Fahey e Prusak (1998), Fidler (2011), Gordon et al } \\
\text { (2005), Godet (1994), Heger e Rohrbeck (2012), Hines e Bishop (2013), Johnston (2013), Kahane (2012), } \\
\text { Kuosa (2011), Lee e Park (2005), Makridakis et al (2009), Rohrbeck e Bade (2013), Roney (2010), Sardar } \\
\text { (2010), Schoemaker (1995), Schwartz (2003), Schwartz (1996), Schwartz (2003), Stacey (1991), Van Der } \\
\text { Heijden (2004), Vecchiato (2012), Wilson (2000), Winklhoffer } \text { et al (1996), Wright e Spers (2006), Wright } \\
\text { et al (2008) }\end{array}$ \\
\hline $\begin{array}{l}\text { Processos de suporte à tomada de } \\
\text { decisão (uso dos resultados } \\
\text { prospectados) }\end{array}$ & $\begin{array}{l}\text { Identificar em quais processos os resultados da prospecção podem ser } \\
\text { aplicados } \\
\text { Forma de avaliar se os resultados são efetivamente utilizados nos processos de } \\
\text { análise } \\
\text { Metodologias para suporte à tomada de decisão a partir de estudos } \\
\text { prospectivos } \\
\text { Recomendações sobre cuidados e abordagens prescritíveis para a boa prática } \\
\text { da prospeç̧ão }\end{array}$ & $\begin{array}{l}\text { Dator (2002a, 2002b), Coates et al, 2001, Godet (1994), Godet e Roubelat (1996), Gordon (1994), Hirsch } \\
\text { et al (2013), Hogarth e Makridakis (1981), Kaivo-Oja et al (2004), Kuosa (2011), Lempert e Groves } \\
\text { (2010), Mentzler e Kahn (1995), Miller e Waller (2013), Roney (2010), Rossel (2012), Schwartz (2003), } \\
\text { Schwartz (1996), Schwarz (2013), Stacey (1991), Vecchiato (2012), Wright e Goodwin (2009) }\end{array}$ \\
\hline $\begin{array}{l}\text { Temas portadores de incertezas de } \\
\text { futuro } \\
\text { Idenfificação de lacunas de análises }\end{array}$ & $\begin{array}{l}\text { Métodos para identificar os temas que portam incertezas de futuro } \\
\text { Possibilitar a checagem de lacunas de análise (pontos cegos) } \\
\text { Forma de identificar temas mais críticos } \\
\text { Avaliação sobre temas mais ou menos analisados } \\
\text { Avaliação de quanto os resultados contribuem nas decisões (por temas) }\end{array}$ & $\begin{array}{l}\text { Alan Porter } \text { et al (1991), Amara (1991), Bazerman e Watkins (2005), Burt (2007), Burt e Van Der Heijden } \\
\text { (2008), Dator (2002a, 2002b), Day e Schoemaker (2004), Day e Schoemaker (2007), Engau e Hoffman } \\
\text { (2011), Fidler (2011), Georgantzas e Acar (1995), Godet (1994), Godet e Roubelat (1996), Gordon et al } \\
\text { (2005), Heger e Rohrbeck (2012), Hines e Bishop (2013), Ilmola e Kuusi (2006), Markley (2011), Milliken } \\
\text { (1987), Nehme } \text { et al (2012), Ramirez et al (2010), Ringland (2006), Roney (2010), Rossel( 2012), Schwarz } \\
\text { (2008), Schwartz (2003), Simon (1997), Walsh (2005) }\end{array}$ \\
\hline $\begin{array}{l}\text { Uso de bases de dados acadêmicas } \\
\text { Pesquisa bibliográfica }\end{array}$ & Subsídio ao processo de análise dos dados bibliométricos aplicados na tese & Archambault et al (2009), Bourgeois (2014), Leydesdorff e Vaughan (2006) \\
\hline
\end{tabular}




\subsection{Fundamentação conceitual para operacionalizar a pesquisa}

Os conceitos da teoria que são mais associados com recomendações de processos de análise prospectiva, e aplicáveis no suporte à tomada de decisões com foco nos projetos analisados, são mostrados no quadro a seguir.

Esses processos foram adaptados a partir das recomendações dos autores ali encontrados, e eles são basicamente recomendações úteis para se utilizar os resultados de estudos prospectivos na tomada de decisões em projetos.

Quadro 7 - Processos de análise prospectiva nos projetos

\begin{tabular}{|c|c|}
\hline $\begin{array}{l}\text { Processos de análise prospectiva para suporte à } \\
\text { decisão }\end{array}$ & Autores \\
\hline $\begin{array}{l}\text { Análise dos contextos futuros dos negócios envolvidos } \\
\text { no projeto }\end{array}$ & Stacey (1991), Godet (1994), Chermack (2011) \\
\hline $\begin{array}{l}\text { Análise do alinhamento do projeto com a estratégia da } \\
\text { organização. }\end{array}$ & $\begin{array}{l}\text { Vecchiato (2012), Georgantzas e Acar (1995), Godet } \\
\text { (1994), Visser e Chermack (2009), Dator (2002a, } \\
\text { 2002b), Estrada e Almeida (2007), Fischmann e } \\
\text { Almeida (1991), Boaventura e Fischmann (2008), } \\
\text { Roney (2010) }\end{array}$ \\
\hline Calibração de premissas utilizadas no projeto & $\begin{array}{l}\text { Ilmola e Kuusi (2006), Schwarz (2013), Hines e } \\
\text { Bishop (2013), Fahey e Prusak (1998), Godet (1994) }\end{array}$ \\
\hline $\begin{array}{l}\text { Definição de sinais ou indicadores que sirvam para } \\
\text { monitorar o futuro acontecendo (ou começando a } \\
\text { acontecer) no âmbito da implantação do projeto }\end{array}$ & $\begin{array}{l}\text { Burt (2007), Rossel (2012), Ilmola e Kuusi (2006), } \\
\text { Schwartz, 2003), Almeida, Fernando et al (2007), } \\
\text { Day e Schoemaker (2004), Day e Schoemaker (2007) }\end{array}$ \\
\hline $\begin{array}{l}\text { Análise do quanto o projeto pode influenciar os } \\
\text { resultados futuros da organização }\end{array}$ & $\begin{array}{l}\text { Godet e Roubelat (1996), Godet (1994), Hines e } \\
\text { Bishop (2013), Cummings e Daellenbach (2009), } \\
\text { Rohrbeck (2011), Grim (2009) }\end{array}$ \\
\hline $\begin{array}{l}\text { Simulação: colocar pessoas para analisarem a } \\
\text { organização dentro do contexto futuro proporcionado } \\
\text { pelo projeto }\end{array}$ & $\begin{array}{l}\text { Lempert e Groves (2010), Schwarz (2013), Hirsch et } \\
\text { al (2013), Roney (2010), Miller e Waller (2003), } \\
\text { Gordon (1994) }\end{array}$ \\
\hline $\begin{array}{l}\text { Estudo de mudanças necessárias na organização em } \\
\text { função do projeto }\end{array}$ & $\begin{array}{l}\text { Roney (2010), Dator (2002a), Schwartz (2003), } \\
\text { Vecchiato (2012) }\end{array}$ \\
\hline $\begin{array}{l}\text { Identificação de necessidades de aprimoramento de } \\
\text { competências para implantar o projeto }\end{array}$ & $\begin{array}{l}\text { Roney (2010), Grim (2009), Rohrbeck e Gemünden } \\
\text { (2008), Burt e Van Der Heijden (2008), Rohrbeck e } \\
\text { Bade (2012) }\end{array}$ \\
\hline Exame das incertezas estratégicas envolvidas no projeto & $\begin{array}{l}\text { Dator (2002b), Gordon et al (2005), Chermack } \\
\text { (2011), Gidley (2013), Heger e Rohrbeck (2012), } \\
\text { Johnston (2013) }\end{array}$ \\
\hline
\end{tabular}

Fonte: Análise do autor, adaptado a partir das proposições dos autores

No quadro seguinte podem ser observadas as recomendações sobre como avaliar a contribuição da prospecção para apoiar as análises prospectivas no âmbito da estratégia. A contribuição aqui referida é em relação à utilização dos resultados da prospecção do futuro para suporte às decisões no âmbito da estratégia. 
Quadro 8 - Contribuição da prospecção na análise prospectiva estratégica

\begin{tabular}{|l|l|}
\hline \multicolumn{1}{|c|}{$\begin{array}{c}\text { Contribuição da prospecção nos processos de } \\
\text { análise prospectiva estratégica }\end{array}$} & \multicolumn{1}{c|}{ Autores } \\
\hline $\begin{array}{l}\text { A prospecção contribuiu para: Identificação dos temas } \\
\text { que representam lacunas de análise, podendo provocar } \\
\text { pontos cegos na análise do projeto }\end{array}$ & $\begin{array}{l}\text { Ilmola e Kuusi (2006), Schwarz (2008), Engau e } \\
\text { Hoffman (2011), Drucker (2010), Heger e Rohrbeck } \\
\text { (2012), Burt (2007), Day e Schoemaker (2007) }\end{array}$ \\
\hline $\begin{array}{l}\text { A prospecção contribuiu para: Aprimoramento do } \\
\text { processo de tomada de decisão no projeto, por meio da } \\
\text { análise das incertezas de futuro }\end{array}$ & $\begin{array}{l}\text { Johnston (2013), Milliken (1987), Hamel e Prahalad } \\
\text { (1996), Godet (1994), Ringland (2006), Heger e } \\
\text { Rohrbeck (2012), Roney (2010), Wilson (2000), } \\
\text { Chermack (2011) }\end{array}$ \\
\hline $\begin{array}{l}\text { A prospecção contribuiu para: Identificação de quais } \\
\text { os principais temas que devem ser monitorados após o } \\
\text { início da implantação do projeto }\end{array}$ & $\begin{array}{l}\text { Roney (2010), Armstrong (1985), Hogarth e } \\
\text { Makridakis (1981), Schwartz (2003), Ramirez et al } \\
\text { (2010), Rohrbeck e Bade (2012), Grim (2009) }\end{array}$ \\
\hline $\begin{array}{l}\text { A prospecção contribuiu para: Identificação de quais } \\
\text { as principais tendências e eventos do ambiente futuro, } \\
\text { estimando as chances de suas ocorrências. }\end{array}$ & $\begin{array}{l}\text { Hines e Bishop (2013), Kuosa (2011), Markley } \\
\text { (2011), Lempert e Groves (2010) }\end{array}$ \\
\hline $\begin{array}{l}\text { A prospecção contribuiu para: Análise de quais as } \\
\text { possíveis consequências de uma alternativa de decisão } \\
\text { no projeto }\end{array}$ & $\begin{array}{l}\text { Rossel (2012), Schwartz (2003), Kaivo-Oja et al } \\
\text { (2004), Miller e Waller (2003), Roney (2010) }\end{array}$ \\
\hline
\end{tabular}

Fonte: Análise do autor, a partir das proposições dos autores

Em seguida se concentra na questão da avaliação da atividade de prospecção, o que alguns autores chamam de maturidade para a prática da prospecção, a exemplo de Grim (2009) e Rohrbeck (2011). Aqui cabe esclarecer que nesta tese a avaliação da atividade de prospecção do futuro se concentrou em apenas partes do que propuseram Grim (2009) e Rohrbeck (2011). O processo é explicado em seguida.

Do proposto por Grim (2009), a inspiração para propor o modelo de contribuição desta tese concentrou-se nas três disciplinas abaixo mencionadas:

(1) Na disciplina Liderança, por ela ser focada na transição da prospecção para a ação, de forma contínua.

(2) Na disciplina Prospecção, pela proposta de avaliar o grau de maturidade de cada processo de análise prospectiva praticado. Grim (2009) usou da intuição de que os gestores possam classificar o seu grau de maturidade para um subconjunto de processos relacionados com a disciplina Prospecção.

(3) Na disciplina Planejamento, que se concentra em analisar a empresa e sua mobilização no contexto de visão do futuro. Isso também tem relação com a transição entre a prospecção e a ação. 
Do proposto por Rohrbeck (2011), a inspiração para propor o modelo de contribuição desta tese concentrou-se em duas das cinco dimensões propostas pelo autor, comentadas a seguir.

(1) $\underline{\text { Uso de Informações } \text { - que se relaciona com a atividade de como gestores extraem }}$ significados a partir de dados e informações disponíveis ou mesmo pesquisadas em outras fontes, e adicionalmente como esses significados são estruturados de forma a gerar utilidade para os gestores da organização.

(2) Sofisticação dos Métodos - dimensão que pode representar quanto capacitada estaria a organização para dar suporte às análises necessárias. Esta dimensão tem relação com os processos utilizados para suporte à tomada de decisões que fazem uso de resultados de estudos prospectivos.

Conforme mencionado anteriormente, Grim (2009) e Rohrbeck (2011) propõem modelos bem completos de avaliação da maturidade da prospecção em organizações. Eles deixam, dessa forma, um amplo campo para pesquisas que possam contribuir para aprimorar seus modelos, e é nesta linha que esta tese busca contribuir.

Nesta tese, utiliza-se partes do que foi proposto por Grim (2009) e Rohrbeck (2011), considerando que os gestores poderiam avaliar sua maturidade sobre processos das disciplinas Liderança, Prospecção e Planejamento (GRIM, 2009), mas com o foco em avaliar o quanto a prospecção é considerada importante, e por decorrência o quanto ela é praticada e finalmente o quanto ela contribui para a tomada de decisões. Em seguida, considerando as dimensões

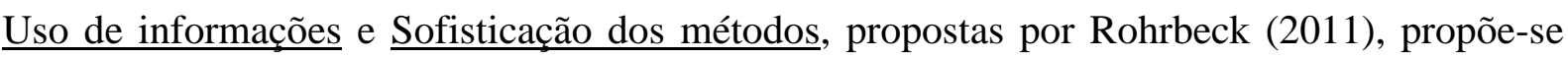
nesta tese que se avaliem duas frentes: (1) a prática e a contribuição dos processos de suporte à decisão, aqui considerados como dentro da dimensão Sofisticação dos Métodos; e (2) o uso de resultados de estudos prospectivos, aqui considerados como dentro da dimensão Uso de informações.

Visualmente, seria como mostrado na ilustração a seguir. 


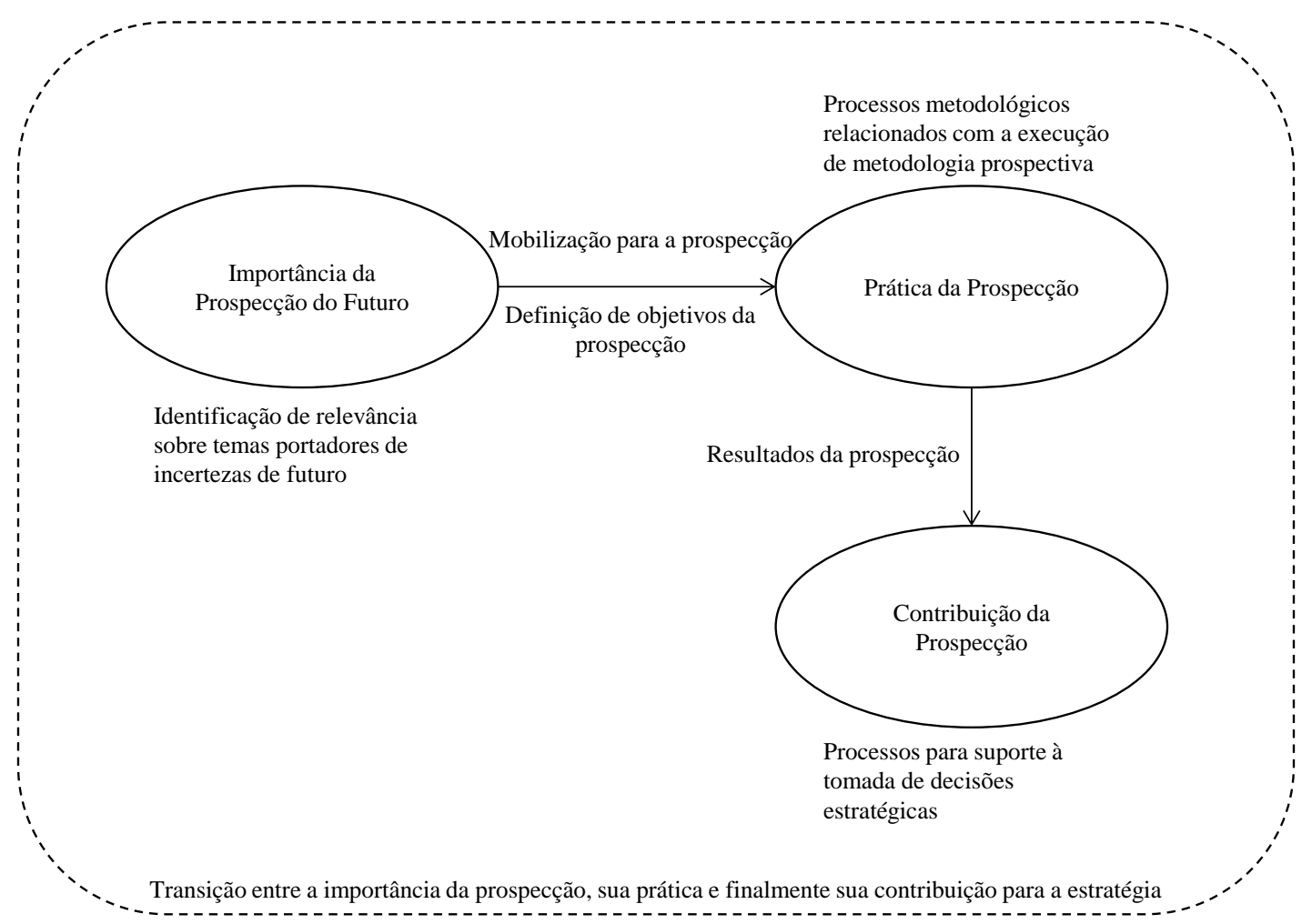

Ilustração 13 - Modelo conceitual preliminar para subsidiar o modelo conceitual teórico

Fonte: Análise do autor

A ilustração serviu de inspiração para a elaboração de um modelo conceitual teórico, este sim, utilizado para facilitar a operacionalização desta pesquisa. Essa ilustração anterior não é o modelo em si, mas serve como base para inspirar o mesmo.

Na figura, propõe-se adotar pressupostos conceituais cujas descrições são:

- Se for esperado dos gestores que eles pratiquem a prospecção, então eles possivelmente a considerem importante atividade para cumprir com suas responsabilidades, conforme argumentado por Chermack (2011), Ringland (2006), Dator (2002a, 2002b), Rohrbeck e Bade (2012).

- Sendo atendido esse pressuposto, então haveria uma mobilização para praticar a prospecção nas organizações, por meio da utilização de métodos e processos prospectivos para suporte à análise do que poderá vir a acontecer, como recomendaram Chermack (2011), Godet (1994), Lempert e Groves (2010), Miller e Waller (2013), Schwarz (2013). 
- Essa mobilização para a prática da prospecção, por sua vez, levaria gestores a conclusões de estudos prospectivos, e estes resultados poderão contribuir para a tomada de decisão, conforme argumentaram Chermack (2011), Greiner et al (2014), Grim (2009), Hirsch et al (2013), Kahane (2012), Rohrbeck e Bade (2012), Rohrbeck (2011) e Roney (2010).

Os pressupostos foram utilizados como base para se desenhar um Modelo Conceitual Teórico, o qual está mostrado na ilustração a seguir.

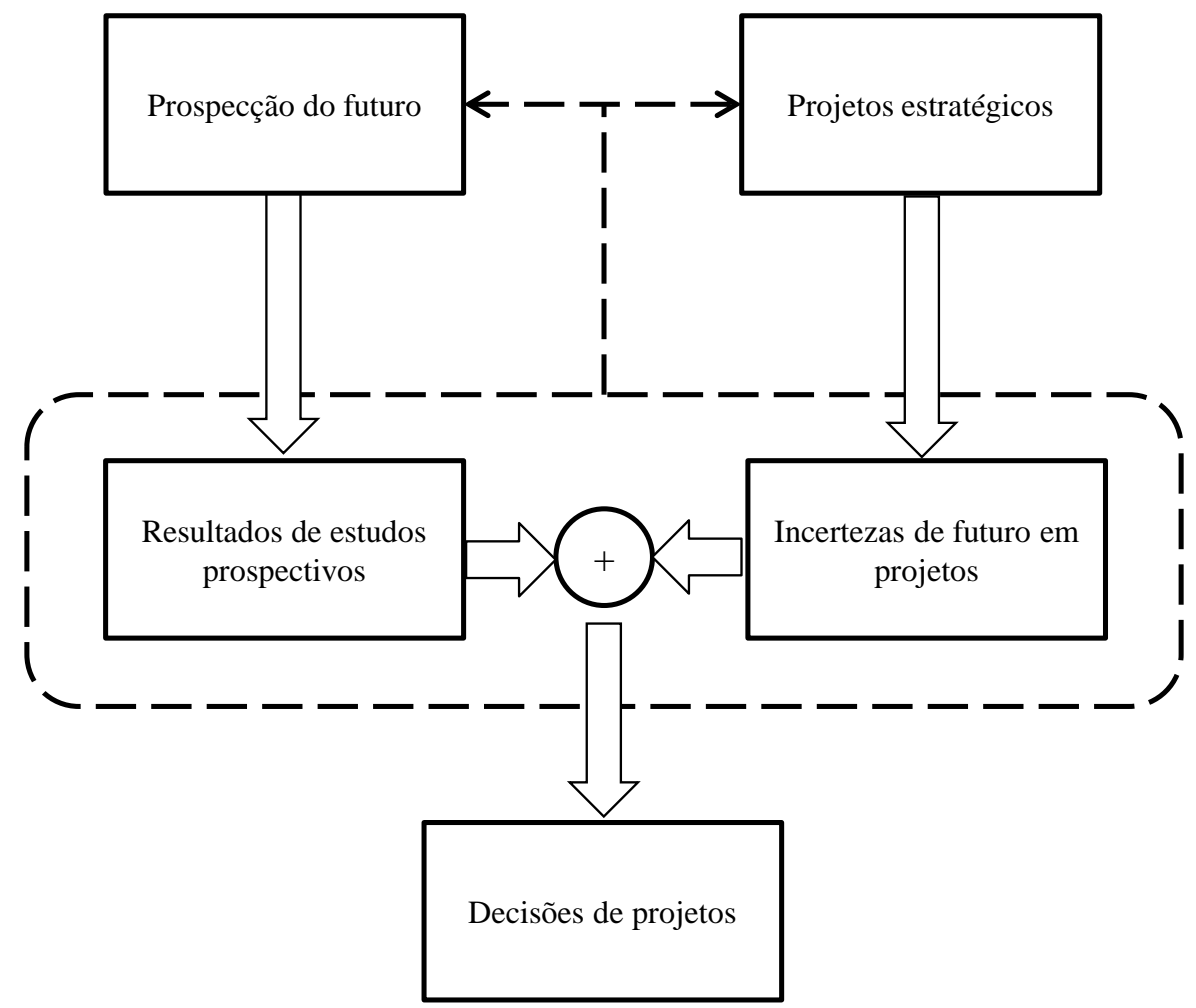

Ilustração 14 - Modelo Conceitual Teórico da pesquisa

Fonte: elaborado pelo autor

O entendimento desse modelo conceitual segue a interpretação a seguir:

- Projetos estratégicos contêm incertezas de futuro, as quais demandam por análise prospectiva.

- A prospecção do futuro é, então, utilizada para se lidar com as incertezas de futuro.

- As incertezas de futuro representam as questões sobre o futuro, presentes em projetos estratégicos, que precisam ser analisadas para a tomada de decisões. 
- Ao se concluir estudos prospectivos sobre diferentes temas e suas incertezas de futuro presentes nos projetos, são obtidos resultados que podem contribuir nas decisões sobre os projetos.

- A utilização de resultados de estudos prospectivos é realizada no processo de tratamento de incertezas de futuro dos projetos, então há integração entre prospecção e tomada de decisões em projetos estratégicos. Contudo, essa integração pode não ser isenta de limitações.

- Na ocorrência de limitações dessa integração, a transição entre a orientação para a prática da prospecção e o apoio à tomada de decisões em projetos estratégicos pode apresentar dificuldades para os gestores.

- As dificuldades enfrentadas poderiam ser mitigadas pela utilização de um modelo que contribua na integração entre a prospecção e as necessidades de análises de incertezas dos projetos estratégicos.

Esse modelo para suporte à integração entre prospecção e decisões em projetos estratégicos é identificado na figura anterior pelo símbolo descritos anteriormente, o modelo de suporte à integração entre prospecção do futuro e decisões em projetos estratégicos é mostrado na figura a seguir. 


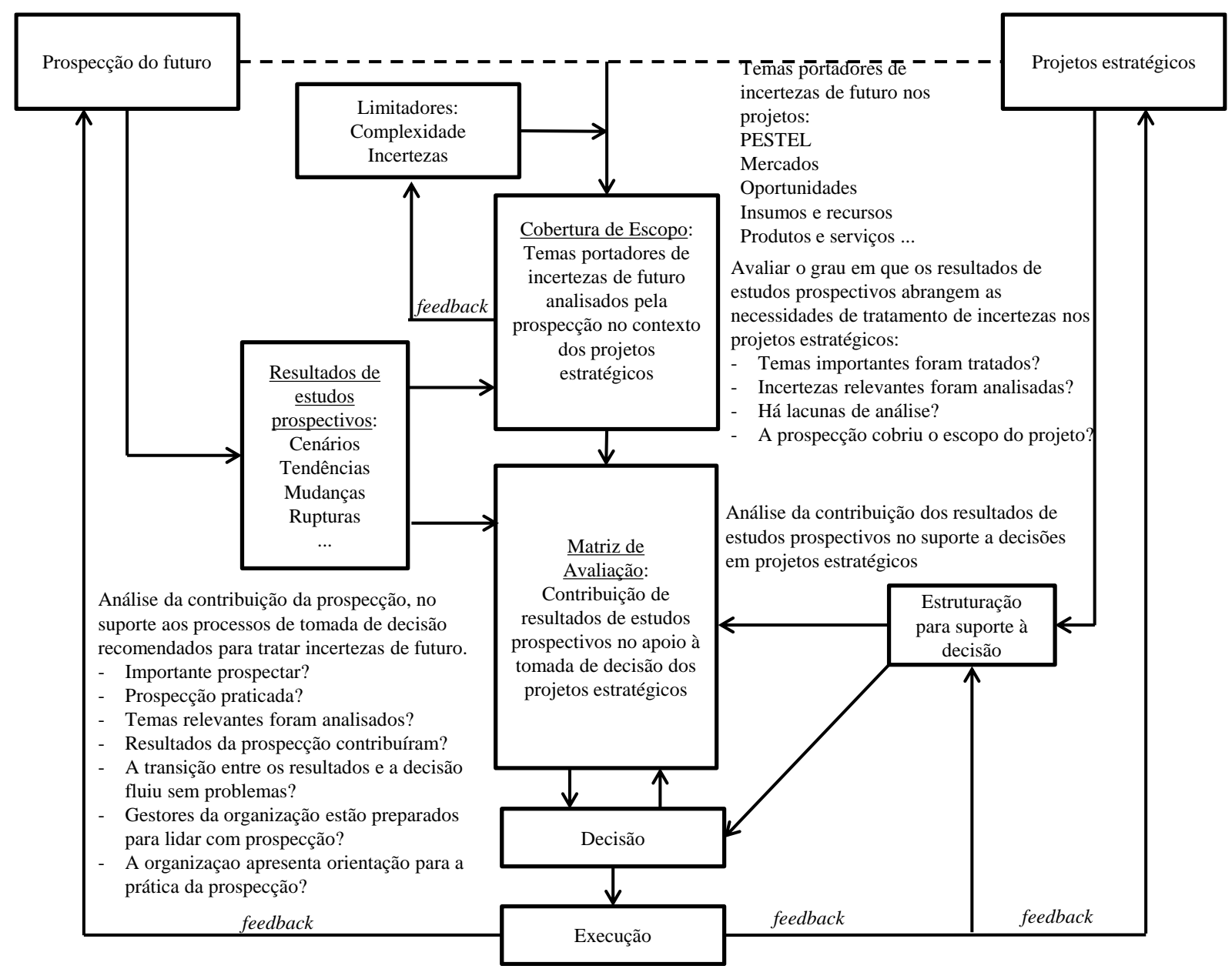

\section{Ilustração 15 - Modelo de suporte à integração entre prospecção do futuro e tomada de decisões em projetos \\ Fonte: Análise do autor}

No modelo proposto, o foco está na Cobertura de Escopo e na Matriz de Avaliação, portanto

nos blocos centrais do modelo, e eles representam o aprofundamento do símbolo

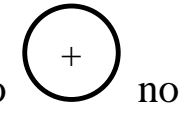

Modelo Conceitual Teórico desta pesquisa. No modelo de Grim (2009) a Cobertura de Escopo estaria relacionada com o aprofundamento da disciplina Prospecção. No modelo de Rohrbeck (2011) seria o aprofundamento dos processos da dimensão Uso de Informação.

Já a Matriz de Avaliação seria, no modelo de Grim (2009), o aprofundamento das disciplinas de Liderança, Prospecção e Planejamento. No modelo de Rohrbeck (2011), seria o aprofundamento dos processos das dimensões Uso de Informações e Sofisticação dos Métodos.

As bases conceituais para se propor os dois blocos do modelo são descritas a seguir. 
Cobertura de Escopo: Razões para se propor esse bloco no modelo:

- Incertezas estratégicas dos projetos podem ter origem em diferentes temas, conforme apontado por Dator (2002b), Gordon et al (2005), Chermack (2011), Gidley (2013), Heger e Rohrbeck (2012).

- É recomendável calibrar premissas nos projetos, e isso demanda avaliar diferentes aspectos dos projetos, conforme Ilmola e Kuusi (2006), Schwarz (2013), Hines e Bishop (2013), Fahey e Prusak (1998), Godet (1994).

- É recomendável simular os resultados em função dos resultados prospectados, também se recomenda definir que sinais ou indicadores devam ser monitorados para monitorar o futuro acontecendo, e também analisar o contexto futuro da organização em função dos projetos. Stacey (1991), Lempert e Groves (2010), Schwarz (2013), Burt (2007), Rossel (2012), Ilmola e Kuusi (2006), Schwartz, 2003), Almeida, Fernando et al (2007), Day e Schoemaker (2004), Day e Schoemaker (2007).

- Um risco tipicamente comum em estudos prospectivos é ignorar coisas importantes, estejam elas no centro ou na periferia do problema de prospecção. Em outras palavras, lacunas de análise. Ilmola e Kuusi (2006), Schwarz (2008), Engau e Hoffman (2011), Drucker (2010), Heger e Rohrbeck (2012), Burt (2007), Day e Schoemaker (2007).

- Com esses fundamentos acima: A operacionalização da Cobertura de Escopo deve ser realizada por meio de processo de avaliação, por parte dos gestores da organização, $\underline{\text { se }}$ todos os temas portadores de incertezas de futuro foram tratados no âmbito estratégico. E isso sendo feito com a participação de tantas pessoas quanto sejam relevantes no processo de análise, internas ou externas à empresa. $\underline{\mathrm{O} \text { resultado da }}$ operacionalização deste bloco é a decisão sobre quais temas devem ser prospectados mais a fundo, e quais não serão. $O$ fato de esta decisão ser tomada pelos principais atores envolvidos nas decisões estratégicas aumenta o potencial de utilização dos $\underline{\text { resultados da prospecção, }}$ porque assim se proporciona a necessária transparência nos processos de prospecção, e também porque se reconhece que, se há lacunas remanescentes, elas foram conscientemente escolhidas. 
Matriz de Avaliação: razões para propor este bloco no modelo:

- Projetos estratégicos podem envolver múltiplas disciplinas, o que induz à necessidade de prospectar muitos temas na análise - Gidley (2013), Sardar (2010), Roney (2010).

- A disponibilidade de resultados de estudos prospectivos não significa necessariamente que sejam úteis na tomada de decisões em projetos. É preciso tratar as incertezas, estimar as principais tendências, antecipar o que deve ser monitorado após a implantação do projeto, e estimar as consequências de alternativas de decisão, dentre outros processos recomendados. A prospecção pode contribuir nesses processos, $\underline{\text { mas }}$ teriam sido praticados esses processos? E caso positivo, teria sido útil a prospecção para suportar esses processos? Ilmola e Kuusi (2006), Schwarz (2008), Engau e Hoffman (2011), Drucker (2010), Milliken (1987), Hamel e Prahalad (1996), Godet (1994), Ringland (2006), Roney (2010), Armstrong (1985), Hogarth e Makridakis (1981), Schwartz (2003), Ramirez et al (2010), Rohrbeck e Bade (2012), Grim (2009), Hines e Bishop (2013), Kuosa (2011), Markley (2011), Lempert e Groves (2010), Rossel (2012), Schwartz (2003), Kaivo-Oja et al (2004).

- A prospecção do futuro pode contribuir para a orientação para o futuro. Dessa forma, a transição entre a prospecção do futuro e a decisão em projetos tenderia a fluir sem limitações. Contudo, inseguranças em relação à cobertura de escopo adequada - por exemplo se as informações corretas foram tratadas, se os processos recomendados foram executados, se os objetivos da prospecção estão alinhados aos dos projetos analisados, se o conhecimento dos gestores está adequado aos desafios dos projetos, e se os gestores da organização estão preparados para lidar com as incertezas do futuro presentes nos projetos - podem reduzir a contribuição que a prospecção pode oferecer à tomada de decisões. Chermack (2011), Rohrbeck (2011), Grim (2009), Rohrbeck e Bade (2012), Rohrbeck e Gemünden (2008), Heger e Rohrbeck (2012), Burt e Van Der Heijden (2008), Roney (2010).

- Com esses fundamentos acima: A operacionalização da Matriz de Avaliação segue com o processo de dar transparência nos estudos desenvolvidos sobre prospecção, agora com foco em capturar a avaliação dos participantes da prospecção, sobre três conjuntos de processos: (I) Quanto os processos de análise prospectiva recomendados 
$\underline{\text { são executados no âmbito dos projetos estratégicos, e também sobre (II) Quanto os }}$ processos de análise prospectiva estratégica são executados sob a ótica da estratégia da organização. Neste bloco também se busca capturar a (III) Avaliação dos participantes sobre a contribuição dos resultados da prospecção. Este último conjunto de processos envolve analisar o quanto os participantes avaliam o (1) seu nível de conhecimento de metodologias prospectivas, (2) a sua capacidade de análise de lacunas estratégicas, (3) o preparo dos gestores da empresa em lidar com incertezas de futuro, (4) a sua capacidade de utilização dos resultados de estudos prospectivos nas decisões, e finalmente (5) o quanto está adequado o nível em que a prospecção é praticada na empresa. A Matriz de Avaliação, portanto, estabelece um processo de auto avaliação dos gestores da empresa, sobre suas competências em lidar com prospecção, e sobre suas competências em integrar os resultados da prospecção na gestão estratégica da empresa. O princípio por trás deste bloco é que: Se os gestores foram capazes de conscientemente definir, na Cobertura de Escopo, o que entra ou sai no estudo prospectivo, então é importante para eles avaliarem, na Matriz de Avaliação, suas competências em aprofundar as análises prospectivas e estratégicas, e usar os resultados dessas análises nas decisões, porque o objetivo da prospecção é subsidiar decisões no âmbito da estratégia.

Esta tese foi desenvolvida seguindo o modelo conceitual teórico, e os passos para seu desenvolvimento serviram para avaliar se o modelo de apoio à integração entre prospecção do futuro e gestão estratégica seria útil, considerando-o como uma ferramenta de suporte para integrar os resultados de estudos prospectivos à tomada de decisões em projetos estratégicos. 


\section{METODOLOGIA}

\subsection{Escopo da metodologia: Estudo exploratório e descritivo}

A pesquisa foi desenvolvida com uma abordagem de predominância exploratória e descritiva. Ela busca aprofundar o conhecimento sobre a prática de prospecção do futuro em organizações, e cujo foco tenha sido a necessidade de se lidar com incertezas de futuro presentes em projetos estratégicos. Foi realizado levantamento quantitativo junto a gestores sobre a importância da atividade, a decorrente prática da mesma e a contribuição dos resultados nos projetos. Também foi pesquisado sobre a prática de processos recomendados na metodologia de prospecção, com a consequente contribuição nas decisões em projetos estratégicos; e ainda mais, foi capturada a avaliação dos respondentes sobre a capacidade de gestores de sua empresa em lidar com prospecção do futuro.

Uma parte da pesquisa foi realizada em metodologia qualitativa, com entrevistas realizadas junto a gestores em organizações, visando a aumentar o poder de análise dos resultados quantitativos.

Os passos seguidos na pesquisa partem de uma fundamentação da teoria referente aos estudos do futuro, com especial foco nas recomendações propostas por autores da área, combinado com os temas portadores de incertezas de futuro. Assume-se que as análises realizadas por gestores em organizações, buscando avaliar de forma antecipada as incertezas de futuro presentes nos projetos estratégicos, podem contribuir nas decisões nesses projetos. Se isso ocorre de fato, então há uma orientação para a prática da prospecção do futuro nas organizações. Contudo, essa orientação pode se manifestar apenas como uma intenção sem a ação correspondente, ou se ela for devidamente tratada, pode culminar na prática da prospecção com intensidade proporcional à importância atribuída à atividade. A prática leva a resultados, sendo que estes últimos podem contribuir nas decisões em projetos estratégicos.

\subsection{Adoção de método misto quantitativo-qualitativo}

Nesta pesquisa a metodologia a ser utilizada foi a de método misto. Foi desenvolvida uma parte qualitativa associada com a parte quantitativa. Entrevistas foram desenvolvidas para verificar como gestores em organizações processam e utilizam os resultados de estudos prospectivos. 
O objetivo principal desta tese é propor um modelo preliminar que facilite a prática da prospecção do futuro em organizações, estimule o surgimento de uma orientação para reforçar a sua prática, e dessa forma gere a respectiva contribuição em decisões que sejam do âmbito da estratégia.

A pesquisa considera diferentes setores e portes de empresas, abordagem esta que não define uma população (universo) específica a ser pesquisada. Essa elevada abrangência é devida ao caráter exploratório da pesquisa.

Como consequência, a pesquisa segue uma metodologia orientada para explorar e entender o fenômeno de forma preliminar, caracterizando-se assim a adequação para um estudo exploratório e descritivo (SAMPIERI et al, 2006, p. 99-103).

A metodologia mista é recomendada para desenvolver pesquisas nas quais a exploração de fenômenos seja o foco, ou seja, a aplicação de mais de um método de pesquisa possibilita aumentar o potencial de análise (CRESWELL, 2010, p. 238-239). Este é o caso desta tese.

Eisenhardt (1989) argumenta que ao se combinar metodologia qualitativa e quantitativa, é possível obter sinergias entre as duas abordagens, incrementando o potencial de análise dos resultados da pesquisa. O método qualitativo permite melhor entendimento dos dados quantitativos. Já estes últimos possibilitam identificar relações que podem não ser facilmente visíveis quando se utiliza somente metodologia qualitativa.

$\mathrm{Na}$ abordagem qualitativa, os estudos de múltiplos casos permitem um confronto, uma justaposição de realidades conflitantes, e dessa forma eles contribuem para "descongelar" o pensamento do pesquisador. Este último pode estar influenciado por vieses originados pelo uso de métodos dedutivos com pouca fundamentação (EISENHARDT, 1989). Nesta tese não foram realizados estudos de casos, mas se utilizou entrevistas em profundidade sobre o tema da pesquisa, e os participantes das entrevistas puderam relatar experiências históricas, alguns deles relataram casos ocorridos em suas empresas. Usar entrevistas como abordagem era mais adequado porque o método de observação direta não poderia ser aplicado nesta pesquisa. Essas características indicavam vantagens da adoção de entrevistas (CRESWELL, 2010, p. 213). 
As principais variáveis do presente estudo são:

- Temas portadores de incertezas de futuro: Categorizados conforme suas respectivas naturezas, e que sejam também portadoras de questões estratégicas, e.g. economia, política, tecnologia, para citar algumas das categorias.

- Horizonte de tempo: Alcance temporal para o qual os métodos de prospecção e o planejamento estratégico são orientados.

- Importância da prospecção do futuro (estudos do futuro): Grau de percepção sobre a relevância da prospecção nas organizações.

- Prática (análise) da prospecção: Execução de processos recomendados nas metodologias para estudar o futuro, visando avaliar o que pode vir a acontecer e, dessa forma, tratar incertezas de futuro do âmbito dos projetos estratégicos, ou do âmbito da estratégia.

- Contribuição da prospecção no processo de tomada de decisões em projetos: Os resultados de estudos prospectivos geram conclusões, as quais podem facilitar a tomada de decisões em projetos que contenham incertezas de futuro.

- Processos praticados em prospecção do futuro: Processos de análise prospectiva de projetos e de análise prospectiva estratégica, cuja prática é recomendada na prospecção do futuro.

- Projeto Estratégico: Projetos de médio e longo prazo, em diferentes áreas da organização, que envolvem muitos recursos físicos, humanos e econômicos, e que tipicamente são de difícil reversão após o início de sua implantação.

- Frequência de recorrência aos métodos de estudos do futuro: Frequência de casos em que se utiliza a prospecção - contínuo versus esporádico ou nunca.

- Aspectos gerais dos respondentes da pesquisa, e também de suas respectivas organizações.

As variáveis mencionadas foram utilizadas na fase quantitativa predominantemente. Na parte qualitativa da pesquisa elas foram utilizadas para contextualizar a situação problema para o entrevistado. Isso foi feito visando aprofundar a pesquisa com informações relacionadas com os temas estudados. 
$\mathrm{Na}$ fase quantitativa o objetivo foi coletar e analisar dados sobre as diversas variáveis da pesquisa, e esses dados foram utilizados para analisar as relações entre as variáveis. Nesse processo, os resultados obtidos foram utilizados para se identificar a opinião dos participantes em relação à importância, à prática e a contribuição da prospecção. Também foram capturados resultados sobre a prática de processos recomendados na prospecção, e a sua consequente contribuição na tomada de decisão em projetos.

A metodologia mista possibilita que a parte qualitativa viabilize a exploração do problema de pesquisa de forma mais flexível. Adicionalmente, o método qualitativo complementa a análise dos dados coletados na fase quantitativa. Segundo Castro (2006, p. 107), a pesquisa qualitativa segue uma argumentação indutiva, com foco na interpretação do significado dos dados, representando o que se busca na presente pesquisa proposta.

A análise dos resultados qualitativos serve, dessa forma, para entender o significado dos temas envolvidos, suas descrições e possíveis relações entre as variáveis presentes no estudo. A pesquisa qualitativa permite, assim, explorar e entender esse significado (CRESWELL, 2010, p. 223).

O método quantitativo, por sua vez, explora aspectos exteriores ao fenômeno, então ele serve para mensurar o fenômeno, para identificar o que ocorre e como ocorre. Já quando o pesquisador busca entender o porquê da sua ocorrência, na maioria das vezes é necessário entender aspectos internos ao fenômeno, e neste ponto o método qualitativo é o que pode ser útil ao pesquisador, segundo Castro (2006, p. 108).

O método quantitativo serviu para aspectos mais dedutivos, que se relacionam mais com questões previamente existentes e que foram colocadas na coleta de dados em campo. A utilização complementar de métodos qualitativo e quantitativo é recomendada quando cada um dos métodos possibilita ao pesquisador chegar aonde o outro método não permite (CASTRO, 2006, p. 108).

Metodologia de pesquisa que combina os dois métodos ao mesmo tempo permite o aumento da força geral do estudo, isso se comparado com a pesquisa realizada por meio apenas de um dos tipos - quantitativo ou qualitativo. Dessa forma, o método misto aproveita as vantagens de cada um dos tipos mencionados (CRESWELL, 2010, p. 238). 
Embora se busquem relações entre variáveis na parte quantitativa, cabe mencionar que não é objetivo desta pesquisa a confirmação de hipóteses a priori. Dada a natureza exploratória da pesquisa, ela não se desenvolve estabelecendo-se hipóteses a priori, mas sim questões e indagações que, sendo respondidas pelo uso das metodologias de pesquisa previstas, poderão gerar conclusões ou hipóteses a posteriori que poderão servir para futuras pesquisas.

A coleta de dados foi realizada em três etapas na pesquisa: (1) entrevista pessoal para explorar a adequação do instrumento de coleta preliminarmente desenvolvido, e avaliar o potencial de retorno de respostas ao questionário; (2) coleta de dados, por meio de questionário em forma de levantamento (survey) para a parte quantitativa, e (3) entrevistas com gestores em organizações, realizadas posteriormente à coleta de dados quantitativos.

A segunda etapa da parte qualitativa foi feita posteriormente à parte quantitativa, e os resultados das duas abordagens foram analisados de forma concomitante. Não se aplicou método de interações que necessitasse de intervalos de tempo específicos entre as etapas quantitativa e qualitativa, a exemplo do que é feito em experimentos ou em estudos longitudinais conduzidos em períodos mais longos. Portanto a coleta de dados aqui utilizada foi transversal (MARCONI; LAKATOS, 2005), e ela assim foi para as duas metodologias utilizadas na pesquisa. Mesmo as entrevistas preliminares, anteriores à coleta de dados quantitativa, também foram transversais, uma vez que o objetivo de sua realização foi calibrar o instrumento de coleta quantitativo, não tendo sido utilizado para outro objetivo que previsse evolução interativa longitudinal na pesquisa.

A metodologia foi, portanto, realizada com a estratégia incorporada concomitante, a qual é caracterizada pelo uso de método principal, no caso desta tese é o método quantitativo. A este método foi incorporado o método secundário, que foi o qualitativo, gerando um banco de dados secundário de apoio na análise dos resultados da parte quantitativa. (CRESWELL, 2010, p.251-253).

No presente estudo as duas coletas foram feitas em momentos diferentes, contudo a análise dos resultados foi realizada concomitantemente, o que não distingue claramente o momento em que os dados da fase quantitativa e da qualitativa foram tomados (CRESWELL, 2010, p. 259). Nesta pesquisa os dados são mostrados predominantemente de forma separada no capítulo 5, embora sejam colocados comentários intercalados sobre os dados quantitativos e 
qualitativos. No capítulo 6 são comentados de forma integrada, visando dar uma visão sintética dos achados desta tese.

Cabe mencionar que o escopo da metodologia adotada não utiliza toda a flexibilidade de um estudo exploratório. Ele se inicia com uma diretriz teórica e a usa como referência para explorar e descrever o fenômeno que se pretende investigar. Seguiu-se, portanto, um modelo conceitual teórico (descrito no capítulo 3) que delimitou a operacionalização da pesquisa ao escopo do problema de pesquisa.

A abordagem adotada foi retrospectiva, pois visou capturar a experiência das pessoas sobre a prática dos métodos de prospecção e a contribuição de seus resultados na tomada de decisões em projetos do âmbito da estratégia das organizações. A transversalidade da aquisição de dados quantitativos foi decorrente de a pessoa participante ter sido solicitada a informar sobre projetos do presente ou de sua experiência passada.

Para a parte qualitativa, o meio de coleta foi por entrevista pessoal semiestruturada, seguindo um roteiro de entrevista (anexo ao projeto) que permitiu flexibilidade ao entrevistado para responder aos temas da pesquisa.

Para a parte quantitativa, a coleta de dados foi por meio de questionário predominantemente fechado, construído a partir do modelo conceitual teórico desenvolvido a partir da teoria. 


\subsection{Universo e amostra: Abordagem adotada}

O alvo (ou população) desta pesquisa é o conjunto de pessoas que se envolvem com análise e implantação de projetos estratégicos nas organizações presentes no Brasil. Em princípio, independentemente do porte ou setor de atuação. Isso é adotado devido à possibilidade de muitos potenciais participantes não apresentarem o perfil desejado ou não poderem participar da pesquisa, por razões relacionadas ao seu contrato de trabalho (por exemplo, por confidencialidade), o que reduziria a quantidade de respostas.

$\mathrm{O}$ universo inquirido, que contém as pessoas com as características desejadas, segundo definição de Hill e Hill (2008), é, portanto, o das pessoas que direta ou indiretamente assumem a responsabilidade por analisar, planejar, tomar decisões e implantar projetos estratégicos.

Para a amostragem dos respondentes, a opção nesta pesquisa é por uma escolha dirigida, por meio de amostragem não probabilística, que segundo Sampieri et al (2006, p. 255), é definida como "subgrupo da população no qual a escolha dos elementos não depende da probabilidade, e sim das características da pesquisa". Nem todas as pessoas nas organizações se envolvem com o tema da pesquisa, dessa forma, uma amostragem mais seletiva é mais eficiente, desde que se tenham condições de controlar os parâmetros de seletividade. Nesta pesquisa, isso é representado pela disponibilidade de uma base de potenciais respondentes, sendo profissionais com experiência executiva, com canais de contato incluídos.

Esta abordagem facilita a escolha da amostra e a coleta de dados, contudo, eliminando a possibilidade de expandir as conclusões para o universo formado pelas pessoas com as características desejadas, porque a probabilidade de seleção de um respondente para a amostra da pesquisa não é conhecida para todos os potenciais respondentes do universo. O perfil da amostra incluiu: supervisores, gerentes, superintendentes, diretores, presidentes e proprietários de organizações, considerando a amostra envolvida. 


\subsection{Fase quantitativa}

A coleta de dados quantitativa realizada foi por meio de questionário estruturado com perguntas predominantemente fechadas, o qual foi respondido por meio de instrumento de coleta disponível via link na internet.

A estrutura do questionário montado utilizou as seguintes orientações: Identificação de características do respondente; identificação de características da empresa do respondente; temas portadores de incertezas de futuro; importância atribuída à prospecção do futuro; prática da prospecção; contribuição dos resultados da prospecção nas decisões; prática de processos recomendados na prospecção do futuro; contribuição da prospecção nos processos de análise prospectiva estratégica; e finalmente, avaliação da atividade da prospecção na organização.

\subsubsection{Metodologias de análise utilizadas para os dados quantitativos}

São três metodologias estatísticas utilizadas no tratamento dos dados para a pesquisa:

- Estatística descritiva

- Estatística inferencial

- Análise multivariada

A estatística descritiva é utilizada para organizar e sumarizar os dados, analisá-los e entender preliminarmente os dados obtidos a partir da amostra de respondentes. Ela é utilizada neste estudo para gerar tabelas de frequência e recursos gráficos, uma vez que as variáveis têm mensuração ordinal ou nominal.

Para a estatística inferencial, os testes de hipóteses utilizados serviram para testar a independência de duas variáveis nominais, ou para comprovar se as amostras apresentam a mesma distribuição (para variáveis de mensuração ordinal). As técnicas utilizadas, respectivamente, foram: Teste de Qui-quadrado $(\chi 2)$ e Teste de Kolmogorov-Smirnov (K-S) para uma amostra e para duas amostras. Essas técnicas foram aplicadas nesta pesquisa com nível de significância $\alpha=0,10$, uma vez que a presente tese tem abordagem exploratória. 
Para a análise com foco na observação de características dos respondentes do questionário, foram aplicadas técnicas de análise de agrupamentos (BASSAB et al, 1990) e de CHAID (Chi-squared Automatic Interaction Detection), análises estas multivariadas.

\subsection{Fase qualitativa}

Lembrando que a fase qualitativa visa complementar o poder de análise dos resultados da fase quantitativa, nesta pesquisa é adotado um modelo conceitual teórico de pesquisa que permite ilustrar como as técnicas de análise estão integradas com as duas metodologias de pesquisa adotadas.

O método de coleta qualitativa foi por entrevista pessoal. Inicialmente pensou-se em utilizar abordagens longitudinais de pesquisa, uma vez que se busca propor modelo preliminar para facilitar a prática da prospecção do futuro. Dentre essas técnicas estaria a da observação direta, que em termos de método seria muito boa para estudar o fenômeno caracterizado no problema de pesquisa. Contudo, além da impossibilidade de tempo para a sua aplicação, há também a dificuldade de se obter o "de acordo" das empresas para se executar tal técnica de pesquisa dentro do ambiente das empresas. Embora atraente enquanto abordagem de campo, a ideia foi abandonada pela inviabilidade.

A entrevista pessoal foi utilizada por ter algumas vantagens, segundo Creswell (2010, p. 213):

- É possível obter informações históricas

- Permite explorar e controlar a linha de questionamento

- É uma alternativa nos casos onde a observação direta não seja viável

Dentre as desvantagens estariam o filtro do ponto de vista do entrevistado, em outras palavras o seu viés. Adicionalmente, a presença do pesquisador pode influenciar as declarações do entrevistado e finalmente o próprio entrevistado pode apresentar alguma limitação de articulação, comunicação e percepção.

A entrevista foi realizada de forma semiestruturada, evitando assim a perda de foco pela liberdade que se tem em uma entrevista. Isso mantém o alvo no tema estudado, no entanto, sem cercear a liberdade e flexibilidade (CASTRO, 2006, p. 113). 
Elaborou-se assim um roteiro de entrevista com certa estruturação, visando manter o foco no tema de pesquisa aqui tratado. $\mathrm{O}$ roteiro de entrevista pode ser encontrado no Apêndice 1 desta tese.

\subsubsection{Metodologia de análise prevista para os dados qualitativos}

A análise dos resultados qualitativos seguiu os seguintes passos, adaptado de Creswell (2010, p. 219):

Passo 1: Organizar as anotações, agregar fontes documentais. Ler todo o material para identificar uma visão geral do fenômeno relatado e o significado que ele tem no contexto do problema de pesquisa.

Passo 2: Analisar os trechos da entrevista, considerando o modelo conceitual teórico da pesquisa e as variáveis em estudo. Identificar no relato geral os temas envolvidos e as descrições contidas sobre o fenômeno estudado, as variáveis relacionadas aos temas e como são representadas e relatadas na narrativa.

Passo 3: Extrair o significado dos dados, compondo uma interpretação sobre os mesmos. Verificar como essa interpretação, considerada segundo o modelo conceitual teórico da pesquisa, pode complementar a análise dos resultados quantitativos. 


\subsection{Modelo Conceitual Teórico da Pesquisa e sua integração com a metodologia}

A Ilustração a seguir mostra o Modelo Conceitual Teórico adotado na presente tese para operacionalizar a pesquisa. Ela é inspirada na figura que ilustra os pressupostos conceituais desta pesquisa, mostrada no final do capítulo anterior.

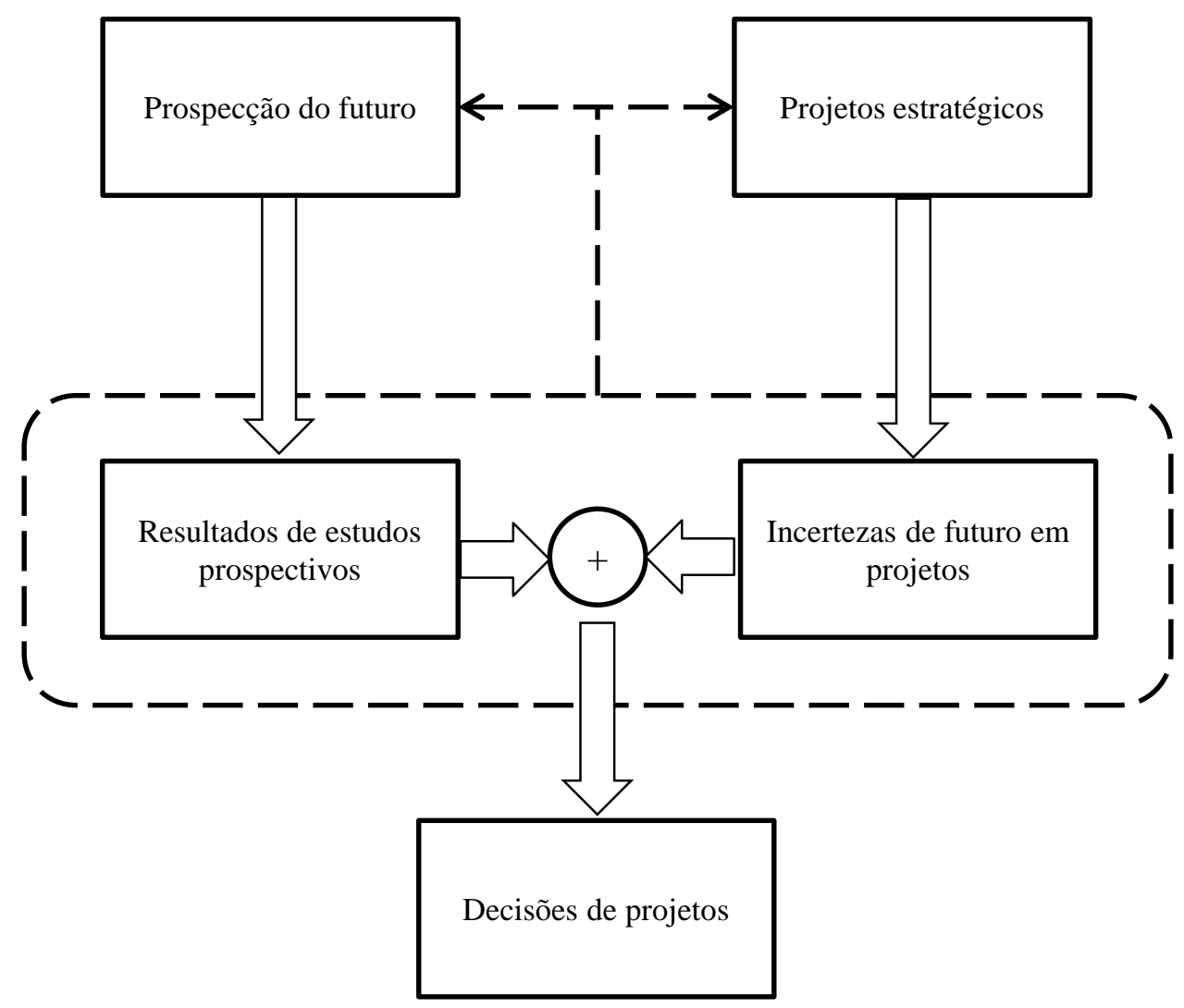

Ilustração 16 - Modelo Conceitual Teórico da pesquisa

Fonte: elaborado pelo autor

O modelo conceitual pressupõe uma diretriz teórica de que a prospecção do futuro é considerada importante, e ela serve para contribuir nas decisões em projetos estratégicos. Essa contribuição é realizada por meio do uso dos resultados de estudos prospectivos nos estudos sobre projetos estratégicos. Este último processo, por sua vez, também é um pressuposto desta pesquisa, uma vez que se assume que ele seja praticado pelos gestores nas organizações, visando a facilitar o processo de tomada de decisão.

Os passos para desenvolvimento desta tese podem ser visualizados na ilustração a seguir. 


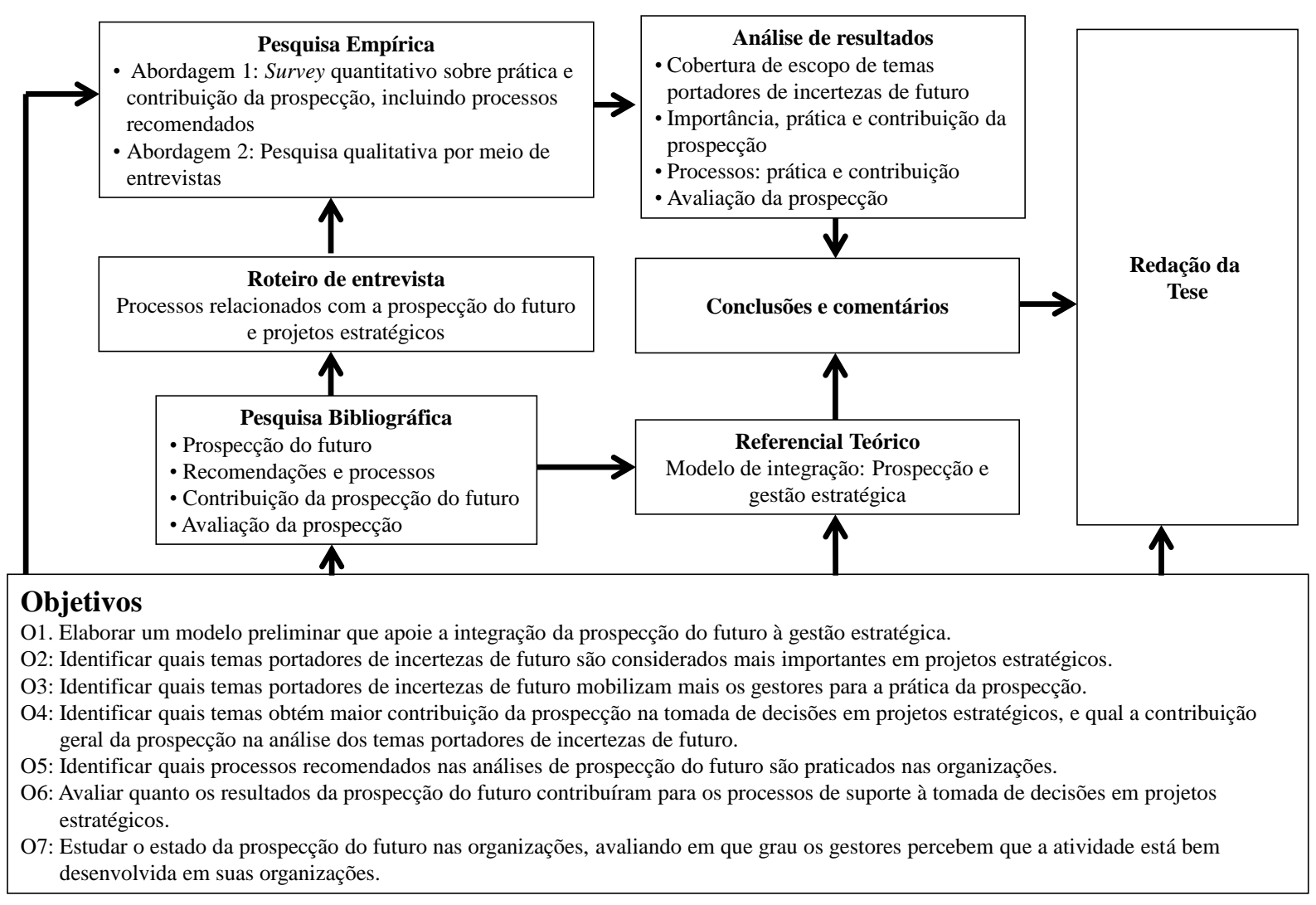

Ilustração 17 - Fases para o desenvolvimento da pesquisa Fonte: Elaborado pelo autor

O Modelo Conceitual Teórico orientou a operacionalização para se desenvolver a pesquisa, e também para subsidiar a proposição do modelo preliminar para integrar a prospecção do futuro com as decisões em projetos do âmbito da estratégia das organizações.

Esse modelo, mostrado anteriormente, foi utilizado para subsidiar a elaboração do roteiro de entrevista para a parte qualitativa, e também para a estruturação do questionário de coleta (survey) aplicado na amostra de respondentes. O roteiro de entrevista e o questionário podem ser controlados nos apêndices 1 e 2 deste projeto.

Seguindo com a descrição da metodologia, cabe mencionar que o Modelo Conceitual Teórico da pesquisa ilustra a integração dos objetivos da pesquisa com as questões de pesquisa, e também com as técnicas de análise previstas para se desenvolver o estudo.

A representação dessa integração metodológica tem o objetivo de dar visibilidade à metodologia de pesquisa adotada nesta tese, e ela é baseada na "Matriz de Amarração" de Mazzon, cujo objetivo é manter o projeto de pesquisa “[...] focalizado na questão da aderência e da compatibilidade entre modelo de pesquisa, objetivos da pesquisa, hipóteses de pesquisa e 
técnicas de análise planejadas para tratamento dos dados em termos qualitativos" (TELLES, 2001).

A matriz de integração metodológica é mostrada na ilustração a seguir. Na primeira coluna é inserida a ilustração simplificada do Modelo Conceitual Teórico da pesquisa, que também inspira o modelo que se propõe avaliar nesta tese - que busca apoiar a integração da prospecção à estratégia empresarial. Na segunda coluna são inseridos os Objetivos da pesquisa e na terceira coluna estão as Questões da pesquisa. Estas últimas estão horizontalmente alinhadas com as variáveis ilustradas na figura do Modelo Conceitual Teórico inserida na primeira coluna. Na coluna final, à direita, estão os métodos e técnicas previstas para proceder à análise dos dados. 
Quadro 9 - Matriz de integração metodológica

Fonte: Análise do autor

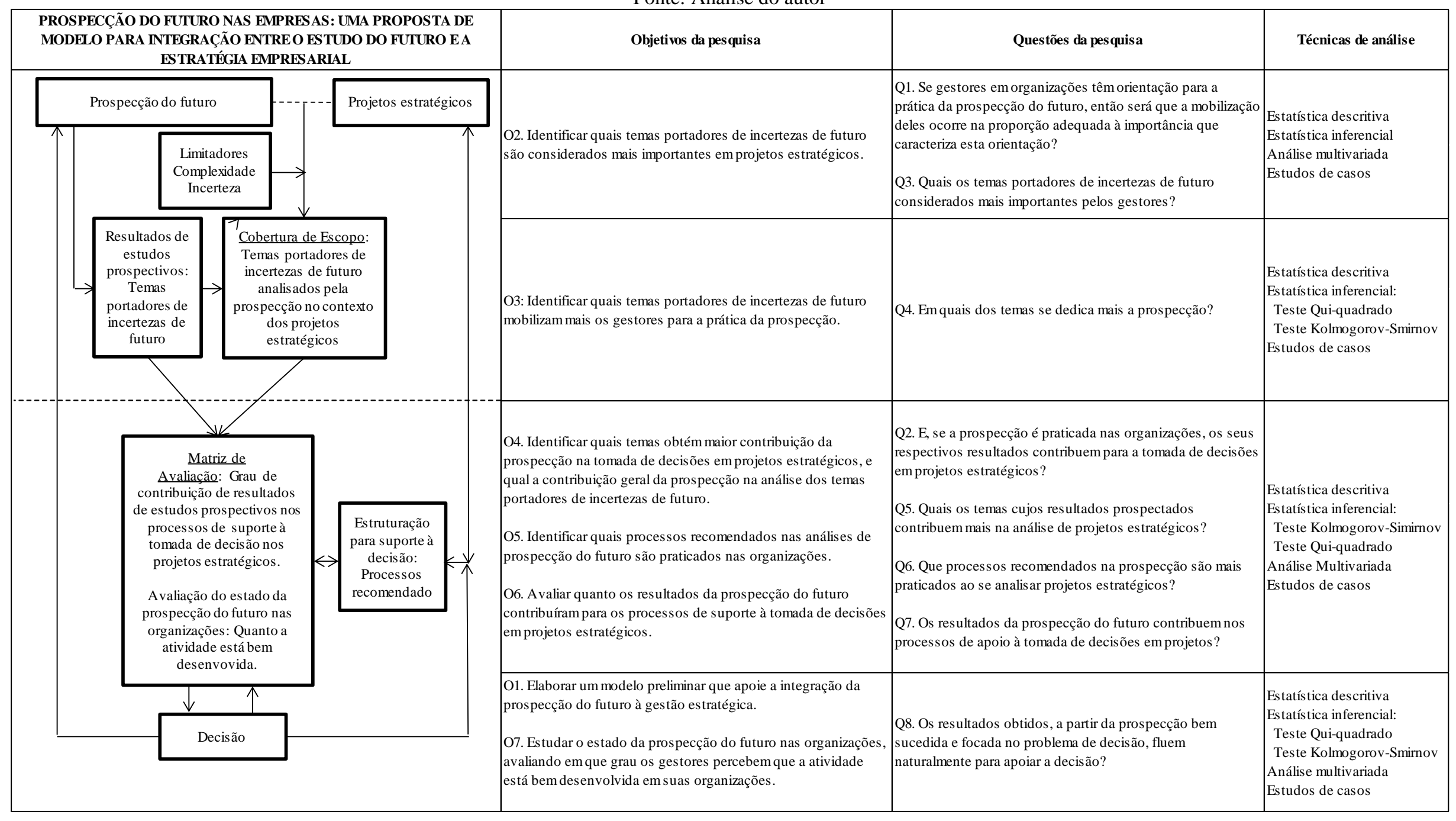




\subsection{Limitações da metodologia}

O presente estudo teve proposta de metodologia exploratória e descritiva, com uso de um levantamento quantitativo associado a uma etapa qualitativa realizada por meio de entrevistas. $\mathrm{O}$ foco da pesquisa estava em entender preliminarmente como ocorre o fenômeno relacionado com o problema de pesquisa, e avaliar a proposta de um modelo que contribua para lidar com o fenômeno. Procurou-se ainda capturar a opinião de gestores que se envolvem com o fenômeno nas organizações, buscando identificar aspectos adicionais que possibilitassem aprofundamento das análises.

A tese se concentra em estudar os processos relacionados com a transição entre a motivação pela prática da prospecção, a sua prática propriamente dita e finalmente a utilização de seus resultados nas decisões de projetos estratégicos. A utilização dos resultados tem relação com a contribuição que a prospecção propicia para as análises de suporte à decisão em projetos de âmbito da estratégia da organização. Encontram-se na literatura estudos com essa abordagem, contudo eles são focados em um determinado problema de prospecção/decisão, portanto, em um contexto específico e de forma dependente do caso estudado.

Esta tese não entra no âmbito do problema de prospecção ou da decisão, portanto trata-se de uma abordagem diferente, não dependente do caso ou contexto de um problema específico de prospecção e decisão. Ela aborda de forma ampla a prática da prospecção e a sua contribuição para as decisões. Isso torna o estudo mais orientado para a análise do quanto a prospecção do futuro é praticada, e como está a avaliação de seu potencial de contribuição para a estratégia nas organizações.

Por decorrência, nesta pesquisa não se aplicou uma delimitação por um segmento específico de mercado ou por determinado porte de empresas. Esta delimitação de forma abrangente se justifica porque neste estudo foram buscadas, de forma exploratória e descritiva, respostas para questões de pesquisa, e não confirmações sobre hipóteses formuladas a priori. As hipóteses formuladas durante a análise dos dados, quando utilizadas, serviram como guia para se responder às questões de pesquisa. Dessa forma, elas foram utilizadas para se elaborar hipóteses a posteriori. E também devido ao tipo de amostra, uma generalização de conclusões somente pode ser obtida por futuras pesquisas confirmatórias. 


\section{APRESENTAÇÃO E DISCUSSÃO DOS RESULTADOS}

A transição entre a prática da prospecção do futuro e as decisões não é um processo fácil. Os resultados obtidos nesta pesquisa indicam haver limitações nesse processo.

Os resultados indicam que há uma diferença entre o quanto gestores da amostra consideram a prospecção importante e o quanto eles avaliam que ela é praticada nas suas organizações. E também há uma diferença entre o quanto eles avaliam que praticam a prospecção e o quanto eles acham que ela contribui nas decisões em projetos. E essas diferenças são decrescentes, o que de certa forma seria esperado, pois nem sempre se consegue seguir recomendações e prescrições ao nível desejado. Contudo, esse resultado reforça o interesse em estudar porque isso acontece com a prospecção do futuro, e se não haveria uma forma de contribuir para que essa transição aqui mencionada ocorra de forma mais tranquila.

Conforme Chermack (2011) argumentou, a literatura de cenários "se concentra mais no desenvolvimento de cenários, dão pouca atenção a como utilizar os cenários, e negligencia completamente a ideia de avaliar os projetos de cenários" (CHERMACK, 2011, ebook, part two). Esse ponto, de certa forma, também já havia sido defendido por Boaventura e Fischmann (2008), quando propuseram que é importante testar a consistência da visão de futuro. Rohrbeck e Gemünden (2008) também corroboraram com esta discussão.

Esta tese foi desenvolvida para que a prospecção do futuro possa contribuir melhor na tomada de decisões, por meio de uma abordagem que se baseia em modelos propostos por autores como Grim (2009) e Rohrbeck (2011). Esses autores propuseram modelos bem abrangentes, que procuram incluir todos os constructos que tenham influência na prospecção. O que se faz nesta tese é aprofundar determinados segmentos desses modelos, buscando se concentrar mais nos aspectos metodológicos e nas informações que são tratadas no estudo do futuro. Portanto, o resultado desta tese visa a contribuir com um detalhamento de uma parte do que propuseram esses autores.

O perfil desejado dos participantes na pesquisa foi de executivos de organizações, que tenham envolvimento com a estratégia e com decisões dentro desse escopo, especialmente em projetos estratégicos. Conforme definido anteriormente, nesta tese os projetos estratégicos são assumidos como sendo do âmbito da estratégia da organização, pois eles são "projetos no contexto dos objetivos e metas da organização" (CALLAHAN; BROOKS, 2004, p. 23). 
A abordagem para associar a estratégia com projetos estratégicos foi decidida devido às entrevistas com executivos, feitas antes da finalização do instrumento de coleta da survey. Nestas entrevistas, que foram duas, ficou claro que os respondentes da survey teriam maior facilidade de responder ao questionário se referindo a um projeto estratégico. Os executivos entrevistados afirmaram que seria difícil responder ao questionário se referindo à estratégia geral da organização, pois muitas vezes ela está declarada de forma generalizada, o que poderia gerar dificuldade de enxergar as relações entre as atividades de prospecção do futuro e a estratégia. Os resultados das entrevistas podem ser vistos mais em detalhes na seção de discussão dos resultados da parte qualitativa desta tese.

Os resultados da pesquisa são apresentados nas seções a seguir. Conforme mencionado anteriormente, os resultados são apresentados separadamente, representando as etapas quantitativa e qualitativa desta tese. A síntese dos principais achados da tese está descrita no Capítulo 6.

\subsection{Resultados quantitativos (survey)}

O objetivo da análise de dados quantitativos foi: Concentrar-se no fenômeno da prática da prospecção do futuro, seus resultados e a contribuição dos mesmos na decisão em projetos estratégicos, e finalmente a avaliação da prospecção do futuro praticada nas empresas dos participantes. Estudando esse fenômeno, a pesquisa avança com objetivo de avaliar a possibilidade de aplicação de um modelo gerencial para suporte à prospecção do futuro nas organizações, analisando se ele traria benefícios, tais como facilitar para os gestores o processo de tomada de decisões em projetos estratégicos. Esta tomada de decisões, em muitos casos, pode ser realizada pelos gestores com base em suas experiências e intuições, com pouco tempo para reflexão, seja pela limitação de prazo, seja pela limitação de recursos humanos ou econômicos disponíveis para a realização de prospecção do futuro. Este estudo, de forma exploratória, que não tem hipóteses a priori, visou mostrar a prática da prospecção do futuro e sua realidade nas empresas dos participantes da pesquisa.

Através das análises estatísticas, buscou-se retratar a realidade das organizações dos respondentes (da amostra) de modo a contribuir para o estudo e a prática da prospecção do futuro nas empresas, e também na sua integração à estratégia empresarial. 


\subsubsection{A amostra e a resposta à survey}

O perfil desejado na amostra induziu à obtenção de uma base de respondentes com 1.328 participantes convidados, sendo eles predominantemente gestores com função executiva, tipicamente gerentes, diretores e presidentes.

A coleta de dados foi operacionalizada por meio de 13 lotes de convites, tendo sido enviados entre os meses de agosto e setembro de 2015. Três lembretes foram enviados aos convidados antes que se encerasse o período de coleta dos dados.

Do total de convidados, 157 preencheram o questionário integralmente, resultando em retorno de $11,8 \%$. O que deve ser comentado aqui é que 316 pessoas iniciaram o preenchimento do questionário, sendo que 159 delas abandonaram o preenchimento, com perda de $50 \%$. Os que iniciaram o preenchimento representaram $24 \%$ da amostra.

Originalmente se imaginava poder desenvolver a pesquisa propondo maior abrangência de fatores relacionados com a prospecção do futuro. Nas entrevistas realizadas antes da survey, contudo, ficou identificado que poderiam ocorrer muitos abandonos de preenchimento devido ao tamanho do questionário. A prospecção do futuro é multidisciplinar, o que leva os pesquisadores a querer incluir muitos fatores ou variáveis, correndo o risco de longos instrumentos de coleta. Ficou bem caracterizado que o instrumento preliminarmente desenvolvido poderia levar à elevada taxa de abandono no preenchimento. Dessa forma, foi ajustado o escopo do modelo de referência conceitual, e consequentemente o questionário também foi adequado ao novo ajuste. Esta decisão se mostrou muito efetiva, pois ainda assim a taxa de abandono chegou à metade dos que iniciaram o preenchimento.

Sobre o instrumento de coleta definitivo que foi utilizado, ele foi testado em forma de préteste com um grupo de pessoas no início do mês de agosto/2015. Neste pré-teste, foi identificado que não haveria necessidade de ajustes de maior âmbito, apenas aspectos de estilo de redação. O tempo médio de resposta no pré-teste foi de 12 minutos.

A amostra foi dividida em 13 lotes menores, e os convites foram encaminhados entre os meses de agosto e setembro de 2015. Para estimular as repostas, foram enviados três lembretes intermediários antes do fechamento da coleta, que ocorreu em outubro/2015. O tempo de resposta médio na coleta total foi de 18 minutos. 
O questionário pode ser encontrado no apêndice 2 desta tese.

\subsubsection{Descrição das variáveis do questionário}

As variáveis representadas no questionário são novamente descritas aqui, para facilitar o entendimento dos procedimentos de análise utilizados.

- Temas portadores de incertezas de futuro: categorizados conforme suas respectivas naturezas, e que sejam também portadoras de questões estratégicas, e.g. economia, política, tecnologia, para citar algumas das categorias.

- Horizonte de tempo: alcance de tempo para o qual os métodos de prospecção e o planejamento estratégico são praticados.

- Importância da prospecção do futuro (estudos do futuro): grau de percepção sobre a relevância da prospecção nas organizações.

- Prática (análise) da prospecção: execução de processos recomendados nas metodologias para estudar o futuro, visando avaliar o que pode vir a acontecer e, dessa forma, tratar incertezas de futuro do âmbito dos projetos estratégicos, ou do âmbito da estratégia.

- Contribuição da prospecção no processo de tomada de decisões em projetos: os resultados de estudos prospectivos geram conclusões, as quais podem facilitar a tomada de decisões em projetos que contenham incertezas de futuro.

- Processos praticados em prospecção do futuro: Processos de análise prospectiva de projetos e de análise prospectiva estratégica, cuja prática é recomendada na prospecção do futuro.

- Projeto Estratégico: Projetos de médio e longo prazo, em diferentes áreas da organização, que envolvem muitos recursos físicos, humanos e econômicos, e que tipicamente são de difícil reversão após o início de sua implantação.

- Frequência de recorrência aos métodos de estudos do futuro: Contínuo versus esporádico ou nunca.

- Aspectos gerais dos respondentes da pesquisa, e também de suas respectivas organizações. 
As definições utilizadas nesta tese, quando necessárias para esclarecer aos respondentes seus significados, foram colocadas no instrumento de coleta.

\subsubsection{Metodologia estatística aplicada}

A metodologia estatística utilizada para suporte à análise de dados da presente tese incluiu:

- Análise descritiva: tabelas de frequência, estatística de soma, gráficos de coluna, gráficos de linha.

- Análise inferencial univariada - Prova de Kolmogoro-Smirnov (K-S) para duas amostras, prova de Kolmogorov-Smirnov para uma amostra, Prova do Qui-Quadrado.

A Prova de Kolmogorov-Smirnov (K-S) para duas amostras foi utilizada para comparar os clusters quanto à distribuição da variável, com hipótese de nulidade $\mathrm{H}_{0}$ : não há diferença de $\%$ de respostas entre os clusters.

O teste de Kolmogorov-Smirnov (K-S) para duas amostras independentes averiguou, nesta tese, se os dois clusters (provenientes da análise de cluster) provêm de populações com a mesma distribuição, em relação à determinada variável, com mensuração ordinal.

A Prova de Kolmogorov-Smirnov para uma amostra comparou, para o total da amostra, a distribuição das contribuições da prospecção do futuro nos processos específicos, com a distribuição da contribuição nos processos em geral. Tendo por hipótese de nulidade $\mathrm{H}_{0}$ : não há diferença de \% entre a contribuição específica e a contribuição geral.

A prova do Qui-Quadrado é adequada para analisar e concluir sobre a associação (ou independência) entre duas variáveis, sendo elas variáveis nominais. Neste estudo realizou-se esta prova para estudar a associação entre cluster e variáveis de perfil da empresa (e.g. origem do capital da empresa, faturamento, tamanho da empresa, forma de controle da empresa). 
As provas estatísticas foram realizadas ao nível de significância igual a $0,10(\alpha=0,10)$, por se tratar de um estudo exploratório. O nível de significância nesta tese se refere a um tipo de erro: Probabilidade de rejeitar a hipótese (de nulidade) quando ela é verdadeira.

- Análise multivariada: Análise de Cluster, Análise CHAID.

A análise de cluster teve por objetivo agregar respondentes da survey de acordo com suas características múltiplas. Ou, explicado de outra forma, ela serviu para separar a amostra de respondentes em agrupamentos distintos entre si e homogêneos internamente, sem qualquer definição prévia de número de agrupamentos.

CHAID é uma técnica que foi utilizada para tentar entender a formação dos clusters em relação às suas múltiplas variáveis.

\subsubsection{Perfil das empresas da amostra}

Praticamente as empresas da amostra estão equilibradas entre empresas brasileiras e estrangeiras (51,6\% e 44,6\%, respectivamente), com participação próxima de 1/3 entre sociedade de capital aberto, sociedade de capital fechado e empresas limitadas, respectivamente. A forma de controle de capital também se mostra equilibrada.

Tabela 5 - Forma de controle da empresa

\begin{tabular}{|l|c|c|}
\hline \multicolumn{1}{|c|}{ Forma de controle da empresa } & Frequência & \% \\
\hline Sociedade de capital aberto & 46 & 29,3 \\
\hline Sociedade de capital fechado & 46 & 29,3 \\
\hline Limitada & 55 & 35 \\
\hline Estatal de capital 100\% público & 1 & 0,6 \\
\hline Organização do terceiro setor OSCIP & 1 & 0,6 \\
\hline Outro & 3 & 1,9 \\
\hline Total & 152 & 96,8 \\
\hline Sem resposta & 5 & 3,2 \\
\hline Total & 157 & 100 \\
\hline
\end{tabular}


Tabela 6 - Predominância da origem de capital da empresa

\begin{tabular}{|l|c|c|}
\hline \multicolumn{1}{|c|}{ Predominância da origem do capital da empresa } & Frequência & \% \\
\hline Brasileira & 81 & 51,6 \\
\hline Estrangeira & 70 & 44,6 \\
\hline Total & 151 & 96,2 \\
\hline Sem resposta & 6 & 3,8 \\
\hline Total & 157 & 100 \\
\hline
\end{tabular}

Em relação à quantidade de funcionários e faturamento, há grande diversidade na amostra. Empresas pequenas de até 100 funcionários representam 24\%, participação muito semelhante à das grandes empresas (acima de 5.000 funcionários), com 22\% de participação na amostra.

Tabela 7 - Quantidade de funcionários da empresa

\begin{tabular}{|l|c|c|}
\hline \multicolumn{1}{|c|}{ Quantidade de funcionários da empresa } & Frequência & $\%$ \\
\hline Até 50 & 26 & 16,6 \\
\hline Entre 51 e 100 & 12 & 7,6 \\
\hline Entre 101 e 300 & 17 & 10,8 \\
\hline Entre 301 e 500 & 12 & 7,6 \\
\hline Entre 501 e 1.000 & 18 & 11,5 \\
\hline Entre 1.001 e 2.000 & 14 & 8,9 \\
\hline Entre 2.001 e 3.000 & 10 & 6,4 \\
\hline Entre 3.001 e 4.000 & 4 & 2,5 \\
\hline Entre 4.001 e 5.000 & 4 & 2,5 \\
\hline Entre 5.001 e 6.000 & 6 & 3,8 \\
\hline Entre 8.001 e 9.000 & 2 & 1,3 \\
\hline Entre 9.001 e 10.000 & 1 & 0,6 \\
\hline Entre 10.001 e 15.000 & 7 & 3,2 \\
\hline Entre 15.001 e 200.00 & 14 & 8,5 \\
\hline Acima de 20.000 & 152 & 96,8 \\
\hline Total & 5 & 3,2 \\
\hline Sem resposta & 157 & 100 \\
\hline Total & &
\end{tabular}

É muito grande a dispersão de porte de empresa por quantidade de funcionários. Foi realizada uma maior agregação das faixas, mostrada a seguir. 
Tabela 8 - Quantidade de funcionários - por porte agregado

\begin{tabular}{|l|c|}
\hline \multicolumn{1}{|c|}{$\begin{array}{c}\text { Quantidade de funcionários de sua empresa (agregação } \\
\text { de faixas) }\end{array}$} & $\mathbf{\%}$ \\
\hline Até 100 & 24,2 \\
\hline Entre 101 e 1.000 & 29,9 \\
\hline Entre 1.001 e 5.000 & 20,3 \\
\hline Acima de 5.000 & 22,3 \\
\hline Sem resposta & 3,2 \\
\hline Total & 100 \\
\hline
\end{tabular}

A agregação das faixas de quantidade de funcionários mostra um perfil distribuído sem predominância de empresas de determinado porte.

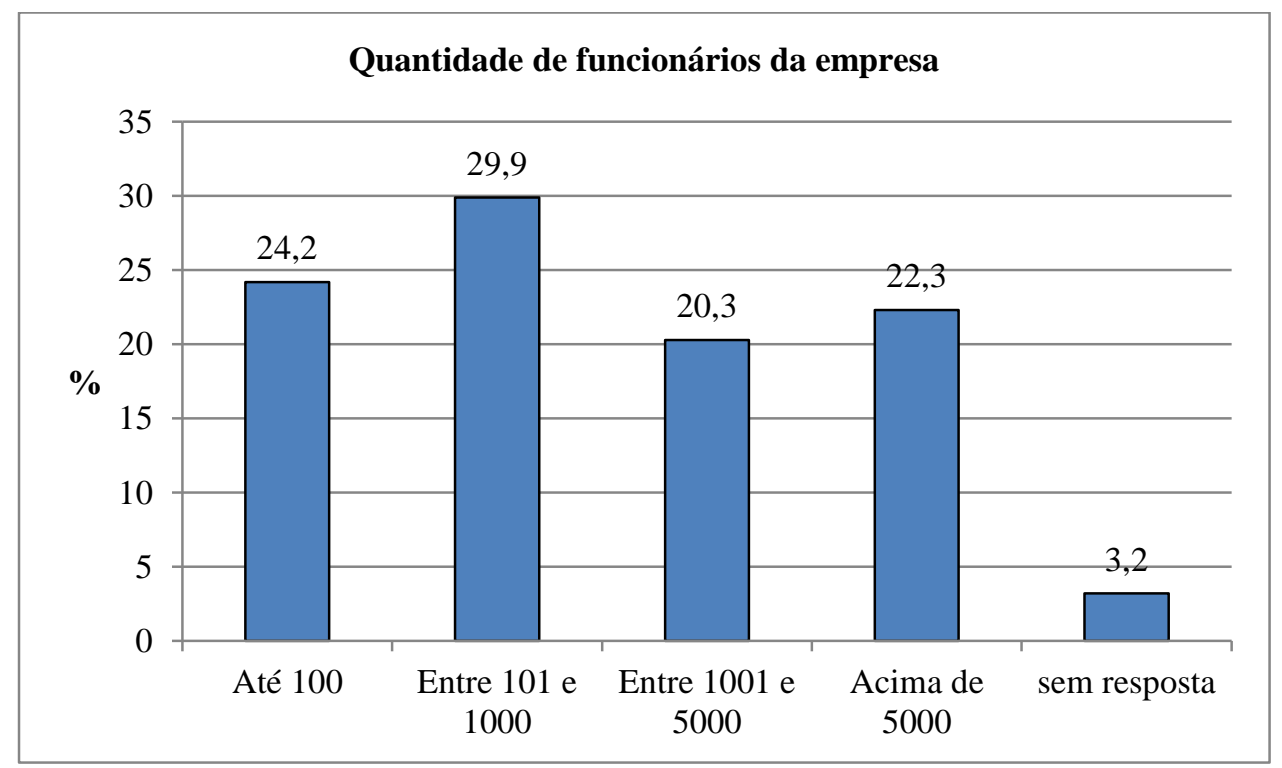

Gráfico 9 - Distribuição das empresas pela quantidade de funcionários

O faturamento da empresa no Brasil também se mostra com grande dispersão. A tabela a seguir mostra a distribuição pelo faturamento anual. 
Tabela 9 - Faturamento anual da empresa no Brasil

\begin{tabular}{|l|c|c|}
\hline \multicolumn{1}{|c|}{ Faturamento anual da empresa no Brasil } & Frequência & \% \\
\hline menos de 10 milhões de reais & 20 & 12,7 \\
\hline de 10 a 20 milhões de reais & 13 & 8,3 \\
\hline de 20 a 50 milhões de reais & 9 & 5,7 \\
\hline de 50 a 100 milhões de reais & 7 & 4,5 \\
\hline de 100 a 300 milhões de reais & 14 & 8,9 \\
\hline de 300 a 500 milhões de reais & 15 & 9,6 \\
\hline de 500 milhões a 1 bilhão de reais & 18 & 11,5 \\
\hline de 1 a 2 bilhões de reais & 18 & 11,5 \\
\hline de 2 a 3 bilhões de reais & 7 & 4,5 \\
\hline de 3 a 5 bilhões de reais & 4 & 2,5 \\
\hline de 5 a 7 bilhões de reais & 3 & 1,9 \\
\hline de 7 a 10 bilhões de reais & 2 & 1,3 \\
\hline de 10 a 13 bilhões de reais & 4 & 2,5 \\
\hline de 13 a 16 bilhões de reais & 2 & 1,3 \\
\hline de 16 a 20 bilhões de reais & 2 & 1,3 \\
\hline de 20 a 25 bilhões de reais & 2 & 1,3 \\
\hline de 25 a 30 bilhões de reais & 2 & 1,3 \\
\hline acima de 30 bilhões de reais & 9 & 5,7 \\
\hline Total & 151 & 96,2 \\
\hline Sem resposta & $\mathbf{1 5 7}$ & 3,8 \\
\hline Total & $\mathbf{1 0 0}$ \\
\hline
\end{tabular}

Ao se agregar mais as faixas de faturamento anual, obtém-se o seguinte perfil na tabela a seguir.

Tabela 10 - Faturamento anual no Brasil - faixas agregadas

\begin{tabular}{|l|c|}
\hline $\begin{array}{c}\text { Faturamento anual da empresa no Brasil (agregação de } \\
\text { faixas) }\end{array}$ & $\mathbf{\%}$ \\
\hline até 20 milhões de reais & 21 \\
\hline de 20 até 500 milhões de reais & 28,7 \\
\hline de 500 milhões até 3 bilhões de reais & 27,5 \\
\hline de 3 bilhões a 30 bilhões de reais & 13,4 \\
\hline acima de 30 bilhões de reais & 5,7 \\
\hline Sem resposta & 3,8 \\
\hline \multicolumn{1}{|c|}{ Total } & $\mathbf{1 0 0}$ \\
\hline
\end{tabular}

O gráfico a seguir ilustra a distribuição das empresas pelo faturamento anual (dados com maior agregação). 
A distribuição das empresas pelo faturamento anual mostra que predominam empresas com faturamento até 3 bilhões de reais (77\%).

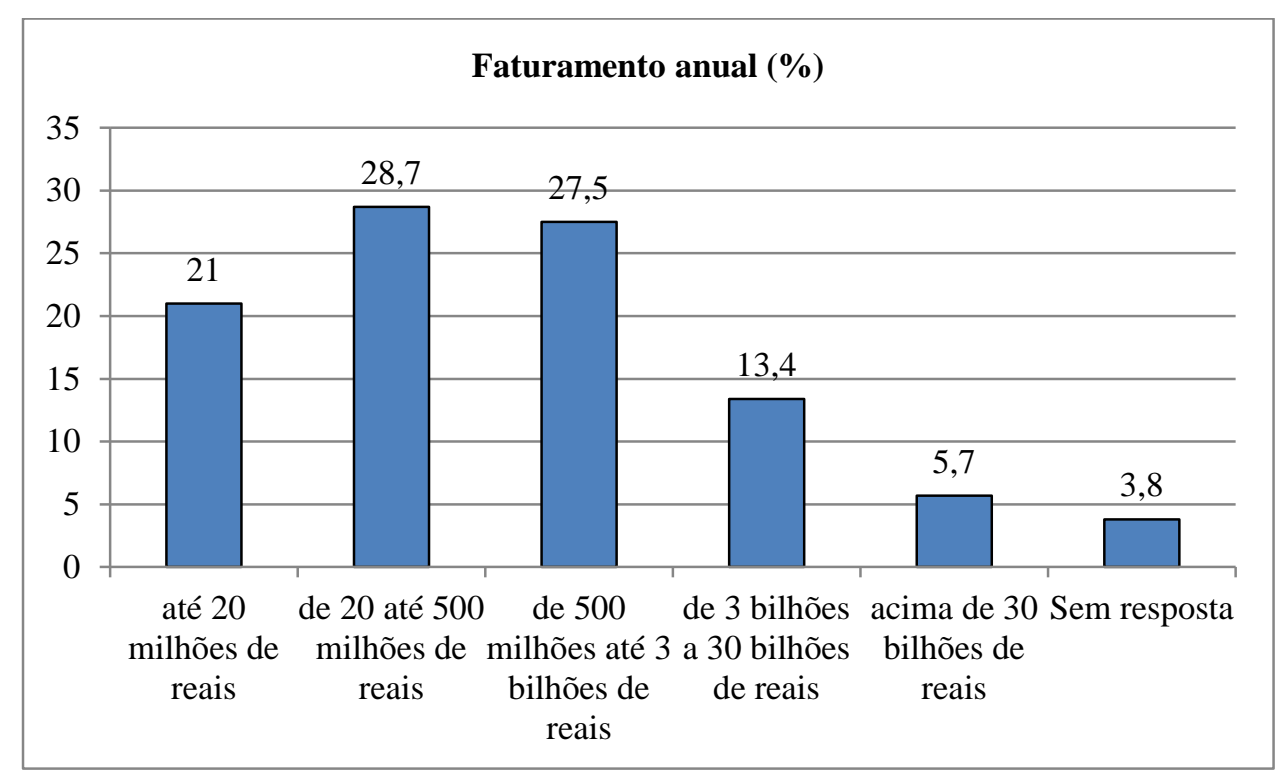

Gráfico 10 - Distribuição das empresas (faturamento anual Brasil)

Há maior concentração de empresas com faturamento menor na amostra pesquisada.

\subsubsection{Perfil dos respondentes}

O perfil de respondentes é de profissionais muito experientes, com $10 \%$ de CEOs ou presidentes, $41 \%$ de diretores e $32 \%$ de gerentes. A amostra foi direcionada para profissionais com experiência executiva elevada, justamente para aumentar o potencial de repostas, pois são profissionais desse perfil que têm maior contato com decisões em projetos no âmbito da estratégia empresarial.

A formação acadêmica é bem elevada, com quase $96 \%$ deles com alguma modalidade de pósgraduação. O menor nível de escolaridade dos respondentes da pesquisa é o superior (graduação), referente a 3,8\% da amostra. Já 71,3\% dos respondentes possui pós-graduação lato sensu. 
Tabela 11 - Formação acadêmica do respondentes

\begin{tabular}{|l|c|c|}
\hline \multicolumn{1}{|c|}{ Formação acadêmica } & Frequência & \% \\
\hline Ensino superior graduação & 6 & 3,8 \\
\hline Ensino superior pós-graduação lato sensu Especialização & 112 & 71,3 \\
\hline Ensino superior pós-graduação stricto sensu mestrado & 33 & 21 \\
\hline Outro & 2 & 1,3 \\
\hline Total & $\mathbf{1 5 3}$ & $\mathbf{9 7 , 5}$ \\
\hline Sem resposta & 4 & 2,5 \\
\hline & 157 & 100 \\
\hline
\end{tabular}

Os participantes apresentam muito tempo de experiência profissional, o que contribui no acúmulo de muitos casos de projetos que demandaram por prospecção. A distribuição percentual pode ser vista no gráfico a seguir.

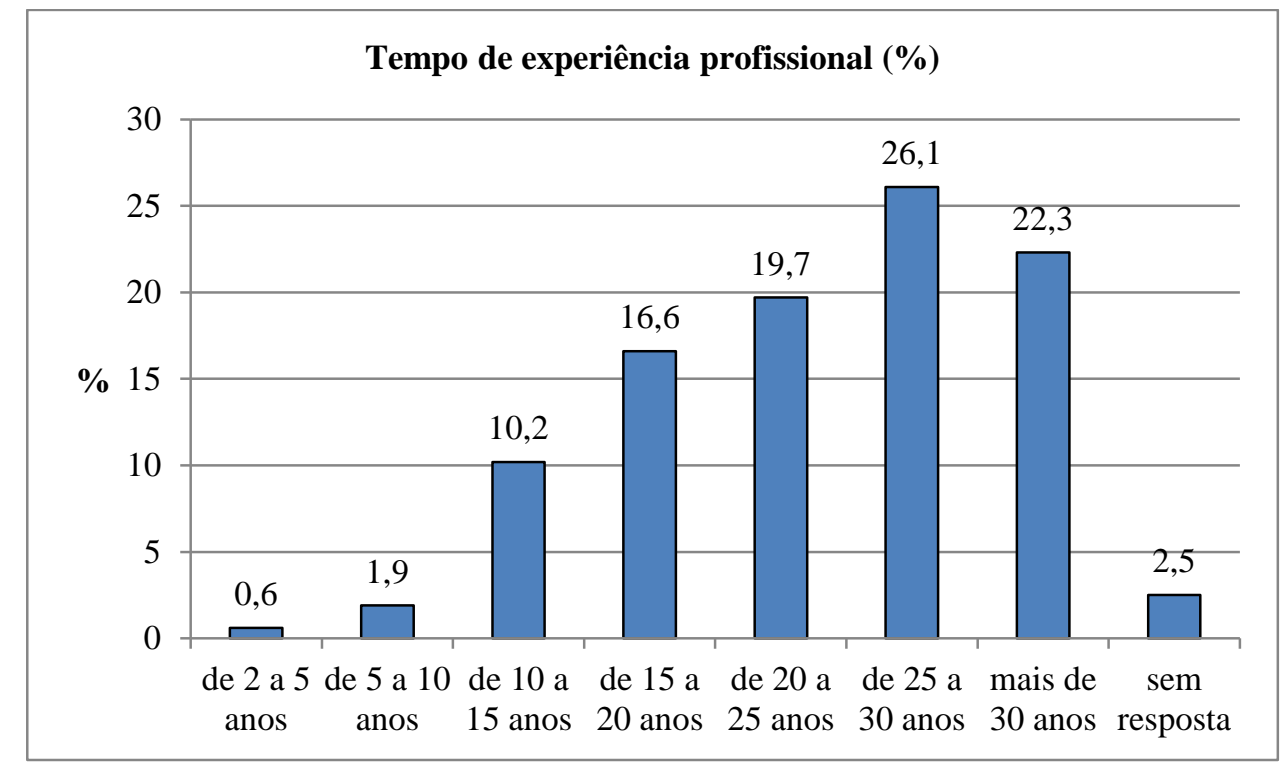

Gráfico 11 - Distribuição da amostra pelo tempo de experiência profissional

A tabela do gráfico anterior está mostrada a seguir. 
Tabela 12 - Tempo de experiência profissional do respondente

\begin{tabular}{|l|c|c|}
\hline \multicolumn{1}{|c|}{ Tempo de experiência profissional } & Frequência & \% \\
\hline de 2 a 5 anos & 1 & 0,6 \\
\hline de 5 a 10 anos & 3 & 1,9 \\
\hline de 10 a 15 anos & 16 & 10,2 \\
\hline de 15 a 20 anos & 26 & 16,6 \\
\hline de 20 a 25 anos & 31 & 19,7 \\
\hline de 25 a 30 anos & 41 & 26,1 \\
\hline mais de 30 anos & 35 & 22,3 \\
\hline Total & $\mathbf{1 5 3}$ & $\mathbf{9 7 , 5}$ \\
\hline Sem resposta & 4 & 2,5 \\
\hline Total & 157 & 100 \\
\hline
\end{tabular}

A amostra apresentava, dessa forma, um bom nível que qualificação para participação nesta pesquisa. Ela foi definida por escolha dirigida para aumentar o potencial da coleta de dados, contudo, a probabilidade de seleção de um respondente para a amostra da pesquisa não é conhecida para todos os potenciais respondentes do universo. Isso foi comentado no capítulo de metodologia.

O perfil da amostra incluiu: supervisores, gerentes, superintendentes, diretores, presidentes e proprietários de organizações, conforme mostrado no gráfico com a quantidade de respondentes por cargo, a seguir. 


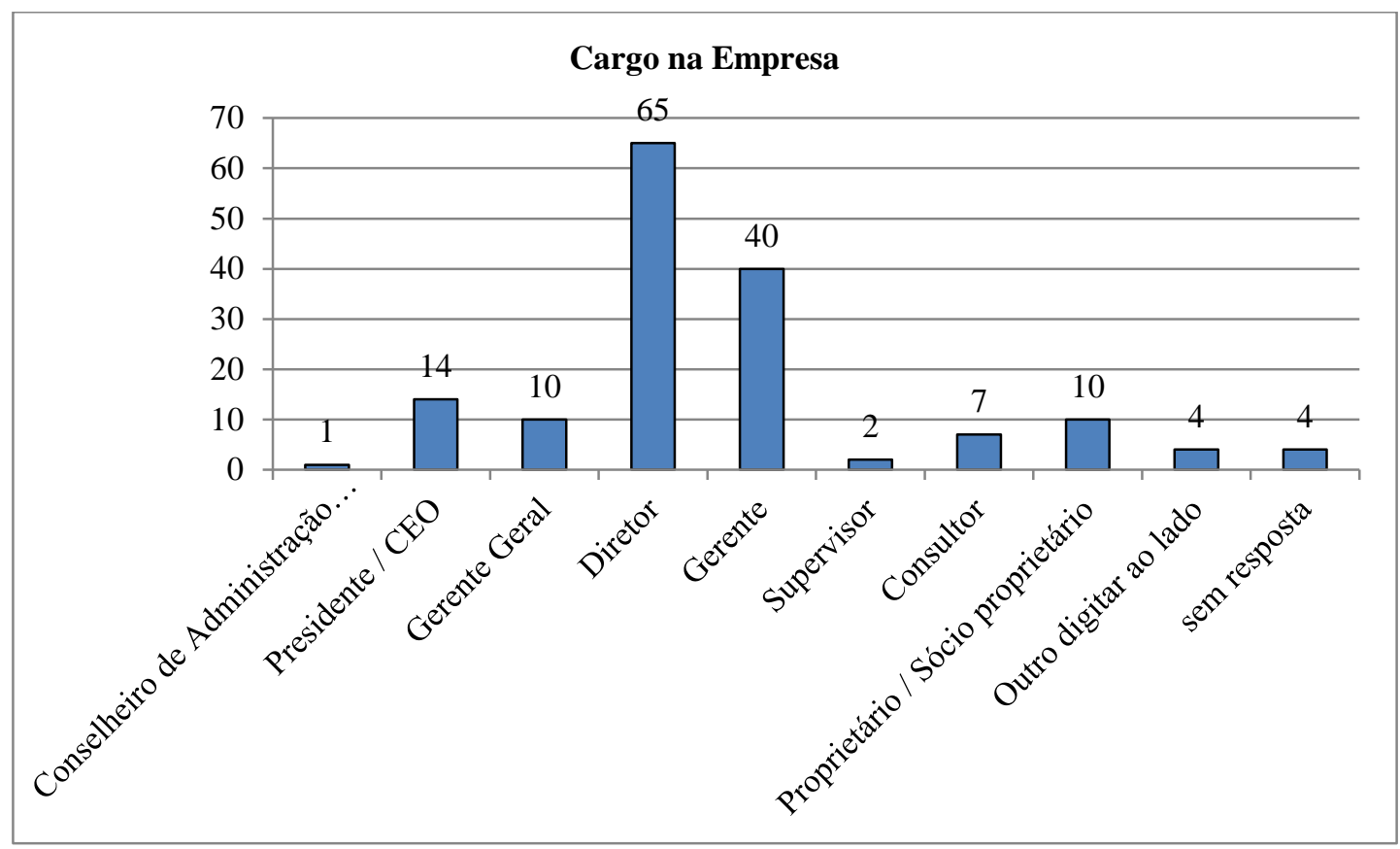

Gráfico 12 - Distribuição dos respondentes pelo cargo na empresa (qtde)

A tabela a seguir mostra os dados do gráfico anterior.

Tabela 13 - Cargo dos respondentes

\begin{tabular}{|l|c|c|}
\hline \multicolumn{1}{|c|}{ Cargo ocupado na empresa } & Frequência & \% \\
\hline Conselheiro de Administração ou Fiscal & 1 & 0,6 \\
\hline Presidente CEO & 14 & 8,9 \\
\hline Gerente Geral & 10 & 6,4 \\
\hline Diretor & 65 & 41,4 \\
\hline Gerente & 40 & 25,5 \\
\hline Supervisor & 2 & 1,3 \\
\hline Consultor & 7 & 4,5 \\
\hline Proprietário / sócio proprietário & 10 & 6,4 \\
\hline Outro & 4 & 2,5 \\
\hline Total & $\mathbf{1 5 3}$ & $\mathbf{9 7 , 5}$ \\
\hline Sem resposta & 4 & 2,5 \\
\hline & 157 & 100 \\
\hline
\end{tabular}

Como se poderia esperar de uma amostra experiente de profissionais, a distribuição das faixas etárias mostra maturidade dos respondentes, conforme o gráfico e a tabela a seguir. 


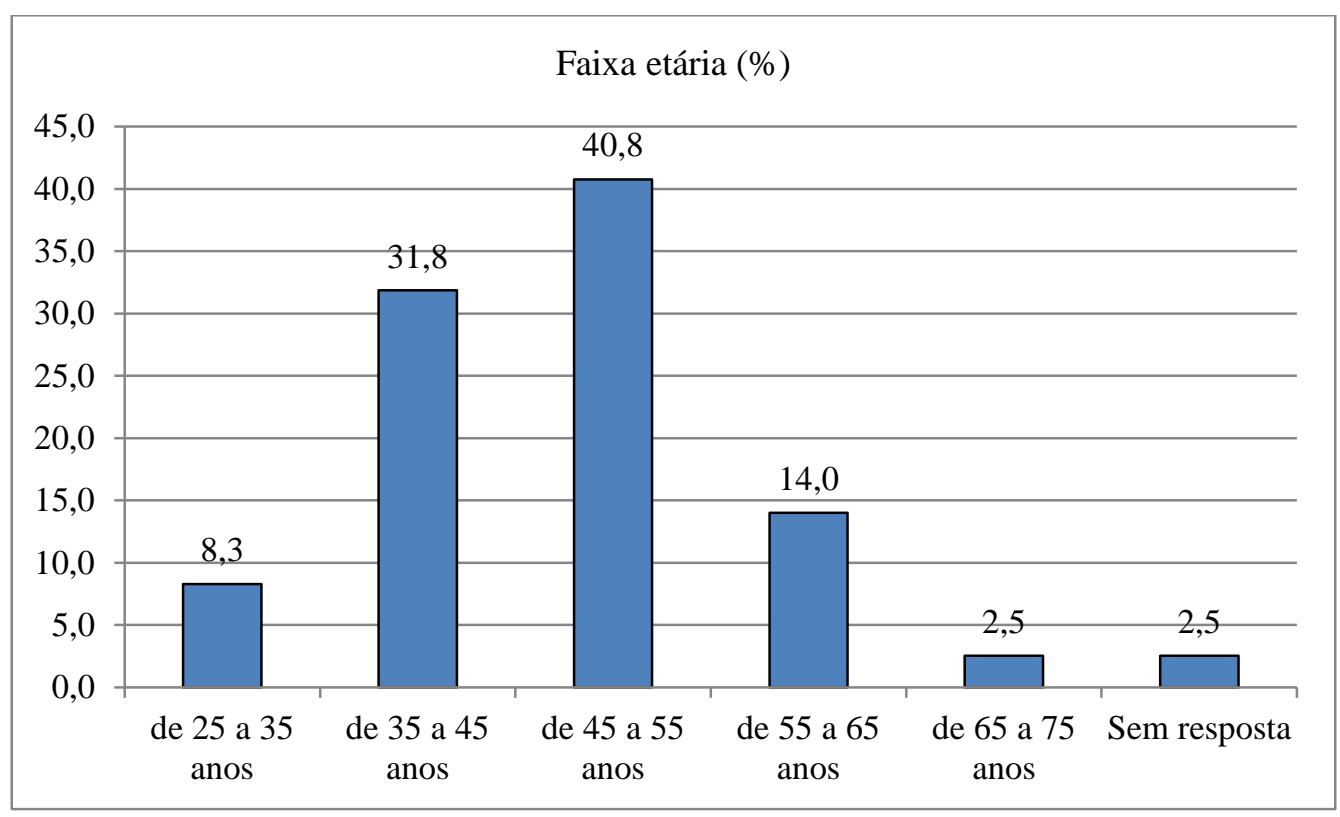

Gráfico 13 - Distribuição dos respondentes por faixa etária (\%)

Tabela 14 - Faixa etária do respondente

\begin{tabular}{|l|c|c|}
\hline \multicolumn{1}{|c|}{ Faixa etária do respondente } & Frequência & \% \\
\hline de 25 a 35 anos & 13 & 8,3 \\
\hline de 35 a 45 anos & 50 & 31,8 \\
\hline de 45 a 55 anos & 64 & 40,8 \\
\hline de 55 a 65 anos & 22 & 14,0 \\
\hline de 65 a 75 anos & 4 & 2,5 \\
\hline Total & $\mathbf{1 5 3}$ & $\mathbf{9 7 , 5}$ \\
\hline Sem resposta & 4 & 2,5 \\
\hline & 157 & 100 \\
\hline
\end{tabular}

\subsubsection{Sobre a prática da prospecção do futuro}

O resultado em relação ao grau de satisfação com a prospecção do futuro mostra que os respondentes da amostra a consideram parcialmente satisfatória, em sua maior parte, mas ainda se encontram $25 \%$ que se declaram no máximo parcialmente insatisfeitos.

Observa-se que não há elevado grau de satisfação quanto aos objetivos atingidos. Isso não pode ser atribuído somente ao tratamento adotado nos projetos, por meio da prospecção do futuro, pois pode haver muitos fatores que influenciam na satisfação. Não esteve no escopo desta tese estudar esses fatores. Para identificar as causas dessa insatisfação, seriam recomendáveis novas pesquisas para averiguar o fenômeno em mais detalhes. Contudo, os 
resultados são indício de que possa haver limitações no potencial de contribuição da prospecção, e dessa forma a proposta de um modelo de suporte que contribua para mitigar as limitações seria importante.

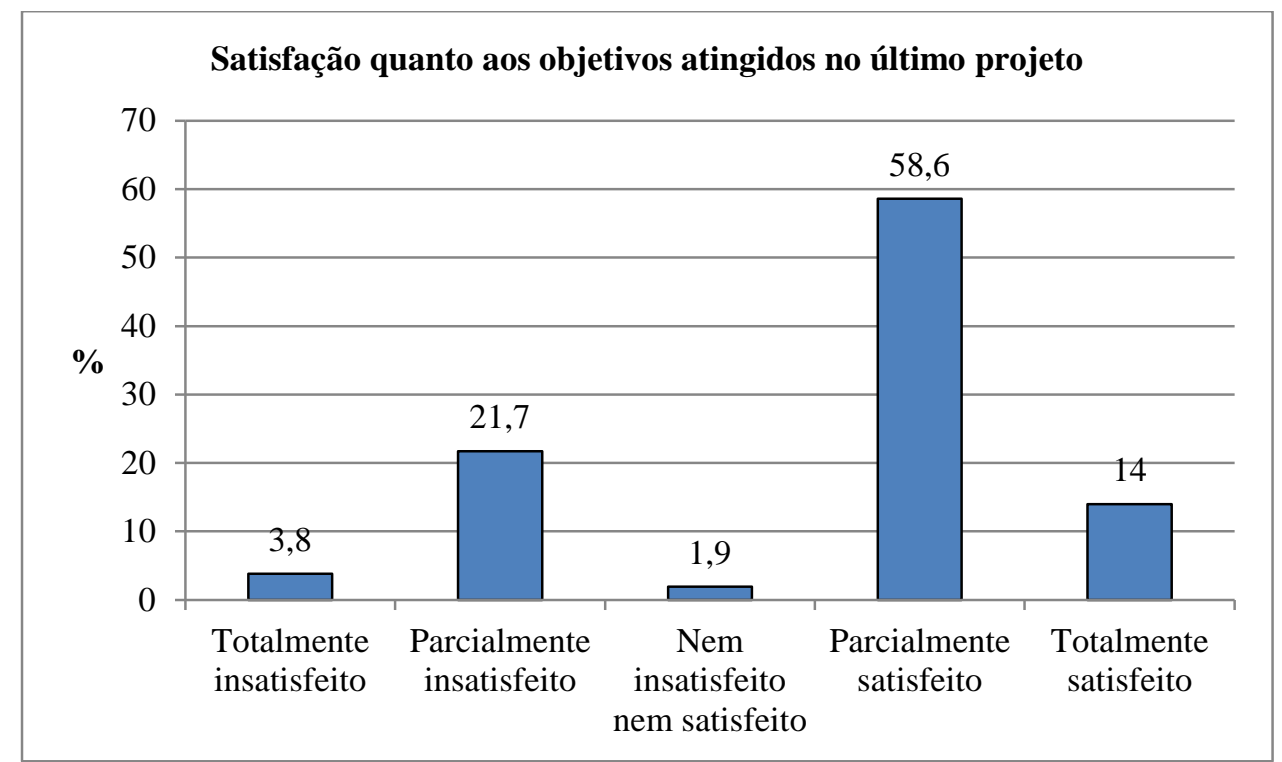

Gráfico 14 - Grau de satisfação com os objetivos atingidos pela prospecção do futuro (\%)

Como antecipado por Chermack (2011), estudos que abordem a utilização de cenários, ou que avaliem o projeto de prospecção em si, são menos frequentes quando se trata do método de cenários.

Nos relatos das entrevistas se identificou que a confiança nos resultados de estudos prospectivos não é uma coisa que se possa considerar como assumida, como que sendo automática a partir do momento em que se tem acesso aos resultados. É preciso confiar neles, conhecendo como se chegou a eles, quem os desenvolveu, quais suas expertises prospectivas, e finalmente quais premissas foram consideradas.

Também é importante garantir que os objetivos dos estudos prospectivos estejam claros antes de seu desenvolvimento, bem entendidos por quem se envolve no desenvolvimento dos estudos, e também que os objetivos individuais dos participantes não sejam potencialmente conflitantes com os objetivos do projeto de prospecção. Deve ser lembrado que o processo participativo mais amplo facilita a assimilação dos resultados obtidos, pois assim se consegue evitar os efeitos da desconfiança sobre os mesmos. Igualmente importante, é preciso cuidado 
para não gerar um viés coletivo, por envolver pessoas que tenderiam a gerar convergência para uma visão de conveniência, como foi identificado em um dos relatos dos entrevistados.

O horizonte de tempo do último projeto estratégico em que o respondente participou está mostrado no gráfico a seguir.

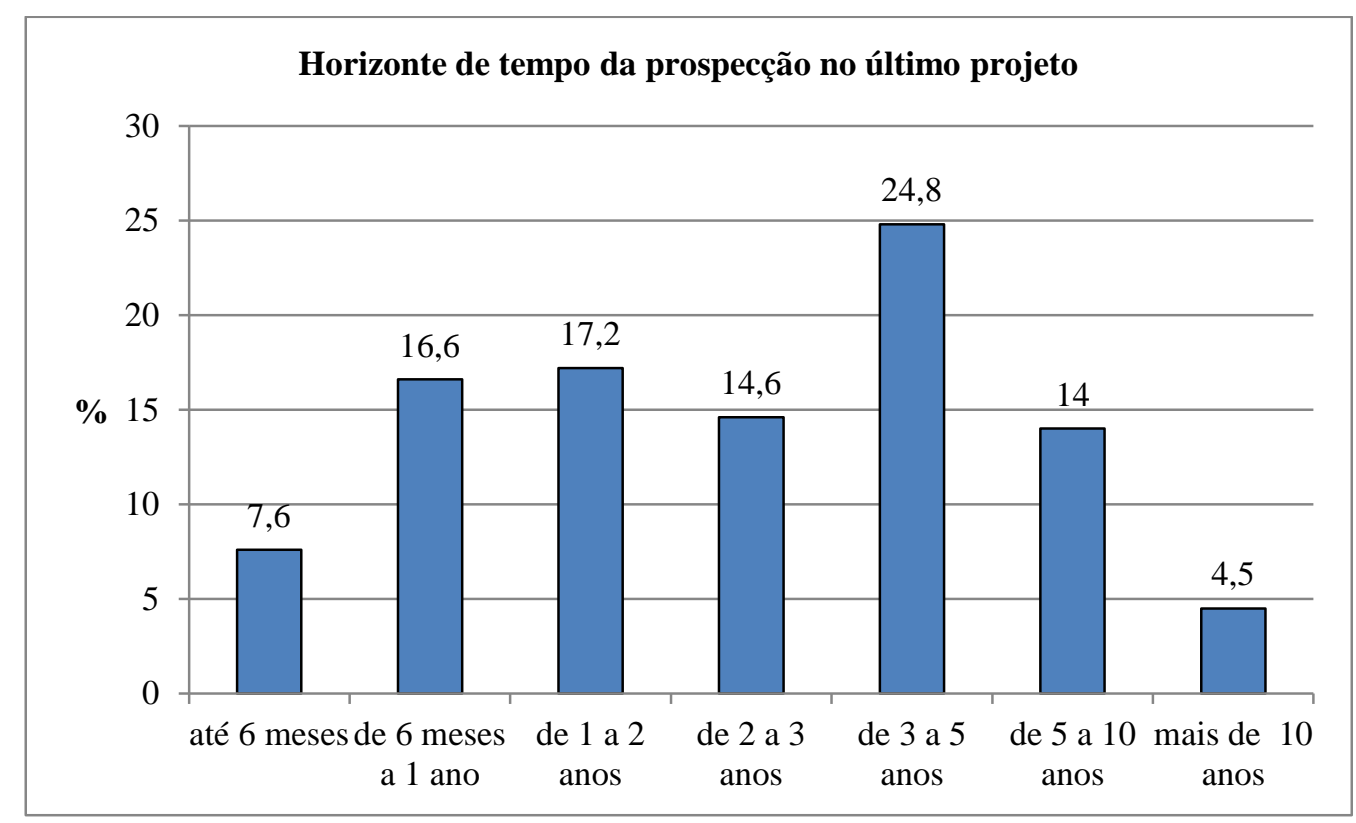

Gráfico 15 - Distribuição (\%) do horizonte de tempo do último projeto estratégico (\%)

Nota-se que $56 \%$ dos projetos demandavam visão de futuro de até três anos, o que é um horizonte ainda curto em se tratando de prospecção do futuro. Predominam, contudo, projetos com horizonte de três a cinco anos $(24,8 \%)$. Ao menos $18,5 \%$ dos projetos são para mais de cinco anos.

Os relatos dos entrevistados, disponíveis na seção 5.2 mais adiante, indicam também que há situações de análises que são para horizontes de tempo muito longos, assim como há necessidade de utilizar métodos prospectivos para suporte a planejamento em horizontes de tempo mais curtos. O alcance para o futuro depende das necessidades dos projetos, e o importante é que as decisões do curto prazo estejam conectadas com as visões do longo prazo. 


\subsubsection{A Importância, a prática e a contribuição}

Considerando agora a importância atribuída à prospecção do futuro, sua prática e a contribuição dos resultados no processo de tomada de decisões, os dados indicam que, descritivamente, há diferenças na avaliação, em função dos temas portadores de incertezas de futuro.

Para as avaliações respondidas acerca das análises dos temas portadores de incertezas de futuro, foram somados os valores atribuídos para importância, prática e contribuição. As variáveis eram avaliadas no questionário com escalas ordinais de 1 a 5 , sendo 1 para a mínima avaliação e 5 para a máxima. Os resultados estão mostrados na tabela e no gráfico a seguir, ordenados decrescentemente pela importância.

Tabela 15 - Os Temas por ordem decrescente de Importância

\begin{tabular}{|l|c|c|c|}
\hline \multirow{2}{*}{\begin{tabular}{c}
\multirow{2}{*}{$\begin{array}{c}\text { Temas (ordenados por ordem } \\
\text { decrescente de Importância) }\end{array}$} \\
Mercado e Demanda
\end{tabular}} & \multicolumn{3}{|c|}{ Soma das avaliações } \\
\cline { 2 - 4 } & Importância & Prática & Contribuição \\
\hline Economia & $\mathbf{7 0 9}$ & $\mathbf{6 4 6}$ & $\mathbf{6 2 9}$ \\
\hline Legislação e Regulação Setorial & $\mathbf{6 5 5}$ & 551 & 520 \\
\hline Tecnologia & 626 & 577 & 550 \\
\hline Inovação em Produtos ou Serviços & 617 & 583 & 555 \\
\hline Competidores & 609 & 566 & 542 \\
\hline Insumos e Recursos & 501 & 562 & 527 \\
\hline Ambiente Político e Governo & 586 & 475 & 459 \\
\hline Outras Oportunidades de Negócios & 531 & 488 & 463 \\
\hline Fornecedores & 523 & 505 & 478 \\
\hline Sociedade & $\underline{517}$ & $\underline{428}$ & $\underline{401}$ \\
\hline Meio Ambiente e Sustentabilidade & $\underline{484}$ & $\underline{413}$ & $\underline{391}$ \\
\hline Média & 587,7 & 529,8 & 502,5 \\
\hline Desvio-Padrão & 64,2 & 68,6 & 67,7 \\
\hline
\end{tabular}

$\mathrm{Na}$ tabela anterior, as células com valor em negrito são aquelas com valor superior à média mais (+) um desvio-padrão: Sendo que isso ocorre nos temas Mercado e Demanda e Economia para Importância, e apenas no tema Mercado e Demanda para Importância, Prática e Contribuição. As células com valores grifados são aquelas com valores abaixo da média 
$\underline{\text { menos (-) um desvio-padrão: Sendo que isso ocorre nos temas Sociedade e Meio Ambiente e }}$

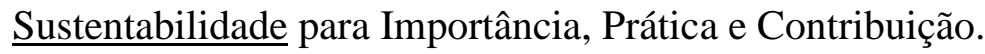

O gráfico a seguir ilustra os resultados da tabela anterior.

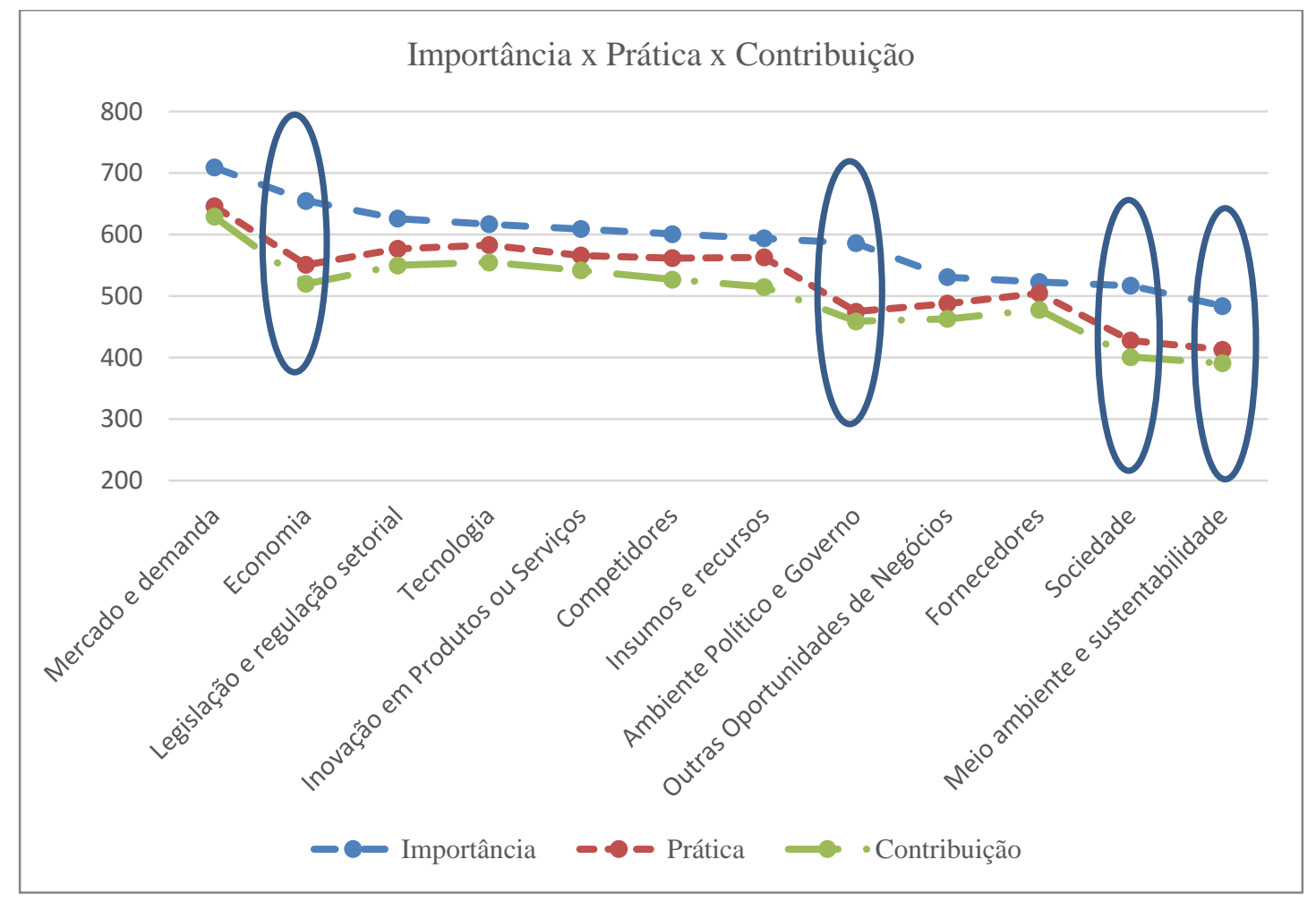

Gráfico 16 - Importância, Prática e Contribuição: Por Temas portadores de incertezas de futuro

Sintetizando os resultados desta seção, o que foi identificado é que os temas considerados mais importantes são:

- Mercado e demanda

- Economia

- Legislação e regulação setorial

- Tecnologia

- Inovação em produtos e serviços

Os temas menos importantes foram (na amostra):

- Meio ambiente e sustentabilidade

- Sociedade 
De certa forma, os temas considerados mais importantes são os que se relacionam diretamente com resultados da organização. E os considerados menos importantes têm relação menos direta com os resultados. Poderia se pensar que Fornecedores têm sim relação direta, o que é fato, contudo, possivelmente o fato de haver contratos, e relacionamentos comerciais estabelecidos, provavelmente mitiga os riscos de incertezas ocorrerem nesse tema.

Já em se tratando de prática de prospecção para analisar os temas, os que são mais analisados são:

- Mercado e demanda

- Tecnologia

- Legislação e regulação setorial

- Inovação em produtos e serviços

- Insumos e recursos

- Competidores

Já os menos analisados foram:

- Meio ambiente e sustentabilidade

- Sociedade

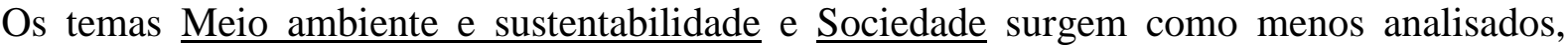
refletindo a menor importância atribuída a estes temas quando se trata de praticar a prospecção.

Quanto à contribuição da prospecção para a análise dos temas, os resultados indicam que os que receberam mais contribuição foram os temas:

- Mercado e demanda

- Tecnologia

- Legislação e regulação setorial

- Inovação em produtos e serviços 
- Competidores

Os que receberam menos contribuição foram:

- Meio ambiente e sustentabilidade

- Sociedade

Dentre os que tiveram menos contribuição da prospecção, Sociedade e Meio ambiente e Sustentabilidade são temas que poderiam ser bem analisados por meio de metodologia prospectiva, contudo nota-se que a prospecção contribui menos nesses temas, se comparado com os outros.

No geral, o tema Mercado e Demanda surge como mais importante em termos de prospecção do futuro, seguido do tema Economia.

Os resultados mostram que a contribuição da prospecção resulta em avaliações menores, comparada com a prática e principalmente com a importância, e isso para todos os temas portadores de incertezas de futuro. A prática, por sua vez, está em nível intermediário de avaliação pelos respondentes. Descritivamente se pode pensar que a prática talvez não esteja sendo realizada ao nível da importância atribuída à prospecção. Em um segundo momento, se pode pensar que a contribuição da prospecção nas decisões em projetos não esteja ao nível do quanto é avaliado que se praticou a prospecção, e menos ainda se comparado com a importância atribuída à prospecção.

Pode ser que isso tenha relação com a avaliação da satisfação com os objetivos atingidos pela prospecção nos projetos estratégicos. Contudo, o constructo satisfação não está amplamente incluído no escopo desta tese, restando recomendar que seja explorado em futuras pesquisas.

As maiores lacunas entre importância e prática ou contribuição ocorrem nos temas Economia, $\underline{\text { Ambiente Político e Governo, }} \underline{\text { Sociedade e finalmente Meio-Ambiente e Sustentabilidade. }}$ Esses temas parecem, descritivamente, gerar mais dificuldade para os respondentes da amostra. Se for analisado pelo grau de importância, talvez economia seja o mais crítico, o que pode estar refletindo a turbulência externa e interna ocorrida nos últimos anos. Pode haver, por hipótese, alguma relação entre economia e ambiente político e governo, porque parte das incertezas econômicas vivenciadas no Brasil pode ter vindo do contexto político recente. 
Trazendo os relatos das entrevistas para compor a análise, foi relatado que possivelmente empresas menores não estejam ao mesmo nível das maiores em relação à prática da prospecção. As opiniões dos entrevistados geraram possíveis explicações, dentre as quais o fato de que nas empresas maiores os comprometimentos de recursos dos projetos estratégicos possam ser maiores. Isto aumenta o risco dos projetos, e por consequência é induzida maior pressão para lidar com incertezas de futuro. Mas é preciso enfatizar que isso (riscos especificamente) não foi estudado como objetivo inicial nesta tese, portanto fica como recomendação para novas pesquisas. Os relatos de cada entrevista podem ser vistos em detalhes mais adiante.

O tema Mercado e demanda está em primeiro lugar em termos de importância, o que é esperado, uma vez que a maioria dos respondentes é do setor privado (quase $96 \%$ dos respondentes).

Fica uma última menção ao tema Meio Ambiente e Sustentabilidade, que está em último em termos de importância. Talvez por ainda não se incluir no campo de atenção das empresas em termos de potenciais impactos, ou porque os respondentes da amostra considerem que esse tema seja menos variável ou turbulento, ou por ser considerado, comparativamente aos outros, de relevância menor. São apenas hipóteses, pois não se podem inferir as causas a partir dos dados coletados.

\subsubsection{Os processos de análise prospectiva dos projetos}

Conforme mencionado no capítulo de revisão de conceitos teóricos desta tese, há recomendações de processos para suporte à análise prospectiva. Esses processos podem fazer uso dos resultados de estudos prospectivos, sendo isto um pressuposto desta tese.

Dessa forma, foram incluídas questões que tratavam da prática desses processos, bem como foi solicitado aos respondentes sua avaliação sobre quanto a prospecção contribuiu para a prática desses processos.

A análise prospectiva dos projetos, por meio desses processos que são recomendados na literatura de prospecção do futuro, pode contribuir para o suporte à tomada de decisões nos projetos estratégicos. 
Os resultados são mostrados a seguir na tabela e gráfico respectivos.

Tabela 16 - Os processos de suporte à análise prospectiva

\begin{tabular}{|l|c|c|c|}
\hline \multicolumn{1}{|c|}{ Processos } & Legenda & \multicolumn{2}{c|}{ Soma das avaliações } \\
\cline { 2 - 4 } & & Prática & Contribuição \\
\hline Análise do alinhamento do projeto com a estratégia da organização & 2 & 648 & 590 \\
\hline $\begin{array}{l}\text { Análise do quanto o projeto pode influenciar os resultados futuros da } \\
\text { organização }\end{array}$ & 5 & 616 & 592 \\
\hline Análise dos contextos futuros dos negócios envolvidos nos projetos & 1 & 547 & 553 \\
\hline Calibração de premissas utilizadas no projeto & 3 & 545 & 541 \\
\hline $\begin{array}{l}\text { Identificação de necessidades de aprimoramento de competências } \\
\text { para implantar o projeto }\end{array}$ & 8 & 529 & 532 \\
\hline Estudo de mudanças necessárias na organização em função do projeto & 7 & 507 & 517 \\
\hline $\begin{array}{l}\text { Definição de sinais ou indicadores que sirvam para monitorar o futuro } \\
\text { acontecendo (ou começando a acontecer) no âmbito da implantação } \\
\text { do projeto }\end{array}$ & 4 & 496 & 508 \\
\hline Exame das incertezas estratégicas envolvidas no projeto & & & 5 \\
\hline $\begin{array}{l}\text { Simulação - colocar pessoas para analisarem a organização dentro do } \\
\text { contexto futuro proporcionado pelo projeto }\end{array}$ & 6 & 408 & 461 \\
\hline
\end{tabular}

A tabela anterior está ordenada decrescentemente pela Prática.

O gráfico a seguir projeta o perfil da diferença entre as avaliações para a Prática e para a Contribuição da prospecção, nos processos de análise prospectiva dos projetos estratégicos.

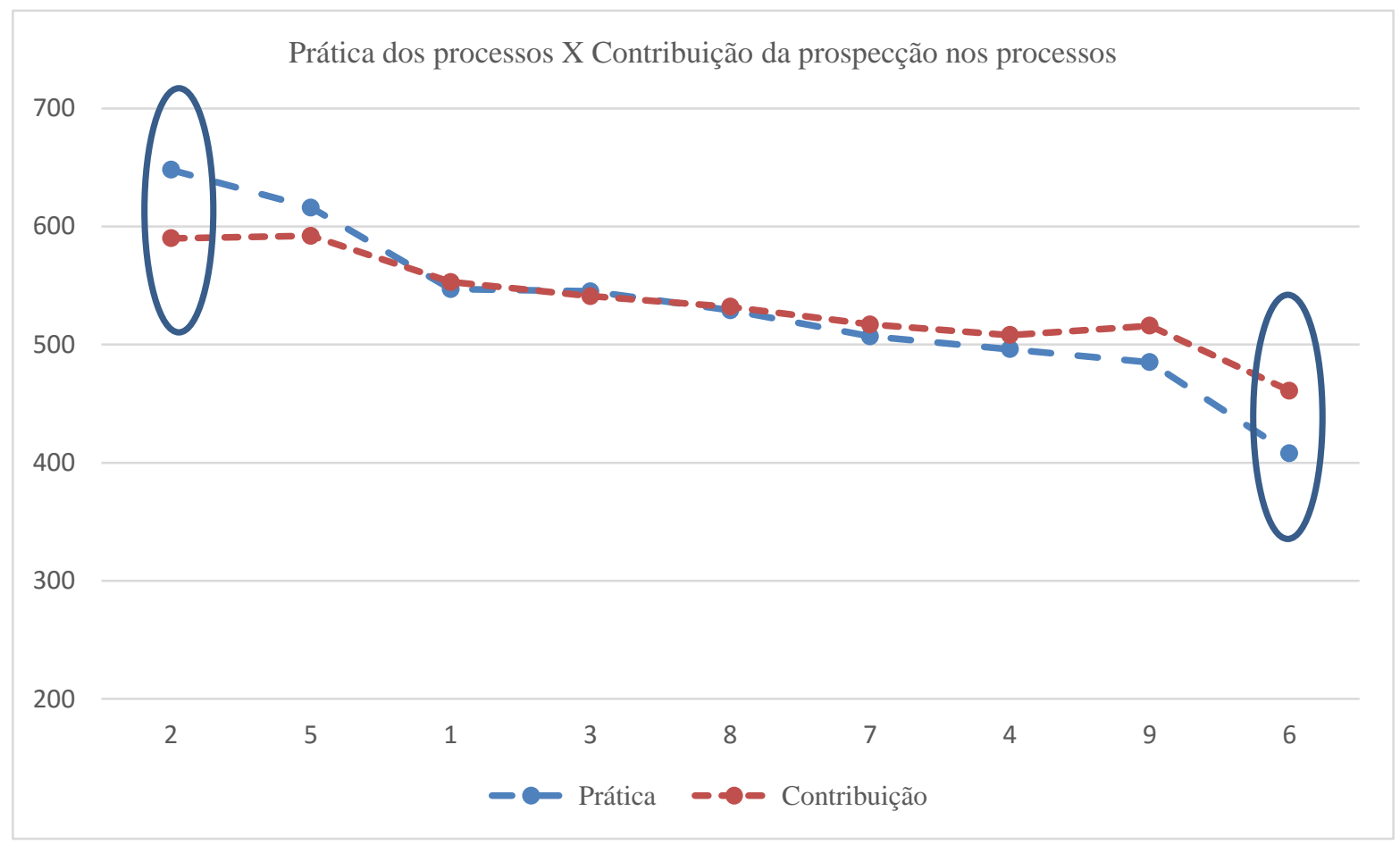

Gráfico 17 - Prática e contribuição de processos de análise prospectiva 
O quadro a seguir contém a legenda numérica do gráfico anterior. Observar que a legenda a seguir se refere ao eixo horizontal do gráfico anterior.

Quadro 10 - Legenda: Processos de análise prospectiva dos projetos

\begin{tabular}{|c|l|}
\hline Legenda & \multicolumn{1}{c|}{ Processos } \\
\hline 2 & Análise do alinhamento do projeto com a estratégia da organização \\
\hline 5 & $\begin{array}{l}\text { Análise do quanto o projeto pode influenciar os resultados futuros da } \\
\text { organização }\end{array}$ \\
\hline 1 & Análise dos contextos futuros dos negócios envolvidos nos projetos \\
\hline 3 & Calibração de premissas utilizadas no projeto \\
\hline 8 & $\begin{array}{l}\text { Identificação de necessidades de aprimoramento de competências para } \\
\text { implantar o projeto }\end{array}$ \\
\hline 7 & Estudo de mudanças necessárias na organização em função do projeto \\
\hline 4 & $\begin{array}{l}\text { Definição de sinais ou indicadores que sirvam para monitorar o futuro } \\
\text { acontecendo (ou começando a acontecer) no âmbito da implantação do projeto }\end{array}$ \\
\hline 9 & Exame das incertezas estratégicas envolvidas no projeto \\
\hline 6 & $\begin{array}{l}\text { Simulação - colocar pessoas para analisarem a organização dentro do contexto } \\
\text { futuro proporcionado pelo projeto }\end{array}$ \\
\hline
\end{tabular}

No gráfico se observa que nos processos $1,3,8,7$ e 4 a contribuição se equipara com a prática. No processo 5 (Análise do quanto o projeto pode influenciar os resultados futuros da organização) e 2 (Análise do alinhamento do projeto com a estratégia da organização) a prática é relativamente melhor avaliada do que sua contribuição, com maior diferença neste último processo. Em outras palavras, quando se analisa se os projetos estratégicos estão alinhados com a estratégia da organização, há certa limitação da contribuição de estudos prospectivos. Isso pode ter relação com o que foi capturado nas entrevistas, quando entrevistados relataram a ocorrência de desconfiança sobre os resultados da prospecção, e também conflitos entre objetivos da prospecção e objetivos de indivíduos ou grupos que participam dos estudos prospectivos dentro da organização. Uma descrição mais detalhada disso pode ser encontrada na parte qualitativa mais adiante, na seção 5.2.

Ainda quanto ao processo 2 (Análise do alinhamento do projeto com a estratégia da organização), a maior diferença pode ser reflexo da dificuldade de se estabelecer uma conexão clara entre a estratégia da organização com os objetivos de um projeto específico. Pode ocorrer de um projeto não ter conexão com a estratégia da organização, ou, pior, pode ocorrer de gestores na organização não conhecerem a estratégia da mesma. Este 
distanciamento pode não ter qualquer relacionamento com a atividade de estudo prospectivo em si.

No processo 9 (Exame das incertezas estratégicas envolvidas nos projetos) a contribuição é melhor avaliada do que a prática. Talvez porque esse tipo de análise possa ser feito sem necessidade de recorrer à prospecção de forma mais estruturada, podendo ser feita por outras formas de análise, como opinião de especialistas ou projeções de executivos. Embora essas formas de análise não deixem de ser prospecção do futuro.

O processo 6 (Simulação - colocar pessoas para analisarem a organização dentro do contexto futuro proporcionado pelo projeto) a contribuição também é melhor avaliada do que sua prática, com maior diferença do que no processo 9 (parágrafo anterior). Por hipótese, seria um indício de que gestores tenham tendência a utilizar esses processos com bastante frequência, e o processo de apoiar as análises sejam realizados adhoc, sob demanda e consultando pessoas para calibrar premissas sem muito registro ou formalização de documentação.

O fato da soma das avaliações da contribuição ser maior do que a soma das avaliações da prática, nos processos 9 e 6, pode ser um indício de que gestores tenham tendência a utilizar esses processos, mas possivelmente haja alguma limitação sobre como apoiar tais processos.

Ao serem perguntados, de forma geral, o quanto a prospecção do futuro contribuiu para os processos, os respondentes geraram resultados com predominância para os graus Moderadamente e Muito, com 74,6\%, conforme tabela e gráfico a seguir.

Tabela 17 - Contribuição da prospecção do futuro nos processos de análise

\begin{tabular}{|l|c|c|c|}
\hline $\begin{array}{l}\text { De forma geral, quanto a prospecção } \\
\text { contribuiu para os processos }\end{array}$ & Frequência & \% & \% acumulado \\
\hline Nada & 2 & 1,3 & 1,3 \\
\hline Pouco & 17 & 10,8 & 12,1 \\
\hline Moderadamente & 61 & 38,9 & 51,0 \\
\hline Muito & 56 & 35,7 & 86,6 \\
\hline Extremamente & 21 & 13,4 & 100,0 \\
\hline Total & $\mathbf{1 5 7}$ & $\mathbf{1 0 0}$ & \\
\hline
\end{tabular}




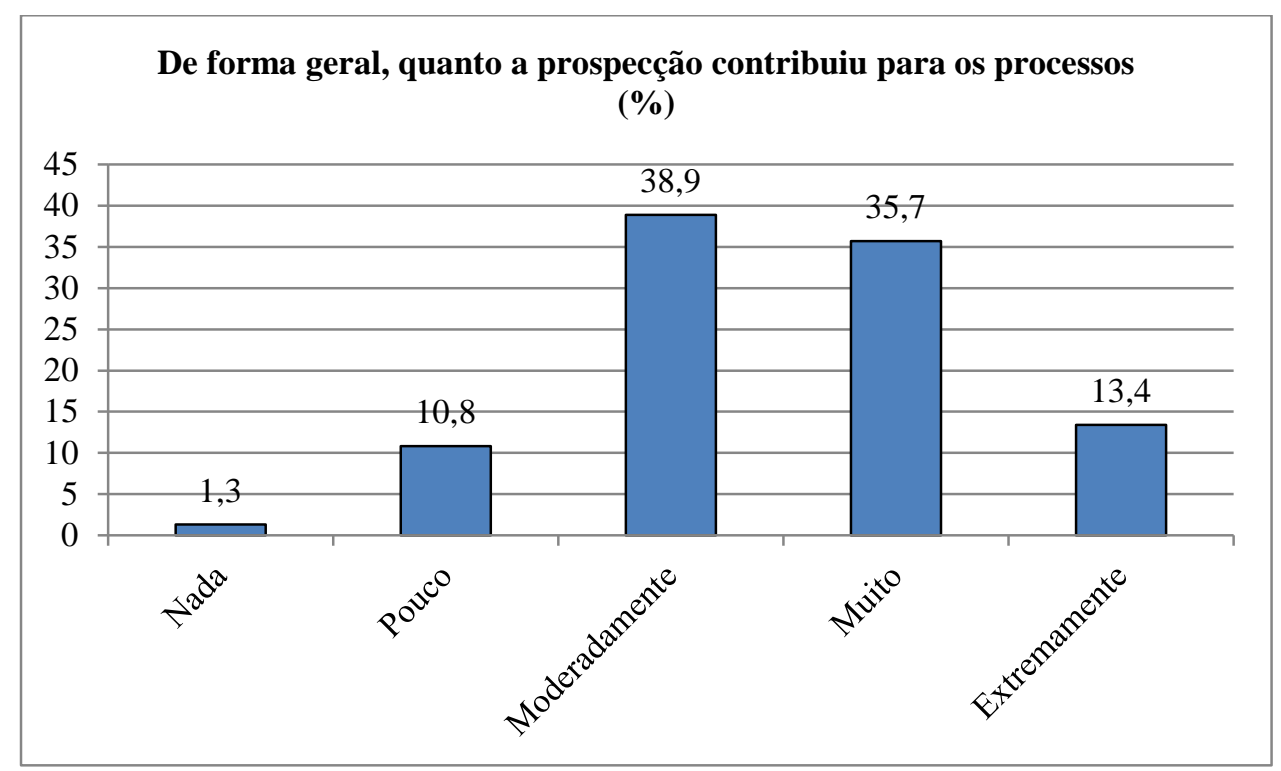

Gráfico 18 - Contribuição da prospecção do futuro nos processos de análise (\%)

Se por um lado é positivo que $88 \%$ que declaram ter contribuído de moderadamente a extremamente, é importante observar que, para $12 \%$ a contribuição foi pouca ou nula, ou ainda que para metade dos respondentes, ela contribuiu de pouco a moderadamente nos processos de análise dos projetos estratégicos. Portanto, há limitações no processo de utilização dos resultados da prospecção.

\subsubsection{Contribuição da análise prospectiva na estratégia}

A tabela a seguir (distribuição acumulada) mostra os resultados da análise de como a prospecção contribui individualmente nos processos, comparada com a contribuição dela em todos os processos de forma geral. Os processos desta seção são diferentes dos tratados na seção anterior, porque nestes o foco está mais orientado para aspectos da estratégia da organização. Já os processos da seção anterior têm foco mais nas análises prospectivas de suporte a decisões nos projetos. 
Tabela 18 - Contribuição dos processos: Específicos versus Geral

\begin{tabular}{|c|c|c|c|c|c|c|}
\hline & $\begin{array}{c}\text { Identificação } \\
\text { dos temas } \\
\text { que } \\
\text { representam } \\
\text { lacunas de } \\
\text { análise, } \\
\text { podendo } \\
\text { provocar } \\
\text { pontos cegos } \\
\text { na análise } \\
\text { do projeto }\end{array}$ & $\begin{array}{c}\text { Aprimoramento } \\
\text { do processo de } \\
\text { tomada de } \\
\text { decisão no } \\
\text { projeto, por } \\
\text { meio da análise } \\
\text { das incertezas } \\
\text { de futuro }\end{array}$ & $\begin{array}{c}\text { Identificação } \\
\text { de quais os } \\
\text { principais } \\
\text { temas que } \\
\text { devem ser } \\
\text { monitorados } \\
\text { após o início } \\
\text { da } \\
\text { implantação } \\
\text { do projeto }\end{array}$ & $\begin{array}{c}\text { Identificação } \\
\text { de quais as } \\
\text { principais } \\
\text { tendências e } \\
\text { eventos do } \\
\text { ambiente } \\
\text { futuro, } \\
\text { estimando as } \\
\text { chances de } \\
\text { suas } \\
\text { ocorrências }\end{array}$ & $\begin{array}{c}\text { Análise de } \\
\text { quais as } \\
\text { possíveis } \\
\text { consequências } \\
\text { de uma } \\
\text { alternativa de } \\
\text { decisão no } \\
\text { projeto }\end{array}$ & $\begin{array}{c}\text { De forma } \\
\text { geral, no } \\
\text { último } \\
\text { projeto, } \\
\text { quanto a } \\
\text { prospecção } \\
\text { contribuiu } \\
\text { nos } \\
\text { processos } \\
\text { acima }\end{array}$ \\
\hline Nada & 1,3 & 3,2 & 1,3 & 2,5 & 3,2 & 1,3 \\
\hline Pouco & $\mathbf{2 2 , 3}$ & 15,3 & 14,6 & 16,6 & 17,8 & $\mathbf{1 2 , 1}$ \\
\hline Moderadamente & 59,9 & 47,8 & 42 & 46,5 & 48,4 & 51 \\
\hline Muito & 87,9 & 84,7 & 85,4 & 80,9 & 86,6 & 86,6 \\
\hline Extremamente & 100 & 100 & 100 & 100 & 100 & 100 \\
\hline
\end{tabular}

Através da prova de Kolmogorov-Smirnov para uma amostra, conclui-se que apenas para o processo - "A prospecção contribuiu para identificação dos temas que apresentam lacunas de análise, podendo provocar pontos cegos na análise do projeto" - é possível se diferenciar a contribuição da prospecção neste processo específico, se comparado com a contribuição geral da prospecção em todos os processos $(\mathrm{D}=0,102>0,097$ (valor crítico) a $\alpha=0,10$ ). A prospecção do futuro neste processo tem, descritivamente, menor contribuição do que em outros processos. Isso pode ser reflexo de ser pouco praticada a análise de lacunas nos projetos, o que significaria que a prospecção, possivelmente, não inclui todos os temas estratégicos relevantes na análise.

Nas entrevistas foi detectado que conflitos de interesses entre objetivos individuais dos participantes do estudo prospectivo podem gerar resultados indesejados. Por exemplo, participantes da área comercial tenderiam a serem conservadores quanto ao potencial futuro de novos produtos. Outro aspecto capturado nas entrevistas é que as pessoas que tomam as decisões, e assumem as respectivas responsabilidades, precisam participar das análises, do contrário, o apoio às decisões fica prejudicado. Os dados quantitativos coletados indicam que nem todos os temas portadores de incertezas do futuro são examinados com o mesmo grau de profundidade. Dessa forma, é possível que a identificação de lacunas de análise não seja bem tratada pelos gestores em organizações. Em outras palavras, esta poderia ser uma das limitações nos processos de análise prospectiva estratégica, e seria importante mitigar seus 
efeitos reforçando-se as recomendações metodológicas sobre este tema nos estudos prospectivos.

Não foi possível diferenciar a contribuição da prospecção em outros processos específicos, comparada com a contribuição dela de forma geral, pela Prova de Kolmogorov-Smirnov (D< 0,097).

\subsubsection{A avaliação da prática da prospecção}

Passa-se agora para a análise dos resultados relativos às afirmações colocadas no questionário, que buscaram capturar a opinião dos respondentes sobre a capacidade dos gestores de praticar a prospecção. Também se desejava verificar sua capacidade de utilizar os resultados nas análises de projetos, e neste caso específico, os dados mostram que os gestores da amostra entendem que as análises e conclusões da prospecção foram utilizadas nas decisões. No total foram cinco afirmações, as quais estão descritas no quadro mais adiante.

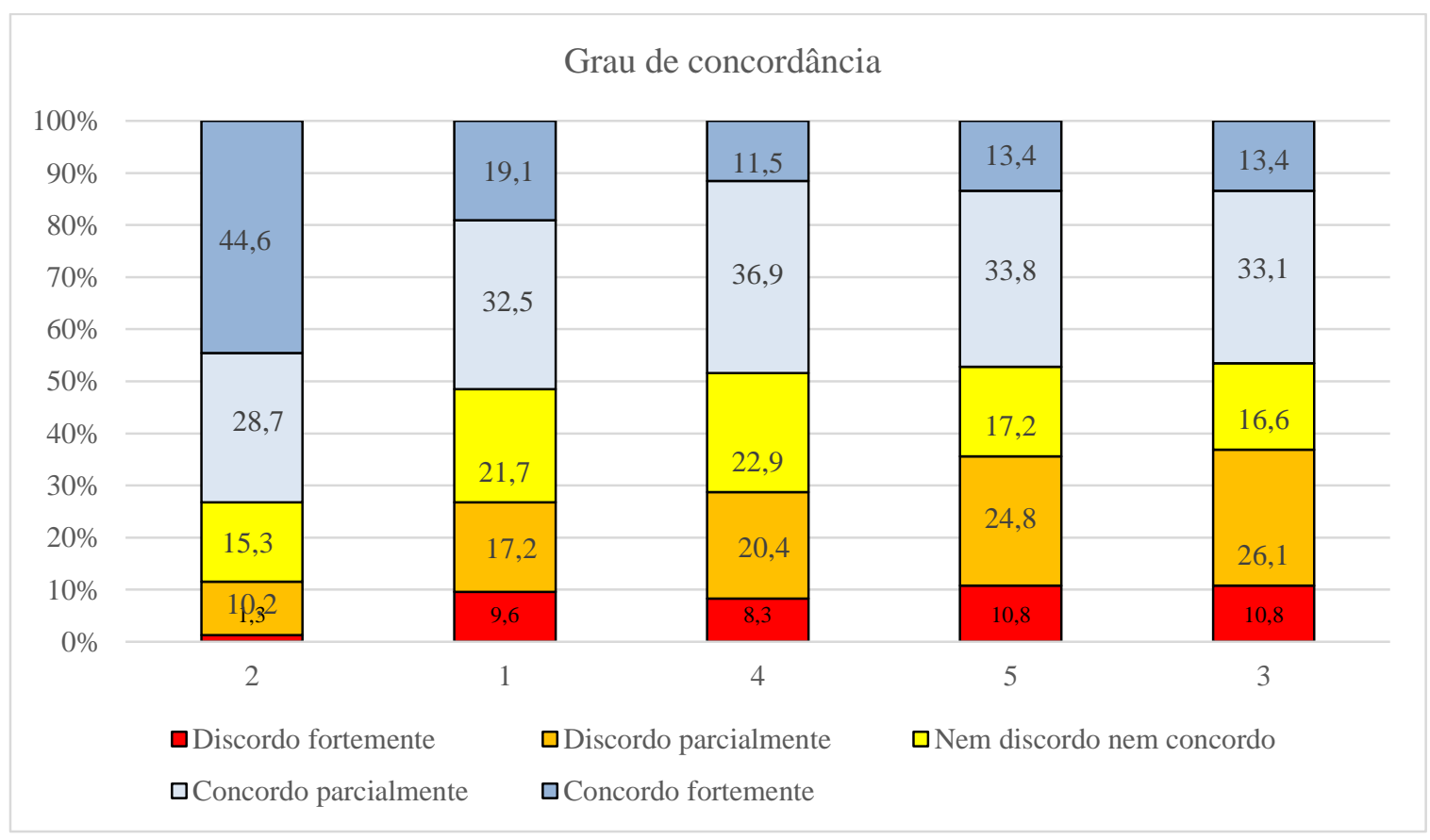

Gráfico 19 - Grau de concordância com as afirmações sobre o domínio da prática de prospecção (\%)

Observando-se o gráfico anterior, pode-se perceber que os gestores da amostra tendem a concordar que os resultados de estudos prospectivos são, efetivamente, utilizados nas decisões (afirmação 2). Entretanto, verifica-se que para as afirmações 1, 4, 5 e 3 o grau de concordância é, descritivamente, mais baixo. As afirmações podem ser vistas na legenda, que aqui segue (eixo horizontal do gráfico anterior). 
Quadro 11 - Afirmações para avaliar a prospecção

\begin{tabular}{|c|c|}
\hline & Afirmação \\
\hline 2 & As análises e conclusões da prospecção foram utilizadas na tomada de decisões \\
\hline 1 & No projeto foi verificado se havia pontos cegos nas análises \\
\hline 4 & A prospecção do futuro foi adequadamente praticada no projeto \\
\hline 5 & $\begin{array}{l}\text { De forma geral, os gestores de minha organização estão preparados para lidar com } \\
\text { incertezas de futuro }\end{array}$ \\
\hline 3 & $\begin{array}{l}\text { O conhecimento de como utilizar os métodos de prospecção estava adequado para os } \\
\text { desafios do projeto }\end{array}$ \\
\hline
\end{tabular}

As outras quatro afirmações geraram maiores graus de discordância, se comparadas com a afirmação 2. Essas afirmações (1, 4, 5 e 3) foram colocadas no questionário para verificar se os gestores da amostra avaliam que sua organização estava preparada para lidar com prospecção do futuro. E os resultados mostram que talvez isso não seja uma realidade amplamente disseminada.

De forma descritiva, há maior concordância quanto à utilização das análises e conclusões da prospecção ser utilizada na tomada de decisões (concorda fortemente / parcialmente: 73,3\%). Enquanto as demais afirmações variam de 46,5\% a 51,6\% o grau de concordância. Ou seja, descritivamente, é possível notar que a prospecção do futuro tem finalidade, mas nem sempre ela é exercida de forma satisfatória.

Para a afirmação 1, a concordância cai, indicando que a análise de pontos cegos é uma atividade que não foi bem conduzida nos projetos.

Nas afirmações 4, 5 e 3, o resultado é ainda pior. A prospecção não foi sempre bem praticada, os gestores podem não estar bem preparados para lidar com incertezas de futuro, e principalmente o conhecimento de como utilizar os métodos prospectivos pode não estar adequado nas organizações.

Essa questão foi colocada no questionário para capturar como os respondentes da amostra avaliam a prática da prospecção, tratando-se do bloco Matriz de Avaliação do modelo de suporte. Lembrando que Chermack (2011) apontou que as pesquisas acadêmicas sobre 
cenários pouco ou nada analisaram os aspectos da avaliação dos projetos de cenários, o campo de oportunidade para pesquisa pode ser também ser reforçado com esse resultado aqui obtido.

As entrevistas indicaram que:

- É difícil engajar pessoas em prospecção.

- Pode haver falta de conhecimento para conduzir estudos prospectivos.

- Os objetivos dos projetos prospectivos são difíceis de alinhar com os dos indivíduos que participam nas análises.

- O ceticismo ou desconfiança dos tomadores de decisão são indiretamente proporcionais ao grau em que os mesmos se envolvem na prospecção.

- É possível evitar lacunas nas análises, mas isso envolve dedicação e custos.

- Deve se evitar o problema de falta de conhecimento da metodologia, sendo possível fazer isso, mas é preciso ter recursos humanos com a expertise sobre prospecção.

- A estrutura de governança da organização, e o processo decisório precisam ser considerados antes de se executar projetos de prospecção.

- A prospecção deve ser realizada de forma contínua, talvez ela não deva ter começo, meio e fim.

Esses resultados são indícios de que seja necessária alguma forma de apoiar decisões por meio de aprimoramento da prática de prospecção. 


\subsubsection{Análise de agrupamentos}

Para explorar mais profundamente os resultados da parte quantitativa, foi desenvolvida uma análise de agrupamentos de respondentes.

Uma vez que a amostra de respondentes se apresentou, relativamente, com grande dispersão de respostas, foi realizada a análise de agrupamentos, com o objetivo de separar os respondentes em grupos mais homogêneos. Essa técnica é aplicável quando se deseja segregar elementos, no caso desta tese foram os respondentes, em grupos homogêneos internamente, e que se comparados os diferentes grupos eles sejam heterogêneos entre si. As características dos elementos de um grupo se distinguem das características dos outros grupos. É uma técnica exploratória e descritiva, não sendo aplicada para estudos inferenciais (FÁVERO et $a l, 2009)$. Ela é adequada para o desenvolvimento desta tese, que é um estudo exploratório e descritivo.

A análise de agrupamentos ou análise de cluster é uma técnica estatística multivariada, aplicada neste estudo, em relação a todas as variáveis com escala de likert e que caracterizam a importância da prospecção, processos e análises efetuadas no âmbito da prática da prospecção, e finalmente suas contribuições (questões: 3 a 9 do questionário).

Para formar os agrupamentos, optou-se pelas técnicas hierárquicas - Método de Wards. As técnicas hierárquicas apresentam como resultado uma figura - dendograma - na qual é possível observar alterações de níveis de similaridade para as sucessivas fusões realizadas na amostra de respondentes. O dendograma representa a ordem em que os respondentes da pesquisa foram unidos num mesmo agrupamento.

A análise de cluster foi realizada em dois processos distintos:

(1) no primeiro, usaram-se os dados originais coletados e;

(2) num segundo procedimento, os dados foram somados, conforme descrito a seguir:

(2.1) Respostas referentes às expressões das questões 3 (importância de se prospectar sobre os temas portadores de incertezas de futuro), 4 (prática da prospecção para 
tratar os temas) e 5 (contribuição da prospecção nas decisões dos projetos estratégicos) - este passo resultou em 13 variáveis;

(2.2) Soma das respostas referentes às expressões das questões 6 (prática dos processos de análise prospectiva de projetos utilizando a prospecção do futuro) e 7 (contribuição da prospecção nos processos de análise prospectiva de projetos). Este processo resultou em 9 variáveis;

(2.3) Soma da questão 8 (processos de análise prospectiva estratégica) e soma da questão 9 (afirmações sobre a qualidade da atividade de prospecção do futuro).

Em ambos os processos, as análises utilizaram a medida de distância euclidiana quadrática, indicada para variáveis intervalares, e método de Wards. Estes dois encaminhamentos, forneceram resultados muito próximos (89\% de concordância entre os dois processos, ou 19 casos discordantes), com $\chi 2=73,917(\mathrm{p}=0,000)$, concluindo-se que os procedimentos não são independentes. A tabela a seguir ilustra os resultados dos dois processos.

Tabela 19 - Teste de agrupamento de respondentes por duas abordagens

\begin{tabular}{|c|l|c|c|c|}
\cline { 3 - 4 } \multicolumn{2}{c|}{} & \multicolumn{2}{c|}{ Wards 2 } & \multirow{2}{*}{ Total } \\
\hline \multirow{2}{*}{$\mathbf{1}$} & frequência & 1 & $\mathbf{2}$ & \\
\hline \multirow{2}{*}{$\mathbf{2}$} & \%total & 107 & 3 & $\mathbf{1 1 0}$ \\
& frequência & 16 & 31 & $\mathbf{4 7}$ \\
& \% total & $10,19 \%$ & $19,75 \%$ & $\mathbf{2 9 , 9 \%}$ \\
\hline \multirow{2}{*}{ Total } & frequência & $\mathbf{1 2 3}$ & $\mathbf{3 4}$ & $\mathbf{1 5 7}$ \\
& \%total & $\mathbf{7 8 , 3 4 \%}$ & $\mathbf{2 1 , 6 6 \%}$ & $\mathbf{1 0 0 \%}$ \\
\hline
\end{tabular}

Da tabela anterior nota-se que há somente $19(16+3)$ casos discordantes, representando $12,1 \%$ apenas. Optou-se, então, pelos resultados obtidos pelos dados originais. E posteriormente são discutidas as características dos clusters.

Em resumo, obteve-se por tamanho dos clusters:

- Cluster 1: 110 casos (ou 70,1\%)

- Cluster 2: 47 casos (ou 29,9\%)

Por resultado da análise de agrupamento, a similaridade entre os casos (respondentes) é identificada pela altura, valor do eixo da distância redimensionada (ver no dendograma a seguir). Observar que a altura, na figura, está na horizontal. 


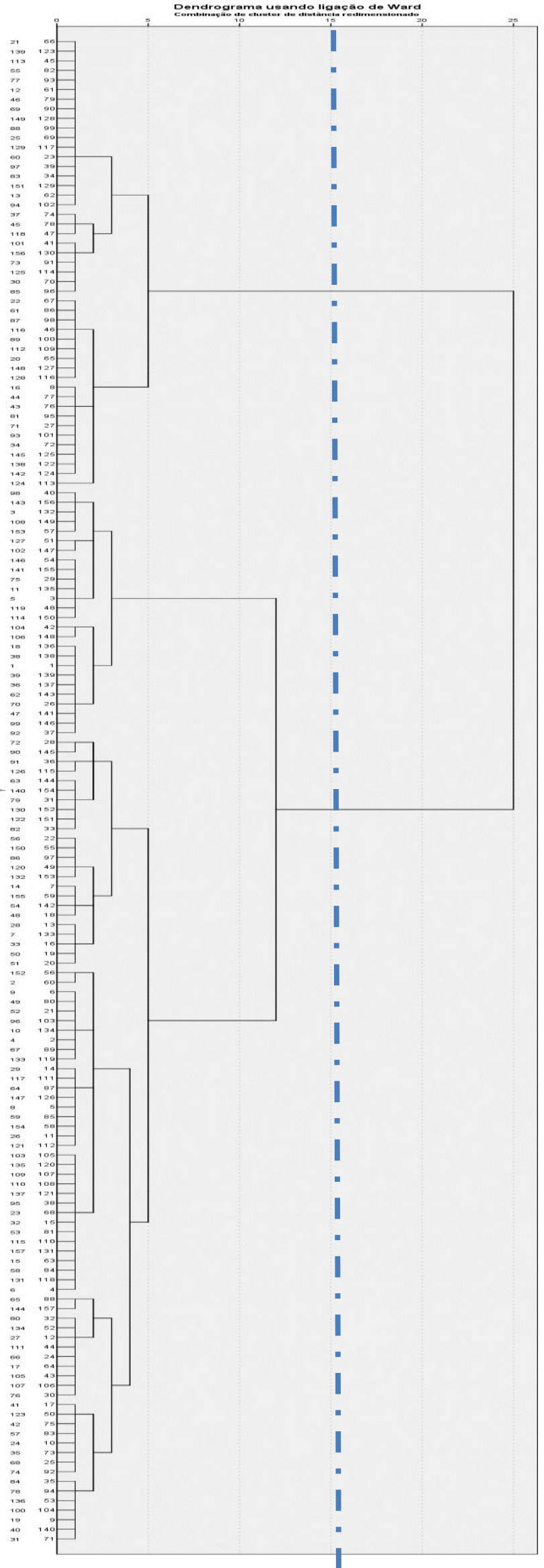

Ilustração 18 - Dendograma da análise de agrupamento 
Ao se analisar a formação hierárquica progressiva dos sucessivos agrupamentos, nota-se que o dendograma mostra um grande salto (o maior) ao unir dois agrupamentos em um, separados pela reta pontilhada na vertical (ver figura anterior), revelando que esta última fusão reúne dois grupos pouco similares, o que não é desejado, pois os respondentes desses dois grupos não são similares. Ou seja, a melhor alternativa foi dividir a amostra em dois grupos distintos, preservando os agrupamentos imediatamente anteriores a esta última junção realizada antes do grande salto. Como mencionado, esses grupos estão identificados pela reta pontilhada vertical, que corta o dendograma na ilustração anterior.

\subsubsection{Os agrupamentos e suas características}

Os dois agrupamentos resultantes foram analisados em relação às características dos respondentes que os integram, e os resultados são mostrados nas tabelas a seguir.

Tabela 20 - Forma de controle da empresa: Nos dois agrupamentos

\begin{tabular}{|l|c|c|c|c|}
\hline \multicolumn{2}{|c|}{} & \multicolumn{2}{c|}{ cluster } & Total \\
\hline Forma de controle da empresa & & $\mathbf{1}$ & $\mathbf{2}$ & \\
\hline Sociedade de capital aberto & $\mathrm{n}$ & 24 & 22 & 46 \\
& $\%$ & $23,8 \%$ & $\mathbf{4 7 , 8 \%}$ & $31,3 \%$ \\
\hline Sociedade de capital fechado & $\mathrm{n}$ & 35 & 11 & 46 \\
& $\%$ & $34,7 \%$ & $23,9 \%$ & $31,3 \%$ \\
\hline Limitada & $\mathrm{n}$ & 42 & 13 & 55 \\
& $\%$ & $\mathbf{4 1 , 6 \%}$ & $28,3 \%$ & $37,4 \%$ \\
\hline Total & $\mathrm{n}$ & 101 & 46 & 147 \\
& $\%$ & $100,0 \%$ & $100,0 \%$ & $100,0 \%$ \\
\hline
\end{tabular}

Nota-se que no Cluster 1 há maior predominância de empresas com capital fechado e limitadas. Enquanto que no Cluster 2, predominam empresas de capital aberto. O resultado faz sentido, uma vez que a diligência esperada de executivos de empresas de capital aberto é esperada que seja proporcional à quantidade de acionistas da empresa. Isso também pode ter relação com o porte da empresa.

Nas entrevistas realizadas foi relatado que empresas grandes apresentam processo estruturado de suporte à tomada de decisão, os quais são seguidos para facilitar o processo de análise. Uma forma de análise e comunicação comum pode contribuir para que as diferentes partes possam compreender melhor o que está sendo foco de análise. Empresas com mais recursos humanos também podem estabelecer processo de gestão de conhecimento, o que pode ser um 
fator que contribui para melhor prática da prospecção. Os grupos formados, pela quantidade de funcionários, mostram o perfil, conforme a tabela a seguir.

Tabela 21 - Quantidade de funcionários da empresa: Nos dois agrupamentos

\begin{tabular}{|c|c|c|c|c|}
\hline \multicolumn{2}{|l|}{ Quantidade de funcionários da empresa } & \multicolumn{2}{|c|}{ cluster } & \multirow[t]{2}{*}{ Total } \\
\hline & & 1 & 2 & \\
\hline \multirow[t]{2}{*}{ Menos de 50} & $\mathrm{n}$ & 20 & 6 & 26 \\
\hline & $\%$ & $19,0 \%$ & $12,8 \%$ & $17,1 \%$ \\
\hline \multirow[t]{2}{*}{ Entre 51 e 100} & $\mathrm{n}$ & 11 & 1 & 12 \\
\hline & $\%$ & $10,5 \%$ & $2,1 \%$ & $7,9 \%$ \\
\hline \multirow{2}{*}{ Entre 101 e 300} & $\mathrm{n}$ & 12 & 5 & 17 \\
\hline & $\%$ & $11,4 \%$ & $10,6 \%$ & $11,2 \%$ \\
\hline \multirow[t]{2}{*}{ Entre 301 e 500} & $\mathrm{n}$ & 8 & 4 & 12 \\
\hline & $\%$ & $7,6 \%$ & $8,5 \%$ & $7,9 \%$ \\
\hline \multirow[t]{2}{*}{ Entre 501 e 1000} & $\mathrm{n}$ & 15 & 3 & 18 \\
\hline & $\%$ & $14,3 \%$ & $6,4 \%$ & $11,8 \%$ \\
\hline \multirow{2}{*}{ Entre 1001 e 2000} & $\mathrm{n}$ & 10 & 4 & 14 \\
\hline & $\%$ & $9,5 \%$ & $8,5 \%$ & $9,2 \%$ \\
\hline \multirow[t]{2}{*}{ Entre 2001 e 3000} & $\mathrm{n}$ & 6 & 4 & 10 \\
\hline & $\%$ & $5,7 \%$ & $8,5 \%$ & $6,6 \%$ \\
\hline \multirow[t]{2}{*}{ Entre 3001 e 4000} & $\mathrm{n}$ & 2 & 2 & 4 \\
\hline & $\%$ & $1,9 \%$ & $4,3 \%$ & $2,6 \%$ \\
\hline \multirow[t]{2}{*}{ Entre 4001 e 5000} & $\mathrm{n}$ & 3 & 1 & 4 \\
\hline & $\%$ & $2,9 \%$ & $2,1 \%$ & $2,6 \%$ \\
\hline \multirow[t]{2}{*}{ Entre 5001 e 6000} & $\mathrm{n}$ & 3 & 3 & 6 \\
\hline & $\%$ & $2,9 \%$ & $6,4 \%$ & $3,9 \%$ \\
\hline \multirow[t]{2}{*}{ Entre 8001 e 9000} & $\mathrm{n}$ & 2 & 0 & 2 \\
\hline & $\%$ & $1,9 \%$ & $0,0 \%$ & $1,3 \%$ \\
\hline \multirow[t]{2}{*}{ Entre 9001 e 10000} & $\mathrm{n}$ & 1 & 0 & 1 \\
\hline & $\%$ & $1,0 \%$ & $0,0 \%$ & $0,7 \%$ \\
\hline \multirow[t]{2}{*}{ Entre 10001 e 15000} & $\mathrm{n}$ & 4 & 1 & 5 \\
\hline & $\%$ & $3,8 \%$ & $2,1 \%$ & $3,3 \%$ \\
\hline \multirow[t]{2}{*}{ Entre 15001 e 20000} & $\mathrm{n}$ & 3 & 4 & 7 \\
\hline & $\%$ & $2,9 \%$ & $8,5 \%$ & $4,6 \%$ \\
\hline \multirow[t]{2}{*}{ Acima de 20000} & $\mathrm{n}$ & 5 & 9 & 14 \\
\hline & $\%$ & $4,8 \%$ & $19,1 \%$ & $9,2 \%$ \\
\hline \multirow[t]{2}{*}{ Total } & $\mathrm{n}$ & 105 & 47 & 152 \\
\hline & $\%$ & $100,0 \%$ & $100,0 \%$ & $100,0 \%$ \\
\hline
\end{tabular}

Prova de Kolmogorov-Smirnov, $\mathrm{p}=0,056$

Obs.: Não houve respondentes para as faixas de quantidade de funcionários entre 6.001 e 7.000 e entre 7.001 e 8.000 . 
Pelo faturamento, observa-se que o agrupamento 2 apresenta proporcionalmente mais empresas de maior faturamento, se comparado com o agrupamento 1.

Tabela 22 - Faturamento da empresa: Nos dois agrupamentos

\begin{tabular}{|c|c|c|c|c|}
\hline \multirow[b]{2}{*}{ Faturamento anual da empresa no Brasil } & & \multicolumn{2}{|c|}{ cluster } & \multirow[t]{2}{*}{ Total } \\
\hline & & 1 & 2 & \\
\hline \multirow[t]{2}{*}{ menos de 10 milhões de reais } & $\mathrm{n}$ & 15 & 5 & 20 \\
\hline & $\%$ & $14,4 \%$ & $10,6 \%$ & $13,2 \%$ \\
\hline \multirow[t]{2}{*}{ de 10 a 20 milhões de reais } & $\mathrm{n}$ & 11 & 2 & 13 \\
\hline & $\%$ & $10,6 \%$ & $4,3 \%$ & $8,6 \%$ \\
\hline \multirow[t]{2}{*}{ de 20 a 50 milhões de reais } & $\mathrm{n}$ & 9 & 0 & 9 \\
\hline & $\%$ & $8,7 \%$ & $0,0 \%$ & $6,0 \%$ \\
\hline \multirow[t]{2}{*}{ de 50 a 100 milhões de reais } & $\mathrm{n}$ & 4 & 3 & 7 \\
\hline & $\%$ & $3,8 \%$ & $6,4 \%$ & $4,6 \%$ \\
\hline \multirow[t]{2}{*}{ de 100 a 300 milhões de reais } & $\mathrm{n}$ & 12 & 2 & 14 \\
\hline & $\%$ & $11,5 \%$ & $4,3 \%$ & $9,3 \%$ \\
\hline \multirow[t]{2}{*}{ de 300 a 500 milhões de reais } & $\mathrm{n}$ & 10 & 5 & 15 \\
\hline & $\%$ & $9,6 \%$ & $10,6 \%$ & $9,9 \%$ \\
\hline \multirow[t]{2}{*}{ de 500 milhões a 1 bilhão de reais } & $\mathrm{n}$ & 12 & 6 & 18 \\
\hline & $\%$ & $11,5 \%$ & $12,8 \%$ & $11,9 \%$ \\
\hline \multirow[t]{2}{*}{ de 1 a 2 bilhões de reais } & $\mathrm{n}$ & 12 & 6 & 18 \\
\hline & $\%$ & $11,5 \%$ & $12,8 \%$ & $11,9 \%$ \\
\hline \multirow[t]{2}{*}{ de 2 a 3 bilhões de reais } & $\mathrm{n}$ & 4 & 3 & 7 \\
\hline & $\%$ & $3,8 \%$ & $6,4 \%$ & $4,6 \%$ \\
\hline \multirow[t]{2}{*}{ de 3 a 5 bilhões de reais } & $\mathrm{n}$ & 3 & 1 & 4 \\
\hline & $\%$ & $2,9 \%$ & $2,1 \%$ & $2,6 \%$ \\
\hline \multirow[t]{2}{*}{ de 5 a 7 bilhões de reais } & $\mathrm{n}$ & 1 & 2 & 3 \\
\hline & $\%$ & $1,0 \%$ & $4,3 \%$ & $2,0 \%$ \\
\hline \multirow[t]{2}{*}{ de 7 a 10 bilhões de reais } & $\mathrm{n}$ & 1 & 1 & 2 \\
\hline & $\%$ & $1,0 \%$ & $2,1 \%$ & $1,3 \%$ \\
\hline \multirow[t]{2}{*}{ de 10 a 13 bilhões de reais } & $\mathrm{n}$ & 2 & 2 & 4 \\
\hline & $\%$ & $1,9 \%$ & $4,3 \%$ & $2,6 \%$ \\
\hline \multirow[t]{2}{*}{ de 13 a 16 bilhões de reais } & $\mathrm{n}$ & 2 & 0 & 2 \\
\hline & $\%$ & $1,9 \%$ & $0,0 \%$ & $1,3 \%$ \\
\hline \multirow[t]{2}{*}{ de 16 a 20 bilhões de reais } & $\mathrm{n}$ & 1 & 1 & 2 \\
\hline & $\%$ & $1,0 \%$ & $2,1 \%$ & $1,3 \%$ \\
\hline \multirow[t]{2}{*}{ de 20 a 25 bilhões de reais } & $\mathrm{n}$ & 0 & 2 & 2 \\
\hline & $\%$ & $0,0 \%$ & $4,3 \%$ & $1,3 \%$ \\
\hline \multirow[t]{2}{*}{ de 25 a 30 bilhões de reais } & $\mathrm{n}$ & 1 & 1 & 2 \\
\hline & $\%$ & $1,0 \%$ & $2,1 \%$ & $1,3 \%$ \\
\hline \multirow[t]{2}{*}{ acima de 30 bilhões de reais } & $\mathrm{n}$ & 4 & 5 & 9 \\
\hline & $\%$ & $3,8 \%$ & $10,6 \%$ & $6,0 \%$ \\
\hline \multirow[t]{2}{*}{ Total } & $\mathrm{n}$ & 104 & 47 & 151 \\
\hline & $\%$ & $100,0 \%$ & $100,0 \%$ & $100,0 \%$ \\
\hline
\end{tabular}


O horizonte de tempo também caracteriza diferenças entre os grupos. No grupo 2 o horizonte de tempo dos projetos estratégicos é maior do que no grupo 1.

Tabela 23 - Horizonte de tempo da prospecção no último projeto estratégico: Nos dois agrupamentos

\begin{tabular}{|l|c|c|c|c|}
\hline & & \multicolumn{2}{|c|}{ cluster } & Total \\
\hline Horizonte de tempo da prospecção no & & $\mathbf{1}$ & $\mathbf{2}$ & \\
\hline último projeto estratégico & & & & \\
\hline até 6 meses & $\mathrm{n}$ & 9 & 3 & 12 \\
& $\%$ & $8,3 \%$ & $6,4 \%$ & $7,7 \%$ \\
\hline de 6 meses a 1 ano & $\mathrm{n}$ & 17 & 9 & 26 \\
& $\%$ & $15,6 \%$ & $19,1 \%$ & $16,7 \%$ \\
\hline de 1 a 2 anos & $\mathrm{n}$ & 22 & 5 & 27 \\
& $\%$ & $\mathbf{2 0 , 2 \%}$ & $10,6 \%$ & $17,3 \%$ \\
\hline de 2 a 3 anos & $\mathrm{n}$ & 18 & 5 & 23 \\
& $\%$ & $\mathbf{1 6 , 5 \%}$ & $10,6 \%$ & $14,7 \%$ \\
\hline de 3 a 5 anos & $\mathrm{n}$ & 31 & 8 & 39 \\
& $\%$ & $\mathbf{2 8 , 4 \%}$ & $\mathbf{1 7 , 0 \%}$ & $25,0 \%$ \\
\hline de 5 a 10 anos & $\mathrm{n}$ & 10 & 12 & 22 \\
& $\%$ & $9,2 \%$ & $\mathbf{2 5 , 5 \%}$ & $14,1 \%$ \\
\hline mais de 10 anos & $\mathrm{n}$ & 2 & 5 & 7 \\
& $\%$ & $1,8 \%$ & $\mathbf{1 0 , 6 \%}$ & $4,5 \%$ \\
\hline Total & $\mathrm{n}$ & 109 & 47 & 156 \\
& $\%$ & $100,0 \%$ & $100,0 \%$ & $100,0 \%$ \\
\hline
\end{tabular}

Prova de Kolmogorov-Smirnov $\quad \mathrm{p}=0,031$

Em síntese, de acordo com os resultados apresentados, a forma de controle da empresa, o faturamento anual, o número de funcionários e o horizonte de tempo da prospecção são variáveis que diferenciam os dois agrupamentos $(\mathrm{p}<0,10)$.

E por decorrência dessa análise de agrupamentos, é possível classificar os clusters como:

Cluster1: Predominam empresas com menor faturamento anual, menor número de

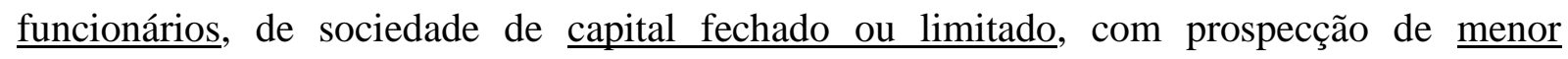
horizonte de tempo.

Cluster2: Ao contrário do Cluster1, predominam empresas com maior estrutura, de capital $\underline{\text { aberto, }}$ maior faturamento, $\underline{\text { maior número de funcionários. }}$

Por outro lado, não foi possível encontrar diferenças entre os agrupamentos quanto ao setor ou quanto à origem de capital. Para analisar se haveria diferenças entre os dois agrupamentos em 
função dos diferentes setores de atuação. Foi realizado um passo de agregação de empresas da amostra em macro setores, os quais podem ser observados na tabela a seguir. Isso foi feito devido à grande dispersão dos resultados em termos de setores nos dados originais.

Mesmo aplicando essa abordagem agregada, foi observado que não há diferenças entre os dois agrupamentos em função do setor, o que é um indício de que o setor de atuação da empresa não determina diferenças entre os dois agrupamentos, para esta amostra.

Tabela 24 - Setores de atuação agregados: Nos dois agrupamentos

\begin{tabular}{|c|c|c|c|c|}
\hline \multirow[b]{2}{*}{ Setor } & & \multicolumn{2}{|c|}{ cluster } & \multirow[t]{2}{*}{ Total } \\
\hline & & 1 & 2 & \\
\hline \multirow[t]{2}{*}{ Setores regulados } & $\mathrm{n}$ & 16 & 8 & 24 \\
\hline & $\%$ & $17,0 \%$ & $19,0 \%$ & $17,6 \%$ \\
\hline \multirow[t]{2}{*}{ Produção / transformação em produtos finais } & $\mathrm{n}$ & 31 & 14 & 45 \\
\hline & $\%$ & $33,0 \%$ & $33,3 \%$ & $33,1 \%$ \\
\hline \multirow[t]{2}{*}{$\begin{array}{l}\text { Setores que dependem de recursos naturais / } \\
\text { insumos básicos }\end{array}$} & $n$ & & & \\
\hline & $\%$ & $7,4 \%$ & $7,1 \%$ & $7,4 \%$ \\
\hline \multirow[t]{2}{*}{ Setores de serviços } & $\mathrm{n}$ & 40 & 17 & 57 \\
\hline & $\%$ & $42,6 \%$ & $40,5 \%$ & $41,9 \%$ \\
\hline \multirow[t]{2}{*}{ Total } & $\mathbf{n}$ & 94 & 42 & 136 \\
\hline & $\%$ & $100 \%$ & $100 \%$ & $100 \%$ \\
\hline
\end{tabular}

$$
\mathrm{X}^{2}=0,102 ; \mathrm{p}=0,992
$$

Pela origem do capital ser brasileira ou estrangeira, nota-se esse fator não influencia a formação dos grupos, o que descritivamente indica que a origem predominante do capital não caracteriza diferenciação para formação de grupos na amostra desta pesquisa.

Tabela 25 - Origem do capital predominante da empresa: Nos dois agrupamentos

\begin{tabular}{|c|c|c|c|c|}
\hline \multirow[b]{2}{*}{ Predominância da origem do capital } & & \multicolumn{2}{|c|}{ cluster } & \multirow[t]{2}{*}{ Total } \\
\hline & & 1 & 2 & \\
\hline \multirow[t]{2}{*}{ brasileira } & $\mathrm{n}$ & 54 & 27 & 81 \\
\hline & $\%$ & $51,4 \%$ & $58,7 \%$ & $53,6 \%$ \\
\hline \multirow[t]{2}{*}{ estrangeira } & $\mathrm{n}$ & 51 & 19 & 70 \\
\hline & $\%$ & $48,6 \%$ & $41,3 \%$ & $46,4 \%$ \\
\hline \multirow[t]{2}{*}{ Total } & $\mathbf{n}$ & 105 & 46 & 151 \\
\hline & $\%$ & $100 \%$ & $100 \%$ & $100 \%$ \\
\hline
\end{tabular}

$$
\mathrm{X}^{2}=0,679 ; \mathrm{p}=0,41
$$


Descritivamente nota-se maior valorização da prospecção de futuro no cluster de empresas mais estruturadas (Cluster 2). Em geral, é o Cluster 2, das empresas mais estruturadas, que mais atribui importância aos temas relacionados à prospecção de futuro.

\subsubsection{Os agrupamentos e a satisfação com a prospecção}

Na tabela a seguir, observa-se que no Cluster 2 há maior percentual de respondentes que se manifestam satisfeitos com os objetivos atingidos pela prospecção, se comparados com os respondentes do Cluster 1. Adicionalmente, a proporção de "parcialmente insatisfeito" é maior do Cluster 1 do que no Cluster 2.

Tabela 26 - Satisfação com a prospecção: Nos dois agrupamentos

\begin{tabular}{|c|c|c|c|c|c|}
\hline \multicolumn{6}{|c|}{ q1.Indique abaixo a satisfação quanto aos objetivos atingidos no último projeto finalizado } \\
\hline & & & \multicolumn{2}{|c|}{ Ward Method } & \multirow{2}{*}{ Total } \\
\hline & & & 1 & 2 & \\
\hline \multirow{10}{*}{$\begin{array}{l}\text { q1.Indique } \\
\text { abaixo a } \\
\text { satisfação quanto } \\
\text { aos objetivos } \\
\text { atingidos no } \\
\text { último projeto } \\
\text { finalizado }\end{array}$} & \multirow[t]{2}{*}{ Totalmente insatisfeito } & Frequência & 3 & 3 & 6 \\
\hline & & $\%$ em Ward Method & $2,7 \%$ & $6,4 \%$ & $3,8 \%$ \\
\hline & \multirow[t]{2}{*}{ Parcialmente insatisfeito } & Frequência & 27 & 7 & 34 \\
\hline & & $\%$ em Ward Method & $24,5 \%$ & $14,9 \%$ & $21,7 \%$ \\
\hline & \multirow{2}{*}{$\begin{array}{l}\text { Nem insatisfeito nem } \\
\text { satisfeito }\end{array}$} & Frequência & 2 & 1 & 3 \\
\hline & & $\%$ em Ward Method & $1,8 \%$ & $2,1 \%$ & $1,9 \%$ \\
\hline & \multirow[t]{2}{*}{ Parcialmente satisfeito } & Frequência & 67 & 25 & 92 \\
\hline & & $\%$ em Ward Method & $60,9 \%$ & $53,2 \%$ & \\
\hline & \multirow[t]{2}{*}{ Totalmente satisfeito } & Frequência & 11 & 11 & 22 \\
\hline & & $\%$ em Ward Method & $10,0 \%$ & $23,4 \%$ & $14,0 \%$ \\
\hline & \multirow[b]{2}{*}{ TOTAL } & Frequência & 110 & 47 & 157 \\
\hline & & $\begin{array}{l}\text { \% em Ward } \\
\text { Method }\end{array}$ & $100,0 \%$ & $100,0 \%$ & $100,0 \%$ \\
\hline
\end{tabular}

Os resultados na tabela anterior indicam que no Cluster 2 os respondentes avaliam que a prospecção atinge os objetivos satisfatoriamente, com 23,4\% de "totalmente satisfeito", contra $10 \%$ no Cluster 1. Para o grau "parcialmente satisfeito", no Cluster 2 são 53,2\% contra 60,9\% no Cluster 1. Agora, dentre os que se declaram "parcialmente insatisfeitos", os do Cluster 1 são quase $25 \%$ dos respondentes, e no Cluster 2 são $15 \%$. Fica constatado que os respondentes do Cluster 1 se manifestam mais insatisfeitos que os do Cluster 2. 


\subsubsection{Os agrupamentos e os temas prospectados}

Para facilitar a identificação, dos temas portadores de incertezas de futuro, nos gráficos a seguir, está reproduzido o quadro contendo a legenda numérica com os respectivos significados. Lembrando que há 12 temas, mais um $13^{\circ}$ relativo ao composto geral dos 12 temas.

Quadro 12 - Legenda de temas portadores de incertezas de futuro

\begin{tabular}{|ll|}
\hline \multicolumn{2}{|c|}{ Legenda: Temas portadores de incertezas de futuro } \\
\hline 1 & Analisar e examinar ambiente Político e Governo \\
\hline 2 & Analisar e examinar Economia \\
\hline 3 & Analisar e examinar Sociedade \\
\hline 4 & Analisar e examinar Tecnologia \\
\hline 5 & Analisar e examinar Meio ambiente e sustentabilidade \\
\hline 6 & Analisar e examinar Legislação e regulação setorial \\
\hline 7 & Analisar e examinar Mercado e demanda \\
\hline 8 & Analisar e examinar Insumos e recursos \\
\hline 9 & Analisar e examinar Inovação em Produtos ou Serviços \\
\hline 10 & Analisar e examinar Outras Oportunidades de Negócios \\
\hline 11 & Analisar e examinar Competidores \\
\hline 12 & Analisar e examinar Fornecedores \\
\hline 13 & Em geral, analisar todos os temas acima \\
\hline
\end{tabular}

Os dois gráficos a seguir permitem observar que o Cluster 2, de fato, avalia como mais importante a prospecção, se comparado com o Cluster 1. Notar que no eixo horizontal estão os diferentes temas portadores de incertezas de futuro, conforme a legenda da tabela anterior. 


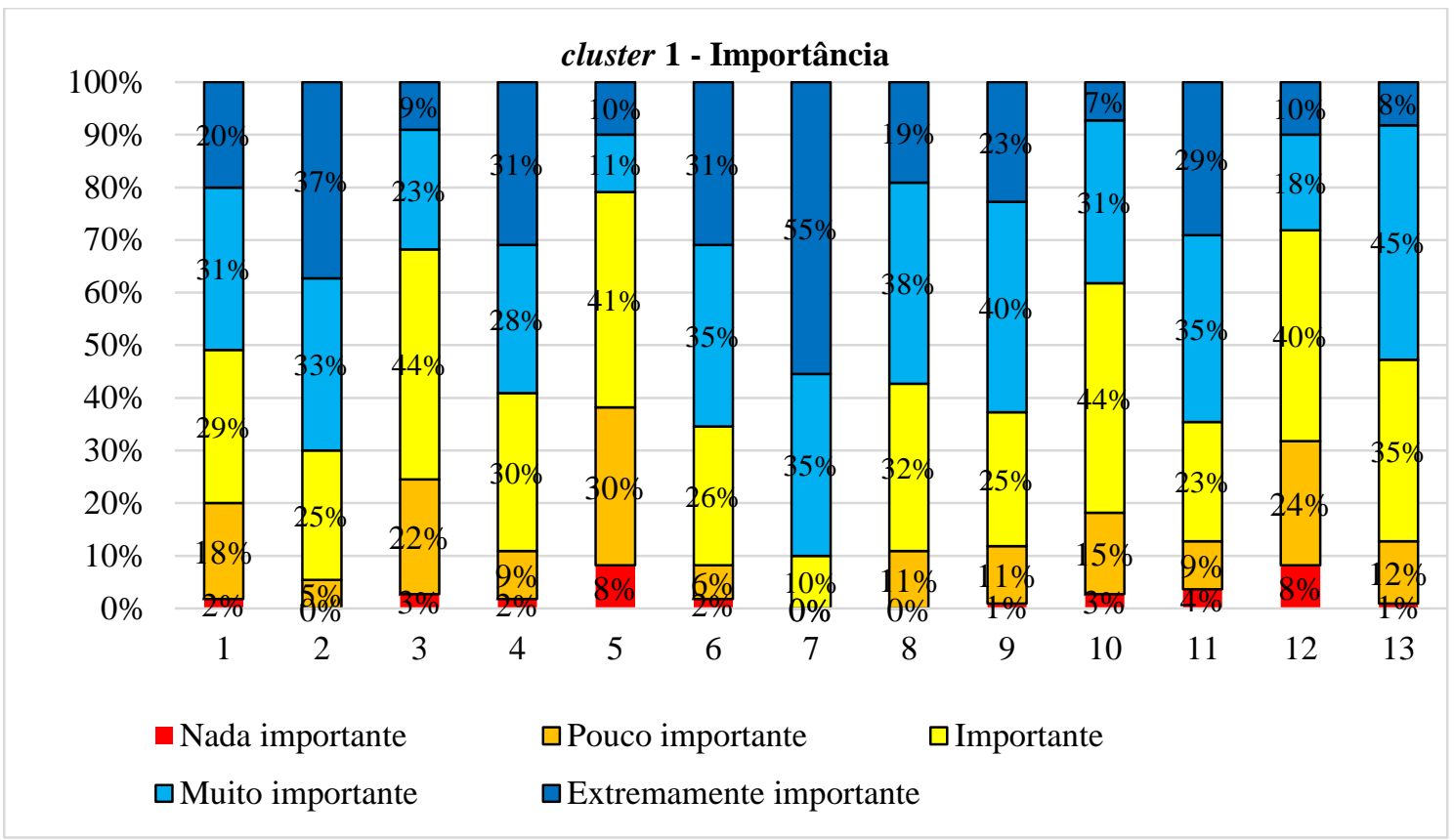

Gráfico 20 - Importância atribuída à prospecção do futuro - Empresas do Cluster 1

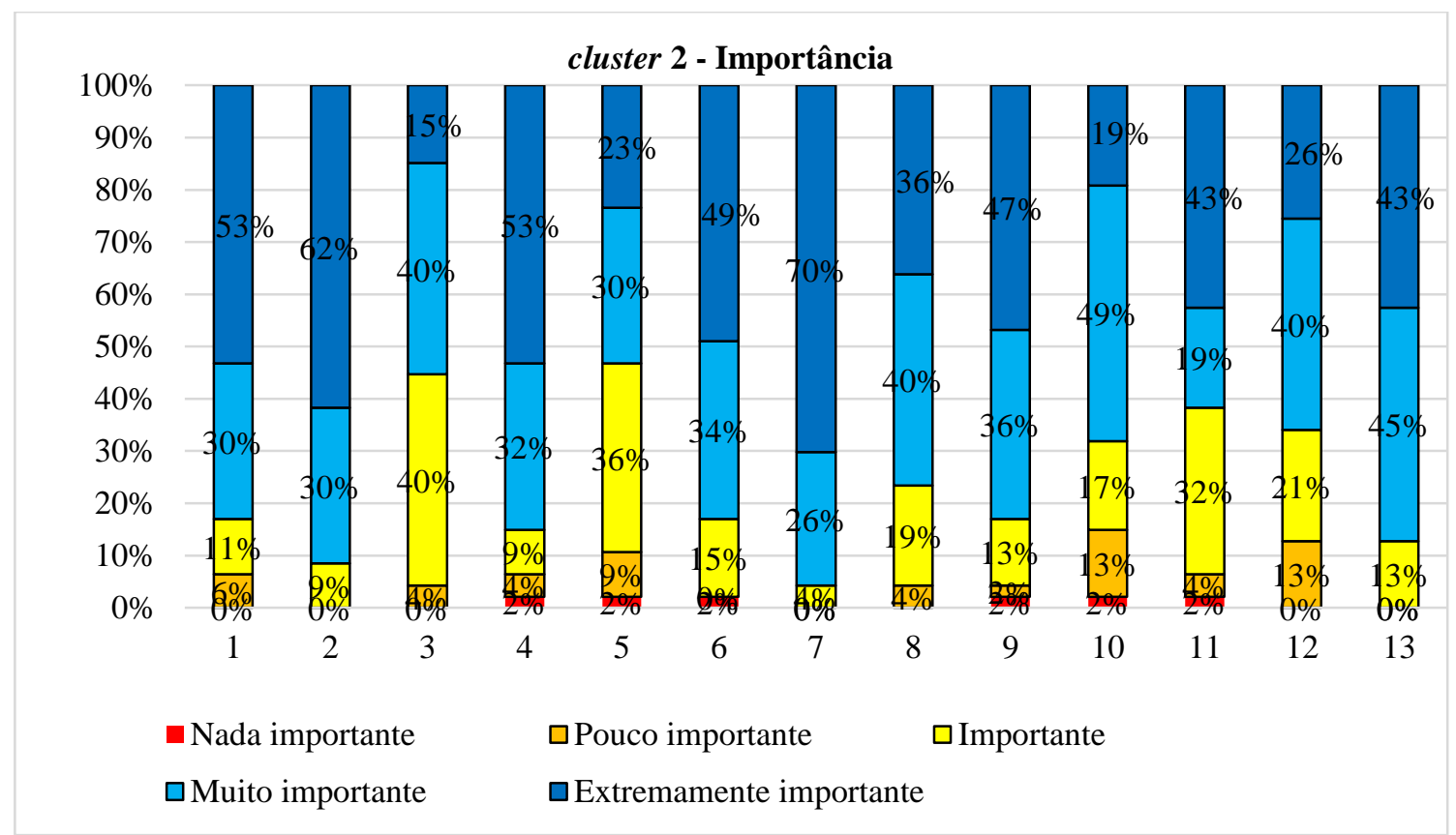

Gráfico 21 - Importância atribuída à prospecção do futuro - Empresas do Cluster 2

Nota-se que $87 \%$ dos respondentes do Cluster 2, avaliam como muito importante ou extremamente importante os temas relacionados à prospecção do futuro, enquanto tais avaliações se referem a apenas $53 \%$ do Clusterl. Isso pode ser observado focando na importância geral da prospecção: o tema 13 (à direta) dos dois gráficos anteriores. Em síntese, em todos os temas portadores de incertezas de futuro, o Cluster 2 tem respondentes que avaliam mais importante a prospecção, se comparado com o Cluster 1 . 
Utilizando-se uma análise por tabelas de dupla entrada nos agrupamentos, pode se observar que, de fato, os dois clusters geram resultados diferentes em relação à avaliação geral da importância da prospecção para analisar todos os temas, conforme mostram as duas tabelas a seguir.

Tabela 27 - Importância geral atribuída à prospecção

q3_13 Em geral, qual a importância de se checar se os temas acima estão analisados em um projeto estratégico? * Ward Method

Tabulação cruzada

\begin{tabular}{|c|c|c|c|c|c|}
\hline & & & clu & ter & \\
\hline & & & 1 & 2 & Total \\
\hline q3_13 Em & Nada importante & Frequência & 1 & 0 & 1 \\
\hline geral, qual a & & $\%$ em Ward Method &, $9 \%$ & $0,0 \%$ &, $6 \%$ \\
\hline se checar se os & Pouco importante & Frequência & 13 & 0 & 13 \\
\hline temas acima & & $\%$ em Ward Method & $11,8 \%$ & $0,0 \%$ & $8,3 \%$ \\
\hline estão & Importante & Frequência & 38 & 6 & 44 \\
\hline um projeto & & $\%$ em Ward Method & $34,5 \%$ & $12,8 \%$ & $28,0 \%$ \\
\hline estratégico? & Muito importante & Frequência & 49 & 21 & 70 \\
\hline & & $\%$ em Ward Method & $44,5 \%$ & $44,7 \%$ & $44,6 \%$ \\
\hline & Extremamente importante & Frequência & 9 & 20 & 29 \\
\hline & & $\%$ em Ward Method & $8,2 \%$ & $42,6 \%$ & $18,5 \%$ \\
\hline & Total & $\begin{array}{l}\text { Frequência } \\
\text { \% em Ward Method }\end{array}$ & $\begin{array}{c}110 \\
100 \%\end{array}$ & $\begin{array}{c}47 \\
100 \%\end{array}$ & $\begin{array}{c}157 \\
100 \%\end{array}$ \\
\hline
\end{tabular}

Tabela 28 - Profundidade de análise na prospecção do futuro

\begin{tabular}{|c|c|c|c|c|c|}
\hline \multicolumn{6}{|c|}{$\begin{array}{c}\text { q4_13 Em geral, quanto este projeto foi analisado pela prospecção do futuro? } * \text { Ward Method } \\
\text { Tabulação cruzada }\end{array}$} \\
\hline & & & \multicolumn{2}{|c|}{ cluster } & \multirow{2}{*}{ Total } \\
\hline & & & 1 & 2 & \\
\hline \multirow{10}{*}{$\begin{array}{l}\text { q4_13 Em } \\
\text { geral, quanto } \\
\text { este projeto } \\
\text { foi analisado } \\
\text { pela } \\
\text { prospecção do } \\
\text { futuro? }\end{array}$} & Nada & Frequência & 2 & 0 & 2 \\
\hline & & $\%$ em Ward Method & $1,8 \%$ & $0,0 \%$ & $1,3 \%$ \\
\hline & Muito pouco & Frequência & 14 & 0 & 14 \\
\hline & & $\%$ em Ward Method & $12,7 \%$ & $0,0 \%$ & $8,9 \%$ \\
\hline & Mnimo suficiente & Frequência & 44 & 4 & 48 \\
\hline & & $\%$ em Ward Method & $40,0 \%$ & $8,5 \%$ & $30,6 \%$ \\
\hline & Com alguma profundidade & Frequência & 48 & 36 & 84 \\
\hline & & $\%$ em Ward Method & $43,6 \%$ & $76,6 \%$ & $53,5 \%$ \\
\hline & Com grande profundidade & Frequência & 2 & 7 & 9 \\
\hline & & $\%$ em Ward Method & $1,8 \%$ & $14,9 \%$ & $5,7 \%$ \\
\hline \multirow{2}{*}{\multicolumn{2}{|c|}{ Total }} & Frequência & 110 & 47 & 157 \\
\hline & & $\%$ em Ward Method & $100 \%$ & $100 \%$ & $100 \%$ \\
\hline
\end{tabular}

De acordo com a tabela anterior, o projeto estratégico foi analisado na prospecção quanto aos diversos temas portadores de incertezas do futuro, e constata-se que os temas são mais 
profundamente analisados pelos gestores do Cluster 2 do que pelo do Cluster 1 (com alguma profundidade / com grande profundidade: $91 \%$ e $45 \%$, respectivamente).

Considerando agora que a importância atribuída à prospecção está presente, conforme mostrado nos resultados anteriores, então seria esperado que gestores se mobilizassem para praticar a atividade, como forma de subsidiar decisões sobre projetos com incertezas de futuro. Os dois gráficos a seguir ilustram bem a situação, e descritivamente se observa que os gestores do Cluster 2 declaram maior profundidade na análise dos temas, se comparados com os gestores do Cluster 1.

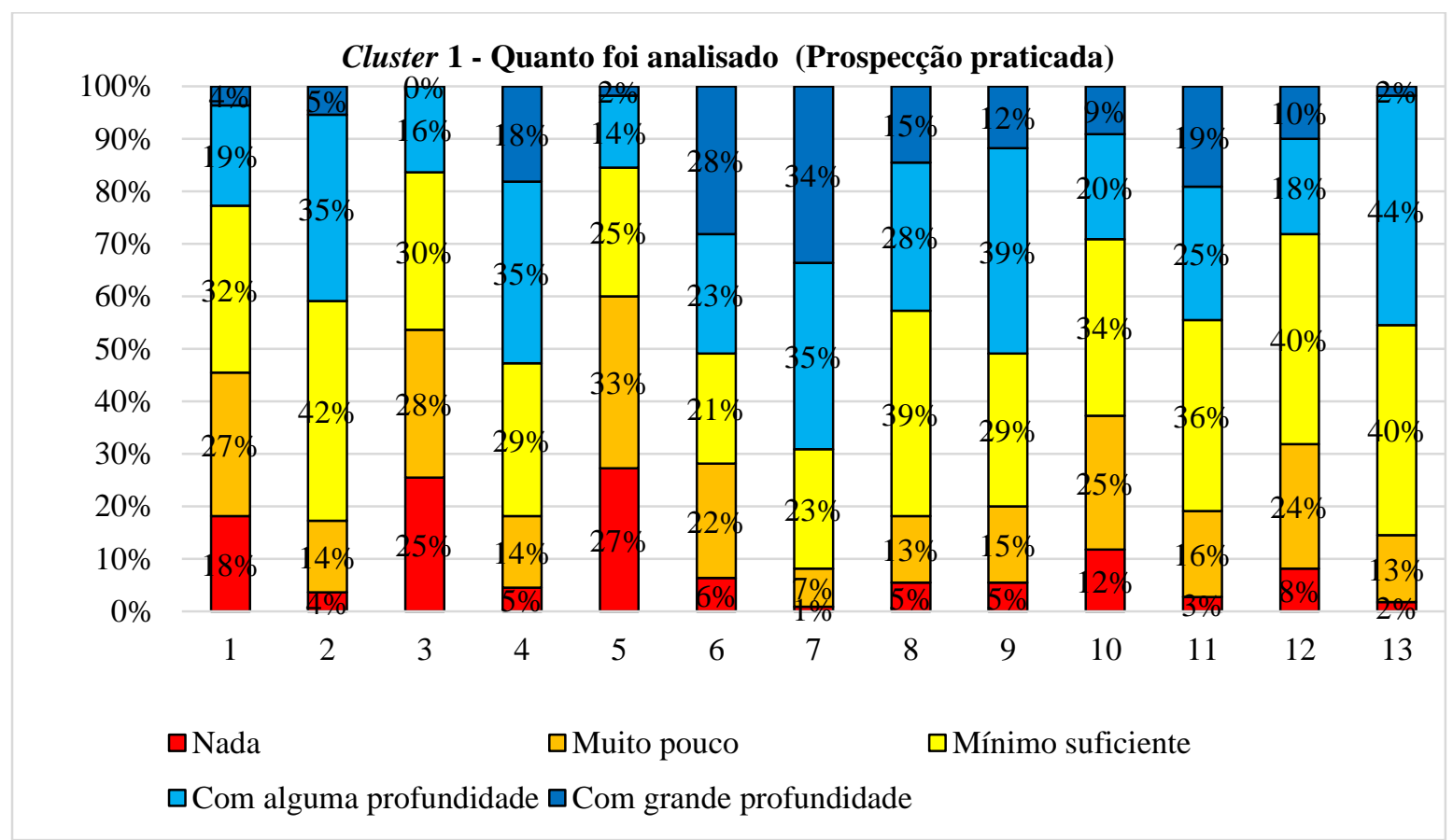

Gráfico 22 - Profundidade da prática da prospecção (por tema): Cluster 1 


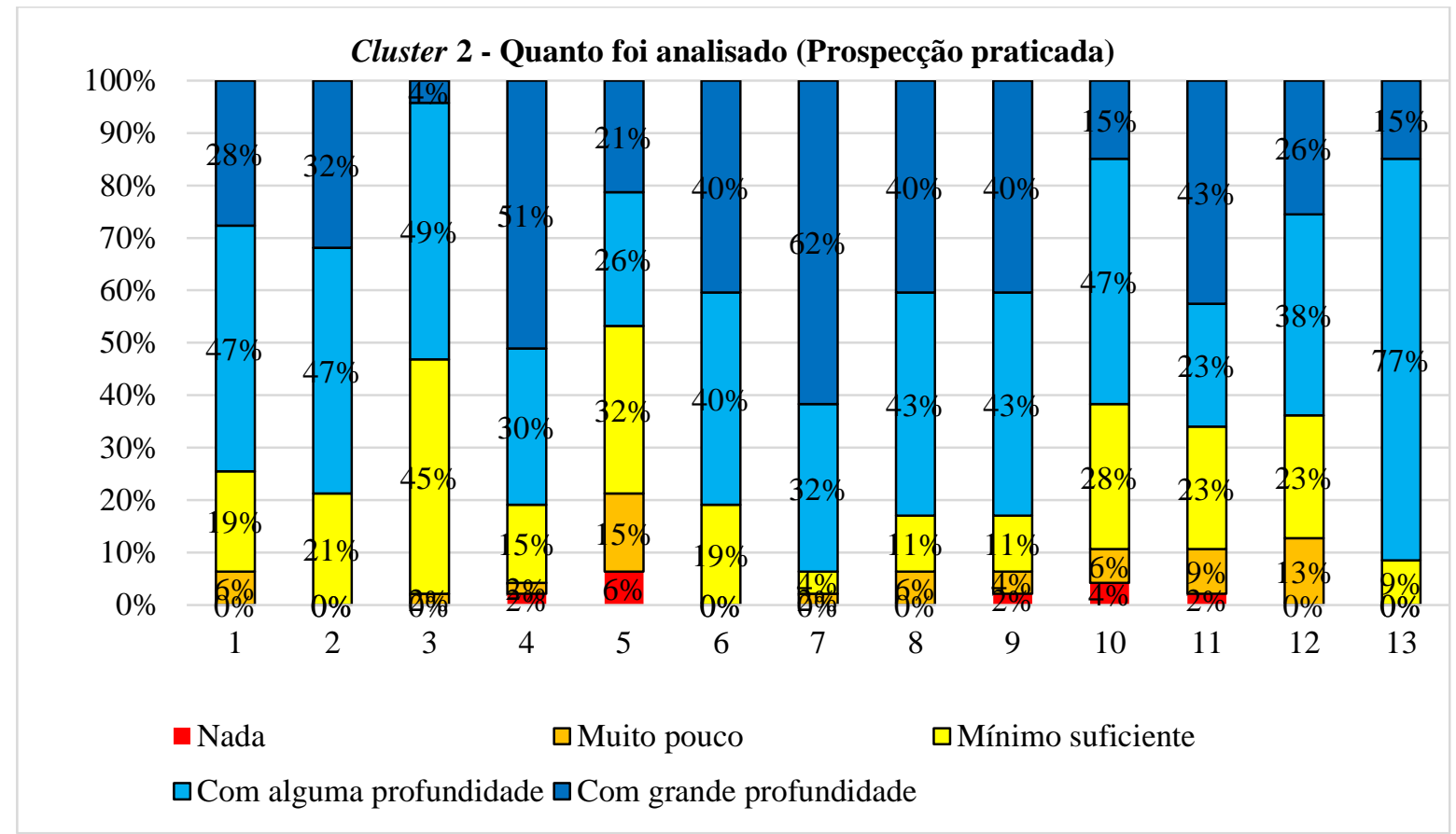

Gráfico 23 - Profundidade da prática da prospecção (por tema): Cluster 2

Considerando agora a opinião dos gestores da amostra acerca da contribuição da prospecção do futuro, a tabela a seguir mostra que os gestores do Cluster 2 consideram que a prospecção contribui mais, se comparado com os do Cluster 1 (em relação ao tema 13 - que representa o composto de todos os 12 temas portadores de incertezas de futuro).

Tabela 29 - Quanto a prospecção contribui na tomada de decisão

\begin{tabular}{|c|c|c|c|c|c|}
\hline \multicolumn{6}{|c|}{$\begin{array}{r}\text { q5_13 Em geral, neste último projeto, quanto a prospecção, sobre os temas acima, } \\
\text { Ward Method }\end{array}$} \\
\hline & & & \multicolumn{2}{|c|}{ cluster } & \multirow{2}{*}{ Total } \\
\hline & & & 1 & 2 & \\
\hline \multirow{4}{*}{$\begin{array}{l}\text { q5_13 Em geral, neste } \\
\text { último projeto, quanto a } \\
\text { prospecção, sobre os temas } \\
\text { acima, contribuiu nas } \\
\text { decisões? }\end{array}$} & Pouco & $\begin{array}{l}\text { Frequência } \\
\text { \% em Ward Method }\end{array}$ & $\begin{array}{c}18 \\
\mathbf{1 6 , 4 \%}\end{array}$ & $\begin{array}{c}1 \\
2,1 \%\end{array}$ & $\begin{array}{c}19 \\
12,1 \%\end{array}$ \\
\hline & Moderado & $\begin{array}{l}\text { Frequência } \\
\% \text { em Ward Method }\end{array}$ & $\begin{array}{c}52 \\
\mathbf{4 7 , 3 \%}\end{array}$ & $\begin{array}{c}9 \\
19,1 \%\end{array}$ & $\begin{array}{c}61 \\
38,9 \%\end{array}$ \\
\hline & Muito & $\begin{array}{l}\text { Frequência } \\
\% \text { em Ward Method }\end{array}$ & $\begin{array}{c}36 \\
32,7 \%\end{array}$ & $\begin{array}{c}32 \\
68,1 \%\end{array}$ & $\begin{array}{c}68 \\
43,3 \%\end{array}$ \\
\hline & Extremamente & $\begin{array}{l}\text { Frequência } \\
\% \text { em Ward Method }\end{array}$ & $\begin{array}{c}4 \\
3,6 \%\end{array}$ & $\begin{array}{c}5 \\
10,6 \% \\
\end{array}$ & $\begin{array}{c}9 \\
5,7 \%\end{array}$ \\
\hline \multicolumn{2}{|l|}{ Total } & $\begin{array}{l}\text { Frequência } \\
\text { \% em Ward Method }\end{array}$ & $\begin{array}{c}110 \\
100 \%\end{array}$ & $\begin{array}{c}47 \\
100 \%\end{array}$ & $\begin{array}{c}157 \\
100 \%\end{array}$ \\
\hline
\end{tabular}


Para visualizar a avaliação da contribuição para todos os temas, os dois gráficos a seguir ilustram isso. Nota-se uma superioridade de nível de contribuição no Cluster 2, com índice de contribuição Muito e Extremamente de 78,7\%, ante 36,3\% do Cluster 1.

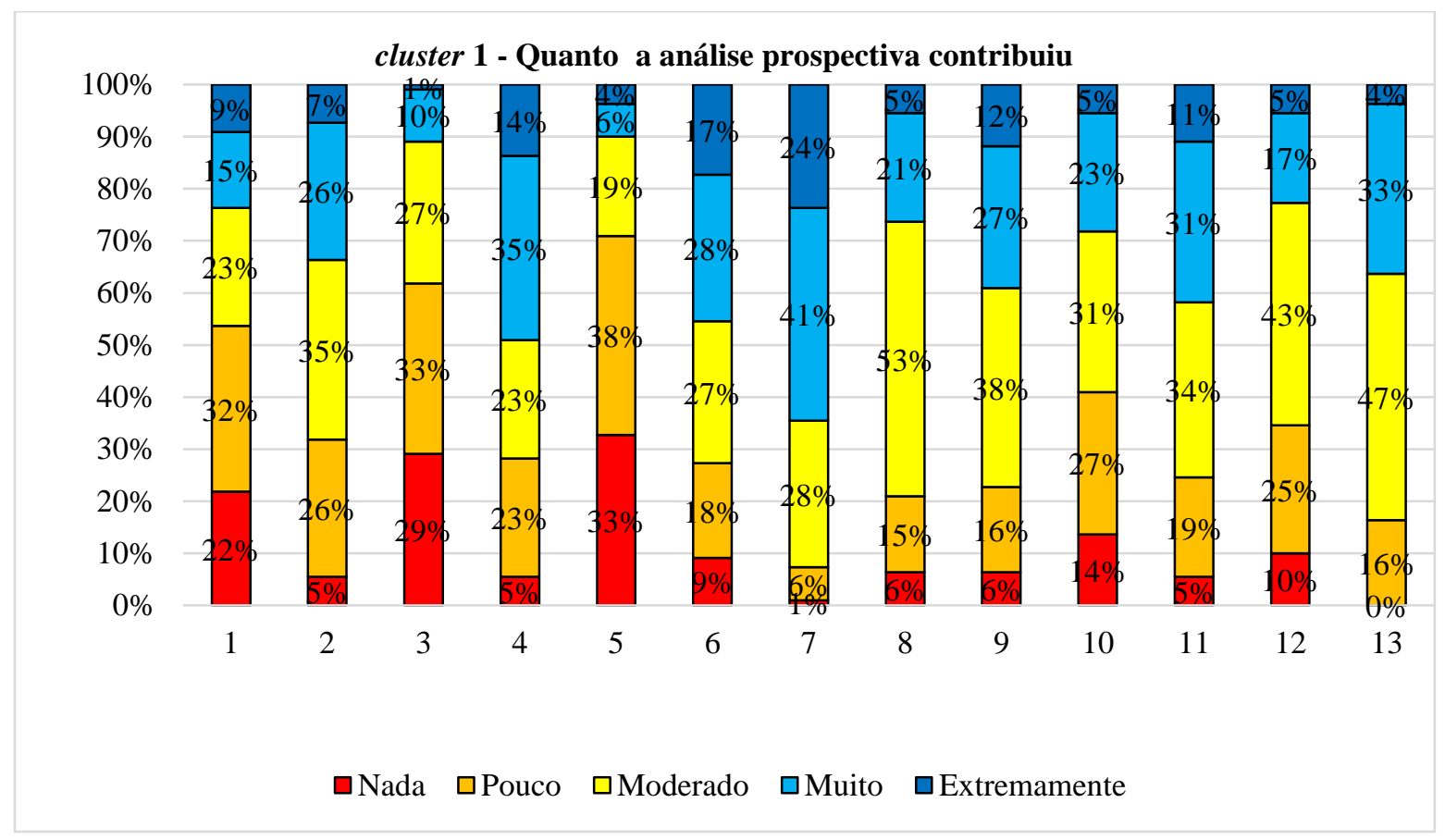

Gráfico 24 - Contribuição da análise da prospecção nas decisões: Cluster 1

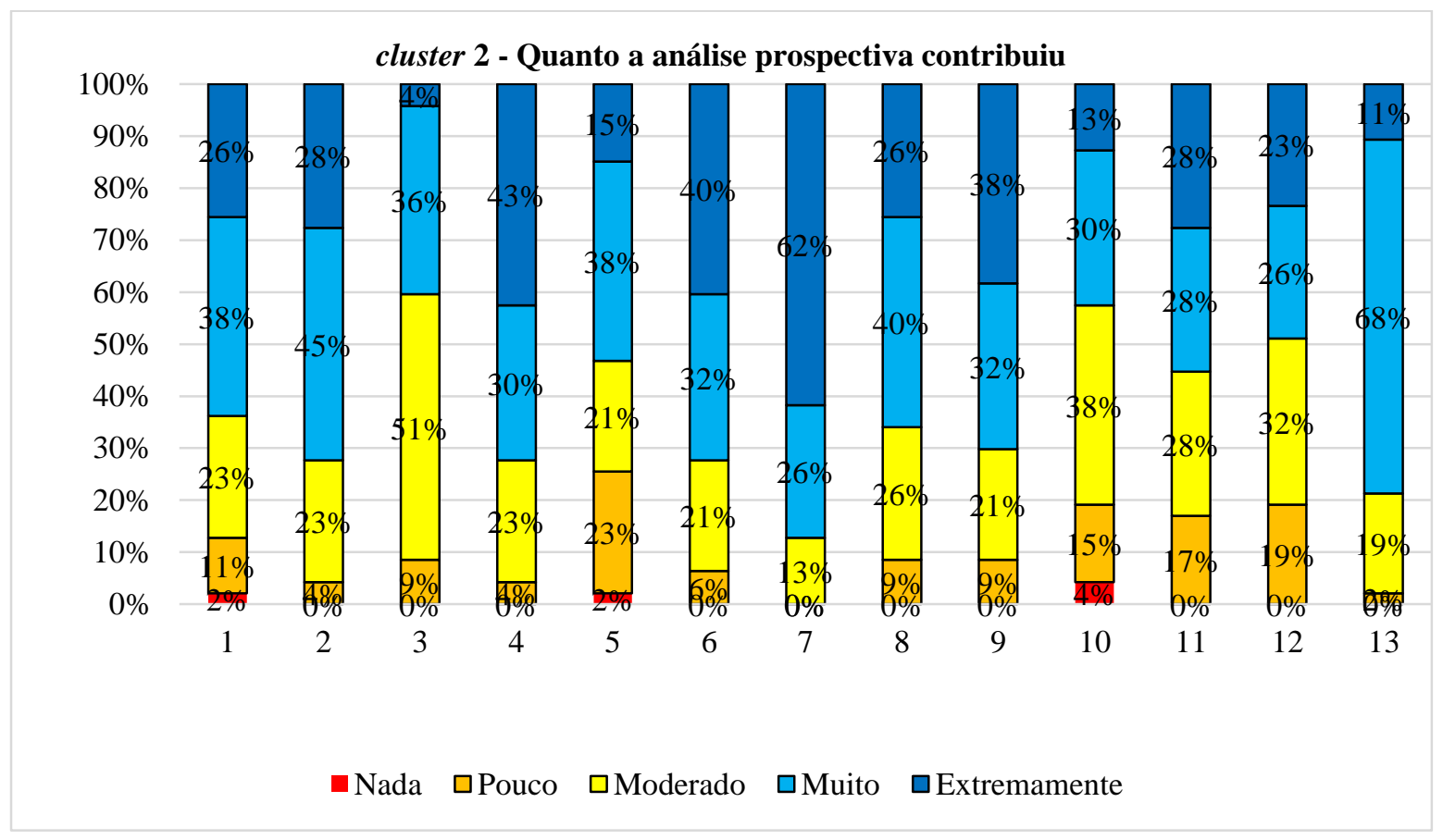

Gráfico 25 - Contribuição da análise da prospecção nas decisões: Cluster 2 
Os gestores do Cluster 1 estão mais sujeitos ao risco de lacunas de análises, pontos cegos que podem levá-los a enfrentar desafios oriundos de eventos que, por meio da prospecção, talvez possam ser analisados com antecedência, e assim possibilitando alguma preparação mais proativa. Os gestores do Cluster 2 estão mais atentos aos diferentes temas portadores de incertezas do futuro, correm menos risco de surpresas, tendem a ter menos lacunas de análise e pontos cegos.

\subsubsection{Os agrupamentos e processos de análise prospectiva}

Descritivamente, a superioridade do Cluster 2 também pode ser verificada em relação à prática de processos de análise prospectiva, que são recomendados quando se estuda o futuro no âmbito dos projetos estratégicos. Assim como as análises e conclusões resultantes da prospecção do futuro também contribuem mais para que os processos de análise prospectiva dos projetos sejam executados, como pode ser visto a seguir.

Esta seção contém duas partes:

- A primeira (A) contém os resultados e discussões sobre a prática de processos de análise prospectiva aplicados nos projetos, para suporte à decisão.

- A segunda $\underline{(\mathbf{B})}$ contém resultados e discussões sobre a contribuição que a prospecção propiciou aos processos de análise prospectiva praticados nos projetos. 
(A) A prática de processos de análise prospectiva nos projetos

Tabela 30 - Análise dos contextos futuros dos negócios envolvidos no projeto

\begin{tabular}{|c|c|c|c|c|c|}
\hline \multicolumn{6}{|c|}{$\begin{array}{c}\text { q6_01 Quanto este processo foi praticado? Análise dos contextos futuros dos negócios envolvidos no } \\
\text { projeto * Ward Method }\end{array}$} \\
\hline & & & \multicolumn{2}{|c|}{ Ward Method } & \multirow{2}{*}{ Total } \\
\hline & & & 1 & 2 & \\
\hline \multirow{10}{*}{$\begin{array}{l}\text { q6_01 Quanto } \\
\text { este processo } \\
\text { foi praticado? } \\
\text { Análise dos } \\
\text { contextos } \\
\text { futuros dos } \\
\text { negócios } \\
\text { envolvidos no } \\
\text { projeto }\end{array}$} & 1 Não foi praticado & Frequência & 5 & 0 & 5 \\
\hline & & $\%$ em Ward Method & $4,5 \%$ & $0,0 \%$ & $3,2 \%$ \\
\hline & 2 Pouco praticado & Frequência & 19 & 1 & 20 \\
\hline & & $\%$ em Ward Method & $17,3 \%$ & $2,1 \%$ & $12,7 \%$ \\
\hline & 3 Moderadamente praticado & Frequência & 45 & 7 & 52 \\
\hline & & $\%$ em Ward Method & $40,9 \%$ & $14,9 \%$ & $33,1 \%$ \\
\hline & 4 Muito praticado & Frequência & 34 & 20 & 54 \\
\hline & & $\%$ em Ward Method & $30,9 \%$ & $42,6 \%$ & $34,4 \%$ \\
\hline & 5 Extremamente praticado & Frequência & 7 & 19 & 26 \\
\hline & & $\%$ em Ward Method & $6,4 \%$ & $40,4 \%$ & $16,6 \%$ \\
\hline \multirow{2}{*}{\multicolumn{2}{|c|}{ Total }} & Frequência & 110 & 47 & 157 \\
\hline & & $\%$ em Ward Method & $100 \%$ & $100 \%$ & $100 \%$ \\
\hline
\end{tabular}

Na tabela anterior nota-se que os gestores do Cluster 2 praticam mais o processo de analisar o contexto futuro dos negócios envolvidos no projeto.

Tabela 31 - Análise do alinhamento do projeto com a estratégia da organização

\begin{tabular}{|c|c|c|c|c|c|}
\hline \multicolumn{6}{|c|}{$\begin{array}{c}\text { q6_02 Quanto este processo foi praticado? Análise do alinhamento do projeto com a estratégia da } \\
\text { organização * Ward Method }\end{array}$} \\
\hline & & & \multicolumn{2}{|c|}{ Ward Method } & \multirow{2}{*}{ Total } \\
\hline & & & 1 & 2 & \\
\hline \multirow{5}{*}{$\begin{array}{l}\text { q6_02 } \\
\text { Quanto este } \\
\text { processo foi } \\
\text { praticado? } \\
\text { Análise do } \\
\text { alinhamento } \\
\text { do projeto } \\
\text { com a } \\
\text { estratégia da } \\
\text { organização }\end{array}$} & 2 Pouco praticado & $\begin{array}{l}\text { Frequência } \\
\% \text { em Ward Method }\end{array}$ & $\begin{array}{c}12 \\
10,9 \%\end{array}$ & $\begin{array}{c}0 \\
0,0 \%\end{array}$ & $\begin{array}{c}12 \\
7,6 \%\end{array}$ \\
\hline & 3 Moderadamente praticado & $\begin{array}{l}\text { Frequência } \\
\text { \% em Ward Method }\end{array}$ & $\begin{array}{c}24 \\
21,8 \% \\
\end{array}$ & $\begin{array}{c}2 \\
4,3 \% \\
\end{array}$ & $\begin{array}{c}26 \\
16,6 \% \\
\end{array}$ \\
\hline & 4 Muito praticado & $\begin{array}{l}\text { Frequência } \\
\% \text { em Ward Method }\end{array}$ & $\begin{array}{c}36 \\
\mathbf{3 2 , 7 \%}\end{array}$ & $\begin{array}{c}13 \\
\mathbf{2 7 , 7 \%}\end{array}$ & $\begin{array}{c}49 \\
31,2 \%\end{array}$ \\
\hline & 5 Extremamente praticado & $\begin{array}{l}\text { Frequência } \\
\% \text { em Ward Method }\end{array}$ & $\begin{array}{c}38 \\
\mathbf{3 4 , 5 \%} \\
\end{array}$ & $\begin{array}{c}32 \\
68,1 \% \\
\end{array}$ & $\begin{array}{c}70 \\
44,6 \% \\
\end{array}$ \\
\hline & & $\begin{array}{l}\text { Frequência } \\
\% \text { em Ward Method }\end{array}$ & $\begin{array}{c}110 \\
100,0 \%\end{array}$ & $\begin{array}{c}47 \\
100,0 \%\end{array}$ & $\begin{array}{c}157 \\
100,0 \%\end{array}$ \\
\hline
\end{tabular}

$\mathrm{O}$ alinhamento do projeto com a estratégia da organização é muito ou extremamente praticado em ambos os Clusters, mas com $68,1 \%$ para extremamente no Cluster 2, contra $34,5 \%$ no Cluster 1. 
Tabela 32 - Calibração de premissas utilizadas no projeto

q6_03 Quanto este processo foi praticado? Calibração de premissas utilizadas no projeto * Ward Method Tabulação cruzada

\begin{tabular}{|c|c|c|c|c|c|}
\hline & & & Ward & Method & Total \\
\hline & & & 1 & 2 & \\
\hline q6_03 Quanto & 1 Não foi praticado & Frequência & 3 & 0 & 3 \\
\hline este processo & & $\%$ em Ward Method & $2,7 \%$ & $0,0 \%$ & $1,9 \%$ \\
\hline Calibração de & 2 Pouco praticado & Frequência & 18 & 1 & 19 \\
\hline premissas & & $\%$ em Ward Method & $16,4 \%$ & $2,1 \%$ & $12,1 \%$ \\
\hline utilizadas no & 3 Moderadamente praticado & Frequência & 49 & 12 & 61 \\
\hline & & $\%$ em Ward Method & $44,5 \%$ & $25,5 \%$ & $38,9 \%$ \\
\hline & 4 Muito praticado & Frequência & 28 & 21 & 49 \\
\hline & & $\%$ em Ward Method & $25,5 \%$ & $44,7 \%$ & $31,2 \%$ \\
\hline & 5 Extremamente praticado & Frequência & 12 & 13 & 25 \\
\hline & & $\%$ em Ward Method & $10,9 \%$ & $27,7 \%$ & $15,9 \%$ \\
\hline Total & & Frequência & 110 & 47 & 157 \\
\hline & & $\%$ em Ward Method & $100 \%$ & $100 \%$ & $100 \%$ \\
\hline
\end{tabular}

A calibração de premissas utilizadas no projeto é mais praticada pelos gestores do Cluster 2. 
Tabela 33 - Definição de sinais ou indicadores que sirvam para monitorar o futuro acontecendo q6_04 Quanto este processo foi praticado? Definição de sinais ou indicadores que sirvam para monitorar o futuro acontecendo (ou começando a acontecer) no âmbito da implantação do projeto * Ward Method Tabulação cruzada

\begin{tabular}{|c|c|c|c|c|c|}
\hline & & & Ward & Gethod & Total \\
\hline & & & 1 & 2 & \\
\hline $\begin{array}{l}\text { q6_04 Quanto este } \\
\text { processo foi } \\
\text { praticado? }\end{array}$ & 1 Não foi praticado & $\begin{array}{l}\text { Frequência } \\
\% \text { em Ward Method }\end{array}$ & $\begin{array}{c}14 \\
12,7 \%\end{array}$ & $\begin{array}{c}0 \\
0,0 \%\end{array}$ & $\begin{array}{c}14 \\
8,9 \%\end{array}$ \\
\hline $\begin{array}{l}\text { Definição de sinais } \\
\text { ou indicadores que }\end{array}$ & 2 Pouco praticado & $\begin{array}{l}\text { Frequência } \\
\% \text { em Ward Method }\end{array}$ & $\begin{array}{c}29 \\
\mathbf{2 6 , 4 \%}\end{array}$ & $\begin{array}{c}1 \\
2,1 \%\end{array}$ & $\begin{array}{c}30 \\
19,1 \%\end{array}$ \\
\hline $\begin{array}{l}\text { Sirvam para } \\
\text { monitorar o futuro } \\
\text { acontecendo (ou }\end{array}$ & $\begin{array}{l}3 \text { Moderadamente } \\
\text { praticado }\end{array}$ & $\begin{array}{l}\text { Frequência } \\
\% \text { em Ward Method }\end{array}$ & $\begin{array}{c}35 \\
\mathbf{3 1 , 8 \%}\end{array}$ & $\begin{array}{c}11 \\
23,4 \%\end{array}$ & $\begin{array}{c}46 \\
29,3 \%\end{array}$ \\
\hline $\begin{array}{l}\text { começando a } \\
\text { acontecer) no } \\
\text { âmbito da }\end{array}$ & 4 Muito praticado & $\begin{array}{l}\text { Frequência } \\
\text { \% em Ward Method }\end{array}$ & $\begin{array}{c}27 \\
24,5 \%\end{array}$ & $\begin{array}{c}24 \\
51,1 \%\end{array}$ & $\begin{array}{c}51 \\
32,5 \%\end{array}$ \\
\hline $\begin{array}{l}\text { implantação do } \\
\text { projeto }\end{array}$ & $\begin{array}{l}5 \text { Extremamente } \\
\text { praticado }\end{array}$ & $\begin{array}{l}\text { Frequência } \\
\% \text { em Ward Method }\end{array}$ & $\begin{array}{c}5 \\
4,5 \%\end{array}$ & $\begin{array}{c}11 \\
\mathbf{2 3 , 4 \%}\end{array}$ & $\begin{array}{c}16 \\
10,2 \%\end{array}$ \\
\hline Total & & $\begin{array}{l}\text { Frequência } \\
\text { \% em Ward Method }\end{array}$ & $\begin{array}{c}110 \\
100 \%\end{array}$ & $\begin{array}{c}47 \\
100 \%\end{array}$ & $\begin{array}{c}157 \\
100 \%\end{array}$ \\
\hline
\end{tabular}

Os sinais ou indicadores que possam ser usados para monitorar o futuro acontecendo, ou em vias de acontecer, é mais praticado pelos gestores do Cluster 2. O que chama atenção em relação a este aspecto é que, se empresas do Cluster 1 praticam menos a prospecção, seria coerente que seus gestores estivessem atentos ao ambiente, para evitar serem surpreendidos por algum evento. Mas, observa-se que isso pode não ser tão disseminado assim nessas empresas.

Tabela 34 - Análise do quanto o projeto pode influenciar os resultados futuros da organização q6_05 Quanto este processo foi praticado? Análise do quanto o projeto pode influenciar os resultados futuros da organização * Ward Method Tabulação cruzada

\begin{tabular}{|c|c|c|c|c|c|}
\hline & & & Ward & Method & Total \\
\hline & & & 1 & 2 & \\
\hline q6_05 Quanto & 1 Não foi praticado & Frequência & 2 & 0 & 2 \\
\hline este processo foi & & $\%$ em Ward Method & $1,8 \%$ & $0,0 \%$ & $1,3 \%$ \\
\hline Análise do & 2 Pouco praticado & Frequência & 9 & 0 & 9 \\
\hline quanto o projeto & & $\%$ em Ward Method & $8,2 \%$ & $0,0 \%$ & $5,7 \%$ \\
\hline pode influenciar & 3 Moderadamente praticado & Frequência & 34 & 5 & 39 \\
\hline futuros da & & $\%$ em Ward Method & $30,9 \%$ & $10,6 \%$ & $24,8 \%$ \\
\hline organização & 4 Muito praticado & Frequência & 38 & 18 & 56 \\
\hline & & $\%$ em Ward Method & $34,5 \%$ & $38,3 \%$ & $35,7 \%$ \\
\hline & 5 Extremamente praticado & Frequência & 27 & 24 & 51 \\
\hline & & $\%$ em Ward Method & $24,5 \%$ & $51,1 \%$ & $32,5 \%$ \\
\hline Total & & Frequência & 110 & 47 & 157 \\
\hline & & \% em Ward Method & $100 \%$ & $100 \%$ & $100 \%$ \\
\hline
\end{tabular}


$\mathrm{Na}$ tabela anterior nota-se que os gestores do Cluster 2 praticam mais o processo de analisar o impacto futuro do projeto nos resultados da organização.

Tabela 35 - Simulação - Colocar pessoas para analisarem a organização dentro do contexto futuro q6_06 Quanto este processo foi praticado? Simulação - colocar pessoas para analisarem a organização dentro do contexto futuro proporcionado pelo projeto * Ward Method

Tabulação

\begin{tabular}{|c|c|c|c|c|c|}
\hline \multicolumn{6}{|c|}{ cruzada } \\
\hline & & & \multicolumn{2}{|c|}{ Ward Method } & \multirow{2}{*}{ Total } \\
\hline & & & 1 & 2 & \\
\hline \multirow{2}{*}{$\begin{array}{l}\text { q6_06 Quanto } \\
\text { este processo }\end{array}$} & 1 Não foi praticado & Frequência & 29 & 5 & 34 \\
\hline & & $\%$ em Ward Method & $26,4 \%$ & $10,6 \%$ & $21,7 \%$ \\
\hline \multirow{2}{*}{$\begin{array}{l}\text { foi praticado? } \\
\text { Simulação - } \\
\text { colocar }\end{array}$} & 2 Pouco praticado & Frequência & 35 & 4 & 39 \\
\hline & & $\%$ em Ward Method & $31,8 \%$ & $8,5 \%$ & $24,8 \%$ \\
\hline \multirow{6}{*}{$\begin{array}{l}\text { pessoas para } \\
\text { analisarem a } \\
\text { organização } \\
\text { dentro do } \\
\text { contexto futuro } \\
\text { proporcionado } \\
\text { pelo projeto }\end{array}$} & 3 Moderadamente praticado & Frequência & 31 & 17 & 48 \\
\hline & & $\%$ em Ward Method & $28,2 \%$ & $36,2 \%$ & $30,6 \%$ \\
\hline & 4 Muito praticado & Frequência & 14 & 14 & 28 \\
\hline & & $\%$ em Ward Method & $12,7 \%$ & $29,8 \%$ & $17,8 \%$ \\
\hline & 5 Extremamente praticado & Frequência & 1 & 7 & 8 \\
\hline & & $\%$ em Ward Method & $0,9 \%$ & $14,9 \%$ & $5,1 \%$ \\
\hline \multicolumn{2}{|l|}{ Total } & $\begin{array}{l}\text { Frequência } \\
\text { \% em Ward Method }\end{array}$ & $\begin{array}{c}110 \\
100 \%\end{array}$ & $\begin{array}{c}47 \\
100 \%\end{array}$ & $\begin{array}{c}157 \\
100 \%\end{array}$ \\
\hline
\end{tabular}

Gestores do Cluster 2 tendem a simular mais como a organização estaria dentro do contexto futuro do projeto estratégico. Os do Cluster 1 pouco fazem isso.

Tabela 36 - Estudo de mudanças necessárias na organização em função do projeto q6_07 Quanto este processo foi praticado? Estudo de mudanças necessárias na organização em função do projeto

\begin{tabular}{|c|c|c|c|c|c|}
\hline \multicolumn{6}{|c|}{ Tabulação cruzada } \\
\hline & & & \multicolumn{2}{|c|}{ Ward Method } & \multirow{2}{*}{ Total } \\
\hline & & & 1 & 2 & \\
\hline \multirow{10}{*}{$\begin{array}{l}\text { q6_07 Quanto } \\
\text { este processo } \\
\text { foi praticado? } \\
\text { Estudo de } \\
\text { mudanças } \\
\text { necessárias na } \\
\text { organização em } \\
\text { função do } \\
\text { projeto }\end{array}$} & 1 Não foi praticado & Frequência & 10 & 1 & 11 \\
\hline & & $\%$ em Ward Method & $9,1 \%$ & $2,1 \%$ & $7,0 \%$ \\
\hline & 2 Pouco praticado & Frequência & 24 & 3 & 27 \\
\hline & & $\%$ em Ward Method & $21,8 \%$ & $6,4 \%$ & $17,2 \%$ \\
\hline & 3 Moderadamente praticado & Frequência & 47 & 10 & 57 \\
\hline & & $\%$ em Ward Method & $42,7 \%$ & $21,3 \%$ & $36,3 \%$ \\
\hline & 4 Muito praticado & Frequência & 22 & 17 & 39 \\
\hline & & $\%$ em Ward Method & $20,0 \%$ & $36,2 \%$ & $24,8 \%$ \\
\hline & 5 Extremamente praticado & Frequência & 7 & 16 & 23 \\
\hline & & $\%$ em Ward Method & $6,4 \%$ & $34,0 \%$ & $14,6 \%$ \\
\hline \multicolumn{2}{|l|}{ Total } & $\begin{array}{l}\text { Frequência } \\
\text { \% em Ward Method }\end{array}$ & $\begin{array}{c}110 \\
100 \%\end{array}$ & $\begin{array}{c}47 \\
100 \%\end{array}$ & $\begin{array}{c}157 \\
100 \%\end{array}$ \\
\hline
\end{tabular}


Empresas do Cluster 2 tem gestores mais atentos ao estudo sobre mudanças necessárias na organização em função dos projetos. Esse processo tem relação com a análise de como a empresa deverá se estruturar para gerenciar as operações a partir de sua implantação.

Tabela 37 - Identificar necessidade de aprimoramento de competências

\begin{tabular}{|c|c|c|c|c|c|}
\hline \multicolumn{6}{|c|}{$\begin{array}{l}\text { q6_08 Quanto este processo foi praticado? Identificação de necessidades de aprimoramento de } \\
\text { competências para implantar o projeto * Ward Method }\end{array}$} \\
\hline & & & \multicolumn{2}{|c|}{ Ward Method } & \multirow{2}{*}{ Total } \\
\hline & & & 1 & 2 & \\
\hline \multirow{5}{*}{$\begin{array}{l}\text { q6_08 Quanto } \\
\text { este processo foi } \\
\text { praticado? } \\
\text { Identificação de } \\
\text { necessidades de } \\
\text { aprimoramento de } \\
\text { competências } \\
\text { para implantar o } \\
\text { projeto }\end{array}$} & 1 Não foi praticado & $\begin{array}{l}\text { Frequência } \\
\% \text { em Ward Method }\end{array}$ & $\begin{array}{c}11 \\
10,0 \%\end{array}$ & $\begin{array}{c}1 \\
2,1 \%\end{array}$ & $\begin{array}{c}12 \\
7,6 \%\end{array}$ \\
\hline & 2 Pouco praticado & $\begin{array}{l}\text { Frequência } \\
\% \text { em Ward Method }\end{array}$ & $\begin{array}{c}22 \\
\mathbf{2 0 , 0} \%\end{array}$ & $\begin{array}{c}0 \\
0,0 \%\end{array}$ & $\begin{array}{c}22 \\
14,0 \%\end{array}$ \\
\hline & 3 Moderadamente praticado & $\begin{array}{l}\text { Frequência } \\
\% \text { em Ward Method }\end{array}$ & $\begin{array}{c}41 \\
\mathbf{3 7 , 3 \%}\end{array}$ & $\begin{array}{c}9 \\
19,1 \%\end{array}$ & $\begin{array}{c}50 \\
31,8 \%\end{array}$ \\
\hline & 4 Muito praticado & $\begin{array}{l}\text { Frequência } \\
\% \text { em Ward Method }\end{array}$ & $\begin{array}{c}24 \\
21,8 \%\end{array}$ & $\begin{array}{c}18 \\
\mathbf{3 8 , 3 \%}\end{array}$ & $\begin{array}{c}42 \\
26,8 \%\end{array}$ \\
\hline & 5 Extremamente praticado & $\begin{array}{l}\text { Frequência } \\
\% \text { em Ward Method }\end{array}$ & $\begin{array}{c}12 \\
10,9 \%\end{array}$ & $\begin{array}{c}19 \\
\mathbf{4 0 , 4 \%}\end{array}$ & $\begin{array}{c}31 \\
19,7 \%\end{array}$ \\
\hline \multicolumn{2}{|l|}{ Total } & $\begin{array}{l}\text { Frequência } \\
\text { \% em Ward Method }\end{array}$ & $\begin{array}{c}110 \\
100 \%\end{array}$ & $\begin{array}{c}47 \\
100 \%\end{array}$ & $\begin{array}{c}157 \\
100 \%\end{array}$ \\
\hline
\end{tabular}

O aprimoramento de competências tende a ser mais praticado pelos gestores do Cluster 2. Um sinal de que possivelmente as empresas do Cluster 1 desenvolvam projetos que demandem menos a preparação de competências, ou por outro lado talvez isso fosse importante para elas, contudo essa análise prospectiva seja menos praticada de forma sistemática. 
Tabela 38 - Exame de incertezas estratégicas envolvidas no projeto

\begin{tabular}{|c|c|c|c|c|c|}
\hline \multicolumn{6}{|c|}{$\begin{array}{r}\text { q6_09 Quanto este processo foi praticado? Exame das incertezas estratégicas } \\
\text { Ward Method }\end{array}$} \\
\hline & & & \multicolumn{2}{|c|}{ Ward Method } & \multirow{2}{*}{ Total } \\
\hline & & & 1 & 2 & \\
\hline \multirow{5}{*}{$\begin{array}{l}\text { q6_09 Quanto } \\
\text { este processo foi } \\
\text { praticado? Exame } \\
\text { das incertezas } \\
\text { estratégicas } \\
\text { envolvidas no } \\
\text { projeto }\end{array}$} & 1 Não foi praticado & $\begin{array}{l}\text { Frequência } \\
\text { \% em Ward Method }\end{array}$ & $\begin{array}{c}12 \\
10,9 \%\end{array}$ & $\begin{array}{c}0 \\
0,0 \%\end{array}$ & $\begin{array}{c}12 \\
7,6 \%\end{array}$ \\
\hline & 2 Pouco praticado & $\begin{array}{l}\text { Frequência } \\
\% \text { em Ward Method }\end{array}$ & $\begin{array}{c}29 \\
\mathbf{2 6 , 4 \%}\end{array}$ & $\begin{array}{c}2 \\
4,3 \%\end{array}$ & $\begin{array}{c}31 \\
19,7 \%\end{array}$ \\
\hline & 3 Moderadamente praticado & $\begin{array}{l}\text { Frequência } \\
\% \text { em Ward Method }\end{array}$ & $\begin{array}{c}48 \\
43,6 \%\end{array}$ & $\begin{array}{c}11 \\
23,4 \%\end{array}$ & $\begin{array}{c}59 \\
37,6 \%\end{array}$ \\
\hline & 4 Muito praticado & $\begin{array}{l}\text { Frequência } \\
\text { \% em Ward Method }\end{array}$ & $\begin{array}{c}19 \\
17,3 \%\end{array}$ & $\begin{array}{c}22 \\
46,8 \%\end{array}$ & $\begin{array}{c}41 \\
26,1 \%\end{array}$ \\
\hline & 5 Extremamente praticado & $\begin{array}{l}\text { Frequência } \\
\text { \% em Ward Method }\end{array}$ & $\begin{array}{c}2 \\
1,8 \%\end{array}$ & $\begin{array}{c}12 \\
\mathbf{2 5 , 5} \%\end{array}$ & $\begin{array}{c}14 \\
8,9 \%\end{array}$ \\
\hline \multicolumn{2}{|l|}{ Total } & $\begin{array}{l}\text { Frequência } \\
\text { \% em Ward Method }\end{array}$ & $\begin{array}{c}110 \\
100 \%\end{array}$ & $\begin{array}{c}47 \\
100 \%\end{array}$ & $\begin{array}{c}157 \\
100 \%\end{array}$ \\
\hline
\end{tabular}

As incertezas estratégicas envolvidas nos projetos são mais analisadas pelos gestores do Cluster 2. No Cluster 1 o resultado indica que $80 \%$ dos respondentes desse grupo de empresas analisa as incertezas até o grau moderado apenas.

(B) A contribuição da prospecção do futuro nos processos de análise prospectiva dos projetos

Nota-se que quando se analisa a contribuição da prospecção para subsidiar os processos de análise prospectiva dos projetos, também ocorrem diferenças entre os dois clusters. No Cluster 2 a prospecção é avaliada como mais contribuinte na análise de contextos futuros dos negócios envolvidos no projeto, conforme mostra a tabela a seguir. 
Tabela 39 - Contribuição da prospecção para a análise de contextos futuros dos negócios

\begin{tabular}{|c|c|c|c|c|c|}
\hline \multicolumn{6}{|c|}{$\begin{array}{c}\text { q7_01 As análises e conclusões referentes à prospecção contribuíram para: Análise dos contextos futuros } \\
\begin{array}{c}\text { dos negócios envolvidos no projeto * Ward Method } \\
\text { Tabulação cruzada }\end{array}\end{array}$} \\
\hline & & & \multicolumn{2}{|c|}{ Ward Method } & \multirow{2}{*}{ Total } \\
\hline & & & 1 & 2 & \\
\hline \multirow{5}{*}{$\begin{array}{l}\text { q7_01 As } \\
\text { análises e } \\
\text { conclusões } \\
\text { referentes à } \\
\text { prospecção } \\
\text { contribuíram } \\
\text { para: Análise } \\
\text { dos contextos } \\
\text { futuros dos } \\
\text { negócios } \\
\text { envolvidos no } \\
\text { projeto }\end{array}$} & 1 Nada & $\begin{array}{l}\text { Frequência } \\
\% \text { em Ward Method }\end{array}$ & $\begin{array}{c}5 \\
4,5 \%\end{array}$ & $\begin{array}{c}0 \\
0,0 \%\end{array}$ & $\begin{array}{c}5 \\
3,2 \%\end{array}$ \\
\hline & 2 Pouco & $\begin{array}{l}\text { Frequência } \\
\% \text { em Ward Method }\end{array}$ & $\begin{array}{c}19 \\
17,3 \%\end{array}$ & $\begin{array}{c}0 \\
0,0 \%\end{array}$ & $\begin{array}{c}19 \\
12,1 \%\end{array}$ \\
\hline & 3 Moderadamente & $\begin{array}{l}\text { Frequência } \\
\text { \% em Ward Method }\end{array}$ & $\begin{array}{c}45 \\
\mathbf{4 0 , 9 \%}\end{array}$ & $\begin{array}{c}3 \\
6,4 \%\end{array}$ & $\begin{array}{c}48 \\
30,6 \%\end{array}$ \\
\hline & 4 Muito & $\begin{array}{l}\text { Frequência } \\
\text { \% em Ward Method }\end{array}$ & $\begin{array}{c}34 \\
\mathbf{3 0 , 9 \%}\end{array}$ & $\begin{array}{c}25 \\
\mathbf{5 3 , 2 \%}\end{array}$ & $\begin{array}{c}59 \\
37,6 \%\end{array}$ \\
\hline & 5 Extremamente & $\begin{array}{l}\text { Frequência } \\
\text { \% em Ward Method }\end{array}$ & $\begin{array}{c}7 \\
6,4 \%\end{array}$ & $\begin{array}{c}19 \\
\mathbf{4 0 , 4 \%}\end{array}$ & $\begin{array}{c}26 \\
16,6 \%\end{array}$ \\
\hline \multicolumn{2}{|l|}{ Total } & $\begin{array}{l}\text { Frequência } \\
\text { \% em Ward Method }\end{array}$ & $\begin{array}{c}110 \\
100 \%\end{array}$ & $\begin{array}{c}47 \\
100 \%\end{array}$ & $\begin{array}{c}157 \\
100 \%\end{array}$ \\
\hline
\end{tabular}

Ao se verificar os resultados para a análise do alinhamento do projeto estratégico com a estratégia da organização, nota-se que também o Cluster 2 apresenta melhor avaliação de contribuição da prospecção.

Tabela 40 - Contribuição da prospecção para a análise do alinhamento do projeto estratégico com a estratégia da organização

q7_02 As análises e conclusões referentes à prospecção contribuíram para: Análise do alinhamento do projeto estratégico com a estratégia da organização. * Ward Method Tabulação cruzada

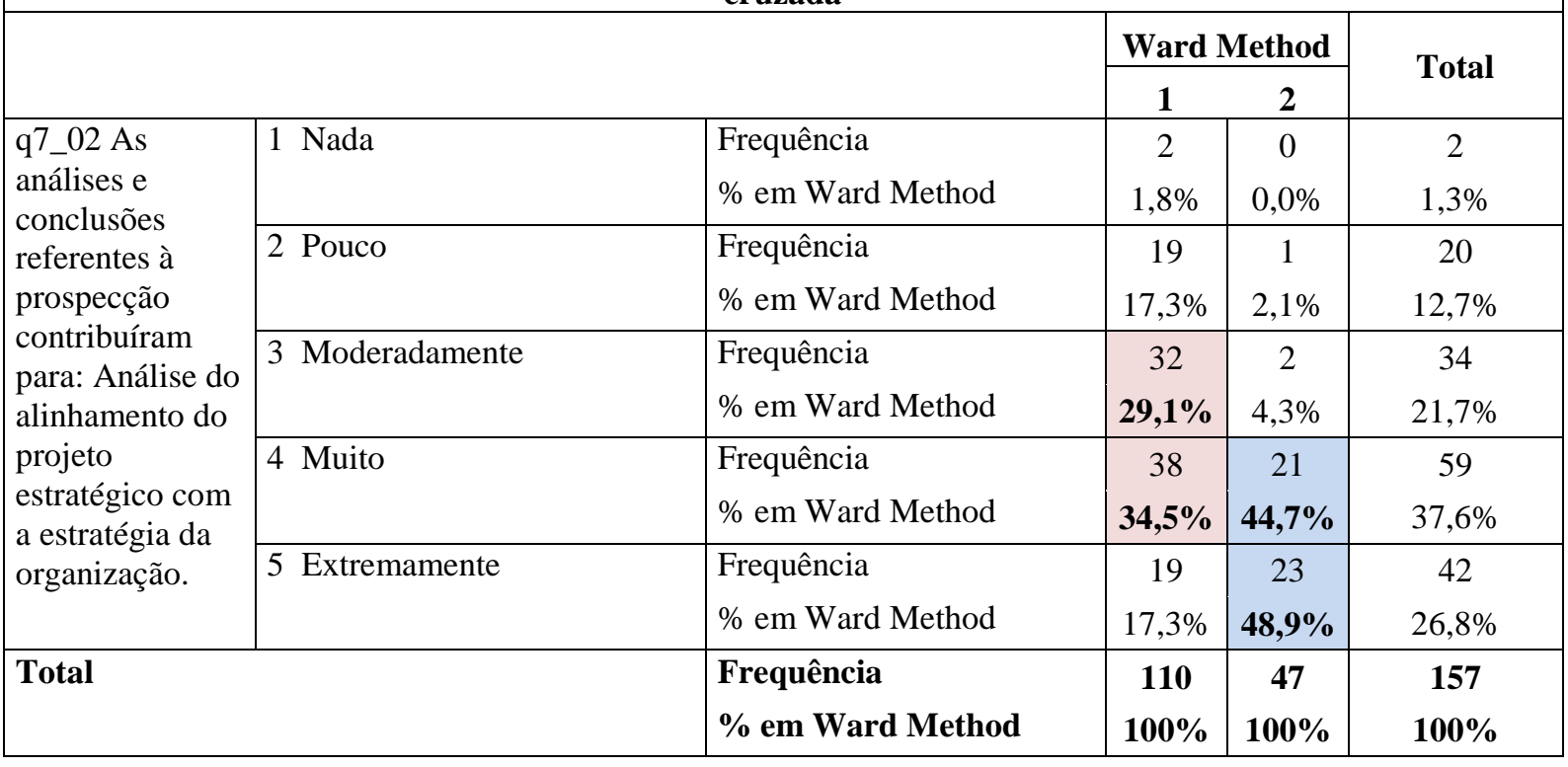


Com relação à análise de calibração de premissas utilizadas nos projetos, o Cluster 2 também resultou em avaliação melhor para a contribuição da prospecção.

Tabela 41 - Contribuição da prospecção para a análise de calibração de premissas utilizadas nos projetos q7_03 As análises e conclusões referentes à prospecção contribuíram para: Calibração de premissas utilizadas no projeto * Ward Method Tabulação cruzada

\begin{tabular}{|c|c|c|c|c|c|}
\hline & & & Ward & Method & Totol \\
\hline & & & 1 & 2 & \\
\hline $\begin{array}{l}\text { q7_03 As análises } \\
\text { e conclusões }\end{array}$ & 1 Nada & $\begin{array}{l}\text { \% em Ward Method } \\
\text { Frequência }\end{array}$ & $\begin{array}{c}4 \\
3,6 \%\end{array}$ & $\begin{array}{c}0 \\
0,0 \%\end{array}$ & $\begin{array}{c}4 \\
2,5 \%\end{array}$ \\
\hline $\begin{array}{l}\text { prospecção } \\
\text { contribuíram }\end{array}$ & 2 Pouco & $\begin{array}{l}\text { \% em Ward Method } \\
\text { Frequência }\end{array}$ & $\begin{array}{c}16 \\
14,5 \%\end{array}$ & $\begin{array}{c}1 \\
2,1 \%\end{array}$ & $\begin{array}{c}17 \\
10,8 \%\end{array}$ \\
\hline $\begin{array}{l}\text { para: Calibração } \\
\text { de premissas } \\
\text { utilizadas no }\end{array}$ & 3 Moderadamente & $\begin{array}{l}\text { \% em Ward Method } \\
\text { Frequência }\end{array}$ & $\begin{array}{c}50 \\
\mathbf{4 5 , 5 \%}\end{array}$ & $\begin{array}{c}10 \\
21,3, \%\end{array}$ & $\begin{array}{c}60 \\
38,2 \%\end{array}$ \\
\hline projeto & 4 Muito & $\begin{array}{l}\text { \% em Ward Method } \\
\text { Frequência }\end{array}$ & $\begin{array}{c}32 \\
\mathbf{2 9 , 1 \%}\end{array}$ & $\begin{array}{c}25 \\
\mathbf{5 3}, \mathbf{2} \%\end{array}$ & $\begin{array}{c}57 \\
36,3 \%\end{array}$ \\
\hline & 5 Extremamente & $\begin{array}{l}\text { \% em Ward Method } \\
\text { Frequência }\end{array}$ & $\begin{array}{c}8 \\
7,3 \%\end{array}$ & $\begin{array}{c}11 \\
\mathbf{2 3}, \mathbf{4 \%}\end{array}$ & $\begin{array}{c}19 \\
12,1 \%\end{array}$ \\
\hline Total & & Frequência & 110 & 47 & 157 \\
\hline & & \% em Ward Method & $100 \%$ & $100 \%$ & $100 \%$ \\
\hline
\end{tabular}

Para o processo de analisar as forças relevantes do futuro que influenciem o projeto, os resultados indicam que o Cluster 2 avalia melhor a contribuição da prospecção para esse processo.

Tabela 42 - Contribuição da prospecção para a análise das forças relevantes do futuro que influenciem o projeto

q7_04 As análises e conclusões referentes à prospecção contribuíram para: Análise de forças relevantes do futuro que influenciem o projeto * Ward Method

Tabulação cruzada

\begin{tabular}{|c|c|c|c|c|c|}
\hline & & & Ward & Method & Total \\
\hline & & & 1 & 2 & \\
\hline $\begin{array}{l}\text { q7_04 As } \\
\text { análises e }\end{array}$ & 1 Nada & $\begin{array}{l}\text { Frequência } \\
\% \text { em Ward Method }\end{array}$ & $\begin{array}{c}5 \\
4,5 \%\end{array}$ & $\begin{array}{c}0 \\
0,0 \%\end{array}$ & $\begin{array}{c}5 \\
3,2 \%\end{array}$ \\
\hline $\begin{array}{l}\text { referentes à } \\
\text { prospecção }\end{array}$ & 2 Pouco & $\begin{array}{l}\text { Frequência } \\
\% \text { em Ward Method }\end{array}$ & $\begin{array}{c}15 \\
13,6 \%\end{array}$ & $\begin{array}{c}0 \\
0,0 \%\end{array}$ & $\begin{array}{c}15 \\
9,6 \%\end{array}$ \\
\hline $\begin{array}{l}\text { contribuíram } \\
\text { para: Análise } \\
\text { de forças }\end{array}$ & 3 Moderadamente & $\begin{array}{l}\text { Frequência } \\
\% \text { em Ward Method }\end{array}$ & $\begin{array}{c}54 \\
49,1 \%\end{array}$ & $\begin{array}{c}8 \\
17,0 \%\end{array}$ & $\begin{array}{c}62 \\
39,5 \%\end{array}$ \\
\hline $\begin{array}{l}\text { relevantes do } \\
\text { futuro que }\end{array}$ & 4 Muito & $\begin{array}{l}\text { Frequência } \\
\% \text { em Ward Method }\end{array}$ & $\begin{array}{c}30 \\
\mathbf{2 7 , 3 \%}\end{array}$ & $\begin{array}{c}22 \\
\mathbf{4 6 , 8} \%\end{array}$ & $\begin{array}{c}52 \\
33,1 \%\end{array}$ \\
\hline projeto & 5 Extremamente & $\begin{array}{l}\text { Frequência } \\
\% \text { em Ward Method }\end{array}$ & $\begin{array}{c}6 \\
5,5 \%\end{array}$ & $\begin{array}{c}17 \\
36,2 \%\end{array}$ & $\begin{array}{c}23 \\
14,6 \%\end{array}$ \\
\hline Total & & Frequência & 110 & 47 & 157 \\
\hline & & \% em Ward Method & $100 \%$ & $100 \%$ & $100 \%$ \\
\hline
\end{tabular}


No processo definir os sinais ou indicadores que sirvam para monitorar o futuro acontecendo (ou começando a acontecer), no âmbito da implantação do projeto, o Cluster 2 avalia melhor a contribuição da prospecção, comparado com o Cluster 1.

Tabela 43- Contribuição da prospecção para definir os sinais ou indicadores que sirvam para monitorar o futuro acontecendo

\begin{tabular}{|c|c|c|c|c|c|}
\hline \multicolumn{6}{|c|}{$\begin{array}{l}\text { q7_05 As análises e conclusões referentes à prospecção contribuíram para: Definição de sinais ou } \\
\text { indicadores que sirvam para monitorar o futuro acontecendo (ou começando a acontecer) no âmbito } \\
\text { da implantação do projeto * Ward Method }\end{array}$} \\
\hline & & & \multicolumn{2}{|c|}{ Ward Method } & \multirow{3}{*}{$\begin{array}{c}\text { Total } \\
4 \\
2,5 \% \\
\end{array}$} \\
\hline & & & 1 & 2 & \\
\hline \multirow{5}{*}{$\begin{array}{l}\text { q7_05 As análises e } \\
\text { conclusões referentes à } \\
\text { prospecção contribuíram } \\
\text { para: Definição de sinais } \\
\text { ou indicadores que } \\
\text { sirvam para monitorar o } \\
\text { futuro acontecendo (ou } \\
\text { começando a acontecer) } \\
\text { no âmbito da } \\
\text { implantação do projeto }\end{array}$} & $1 \mathrm{Nada}$ & $\begin{array}{l}\text { Frequência } \\
\% \text { em Ward Method }\end{array}$ & $\begin{array}{c}4 \\
3,6 \%\end{array}$ & $\begin{array}{c}0 \\
0,0 \%\end{array}$ & \\
\hline & 2 Pouco & $\begin{array}{l}\text { Frequência } \\
\% \text { em Ward Method }\end{array}$ & $\begin{array}{c}33 \\
30,0 \% \\
\end{array}$ & $\begin{array}{c}1 \\
2,1 \% \\
\end{array}$ & $\begin{array}{c}34 \\
21,7 \% \\
\end{array}$ \\
\hline & 3 Moderadamente & $\begin{array}{l}\text { Frequência } \\
\text { \% em Ward Method }\end{array}$ & $\begin{array}{c}42 \\
\mathbf{3 8 , 2} \%\end{array}$ & $\begin{array}{c}15 \\
31,9 \% \\
\end{array}$ & $\begin{array}{c}57 \\
36,3 \% \\
\end{array}$ \\
\hline & 4 Muito & $\begin{array}{l}\text { Frequência } \\
\% \text { em Ward Method }\end{array}$ & $\begin{array}{c}27 \\
\mathbf{2 4 , 5} \%\end{array}$ & $\begin{array}{c}18 \\
\mathbf{3 8 , 3} \%\end{array}$ & $\begin{array}{c}45 \\
28,7 \%\end{array}$ \\
\hline & 5 Extremamente & $\begin{array}{l}\text { Frequência } \\
\text { \% em Ward Method }\end{array}$ & $\begin{array}{c}4 \\
3,6 \%\end{array}$ & $\begin{array}{c}13 \\
27,7 \%\end{array}$ & $\begin{array}{c}17 \\
10,8 \% \\
\end{array}$ \\
\hline \multicolumn{2}{|l|}{ Total } & $\begin{array}{l}\text { Frequência } \\
\text { \% em Ward Method }\end{array}$ & $\begin{array}{c}110 \\
100 \%\end{array}$ & $\begin{array}{c}47 \\
100 \%\end{array}$ & $\begin{array}{c}157 \\
100 \%\end{array}$ \\
\hline
\end{tabular}

Para analisar quanto o projeto estratégico pode influenciar o futuro da organização, a contribuição da prospecção é avaliada melhor pelo Cluster 2, conforme mostrado na tabela a seguir. 
Tabela 44 - Contribuição da prospecção para análise do quanto o projeto pode influenciar os resultados futuros da organização

q7_06 As análises e conclusões referentes à prospecção contribuíram para: Análise do quanto o projeto estratégico pode influenciar os resultados futuros da organização * Ward Method Tabulação cruzada

\begin{tabular}{|c|c|c|c|c|c|}
\hline & & & Ward & Iethod & Tetal \\
\hline & & & 1 & 2 & \\
\hline $\begin{array}{l}\text { q7_06 As } \\
\text { análises e }\end{array}$ & 1 Nada & $\begin{array}{l}\text { Frequência } \\
\% \text { em Ward Method }\end{array}$ & $\begin{array}{c}1 \\
0,9 \%\end{array}$ & $\begin{array}{c}0 \\
0,0 \%\end{array}$ & $\begin{array}{c}1 \\
0,6 \%\end{array}$ \\
\hline $\begin{array}{l}\text { referentes à } \\
\text { prospecção }\end{array}$ & 2 Pouco & $\begin{array}{l}\text { Frequência } \\
\text { \% em Ward Method }\end{array}$ & $\begin{array}{c}11 \\
10,0 \%\end{array}$ & $\begin{array}{c}0 \\
0,0 \%\end{array}$ & $\begin{array}{c}11 \\
7,0 \%\end{array}$ \\
\hline $\begin{array}{l}\text { contribuiram } \\
\text { para: Análise } \\
\text { do quanto o }\end{array}$ & 3 Moderadamente & $\begin{array}{l}\text { Frequência } \\
\text { \% em Ward Method }\end{array}$ & $\begin{array}{c}42 \\
\mathbf{3 8 , 2} \%\end{array}$ & $\begin{array}{c}7 \\
14,9 \%\end{array}$ & $\begin{array}{c}49 \\
31,2 \%\end{array}$ \\
\hline $\begin{array}{l}\text { projeto } \\
\text { estratégico }\end{array}$ & 4 Muito & $\begin{array}{l}\text { Frequência } \\
\% \text { em Ward Method }\end{array}$ & $\begin{array}{c}36 \\
\mathbf{3 2 , 7 \%}\end{array}$ & $\begin{array}{c}22 \\
\mathbf{4 6 , 8 \%}\end{array}$ & $\begin{array}{c}58 \\
36,9 \%\end{array}$ \\
\hline $\begin{array}{l}\text { influenciar os } \\
\text { resultados } \\
\text { futuros da } \\
\text { organização }\end{array}$ & 5 Extremamente & $\begin{array}{l}\text { Frequência } \\
\% \text { em Ward Method }\end{array}$ & $\begin{array}{c}20 \\
18,2 \%\end{array}$ & $\begin{array}{c}18 \\
\mathbf{3 8 , 3 \%}\end{array}$ & $\begin{array}{c}38 \\
24,2 \%\end{array}$ \\
\hline Total & & $\begin{array}{l}\text { Frequência } \\
\text { \% em Ward Method }\end{array}$ & $\begin{array}{c}110 \\
100 \%\end{array}$ & $\begin{array}{c}47 \\
100 \%\end{array}$ & $\begin{array}{c}157 \\
100 \%\end{array}$ \\
\hline
\end{tabular}

Para o processo de simulação, que significa colocar pessoas para analisar a organização no contexto futuro, o Cluster 2 avalia melhor a contribuição da prospecção para esse processo.

Tabela 45 - Contribuição da prospecção para simulação - analisar a organização no contexto futuro q7_07 As análises e conclusões referentes à prospecção contribuíram para: Simulação - colocar pessoas para analisarem a organização dentro do contexto futuro proporcionado pelo projeto * Ward Method Tabulacão cruzada

\begin{tabular}{|c|c|c|c|c|c|}
\hline & & & Ward I & Iethod & Total \\
\hline & & & 1 & 2 & \\
\hline $\begin{array}{l}\text { q7_07 As análises e } \\
\text { conclusões }\end{array}$ & 1 Nada & $\begin{array}{l}\text { Frequência } \\
\% \text { em Ward Method }\end{array}$ & $\begin{array}{c}13 \\
11,8 \%\end{array}$ & $\begin{array}{c}1 \\
2,1 \%\end{array}$ & $\begin{array}{c}14 \\
8,9 \%\end{array}$ \\
\hline $\begin{array}{l}\text { prospecção } \\
\text { contribuíram para: }\end{array}$ & 2 Pouco & $\begin{array}{l}\text { Frequência } \\
\% \text { em Ward Method }\end{array}$ & $\begin{array}{c}40 \\
\mathbf{3 6 , 4 \%}\end{array}$ & $\begin{array}{c}4 \\
8,5 \%\end{array}$ & $\begin{array}{c}44 \\
28,0 \%\end{array}$ \\
\hline $\begin{array}{l}\text { Simulaçao - colocar } \\
\text { pessoas para } \\
\text { analisarem a }\end{array}$ & 3 Moderadamente & $\begin{array}{l}\text { Frequência } \\
\% \text { em Ward Method }\end{array}$ & $\begin{array}{c}38 \\
\mathbf{3 4 , 5 \%}\end{array}$ & $\begin{array}{c}13 \\
\mathbf{2 7 , 7 \%}\end{array}$ & $\begin{array}{c}51 \\
32,5 \%\end{array}$ \\
\hline $\begin{array}{l}\text { organização dentro } \\
\text { do contexto futuro }\end{array}$ & 4 Muito & $\begin{array}{l}\text { Frequência } \\
\% \text { em Ward Method }\end{array}$ & $\begin{array}{c}17 \\
15,5 \%\end{array}$ & $\begin{array}{c}17 \\
\mathbf{3 6 , 2 \%}\end{array}$ & $\begin{array}{c}34 \\
21,7 \%\end{array}$ \\
\hline projeto & 5 Extremamente & $\begin{array}{l}\text { Frequência } \\
\% \text { em Ward Method }\end{array}$ & $\begin{array}{c}2 \\
1,8 \%\end{array}$ & $\begin{array}{c}12 \\
\mathbf{2 5 , 5 \%}\end{array}$ & $\begin{array}{c}14 \\
8,9 \%\end{array}$ \\
\hline Total & & $\begin{array}{l}\text { Frequência } \\
\text { \% em Ward Method }\end{array}$ & $\begin{array}{c}110 \\
100 \%\end{array}$ & $\begin{array}{c}47 \\
100 \%\end{array}$ & $\begin{array}{c}157 \\
100 \%\end{array}$ \\
\hline
\end{tabular}

O estudo de mudanças necessárias na organização teve melhor contribuição da prospecção do futuro para o Cluster 2 do que para o Cluster 1. 
Tabela 46 - Contribuição da prospecção para o estudo de mudanças necessárias na organização q7_08 As análises e conclusões referentes à prospecção contribuíram para: Estudo de mudanças necessárias na organização em função do projeto * Ward Method Tabulação cruzada

\begin{tabular}{|c|c|c|c|c|c|}
\hline & & & Ward & Method & Total \\
\hline & & & 1 & 2 & \\
\hline $\begin{array}{l}\text { q7_08 As } \\
\text { análises e }\end{array}$ & $1 \mathrm{Nada}$ & $\begin{array}{l}\text { Frequência } \\
\% \text { em Ward Method }\end{array}$ & $\begin{array}{c}6 \\
55 \%\end{array}$ & $\begin{array}{c}0 \\
0.0 \%\end{array}$ & $\begin{array}{c}6 \\
38 \%\end{array}$ \\
\hline $\begin{array}{l}\text { referentes à } \\
\text { prospecção }\end{array}$ & 2 Pouco & $\begin{array}{l}\text { Frequência } \\
\text { \% em Ward Method }\end{array}$ & $\begin{array}{c}27 \\
\mathbf{2 4 , 5} \%\end{array}$ & $\begin{array}{c}4 \\
8,5 \%\end{array}$ & $\begin{array}{c}31 \\
19,7 \%\end{array}$ \\
\hline $\begin{array}{l}\text { contribuíram } \\
\text { para: Estudo } \\
\text { de mudanças }\end{array}$ & 3 Moderadamente & $\begin{array}{l}\text { Frequência } \\
\% \text { em Ward Method }\end{array}$ & $\begin{array}{c}43 \\
\mathbf{3 9 , 1 \%}\end{array}$ & $\begin{array}{c}10 \\
21,3 \%\end{array}$ & $\begin{array}{c}53 \\
33,8 \% \\
\end{array}$ \\
\hline $\begin{array}{l}\text { necessárias na } \\
\text { organização }\end{array}$ & 4 Muito & $\begin{array}{l}\text { Frequência } \\
\% \text { em Ward Method }\end{array}$ & $\begin{array}{c}27 \\
24,5 \%\end{array}$ & $\begin{array}{c}18 \\
\mathbf{3 8 , 3} \%\end{array}$ & $\begin{array}{c}45 \\
28,7 \%\end{array}$ \\
\hline projeto & 5 Extremamente & $\begin{array}{l}\text { Frequência } \\
\% \text { em Ward Method }\end{array}$ & $\begin{array}{c}7 \\
6,4 \%\end{array}$ & $\begin{array}{c}15 \\
31,9 \%\end{array}$ & $\begin{array}{c}22 \\
14,0 \%\end{array}$ \\
\hline Total & & $\begin{array}{l}\text { Frequência } \\
\text { \% em Ward Method }\end{array}$ & $\begin{array}{c}110 \\
100 \%\end{array}$ & $\begin{array}{c}47 \\
100 \%\end{array}$ & $\begin{array}{r}157 \\
100 \%\end{array}$ \\
\hline
\end{tabular}

Em relação à análise de necessidades de aprimoramento de competências para implantar o projeto, a contribuição da prospecção também é melhor avaliada pelo Cluster 2.

Tabela 47 - Contribuição da prospecção para a identificação das necessidades de aprimoramento de competências

\begin{tabular}{|c|c|c|c|c|c|}
\hline \multicolumn{6}{|c|}{$\begin{array}{l}\text { q7_09 As análises e conclusões referentes à prospecção contribuíram para: Identificação de } \\
\text { necessidades de aprimoramento de competências para implantar o projeto * Ward Method } \\
\text { Tabulação cruzada }\end{array}$} \\
\hline & & & \multicolumn{2}{|c|}{ Ward Method } & \multirow{2}{*}{ Total } \\
\hline & & & 1 & 2 & \\
\hline \multirow{5}{*}{$\begin{array}{l}\text { q7_09 As análises e } \\
\text { conclusões referentes } \\
\text { à prospecção } \\
\text { contribuíram para: } \\
\text { Identificação de } \\
\text { necessidades de } \\
\text { aprimoramento de } \\
\text { competências para } \\
\text { implantar o projeto }\end{array}$} & 1 Nada & $\begin{array}{l}\text { Frequência } \\
\% \text { em Ward Method }\end{array}$ & $\begin{array}{c}7 \\
6,4 \%\end{array}$ & $\begin{array}{c}0 \\
0,0 \%\end{array}$ & $\begin{array}{c}7 \\
4,5 \%\end{array}$ \\
\hline & 2 Pouco & $\begin{array}{l}\text { Frequência } \\
\% \text { em Ward Method }\end{array}$ & $\begin{array}{c}25 \\
22,7 \%\end{array}$ & $\begin{array}{c}2 \\
4,3 \%\end{array}$ & $\begin{array}{c}27 \\
17,2 \%\end{array}$ \\
\hline & 3 Moderadamente & $\begin{array}{l}\text { Frequência } \\
\% \text { em Ward Method }\end{array}$ & $\begin{array}{c}40 \\
\mathbf{3 6}, \mathbf{4 \%}\end{array}$ & $\begin{array}{c}7 \\
14,9 \%\end{array}$ & $\begin{array}{c}47 \\
29,9 \%\end{array}$ \\
\hline & 4 Muito & $\begin{array}{l}\text { Frequência } \\
\% \text { em Ward Method }\end{array}$ & $\begin{array}{c}28 \\
\mathbf{2 5 , 5 \%}\end{array}$ & $\begin{array}{c}22 \\
\mathbf{4 6 , 8 \%}\end{array}$ & $\begin{array}{c}50 \\
31,8 \% \\
\end{array}$ \\
\hline & 5 Extremamente & $\begin{array}{l}\text { Frequência } \\
\% \text { em Ward Method }\end{array}$ & $\begin{array}{c}10 \\
9,1 \%\end{array}$ & $\begin{array}{c}16 \\
\mathbf{3 4 , 0} \%\end{array}$ & $\begin{array}{c}26 \\
16,6 \%\end{array}$ \\
\hline \multicolumn{2}{|l|}{ Total } & $\begin{array}{l}\text { Frequência } \\
\text { \% em Ward Method }\end{array}$ & $\begin{array}{c}110 \\
100 \%\end{array}$ & $\begin{array}{c}47 \\
100 \%\end{array}$ & $\begin{array}{c}157 \\
100 \%\end{array}$ \\
\hline
\end{tabular}

O exame das incertezas estratégicas envolvidas no projeto tem a contribuição da prospecção como melhor avaliada pelo Cluster 2, para suporte a esse processo de análise prospectiva no projeto. 
Tabela 48 - Contribuição da prospecção para o exame das incertezas estratégicas envolvidas no projeto q7_10 As análises e conclusões referentes à prospecção contribuíram para: Exame das incertezas estratégicas envolvidas no projeto * Ward Method Tabulação cruzada

\begin{tabular}{|c|c|c|c|c|c|}
\hline & & & Ward I & Method & Totol \\
\hline & & & 1 & 2 & \\
\hline q7_10 As & 1 Nada & Frequência & 5 & 0 & 5 \\
\hline análises e & & $\%$ em Ward Method & $4,5 \%$ & $0,0 \%$ & $3,2 \%$ \\
\hline referentes à & 2 Pouco & Frequência & 31 & 2 & 33 \\
\hline prospecção & & $\%$ em Ward Method & $28,2 \%$ & $4,3 \%$ & $21,0 \%$ \\
\hline contribuíram & 3 Moderadamente & Frequência & 42 & 7 & 49 \\
\hline & & $\%$ em Ward Method & $38,2 \%$ & $14,9 \%$ & $31,2 \%$ \\
\hline incertezas & 4 Muito & Frequência & 28 & 24 & 52 \\
\hline estratégicas & & $\%$ em Ward Method & $25,5 \%$ & $51,1 \%$ & $33,1 \%$ \\
\hline no projeto & 5 Extremamente & Frequência & 4 & 14 & 18 \\
\hline & & $\%$ em Ward Method & $3,6 \%$ & $29,8 \%$ & $11,5 \%$ \\
\hline Total & & Frequência & 110 & 47 & 157 \\
\hline & & $\%$ em Ward Method & $100 \%$ & $100 \%$ & $100 \%$ \\
\hline
\end{tabular}

Sintetizando os resultados, o Cluster 2 apresenta sempre melhor avaliação sobre a profundidade em que os processos são praticados, e também sobre a contribuição da prospecção para os processos de análise prospectiva dos projetos, se comparado com o Cluster 1.

Esses processos são recomendados para suporte a análises prospectivas visando apoiar decisões nos projetos estratégicos. Os gestores do Cluster 2 avaliam recorrentemente melhor a profundidade com que se executam os processos, e talvez por decorrência disso, avaliam melhor a contribuição da prospecção para esses processos, se comparados com os gestores do Cluster 1. O Cluster 2 se mostra mais orientado para a prática da prospecção.

Existe, dessa forma, maior atenção à prospecção, maior profundidade de análise prospectiva e finalmente maior contribuição dela nas decisões em projetos de empresas do Cluster 2.

\subsubsection{Processos de análise prospectiva estratégica}

Como mencionado, no questionário foram incluídos alguns processos, também de análise prospectiva, mas que são mais abrangentes que aqueles discutidos na seção anterior. O foco desses processos é tipicamente mais relacionado com estratégia ampla da organização. Eles trazem igualmente a questão da prospecção do futuro como estrutura conceitual, contudo, a 
origem da propensão à análise prospectiva pelo uso desses processos está na estratégia da organização.

Lembrando o que recomendaram autores como Estrada e Almeida (2007), Godet (1994), Dator (2002a), Roney (2010) e Visser e Chermack (2009), a conexão entre prospecção e estratégia é muito importante, e ela tem papel fundamental na tomada de decisões. Por essa razão, esses processos que são mais orientados à estratégia, foram colocados em uma questão separada daquela que contém os processos mais focados no problema de prospecção específico. Estes últimos foram tratados na seção anterior. Cabe mencionar, contudo, que mesmo para esses processos relacionados mais com a estratégia, a questão colocada no questionário colocava os respondentes no contexto dos projetos estratégicos.

Haveria o risco dos respondentes não entenderem porque havia duas questões, perguntando sobre a contribuição da prospecção, contendo processos de análise prospectiva, e não somente uma questão. Este aspecto teve especial atenção no pré-teste realizado, e apenas um dos participantes mencionou isso, sendo que ele concluiu que a separação era uma decisão do pesquisador e, mais importante, isso não afetava sua possibilidade de dar respostas ao instrumento de coleta.

Esclarecido esse ponto, nesta seção está apresentada e discutida a contribuição da prospecção, com foco nos processos de análise prospectiva estratégica. São cinco processos no total, com mais um que era o composto geral dos outros cinco processos. Os resultados estão mostrados a seguir. 
Tabela 49 - Contribuição da prospecção na identificação de lacunas estratégicas

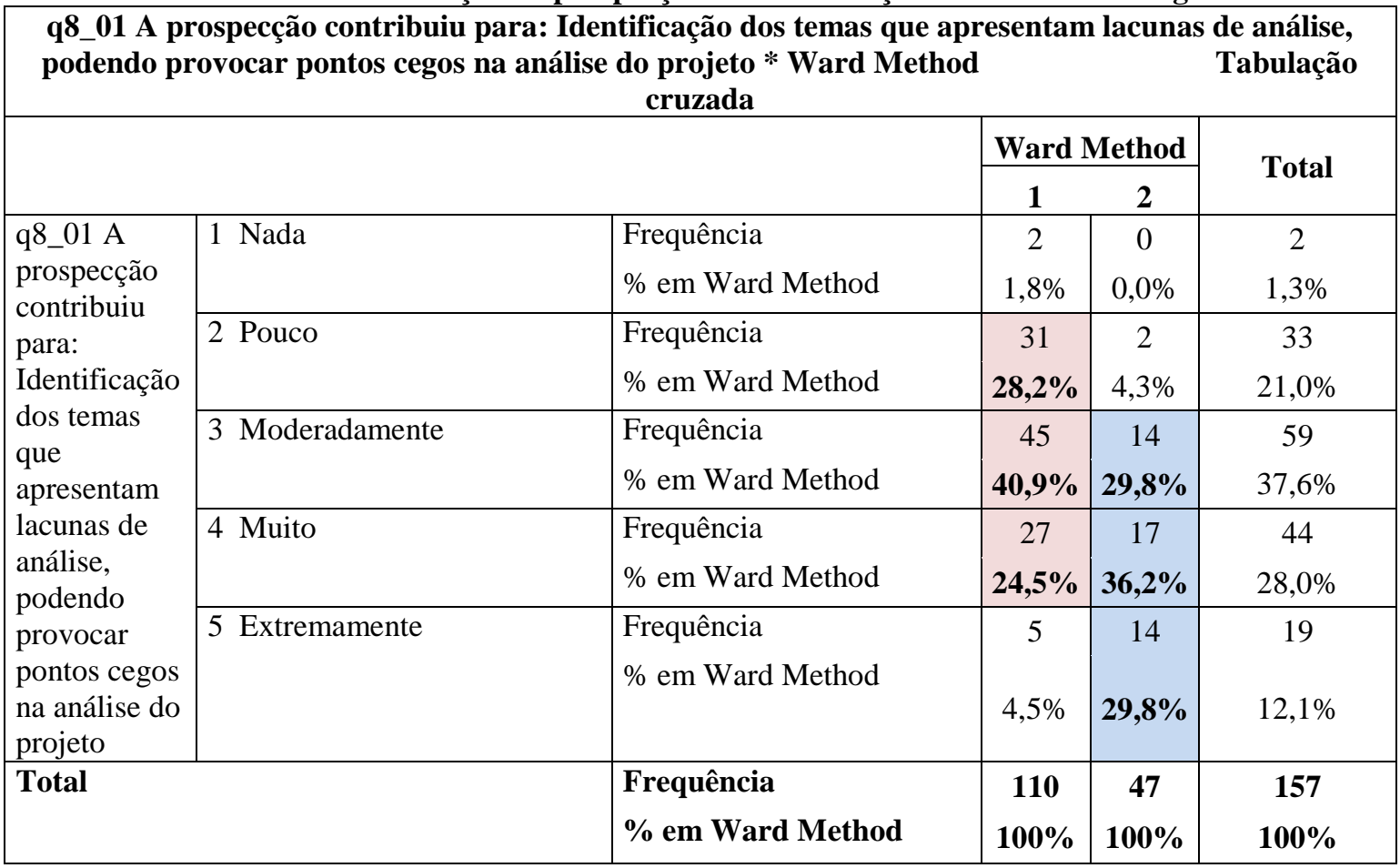

Observa-se pela tabela anterior que os respondentes do Cluster 2 avaliam melhor a contribuição da prospecção para identificar temas que possam representar lacunas, pontos cegos na análise estratégica. Os respondentes deste cluster demonstram conseguir melhor integração entre prospecção e estratégia, se comparados com os respondentes do Cluster 1.

Outro processo de análise prospectiva estratégica está relacionado com o aprimoramento do processo de tomada de decisão. Pelos resultados obtidos (tabela a seguir) se pode notar que os respondentes do Cluster 2 avaliam melhor a contribuição da prospecção para aprimorar o processo decisório na organização. 
Tabela 50 - Contribuição da prospecção para aprimorar a tomada de decisão em projetos estratégicos

\begin{tabular}{|c|c|c|c|c|c|}
\hline \multicolumn{6}{|c|}{$\begin{array}{l}\text { q8_02 A prospecção contribuiu para: Aprimoramento do processo de tomada de decisão no projeto, } \\
\text { por meio da análise das incertezas de futuro } * \text { Ward Method }\end{array}$} \\
\hline & & & \multicolumn{2}{|c|}{ Ward Method } & \multirow{2}{*}{ Total } \\
\hline & & & 1 & 2 & \\
\hline \multirow{10}{*}{$\begin{array}{l}\text { q8_02 A } \\
\text { prospecção } \\
\text { contribuiu para: } \\
\text { Aprimoramento } \\
\text { do processo de } \\
\text { tomada de } \\
\text { decisão no } \\
\text { projeto, por meio } \\
\text { da análise das } \\
\text { incertezas de } \\
\text { futuro }\end{array}$} & 1 Nada & Frequência & 5 & 0 & 5 \\
\hline & & $\%$ em Ward Method & $4,5 \%$ & $0,0 \%$ & $3,2 \%$ \\
\hline & 2 Pouco & Frequência & 18 & 1 & 19 \\
\hline & & $\%$ em Ward Method & $16,4 \%$ & $2,1 \%$ & $12,1 \%$ \\
\hline & 3 Moderadamente & Frequência & 46 & 5 & 51 \\
\hline & & $\%$ em Ward Method & $41,8 \%$ & $10,6 \%$ & $32,5 \%$ \\
\hline & 4 Muito & Frequência & 35 & 23 & 58 \\
\hline & & $\%$ em Ward Method & $31,8 \%$ & $48,9 \%$ & $36,9 \%$ \\
\hline & 5 Extremamente & Frequência & 6 & 18 & 24 \\
\hline & & $\%$ em Ward Method & $5,5 \%$ & $38,3 \%$ & $15,3 \%$ \\
\hline \multicolumn{2}{|l|}{ Total } & $\begin{array}{l}\text { Frequência } \\
\text { \% em Ward Method }\end{array}$ & $\begin{array}{c}110 \\
100 \%\end{array}$ & $\begin{array}{c}47 \\
100 \% \\
\end{array}$ & $\begin{array}{c}157 \\
100 \%\end{array}$ \\
\hline
\end{tabular}

A prospecção é utilizada, dentre outras aplicações, para monitorar temas que podem se tornar estrategicamente relevantes no futuro. No presente é possível que eles não chamem atenção dos gestores, contudo, uma visão prospectiva estratégica pode indicar relevância crescente no horizonte de tempo futuro. Conforme relatado na fundamentação, utilizada para apresentar o modelo conceitual teórico desta pesquisa, a análise prospectiva sobre incertezas de futuro presentes em projetos estratégicos tem, como próxima etapa, um processo de tomada de decisões. E nesse processo os aspectos amplos da estratégia da organização têm peso significativo.

O processo de avaliar que temas podem ganhar relevância estratégica, e dessa forma devam ser monitorados, resultou que o Cluster 2 avalia melhor a contribuição da prospecção para esse processo, conforme a seguir. 
Tabela 51 - Contribuição da prospecção para a identificação de temas estratégicos a serem monitorados q8_03 A prospecção contribuiu para: Identificação de quais os principais temas que devem ser monitorados após o início da implantação do projeto * Ward Method Tabulação cruzada

\begin{tabular}{|c|c|c|c|c|c|}
\hline & & & Ward I & Method & Tetal \\
\hline & & & 1 & 2 & \\
\hline $\begin{array}{l}\text { q8_03 A } \\
\text { prospecção }\end{array}$ & 1 Nada & $\begin{array}{l}\text { Frequência } \\
\% \text { em Ward Method }\end{array}$ & $\begin{array}{c}2 \\
1,8 \%\end{array}$ & $\begin{array}{c}0 \\
0,0 \%\end{array}$ & $\begin{array}{c}2 \\
1,3 \%\end{array}$ \\
\hline $\begin{array}{l}\text { para: } \\
\text { Identificação }\end{array}$ & 2 Pouco & $\begin{array}{l}\text { Frequência } \\
\% \text { em Ward Method }\end{array}$ & $\begin{array}{c}20 \\
18,2 \%\end{array}$ & $\begin{array}{c}1 \\
2,1 \%\end{array}$ & $\begin{array}{c}21 \\
13,4 \%\end{array}$ \\
\hline $\begin{array}{l}\text { de quais os } \\
\text { principais } \\
\text { temas que }\end{array}$ & 3 Moderadamente & $\begin{array}{l}\text { Frequência } \\
\% \text { em Ward Method }\end{array}$ & $\begin{array}{c}38 \\
\mathbf{3 4 , 5 \%}\end{array}$ & $\begin{array}{c}5 \\
10,6 \%\end{array}$ & $\begin{array}{c}43 \\
27,4 \%\end{array}$ \\
\hline $\begin{array}{l}\text { devem ser } \\
\text { monitorados }\end{array}$ & 4 Muito & $\begin{array}{l}\text { Frequência } \\
\% \text { em Ward Method }\end{array}$ & $\begin{array}{c}43 \\
39,1 \%\end{array}$ & $\begin{array}{c}25 \\
\mathbf{5 3 , 2 \%}\end{array}$ & $\begin{array}{c}68 \\
43,3 \%\end{array}$ \\
\hline $\begin{array}{l}\text { da } \\
\text { implantação } \\
\text { do projeto }\end{array}$ & 5 Extremamente & $\begin{array}{l}\text { Frequência } \\
\% \text { em Ward Method }\end{array}$ & $\begin{array}{c}7 \\
6,4 \%\end{array}$ & $\begin{array}{c}16 \\
\mathbf{3 4 , 0 \%}\end{array}$ & $\begin{array}{c}23 \\
14,6 \%\end{array}$ \\
\hline Total & & $\begin{array}{l}\text { Frequência } \\
\text { \% em Ward Method }\end{array}$ & $\begin{array}{c}110 \\
100 \%\end{array}$ & $\begin{array}{c}47 \\
100 \%\end{array}$ & $\begin{array}{c}157 \\
100 \%\end{array}$ \\
\hline
\end{tabular}

Os respondentes do Cluster 2 demonstram, novamente, avaliar melhor a contribuição da prospecção para identificar temas estratégicos relevantes para o futuro da organização.

Sobre identificar as principais tendências e eventos do ambiente, a contribuição da prospecção é percebida, descritivamente, como melhor pelo Cluster 2 do que pelo Cluster 1. A visão estratégica das tendências e dos eventos possíveis deve moldar a análise da estratégia, e a prospecção tem contribuição nesse processo. As empresas do Cluster 1 se mostram menos atentas a esse processo, indicando que nessas empresas pode haver necessidade de algum aprimoramento ou suporte para esse processo, pois quase $2 / 3$ dos respondentes indicaram contribuição no máximo moderada. 
Tabela 52 - Contribuição da prospecção na identificação de tendências e eventos do ambiente q8_04 A prospecção contribuiu para: Identificação de quais as principais tendências e eventos do ambiente futuro, estimando as chances de suas ocorrências. * Ward Method Tabulação cruzada

\begin{tabular}{|c|c|c|c|c|c|}
\hline & & & Ward & Iethod & Total \\
\hline & & & 1 & 2 & \\
\hline $\begin{array}{l}\text { q8_04 A } \\
\text { prospecção }\end{array}$ & $1 \mathrm{Nada}$ & $\begin{array}{l}\text { Frequência } \\
\% \text { em Ward Method }\end{array}$ & $\begin{array}{c}4 \\
3,6 \%\end{array}$ & $\begin{array}{c}0 \\
0,0 \%\end{array}$ & $\begin{array}{c}4 \\
2,5 \%\end{array}$ \\
\hline $\begin{array}{l}\text { para: } \\
\text { Identificação }\end{array}$ & 2 Pouco & $\begin{array}{l}\text { Frequência } \\
\text { \% em Ward Method }\end{array}$ & $\begin{array}{c}22 \\
20,0 \%\end{array}$ & $\begin{array}{c}0 \\
0,0 \%\end{array}$ & $\begin{array}{c}22 \\
14,0 \%\end{array}$ \\
\hline $\begin{array}{l}\text { de quais as } \\
\text { principais } \\
\text { tendências e }\end{array}$ & 3 Moderadamente & $\begin{array}{l}\text { Frequência } \\
\% \text { em Ward Method }\end{array}$ & $\begin{array}{c}40 \\
36,4 \%\end{array}$ & $\begin{array}{c}7 \\
14,9 \%\end{array}$ & $\begin{array}{c}47 \\
29,9 \%\end{array}$ \\
\hline $\begin{array}{l}\text { eventos do } \\
\text { ambiente } \\
\text { futuro. }\end{array}$ & 4 Muito & $\begin{array}{l}\text { Frequência } \\
\text { \% em Ward Method }\end{array}$ & $\begin{array}{c}33 \\
\mathbf{3 0 , 0} \%\end{array}$ & $\begin{array}{c}21 \\
\mathbf{4 4 , 7} \% \\
\end{array}$ & $\begin{array}{c}54 \\
34,4 \% \\
\end{array}$ \\
\hline $\begin{array}{l}\text { estimando as } \\
\text { chances de } \\
\text { suas } \\
\text { ocorrências. }\end{array}$ & 5 Extremamente & $\begin{array}{l}\text { Frequência } \\
\% \text { em Ward Method }\end{array}$ & $\begin{array}{c}11 \\
10,0 \%\end{array}$ & $\begin{array}{c}19 \\
\mathbf{4 0 , 4 \%}\end{array}$ & $\begin{array}{c}30 \\
19,1 \%\end{array}$ \\
\hline Total & & $\begin{array}{l}\text { Frequência } \\
\text { \% em Ward Method }\end{array}$ & $\begin{array}{c}110 \\
100 \%\end{array}$ & $\begin{array}{c}47 \\
100 \%\end{array}$ & $\begin{array}{c}157 \\
100 \%\end{array}$ \\
\hline
\end{tabular}

Ao se analisar as possíveis consequências de alternativas de decisão no projeto estratégico, os gestores podem aprimorar sua visão estratégica ao estimar consequências de suas decisões. $\mathrm{O}$ Cluster 2 avalia que a prospecção contribui mais para esse processo, comparado com o Cluster 1. Dessa forma, na amostra pesquisada se observa que há significativo contingente de empresas que podem estar com limitações no processo de identificação de tendências do ambiente, o que pode causar o fenômeno de surpresas inevitáveis, conforme apontado por Schwartz (2003).

Quanto ao processo de análise das consequências de alternativas de decisão, também o Cluster 2 se mostra mais confiante de que a prospecção contribuiu para explorar como as alternativas de decisão poderiam se desdobrar caso fossem implantadas, conforme a seguir. 
Tabela 53 - Contribuição da prospecção para análise das consequências de alternativas de decisão estratégica

\begin{tabular}{|c|c|c|c|c|c|}
\hline \multicolumn{6}{|c|}{$\begin{array}{c}\text { q8_05 A prospecção contribuiu para: Análise de quais as possíveis consequências de uma alternativa } \\
\text { de decisão no projeto } * \text { Ward Method }\end{array}$} \\
\hline & & & \multicolumn{2}{|c|}{ Ward Method } & \multirow{2}{*}{ Total } \\
\hline & & & 1 & 2 & \\
\hline \multirow{5}{*}{$\begin{array}{l}\text { q8_05 A } \\
\text { prospecção } \\
\text { contribuiu para: } \\
\text { Análise de } \\
\text { quais as } \\
\text { possíveis } \\
\text { consequências } \\
\text { de uma } \\
\text { alternativa de } \\
\text { decisão no } \\
\text { projeto }\end{array}$} & 1 Nada & $\begin{array}{l}\text { Frequência } \\
\% \text { em Ward Method }\end{array}$ & $\begin{array}{c}5 \\
4,5 \%\end{array}$ & $\begin{array}{c}0 \\
0,0 \%\end{array}$ & $\begin{array}{c}5 \\
3,2 \%\end{array}$ \\
\hline & 2 Pouco & $\begin{array}{l}\text { Frequência } \\
\% \text { em Ward Method }\end{array}$ & $\begin{array}{c}23 \\
20,9 \%\end{array}$ & $\begin{array}{c}0 \\
0,0 \%\end{array}$ & $\begin{array}{c}23 \\
14,6 \%\end{array}$ \\
\hline & 3 Moderadamente & $\begin{array}{l}\text { Frequência } \\
\text { \% em Ward Method }\end{array}$ & $\begin{array}{c}41 \\
\mathbf{3 7 , 3 \%}\end{array}$ & $\begin{array}{c}7 \\
14,9 \%\end{array}$ & $\begin{array}{c}48 \\
30,6 \%\end{array}$ \\
\hline & 4 Muito & $\begin{array}{l}\text { Frequência } \\
\text { \% em Ward Method }\end{array}$ & $\begin{array}{c}35 \\
\mathbf{3 1 , 8 \%}\end{array}$ & $\begin{array}{c}25 \\
\mathbf{5 3 , 2 \%}\end{array}$ & $\begin{array}{c}60 \\
38,2 \%\end{array}$ \\
\hline & 5 Extremamente & $\begin{array}{l}\text { Frequência } \\
\% \text { em Ward Method }\end{array}$ & $\begin{array}{c}6 \\
5,5 \%\end{array}$ & $\begin{array}{c}15 \\
\mathbf{3 1 , 9 \%}\end{array}$ & $\begin{array}{c}21 \\
13,4 \%\end{array}$ \\
\hline \multicolumn{2}{|l|}{ Total } & $\begin{array}{l}\text { Frequência } \\
\text { \% em Ward Method }\end{array}$ & $\begin{array}{c}110 \\
100 \%\end{array}$ & $\begin{array}{c}47 \\
100 \%\end{array}$ & $\begin{array}{c}157 \\
100 \%\end{array}$ \\
\hline
\end{tabular}

Em grandes linhas, os processos de análise prospectiva de âmbito da estratégia da organização, tem maior apoio da prospecção do futuro nas empresas do Cluster 2. A prospecção contribui muito ou extremamente em $85 \%$ dos casos do Cluster 2, enquanto apenas $33 \%$ do Cluster 1, conforme mostrado na tabela a seguir.

Tabela 54 - Contribuição geral da prospecção do futuro nos processos de análise prospectiva dos projetos q8_06 De forma geral, quanto a prospecção do futuro contribuiu nos processos acima? * Ward Method Tabulação cruzada

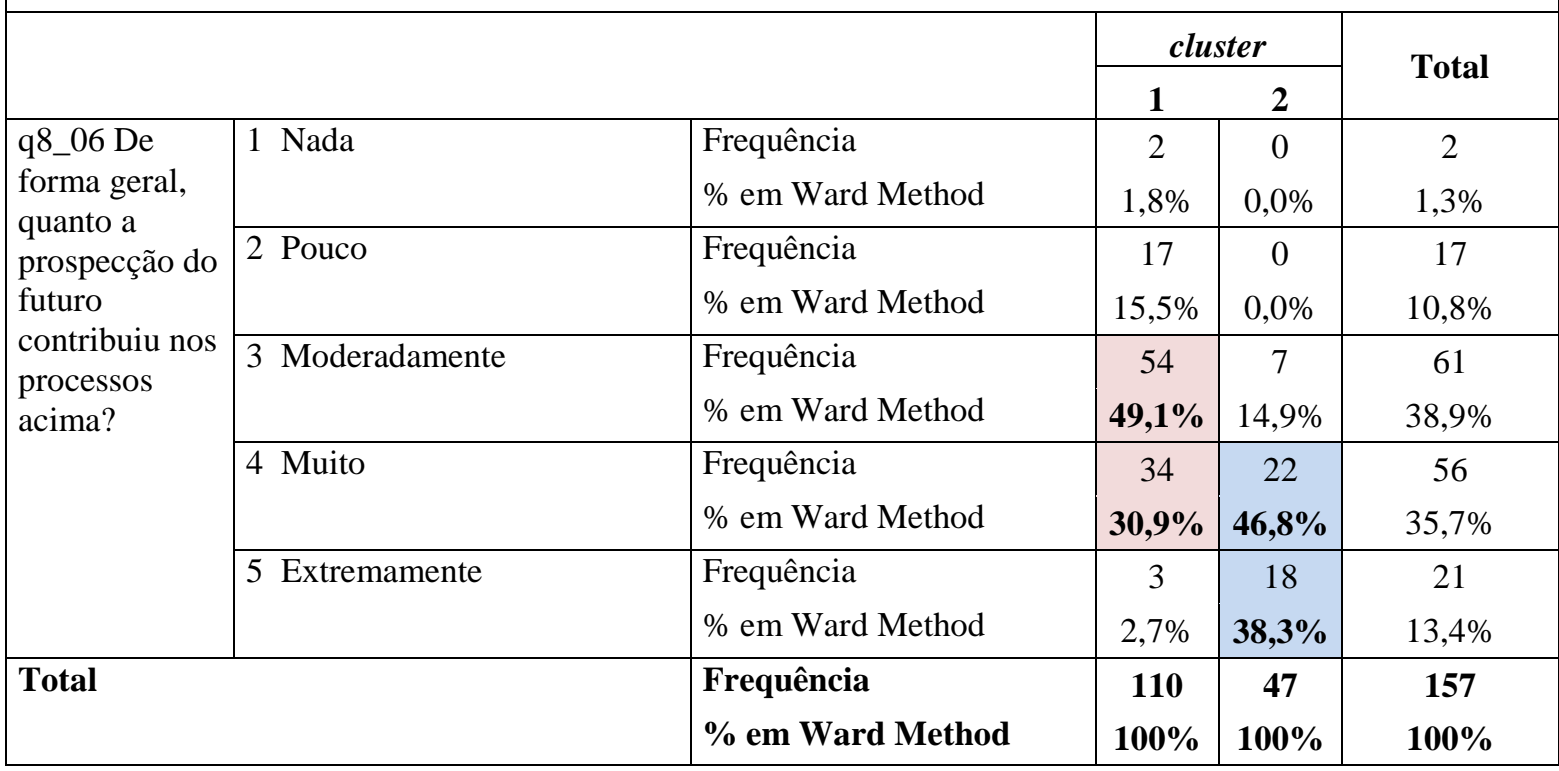


Observa-se pela tabela anterior que a prospecção tende a ser percebida como mais útil, para analisar incertezas de futuro nos projetos estratégicos, pelos gestores do Cluster 2.

Esses resultados sobre os processos de análise estratégica, que faz uso da prospecção como suporte a decisões, mostram que há empresas mais estruturadas para executar os processos, seus gestores avaliam a importância em nível maior, praticam mais os processos de prospecção, conectam a atividade com a estratégia da organização e relatam maior contribuição da prospecção no suporte às decisões. Cabe, contudo, mencionar que a amostra da pesquisa contém mais empresas do Cluster 1, o que significa que há mais empresas que possam estar vivenciando as limitações da menor orientação para a prática da prospecção. Estas empresas estariam, por hipótese, com dificuldades de integrar a prospecção do futuro com a estratégia empresarial.

\subsubsection{Avaliação da atividade de prospecção do futuro}

Quando se analisa a concordância com as afirmações sobre o conhecimento e o domínio das práticas recomendadas de prospecção do futuro, nota-se que há diferenças entre os gestores dos dois clusters. Esse resultado se verifica quanto à concordância com as afirmações da questão 9 do questionário (q9). As tabelas a seguir trazem os resultados.

Tabela 55 - Grau de concordância: No projeto foi avaliado se havia pontos cegos nas análises

\begin{tabular}{|c|c|c|c|c|c|}
\hline \multicolumn{6}{|c|}{$\begin{array}{c}\text { q9_01 Grau de concordância: No projeto foi verificado se havia pontos cegos nas análises * Ward } \\
\text { Method }\end{array}$} \\
\hline & & & \multicolumn{2}{|c|}{ Ward Method } & \multirow{2}{*}{ Total } \\
\hline & & & 1 & 2 & \\
\hline \multirow{5}{*}{$\begin{array}{l}\text { q9_01 Grau de } \\
\text { concordância: } \\
\text { No projeto foi } \\
\text { verificado se } \\
\text { havia pontos } \\
\text { cegos nas } \\
\text { análises }\end{array}$} & 1 Discordo fortemente & $\begin{array}{l}\text { Frequência } \\
\% \text { em Ward Method }\end{array}$ & $\begin{array}{c}14 \\
12,7 \%\end{array}$ & $\begin{array}{c}1 \\
2,1 \%\end{array}$ & $\begin{array}{c}15 \\
9,6 \%\end{array}$ \\
\hline & 2 Discordo parcialmente & $\begin{array}{l}\text { Frequência } \\
\text { \% em Ward Method }\end{array}$ & $\begin{array}{c}26 \\
\mathbf{2 3 , 6} \%\end{array}$ & $\begin{array}{c}1 \\
2,1 \%\end{array}$ & $\begin{array}{c}27 \\
17,2 \%\end{array}$ \\
\hline & $\begin{array}{l}3 \text { Nem discordo nem } \\
\text { concordo }\end{array}$ & $\begin{array}{l}\text { Frequência } \\
\text { \% em Ward Method }\end{array}$ & $\begin{array}{c}28 \\
\mathbf{2 5 , 5 \%}\end{array}$ & $\begin{array}{c}6 \\
12,8 \%\end{array}$ & $\begin{array}{c}34 \\
21,7 \%\end{array}$ \\
\hline & 4 Concordo parcialmente & $\begin{array}{l}\text { Frequência } \\
\text { \% em Ward Method }\end{array}$ & $\begin{array}{c}32 \\
\mathbf{2 9 , 1 \%}\end{array}$ & $\begin{array}{c}19 \\
\mathbf{4 0 , 4 \%}\end{array}$ & $\begin{array}{c}51 \\
32,5 \%\end{array}$ \\
\hline & 5 Concordo fortemente & $\begin{array}{l}\text { Frequência } \\
\% \text { em Ward Method }\end{array}$ & $\begin{array}{c}10 \\
9,1 \%\end{array}$ & $\begin{array}{c}20 \\
42,6 \%\end{array}$ & $\begin{array}{c}30 \\
19,1 \%\end{array}$ \\
\hline \multicolumn{2}{|l|}{ Total } & $\begin{array}{l}\text { Frequência } \\
\text { \% em Ward Method }\end{array}$ & $\begin{array}{c}110 \\
100 \%\end{array}$ & $\begin{array}{c}47 \\
100 \%\end{array}$ & $\begin{array}{c}157 \\
100 \%\end{array}$ \\
\hline
\end{tabular}


Observa-se que os gestores do Cluster 2 tendem a apresentar maior concordância com a afirmação, sendo que 42,6\% concordam fortemente. Esse é um indício de que gestores de empresas mais orientadas à prática da prospecção estejam mais atentos às lacunas estratégicas. Nas entrevistas foi identificado que empresas maiores têm mais ativos em risco, e por consequência seus gestores podem adotar diligência maior em favor da prospecção.

Agora, em se tratando de utilizar os resultados da prospecção na tomada de decisões, o Cluster 2 mostra haver muito mais concordância com a afirmação (74,5\%), comparado com o Cluster $1(31,8 \%)$.

Tabela 56 - Grau de concordância: As análises e conclusões da prospecção foram utilizadas na tomada de decisões

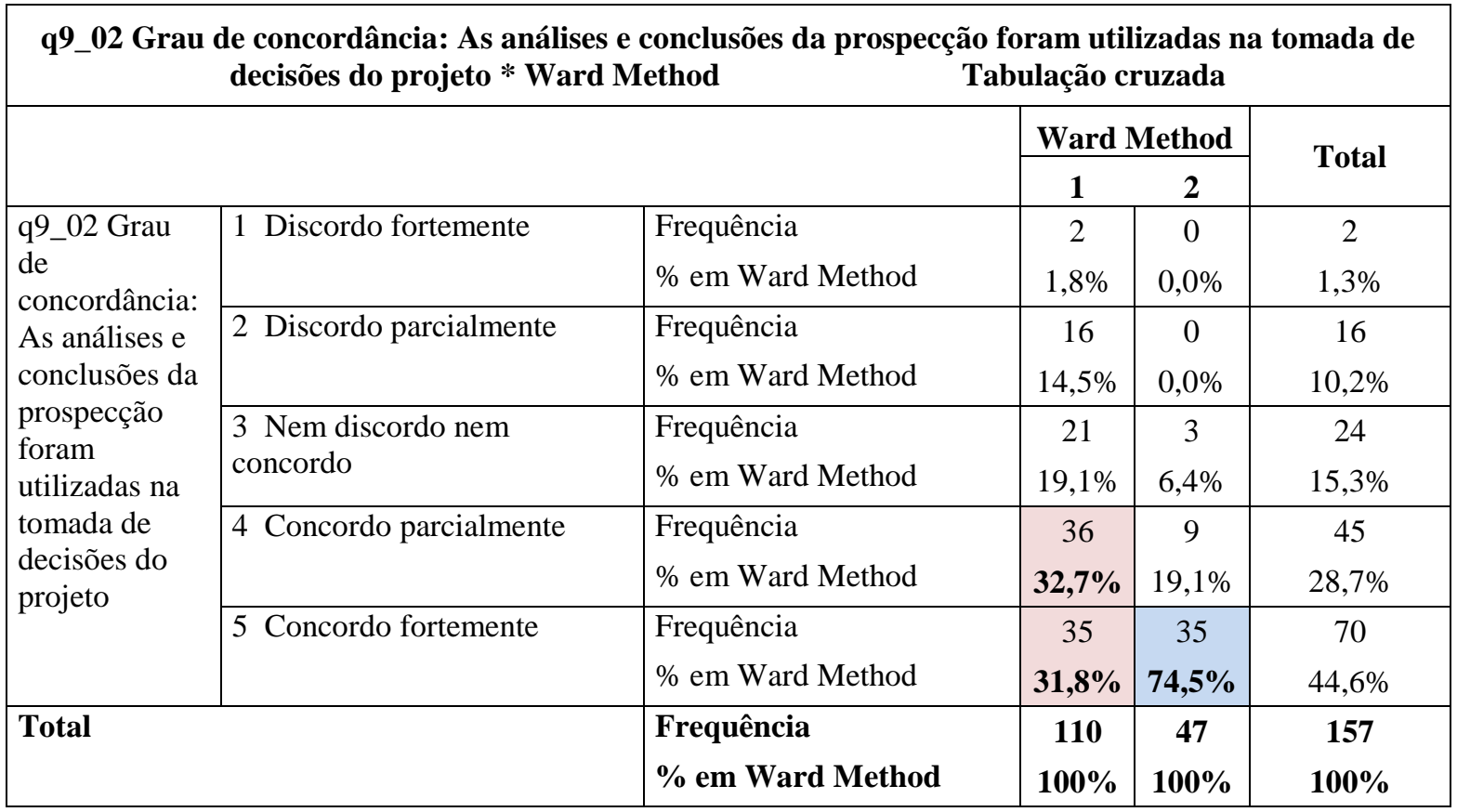

O conhecimento sobre a prospecção do futuro é marcado pela presença de limitações, segundo autores da área, como Chermack (2011). O fato de o futuro ser imprevisível, de não haver a possibilidade de utilizar algum determinismo no processo (MAKRIDAKIS et al, 2009) conflita, de certa forma, com o que as pessoas estejam acostumadas a lidar no mundo corporativo. Por outro lado, se essa limitação é reconhecida, então a mobilização para se mitigar seus efeitos seria natural, o que potencialmente levaria a esforços para se desenvolver conhecimento sobre práticas e recomendações sobre estudos do futuro. 
Os resultados da pesquisa na amostra mostram que isso pode ser uma premissa apenas parcialmente verdadeira. Observa-se que apenas empresas do Cluster 2 parecem ter gestores que concordam mais com a afirmação sobre adequação do conhecimento, e, importante mencionar, mesmo neste grupo de respondentes há 57\% deles que concordam parcialmente com a afirmação, conforme a seguir.

Tabela 57 - Grau de concordância: O conhecimento sobre prospecção do futuro estava adequado para os desafios do projeto

\begin{tabular}{|l|l|l|c|c|c|}
\hline \multicolumn{2}{|c|}{$\begin{array}{l}\text { q9_03 Grau de concordância: O conhecimento de como utilizar os métodos de prospecção estava } \\
\text { adequado para os desafios do projeto * Ward Method }\end{array}$} \\
\hline \multicolumn{2}{|c|}{ Tabulação cruzada } \\
\cline { 2 - 6 } \\
\cline { 2 - 6 }
\end{tabular}

No Cluster 1 há quase 2/3 dos respondentes que discordam em algum grau ou no máximo são indiferentes com essa afirmação, indicando que o conhecimento sobre prospecção pode ser um recurso pouco presente nas empresas com as características deste cluster.

Em geral, os gestores da amostra integral pesquisada formam, coletivamente, uma percepção de limitação sobre a disponibilidade de conhecimento adequado sobre prospecção do futuro nas organizações.

O estudo do futuro pode ter sido adequadamente praticado na organização, ou talvez não, mesmo nos casos em que o conhecimento sobre as práticas e metodologias estivesse disponível. Fatores como a disponibilidade de dados e informações, tempo para desenvolver estudos, ou mesmo recursos financeiros podem influenciar o grau em que a prospecção pode ser adequadamente praticada nas empresas. 
Ao serem perguntados sobre a concordância com a afirmação sobre adequação da prospecção praticada no projeto, as respostas indicam que os respondentes do Cluster 1 apresentam mais discordância do que os do Cluster 2.

Tabela 58 - Grau de concordância: A prospecção do futuro foi adequadamente praticada no projeto q9_04 Grau de concordância: A prospecção do futuro foi adequadamente praticada no projeto * Ward Method Tabulação cruzada

\begin{tabular}{|c|c|c|c|c|c|}
\hline & & & Ward & Method & Tetol \\
\hline & & & 1 & 2 & \\
\hline $\begin{array}{l}\text { q9_04 Grau de } \\
\text { concordância: }\end{array}$ & 1 Discordo fortemente & $\begin{array}{l}\text { Frequência } \\
\% \text { em Ward Method }\end{array}$ & $\begin{array}{c}13 \\
11,8 \%\end{array}$ & $\begin{array}{c}0 \\
0,0 \%\end{array}$ & $\begin{array}{c}13 \\
8,3 \%\end{array}$ \\
\hline $\begin{array}{l}\text { do futuro foi } \\
\text { adequadamente }\end{array}$ & 2 Discordo parcialmente & $\begin{array}{l}\text { Frequência } \\
\% \text { em Ward Method }\end{array}$ & $\begin{array}{c}29 \\
\mathbf{2 6 , 4 \%}\end{array}$ & $\begin{array}{c}3 \\
6,4 \%\end{array}$ & $\begin{array}{c}32 \\
20,4 \%\end{array}$ \\
\hline $\begin{array}{l}\text { praticada no } \\
\text { projeto }\end{array}$ & $\begin{array}{l}3 \text { Nem discordo nem } \\
\text { concordo }\end{array}$ & $\begin{array}{l}\text { Frequência } \\
\% \text { em Ward Method }\end{array}$ & $\begin{array}{c}34 \\
\mathbf{3 0 , 9 \%}\end{array}$ & $\begin{array}{c}2 \\
4,3 \%\end{array}$ & $\begin{array}{c}36 \\
22,9 \%\end{array}$ \\
\hline & 4 Concordo parcialmente & $\begin{array}{l}\text { Frequência } \\
\% \text { em Ward Method }\end{array}$ & $\begin{array}{c}29 \\
\mathbf{2 6 , 4 \%}\end{array}$ & $\begin{array}{c}29 \\
61,7 \%\end{array}$ & $\begin{array}{c}58 \\
36,9 \%\end{array}$ \\
\hline & 5 Concordo fortemente & $\begin{array}{l}\text { Frequência } \\
\% \text { em Ward Method }\end{array}$ & $\begin{array}{c}5 \\
4,5 \%\end{array}$ & $\begin{array}{c}13 \\
27,7 \%\end{array}$ & $\begin{array}{c}18 \\
11,5 \%\end{array}$ \\
\hline Total & & $\begin{array}{l}\text { Frequência } \\
\text { \% em Ward Method }\end{array}$ & $\begin{array}{c}110 \\
100 \%\end{array}$ & $\begin{array}{c}47 \\
100 \%\end{array}$ & $\begin{array}{c}157 \\
100 \%\end{array}$ \\
\hline
\end{tabular}

O resultado da tabela anterior mostra um perfil similar ao obtido para a afirmação sobre o conhecimento sobre prospecção do futuro. No Cluster 2 a concordância é maior, mas mesmo assim ela ocorre predominantemente no nível parcial $(61,7 \%)$. Dessa forma, isso pode ser um indício de que a utilização dos resultados da prospecção não seja uma atividade livre de limitações nas organizações. Esse resultado corrobora o que autores da área de estudos do futuro argumentam, de que um dos principais desafios da prospecção do futuro é a sua contribuição para o apoio nas decisões, sua integração com a estratégia.

Os resultados corroboram as argumentações de autores como Godet (1994), Chermack (2011), Rohrbeck (2011) e Grim (2009) que enfatizam a questão da utilidade dos estudos do futuro, dos seus objetivos e de como eles devem estar estruturados para fazer sentido em um projeto de prospecção. Os três últimos autores ainda vão mais longe, ao mencionarem que ainda faltam estudos que tratem com foco a avaliação da atividade de prospecção.

Por causa dessa lacuna, Grim (2009) e Rohrbeck (2011) vêm desenvolvendo estudos sobre como avaliar a qualidade, ou maturidade da atividade de prospecção do futuro. Esse campo de 
estudo é recente, contudo, a produção acadêmica anterior permite estruturar modelos preliminares bem abrangentes, o que fizeram esses dois autores.

\subsubsection{Empresas EXPLORADORAS ESTRUTURADAS E EXPLORADORAS REATIVAS}

Como mostrado, os resultados indicam haver dois agrupamentos de empresas, sendo que as características que as diferenciam são a forma de controle da empresa, o faturamento anual, o número de funcionários e o horizonte de tempo da prospecção $(\mathrm{p}<0,10)$.

Analisando as características dos dois grupos de empresas, definiu-se que o agrupamento do Cluster 1 teria a denominação EXPLORADORAS REATIVAS (ER), porque trata-se de empresas onde se pratica menos a prospecção do futuro. $\mathrm{O}$ grau em que seus gestores avaliam a contribuição dos resultados da prospecção na tomada de decisão de projetos estratégicos é, também, menor do que avaliam os gestores do outro agrupamento.

Outro aspecto relevante é o fato de que as empresas ER revelam a ocorrência de menor conhecimento sobre prospecção do futuro, e também menor adequação da prática da atividade em suas organizações.

Já as empresas onde se pratica mais a prospecção são aqui denominadas como EXPLORADORAS ESTRUTURADAS (EE), e são assim denominadas devido ao maior comprometimento com a prática prospectiva. Eles demonstram maior domínio de conhecimento e de adequação da prática nas suas organizações. Dessa forma, apresentam maior orientação para a prática da prospecção do futuro, se comparados com os gestores do grupo ER.

$\mathrm{Na}$ amostra pesquisada nesta tese, os respondentes das empresas EE compõem aproximadamente $30 \%$ da amostra, e os do grupo de empresas ER representam $70 \%$.

Nesta seção da tese, são aprofundadas as análises sobre esses dois agrupamentos de empresas, em especial com o objetivo de entender que variáveis podem ser as que definem os agrupamentos.

Ao se analisar os dados coletados, os resultados obtidos mostraram que: 
- Os gestores da amostra consideram importante a prospecção do futuro

- A sua prática está constatada nas organizações

- Há a respectiva contribuição na tomada de decisão em projetos estratégicos

Existe, contudo, uma avaliação decrescente da importância, da prática e da contribuição que seria esperada, conforme mencionado anteriormente. O interesse em aprofundar a análise, comparando os grupos de empresas EE e ER, tem objetivo de explorar as possíveis explicações das diferenças entre os grupos, e assim avaliar se o modelo de suporte à integração entre prospecção e estratégia empresarial poderia ser útil no processo.

A queda na avaliação dos gestores, sobre a importância, a prática e a contribuição da prospecção, é um indício de que a atividade não seja praticada ao nível em que os gestores da amostra gostariam. Em outras palavras, os gestores da amostra gostariam que a profundidade da prática refletisse a importância atribuída; e que também a contribuição dos resultados na tomada de decisões em projetos fosse significativa, refletindo assim a importância atribuída.

Pelos resultados obtidos na amostra de todos os gestores, constatou-se que isso não é totalmente verdade. Dessa forma, a análise dos resultados mostra que a prospecção é uma atividade que não está isenta de limitações ou dificuldades. Por consequência disso, surge a questão:

- A queda nas avaliações da amostra para importância, prática e contribuição da prospecção do futuro será igual para os dois agrupamentos de empresas identificados?

Para elucidar essa questão surgida no aprofundamento da análise, criaram-se variáveis que designam tais diferenças de avaliação. Para as repostas de cada respondente foram realizadas as seguintes operações:

(a) Avaliação de importância menos (-) avaliação de prática. Operacionalmente trata-se de subtrair as avaliações da questão 3 e da questão 4 do questionário (q3 menos q4); 
(b) Avaliação de importância menos (-) avaliação de contribuição. Por meio da subtração das avaliações da questão 3 e da questão 5 (q3 menos q5);

(c) Avaliação da prática menos (-) avaliação de contribuição. Por meio da subtração das avaliações da questão 4 e da questão 5 (q4 menos q5);

(d) Avaliação da prática dos processos de análise prospectiva menos (-) a contribuição da prospecção para esses processos. Por meio da subtração das avaliações das questões 6 e 7 (q6 menos q7).

As variáveis de avaliação originais nas questões são de mensuração ordinal, portanto as subtrações descritas acima geram variáveis criadas de mensuração também ordinal.

Os dados foram analisados em função dessas variáveis criadas na análise.

\subsubsection{Importância e prática da prospecção nos grupos EE e ER}

Para comparar os 2 agrupamentos quanto a essas diferenças (pelas variáveis criadas) procedeu-se à prova de Kolmogorov-Smirnov para 2 amostras, com resultados a seguir:

Tabela 59 - Avaliação da importância menos (-) avaliação da prática da prospecção

\begin{tabular}{|c|c|c|c|c|c|c|c|c|c|c|c|c|c|c|}
\hline \multicolumn{15}{|c|}{ Importância menos Prática (q3menosq4) } \\
\hline \multicolumn{2}{|c|}{ Estatísticas de teste } & 1 & 2 & 3 & 4 & 5 & 6 & 7 & 8 & 9 & 10 & 11 & 12 & 13 \\
\hline \multirow{2}{*}{$\begin{array}{l}\text { Diferenças } \\
\text { Mais } \\
\text { Extremas }\end{array}$} & Absoluto & 0,296 & 0,217 & 0,393 & 0,126 & 0,108 & 0,187 & 0,221 & 0,215 & 0,196 & 0,114 & 0,23 & 0,166 & 0,064 \\
\hline & Negativo & $-0,296$ & $-0,217$ & $-0,393$ & $-0,126$ & $-0,108$ & $-0,187$ & $-0,221$ & $-0,215$ & $-0,196$ & $-0,114$ & $-0,23$ & $-0,166$ & $-0,064$ \\
\hline \multicolumn{2}{|c|}{ Z Kolmogorov-Smirnov } & 1,698 & 1,245 & 2,257 & 0,726 & 0,619 & 1,073 & 1,265 & 1,231 & 1,127 & 0,656 & 1,319 & 0,953 & 0,365 \\
\hline $\mathrm{p}$ & & 0,006 & 0,09 & 0,000 & 0,668 & 0,838 & 0,200 & 0,081 & 0,097 & 0,158 & 0,783 & 0,062 & 0,323 & 0,999 \\
\hline
\end{tabular}

Na tabela anterior, estão representadas as diferenças de avaliação, importância menos prática, para os 12 temas portadores de incertezas de futuro e também para o composto geral de todos eles $\left(13^{\circ}\right.$ na última coluna à direita). 
A legenda dos temas portadores de incertezas de futuro pode ser encontrada no quadro a seguir.

Quadro 13 - Legendas de temas portadores de incertezas de futuro

\begin{tabular}{|ll|}
\hline Legenda: Temas portadores de incertezas de futuro \\
\hline 1 & Analisar e examinar ambiente Político e Governo \\
\hline 2 & Analisar e examinar Economia \\
\hline 3 & Analisar e examinar Sociedade \\
\hline 4 & Analisar e examinar Tecnologia \\
\hline 5 & Analisar e examinar Meio ambiente e sustentabilidade \\
\hline 6 & Analisar e examinar Legislação e regulação setorial \\
\hline 7 & Analisar e examinar Mercado e demanda \\
\hline 8 & Analisar e examinar Insumos e recursos \\
\hline 9 & Analisar e examinar Inovação em Produtos ou Serviços \\
\hline 10 & Analisar e examinar Outras Oportunidades de Negócios \\
\hline 11 & Analisar e examinar Competidores \\
\hline 12 & Analisar e examinar Fornecedores \\
\hline 13 & Em geral, analisar todos os temas acima \\
\hline
\end{tabular}

A diferença entre as avaliações de importância e prática da prospecção, quando positiva, significa que a prática não é avaliada no mesmo nível que a importância. Em outras palavras, a atividade é considerada importante, contudo sua prática possivelmente apresenta limitações.

As diferenças entre importância e prática da prospecção para análise dos temas 1, 2, 3, 7, 8 e 11 têm suas distribuições significativamente diferentes entre os clusters. E descritivamente, pode-se notar que no cluster ER, a proporção de diferenças positivas é maior, ou seja, no cluster ER é mais frequente atribuir maior importância para a análise do tema, do que efetivamente é praticada a prospecção para analisar o tema. Nas demais atividades não foi possível apontar diferença ao nível de significância de 0,10. 
Para o tema Política e Governo, a tabela a seguir mostra que a diferença entre as avaliações de importância e de prática da prospecção é positivamente maior no agrupamento ER (40,9\% com valor 1 e 20,9\% com valor 2$)$ do que no agrupamento $\mathrm{EE}$ (61,7\% com valor 0 e 29,8\% com valor 1). Neste último agrupamento, $61,7 \%$ dos respondentes avaliaram que não há diferença entre importância e prática, o que é um indício de que eles consideram que a prática da prospecção é proporcional à importância atribuída à atividade, para o tema Política e governo.

Tabela 60 - Avaliação da importância menos (-) avaliação da prática da prospecção: Tema Política e Governo

\begin{tabular}{|c|c|c|c|c|}
\hline \multirow{2}{*}{\multicolumn{2}{|c|}{$\begin{array}{c}\text { q3menosq4_01 } \\
\text { (Política e } \\
\text { Governo) - } \\
\text { Ward Method }\end{array}$}} & \multicolumn{2}{|c|}{ cluster } & \multirow{4}{*}{$\begin{array}{c}\text { Total } \\
\\
1 \\
0,60 \%\end{array}$} \\
\hline & & \multirow{3}{*}{$\begin{array}{c}1 \text { Exploradoras } \\
\text { Reativas ER } \\
0 \\
0,00 \% \\
\end{array}$} & \multirow{3}{*}{$\begin{array}{c}2 \text { Exploradoras } \\
\text { Estruturadas } \\
\text { EE }\end{array}$} & \\
\hline 2 & $\mathrm{n}$ & & & \\
\hline & $\%$ & & & \\
\hline \multirow{2}{*}{-1} & $\mathrm{n}$ & 3 & 1 & 4 \\
\hline & $\%$ & $2,70 \%$ & $2,10 \%$ & $2,50 \%$ \\
\hline \multirow{2}{*}{0} & $\mathrm{n}$ & 37 & 29 & 66 \\
\hline & $\%$ & $33,60 \%$ & $61,70 \%$ & $42,00 \%$ \\
\hline \multirow{2}{*}{1} & $\mathrm{n}$ & 45 & 14 & 59 \\
\hline & $\%$ & $40,90 \%$ & $29,80 \%$ & $37,60 \%$ \\
\hline \multirow{2}{*}{2} & $\mathrm{n}$ & 23 & 1 & 24 \\
\hline & $\%$ & $20,90 \%$ & $2,10 \%$ & $15,30 \%$ \\
\hline \multirow{2}{*}{3} & $\mathrm{n}$ & 1 & 1 & 2 \\
\hline & $\%$ & $0,90 \%$ & $2,10 \%$ & $1,30 \%$ \\
\hline \multirow{2}{*}{4} & $\mathrm{n}$ & 1 & 0 & 1 \\
\hline & $\%$ & $0,90 \%$ & $0,00 \%$ & $0,60 \%$ \\
\hline \multirow{2}{*}{ Total } & $\mathbf{n}$ & 110 & 47 & 157 \\
\hline & $\%$ & $100 \%$ & $100 \%$ & $100 \%$ \\
\hline
\end{tabular}


Para o tema Economia, a tabela a seguir mostra que os resultados também indicam que empresas ER tendem a avaliar que a prática da prospecção se dá em grau menor do que a importância atribuída à atividade, $40 \%$ com valor 1 e mais $20 \%$ para valores 2 e 3. Já as empresas EE têm 57,4\% com valor 0 , ou seja, a prática é proporcional à importância de prospectar o tema Economia. Os resultados estão mostrados na tabela a seguir.

Tabela 61 - Avaliação da importância menos (-) avaliação da prática da prospecção: Tema Economia

\begin{tabular}{|c|c|c|c|c|}
\hline \multirow{2}{*}{\multicolumn{2}{|c|}{$\begin{array}{c}\text { q3menosq4_02 } \\
\text { (Economia) - } \\
\text { Ward Method }\end{array}$}} & \multicolumn{2}{|c|}{ cluster } & \multirow{4}{*}{$\begin{array}{c}\text { Total } \\
1 \\
0,60 \% \\
\end{array}$} \\
\hline & & $\begin{array}{c}1 \text { Exploradoras } \\
\text { Reativas ER }\end{array}$ & $\begin{array}{c}2 \text { Exploradoras } \\
\text { Estruturadas }\end{array}$ & \\
\hline \multirow{2}{*}{-2} & $\mathrm{n}$ & 1 & 0 & \\
\hline & $\%$ & $0,90 \%$ & $0,00 \%$ & \\
\hline \multirow{2}{*}{-1} & $\mathrm{n}$ & 6 & 2 & 8 \\
\hline & $\%$ & $5,50 \%$ & $4,30 \%$ & $5,10 \%$ \\
\hline \multirow{2}{*}{0} & $\mathrm{n}$ & 37 & 27 & 64 \\
\hline & $\%$ & $33,60 \%$ & $57,40 \%$ & $40,80 \%$ \\
\hline \multirow{2}{*}{1} & $\mathrm{n}$ & 44 & 14 & 58 \\
\hline & $\%$ & $40,00 \%$ & $29,80 \%$ & $36,90 \%$ \\
\hline \multirow{2}{*}{2} & $\mathrm{n}$ & 18 & 4 & 22 \\
\hline & $\%$ & $16,40 \%$ & $8,50 \%$ & $14,00 \%$ \\
\hline \multirow{2}{*}{3} & $\mathrm{n}$ & 4 & 0 & 4 \\
\hline & $\%$ & $3,60 \%$ & $0,00 \%$ & $2,50 \%$ \\
\hline \multirow{2}{*}{ Total } & n & 110 & 47 & 157 \\
\hline & $\%$ & $100 \%$ & $100 \%$ & $100 \%$ \\
\hline
\end{tabular}


Para o tema Sociedade, os resultados mostram que no agrupamento ER se observa 44,5\% com valor 1, enquanto que as EE têm apenas 19,1\% para esse valor. Já para o valor 0, as empresas EE têm 59,6\%, ao passo que as empresas ER têm 30\%. Novamente as empresas EE têm mais respondentes que consideram que a importância da prospecção está levando a organização a praticá-la na devida proporção, com 59,6\% avaliando não haver diferença entre importância e prática (valor 0), conforme mostrado na tabela a seguir.

Tabela 62 - Avaliação da importância menos (-) avaliação da prática da prospecção: Tema Sociedade

\begin{tabular}{|c|c|c|c|c|}
\hline & & clu & ter & \\
\hline $\begin{array}{r}\text { q3me } \\
\text { (Socieda } \\
\mathbf{M}\end{array}$ & $\begin{array}{l}\quad 03 \\
\text { Ward }\end{array}$ & $\begin{array}{l}1 \text { Exploradoras } \\
\text { Reativas ER }\end{array}$ & $\begin{array}{c}2 \text { Exploradoras } \\
\text { Estruturadas } \\
\text { EE }\end{array}$ & Total \\
\hline 1 & $\mathrm{n}$ & 8 & 8 & 16 \\
\hline & $\%$ & $7,30 \%$ & $17,00 \%$ & $10,20 \%$ \\
\hline 0 & $\mathrm{n}$ & 33 & 28 & 61 \\
\hline & $\%$ & $30,00 \%$ & $59,60 \%$ & $38,90 \%$ \\
\hline 1 & $\mathrm{n}$ & 49 & 9 & 58 \\
\hline & $\%$ & $44,50 \%$ & $19,10 \%$ & $36,90 \%$ \\
\hline 2 & $\mathrm{n}$ & 17 & 2 & 19 \\
\hline 2 & $\%$ & $15,50 \%$ & $4,30 \%$ & $12,10 \%$ \\
\hline 3 & $\mathrm{n}$ & 3 & 0 & 3 \\
\hline 3 & $\%$ & $2,70 \%$ & $0,00 \%$ & $1,90 \%$ \\
\hline Totol & $\mathbf{n}$ & 110 & 47 & 157 \\
\hline & $\%$ & $100 \%$ & $100 \%$ & $100 \%$ \\
\hline
\end{tabular}


Para o tema Mercado e Demanda, os resultados da tabela a seguir mostram que o Cluster 1 (ER) tem as diferenças mais positivas, o que reflete que a prática se dá em nível abaixo do que a importância atribuída. Esse resultado indica que, mesmo para um tema que tem relação direta com os resultados da empresa, os gestores das empresas ER mostram que têm atenção menor com a prospecção, se comparados com os das empresas EE.

Tabela 63 - Avaliação da importância menos (-) avaliação da prática da prospecção: Tema Mercado e Demanda

\begin{tabular}{|c|c|c|c|c|}
\hline \multirow{2}{*}{\multicolumn{2}{|c|}{$\begin{array}{c}\text { q3menosq4_07 } \\
\text { (Mercado e } \\
\text { Demanda) - } \\
\text { Ward Method }\end{array}$}} & \multicolumn{2}{|c|}{ cluster } & \multirow[b]{2}{*}{ Total } \\
\hline & & \multirow{3}{*}{$\begin{array}{c}\mathbf{1} \\
\text { Exploradoras } \\
\text { Reativas ER } \\
0 \\
0,00 \%\end{array}$} & \multirow{3}{*}{$\begin{array}{c}\mathbf{2} \\
\text { Exploradoras } \\
\begin{array}{c}\text { Estruturadas } \\
\text { EE }\end{array} \\
1 \\
2,10 \%\end{array}$} & \\
\hline-2 & $\mathrm{n}$ & & & 1 \\
\hline & $\%$ & & & $0,60 \%$ \\
\hline \multirow{2}{*}{-1} & $\mathrm{n}$ & 9 & 4 & 13 \\
\hline & $\%$ & $8,20 \%$ & $8,50 \%$ & $8,30 \%$ \\
\hline \multirow{2}{*}{0} & $\mathrm{n}$ & 51 & 31 & 82 \\
\hline & $\%$ & $46,40 \%$ & $66,00 \%$ & $52,20 \%$ \\
\hline \multirow{2}{*}{1} & $\mathrm{n}$ & 37 & 10 & 47 \\
\hline & $\%$ & $33,60 \%$ & $21,30 \%$ & $29,90 \%$ \\
\hline \multirow{2}{*}{2} & $\mathrm{n}$ & 11 & 1 & 12 \\
\hline & $\%$ & $10,00 \%$ & $2,10 \%$ & $7,60 \%$ \\
\hline \multirow{2}{*}{3} & $\mathrm{n}$ & 1 & 0 & 1 \\
\hline & $\%$ & $0,90 \%$ & $0,00 \%$ & $0,60 \%$ \\
\hline \multirow{2}{*}{4} & $\mathrm{n}$ & 1 & 0 & 1 \\
\hline & $\%$ & $0,90 \%$ & $0,00 \%$ & $0,60 \%$ \\
\hline \multirow{2}{*}{ Total } & $\mathbf{n}$ & 110 & 47 & 157 \\
\hline & $\%$ & $100 \%$ & $100 \%$ & $100 \%$ \\
\hline
\end{tabular}


Em relação ao tema Insumos e Recursos, os resultados da tabela a seguir mostram que no agrupamento ER há mais respondentes que avaliam a prática como sendo proporcionalmente menor que a importância, se comparado com o grupo de empresas EE.

Tabela 64 - Avaliação da importância menos (-) avaliação da prática da prospecção: Tema Insumos e Recursos

\begin{tabular}{|c|c|c|c|c|}
\hline \multirow{2}{*}{\multicolumn{2}{|c|}{$\begin{array}{c}\text { q3menoq4_08 (Insumos } \\
\text { e Recursos) - Ward } \\
\text { Method }\end{array}$}} & \multicolumn{2}{|c|}{ cluster } & \multirow{3}{*}{$\begin{array}{c}\text { Total } \\
\\
1 \\
0,60 \% \\
\end{array}$} \\
\hline & & $\begin{array}{l}1 \text { Exploradoras } \\
\text { Reativas ER }\end{array}$ & $\begin{array}{c}2 \text { Exploradoras } \\
\text { Estruturadas } \\
\text { EE }\end{array}$ & \\
\hline-3 & $\begin{array}{l}\mathrm{n} \\
\%\end{array}$ & $\begin{array}{c}1 \\
0,90 \% \\
\end{array}$ & $\begin{array}{c}0 \\
0,00 \% \\
\end{array}$ & \\
\hline-2 & $\begin{array}{l}\mathrm{n} \\
\%\end{array}$ & $\begin{array}{c}6 \\
5,50 \%\end{array}$ & $\begin{array}{c}3 \\
6,40 \%\end{array}$ & $\begin{array}{c}9 \\
5,70 \%\end{array}$ \\
\hline-1 & $\begin{array}{l}\mathrm{n} \\
\%\end{array}$ & $\begin{array}{c}12 \\
10,90 \% \\
\end{array}$ & $\begin{array}{c}8 \\
17,00 \% \\
\end{array}$ & $\begin{array}{c}20 \\
12,70 \% \\
\end{array}$ \\
\hline 0 & $\begin{array}{l}\mathrm{n} \\
\%\end{array}$ & $\begin{array}{c}44 \\
\mathbf{4 0 , 0 0 \%} \\
\end{array}$ & $\begin{array}{c}26 \\
\mathbf{5 5 , 3 0 \%} \\
\end{array}$ & $\begin{array}{c}70 \\
44,60 \% \\
\end{array}$ \\
\hline 1 & $\begin{array}{l}\mathrm{n} \\
\%\end{array}$ & $\begin{array}{c}33 \\
30,00 \%\end{array}$ & $\begin{array}{c}10 \\
21,30 \%\end{array}$ & $\begin{array}{c}43 \\
27,40 \% \\
\end{array}$ \\
\hline 2 & $\begin{array}{l}\mathrm{n} \\
\%\end{array}$ & $\begin{array}{c}13 \\
11,80 \% \\
\end{array}$ & $\begin{array}{c}0 \\
0,00 \% \\
\end{array}$ & $\begin{array}{c}13 \\
8,30 \% \\
\end{array}$ \\
\hline 3 & $\begin{array}{l}\mathrm{n} \\
\%\end{array}$ & $\begin{array}{c}1 \\
0,90 \%\end{array}$ & $\begin{array}{c}0 \\
0,00 \%\end{array}$ & $\begin{array}{c}1 \\
0,60 \%\end{array}$ \\
\hline Total & $\begin{array}{l}\mathbf{n} \\
\%\end{array}$ & $\begin{array}{c}110 \\
100 \%\end{array}$ & $\begin{array}{c}47 \\
100 \%\end{array}$ & $\begin{array}{c}157 \\
100 \%\end{array}$ \\
\hline
\end{tabular}


$\mathrm{Na}$ próxima tabela estão os resultados para o tema Competidores. Nota-se que para as empresas ER 42,7\% avaliam importância e prática no mesmo nível, enquanto para as empresas EE são 70,2\%.

Tabela 65 - Avaliação da importância menos (-) avaliação da prática da prospecção: Tema Competidores

\begin{tabular}{|c|c|c|c|c|}
\hline \multirow{2}{*}{\multicolumn{2}{|c|}{$\begin{array}{c}\text { q3menoq4_11 } \\
\text { (Competidores) - Ward } \\
\text { Method }\end{array}$}} & \multicolumn{2}{|c|}{ cluster } & \multirow[b]{2}{*}{ Total } \\
\hline & & $\begin{array}{l}1 \text { Exploradoras } \\
\text { Reativas ER }\end{array}$ & $\begin{array}{c}2 \text { Exploradoras } \\
\text { Estruturadas }\end{array}$ & \\
\hline \multirow{2}{*}{-3} & $\mathrm{n}$ & 1 & 0 & 1 \\
\hline & $\%$ & $0,90 \%$ & $0,00 \%$ & $0,60 \%$ \\
\hline \multirow{2}{*}{-2} & $\mathrm{n}$ & 2 & 2 & 4 \\
\hline & $\%$ & $1,80 \%$ & $4,30 \%$ & $2,50 \%$ \\
\hline \multirow{2}{*}{-1} & $\mathrm{n}$ & 16 & 4 & 20 \\
\hline & $\%$ & $14,50 \%$ & $8,50 \%$ & $12,70 \%$ \\
\hline \multirow{2}{*}{0} & $\mathrm{n}$ & 47 & 33 & 80 \\
\hline & $\%$ & $42,70 \%$ & $70,20 \%$ & $51,00 \%$ \\
\hline \multirow{2}{*}{1} & $\mathrm{n}$ & 27 & 8 & 35 \\
\hline & $\%$ & $24,50 \%$ & $17,00 \%$ & $22,30 \%$ \\
\hline \multirow{2}{*}{2} & $\mathrm{n}$ & 16 & 0 & 16 \\
\hline & $\%$ & $14,50 \%$ & $0,00 \%$ & $10,20 \%$ \\
\hline \multirow{2}{*}{3} & $\mathrm{n}$ & 1 & 0 & 1 \\
\hline & $\%$ & $0,90 \%$ & $0,00 \%$ & $0,60 \%$ \\
\hline \multirow{2}{*}{ Total } & $\mathbf{n}$ & 110 & 47 & 157 \\
\hline & $\%$ & $100 \%$ & $100 \%$ & $100 \%$ \\
\hline
\end{tabular}

Em síntese, a diferença entre as avaliações de importância e prática, para os grupos de empresas ER e EE, mostra que para os temas Política e Governo, Economia, Sociedade, Mercado e Demanda, Insumos e Recursos e Competidores, o grupo de empresas mais estruturadas (EE) tende a gerar diferenças menores do que o grupo ER. Para esses temas, as empresas EE avaliam a prática da prospecção de forma mais aproximada ao grau em que avaliam a importância da atividade. Em outras palavras, a mobilização para prospectar é maior nesses temas para empresas EE, comparando com empresas ER. 


\subsubsection{Importância e contribuição da prospecção nos grupos EE e ER}

A análise dos resultados, quando se compara os dois agrupamentos de empresas, e considerando a importância da prospecção e a sua contribuição para o processo de tomada de decisão em projetos, mostra também que há diferenças entre empresas ER e EE.

A tabela a seguir traz os resultados gerais para cada um dos temas portadores de incertezas de futuro.

Tabela 66 - Avaliação da importância menos (-) avaliação da contribuição da prospecção

\begin{tabular}{|c|c|c|c|c|c|c|c|c|c|c|c|c|c|c|}
\hline \multicolumn{15}{|c|}{ Importância menos Contribuição (q3menosq5) } \\
\hline \multicolumn{2}{|c|}{ Estatísticas de teste } & 1 & 2 & 3 & 4 & 5 & 6 & 7 & 8 & 9 & 10 & 11 & 12 & 13 \\
\hline \multirow{3}{*}{$\begin{array}{l}\text { Diferenças } \\
\text { Mais } \\
\text { Extremas }\end{array}$} & Absoluto & 0,215 & 0,265 & 0,263 & 0,114 & 0,22 & 0,232 & 0,248 & 0,275 & 0,178 & 0,082 & 0,147 & 0,123 & 0,138 \\
\hline & Positivo & 0,018 & 0,051 & 0 & 0,006 & 0,009 & 0,009 & 0 & 0,091 & 0,036 & 0,055 & 0,024 & 0,064 & 0,138 \\
\hline & Negativo & $\overline{0,215}$ & $0, \overline{265}$ & 0,263 & $0, \overline{114}$ & $-0,22$ & $0, \overline{232}$ & $\begin{array}{c}- \\
0,248\end{array}$ & $\begin{array}{c}- \\
0,275\end{array}$ & $0, \overline{178}$ & 0,082 & $0, \overline{147}$ & $\begin{array}{c}- \\
0,123\end{array}$ & $\overline{-}$ \\
\hline \multicolumn{2}{|c|}{$\begin{array}{l}\text { Z Kolmogorov- } \\
\text { Smirnov }\end{array}$} & 1,233 & 1,523 & 1,512 & 0,655 & 1,263 & 1,334 & 1,422 & 1,577 & 1,02 & 0,468 & 0,846 & 0,707 & 0,791 \\
\hline \multicolumn{2}{|c|}{$\mathrm{p}$} & 0,096 & 0,019 & 0,021 & 0,784 & 0,082 & 0,057 & 0,035 & 0,014 & 0,249 & 0,981 & 0,472 & 0,699 & 0,558 \\
\hline
\end{tabular}

A legenda de temas está reproduzida aqui para facilitar a leitura.

Quadro 14 - Legendas de temas portadores de incertezas de futuro

\begin{tabular}{|ll|}
\hline Legenda: Temas portadores de incertezas de futuro \\
\hline 1 & Analisar e examinar ambiente Político e Governo \\
\hline 2 & Analisar e examinar Economia \\
\hline 3 & Analisar e examinar Sociedade \\
\hline 4 & Analisar e examinar Tecnologia \\
\hline 5 & Analisar e examinar Meio ambiente e sustentabilidade \\
\hline 6 & Analisar e examinar Legislação e regulação setorial \\
\hline 7 & Analisar e examinar Mercado e demanda \\
\hline 8 & Analisar e examinar Insumos e recursos \\
\hline 9 & Analisar e examinar Inovação em Produtos ou Serviços \\
\hline 10 & Analisar e examinar Outras Oportunidades de Negócios \\
\hline 11 & Analisar e examinar Competidores \\
\hline 12 & Analisar e examinar Fornecedores \\
\hline 13 & Em geral, analisar todos os temas acima \\
\hline
\end{tabular}


As diferenças entre a avaliação da importância e a da contribuição da prospecção na tomada de decisão, referente aos temas 1, 2, 3, 5, 6, 7 e 8 têm suas distribuições significativamente diferentes entre os clusters. E descritivamente, pode-se notar que: Para empresas ER, a proporção de diferenças positivas é maior, ou seja, no cluster ER é mais frequente conceder avaliação maior para importância do que para contribuição da prospecção na tomada de decisão. Portanto, para empresas ER a contribuição da prospecção é proporcionalmente menor do que nas empresas EE. Nas demais atividades não foi possível apontar diferença ao nível de significância de 0,10 .

Na tabela a seguir são mostrados os resultados para as diferenças entre importância e contribuição, para o tema Política e Governo. Nota-se que há maior proporção de resultados positivos para o agrupamento ER, o que indica que este grupo de respondentes avalia que a contribuição da prospecção não está no mesmo nível avaliado pelas EE, para o tema Política e Governo.

Tabela 67 - Avaliação da importância menos (-) avaliação da contribuição da prospecção: Tema Política e Governo

\begin{tabular}{|c|c|c|c|c|}
\hline \multirow{2}{*}{\multicolumn{2}{|c|}{$\begin{array}{c}\text { q3menosq5_01 } \\
\text { (Política e } \\
\text { Governo) - em } \\
\text { Ward Method }\end{array}$}} & \multicolumn{2}{|c|}{ cluster } & \multirow{4}{*}{$\begin{array}{c}\text { Total } \\
2 \\
1,30 \% \\
\end{array}$} \\
\hline & & $\begin{array}{l}1 \text { Exploradoras } \\
\text { Reativas ER }\end{array}$ & $\begin{array}{c}2 \text { Exploradoras } \\
\text { Estruturadas } \\
\text { EE }\end{array}$ & \\
\hline \multirow{2}{*}{-2} & $\mathrm{n}$ & 2 & 0 & \\
\hline & $\%$ & $1,80 \%$ & $0,00 \%$ & \\
\hline \multirow{2}{*}{-1} & $\mathrm{n}$ & 5 & 3 & 8 \\
\hline & $\%$ & $4,50 \%$ & $6,40 \%$ & $5,10 \%$ \\
\hline \multirow{2}{*}{0} & $\mathrm{n}$ & 33 & 21 & 54 \\
\hline & $\%$ & $30,00 \%$ & $44,70 \%$ & $34,40 \%$ \\
\hline \multirow{2}{*}{1} & $\mathrm{n}$ & 37 & 19 & 56 \\
\hline & $\%$ & $33,60 \%$ & $40,40 \%$ & $35,70 \%$ \\
\hline \multirow{2}{*}{2} & $\mathrm{n}$ & 28 & 2 & 30 \\
\hline & $\%$ & $25,50 \%$ & $4,30 \%$ & $19,10 \%$ \\
\hline \multirow{2}{*}{3} & $\mathrm{n}$ & 3 & 2 & 5 \\
\hline & $\%$ & $2,70 \%$ & $4,30 \%$ & $3,20 \%$ \\
\hline \multirow{2}{*}{4} & $\mathrm{n}$ & 2 & 0 & 2 \\
\hline & $\%$ & $1,80 \%$ & $0,00 \%$ & $1,30 \%$ \\
\hline \multirow{2}{*}{ Total } & $\mathbf{n}$ & 110 & 47 & 157 \\
\hline & $\%$ & $100 \%$ & $100 \%$ & $100 \%$ \\
\hline
\end{tabular}

Graficamente pode se verificar a diferença entre os valores obtidos, a seguir. 


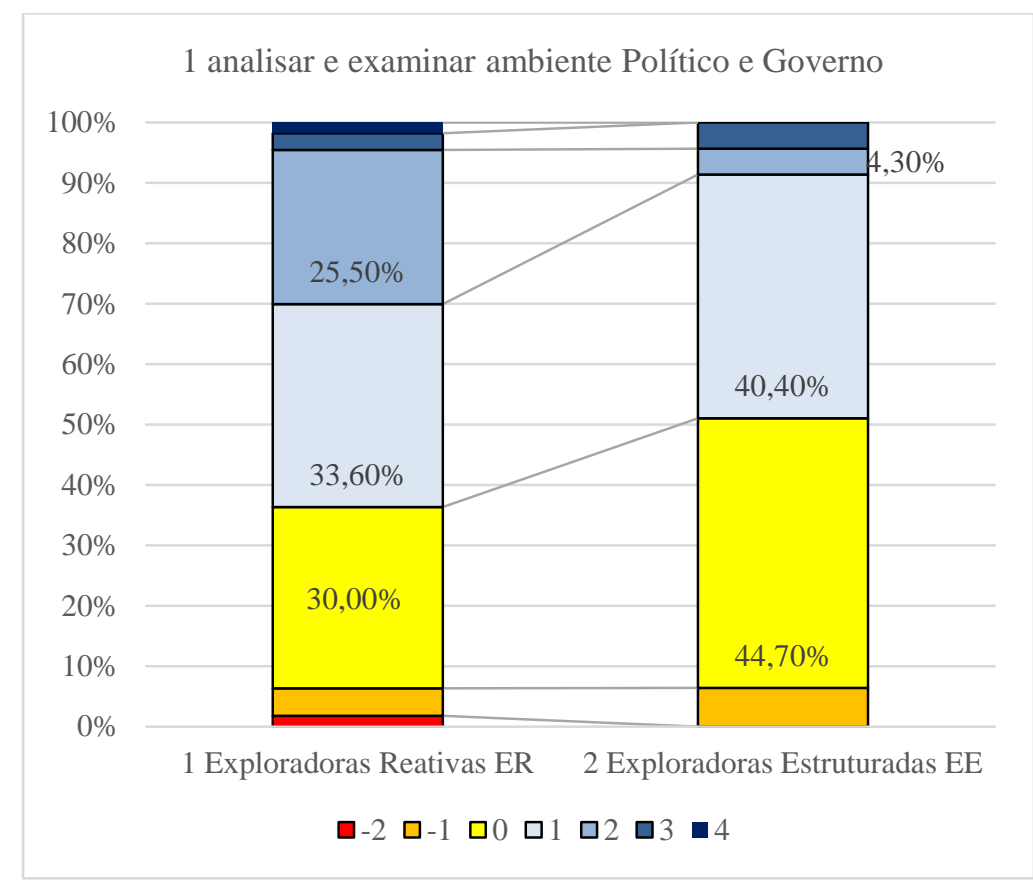

Gráfico 26 - Avaliação da importância menos (-) avaliação da contribuição da prospecção: Tema Política e Governo

Para o tema Economia, observa-se que a proporção de valores positivos é maior para o grupo ER, o que é um indício de que neste grupo a contribuição é avaliada em grau menor que a importância da prospecção. Ou seja, há limitação maior da contribuição da prospecção na análise da Economia no grupo de empresas ER, quando comparado com as empresas do grupo EE.

Tabela 68 - Avaliação da importância menos (-) avaliação da contribuição da prospecção: Tema Economia

\begin{tabular}{|c|c|c|c|c|}
\hline \multirow{2}{*}{$\begin{array}{c}\text { q3menosq5_02 } \\
\text { (Economia) } \\
\text { Ward Method }\end{array}$} & $\begin{array}{c}\text { 1 } \\
\text { Exploradoras } \\
\text { Reativas ER }\end{array}$ & $\begin{array}{c}\text { cluster } \\
\text { Exploradoras } \\
\text { Estruturadas } \\
\text { Total }\end{array}$ & \\
\hline \multirow{2}{*}{2} & $\mathrm{n}$ & 0 & 0 & 0 \\
\hline \multirow{2}{*}{-1} & $\%$ & $0,00 \%$ & $0,00 \%$ & $0,00 \%$ \\
\hline \multirow{2}{*}{0} & $\mathrm{n}$ & 8 & 1 & 9 \\
& $\%$ & $7,30 \%$ & $2,10 \%$ & $5,70 \%$ \\
\hline \multirow{2}{*}{1} & $\mathrm{n}$ & 26 & 26 & 52 \\
& $\%$ & $23,60 \%$ & $\mathbf{5 5 , 3 0 \%}$ & $33,10 \%$ \\
\hline \multirow{2}{*}{2} & $\mathrm{n}$ & 42 & 13 & 55 \\
& $\%$ & $\mathbf{3 8 , 2 0 \%}$ & $\mathbf{2 7 , 7 0 \%}$ & $35,00 \%$ \\
\hline \multirow{2}{*}{3} & $\mathrm{n}$ & 28 & 6 & 34 \\
& $\%$ & $\mathbf{2 5 , 5 0 \%}$ & $12,80 \%$ & $21,70 \%$ \\
\hline \multirow{2}{*}{ Total } & $\mathbf{n}$ & $\mathbf{1 1 0}$ & 1 & 7 \\
& $\%$ & $\mathbf{1 0 0 \%}$ & $\mathbf{1 0 0 \%}$ & $\mathbf{1 0 0 \%}$ \\
\hline
\end{tabular}


Observando-se o gráfico a seguir, é visível a diferença entre os dois agrupamentos.

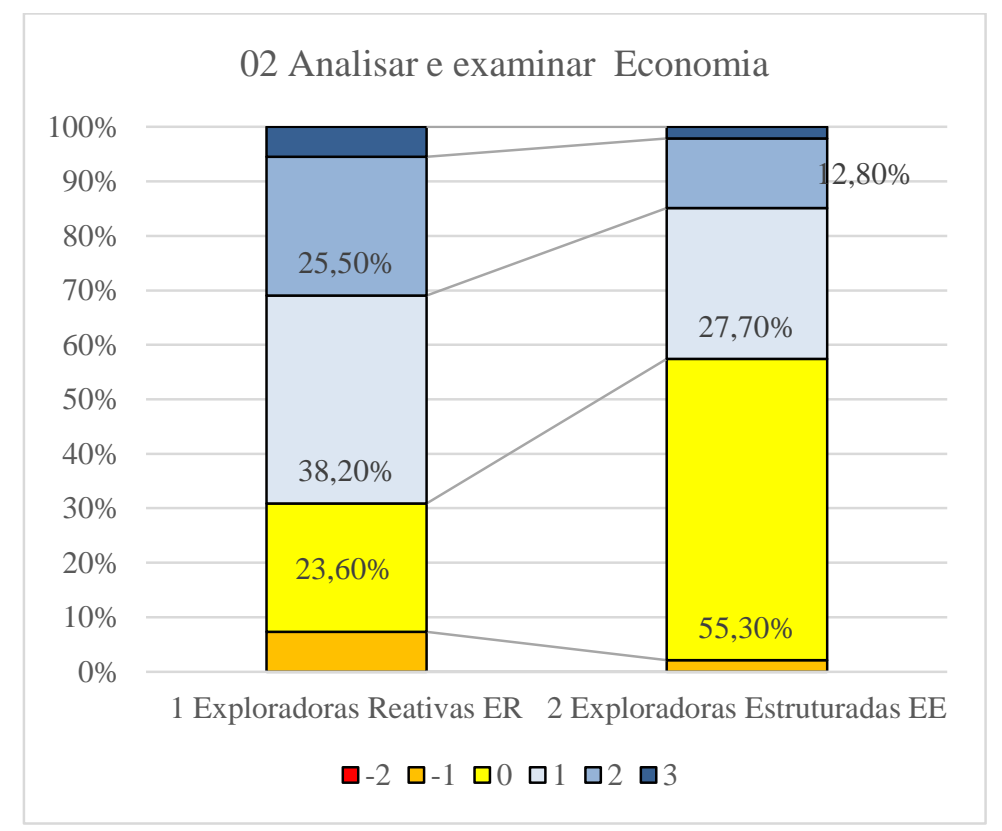

Gráfico 27 - Avaliação da importância menos (-) avaliação da contribuição da prospecção: Tema Economia

Quando se analisam as avaliações para Sociedade, o fenômeno se repete. Há maior proporção de resultados positivos para as empresas ER do que para EE, conforme a tabela a seguir.

Tabela 69 - Avaliação da importância menos (-) avaliação da contribuição da prospecção: Tema Sociedade

\begin{tabular}{|c|c|c|c|c|}
\hline \multirow{2}{*}{\multicolumn{2}{|c|}{$\begin{array}{c}\text { q3menosq5_03 } \\
\text { (Sociedade) - em } \\
\text { Ward Method }\end{array}$}} & $\begin{array}{c}\text { cluster } \\
\text { Exploradoras } \\
\text { Reativas ER }\end{array}$ & $\begin{array}{c}\text { 2 } \\
\text { Exploradoras } \\
\text { Estruturadas } \\
\text { EE }\end{array}$ & Total \\
\hline \multirow{2}{*}{-2} & $\mathrm{n}$ & 1 & 2 & 3 \\
\hline \multirow{2}{*}{-1} & $\%$ & $0,90 \%$ & $4,30 \%$ & $1,90 \%$ \\
\hline \multirow{2}{*}{0} & $\mathrm{n}$ & 8 & 4 & 12 \\
& $\%$ & $7,30 \%$ & $8,50 \%$ & $7,60 \%$ \\
\hline \multirow{2}{*}{1} & $\mathrm{n}$ & 28 & 22 & 50 \\
& $\%$ & $25,50 \%$ & $\mathbf{4 6 , 8 0 \%}$ & $31,80 \%$ \\
\hline \multirow{2}{*}{2} & $\mathrm{n}$ & 37 & 16 & 53 \\
& $\mathrm{n}$ & $\mathbf{3 3 , 6 0 \%}$ & $34,00 \%$ & $33,80 \%$ \\
\hline \multirow{2}{*}{3} & $\mathrm{n}$ & 33 & 3 & 36 \\
& $\%$ & $\mathbf{3 0 , 0 0 \%}$ & $6,40 \%$ & $22,90 \%$ \\
\hline \multirow{2}{*}{ Total } & $\mathbf{n}$ & 3 & 0 & 3 \\
& \% & $\mathbf{1 1 0 0 \%}$ & $\mathbf{1 0 0 \%}$ & $\mathbf{1 0 0 \%}$ \\
\hline
\end{tabular}


Graficamente é possível identificar a diferença entre importância e contribuição para o tema Sociedade.

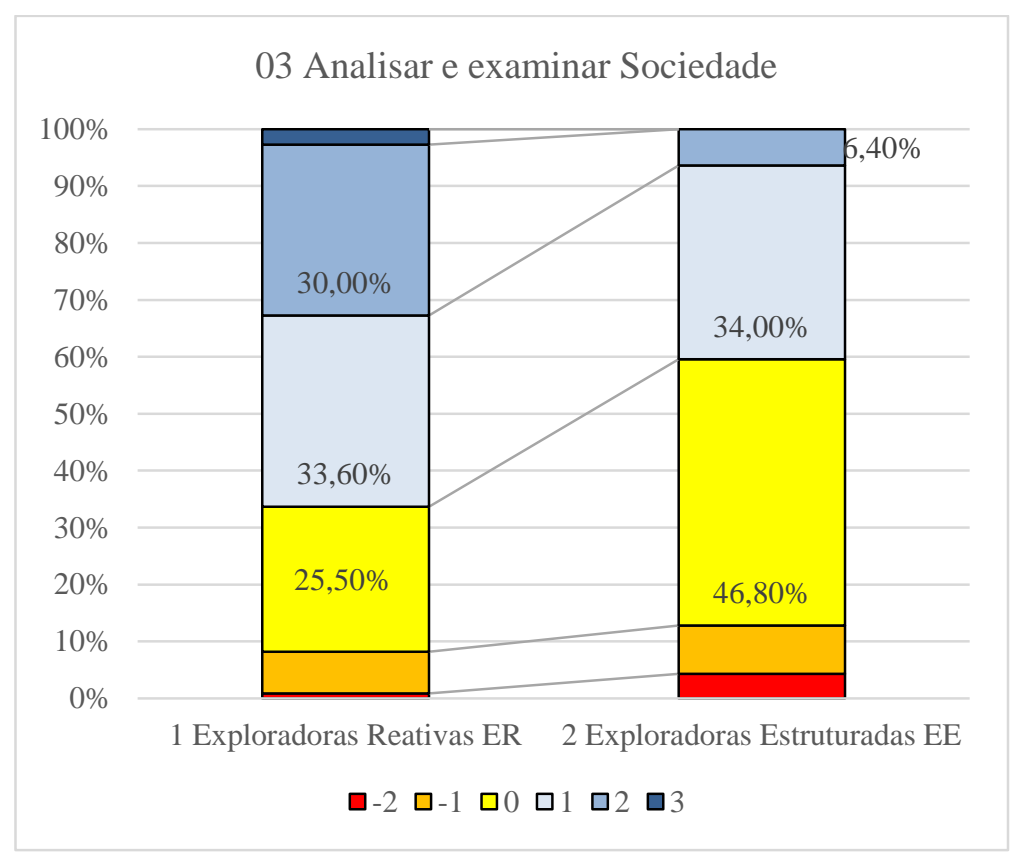

Gráfico 28 - Avaliação da importância menos (-) avaliação da contribuição da prospecção: Tema Sociedade

Para o tema Meio Ambiente e Sustentabilidade os resultados da tabela a seguir mostram que no agrupamento ER há maior proporção de valores positivos do que no EE.

Tabela 70 - Avaliação da importância menos (-) avaliação da contribuição da prospecção: Tema Meio Ambiente e

\begin{tabular}{|c|c|c|c|c|}
\hline \multicolumn{5}{|c|}{ Sustentabilidade } \\
\hline \multirow{2}{*}{\multicolumn{2}{|c|}{$\begin{array}{c}\text { q3menosq5_05 (Meio } \\
\text { Ambiente e } \\
\text { Sustentabilidade) - em } \\
\text { Ward Method }\end{array}$}} & \multicolumn{2}{|c|}{ cluster } & \multirow{4}{*}{$\begin{array}{c}\text { Total } \\
1 \\
0,60 \% \\
\end{array}$} \\
\hline & & \multirow{3}{*}{$\begin{array}{c}\mathbf{1} \\
\begin{array}{c}\text { Exploradoras } \\
\text { Reativas ER }\end{array} \\
1 \\
0,90 \%\end{array}$} & \multirow{3}{*}{$\begin{array}{c}\mathbf{2} \\
\text { Exploradoras } \\
\text { Estruturadas } \\
\text { EE } \\
0 \\
0,00 \%\end{array}$} & \\
\hline 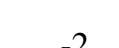 & $\mathrm{n}$ & & & \\
\hline & $\%$ & & & \\
\hline \multirow{2}{*}{-1} & $\mathrm{n}$ & 4 & 9 & 13 \\
\hline & $\%$ & $3,60 \%$ & $19,10 \%$ & $8,30 \%$ \\
\hline \multirow{2}{*}{0} & $\mathrm{n}$ & 41 & 21 & 62 \\
\hline & $\%$ & $37,30 \%$ & $44,70 \%$ & $39,50 \%$ \\
\hline \multirow{2}{*}{1} & $\mathrm{n}$ & 47 & 14 & 61 \\
\hline & $\%$ & $42,70 \%$ & $29,80 \%$ & $38,90 \%$ \\
\hline \multirow{2}{*}{2} & $\mathrm{n}$ & 11 & 3 & 14 \\
\hline & $\%$ & $10,00 \%$ & $6,40 \%$ & $8,90 \%$ \\
\hline \multirow{2}{*}{3} & $\mathrm{n}$ & 5 & 0 & 5 \\
\hline & $\%$ & $4,50 \%$ & $0,00 \%$ & $3,20 \%$ \\
\hline \multirow{2}{*}{4} & $\mathrm{n}$ & 1 & 0 & 1 \\
\hline & $\%$ & $0,90 \%$ & $0,00 \%$ & $0,60 \%$ \\
\hline \multirow{2}{*}{ Total } & $\mathbf{n}$ & 110 & 47 & 157 \\
\hline & $\%$ & $100 \%$ & $100 \%$ & $100 \%$ \\
\hline
\end{tabular}


O gráfico a seguir ilustra a diferença.

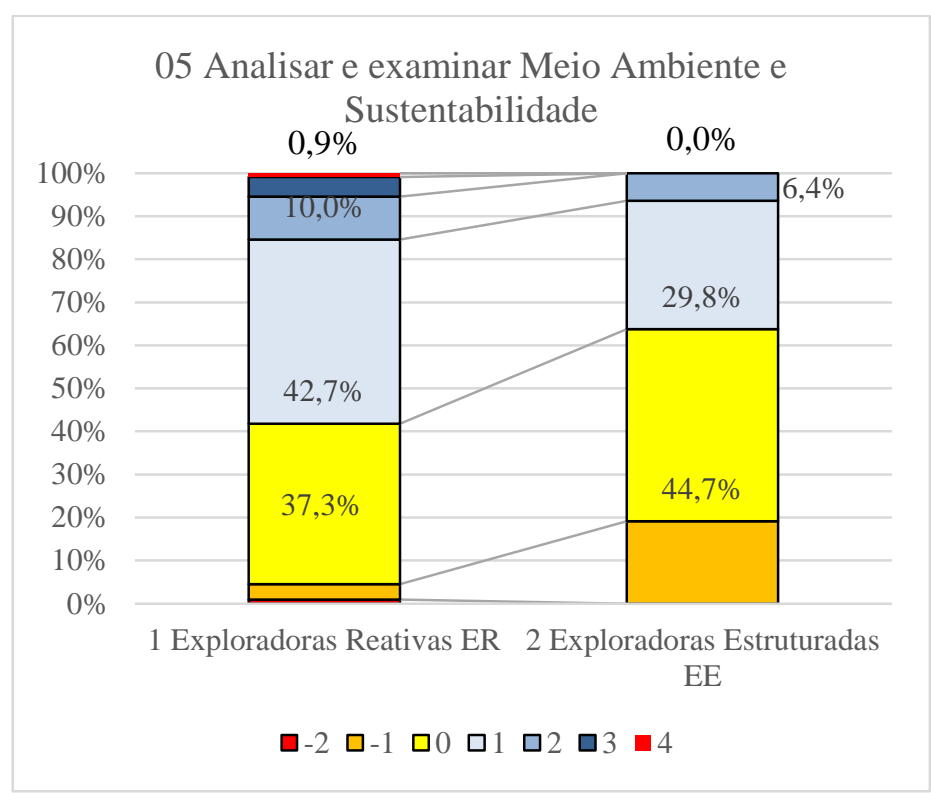

Gráfico 29 - Avaliação da importância menos (-) avaliação da contribuição da prospecção: Tema Meio Ambiente e Sustentabilidade

Para Legislação e Regulação Setorial, no agrupamento ER há proporcionalmente mais resultados positivos do que no EE. A avaliação da contribuição da prospecção para este tema é maior nas empresas EE do que nas ER.

Tabela 71 - Avaliação da importância menos (-) avaliação da contribuição da prospecção: Tema Legislação e Regulação Setorial

\begin{tabular}{|c|c|c|c|c|}
\hline \multirow{2}{*}{\multicolumn{2}{|c|}{$\begin{array}{c}\text { q3menosq5_06 } \\
\text { (Legislação e } \\
\text { regulação setorial) - } \\
\text { em Ward Method }\end{array}$}} & \multicolumn{2}{|c|}{ cluster } & \multirow{3}{*}{$\begin{array}{c}\text { Total } \\
1 \\
0,60 \%\end{array}$} \\
\hline & & \multirow{2}{*}{$\begin{array}{c}\mathbf{1} \\
\begin{array}{c}\text { Exploradoras } \\
\text { Reativas ER }\end{array} \\
1 \\
0,90 \% \\
\end{array}$} & \multirow{2}{*}{$\begin{array}{c}\mathbf{2} \\
\text { Exploradoras } \\
\text { Estruturadas } \\
\text { EE } \\
0 \\
0,00 \% \\
\end{array}$} & \\
\hline-2 & $\begin{array}{l}\mathrm{n} \\
\%\end{array}$ & & & \\
\hline-1 & $\begin{array}{l}\mathrm{n} \\
\%\end{array}$ & $\begin{array}{c}13 \\
11,80 \% \\
\end{array}$ & $\begin{array}{c}7 \\
14,90 \% \\
\end{array}$ & $\begin{array}{c}20 \\
12,70 \% \\
\end{array}$ \\
\hline 0 & $\begin{array}{l}\mathrm{n} \\
\%\end{array}$ & $\begin{array}{c}40 \\
\mathbf{3 6 , 4 0 \%}\end{array}$ & $\begin{array}{c}27 \\
\mathbf{5 7}, \mathbf{4 0} \% \\
\end{array}$ & $\begin{array}{c}67 \\
42,70 \% \\
\end{array}$ \\
\hline 1 & $\begin{array}{l}\mathrm{n} \\
\%\end{array}$ & $\begin{array}{c}37 \\
\mathbf{3 3 , 6 0 \%} \\
\end{array}$ & $\begin{array}{c}9 \\
19,10 \% \\
\end{array}$ & $\begin{array}{c}46 \\
29,30 \% \\
\end{array}$ \\
\hline 2 & $\begin{array}{l}\mathrm{n} \\
\% \\
\end{array}$ & $\begin{array}{c}14 \\
12,70 \% \\
\end{array}$ & $\begin{array}{c}4 \\
8,50 \% \\
\end{array}$ & $\begin{array}{c}18 \\
11,50 \% \\
\end{array}$ \\
\hline 3 & $\begin{array}{l}\mathrm{n} \\
\% \\
\end{array}$ & $\begin{array}{c}4 \\
3,60 \% \\
\end{array}$ & $\begin{array}{c}0 \\
0,00 \% \\
\end{array}$ & $\begin{array}{c}4 \\
2,50 \% \\
\end{array}$ \\
\hline 4 & $\begin{array}{l}\mathrm{n} \\
\%\end{array}$ & $\begin{array}{c}1 \\
0,90 \% \\
\end{array}$ & $\begin{array}{c}0 \\
0,00 \% \\
\end{array}$ & $\begin{array}{c}1 \\
0,60 \% \\
\end{array}$ \\
\hline Total & $\begin{array}{l}\mathbf{n} \\
\%\end{array}$ & $\begin{array}{c}110 \\
100 \%\end{array}$ & $\begin{array}{c}47 \\
100 \%\end{array}$ & $\begin{array}{c}157 \\
100 \%\end{array}$ \\
\hline
\end{tabular}


O gráfico a seguir mostra descritivamente as diferenças para o tema Legislação e Regulação Setorial.

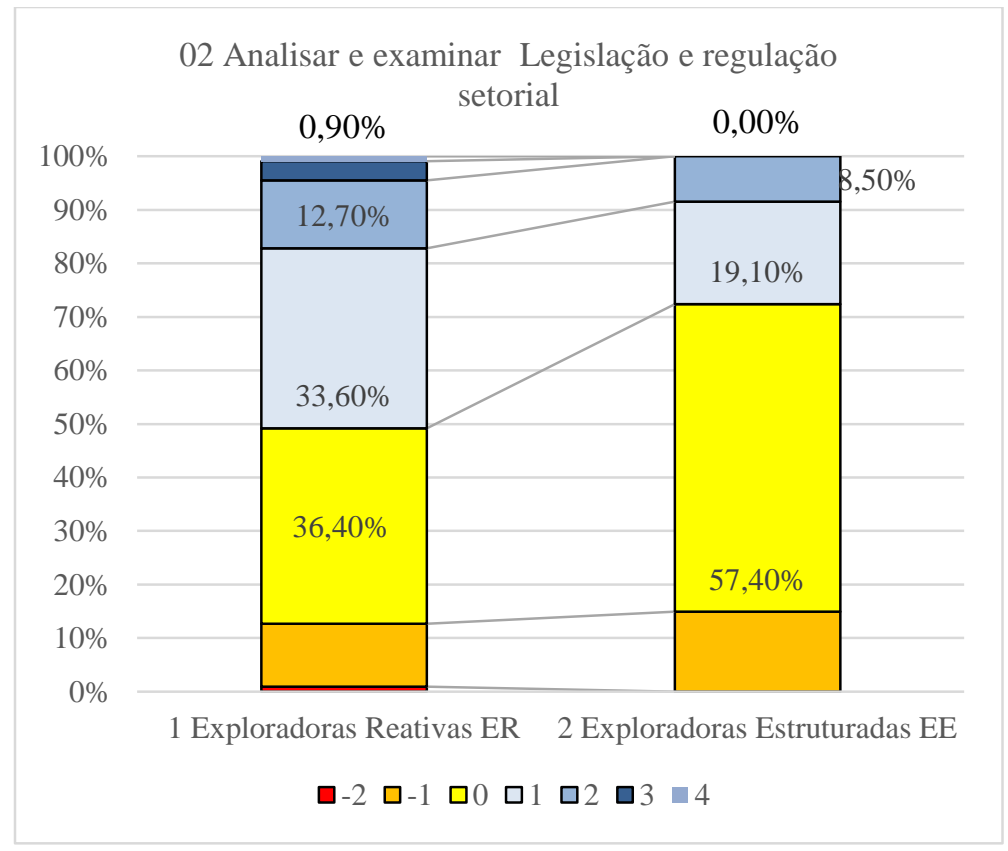

Gráfico 30 - Avaliação da importância menos (-) avaliação da contribuição da prospecção: Tema Legislação e regulação setorial

Para o tema Mercado e Demanda, nota-se que o grupo de empresas ER apresenta maiores percentuais para valores positivos, o que é sinal de que a avaliação da contribuição da prospecção neste grupo é menor do que apresenta o grupo EE. Isso é um indício de que mesmo para temas que têm relação mais direta com resultados da empresa, nas empresas ER a contribuição da prospecção é avaliada em nível menor do que a importância atribuída à atividade.

Os resultados estão mostrados na tabela a seguir. 
Tabela 72 - Avaliação da importância menos (-) avaliação da contribuição da prospecção: Tema Mercado e Demanda

\begin{tabular}{|c|c|c|c|c|}
\hline \multirow{2}{*}{$\begin{array}{c}\text { q3menosq5_07 } \\
\text { (Mercado e } \\
\text { Demanda) - em } \\
\text { Ward Method }\end{array}$} & $\begin{array}{c}\text { 1 } \\
\text { Exploradoras } \\
\text { Reativas ER }\end{array}$ & $\begin{array}{c}\text { cluster } \\
\text { Exploradoras } \\
\text { Estruturadas } \\
\text { EE }\end{array}$ & \\
\hline \multirow{2}{*}{-2} & $\mathrm{n}$ & 1 & 1 & 2 \\
& $\%$ & $0,90 \%$ & $2,10 \%$ & $1,30 \%$ \\
\hline \multirow{2}{*}{-1} & $\mathrm{n}$ & 5 & 3 & 8 \\
& $\%$ & $4,50 \%$ & $6,40 \%$ & $5,10 \%$ \\
\hline 0 & $\mathrm{n}$ & 51 & 32 & 83 \\
& $\%$ & $\mathbf{4 6 , 4 0 \%}$ & $\mathbf{6 8 , 1 0 \%}$ & $52,90 \%$ \\
\hline \multirow{2}{*}{1} & $\mathrm{n}$ & 30 & 9 & 39 \\
& $\%$ & $\mathbf{2 7 , 3 0 \%}$ & $\mathbf{1 9 , 1 0 \%}$ & $24,80 \%$ \\
\hline 2 & $\mathrm{n}$ & 20 & 2 & 22 \\
& $\%$ & $\mathbf{1 8 , 2 0 \%}$ & $4,30 \%$ & $14,00 \%$ \\
\hline 3 & $\mathrm{n}$ & 3 & 0 & 3 \\
& $\%$ & $2,70 \%$ & $0,00 \%$ & $1,90 \%$ \\
\hline \multirow{2}{*}{ Total } & $\mathbf{n}$ & $\mathbf{1 1 0}$ & $\mathbf{4 7}$ & $\mathbf{1 5 7}$ \\
& $\mathbf{\%}$ & $\mathbf{1 0 0 \%}$ & $\mathbf{1 0 0 \%}$ & $\mathbf{1 0 0 \%}$ \\
\hline
\end{tabular}

O gráfico ilustra visualmente os resultados da tabela anterior.

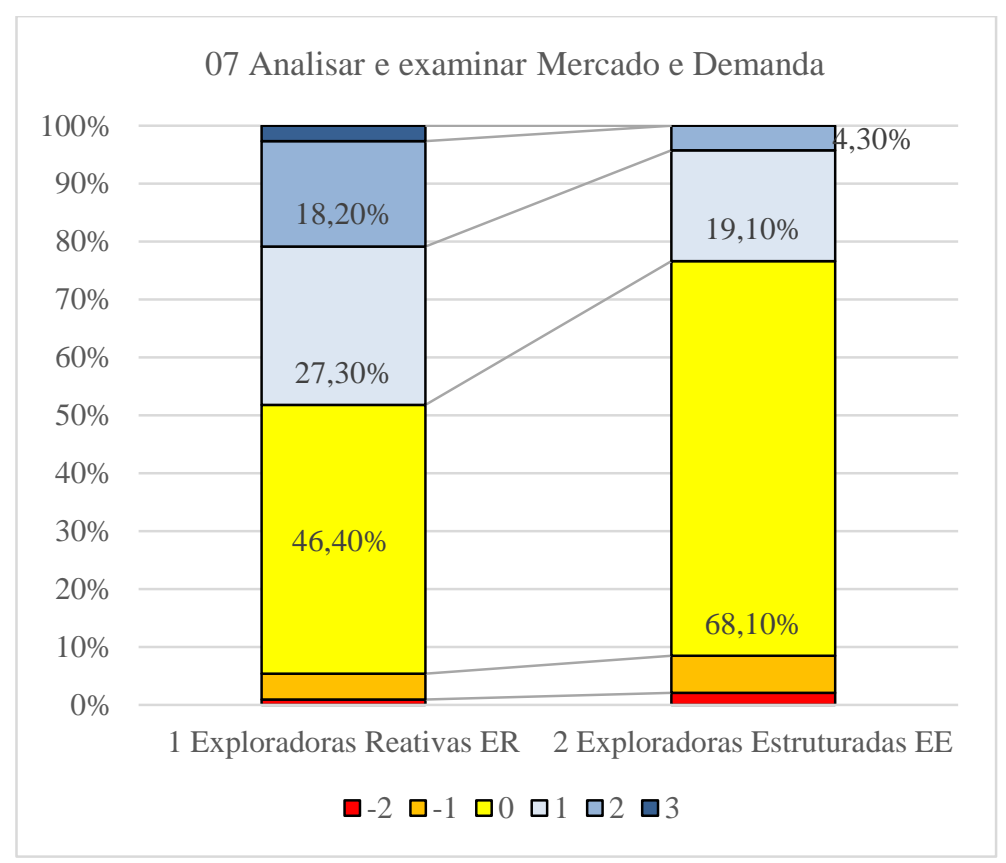

Gráfico 31 - Avaliação da importância menos (-) avaliação da contribuição da prospecção: Tema Mercado e Demanda 
Quando se analisa o tema Insumos e Recursos, nota-se que a diferença entre importância e contribuição da prospecção gera maior proporção de resultados positivos no grupo ER. Este grupo, por decorrência, considera que a prospecção contribui menos do que o grupo EE, para o tema Insumos e Recursos. Isso pode ser um indício de limitações da prospecção nas organizações que apresentam as características que discriminam esse agrupamento.

Para o tema Insumos e Recursos, os relacionamentos comerciais e contratuais podem amenizar riscos de incertezas de futuro, contudo, não os elimina, uma vez que há fatores que podem afetar o suprimento e que precisam de atenção prospectiva.

Tabela 73 - Avaliação da importância menos (-) avaliação da contribuição da prospecção: Tema Insumos e Recursos

\begin{tabular}{|c|c|c|c|c|}
\hline \multirow{2}{*}{\multicolumn{2}{|c|}{$\begin{array}{l}\text { q3menosq5_08 } \\
\text { (Insumos e } \\
\text { Recursos) - em } \\
\text { Ward Method }\end{array}$}} & \multicolumn{2}{|c|}{ cluster } & \multirow{3}{*}{$\begin{array}{c}\text { Total } \\
\\
1 \\
0,60 \%\end{array}$} \\
\hline & & \multirow{2}{*}{$\begin{array}{c}\mathbf{1} \\
\begin{array}{c}\text { Exploradoras } \\
\text { Reativas ER }\end{array} \\
1 \\
0,90 \% \\
\end{array}$} & \multirow{2}{*}{$\begin{array}{c}\mathbf{2} \\
\begin{array}{c}\text { Exploradoras } \\
\text { Estruturadas } \\
\mathbf{E E}\end{array} \\
0 \\
0,00 \% \\
\end{array}$} & \\
\hline-2 & $\begin{array}{l}\mathrm{n} \\
\%\end{array}$ & & & \\
\hline-1 & $\begin{array}{l}\mathrm{n} \\
\%\end{array}$ & $\begin{array}{c}16 \\
14,50 \%\end{array}$ & $\begin{array}{c}3 \\
6,40 \%\end{array}$ & $\begin{array}{c}19 \\
12,10 \%\end{array}$ \\
\hline 0 & $\begin{array}{l}\mathrm{n} \\
\%\end{array}$ & $\begin{array}{c}30 \\
27,30 \%\end{array}$ & $\begin{array}{c}30 \\
\mathbf{6 3 , 8 0 \%}\end{array}$ & $\begin{array}{c}60 \\
38,20 \%\end{array}$ \\
\hline 1 & $\begin{array}{l}\mathrm{n} \\
\%\end{array}$ & $\begin{array}{c}45 \\
\mathbf{4 0 , 9 0 \%} \\
\end{array}$ & $\begin{array}{c}13 \\
27,70 \% \\
\end{array}$ & $\begin{array}{c}58 \\
36,90 \% \\
\end{array}$ \\
\hline 2 & $\begin{array}{l}\mathrm{n} \\
\%\end{array}$ & $\begin{array}{c}14 \\
12,70 \%\end{array}$ & $\begin{array}{c}1 \\
2,10 \%\end{array}$ & $\begin{array}{c}15 \\
9,60 \%\end{array}$ \\
\hline 3 & $\begin{array}{l}\mathrm{n} \\
\%\end{array}$ & $\begin{array}{c}4 \\
3,60 \%\end{array}$ & $\begin{array}{c}0 \\
0,00 \%\end{array}$ & $\begin{array}{c}4 \\
2,50 \%\end{array}$ \\
\hline Total & $\begin{array}{l}\mathbf{n} \\
\%\end{array}$ & $\begin{array}{c}110 \\
100 \%\end{array}$ & $\begin{array}{c}47 \\
100 \%\end{array}$ & $\begin{array}{c}157 \\
100 \%\end{array}$ \\
\hline
\end{tabular}

A tabela está visualmente refletida no gráfico a seguir. 


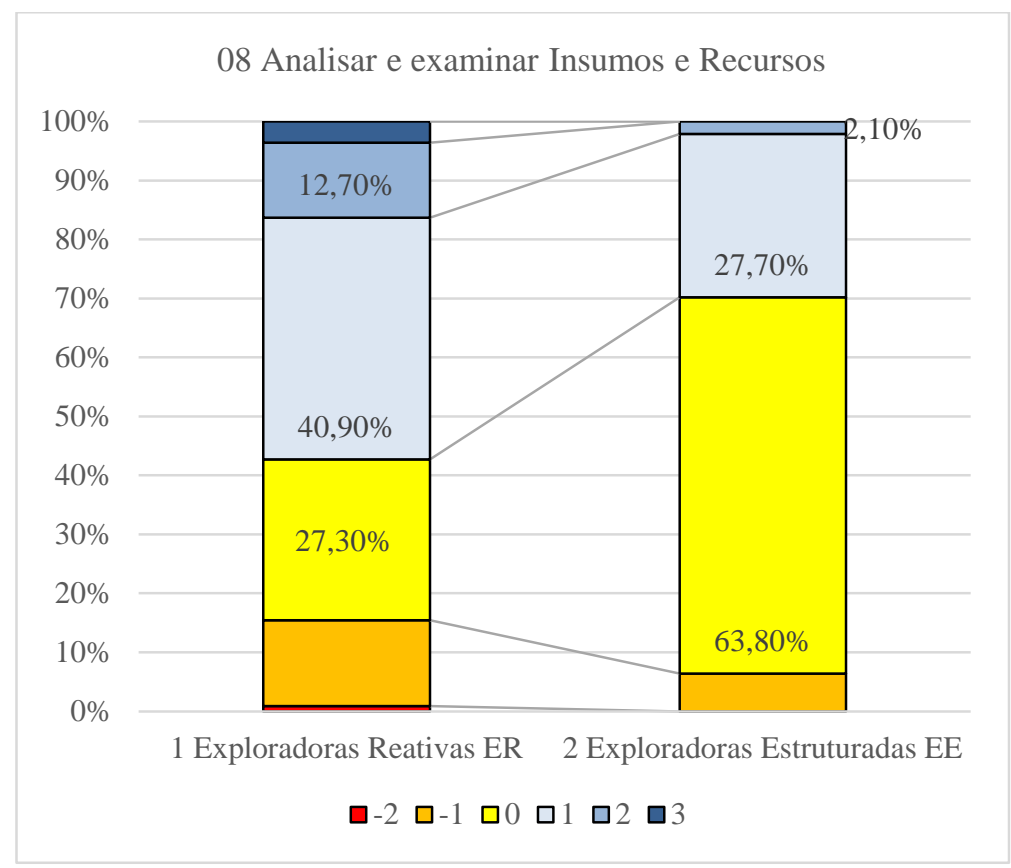

Gráfico 32 - Avaliação da importância menos (-) avaliação da contribuição da prospecção: Tema Insumos e Recursos

\subsubsection{Prática e contribuição nos grupos EE e ER para os diferentes temas}

A análise dos resultados, quando se compara os dois agrupamentos de respondentes, e considerando a avaliação da profundidade em que se pratica a prospecção, e a respectiva avaliação de sua contribuição para o processo de tomada de decisão em projetos, observa-se que não há diferenças entre os grupos, para quaisquer temas portadores de incertezas de futuro. A tabela a seguir traz os resultados.

Tabela 74 - Avaliação da prática menos (-) avaliação da contribuição da prospecção

\begin{tabular}{|c|c|c|c|c|c|c|c|c|c|c|c|c|c|c|}
\hline \multicolumn{15}{|c|}{ Prática menos Contribuição (q4menosq5) } \\
\hline \multicolumn{2}{|c|}{ Estatísticas de teste } & 1 & 2 & 3 & 4 & 5 & 6 & 7 & 8 & 9 & 10 & 11 & 12 & 13 \\
\hline \multirow{2}{*}{$\begin{array}{c}\text { Diferenças } \\
\text { Mais } \\
\text { Extremas } \\
\end{array}$} & Absoluto & 0,1 & 0,093 & 0,064 & 0,048 & 0,096 & 0,157 & 0,151 & 0,109 & 0,111 & 0,098 & 0,091 & 0,037 & 0,148 \\
\hline & Positivo & 0,1 & 0,073 & 0,063 & 0,018 & 0 & 0,088 & 0,036 & 0,109 & 0,085 & 0,098 & 0,091 & 0,037 & 0,148 \\
\hline \multicolumn{2}{|c|}{ Z Kolmogorov-Smirnov } & 0,574 & 0,534 & 0,365 & 0,274 & 0,553 & 0,901 & 0,867 & 0,625 & 0,639 & 0,563 & 0,521 & 0,214 & 0,851 \\
\hline \multicolumn{2}{|c|}{$\mathrm{p}$} & 0,897 & 0,938 & 0,999 & 1,000 & 0,92 & 0,391 & 0,44 & 0,83 & 0,808 & 0,909 & 0,949 & 1,000 & 0,463 \\
\hline
\end{tabular}

Na tabela anterior, comparando-se a diferença entre a avaliação para a prática, com a avaliação para a contribuição da prospecção para a tomada de decisão, em cada tema portador 
de incertezas de futuro, não foi possível identificar diferença entre os agrupamentos, $p>0,10$ de acordo com a prova de Kolmogorov-Smirnov.

Esse resultado talvez seja um indício que uma das principais lacunas da prospecção do futuro seja a transição entre importância e a prática da prospecção. E a utilização dos resultados para o suporte à decisão sofre a consequência da prática ocorrer em grau menor do que a importância faz supor necessário. A contribuição da prospecção na decisão estratégica, dessa forma, representa um grande desafio para os gestores.

Para aprofundar a análise sobre essa questão, o questionário de coleta incluiu também questões para capturar o quanto alguns processos, de análise prospectiva de incertezas de futuro, são praticados para suporte à decisão nos projetos estratégicos. E seguindo ainda o modelo de referência da pesquisa, também se buscou analisar se a prospecção do futuro contribuiu para a prática desses processos. Os resultados dessa abordagem estão mostrados na seção a seguir.

\subsubsection{Prática e contribuição de processos de análise prospectiva nos grupos EE e ER}

Esta seção se concentra na avaliação dos processos de análise prospectiva recomendados para suporte à tomada de decisões em projetos estratégicos. Os resultados mostram que não há diferenças entre os dois agrupamentos de respondentes.

A tabela a seguir traz os dados, também configurados na forma de diferenças entre a prática dos processos e as contribuições que a prospecção do futuro possa ter propiciado para a execução dos processos.

Tabela 75 - Avaliação da prática menos (-) avaliação da contribuição da prospecção

\begin{tabular}{|c|c|c|c|c|c|c|c|c|c|c|}
\hline \multicolumn{11}{|c|}{$\begin{array}{l}\text { Prática de processos de análise prospectiva menos Contribuição da prospecção nos } \\
\text { processos (q6menosq7) }\end{array}$} \\
\hline \multicolumn{2}{|c|}{ Estatísticas de teste } & 1 & 2 & 3 & 4 & 5 & 6 & 7 & 8 & 9 \\
\hline \multirow{3}{*}{$\begin{array}{l}\text { Diferenças Mais } \\
\text { Extremas }\end{array}$} & Absoluto & 0,145 & 0,138 & 0,036 & 0,163 & 0,039 & 0,063 & 0,051 & 0,036 & 0,063 \\
\hline & Positivo & 0,03 & 0,045 & 0,009 & 0,163 & 0,033 & 0,018 & 0,051 & 0,036 & 0,063 \\
\hline & Negativo & $0, \overline{145}$ & $0, \overline{-}$ & 0,036 & $-0,03$ & 0,039 & $0, \overline{-}$ & $0, \overline{-} 21$ & $0, \overline{-}$ & 0,012 \\
\hline \multicolumn{2}{|l|}{$\begin{array}{l}\text { Z Kolmogorov- } \\
\text { Smirnov }\end{array}$} & 0,832 & 0,795 & 0,205 & 0,936 & 0,225 & 0,363 & 0,291 & 0,209 & 0,361 \\
\hline \multicolumn{2}{|l|}{$\mathrm{p}$} & 0,492 & 0,553 & 1,000 & 0,345 & 1,000 & 0,999 & 1,000 & 1,000 & 0,999 \\
\hline
\end{tabular}


A legenda dos processos pode ser consultada no quadro a seguir.

Quadro 15 - Legendas de processos de análise prospectiva

\begin{tabular}{|ll|}
\hline \multicolumn{2}{|c|}{ Processos de análise prospectiva aplicáveis em projetos estratégicos } \\
\hline 1 & Análise dos contextos futuros dos negócios envolvidos no projeto \\
\hline 2 & Análise do alinhamento do projeto com a estratégia da organização \\
\hline 3 & Calibração de premissas utilizadas no projeto \\
\hline 4 & Definição de sinais ou indicadores que sirvam para monitorar o futuro acontecendo (ou \\
começando a acontecer) no âmbito da implantação do projeto
\end{tabular}

Pela tabela de resultados anterior, ao se comparar os clusters quanto à diferença entre prática de determinado processo, e o quanto os resultados da prospecção contribuíram para o processo em questão, não foi possível diferenciar os agrupamentos em relação a qualquer uma das diferenças, p>0,10 de acordo com a prova de Kolmogorov-Smirnov.

Analisando os resultados, as análises sobre os mesmos podem levar às seguintes conclusões:

- Os gestores de empresas EXPLORADORAS REATIVAS (ER) concedem grande importância à prospecção de futuro, mas relativamente se mobilizam menos para a sua prática, e por consequência chegam a menor nível de contribuição da prospecção.

- Os gestores de empresas EXPLORADORAS ESTRUTURADAS (EE) se distinguem positivamente em relação à importância atribuída à prospecção, a mobilização para sua prática para suporte a decisões em projetos, e as respectivas contribuições em decisões nos projetos. 


\subsubsection{Variáveis relevantes que influenciam as diferenças entre os grupos de empresas}

Com o objetivo de entender a prospecção do futuro como suporte às decisões nos projetos estratégicos, os resultados foram analisados buscando-se a identificação e a priorização das variáveis importantes que tenham maior associação com os agrupamentos de respondentes desta pesquisa, em relação à prospecção do futuro.

Para tanto, foi utilizada a técnica de CHAID (Chi-Squared Automatic Interaction Detection), uma técnica estatística multivariada que propicia um modelo no qual se tem uma variável dependente (cluster ou agrupamento, neste estudo) e demais variáveis independentes (categóricas) e preditoras da variável resposta (BASSAB et al, 1990). A técnica foi utilizada sobre as questões 3 a 9 do questionário de coleta, sendo que as variáveis dessas questões são as preditoras. O resultado da aplicação da técnica de CHAID se apresenta como um diagrama em árvore, com ramos.

Visualmente, o topo da árvore representa a amostra inteira, sem segmentações. A primeira camada de ramificações, a mais próxima ao topo, apresenta a primeira variável mais fortemente associada à variável dependente, portanto, esta variável é a que mais determina a diferença entre os clusters / agrupamentos, constituindo-se assim na variável mais relevante. Determinam-se assim os grupos de categorias de resposta desta primeira variável, e dessa forma se possibilita a análise de novas ramificações (BASSAB et al, 1990).

A partir do resultado obtido dessa primeira variável mais associada à variável dependente (cluster ou agrupamento), parte-se para uma nova procura de variável mais associada à variável dependente. Este processo continua até o final de ramificações, quando não é mais possível encontrar variáveis preditoras estatisticamente significantes, ou até uma regra de parada seja validada.

Para a presente tese, a análise CHAID foi aplicada para se determinar quais variáveis são as que mais estão associadas com os agrupamentos de respondentes da pesquisa. Os resultados estão mostrados na árvore a seguir. 


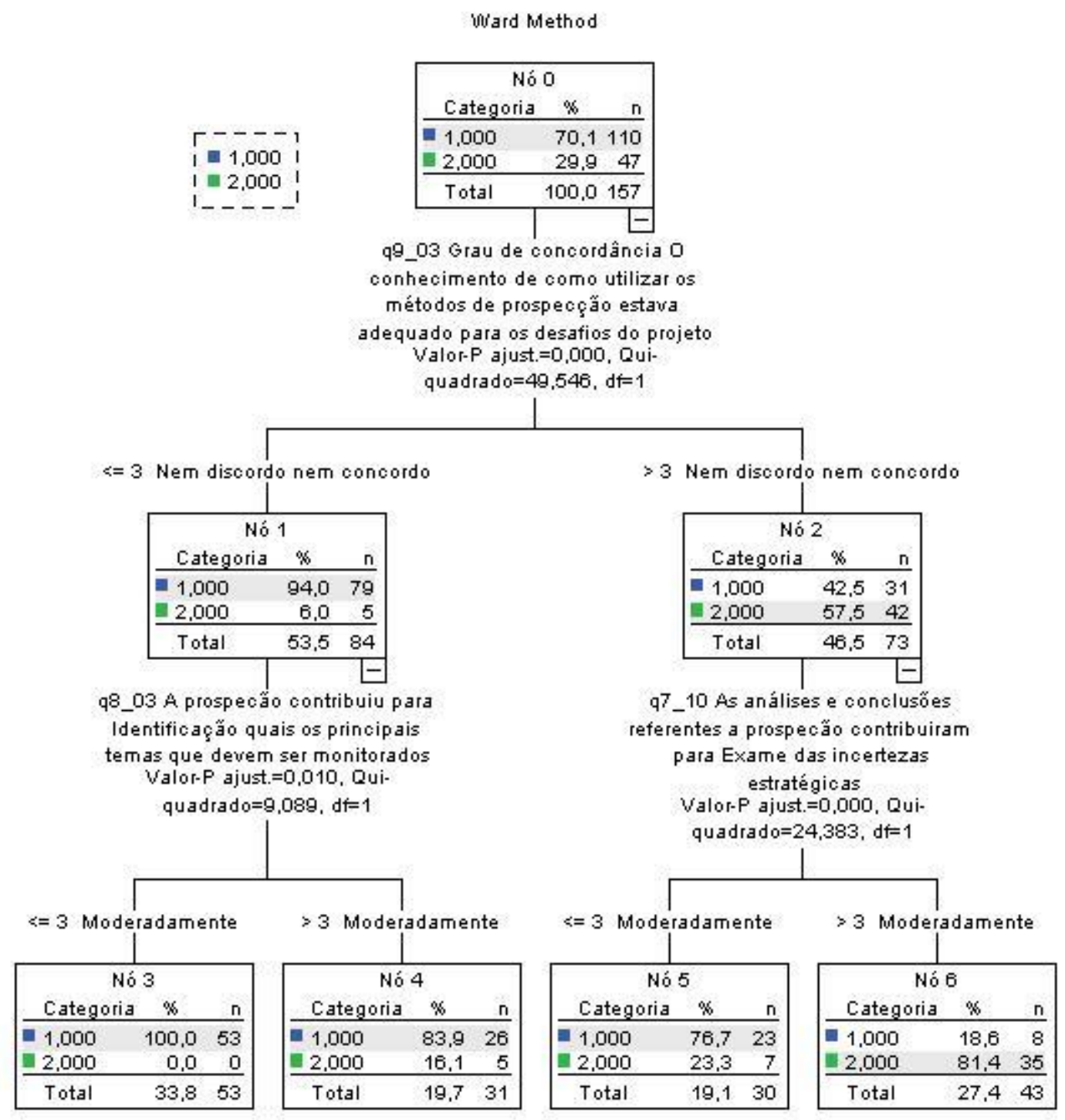

\section{Ilustração 19 - Árvore de relevância de variáveis para os grupos}

Pela análise da árvore classificatória, nota-se que a variável mais importante na predição/explicação do cluster (agrupamento de respondentes) é o conhecimento adequado de como utilizar os métodos de prospecção no projeto. Dessa forma, a concordância com a afirmação de que "O $\mathrm{O}$ conhecimento de como praticar a prospecção do futuro foi adequado no projeto" se constitui na variável que discrimina os grupos de empresas Exploradoras Reativas (ER) das empresas que compõem o grupo de Exploradoras Estruturadas (EE).

Cada classe acima após a primeira ramificação, sendo à direita de concordância parcial/forte (empresas EE) ou à esquerda de não concordância parcial/forte ou indiferente (Empresas ER), comporta-se de forma diferente em relação ao cluster. Entre os discordantes e indiferentes, 
que indicam projetos com falta de conhecimento sobre como utilizar a prospecção do futuro, há predomínio do cluster Exploradoras Reativas - ER (com 94\% no Nó 1). Ao passo que entre os concordantes, que indica que o conhecimento estava adequado, há maior proporção de empresas do cluster Exploradoras Estruturadas - EE (com 57,5\% no Nó 2).

Apesar da pequena amostra, o teste de qui-quadrado $\left(\chi^{2}\right)$ ainda é válido. Pode-se ainda notar que para projetos com conhecimento adequado da prospecção (Nó 2), a afirmação “ÁÁálises e conclusões da prospecção contribuíram no exame das incertezas estratégicas" está associada à formação dos clusters no segundo nível de ramificação a partir do Nó 2. A contribuição Nada/Pouco/Moderada para esta afirmação tem maior participação de empresas do cluster Exploradoras Reativas - ER (com 76,7\% no Nó 5). Por outro lado, a contribuição Muito/Extremamente tem maior participação de empresas do cluster Exploradoras Estruturadas - EE (com 81,4\% no Nó 6).

Para projetos com falha no conhecimento adequado da prospecção (Nó 1), as análises e conclusões da prospecção estão associadas à afirmação "A prospecção contribuiu para a identificação dos principais temas que devem ser monitorados" (prova de Fisher, p=0,006). Em relação à contribuição (Nada/Pouco/Moderada) na identificação de principais temas a monitorar, o cluster Exploradoras Reativas (ER) responde pela totalidade da amostra (com 100\% no Nó 3). Já para a situação de concordância alta (Muito/Extremamente), ela responde por 83,9\% da amostra (Nó 4). Ou seja, relativamente, a contribuição (Muito/Extremamente) dos principais temas a monitorar, ainda é maior no cluster de empresas Exploradoras Estruturadas (EE), mesmo entre os que tiveram problemas de conhecimento adequado da prospecção (16,1\% de empresas EE no Nó 4, ante 0\% no Nó 3). É o cluster de empresas Exploradoras Estruturadas (EE) que melhor absorve as análises e conclusões frente a temas relevantes a monitorar, mesmo nos casos em que seus gestores tenham respondido que o conhecimento sobre prospecção não estaria adequado o suficiente (Nó 4).

Nesta análise, o que é relevante é a identificação do conhecimento como ponto de partida para a prospecção adequada, e suas conclusões e análises levam à alta contribuição no tratamento de incertezas estratégicas, que é potencialmente o objetivo primeiro da prospecção. E este objetivo é atingido pelas empresas do grupo Exploradoras Estruturadas (EE). Estas empresas conseguem fazer melhor uso dos resultados da prospecção do futuro, portanto, elas integram melhor a prospecção do futuro com a estratégia empresarial. 
Empresas do grupo Exploradoras Estruturadas (EE) também lidam melhor com a identificação de temas que devem ser monitorados, o que reduz os riscos de lacunas de análise e de pontos cegos na estratégia empresarial. Em contraste, empresas do grupo Exploradoras $\underline{\text { Reativas (ER) demonstram sérias limitações no processo de identificar temas relevantes para }}$ $\underline{\text { serem monitorados, }} \underline{\text { o que as coloca em risco elevado de lacunas de análise e pontos cegos na }}$ estratégia empresarial.

As empresas do grupo Exploradoras Reativas apresentam, dessa forma, mais limitação no processo de integrar prospecção do futuro com estratégia empresarial. $\mathrm{Na}$ amostra de respondentes da pesquisa desta tese, elas representam $70 \%$ da amostra (110 empresas). As Exploradoras Estruturadas (EE) representam 30\% da amostra (47 empresas).

\subsubsection{Abordagem fundamental na análise dos dados quantitativos: A segmentação da amostra}

Com o objetivo de elucidar as questões de pesquisa e atingir os objetivos desta tese, foi muito importante a segmentação da amostra, resultando em 2 segmentos de empresas. A análise do total agregado da amostra não revela uma realidade única, e sim, uma realidade bipolar.

De um lado, há empresas mais estruturadas e orientadas para a prospecção do futuro. E de outro lado, empresas menos estruturadas e com menor orientação para a prospecção de futuro. Projetos estratégicos desenvolvidos nestes dois segmentos apresentam padrões de orientação para a prospecção do futuro de forma muito diferenciada.

Fica identificada uma questão, que deriva desses resultados aqui apresentados na parte quantitativa. Pergunta esta, para ser analisada e respondida por meio das entrevistas desenvolvidas na parte qualitativa desta tese:

- Será que é preciso grande estrutura empresarial para desenvolver um conhecimento apropriado de técnicas de prospecção do futuro, e dessa forma potencializar a orientação para o futuro em organizações? 
Lembrando o que Rohrbeck e Bade (2012) argumentaram sobre a literatura de prospecção do futuro: Nos anos 1980 ela estava concentrada em explicar a "razão de ser" dos estudos do futuro, ou seja, buscava justificar porque prospecção deveria ser praticada. Já nos anos 1990 o foco se voltou para os métodos, suas recomendações e prescrições e também no escopo mais amplo, de ambiente externo e do que deveria entrar num estudo prospectivo, ou seja, no cuidado com a definição de que temas portadores de incertezas deveriam ser analisados. Em outras palavras, houve nos anos 1990 uma ênfase à recomendação da prospecção para evitar pontos cegos na estratégia empresarial.

Mais tarde, nos anos 2000, o próprio Rohrbeck publicou com Gemünden em 2008 um artigo que buscava sistematizar uma forma de medir quão evoluída estaria a prática da prospecção em uma organização. Em seguida, Grim (2009) propôs o Foresight Maturity Model (FMM) para contribuir sobre o tema de avaliar a maturidade da atividade de prospecção em uma organização. Rohrbeck (2011) continuou a jornada para o desenvolvimento de uma estrutura que permitiria avaliar a prática nas organizações.

Esses autores propuseram caminhos para suprir as lacunas ainda existentes na literatura dentre as quais a de que a utilização de resultados da prospecção era ainda pouco estudada, e a de que a avaliação da prospecção ainda menos (CHERMACK, 2011). 


\subsection{Discussão das entrevistas}

Como mencionado no capítulo de metodologia, nesta tese se utilizam entrevistas para contribuir na análise dos resultados da parte quantitativa. Dessa forma, o método principal da tese é o quantitativo, contudo as entrevistas realizadas serviram a dois objetivos: (1) calibrar o instrumento de coleta da survey (questionário da coleta quantitativa), e (2) capturar relatos de entrevistados acerca da prática da prospecção do futuro em suas organizações, visando à descrição do fenômeno e ao aumento do poder de explicação dos resultados quantitativos.

Nesta parte da metodologia prevista para esta tese, foram realizadas entrevistas com profissionais de seis organizações, totalizando sete entrevistados.

\subsubsection{Aspectos de confidencialidade}

Gubrium et al (2012) propõe que a proteção da confidencialidade tem relevância quando se realizam entrevistas. Os autores argumentam que em primeiro lugar, é esperado que os pesquisadores protejam a identidade dos participantes da pesquisa, e isto em todas as etapas da pesquisa. O objetivo principal é a confidencialidade completa. A intenção é proteger o participante de qualquer problema que possa surgir em razão da pesquisa. O benefício para o pesquisador, de adotar confidencialidade, é estimular a riqueza dos relatos pela criação de confiança e relacionamento durante a pesquisa (GUBRIUM et al, 2012, p. 459).

Pelo tema tratado nesta tese, a prospecção do futuro, o qual se relaciona com decisões estratégicas nas organizações, foi dada a condição de sigilo dos entrevistados. Esta abordagem visou dar tranquilidade aos entrevistados quanto aos assuntos relatados, mesmo se tratando de entrevista mais focada na metodologia, sem entrar no mérito da decisão ou do contexto estratégico das empresas. A discussão nas entrevistas foi sobre o método ou metodologia para a prática da prospecção. Em outras palavras, sobre o meio que se utiliza para suporte às decisões, e a profundidade em que esse meio é utilizado.

Dessa forma, a tese tinha objetivo de levantar como se chega, ou como se chegou a conclusões a partir de estudos prospectivos nas organizações dos entrevistados, portanto, nas entrevistas estaria sendo declarado o grau ou a profundidade em que a atividade é ou foi praticada. Isso poderia criar desconforto nos entrevistados, o que limitaria o quanto eles informariam sobre o tema. Tal situação foi detectada nas duas entrevistas que foram 
realizadas antes da survey quantitativa. Aspectos de confidencialidade foram mencionados pelos entrevistados, uma vez que a preocupação não era somente com a estratégia das organizações, mas especialmente com declarações sobre a profundidade em que a prospecção é praticada nelas, o que poderia conter risco de desconforto para os entrevistados. Informações sobre isso exporiam os entrevistados, como profissionais individualmente, e também as organizações em que atuam, porque elas têm partes interessadas (stakeholders) que poderiam questionar a exposição das mesmas, ou de seus profissionais colaboradores.

Outro aspecto que precisou ser considerado é o termo de confidencialidade que alguns gestores possam ter com suas organizações, seja no contrato de trabalho ou em forma de um NDA (non-disclosure agreement) específico e separado do contrato de trabalho, que tipicamente estabelece limites quanto ao grau em que eles possam externar publicamente aspectos de sua organização, ou mesmo de sua individualidade enquanto colaborador daquela organização. Alguns desses instrumentos contratuais alcançam um período de tempo de responsabilização significativo, posterior à saída do profissional da organização.

Esses aspectos de confidencialidade mencionados aqui, somados ao fato de que a liberdade de relatar os fatos com confidencialidade induz à riqueza narrativa, situação buscada nessas entrevistas, deram suporte à decisão de manter a confidencialidade dos entrevistados e de suas organizações. Apenas algumas informações gerais sobre setor, ou experiência prévia dos entrevistados, podem ser observadas nesta tese.

Ao final das entrevistas os participantes receberam a informação de que a confidencialidade poderia ser determinada pela sua diretriz pessoal ou corporativa, e que caso o autor desta tese desejasse aumentar o grau de identificação dedutível a partir da quebra da confidencialidade interna $^{6}$ (TOLICH, 2004), então nesse caso seria feito contato prévio antes da edição final da tese, com o descritivo anexo, solicitando autorização ou orientação.

As entrevistas foram feitas com profissionais de organizações, os quais se envolvem (ou se envolveram) em decisões que contenham incertezas de futuro.

\footnotetext{
${ }^{6}$ Do original em inglês: Internal confidentiality - significa a confidencialidade que, se preservada, evita que pessoas que tenham relações entre si sejam capazes de deduzir quem foi o entrevistado em uma pesquisa, pelo conteúdo apresentado na pesquisa publicada.
} 
Por final, cabe mencionar aqui que tanto Gubrium et al (2012) quanto Tolich (2004) tecem argumentos em prol da confidencialidade utilizando como exemplos casos de pesquisas de áreas das ciências sociais ou biomédicas, notadamente mais críticas em termos de severidade quando não se preserva confidencialidade. Entretanto, é pertinente considerar que mesmo na área da administração o risco existe, e dado que teses e dissertações são documentos eminentemente públicos, o cuidado tomado se justifica.

\subsubsection{Entrevistas prévias à coleta de dados quantitativa}

Dentre os entrevistados das seis organizações, em duas delas os entrevistados participaram antes da finalização do instrumento de coleta quantitativo, e nas outras quatro organizações as entrevistas foram realizadas após a coleta de dados e das análises desenvolvidas sobre os mesmos.

As duas primeiras entrevistas visavam à calibração do questionário de coleta e a definição do quanto se aprofundaria nas questões do questionário. Elas foram desenvolvidas de forma menos direcionada do que as outras, para permitir aos entrevistados livre manifestação sobre suas opiniões. A abordagem foi aberta, apenas mantendo certo foco nos aspectos que poderiam identificar dificuldades ou limitações potenciais dos participantes da survey em responderem as questões do questionário, mas ainda assim, tratavam de prospecção do futuro e estratégia empresarial.

As demais entrevistas eram mais focadas para subsidiar as análises dos dados quantitativos obtidos pelo instrumento de coleta (survey). Os relatos estão descritos nas seções a seguir.

\subsubsection{Entrevista I}

O entrevistado e a empresa não são revelados nesta tese, pelas razões expostas anteriormente, mas também porque originalmente a entrevista foi programada para ter duas etapas, a primeira com foco especificamente para capturar a opinião sobre o potencial de respostas à pesquisa. A segunda etapa seria com foco na prática da prospecção do futuro na sua organização, contudo, não foi possível viabilizar a segunda etapa pela dificuldade de agenda do entrevistado. Deve ser lembrado que o ano de 2015 foi muito turbulento para executivos de empresas, e talvez mais fortemente para aqueles do setor B2B, que é o caso de sua empresa. 
Dessa forma não foi realizada consulta sobre confidencialidade das partes, e o autor da tese decidiu manter confidencialidade, motivado pela prudência.

Esta entrevista foi sobre uma multinacional que produz ingredientes para empresas que produzem uma ampla gama de produtos do setor de alimentos, material esportivo, construção civil, químicos, têxteis, dentre outros. A empresa tem faturamento mundial da ordem de R\$ 43 bilhões/ano (base 2014), com pouco mais de 24.000 funcionários e tem seu capital aberto, com ações em bolsa de valores no exterior.

A empresa mantém três unidades de pesquisas em inovação, que suportam as necessidades das unidades de negócios ao redor do mundo. A operação industrial tem presença em quatro continentes, excetuando a Oceania.

Na apresentação ao mercado, a empresa enfatiza que o crescimento dela é baseado em análise de tendências globais. Esse é um sinal que indica a orientação para o futuro da organização.

A entrevista foi realizada pessoalmente com um executivo da empresa, e o objetivo desta foi especificamente capturar sua opinião sobre dificuldades ou limitações dos participantes da pesquisa em dar repostas ao instrumento de coleta. Os temas da pesquisa foram explicados ao entrevistado, e foi dada flexibilidade para ele se manifestar, visando estimular manifestações de qualquer natureza sobre essas possíveis limitações.

Em primeiro lugar, ele mencionou que dependendo do tipo de empresa do respondente, poderia ocorrer uma variação nas repostas devido ao local em que as decisões estratégicas são tomadas. Algumas empresas internacionais, com sedes fora do Brasil, poderiam centralizar mais as análises e estudos relacionados com estratégias, e por decorrência com o futuro. Nesses casos, os participantes dessas empresas talvez deixassem de participar da pesquisa, ou se participassem poderiam deixar de responder algumas das questões. Para esta situação, foi explicado que se utilizaria uma amostra grande de participantes potenciais, e que aquele risco poderia ser mitigado pela quantidade de convidados. Como se viu nos dados da parte quantitativa, de fato a taxa de resposta geral foi de pouco menos de $12 \%$ da amostra, o que confirmou como positiva a decisão de ter amostra grande. 
Essa hipótese colocada pelo entrevistado talvez tenha relação com o fato de a sua empresa operar com muitas unidades de negócios, com uma diversidade de áreas elevada, o que pode estratificar as decisões e ainda limitar um pouco o escopo das decisões tomadas em cada unidade.

Houve consideração por parte do entrevistado que poderia haver perda de respostas para os casos de questões envolvendo muitos fatores. Em especial porque naquela altura do desenvolvimento da tese, o instrumento de coleta previa muitas questões, pois elas refletiam a abrangência proposta por autores, mais especificamente Grim (2009) e Rohrbeck (2011), que são os que propõem a avaliação de maturidade da prospecção em organizações, por meio de modelos mais operacionais.

O entrevistado ponderou que a prospecção do futuro ocorra mais fortemente nos locais nos quais são tomadas as decisões sobre estratégia. Dessa forma, talvez fosse um pouco difícil encontrar os respondentes que pudessem participar da pesquisa, e de fato contribuir para uma pesquisa que tivesse foco em prospecção do futuro e estratégia de forma ampla. O seu relato corroborou a decisão de se concentrar na prática da prospecção para suporte a decisões em projetos estratégicos, e não mais em estratégia de forma ampla. Isso aumentaria o potencial de respondentes à coleta, pois seria muito mais viável encontrar gestores que tenham se envolvido com projetos no âmbito da estratégia, do que com estratégia geral de suas organizações.

A impossibilidade de realizar a segunda parte da entrevista com essa empresa foi um problema no início do desenvolvimento desta tese, mas que foi contornado porque foi possível realizar outra entrevista antes da survey, com executivo de outra empresa (Entrevista II).

A razão por se escolher a empresa da Entrevista I para as duas etapas antes da coleta de dados (survey) foi porque ela atua no setor de suprimentos para outras empresas, sendo estas de diferentes setores da economia, e por esta razão a empresa da Entrevista I precisa estar atenta ao futuro de uma ampla gama de setores da economia.

A empresa da Entrevista II foi, dessa forma, escolhida considerando essa mesma característica. E o executivo entrevistado teve a possibilidade de participar da entrevista 
considerando tanto a opinião sobre o potencial de respostas, quanto à parte relativa à prospecção propriamente dita.

\subsubsection{Entrevista II}

Também relacionada a uma empresa que atua no mercado B2B, sendo produtora e fornecedora de ingredientes para outras empresas, a empresa do entrevistado é uma multinacional com longa história, que se iniciou há mais de cem anos e opera em dezenas de países.

Os clientes da empresa são de diversos setores, como automotivo, máquinas e equipamentos, indústria de transportes, aeroespacial, construção civil e embalagens. Trata-se de uma empresa que investe significativamente em pesquisa e desenvolvimento, razão pela qual tem resultados expressivos em termos de participação de mercado, e também de reconhecimento público de seus clientes da qualidade de seus produtos e soluções.

A empresa tem pouco mais de 40 mil funcionários no mundo, opera nos cinco continentes, e apresenta faturamento de R $\$ 57$ bilhões/ano (base de 2014). Suas ações são negociadas em bolsa de valores no exterior. O entrevistado é diretor geral da empresa no Brasil.

\section{Sobre o questionário (survey) e seu potencial de respostas}

O entrevistado opinou que de fato poderia haver alguma perda de respondentes, caso o escopo do instrumento de coleta fosse extenso. Isso convergiu com a opinião do entrevistado da Entrevista I, o que reforçou a recomendação de se concentrar a pesquisa nos elementos principais, no caso a transição entre prática da prospecção e a contribuição dos seus resultados na decisão, bem como os processos prospectivos praticados para suporte à decisão, com foco em projetos no âmbito da estratégia empresarial.

Mesmo sendo a matriz da empresa fora do Brasil, é necessário analisar o contexto local, suas tendências e ambiente mercadológico e político-econômico. Isso, segundo seu relato, induz executivos locais a se envolverem muito nas análises que tratam do futuro. Para ele, não basta receber uma análise bem aprofundada e detalhada de alguma fonte, por mais reconhecida que fosse esta fonte. É preciso considerar que os executivos envolvidos com a responsabilidade da decisão, e por decorrência pelos resultados gerados por ela, podem e devem querer saber 
detalhes das análises, que premissas foram utilizadas, como foram provadas as alternativas analisadas. Enfim, o envolvimento na atividade de prospecção daqueles que vão assumir o risco pela decisão, e depois pelos seus resultados, deve ser proporcional aos riscos e responsabilidades. Traduzindo em outras palavras, os tomadores de decisão devem fazer parte da prospecção, do contrário pode ocorrer limitação na fase de implantação do projeto.

Esse relato indica que na opinião dele, embora haja risco de alguma perda de respondentes pelo fato das decisões estratégicas serem feitas nas matrizes, nos casos de empresas estrangeiras, esse risco não seria grande. Afinal, ele mesmo e muitos de seus contatos em empresas desse tipo, se envolvem nas discussões sobre o futuro, mesmo tendo as matrizes o poder da decisão final.

Como o futuro envolve muitos fatores, se a pesquisa incluísse um foco muito amplo em relação aos fatores, seria possível ocorrer muitos abandonos durante o processo de resposta. Esse comentário foi devidamente anotado, e levado em consideração nesta tese. Cabe mencionar aqui que, mesmo buscando concentrar a pesquisa nos principais temas estudados nesta tese, e assim reduzir o instrumento de coleta, a taxa de abandono no meio do preenchimento foi de $50 \%$. Se as precauções não tivessem sido tomadas, essa taxa poderia ser muito superior.

\section{Sobre a prospecção e sua prática na empresa}

Empresas estrangeiras tendem a praticar bastante a prospecção do futuro. E essa opinião se baseia mais no fato delas serem empresas maiores, que já passaram por processo de internacionalização. Na opinião do entrevistado, o porte da empresa pode influenciar mais do que o fato dela ser estrangeira. E os dados da survey corroboram a opinião do executivo, pois a origem do capital não influencia a composição dos grupos. Nesse tipo de empresa há maiores riscos envolvidos, há mais ativos e recursos financeiros comprometidos nas operações, e isso certamente potencializa a busca por estudar o futuro. Claro, segundo ele, existe sim uma componente cultural do ambiente de negócios do país de origem, e talvez ela tenha influência no grau em que se estuda o futuro, pela forma em que gestores estruturam as incertezas, os problemas de decisão e os de prospecção. As culturas anglo-saxã e germânica são mais prescritivas nesse aspecto, segundo ele, e isso induz à maior estruturação, ao maior 
domínio, talvez, de metodologias para suporte à decisão. $\mathrm{O}$ entrevistado foi executivo de empresa alemã no passado.

Por outro lado, ele argumenta que mesmo no caso de uma empresa brasileira, que tenha se internacionalizado e esteja operando em outro país, a análise de incertezas de futuro possivelmente ocorra no mesmo nível em que ocorre em sua empresa. Talvez a forma com que os processos são conduzidos seja diferente, mas ele assume a hipótese de que a diferença na profundidade não seria grande. Tudo tem relação ao montante de recursos em risco, segundo sua análise. Os resultados da survey para a amostra de respondentes mostra que a origem do capital, nacional ou estrangeira, não discrimina os grupos de empresas.

Quanto ao escopo do que é prospectado, ele depende do contexto de análise, do problema que se tem em mãos. Se ele envolve aspectos amplos relacionados à estratégia da empresa, tendese a incluir tudo que possa ter alguma influência. $\mathrm{O}$ horizonte de tempo também é importante, quanto mais longo for, mais coisas entram na análise, segundo ele. E existe a proporcionalidade direta entre o montante em risco e a frequência e a profundidade que a prospecção é executada.

É difícil prospectar, embora seja importante, necessário e talvez até assumido como uma competência obrigatória de executivos. Dessa forma, quando contratados, eles já são considerados como capacitados para lidar com incertezas de futuro. Mas, talvez isso não seja sempre realidade, segundo ele. Ele menciona que recorrentemente encontra pessoas em dificuldades para lidar com incertezas de futuro, mais devido ao desconhecimento sobre técnicas que podem dar suporte a essa atividade. E isso, somado ao fato de que, em muitas vezes, o tempo disponível não permite mais do que a discussão entre pessoas, a troca de ideias, opiniões e projeções baseadas na experiência ou intuição dos gestores. Contudo, nos casos em que há muita coisa em jogo, segundo ele, os esforços são multiplicados, eles são analisados com o devido tempo necessário, e com a possibilidade de se aprofundar os estudos prospectivos. Apenas seria interessante ser mais eficiente ou eficaz, talvez por meio da aplicação de técnicas ou ferramentas que facilitassem as análises. Isso corrobora o constatado na survey, tendo sido o conhecimento sobre metodologias de prospecção a variável mais importante para caracterizar os agrupamentos. 
Em relação aos processos prospectivos utilizados, o entrevistado menciona que em grande parte das vezes, se o projeto demanda por aprofundamento, as premissas são calibradas e discutidas, os cenários vislumbrados são debatidos, os sinais ou indicadores importantes para monitoramento são identificados e os resultados esperados são testados em diferentes contextos de futuro. Segundo ele, não se verifica o alinhamento com a estratégia, pois em princípio isso já foi realizado previamente. Quanto à avaliação de mudanças na organização para se adequar ao cenário futuro, e a análise sobre necessidade de competências a serem adquiridas, isso depende do que está sendo analisado, do projeto ou do problema de decisão. Se estes demandam por alguma mudança na empresa, então elas são avaliadas conforme a necessidade, e neste caso, as análises dependem do caminho ou da rota estimada para 0 futuro.

Em grandes linhas, o caso da empresa do entrevistado demonstra boa utilização da prospecção nos processos de suporte à decisão, e isso tem a ver com o porte da empresa, segundo ele.

A conclusão que pode ser tirada desta entrevista é que a propensão para a prospecção é um comportamento inevitável, é imperativo. Paradoxalmente, os gestores podem não estar preparados para conduzir a atividade sem problemas, e talvez isso tenha relação com o domínio das metodologias. 


\subsubsection{Entrevistas posteriores à coleta de dados quantitativa}

\subsubsection{Entrevista III}

A organização do participante atua no setor de saúde. As operações se caracterizam pela inovação em processos e em modelos de relacionamento com os diversos agentes da cadeia de valor, bem como com seus clientes. No período entre os últimos vinte e cinco anos desta organização, houve transformações consideráveis, que abrangeram praticamente a maior parte da sua cadeia de valor. O portfólio de produtos e serviços foi ampliado, os processos aprimorados, a forma de relacionar-se com clientes e fornecedores foi modificada com o uso eficiente de tecnologia. Esse processo também incluiu mudanças na estrutura de gestão, incluindo o nível operacional e chegando à alta gestão da organização e suas relações com stakeholders externos.

O participante foi executivo da organização, e após anos de atuação agora se dedica ao conselho de administração. Os relatos aqui apresentados devem ser entendidos como sendo a visão de um conselheiro, não executivo, portanto.

Em primeiro lugar, o entrevistado declara que a prospecção do futuro é extremamente importante. É preciso manter profunda atenção aos eventos, ao ambiente e às mudanças potenciais que possam impactar a organização. Ele argumenta que empresas grandes são mais propensas à prospecção, mantêm mais foco no aprimoramento de suas visões de futuro, e seus gestores se mobilizam para dar a devida atenção ao futuro. Em sua opinião, a profundidade na qual o futuro é estudado, em organizações desse porte, é proporcional ao grau de importância que é atribuído à atividade. Sua hipótese é de que não haja diferença entre importância atribuída e a profundidade da prática da prospecção.

Quanto maior a empresa, mais recursos podem ser alocados para prospectar, sejam humanos, sejam financeiros. E isso envolveria áreas específicas para realizar a atividade, processos praticados e mesmo a busca pelo conhecimento para realizar estudos prospectivos, segundo seu relato.

Dentre os temas importantes que demandam atenção, o entrevistado menciona a inovação tecnológica, podendo ser radical ou incremental, que pode trazer impactos ao portfólio da organização. Os impactos podem ser positivos ou negativos, pois podem representar 
oportunidades ou ameaças. Ele relata um caso no qual foi analisada uma nova tecnologia de automação para a empresa, e que poderia representar uma mudança na forma com que as soluções eram desenvolvidas, aplicadas e tornadas disponíveis ao mercado. Os parâmetros que faziam parte dessa nova tecnologia apontavam a necessidade de operar com altos volumes, portanto, seria uma inovação de capital intensivo, e quem a adotasse antes poderia ter uma vantagem significativa no mercado. Havia também uma análise de que a adoção ou não, da nova tecnologia, poderia definir uma mudança no patamar de operações da organização, seria um divisor de águas entre aumentar consideravelmente a escala das operações, ou ficar no patamar anterior. E neste último caso, segundo ele, poderia até ocorrer de a empresa não conseguir competir com empresas de escala muito maior, com risco de provocar o encerramento das operações.

Ele retoma a questão da importância da prospecção para reforçar que ter orientação para o futuro é responsabilidade dos altos executivos. A prospecção do futuro foi importante para a organização no passado, e considerando o mundo atual, ela ganha ainda mais relevância, pois as mudanças estão acontecendo de forma mais rápida ainda.

Ele chama a atenção sobre coisas que possam estar em desenvolvimento em algum lugar, e que ainda não estão no campo de atenção dos gestores, mas cujas consequências de seu sucesso podem ser muito impactantes para a organização no futuro. Segundo ele, as chances de isso estar acontecendo, no momento em que ocorria a entrevista, seriam muito maiores do que no passado. Ele propõe que haja um comitê permanente de estratégia nas empresas, com alguma instância como conselho consultivo para suporte à análise de riscos e oportunidades estratégicas para a organização. Especialmente em se tratando de inovações radicais, que possam mudar a forma como as coisas são feitas atualmente.

As lideranças das organizações precisam estar atentas aos riscos e oportunidades. É preciso ter bons recursos humanos, e ainda multidisciplinares porque assim é possível aumentar as chances de lidar melhor com incertezas de futuro. Mesmo na condição de ter disponível capital financeiro, o fator humano é crucial para uma boa integração entre pensamento estratégico e prospectivo. Agora, enfatiza ele, embora o capital humano de qualidade seja uma recomendação sensata e talvez com grande nível de concordância entre os executivos, o processo de lidar com incertezas de futuro é muito difícil de ser conduzido. 
Mesmo sendo difícil, é preciso manter atenção ao futuro, é preciso lidar com incertezas, analisar o que elas podem conter de significados, como podem compor contextos de futuros alternativos para a organização. Se isso não for feito, corre-se om risco de desaparecimento no longo prazo, segundo seu relato.

\section{Processos praticados no âmbito da prospecção}

Sobre a questão de processos tipicamente praticados quando se estuda o futuro, o entrevistado relata que o mais utilizado é a análise de contextos futuros, e como a organização estaria dentro desses contextos. Ele menciona a curva de aprendizado trilhada pelos participantes de

processos de estudar o futuro. É preciso investir nesse processo, as lideranças da organização precisam se envolver nessa atividade, dar suporte e estimular que ela ocorra. Ela gera conhecimento útil, estimula o incremento e aquisição de habilidades e também proporciona o surgimento de atitudes mais orientadas à estratégia, ao futuro e suas nuances que podem representar oportunidades e ameaças. Os benefícios disso são visíveis, segundo ele.

A calibração de premissas é importante para poder suportar a visualização de contextos futuros da organização, segundo o relato. Trata-se de uma atividade recorrentemente praticada na empresa, sendo que ela tem predominância de horizonte de tempo de curto a médio prazo. A prospecção proporciona a condição de avaliar como devem ser calibradas as premissas.

Quanto ao monitoramento de sinais ou indicadores que possam servir de pistas sobre o futuro acontecendo, ou na iminência de acontecer, o entrevistado relata que isso é feito especialmente para identificar o grau de impacto nos negócios da empresa. Uma forma adaptada do que Gordon (1994) propôs no seu modelo de análise de tendências impactadas.

Por ser realizado monitoramento da empresa, a simulação de como ela se encontraria em um futuro visualizado é realizada na empresa. Este é um passo natural no processo, segundo o entrevistado. $\mathrm{O}$ exame das incertezas de futuro também é praticado na empresa, e a forma que isso é feito é por meio de montagem de mapa de tendências, segundo as palavras do entrevistado. Este mapa é montado utilizando-se árvores de decisão, análise de rotas possíveis de ocorrerem para cada área analisada, identificando quais delas vão consolidar-se, quais vão enfraquecer. 
Sobre lacunas de análise prospectiva, o entrevistado declarou que isso não ocorre na organização. Há muita preocupação com o futuro, há instâncias na organização que analisam questões de estratégia e de futuro, e isso de forma recorrente, o que limita a possibilidade de ocorrência de lacunas de análise, de pontos cegos deixados para trás. Para garantir que isso não ocorra, há um reconhecimento na organização de que o mundo está acelerando, e as mudanças por consequência disso também seguem o mesmo passo. Então há sempre questionamentos sobre os temas que precisam ser analisados e monitorados, o que dá boa cobertura de temas que portam incertezas de futuro, e assim se evitam lacunas de análise. Isso foi constatado na survey, pois as empresas EXPLORADORAS ESTRUTURADAS (EE) lidam melhor com a prospecção, e a empresa do entrevistado é de perfil de empresas EE.

A prospecção é um meio de suporte à tomada de decisão, esta é a abordagem na organização. O principal objetivo de se estudar o futuro é aprimorar o processo de tomada de decisão. $\mathrm{O}$ entrevistado enfatiza que muitas pessoas na empresa se dedicam fortemente à atividade de analisar as tendências de futuro.

Sendo significativa a ocorrência de atividades de prospecção do futuro, o entrevistado declara que os resultados da prospecção do futuro são muito utilizados, e apresentam grande utilidade para o processo de tomada de decisão. Esta, por sua vez, somente é tomada se for considerado que ocorreu suficiente suporte em termos de análises, com estudos e premissas assumidas devidamente. Recorre-se bastante a consultorias externas.

O conhecimento dos gestores da organização em relação aos métodos de estudar o futuro é suficiente para as necessidades, isso demanda ter boas pessoas, com competências adquiridas. Mas é bom ter algum facilitador que coordene as atividades de prospecção, segundo o entrevistado. A prática da prospecção necessariamente precisa do envolvimento de muitas pessoas, e não se pode fugir da reponsabilidade de envolvê-las no processo. Isso porque, se for necessário implantar decisões que alterem significativamente a forma como a empresa realiza suas atividades, são elas que precisarão implantar essas mudanças.

O entrevistado enfatiza que os gestores da organização estão preparados para a prospecção do futuro, por uma série de fatores: (1) a empresa opera num setor de alto uso de conhecimento, então este está disponível dentro da empesa, (2) o modelo de pensar estratégia na organização 
está bem maduro, e é praticado de forma bem natural, o que facilita o pensamento prospectivo e estratégico.

O tema que mais incomoda o entrevistado é o contexto político. Há muitas coisas que mudam repentinamente no cenário político, e isso acaba gerando mudanças abruptas no setor, o que prejudica a estratégia e condução de projetos estratégicos.

O entrevistado enfatiza a importância da prospecção do futuro. Em especial com relação ao porte da organização e ao histórico apresentado por ela. Quanto maior o porte, mais relevância precisa ser dada ao estudo do futuro, pois há muito mais em risco caso haja mudanças significativas que impactem a organização. $\mathrm{O}$ entrevistado afirma que organizações de maior porte certamente praticam a prospecção do futuro, sendo que essa afirmação vem de sua experiência e intuição. Para ele, seria praticamente impossível ser executivo em empresas de grande porte sem estudar o futuro, sem demonstrar zelo com a perpetuidade da empresa. É esperado de um executivo que ele saiba lidar com isso, e os processos de sucessão ou contratação de executivos buscam identificar isso nos candidatos, em sua empresa.

Em adição à questão do porte da empresa, o longo histórico da organização tem um amplo conjunto de possíveis fatores que influenciam a importância dada à prospecção. Um possível fator é que ele gera uma carga de tradição, e nenhum gestor gostaria de estar na condição de colocar em risco um histórico tão longo. Outro fator é que uma trajetória longa gera percepção de competência estratégica, e essa percepção induz maior pressão sobre os executivos da organização. Ou seja, ao mesmo tempo em que isso é um endosso aos executivos da empresa, também é uma responsabilidade grande ter que desempenhar conforme as expectativas. A atenção com a estratégia, o ambiente externo, as mudanças que potencialmente possam gerar oportunidades ou trazer riscos estão, dessa forma, entre as preocupações máximas dos gestores da organização.

O horizonte de tempo típico informado pelo entrevistado é de cinco anos, com variações que podem chegar a vinte anos, como já ocorreu segundo ele. Às vezes o contexto leva os gestores a considerar coisas que vão muito além de cinco anos à frente, devido a aspectos de mudanças à vista que possam impactar a organização, e esses impactos não se consolidam em período de cinco anos apenas. Nesses casos, é necessário estender o horizonte até o ponto no qual se considera que as mudanças e seus impactos se estabilizariam. Esta declaração reflete o que 
ensinou Gordon (1994). O entrevistado não menciona explicitamente a Análise de Tendências Impactadas, mas se observa que a base da mobilização está no reconhecimento de que as mudanças precisam ser analisadas, justamente porque elas tenham condições de impactar o futuro da organização, seja em amplitude, assim como em intervalo de tempo.

Conviver com a preocupação em relação a incertezas faz parte da vida do executivo, e por consequência seu papel é lidar com elas porque, ao final, decisões que envolvam estratégia precisarão ser tomadas. Segundo o entrevistado, as análises devem envolver pessoas que possam contribuir com suas visões e opiniões, o processo não é conduzido por poucas pessoas, ele inclui profissionais internos e externos à organização. E, como se trata do futuro, não é esperado que as incertezas de futuro tratadas resultem em certezas, porque isso não é possível. Contudo, as análises realizadas permitem lidar com as incertezas ao ponto de permitir a tomada de decisões, em situação de conhecer os riscos que estariam ainda presentes nas incertezas tratadas ou analisadas. Esta situação, segundo o entrevistado, é a que deve ocorrer nas organizações que se orientem para a estratégia, para o futuro, mas é importante enfatizar que, ainda assim, é muito importante ter coragem, ter confiança em si mesmo e na equipe, porque as decisões são tomadas em condições de incertezas ainda remanescentes.

Uma parte significativa do tempo dedicado ao estudo do que poder vir a acontecer é sobre questões de legislação e regulamentação. Como se trata da área de saúde, não seria esperado que fosse diferente. Mas o ponto enfatizado pelo entrevistado é que muitas vezes as incertezas eram geradas porque a regulamentação se mostrava muito intervencionista. Em outras palavras, era preciso estimar o que pensavam os agentes que detinham o poder discricionário de determinar o que seria regulamentado. E isso é uma coisa mais difícil de analisar do que, segundo ele, ter que estimar o que ocorreria no mercado se ele fosse deixado mais livre.

Um aspecto importante mencionado pelo entrevistado foi a das fontes de financiamento, ou mais especificamente o custo do capital no Brasil. A área de atuação da organização apresenta a característica de ser intensiva em uso de capital. E isso, nos aspectos da necessidade de ativos como instrumentação, máquinas e equipamentos, ou ainda na forma de aquisição, integração ou desenvolvimento de sistemas de suporte a negócios, controle e gestão operacional. Dessa forma, como o capital estrangeiro ficou impedido de entrar no setor por um período razoável, as decisões estratégicas tinham que considerar o uso do capital próprio, considerando os limites de riscos representados pela estrutura de capital mais agressiva para 
financiar novos posicionamentos estratégicos. Em outras palavras, era preciso coragem e confiança para fazer as visões estratégicas se tornarem realidade no futuro.

Sobre o que ele proporia para aprimorar a atividade de estudar o futuro, as sugestões passam por:

(1) Ter pessoas especializadas nisso na organização, sem significar uma área específica, mas sim uma forma contínua de disseminar o pensamento prospectivo e estratégico, possibilitando uma orientação geral para o futuro permeando a organização.

(2) Estar atento para monitorar o ambiente, pois nem tudo pode ser analisado pela prospecção.

(3) Ter controle sobre o que está em implantação na empresa, especialmente os projetos de prazo maior (estratégicos). Isso facilita enxergar convergências ou divergências em relação aos futuros colocados em análise na empresa.

(4) Garantir conhecimento multidisciplinar na empresa, com objetivo de limitar a possibilidade de ocorrência de lacunas de análise.

Novamente, o entrevistado reforça que somado a essas sugestões, é preciso dedicação, coragem e confiança.

As sugestões propostas pelo entrevistado deste caso ilustram bem o que seria importante considerar em termos de contribuição para a aplicabilidade de metodologia prospectiva em organizações. 


\subsubsection{Entrevista IV}

O entrevistado deste caso é hoje atuante na academia, mas tem trajetória como executivo em corporações das áreas de tecnologia da informação e telecomunicações. São multinacionais do setor, sendo a última empresa em que trabalhou um exemplo de investimentos em pesquisa e desenvolvimento, com soluções tecnológicas em contínuo desenvolvimento.

O autor desta tese tinha autorização do entrevistado para identificá-lo, contudo, por motivo de prudência foi decidido não fazer a identificação.

Sobre a contribuição da prospecção do futuro na tomada de decisões em projetos estratégicos, o entrevistado relata aspectos de sua experiência profissional, a seguir.

Esta questão tem uma abrangência ampla, pois são múltiplos fatores que influenciam no processo de se decidir sobre um projeto estratégico. Em primeiro lugar, é preciso analisar se o escopo da prospecção pode envolver desde a concepção inicial do projeto, passando pelo levantamento de possíveis alternativas e chegando finalmente até a definição sobre como será a implantação do mesmo.

Uma questão que influencia o processo de lidar com incertezas de futuro tem relação com a seguinte pergunta: Quem desenvolve o estudo no âmbito do projeto? Ou seja, quem efetivamente se dedica ou se dedicou sobre o tema, e por decorrência disso, quais foram as análises e conclusões a que chegaram. Isso foi explicado pelo entrevistado, por exemplo, se a prospecção foi desenvolvida por pessoas sobre as quais o entrevistado não tem conhecimento prévio sobre a expertise delas, então ocorre certa insegurança acerca dos resultados dos estudos desenvolvidos.

Dessa forma, pode-se considerar que a contribuição da prospecção do futuro poderia ocorrer em maior ou menor grau em função de quem desenvolveu as análises.

O entrevistado relata que, de sua experiência como executivo em empresas, buscava sempre ter um parâmetro de análise próprio sobre incertezas de futuro. Seja esta análise tendo sido feita por ele próprio, ou por uma equipe de pessoas sobre as quais ele tivesse conhecimento sobre o quanto elas conheciam sobre o tema, ou mesmo quanto elas conheciam as possíveis metodologias aplicáveis para se prospectar o futuro. Em outras palavras, em se tratando de 
lidar com incertezas de futuro, independente do tema em análise, é importante, segundo ele, ter um parâmetro de comparação para aumentar a capacidade de se debater, discutir e desenvolver uma opinião mais fundamentada sobre o tema em análise. E isso mesmo nos casos em que se dispunha de serviços de consultoria externa.

\section{Sobre a importância da prospecção do futuro e a utilização dos resultados}

O entrevistado considera importante a prática da prospecção do futuro, em qualquer contexto em que haja incertezas de futuro, e envolvendo tantos e quantos temas portadores de incertezas de futuro.

Segundo seu relato, a responsabilidade de gestores envolve a construção de visões prospectivas, as quais devem servir para o suporte à tomada de decisão. Ainda mais, não somente os resultados obtidos são importantes, mas especialmente a forma em que os estudos prospectivos são realizados tem influência na utilização dos resultados. Ele aponta não ter dúvida de que o grau em que os resultados de estudos prospectivos contribuem nos projetos estratégicos tem forte relação com a forma em que os estudos foram realizados. Em outras palavras, possivelmente a integração entre prospecção e estratégia empresarial seja limitada se não houver transparência sobre como foram elaborados os estudos.

Ao ser perguntado sobre maiores detalhes sobre essa relação entre os resultados da prospecção e a decisão em projetos, o entrevistado descreve que em sua opinião há alguns fatores importantes a serem considerados.

Em primeiro lugar, como já descrito, ele defende que se comparem as conclusões propostas pela equipe que desenvolveu o trabalho com as que sua equipe própria desenvolveu. Ou com a que ele mesmo desenvolveu, caso não houvesse possibilidade de alocar seus recursos humanos para se desenvolver a análise. A presença de incertezas de futuro em projetos estratégicos é um fato, diz ele, assim como é fato que para a tomada de decisão é preciso

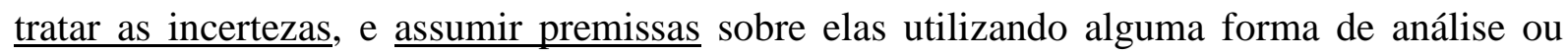
estudo prospectivo. Ao final, o ato da decisão inclui um comprometimento com os resultados futuros, portanto é recomendável testar se as conclusões da equipe de prospecção são robustas. 
Dessa forma, deve se conhecer as propostas da equipe que desenvolveu a prospecção, e especialmente conhecer como foi desenvolvido o estudo - $\underline{\text { metodologia, }} \underline{\text { dados e informações }}$ utilizadas. Ao final, as conclusões propostas pela equipe que desenvolveu o estudo podem ser incorporadas no processo de tomada de decisão do projeto, e o grau de incorporação pode ser desde uma integração total, até podendo ser completamente nula. "Sigo totalmente" ou "ignoro totalmente" o que a equipe concluiu, e dentre esses dois extremos podem ser adotados níveis intermediários de integração, segundo ele relata. Isto reflete uma visão de que a integração entre prospecção do futuro e estratégia empresarial apresenta, de fato, limitações.

O que pode desencadear uma integração nula ou total é o grau em que a equipe que desenvolveu a prospecção fundamentou $\mathrm{o}$ trabalho, e também deu transparência à metodologia. Isso envolve os esclarecimentos de como se chegaram às conclusões propostas. A transparência acerca da metodologia adotada, das fontes de dados e informações utilizadas e quais as análises desenvolvidas para se chegar à conclusão são itens relevantes para se definir o quanto os resultados são integrados no processo de decisão dos projetos, segundo ele.

Em grandes linhas, o entrevistado demonstra que a contribuição oriunda de análises e conclusões de estudos prospectivos depende muito de como foi desenvolvido o processo, de quem participou do estudo, sua expertise, e como foram apresentadas e argumentadas as análises e conclusões resultantes.

Sobre a utilização dos resultados dos estudos prospectivos nas decisões dos projetos, especificamente, o relato do entrevistado mostra que é necessário colocar a empresa no contexto futuro, com o projeto entregando resultados.

Ao ser questionado sobre as possíveis causas que possam influenciar a prática da prospecção, e a consequente utilização das análises e conclusões nas decisões sobre projetos, o entrevistado enfatiza que é preciso testar os resultados da equipe, eventualmente contrapor as

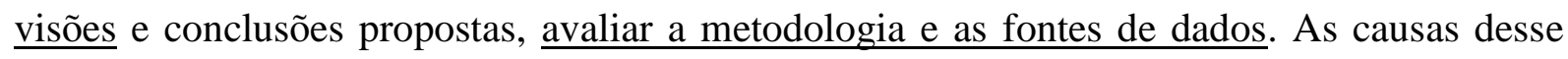
comportamento foram explicadas por ele, levando às três situações abaixo descritas: 
1- Prospecção desenvolvida por equipe interna da empesa: Pode ocorrer de o estudo do futuro ter sido feito por pessoas que não são conhecidas pelos gestores que se envolverão com a decisão. Mesmo que tenha sido uma equipe de pessoas internas à organização.

Ao não conhecerem essas pessoas e a sua expertise sobre o tema, ou sobre a metodologia de prospecção do futuro utilizada, não há segurança de que os resultados devam ser aplicados sem avaliar alternativas, ou sem comparar com as suas próprias conclusões e análises. Se o nível de envolvimento com a equipe que desenvolve a prospecção não for elevado, fica maior o grau de desconforto com os resultados finais dos estudos. Afinal, se a decisão envolve assumir responsabilidade pelos resultados do projeto, sempre será preciso avaliar de forma ampla as conclusões e análises apresentadas pela equipe que desenvolveu a prospecção.

2- Prospecção desenvolvida por equipe de fora da organização: Em muitas situações, as pessoas que desenvolvem os estudos prospectivos são externas à organização. E a $\underline{\text { determinação sobre quem são essas pessoas, ou qual empresa vai desenvolver os estudos, não }}$ depende integralmente dos gestores que vão se envolver posteriormente com a decisão no projeto. É certo que os gestores poderão interagir com esses profissionais, opinar e dar sugestões sobre o desenvolvimento dos estudos. Contudo, lembrando o que o entrevistado mencionou no item anterior, se o nível de envolvimento não for forte o suficiente, o mesmo desconforto ali mencionado poderá ocorrer. Fica ainda mais curioso de se notar, segundo ele, que muitas vezes isso ocorre em grandes empresas, as quais poderiam estar melhor estruturadas para lidar com prospecção do futuro. Ele explica, muitas empresas grandes

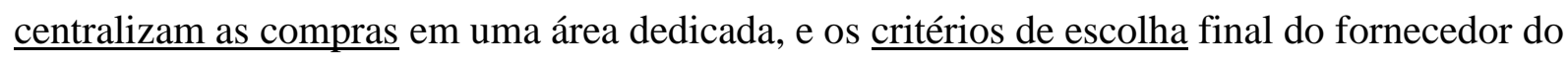
serviço nem sempre consideram a expertise como principal critério, mas ponderam com maior peso o critério de preço.

3- A prospecção chega à conclusão que confronta uma visão previamente estabelecida: Uma terceira situação, quando se desenvolve estudos prospectivos, ocorre quando as conclusões confrontam visões distintas: os gestores da empresa podem já ter uma visão sobre as incertezas de futuro do projeto, mas a equipe de prospecção pode propor uma visão que confronta o que os gestores estimaram.

Esta terceira situação pode ser muito comum, pois uma equipe que se dedica em analisar o tema portador de incertezas de futuro, pode pensar em diferentes contextos e cenários, o que 
lhes permite analisar abordagens que podem não ser contempladas pelos gestores previamente.

O lado positivo dessa situação é enriquecer o debate e a discussão sobre o tema em análise, e dessa forma a decisão pode ficar bem fundamentada para que possa ser tomada. Ou seja, $\underline{\text { mesmo sendo antagônicas, }}$ as conclusões da equipe de prospecção contribuem no processo de $\underline{\text { decisão, }}$ independentemente de se decidir por seguir ou não as suas conclusões. Qualquer que seja a decisão, é certo que ela foi bem fundamentada nesse caso, segundo o entrevistado.

\section{Em relação às questões relacionadas com as reponsabilidades a serem assumidas pelos}

tomadores de decisão, o entrevistado menciona que elas pesam no processo. Se houve a possibilidade de se recorrer a alguma forma de prospecção, melhor assim, porque se enriquece o debate e a discussão sobre o projeto. E isso ocorre mesmo que se decida, posteriormente, a não adotar as análises e conclusões propostas pela equipe de prospecção. O benefício seria como se fosse um teste de consistência, uma forma de avaliar se não houve nenhuma lacuna na análise das incertezas de futuro do projeto.

O entrevistado relata que se existem recursos, tempo e pessoas para se dedicar à prospecção, isso é positivo, contudo os resultados dos estudos podem contribuir como também podem atrapalhar o processo de análise. A equipe pode chegar a conclusões diferentes daquelas que ele já tem previamente estabelecidas. Decidir pela não adoção dos resultados é uma ação que precisa ser fundamentada. Este relato tem similaridade com o que argumentaram Wright et al (2008), sobre a influência do que eles chamaram de inércia estratégica.

Por outro lado, se a equipe de prospecção concluir propondo orientação alinhada com o que previamente estava previsto pelo gestor, isso poderia ser bom em primeira análise. Haveria uma corroboração de visões que facilitaria a tomada de decisão. Contudo, esse alinhamento não poderia trazer algum risco adicional? Não se correria o risco de ocorrer pontos cegos no processo de análise prospectiva? Em outras palavras, poderia haver maior valor no processo de tomada de decisão dos projetos se ocorrerem diferenças de visões sobre as incertezas de futuro. Esse é um dos desafios dos gestores, o de testar as próprias visões, questionar sua validade, seja para confrontar conclusões contrárias, seja para reforçar as visões favoráveis sem com isso criar lacunas de visão. 


\section{Orientação para o futuro}

É bem certo que a prospecção do futuro seja uma atividade importante, e também é certo que ela representa desafios para gestores. O relato do entrevistado mostra que a segurança acerca dos resultados de estudos prospectivos depende de se conhecer como eles foram feitos. Em outras palavras, é especialmente importante saber como se chegou a eles. Ainda mais, mesmo recorrendo à expertise externa, a discussão sobre os resultados deve envolver as visões internas, portanto, as pessoas internas precisam participar, debater, discutir e, eventualmente construir as suas visões para corroborar ou contrapor os resultados. Porque elas serão responsáveis por implantar o que for decidido, em última instância.

Pelo relato do entrevistado, os resultados da prospecção contribuem na tomada de decisão, mas essa contribuição seria tão maior se as pessoas da empresa estiverem engajadas a discutir sobre o futuro, se estiverem orientadas para o futuro. Isso corrobora o que foi argumentado por WRIGHT et al (2008), quando estes autores enfatizaram a importância da receptividade para a atividade de prospecção por parte do corpo de executivos.

\subsubsection{Entrevista $V$}

O entrevistado deste caso foi presidente de uma multinacional do setor de componentes mecânicos utilizados em diversos equipamentos que envolvem desde bens de capital como máquinas e sistemas de transformação e processamento, até bens de consumo duráveis para consumidores individuais ou corporativos. Atualmente é presidente de uma empresa de serviços profissionais para clientes empresariais, envolvendo diferentes processos e sistemas da cadeia de valor das empresas clientes.

Profissional com mais de vinte anos de experiência no setor produtivo industrial, o entrevistado tem profundo conhecimento e experiência dos diversos fatores que influenciam a área.

Seu relato indica que a atividade de prospecção faz parte do cotidiano da empresa. No caso da empresa multinacional, estava na diretriz da empresa discutir sobre o futuro. Praticamente todos os projetos, que envolviam comprometimento de recursos da empesa, eram analisados com utilização de algum recurso ou técnica prospectiva. Era parte da cultura da empresa, 
voltada para o uso de dados e informações, com estruturação de problemas seguindo metodologia de suporte à tomada de decisão racional.

O processo de análise tomava bastante tempo dos executivos, era cuidadoso e apresentava comprometimento e formalização. A empresa é grande, opera nos cinco continentes, em mais de setenta países. E por causa disso segue a diretriz de ter um arcabouço mínimo de práticas para facilitar a comunicação e a integração de diferentes países. Estudar o futuro, suas incertezas e potenciais desafios, é uma reponsabilidade natural de seus executivos. O entrevistado declara que vivenciou e vivencia isso todos os dias. Muitos dos projetos que conduziu continham premissas sobre cenários e perspectivas de futuro.

Segundo ele, um dos grandes desafios sobre esse tema são as pessoas. No sentido de que é complexo envolve-las, alinhar objetivos e expectativas quando se trata de lidar com incertezas de futuro. Em especial, quando se sabe que os resultados podem ser difíceis de defender, ou mesmo de comunicar claramente de forma fundamentada. Outro aspecto que tem influência, segundo ele, é que as pessoas também analisam os problemas prospectivos sob a sua ótica individual, suas experiências e intuições, e finalmente as suas próprias metas e objetivos corporativos. Isso gera uma dissonância nas pessoas, porque além de ter que analisar algo que seja inerentemente incerto (o futuro), as pessoas têm que analisar o que os resultados daquele exercício prospectivo podem significar em termos de suas metas individuais a serem cumpridas na empresa. Em resumo, isso pode gerar um comportamento defensivo, ou conservador, limitando a amplitude em que os eventos, os cenários estudados e as análises respectivas possam gerar de resultados. Posto com outras palavras, agendas individuais podem gerar vieses nos exercícios prospectivos, e pode se chegar a resultados que não consideram mudanças radicais, ou transformações importantes que impactariam a empresa significativamente, o que poderia significar que o futuro aconteceria, e os riscos e oportunidades seriam ignorados. Esse é um contexto muito indesejável para executivos de empresas do porte da do entrevistado.

Esse problema é contextualizado pelo executivo, ao mencionar que a situação ocorre quando se trata de conectar os resultados prospectados com o planejamento. Porque ao final isso resulta em objetivos a serem atingidos, ou metas a serem cumpridas por pessoas que estão participando da prospecção, e elas tendem a recear sobre essas metas, pois estariam baseadas em estudos prospectivos que, como se reconhece, não tem objetivo de prever o futuro. 
E assim se tem um dilema executivo, que é definir quem participa do processo. Se por um lado é preciso que haja a participação de muitas pessoas para evitar a predominância de vieses de poucas delas, por outro lado pode ocorrer o efeito indesejado de uma convergência para a média, sendo esta última uma média de conveniência que pode ser involuntária, não explicitamente percebida pelos participantes, ou voluntária, devidamente deliberada pelas pessoas. O relato lembra o que argumentou Schoemaker (1995), que apontou isso como o pior dos vieses - a tendência a encontrar evidências para corroborar uma visão já previamente estabelecida, e desejada pelas pessoas.

Esse fenômeno é real, segundo o executivo, já foi presenciado na sua trajetória profissional. E a sua ocorrência é bem possível, considerando sua explicação. De certa forma, ele reflete um dos principais problemas da prospecção, que é a confusão entre prospecção e planejamento. Armstrong (1985) já tinha alertado para esse fenômeno, ao afirmar que forecasting (prospecção) não é planejamento, são coisas diferentes e complementares, não se confundem. O relato do entrevistado parece ser muito próximo da descrição desse problema. Burt e Van Der Heijden (2008) também chamaram a atenção para isso, ao afirmar que lidar melhor com os objetivos de projetos de estudos do futuro é de extrema importância, porque é comum haver erros de entendimento sobre os mesmos. O entrevistado relata situações em que esse fenômeno ocorreu em suas experiências.

Talvez, reflete o executivo, fosse recomendado categorizar os projetos de prospecção, de forma a contribuir na decisão de quem participa ou não. Uma questão pertinente, possivelmente. Especialmente porque ele demonstra preocupação com a conexão entre a estratégia e o estudo do futuro, pois este último deve servir de suporte à estratégia, e não deve servir de suporte a áreas específicas da empresa, mas a ela como um todo. Sua reflexão é que dependendo de quem desenvolve o estudo prospectivo, as incertezas estratégicas analisadas podem não ser as mais relevantes para a empresa, criando um vazio de análise estratégica.

Seguindo com sua narrativa, o executivo reflete sobre a questão de integrar os resultados da prospecção ao processo decisório. De sua experiência, se a empresa adota alguma formalização, seguindo uma diretriz de orientação para o futuro, essa contribuição dos resultados de estudos prospectivos nas decisões ocorre naturalmente. Contudo, não é de todo isenta de dificuldades, pois dependendo do tipo de decisão, a fase de análises pode ter ruídos oriundos de conflitos de interesse entre áreas diferentes, ou no pior dos casos, entre unidades 
diferentes da empresa. O processo se manifesta na forma de disputa por projetos entre áreas ou unidades diferentes, e esse conflito pode se caracterizar por meio do uso dos dados e das informações e como se faz a calibração de premissas do projeto. Cada área/unidade trará sua visão, visando somar pontos na disputa pelo projeto. Nestes casos, pondera ele, é necessário definir antecipadamente objetivos e participantes neutros para estudar alternativas, dentro de diferentes contextos de futuro.

Sua descrição da prática de prospecção tem certa dose de reflexão, e ela é pertinente sob a ótica de recomendar ou prescrever cuidados com a atividade. Por exemplo, o fato de uma empresa grande ter diretrizes e recomendações sobre a atividade é positivo, mas é preciso se precaver dos potenciais problemas que possam surgir. Há fatores como cultura organizacional, e também estrutura organizacional, que moldam como o processo é executado, e isso pode ocorrer de forma indesejada. A governança tem papel importante, seja nas decisões estratégicas ou nos estudos prospectivos.

Há seguramente benefícios na prática da prospecção, o relado do entrevistado não deixa dúvidas quanto a isso. No balanço entre praticar ou não, sempre se deve optar pela primeira opção. Problemas podem ocorrer? Sim, sem dúvidas, mas é melhor conviver com eles do que com os outros problemas que podem acontecer devido à omissão ou negligência. Os primeiros problemas são gerenciáveis ao nível executivo, mas os outros podem ser de difícil gerenciamento, mesmo com as prerrogativas de um executivo, porque no limite são decorrentes da própria falta de diligência como executivo. 


\subsubsection{Entrevista VI}

Nesta entrevista houve a participação de duas pessoas da organização. Uma delas é um executivo de muita experiência de mercado, tendo sido presidente de duas importantes empresas no Brasil, uma delas multinacional e a outra nacional. A primeira tem, inclusive, importantes casos relacionados com a aplicação de metodologia de estudos do futuro. A cultura existente nessa empresa é a da orientação para o futuro, reconhecidamente.

Atualmente, esse executivo atua em organização da área da saúde, de reconhecida competência no setor.

A outra pessoa participante dessa organização é responsável pelas atividades de planejamento estratégico da organização, envolvendo a mobilização de pessoas, das diversas áreas da organização, para participarem com sua expertise e conhecimento no processo de planejamento, e de detecção de mudanças ou incertezas de futuro.

O relato dos entrevistados tem muita relação com o desenvolvimento e implantação de processo de planejamento estratégico, pois este representa o contexto do momento vivenciado pelos mesmos. E como estratégia tem relação com o futuro, as entrevistas foram analisadas pelos relatos sobre o planejamento estratégico, e a partir dessa abordagem foram extraídos os temas relacionados com a prospecção do futuro.

As sessões de entrevista com eles ocorreram em momentos diferentes, para que os relatos pudessem refletir como cada um percebe a atividade de prospecção. Nesta seção, os relatos coletados são apresentados em conjunto.

O executivo relata que o desafio inicial foi elaborar um processo que fosse capaz de capturar $\underline{\text { o conhecimento das pessoas da organização, e canalizar esse conhecimento para identificar }}$ quais são os principais fatores de mudanças que influenciam a organização. Uma vez que o setor de saúde envolve muitas áreas do conhecimento, os fatores elencados preliminarmente eram muitos, na casa das centenas. Seu principal argumento é que o pensamento estratégico precisa estar presente, e mais ainda, precisa sempre provocar questionamentos sobre coisas ausentes nas análises, que podem gerar impactos significativos. 
O desafio de incluir muitas pessoas no planejamento é a quantidade de fatores que resultam disso. Era preciso reduzir a quantidade, mas não simplesmente por meio de análise fundamentada. Não seria suficiente, segundo relato do executivo. Mesmo uma análise robusta poderia não ter os efeitos que facilitassem os próximos passos, e isso tem relação com a participação de stakeholders importantes da organização. Em geral, os entrevistados argumentam que o contexto atual da organização demanda que o processo de planejamento seja participativo.

O racional utilizado para a adoção de um processo mais amplo e participativo também se justifica pela característica multidisciplinar da organização. O modelo organizacional tem influência no processo decisório, portanto, é importante considerá-lo para desenvolver o processo de planejamento. Como consequência, isso gera uma variedade de visões que resultam em diversos fatores para cada área ou disciplina, ao final, o produto resultante é uma quantidade substancial de fatores.

Para reduzir a quantidade, foi utilizado um processo de agrupamento, formando clusters. Esse agrupamento foi realizado de forma participativa, envolvendo pessoas que representavam as diferentes áreas do conhecimento, seja técnico ou de natureza funcional das operações das diferentes áreas.

Foram desenvolvidas visões a partir do engajamento dos participantes e essas visões foram formadas com constructos, os quais continham os fatores considerados mais associados a esses constructos. Esta associação foi realizada por processo qualitativo. As visões, por sua vez carregam questões de futuro relevantes para a organização. Grande parte dos fatores foi resultado de opiniões que ainda não estavam explicitadas pelos participantes, e foram identificadas porque emergiram no processo de análise. Isso representou um lado positivo em termos de riqueza descritiva, mas ao mesmo tempo foi desafiador porque aumentava a quantidade de fatores também. Mas o maior benefício é que, se ocorrerem lacunas estratégicas, que elas tenham sido consequência de decisões, e não de negligências quanto a pontos cegos.

O objetivo da organização é poder aplicar o processo de forma recorrente, agregando novas informações e processos, para se chegar a uma condição de poder obter, não somente, o 
orçamento anual, mas também um planejamento que contemple horizonte de três a cinco anos e, com especial destaque, também a visão prospectiva de prazo mais longo.

As operações da organização incluem muitas áreas do conhecimento, pela diversidade de especialidades. Como consequência disso, a atenção com o desenvolvimento das fronteiras do conhecimento e com os avanços tecnológicos é de extrema importância na organização. Coisas que estão em desenvolvimento hoje podem trazer oportunidades ou mesmo riscos no futuro. A dimensão dos desafios prospectivos é elevada, pois na grande maioria das áreas que formam a organização, há pesquisas e desenvolvimentos sendo realizadas, e em escala mundial por se tratar de saúde humana. A quantidade de temas a serem analisados e monitorados é grande, e todos eles são potenciais candidatos a serem prospectados.

Outro aspecto importante é que a área da saúde está cada vez mais multidisciplinar e interconectada a outras áreas do conhecimento que, no passado, não apresentavam tanta relação. Em futuro breve, essa característica vai se acelerar, porque há convergência cada vez maior na utilização de conhecimento clínico com diferentes áreas das engenharias, com ciência da computação, com bioquímica e farmacologia, e isso para citar apenas algumas das áreas correlatas. O resultado dessa convergência é que, talvez, o setor de atuação da organização dos entrevistados seja uma das que mais apresenta desafios em relação à prospecção do futuro.

Ela também apresenta bastante conexão com o setor de seguros de saúde, e dessa forma sofre influência desse setor, e indiretamente também do setor público, pois as políticas definidas pelo Estado moldam a área de saúde pública, regulam o setor de saúde privada relativa aos planos, o que induz à necessidade de monitorar também o cenário considerando o ambiente político-institucional.

O executivo menciona aspectos em relação à gestão de negócios, pensamento prospectivo estratégico de alguns setores pelos quais acumulou experiências, para ressaltar o contraste com o setor atual de sua organização. Há setores, segundo ele, que são razoavelmente estáveis se as variáveis preponderantes estão associadas com fatores largamente monitorados, como o Produto Interno Bruto (PIB), por exemplo. Setores de consumo sensíveis ao PIB podem analisar os impactos relacionando PIB x consumo. 
Outros setores, como os regulados pelo Estado, tendem a ser mais estáveis por razão da regulamentação, a exemplo das telecomunicações. No caso da aviação civil, há a regulação do setor, e também um modelo estrutural de operação que se baseia na combinação de equipamentos com recursos humanos e fornecedores (sistemas de reservas e vendas de passagens, catering, operadores de aeroportos), e sem esquecer que é setor sensível à economia, que tem indicadores largamente monitorados. Obviamente há desafios como a previsão de demanda, o planejamento de rotas, o dimensionamento dos aviões, enfim, questões relacionadas com inteligência estratégica de mercado.

Na saúde, dentro do contexto específico de sua organização, é mais difícil afirmar que a previsibilidade é plausível, pois muitas coisas podem acontecer e impactar os resultados. Por causa disso, é muito importante se planejar, considerar cenários de prazo longo. Tipicamente se analisa por três horizontes de tempo, de curto, médio e longo prazo - um ano relativo ao orçamento, cinco anos para coordenar projetos a implantar, e dez anos para analisar riscos, oportunidades e mudanças que possam ser significativas, e que precisem ser integradas ao contexto da visão de cinco anos para frente.

O processo de planejamento estratégico dessa organização está em andamento neste momento, e as etapas já desenvolvidas e as que ainda estão sendo estudadas para o futuro, representam um esforço coordenado para integrar prospecção do futuro com estratégia. Os relatos indicam que há importantes etapas para serem implantadas, mas também já houve significativa evolução, pois observa-se que há evidente preocupação com a integração do pensamento prospectivo com o pensamento estratégico nessa organização.

\subsubsection{Sumário dos principais temas das entrevistas realizadas}

Em resumo, as entrevistas realizadas permitem caracterizar o seguinte contexto:

- A estrutura de como uma empresa analisa e toma decisões influencia a atividade de prospecção.

- Empresas grandes certamente praticam prospecção, contudo não se tem muita segurança de que a transição para a decisão seja fluida.

- O domínio das metodologias não é uma coisa certa, mesmo nas empresas grandes. 
- A prospecção deve ser feita de forma participativa, tomadores de decisão devem se envolver com a coordenação dos estudos. Os riscos da decisão pressupõem que aquele que os assumam tenham se envolvido minimamente com as análises.

- A multidisciplinariedade deve ser exercitada sempre que se desenvolve um projeto de prospecção.

- Um dos principais problemas para a prospecção é a visão limitada sobre a abrangência de temas portadores de incertezas.

- O melhor estudo prospectivo pode não contribuir de forma relevante, caso não tenha havido a transparência metodológica e a participação de stakeholders importantes. 


\section{CONCLUSÕES, RECOMENDAÇÕES E COMENTÁRIOS}

Os resultados da pesquisa permitem descrever algumas conclusões a partir da análise e discussão dos dados coletados.

Em grandes linhas, nesta tese se constatou que a transição entre a prospecção do futuro e a gestão estratégica é possível de ser apoiada, contudo, limitações relacionadas ao nível de conhecimento sobre metodologias prospectivas podem causar lacunas de análise estratégica, reduzindo o potencial de lidar com incertezas estratégicas nas organizações.

\subsection{Sobre a questão geral que inspirou o problema de pesquisa}

A questão geral que inspirou o desenvolvimento da pesquisa era se um modelo de apoio à integração de resultados de estudos prospectivos pode contribuir para apoiar decisões em projetos estratégicos.

Os resultados mostraram que há formas de apoiar a integração, em especial utilizando o modelo para identificar quais são as limitações, sendo que elas podem ser especialmente originadas por lacunas de análise de temas portadores de incertezas de futuro. Adicionalmente, se não ocorrem essas lacunas, pode acontecer de os resultados da prospecção do futuro não serem utilizados nos processos de decisão no âmbito da estratégia.

Foi constatado que o modelo proposto contribuiria para gestores avaliarem se eles (1) estão considerando todos os temas relevantes na prospecção, se (2) os resultados das análises estão sendo utilizados, se (3) contribuem nas decisões em análise, e finalmente se gestores (4) avaliam que a prospecção do futuro está sendo bem conduzida nas suas empresas. Cada uma dessas avaliações permitiria aos gestores chegarem a uma visão mais abrangente sobre o quanto eles estão orientados para a prática da prospecção do futuro.

Adicionalmente, o uso do modelo também poderia contribuir para servir como um indicador do quanto os gestores estão mobilizados para a busca de objetivos de futuro. Ao final, isso os levaria à condição, de proporcionar à empresa a estruturação de projetos estratégicos para prepará-la para o futuro desejado. 
Dessa forma, os resultados indicam que o modelo de suporte contribuiria para facilitar a utilização de resultados de estudos prospectivos para apoiar decisões em projetos estratégicos. E isso é constatado porque os resultados mostram que nem todas as empresas lidam bem com esse processo.

Esse resultado é identificado para a maior parte das empresas pesquisadas, especificamente em um grupo de empresas que representou $70 \%$ da amostra. Elas são menos estruturadas para a prospecção, apresentam menor faturamento, menor quantidade de funcionários, são predominantemente de capital fechado e, nestas empresas a prospecção realizada é para horizonte de tempo mais curto. Elas são denominadas nesta tese de EXPLORADORAS REATIVAS (ER).

Essas empresas apresentam pouco domínio das metodologias prospectivas, o que limita a sua prática e a contribuição que elas poderiam propiciar nas decisões. A consequência disso, que foi o resultado marcante para essas empresas, é que elas apresentam problemas de lacunas de $\underline{\text { análise, }}$ com pontos cegos estratégicos que podem trazer riscos ou perdas de oportunidades relevantes. Os resultados mostraram que a principal consequência do menor conhecimento sobre metodologias prospectivas são as lacunas de análise prospectiva e estratégica.

Importante mencionar que o nível geral de satisfação com a prospecção é baixo; houve maior percentual de respondentes para o grau de satisfação parcial com a prospecção $(58,6 \%)$, e em segundo lugar ficou a insatisfação parcial $(21,7 \%)$, enquanto o nível "totalmente satisfeito" ficou com $14 \%$. Isso reflete a maior quantidade relativa de respondentes de empresas EXPLORADORAS REATIVAS (ER), pois entre as empresas EXPLORADORAS ESTRUTURADAS (EE), que em contraste apresentam maior conhecimento das metodologias, o nível de satisfação total ou parcial foi de $23,4 \%$ e 53,2\%, respectivamente. Já para as EXPLORADORAS REATIVAS, foi de $10 \%$ e 60,9\%. Também cabe mencionar que nas EXPLORADORAS REATIVAS há quase $25 \%$ de respondentes com "parcialmente insatisfeito", enquanto nas EXPLORADORAS ESTRUTURADAS são $15 \%$.

As empresas de capital aberto, com maior faturamento, maior quantidade de funcionários e que praticam prospecção de horizonte de tempo mais longo são denominadas nesta pesquisa de EXPLORADORAS ESTRUTURADAS (EE). E no caso dos entrevistados da parte qualitativa desta tese, eles são de empresas com este perfil. 
Nas entrevistas realizadas foi constatado que as grandes empresas estão atentas com a prospecção do futuro, e praticam a atividade ao nível necessário demandado pelo risco de seus ativos, que são significativos nesse porte de empresas. Apesar disso, a prática da atividade é $\underline{\text { considerada difícil, }}$ pois ela não elimina todas as incertezas, depende de um processo participativo que precisa envolver pessoas relevantes, e os tomadores de decisão que vão utilizar os resultados precisam ter participado do projeto de prospecção. É preciso ter escopo amplo e multidisciplinar, portanto, é necessário ocorrer o envolvimento de pessoas internas e externas à organização. Os objetivos da prospecção precisam estar alinhados com a estratégia, e a comunicação dos resultados precisa estar fundamentada. A credibilidade quanto aos

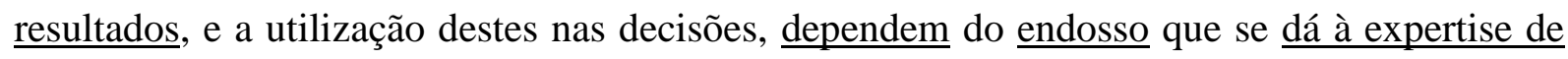
quem desenvolveu as análises prospectivas. Quem participa dos estudos prospectivos imprime $\underline{\text { a eles o seu viés, }}$ portanto, a escolha das pessoas pode gerar vieses, com excesso de $\underline{\text { tratamento de alguns tópicos, e falta de outros, novamente a questão das lacunas estratégicas }}$ também se apresenta.

\subsubsection{Sobre as questões específicas da pesquisa}

A primeira questão específica (Q1) proposta nesta tese foi: Se gestores em organizações têm orientação para a prática da prospecção do futuro, então será que a mobilização deles ocorre na proporção adequada à importância que caracteriza esta orientação?

$\mathrm{Na}$ amostra da pesquisa, os resultados indicam que gestores estão atentos à importância da prospecção do futuro, contudo, a avaliação sobre a mobilização para a sua prática resultou descritivamente em nível menor que a avaliação para a sua importância.

Aprofundando a análise, identificou-se que esse fenômeno é associado ao menor conhecimento sobre as metodologias prospectivas, especialmente nas empresas EXPLORADORAS REATIVAS (ER). As empresas EXPLORADORAS ESTRUTURADAS (EE), em contraste, apresentam maior conhecimento das metodologias, e apresentam melhor satisfação com os resultados do uso das práticas prospectivas.

As entrevistas capturaram a opinião de que a importância está em nível alto (Entrevista II, Entrevista III, Entrevista VI), e daí a mobilização se dá naturalmente. Entretanto, são 
necessários recursos adequados, especialmente humanos, e o requisito da multidisciplinaridade necessária pode ser um problema em relação aos recursos disponíveis. O contexto do problema prospectivo que se tem em mãos define, em parte, quanto a empresa poderá se mobilizar para a prospecção, portanto, ela é dependente do caso e dos recursos que a empresa dispõe.

A segunda questão (Q2) era se a prospecção é praticada nas organizações, os seus respectivos resultados contribuem para a tomada de decisões em projetos estratégicos.

Os resultados permitem suportar a conclusão que sim, seus resultados contribuem para a tomada de decisão. Os dados quantitativos da pesquisa mostram que em especial as empresas EXPLORADORAS ESTRUTURADAS (EE), que dominam (conhecem) melhor as metodologias prospectivas apresentam um forte índice de contribuição dos estudos prospectivos para tomada de decisão $(78,7 \%$ para os graus de contribuição "muito" e "extremamente"). Mesmo nas empresas ER, que apresentam menor conhecimento e aplicam menos recursos para a atividade de prospecção, uma parcela significativa de 36,3\% indica uma efetiva contribuição ("muito" e "extremamente") da prospecção para a tomada de decisões em projetos estratégicos.

A terceira questão (Q3) indagou: quais os temas portadores de incertezas de futuro considerados mais importantes pelos gestores?

Os temas mais importantes que a pesquisa identificou foram aqueles mais diretamente relacionados com os resultados da empresa, o que não é surpresa. Mercado e Demanda foi considerado mais importante, seguido por Economia como o segundo tema mais importante, sendo que este ficou mais próximo de Mercado e Demanda do que os temas subsequentes, que foram Legislação e Regulação Setorial, Tecnologia, Inovação em Produtos e Serviços, e Competidores.

Os temas considerados menos importantes para a prática de prospecção pelos gestores da amostra foram Sociedade e Meio Ambiente e Sustentabilidade. Contudo, cabe mencionar que esse resultado não permite concluir que esses temas sejam negligenciados. Eles apenas têm avaliação menor na importância comparada a outros temas para efeitos de estudos prospectivos. Talvez os respondentes considerem que haja mais chances de as organizações 
serem surpreendidas por pontos cegos oriundos de temas referentes à demanda e mercado, economia, tecnologia e legislação, do que nas transformações da sociedade e do meio ambiente. Alternativamente, oportunidades oriundas destes últimos temas têm mais chance de serem ignoradas, comparadas com os demais temas considerados "mais importantes" para a prospecção.

Nas entrevistas foi identificado que os entrevistados têm atenção em duas frentes em relação à prospecção: (1) visão de planejamento, que possa suportar decisões sobre orçamento e suas relações com projetos que estarão em desenvolvimento no curto prazo, e (2) visão prospectiva de prazo mais longo, com ênfase na identificação de cenários de mudanças. A abordagem (1) identificada nas entrevistas corrobora os resultados quantitativos da survey, os temas assim chamados "do presente", são considerados mais importantes pelos gestores da amostra, porque esses temas envolvem decisões que definem a alocação de recursos no presente.

Outra questão proposta (Q4) foi identificar em quais dos temas se dedica mais a prospecção, sendo que de acordo com o levantamento realizado, a prática da prospecção é mais executada quando envolve os temas Mercado e Demanda, Tecnologia, Legislação e Regulação Setorial, Inovação em Produtos e Serviços e Insumos e Recursos. Dentre estes temas, Mercado e

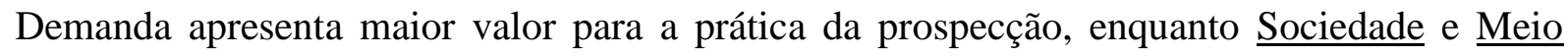
Ambiente e Sustentabilidade resultaram em menor nível de prática da prospecção, segundo os respondentes da pesquisa.

Comparando-se a lista de temas, que mais são prospectados, com o resultado quanto à importância de cada tema, nota-se que Tecnologia sobe ao segundo lugar, e Insumos e

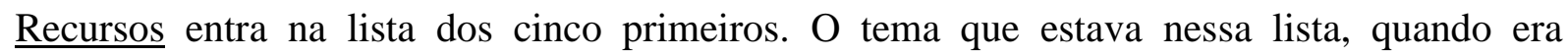
considerada a importância como critério, e que saiu da lista foi Economia, que pelo critério de dedicação da prospecção caiu para $7^{\circ}$ lugar em uma lista total de 12 temas. Este resultado talvez seja explicado porque Economia seja um tema largamente monitorado por diversos meios de análise e comunicação, o que pode significar menor necessidade de colocar recursos próprios para prospectar este assunto.

Ao analisarmos (Q5) quais os temas cujos resultados prospectados contribuem mais na análise de projetos estratégicos, identificou-se na pesquisa que os cinco primeiros temas são 
Mercado e Demanda, Tecnologia, Legislação e Regulação Setorial, Inovação em Produtos e $\underline{\text { Serviços e Competidores. }}$

Analisando os resultados descritivos para Importância $\mathrm{x}$ Prática $\mathrm{x}$ Contribuição da prospecção, pode se concluir que a atenção dos gestores se concentra em temas sobre os quais eles percebem maior conexão com os resultados da organização. Foi constatado que eles não ignoram certos aspectos do ambiente externo amplo, como Economia, Tecnologia ou Legislação e Regulação Setorial, contudo, talvez isso ocorra porque esses temas tenham impacto mais significativo nos resultados da organização. Outros temas que também são de ambiente externo amplo, como Sociedade e Meio Ambiente e Sustentabilidade, mas que não tenham tanta conexão direta e imediata com os resultados da organização são considerados menos importantes. Nestes últimos a prospecção é menos praticada e a sua contribuição é avaliada em nível menor.

Com relação à identificação de quais processos recomendados na teoria sobre prospecção são efetivamente mais praticados (Q6), ao se analisar projetos estratégicos, os resultados indicam que a "Análise do alinhamento do projeto com a estratégia da organização" é o processo mais praticado pelos gestores da amostra. Em segundo ficou "Análise do quanto o projeto pode influenciar os resultados futuros da organização", e estes dois processos se destacam em relação aos demais. Em terceiro veio "Análise dos contextos futuros dos negócios envolvidos nos projetos".

Importante comentar que os dois primeiros têm conexão com a estratégia da organização, o que é positivo, pois mostra que há preocupação em avaliar como o projeto se encaixa dentro da visão estratégica da empresa. O terceiro ilustra bem a aplicabilidade que os gestores da amostra fazem dos resultados da prospecção, ao analisarem o contexto futuro dos negócios proporcionados pelo projeto.

Esses processos de análise prospectiva, recomendados para suporte a decisões, são orientações encontradas na literatura que podem contribuir para analisar incertezas de futuro, e também podem gerar feedback para a organização aprimorar o processo de prospecção. Este feedback serve para indicar a necessidade de novos estudos prospectivos, especialmente para tratar lacunas identificadas nos processos anteriormente executados. 
São processos tipicamente mais focados nos problemas de prospecção. E estes, por sua vez, devem estar bem conectados com as necessidades dos projetos estratégicos.

Que processos foram menos praticados? A "Definição de sinais ou indicadores que sirvam para monitorar o futuro acontecendo (ou começando a acontecer) no âmbito da implantação do projeto", o "Exame das incertezas estratégicas envolvidas no projeto" e a "Simulação colocar pessoas para analisarem a organização dentro do contexto futuro proporcionado pelo projeto" em último lugar.

Esses processos que ficaram nos últimos lugares, em relação à prática da prospecção, geram sinais de preocupação. Principalmente porque dentre eles ficou aquele que representa a análise do que é relevante estrategicamente para a empresa. Se o "Exame das incertezas estratégicas envolvidas no projeto" não for bem examinado no âmbito da estratégia, pode ser difícil extrair maior contribuição do projeto de prospecção para a decisão estratégica da empresa. Posto de outra forma, a empresa pode implantar o que não precisa, e deixar de implantar o que precisa para a estratégia, criando uma lacuna na sua estratégia.

Nas entrevistas, um dos entrevistados (Entrevista V) mencionou que há dificuldades em se definir quem deve participar de um projeto de prospecção. O problema, segundo o relato, é que dependendo de quem participa da prospecção, $\underline{\text { as incertezas estratégicas analisadas podem }}$ não ser as mais relevantes para a estratégia da empresa, o que, segundo ele, gera um problema de falha de escopo do que deve ser prospectado. Um vazio estratégico, ou lacuna de análise estratégica.

Nas entrevistas (Entrevista VI) também foram mencionadas preocupações com a questão de pontos cegos. O processo de planejamento estratégico da organização tem mobilizado muitas pessoas, e de diversas áreas. Há um esforço coordenado muito grande para viabilizar o processo. Os entrevistados reconhecem que os riscos de ocorrerem lacunas de análise estratégica sempre estarão presentes, independentemente dos esforços. Há, contudo, um grande benefício em mobilizar esses esforços, que é o aprendizado contínuo no pensamento estratégico e na sua prática recorrente. Ao final, até podem ocorrer lacunas estratégicas, mas é preferível que elas tenham sido consequência de decisões, e não de negligência estratégica. 
Em síntese, observa que os entrevistados apresentam orientação para a estratégia e para a prospecção do futuro, e alocam muito esforço para evitar lacunas de análise, pois consideram essa questão um dos grandes desafios em suas organizações. Os resultados da survey, contudo, mostram que o exame de incertezas estratégicas nos projetos está entre os processos menos praticados. Esse paradoxo talvez possa ser explicado pela maior presença de respondentes de empresas ER na amostra, e este tipo de empresa é claramente diferente do perfil das empresas dos entrevistados desta tese.

Uma questão fundamental (Q7) desta pesquisa era se os resultados da prospecção do futuro contribuem nos processos de apoio à tomada de decisões em projetos.

Os resultados indicam que sim, mas isso ocorre em graus diferentes dependendo do perfil da empresa. As empresas mais estruturadas, as EXPLORADORAS ESTRUTURADAS (EE), mostram que além de ser considerada muito importante, a prospecção é praticada, $\underline{\text { seus }}$

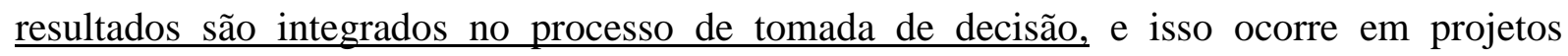
alinhados com a estratégia. Ainda mais, as incertezas estratégicas são examinadas e ocorre de fato contribuição para que as decisões possam ser tomadas. A integração entre prospecção do futuro e estratégia empresarial nessas empresas está em nível melhor do que em outras organizações, mais especificamente as empresas EXPLORADORAS REATIVAS (ER).

Uma constatação das entrevistas é que faz diferença na prática da prospecção a quantidade de

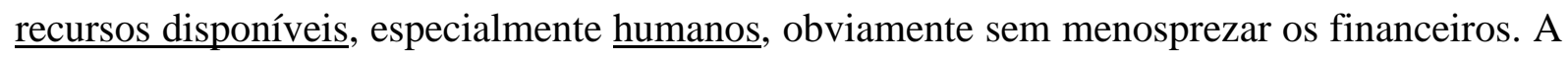
empresa pode ter recursos financeiros, mas se não tiver capital humano para desenvolver a prospecção de forma integrada com a estratégia, de nada adianta.

Das entrevistas, se pode concluir que é preciso conhecer o processo aplicado nos estudos prospectivos, para que os seus resultados possam ser utilizados mais facilmente nas análises de decisão. Essa questão leva à consideração de que mesmo empresas estruturadas para a prospecção possam sofrer com limitações na hora de integrar prospecção com estratégia empresarial. É preciso ter objetivos bem fundamentados no projeto de prospecção, eles devem refletir alinhamento com a estratégia da organização, e a comunicação de como foram desenvolvidos os processos de prospecção deve estar muito clara. Não ter isso em foco pode levar à baixa integração entre prospecção e estratégia, ou seja, baixa contribuição da prospecção nos processos de análise e decisão estratégica. 
A última das questões de pesquisa propostas (Q8) era se os resultados obtidos, a partir da prospecção bem-sucedida e focada no problema de decisão, fluem naturalmente para apoiar a decisão.

Os resultados quantitativos mostram que sim, mas não de forma generalizada. Isso ocorre em empresas estruturadas EE, mas não em empresas ER. Nestas últimas o processo é mais limitado, e a transição entre a prospecção e a decisão não é fluida, principalmente porque o conhecimento das metodologias prospectivas é mais limitado nessas empresas. Isso as leva a não lidarem bem com a identificação de temas relevantes a serem monitorados, por decorrência elas têm maior propensão a apresentarem lacunas de análise estratégica, pontos cegos que podem trazer surpresas com impacto futuro para as empresas. E, sempre é bom lembrar, os pontos cegos não são somente riscos, mas também oportunidades que poderão não ser aproveitadas porque não foram percebidas a tempo. Em linhas gerais, empresas EXPLORADORAS REATIVAS (ER) podem, no máximo, reagir aos eventos e mudanças, pois é possível que quando a ocorrência dos mesmos for iminente e perceptível, o momento ideal para preparar a empresa já tenha passado.

Empresas EXPLORADORAS ESTRUTURADAS (EE), em contraste, podem ter mais condições de avaliar como mitigar os efeitos de eventos ou cenários adversos, ou aproveitar melhor as mudanças que estejam por vir. Elas podem se beneficiar da boa prática da prospecção do futuro, dos seus resultados, da utilização dos mesmos nas decisões em projetos estratégicos, enfim, da melhor integração entre prospecção e estratégia empresarial. 


\subsection{Sobre os objetivos específicos da tese}

O processo de elucidar as questões da pesquisa foi conduzido buscando apoiar e enriquecer o objetivo geral deste trabalho, que teve como foco elaborar um modelo de apoio à integração da prospecção do futuro à gestão estratégica.

Esse modelo foi elaborado a priori, baseado em análise do autor desta tese a partir das recomendações de autores da área de prospecção do futuro. Para atingir este objetivo geral, foi pesquisada a transicão entre a (1) propensão à prática da prospecção, representada pela importância atribuída à prospecção, (2) a sua prática propriamente dita, gerando resultados de estudos prospectivos, e finalmente a (3) sua contribuição em processos de análise que possam apoiar decisões de escopo estratégico. Para facilitar a visão dessa transição, que serviu de inspiração para elaborar o problema de pesquisa desta tese, reproduz-se aqui a figura do capítulo de revisão conceitual (Capítulo 3).

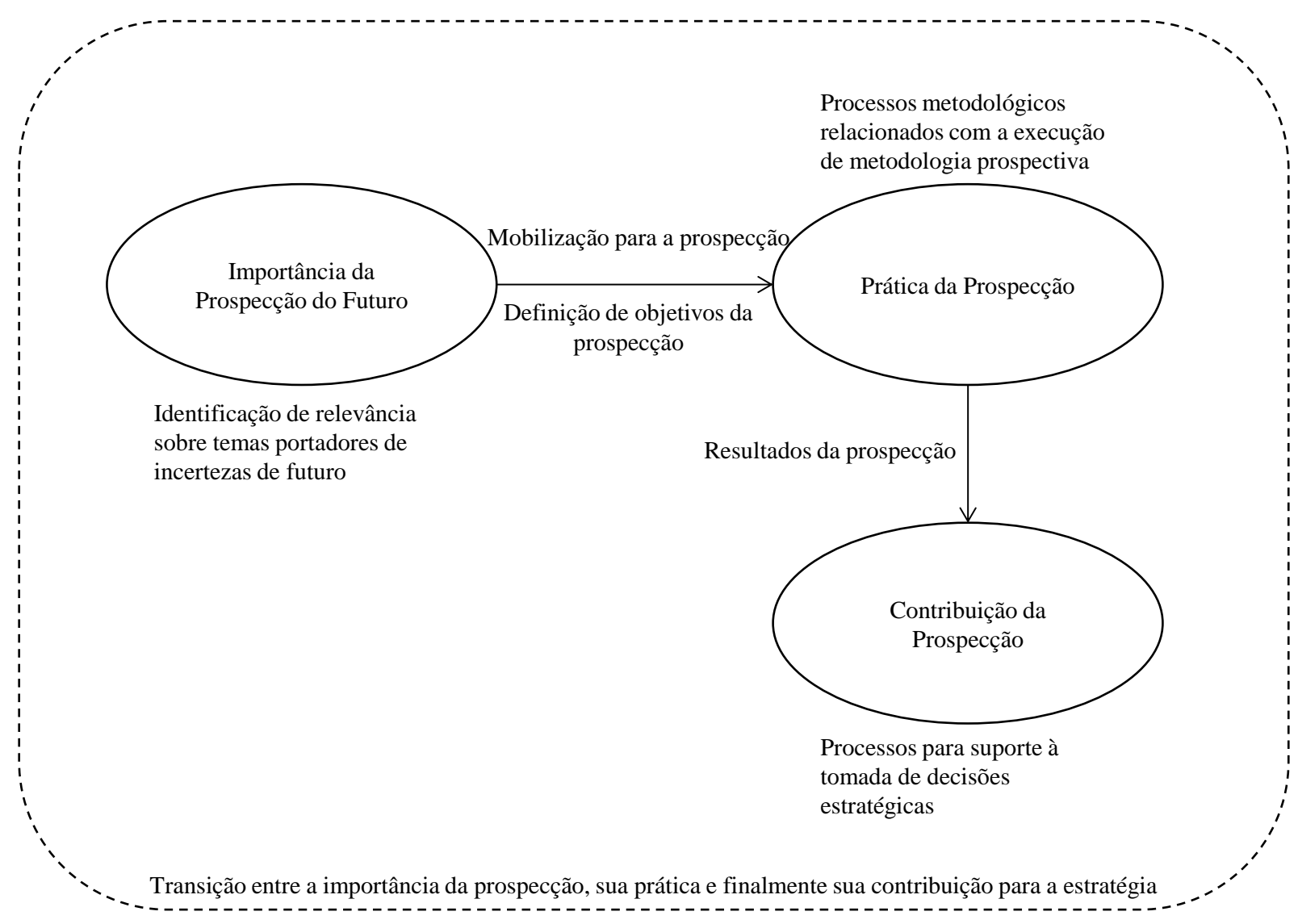

Ilustração 20 - Pressupostos conceituais para subsídio à proposta de modelo conceitual teórico da tese 
Os processos envolvendo essa transição foram estudados nesta tese, visando avaliar se o modelo de apoio proposto estaria em acordo com as necessidades presentes em um processo de integração entre prospecção do futuro e gestão estratégica. Também se buscava avaliar se o modelo poderia ser útil para facilitar a transição descrita anteriormente.

Antes de mostrar as conclusões e comentários sobre o objetivo geral da tese, descrevem-se os achados relacionados com os objetivos específicos, os quais serviram de apoio para fortalecer a orientação proporcionada pelo objetivo geral.

O2: Identificar quais temas portadores de incertezas de futuro são considerados mais importantes em projetos estratégicos.

Este objetivo está relacionado com a questão Q3, cujas respostas foram descritas na seção anterior. A identificação dos temas foi realizada, e foi possível descrever quais os temas considerados mais relevantes. O que se buscava com este objetivo é analisar se alguns dos temas resultariam em importância significativamente diferente da dos demais temas. Isso não ocorreu na amostra pesquisada, mostrando que os temas foram considerados relevantes, com diferenças entre eles, mas descritivamente não se pode afirmar que algum deles seja irrelevante.

Outro aspecto importante sobre este objetivo é que, tendo sido atingido, seria possível comparar em seguida o próximo passo da transição, que é o da prática da prospecção propriamente dita - que é o objetivo $\mathrm{O} 3$ a seguir.

O3: Identificar quais temas portadores de incertezas de futuro mobilizam mais os gestores para a prática da prospecção

Essa identificação foi realizada, conforme descrita nas conclusões sobre a questão Q4 desta tese, na seção anterior. Tratava-se de verificar se a constatação da importância, de se prospectar os temas portadores de incertezas do futuro, gerava mobilização para a prática da prospecção de fato. Se algum tema fosse avaliado pelos respondentes em menor grau com relação à importância da prospecção para avaliar o tema, então seria o caso de o tema respectivo apresentar limitações na sua análise. Ocorreram de fato algumas diferenças, as quais foram comentadas na seção anterior (questão Q4). No geral a prática da prospecção para 
analisar os diferentes temas é avaliada em um nível pouco mais baixo do que a importância atribuída à análise prospectiva dos temas. Aqui se chega à conclusão de que o fato da análise prospectiva do tema ser considerada importante, não significativa necessariamente que ela seja praticada. Em outras palavras, há limitações nesse primeiro passo da transição, o que induz à ocorrência de lacunas de análise prospectiva já neste primeiro passo.

O4: Identificar quais temas obtém maior contribuição da prospecção na tomada de decisões em projetos estratégicos, e qual a contribuição geral da prospecção na análise dos temas portadores de incertezas de futuro.

Esse objetivo também foi atingido. Ele tem relação com a questão Q5, cujas conclusões e comentários foram descritas na seção anterior. Este objetivo representa o segundo passo da transição, entre a disponibilidade de resultados dos estudos prospectivos e a sua contribuição para suporte a decisões em projetos estratégicos. $\mathrm{O}$ fato de se ter desenvolvido e concluído estudos prospectivos não significa, necessariamente, que seus resultados tenham contribuído no processo de decisão. E de fato se observou que os respondentes avaliam a contribuição em menor nível se comparado com a avaliação da prática. Conforme mencionado na Entrevista IV, os resultados da prospecção são de credibilidade relativa, e a desconfiança quanto a eles é inversamente proporcional ao grau em que se conhece sobre a expertise dos que a desenvolveram. Ainda mais, na Entrevista V foi mencionado que é possível cometer erros na escolha dos que vão desenvolver um estudo prospectivo, comprometendo os resultados, que neste caso, tenderiam a contribuir menos nas decisões.

Em síntese, com o atingimento deste objetivo se chega à conclusão de que é preciso usar alguma estrutura que permita disseminar e comunicar melhor o que está sendo feito, ou o que foi feito no desenvolvimento de um estudo prospectivo. Não basta fazer o estudo e comunicar os resultados, por melhor que estes sejam, é preciso ter um processo que garanta que stakeholders importantes se sintam como tendo participado do processo de prospecção. Isso foi mencionado explicitamente na Entrevista VI, e de certa forma também nas entrevistas III, IV e V.

Há, portanto, necessidade de apoiar melhor a prospecção do futuro para que seus resultados possam ser melhor integrados na gestão estratégica empresarial. E este apoio deve ser de 
forma estruturada, para dar facilidade para participação e aumentar o potencial de disseminação interna.

O5: Identificar quais processos recomendados nas análises de prospecção do futuro são praticados nas organizações.

Esses processos são recomendados por autores da área da prospecção, e têm relação com métodos e técnicas que podem apoiar processos de tomada de decisão, nos quais haja incertezas de futuro que possam ser tratadas com o uso dos resultados de estudos prospectivos. As conclusões sobre a prática desses processos foram descritas na seção anterior - questão Q6.

Observou-se que há processos mais praticados, o que foi positivo para se constatar que os resultados de estudos prospectivos poderiam, de fato, estar sendo utilizados nesses processos. Por outro lado, também foi constatado que há processos menos praticados, o que explica talvez porque descritivamente os respondentes da amostra avaliam a contribuição da prospecção em menor nível que sua prática.

Se algum processo deixa de ser praticado, não é possível utilizar os resultados da prospecção de forma mais efetiva. Então esta seria uma fonte de lacuna de análise. E autores como Burt e Van Der Heijden (2008), Engau e Hoffman (2011) e Schwarz (2008) enfatizam que a prospecção tem como objetivo evitar lacunas de análise. Os resultados da pesquisa indicam que na amostra o fenômeno de lacunas de análise está presente, e é significativamente elevado, especialmente nas empresas EXPLORADORAS REATIVAS (ER).

O6: Avaliar quanto os resultados da prospecção do futuro contribuíram para os processos de suporte à tomada de decisões em projetos estratégicos.

Este objetivo também foi atingido, e tem relação com o que foi descrito na seção anterior questão Q7. Trata-se do passo (3) da transição que se pesquisa nesta tese.

A contribuição existe, e ocorre mais nas empresas estruturadas EE. Nestas empresas as metodologias são mais dominadas, dessa forma se observa a boa prática da prospecção, ela gera resultados e eles são utilizados nos processos de apoio à análise prospectiva em projetos estratégicos. Os temas são bem cobertos em escopo, com menor possibilidade de lacunas de 
análise, e também se praticam mais os processos de análise estratégica prospectiva, o que é um indício de que há boa integração entre prospecção e gestão estratégica.

Cabe, contudo, mencionar que na amostra as empresas EE representam apenas $30 \%$ dos respondentes. E nos outros $70 \%$ que representam as empresas mais reativas ER, o que observa é que o domínio das metodologias é menor, por decorrência a prática da prospecção se dá em menor grau, os seus processos de análise prospectiva são menos executados, o que significa que os resultados de estudos prospectivos contribuem menos na tomada de decisões. Nestas empresas (ER) a integração entre prospecção do futuro com estratégia empresarial é mais limitada.

O7: Estudar o estado da prospecção do futuro nas organizações, avaliando em que grau os gestores percebem que a atividade está bem desenvolvida em suas organizações.

Objetivo também atingido. Ele tem relação com a questão Q8 desta tese, e os achados em relação a ele foram descritos na seção anterior. Em grandes linhas, observa-se que há respondentes que avaliam ter sido praticada de forma adequada a prospecção do futuro. E também que o conhecimento sobre metodologia prospectiva está adequado, o corpo de gestores da organização está preparado para lidar com incertezas de futuro, os resultados da prospecção são utilizados na tomada de decisão e que as lacunas de análises foram tratadas.

Em contraponto, há respondentes que indicam menor conhecimento sobre as metodologias prospectivas, a avaliação sobre a prática adequada se dá em menor nível, os gestores da empresa são considerados com menor preparo para lidar com incertezas de futuro, os resultados da prospecção são menos utilizados na tomada de decisão e finalmente eles avaliam que as lacunas de análise foram tratadas em menor nível. 


\subsection{Sobre o objetivo geral da tese}

Atingidos os objetivos $\mathrm{O} 2$ a O7, conforme descrito, resta explicar como o objetivo geral da tese foi atingido. Para isso, reproduz-se a seguir a figura do modelo proposto para apoiar a integração entre prospecção do futuro e gestão estratégica.

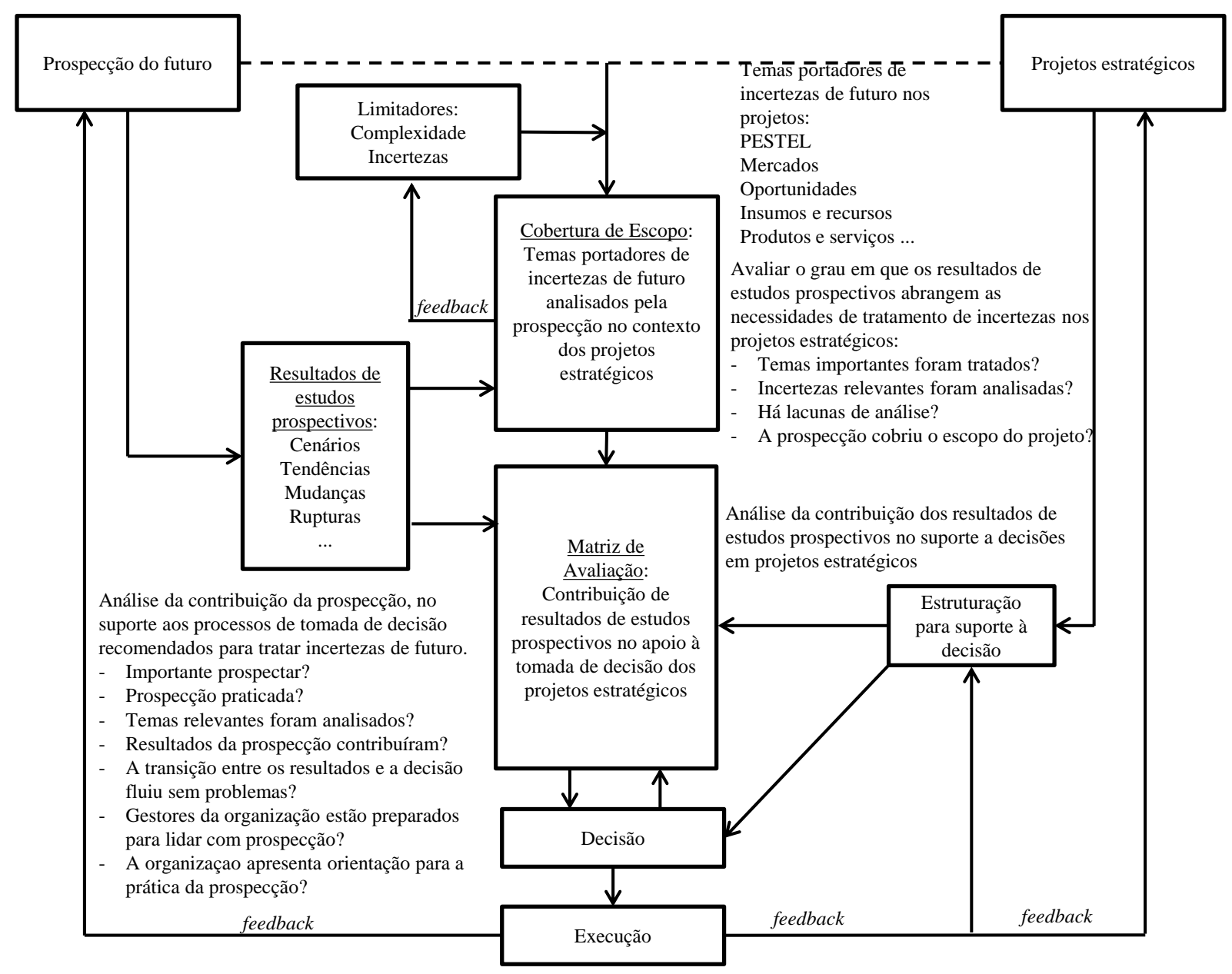

Ilustração 21 - Modelo de suporte à integração entre prospecção do futuro e tomada de decisões em projetos

Os resultados quantitativos mostraram que, dentre os principais pontos de atenção sobre a prospecção, está a limitação no conhecimento sobre as metodologias de prospecção. Esta variável (conhecimento) definiu a separação da amostra em dois grupos distintos, e num deles, a das empresas EXPLORADORAS REATIVAS (ER), foi identificado haver limitações na integração entre prospecção e gestão estratégica. A segunda variável mais relevante que caracteriza os grupos de empresas EE e ER foi a identificação dos principais temas que devem $\underline{\text { ser monitorados, e sobre este processo os respondentes das empresas ER indicaram que têm }}$ 
sérias limitações para lidar com esse tema. Em outras palavras, um dos principais desafios enfrentados por esses gestores é a ocorrência de lacunas de análise, em outras palavras, a falta de cobertura de escopo na prospecção. No modelo proposto está previsto um bloco que trata especificamente disso - Cobertura de Escopo. Sua operacionalização envolve aplicar um procedimento similar ao que foi feito na survey desta pesquisa, com adaptações para poder avaliar se os temas relevantes estão sendo efetivamente tratados na organização. A descrição sobre esta operacionalização está disponível no final do capitulo de revisão conceitual (Cap. $3)$.

Quanto ao outro bloco previsto no modelo, o da Matriz de Avaliação, que busca avaliar se os resultados da prospecção contribuem na tomada de decisões, a operacionalização prevista envolve avaliar quanto os processos de análise prospectiva são executados no âmbito dos projetos estratégicos da empresa, e também quanto os processos de análise prospectiva estratégica são executados no âmbito da estratégia da empresa. Os resultados da pesquisa mostraram que os dois conjuntos de processos são menos executados pelas empresas ER.

É prudente mencionar que os resultados não permitem afirmar que a menor execução deles seja devida à menor disponibilidade de resultados de estudos prospectivos. Mas como mencionado nas entrevistas da parte qualitativa, é importante participar de processos de prospecção, talvez até mais do que ter os resultados prontos em mãos. E isso é um indício de que, para integrar a prospecção do futuro à gestão estratégica, seria muito importante ter uma estrutura que permita, aos envolvidos nas decisões estratégicas, participar de todos os três passos da transição entre a prospecção e as decisões no âmbito da gestão estratégica.

O modelo proposto, dessa forma, proporciona soluções para contribuir com as principais limitações identificadas nos processos de integração entre prospecção do futuro e gestão estratégica.

Ele poderia ser aplicado em empresas com características dos dois grupos identificados nesta tese: EXPLORADORAS REATIVAS (ER) e EXPLORADORAS ESTRUTURADAS (EE). Para as ER ele poderia ser operacionalizado de forma mais simples, sem muitos passos para serem executados nos dois blocos. Isso possibilitaria maior rapidez de aplicação, sem significar profundidade rasa, porque análise de cobertura de escopo, e de auto avaliação de 
competências nos temas envolvidos nesta tese, não demandam necessariamente tempo longo de execução.

\subsection{Limitação de generalização}

O estudo explora preliminarmente um fenômeno sobre o qual a literatura não é abundante, conforme Chermack (2011) e Grim (2009). Não estava dentro do escopo dos objetivos da pesquisa que os resultados e conclusões representem significância estatística sobre o universo de organizações atuantes no país. Tal limitação advém da decisão sobre a amostragem definida no estudo, a qual foi apresentada no capítulo de metodologia (Cap. 4).

O critério para gerar a base da amostra de respondentes visou buscar profissionais com responsabilidade de gestão que cursam ou cursaram MBA (Masters in Business Administration) em escolas de negócios. Esse critério representa uma amostragem não probabilística.

As respostas às questões desta tese indicam, para a amostra desta pesquisa, possíveis limitações identificadas na prática da prospecção do futuro e suas respectivas contribuições em projetos estratégicos. A identificação dessas limitações e suas possíveis causas, bem como a avaliação do modelo preliminar para apoiar ou estimular a ocorrência de uma orientação à prática da prospecção do futuro, e a sua integração com a gestão estratégica é o limite desta tese. E ainda mais, considerando que a amostra não foi probabilística, conclusões que vão além deste limite não podem ser feitas a partir dos resultados aqui obtidos.

\subsection{Comentários finais e recomendações}

O conhecimento sobre as metodologias foi o fator importante para determinar o grau da integração entre prospecção do futuro e gestão estratégica. As implicações desse resultado podem ser comentadas, e eventualmente servir para algumas recomendações:

(1) O conhecimento das metodologias foi menor, na amostra pesquisada, em empresas de capital fechado, de menor faturamento e com menos funcionários. Além disso, nessas empresas a prospecção do futuro é de horizonte de tempo mais curto. Não se pode concluir se, nessas empresas, a prospecção realizada é para horizontes mais curtos por causa da falta de conhecimento das metodologias. É possível que empresas menores também estejam expostas 
a riscos estratégicos de horizonte de tempo mais longos, e que uma atividade estruturada de prospecção poderia contribuir para mitigar tais riscos. Por outro lado, dado que as empresas menores têm, em princípio, menos acesso a recursos humanos e financeiros para a realização de tais estudos, o desenvolvimento de metodologias estruturadas adequadas a este perfil poderia ser importante. Uma pesquisa futura poderia ser desenvolvida para elucidar esta questão.

(2) Dator (2002a, p. 21) menciona que os estudos do futuro são eminentemente multidisciplinares, e não deveriam ser tratados em uma disciplina singular. Roney (2010) e Gidley (2013) corroboram a multidisciplinaridade natural da área. Mas, se há falta de conhecimento disseminado sobre os métodos nas empresas, especialmente nas menores, talvez essa situação não tenha muitas chances de mudar. Isso porque Dator (2002a) argumenta que as grades curriculares de cursos de graduação no mundo, e mais especificamente nos Estados Unidos, tendem a tratar os conteúdos acadêmicos tradicionalmente por disciplinas. Os resultados desta tese indicam que talvez haja necessidade de maior disseminação dos conceitos e métodos prospectivos. Como fazer isso talvez demande análises de natureza incremental, ou disruptivas.

Essa disseminação dos conceitos e métodos prospectivos poderia ter abordagens diferentes, por exemplo, para a academia ela envolveria discutir como os conceitos sobre prospecção deveriam ser abordados nos cursos, mais especificamente na graduação, que é onde ocorre maior lacuna. Ao nível dos cursos de pós-graduação, a prospecção do futuro se mostra bem mais presente, segundo Dator (2002a), e isso também se confirma ao se observar que programas de pós-graduação stricto sensu, por exemplo, o PPGA FEA/USP; e lato sensu, por exemplo, os cursos de MBA, incluem disciplinas que tratam sobre o tema nas disciplinas relacionadas à estratégia, ou mesmo em disciplinas específicas sobre a prospecção.

Em se tratando de gestores nas organizações, a disseminação do conhecimento sobre prospecção já é tratada pelas diferentes ofertas de cursos de pós-graduação. Contudo, nota-se que a prática da prospecção e a sua contribuição em decisões estratégicas não está totalmente disseminada.

(3) O modelo de suporte proposto nesta tese, de integração entre prospecção do futuro e estratégia empresarial, se mostrou adequado para o objetivo. Conforme discutido na seção 
6.3, seria muito importante ter uma estrutura que permita, aos envolvidos nas decisões estratégicas, participar de todos os três passos da transição entre a prospecção e as decisões no âmbito da gestão estratégica. Os dados quantitativos mostram que, para a prospecção do futuro fluir bem, o domínio do conhecimento é o fator mais relevante para determinar grupos de gestores que praticam mais (ou menos) a prospecção, e por decorrência os seus resultados possam ser utilizados e, dessa forma eles possam contribuir nas decisões em projetos estratégicos. O segundo fator mais relevante é a identificação dos principais temas que devem ser monitorados, o que evitaria a ocorrência de lacunas de análise.

Dessa forma, para gestores em organizações, a recomendação poderia envolver um processo de avaliação sobre o quanto eles estariam orientados para a prática da prospecção do futuro. Em mais detalhes, essa avaliação seria realizada considerando os dois blocos do modelo proposto nesta tese: (1) Cobertura de Escopo e (2) Matriz de Avaliação.

Na Cobertura de Escopo gestores poderiam avaliar se não estão deixando de analisar temas relevantes de futuro, que possam representar potenciais riscos ou oportunidades perdidas para a empresa. Dessa forma, gestores estariam avaliando se a cobertura de escopo estaria adequada para os desafios da tomada de decisão em curso. Posto de outra forma, seria uma forma de evitar lacunas de análise prospectiva que, ao final, poderiam resultar em lacunas estratégicas para a organização.

A Matriz de Avaliação serviria para que os gestores possam avaliar se os processos de análise prospectiva estão sendo praticados, e também se a atividade de prospecção do futuro está adequadamente conduzida na empresa. A utilidade da Matriz da Avaliação é explicada porque não basta cobrir o escopo com análise de todos os temas relevantes. De fato, isso geraria os resultados com menor risco de lacunas de análise, contudo, os resultados devem ser úteis no processo de análise das decisões. E é neste ponto que a Matriz de Avaliação pode contribuir, pois uma avaliação sobre os processos de análise prospectiva, que fazem uso dos resultados prospectados, pode indicar se os gestores estão sendo eficazes na integração entre a prospecção e a estratégia.

Indo um pouco mais adiante, seguindo as recomendações anteriores comentadas e propostas nesta seção, a operacionalização do que se recomendaria, nos blocos Cobertura de Escopo e 
$\underline{\text { Matriz de Avaliação, }}$, poderia servir para indicar o quanto os gestores de uma empresa estão orientados para a prática da prospecção do futuro.

Se os gestores avaliam que estão bem nos dois blocos, então eles estarão em condições de preparar a empresa para buscar objetivos de futuro, o que representaria a construção de um estado de prontidão para o futuro desejado, por meio de projetos estratégicos alinhados com a estratégia.

Se eles avaliam que sofrem limitações somente na Matriz de Avaliação, então eles saberiam que a integração entre prospecção e estratégia não estaria bem realizada em sua empresa, apesar de saberem evitar lacunas de análise de temas relevantes. Neste caso se recomendaria aos gestores avaliarem que processos de análise prospectiva estão sendo menos praticados, e quais seriam as causas que estariam por trás disso. Isso permitiria a eles estudarem alternativas para solucionar as limitações, ou caso não haja como solucionar todas elas, reconhecerem quais são as limitações e como mitigar as consequências advindas da presença das mesmas na empresa.

Por final, se eles avaliam que sofrem limitações, tanto na Cobertura de Escopo quanto na Matriz de Avaliação, então eles estariam em condições de saber indicar quais os temas que estão sendo menos analisados. Adicionalmente, eles também estariam em condições de saber que processos de análise prospectiva estão sendo menos praticados. Estar ciente sobre a existência dessas limitações poderia subsidiar análises sobre alternativas de como lidar com elas, seja atuando para eliminar parte delas, seja desenvolvendo ações para mitigar as consequências daquelas que, por falta de recursos adequados, continuarão a ocorrer na empresa.

Enfim, o importante é que gestores não ignorem a condição em que se encontra a sua própria capacidade de prospecção do futuro, e também não esqueçam que ela deve se conectar com a estratégia. 


\section{REFERÊNCIAS}

ALMEIDA, Fernando C.; ONUSIC, Luciana M.; LESCA, Humbert. Criação de sentido e criatividade no monitoramento estratégico do ambiente. Revista de Administração da Universidade de São Paulo, São Paulo, v.42, n.4, p.405-413, out/nov/dez 2007.

ALMEIDA, Martinho I. R. Manual de planejamento estratégico: desenvolvimento de um plano estratégico com a utilização de planilhas Excel. $3^{\text {a }}$ ed. São Paulo, Atlas, 2010.

AMARA, Roy. Views on future research methodology. Futures, July/August, 1991.

ARCHAMBAUlT, E.; CAMPBELL, D.; GINGRAS, Y.; LARIVIÈRE, V. Comparing Bibliometric Statistics Obtained from the Web of Science and Scopus. Journal of the American society for information science and technology, 60 (7), p.1320-1326, 2009.

ARMSTRONG, J. Scott. Long-range forecasting - From crystal ball to computer. John Wiley \& Sons, Inc, 1985. Second Edition.

BASSAB, Wilton O.; MIAZAKI, Édina, S.; ANDRADE, Dalton F. Introdução à análise de agrupamentos. Associação Brasileira de Estatística - $9^{\circ}$ Simpósio Nacional de Probabilidade e Estatística. São Paulo, junho de 1990.

BAZERMAN, Max H.; WATKINS, Michael. Airline security, the failure of 9/11, and predictable surprises. International Public Management Journal; 8, 3; 2005.

BELL, Wendell. Foundations of Futures Studies: Human Science for a New Era: History, Purposes, Knowledge. New Brunswick: Transaction Publishers, vol I e II, 1997.

BOAVENTURA, João M. G.; FISCHMANN, Adalberto A. Is your vision consistent? A method for checking, based on scenario concepts. Futures 40, 597-612, 2008.

BOURGEOIS, Robin. A Glossary of Terms commonly used in Futures Studies. Forward Thinking Platform - supported by The Global Forum on Agricultural Research (GFAR), September 2014. Disponível em: < http://www.fao.org/docs/eims/upload/315951/Glossary of Terms.pdf $>$. Acesso em: 01/01/2015.

BURT, George. Why are we surprised at surprises? Integrating disruption theory and system analysis with the scenario methodology to help identify disruptions and discontinuities. Technological Forecasting \& Social Change, 74, 731-749, 2007.

BURT, George; VAN DER HEIJDEN, Kees. Towards a framework to understand purpose in Futures Studies: The role of Vickers' Appreciative System. Technological Forecasting \& Social Change, 75, p. 1109-1127, 2008. 
CALLAHAN, Kevin R.; BROOKS, Lynne M. Essentials of strategic project management. John Wiley \& Sons INc, 2004.

CASTRO, Claudio M. A Prática da Pesquisa $2^{\circ}$ Ed. São Paulo: Pearson Prentice Hall, 2006.

CHERMACK, Thomas J. Assessing the quality of scenarios in scenario planning. Futures Research Quarterly, Winter 2006.

CHERMACK, Thomas J. Improving decision-making with scenario planning. Futures, 36, p. 295-309, 2004.

CHERMACK, Thomas J. Scenario planning in organizations: how to create, use, and assess scenarios. Berrett-Koehler Publishers, Inc., ebook, 2011.

COATES, Vary; FAROOQUE, Mahmud; KLAVANS, Richard; LAPID, Koty; LINSTONE, Harold A.; PISTORIUS, Carl; PORTER, Alan L. On the future of technological forecasting. Technological Forecasting and Social Change, 67, p. 1-17, 2001.

CUMMINGS, Stephen; DAELLENBACH, Urs. A Guide to the Future of Strategy? The History of Long Range Planning. Long Range Planning, 42, p. 234-263, 2009.

CRESWELL. John W. Projeto de pesquisa: métodos qualitativo, quantitativo e misto $-3^{\mathrm{a}}$ Ed. - Porto Alegre: Artmed, 2010.

DAIM, Tugrul U.; RUEDA, Guillermo R.; MARTIN, Hilary, GERDSRI, Pisek. Forecasting emerging technologies: Use of bibliometrics and patent analysis. Technological Forecasting \& Social Change 73 (2006) 981-1012.

DATOR, James A. Advancing futures: Futures studies in higher education. Greenwood Publishing Group, 2002a.

DATOR, James A. Future studies as applied knowledge. In: SLAUGHTER, Richard A. (ed.). New thinking for a new millennium. Routledge, 2002b.

DATOR, James A. What futures studies is, and is not. Hawaii Research Center for Futures Studies. Disponível em: <http://www.futures.hawaii.edu/publications/futuresstudies/WhatFSis.pdf>. Acesso em: 31/12/2015.

DAY, George S.; SCHOEMAKER, Paul J.H. Driving Through the Fog: Managing at the Edge. Long Range Planning 37, 127-142, 2004.

DAY, George S.; SCHOEMAKER, Paul J.H. Visão Periférica: como perceber os indícios de sucesso (ou de fracasso) de sua empresa. Porto Alegre: Bookman, 2007.

DRUCKER, Peter F. Gestão / Peter F. Drucker com Joseph A. Maciariello. Rio de Janeiro: Agir, 2010. 
EISENHARDT, Kathleen M. Building theories from case study research. The Academy of Management Review, Vol. 14, No. 4. (Oct., 1989), pp. 532-550, 1989.

EISENHARDT, Kathleen M.; ZBARACKI, Mark J. Strategic Decision Making. Strategic Management Journal, Vol. 13, 17-37, 1992.

ENGAU, Christian; HOFFMAN, Volker H. Strategizing in an Unpredictable Climate: Exploring Corporate Strategies to Cope with Regulatory Uncertainty. Long Range Planning, 44, p. 42-63, 2011.

ERICSON, Mona. Towards a sensed decision-making approach: From déjà vu to vu jàdé. Management Decision, vol. 48, nº1, p. 132-155, 2010.

ERIKSSON, E. Anders; WEBER, K. Matthias. Adaptive Foresight: Navigating the complex landscape of policy strategies. Technological Forecasting \& Social Change, 75, p. 462-482, 2008.

ESTRADA, Rolando J.S.; ALMEIDA, Martinho I.R. A eficiência e a eficácia da gestão estratégica: do planejamento estratégico à mudança organizacional. Revista de Ciências da Administração, vol. 9, n. 19, p. 147-178, set/dez 2007.

FAHEY, Liam; PRUSAK, Laurence. The eleven deadliest sins of knowledge management. California Management Review, vol. 40, nº 3, Spring, 1998.

FÁVERO, Luiz P.; BELFIORE, Patrícia; SILVA, Fabiana L.; CHAN, Betty L. Análise de Dados modelagem multivariada para tomada de decisões. Rio de Janeiro: Elsevier, 2009.

FIDLER, Devin. Foresight defined as a component of Strategic Management. Futures, 43, p. 540-544, 2011.

FISCHMANN, Adalberto A.; ALMEIDA, Martinho I.R. Planejamento estratégico na prática 2 ed. São Paulo, Atlas, 1991.

GEORGANTZAS, Nicholas C.; ACAR, William Scenario-Driven Planning: Learning to manage strategic uncertainty. Quorum Books, 1995.

GIDLEY, Jennifer M. Are futures organisations "ahead of their times"? A view of the World Futures Studies Federation in the 21 st century. Futures, vol. 45, January 2013, p. S16-S31, 2013.

GILAD, Ben. Early Warning: Using competitive intelligence to anticipate market shifts, control risk, and create powerful strategies. Amacom, New York, 2004.

GODET, Michel. From anticipation to action: a handbook of strategic prospective. United Nations Educational, Scientific and Cultural Organization, 1994. 
GODET, Michel; ROUBELAT, Fabrice. Creating the future: the use and misuse of scenarios. Long Range Planning, Vol. 29, No. 2, pp. 164 to 171, 1996

GORDON, Theodore J. Trend Impact Analysis. AC/UNU The Millenium Project - Future Research Methodology, 1994. Disponível em: http://www1.ximb.ac.in/users/fac/dpdash/dpdash.nsf/23e5e39594c064ee852564ae004fa010/2 a7a6240bcf05ebde5256906000a7322/\$FILE/Trendimp.pdf > . Acesso em: 02/01/2016.

GORDON, Theodore J.; GLEN, Jerome C.; JAKIL, Ana. Frontiers of futures research: What's next? Technological Forecasting \& Social Change, 72, p. 1064-1069, 2005.

GREINER, Romy; PUIG, Javier; HUCHERY, Cindy; COLLIER, Neil; GARNETT, Stephen T. Scenario modelling to support industry strategic planning and decision making. Environmental Modelling \& Software, 55, p. 120-131, 2014.

GRIM, Terry. Foresight Maturity Model (FMM): Achieving Best Practices in the Foresight Field. Journal of Futures Studies, May 2009, 13(4), p. $69-80$.

GUBRIUM, Jaber F.; HOLSTEIN, James A.; MARVASTI, Amir B.; McKINNEY, Karyn D. (Org.). The SAGE handbook on interview research: The complexity of the craft $2^{\text {nd }}$ ed. SAGE Publications, Inc., 2012.

HAMEL, Gary; PRAHALAD, C.K. Competing for the future. Harvard Business School Press, ebook, 1996.

HEGER, Tobias; ROHRBECK, René. Strategic foresight for collaborative exploration of new business fields. Technological Forecasting \& Social Change, 79, p. 819-831, 2012.

HILL, Manuela M.; HILL, Andrew. Investigação por questionário. Edições Sílabo Ltda, $2^{\mathrm{a}}$

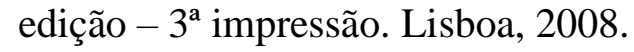

HINES, Andy. A practitioner's view of the future of futures studies. Futures, 34, p. 337-347, 2002.

HINES, Andy; BISHOP, Peter. Thinking about the future: Guidelines for strategic foresight. Smashwords edition, ebook, 2013.

HIRSCH, Sven; BURGGRAF, Paul; DAHEIN, Cornelia. Scenario planning with integrated quantification - managing uncertainty in corporate strategy building. Foresight, vol. $15, \mathrm{n}^{\circ} 5$, p. 363-374, 2013.

HITT, Michael; IRELAND, R. Duane; HOSKISSON, Robert E. Administração estratégica: competitividade e globalização. São Paulo: Pioneira Thomson Learning, 2005.

HOGARTH, Robin M.; MAKRIDAKIS, Spyros. Forecasting and planning: an evaluation. Management Science (pre-1986); Feb 1981; 27, 2, 1981. 
ILMOLA, Leena; KUUSI, Osmo. Filters of weak signals hinder foresight: Monitoring weak signals efficiently in corporate decision-making. Futures, 38, p. 908-924, 2006.

JOHNSTON, Ron. Developing the capacity to assess the impact of foresight. Foresight, vol. 14, n. 1, p. 56-68, 2012.

KAHANE, Adam. Transformative Scenario Planning - Working together to change the future. Reos Partner publications, 2012.

KAIVO-OJA, Jari Y.; KATKO, Tapio S.; SEPÄLLÄ, Osmo T. Seeking convergence between history and futures research. Futures, 36, p. 527-547, 2004.

KUOSA, Tuomo. Evolution of futures studies. Futures, 43, p. 327-336, 2011.

LEE, Sungjoo; PARK, Yongtae. Customization of technology roadmaps according to roadmapping purposes: Overall process and detailed modules. Technological Forecasting \& Social Change, 72, p. 567-583, 2005.

LEMPERT, Robert J.; GROVES, David G. Identifying and evaluating robust adaptive policy responses to climate change for water management agencies in the American west. Technological Forecasting \& Social Change, 77, p. 960-974, 2010.

LESTER, Albert. Project management, planning and control: Managing engineering, construction, manufacturing, projects to PMI, APM, and BSI standards $6^{\text {th }}$ ed. Elsevier Ltd, 2014.

LEYDESDORFF, Loet; VAUGHAN, Liwen. Co-occurrence Matrices and Their Applications in Information Science: Extending ACA to the Web Environment. Journal of the American Society for Information Science and Technology, 57(12), p. 1616-1628, 2006.

LINSTONE, Harold A. Corporate planning, forecasting, and the long wave. Futures, 34, p. 317-336, 2002.

LIST, Dennis. Action research cycles for multiple futures perspectives. Futures, 38, p. 673684, 2006.

MAKRIDAKIS, Spyros; HOGARTH, Robin M.; GABA, Anil. Forecasting and uncertainty in the economic and business world. International Journal of Forecasting, 25, p.794-812, 2009.

MANKOFF, Jennifer; RODE, Jennifer A.; FASTE, Haakon. Looking past yesterday's tomorrow: Using futures studies methods to extend the research horizon. CHI 2013, Changing Perspectives, April 27-May 2, 2013, Paris, France.

MARCONI, Marina A.; LAKATOS, Eva M. Fundamentos de metodologia científica $-6^{\mathrm{a}}$ Ed. - São Paulo: Atlas, 2005. 
MARKLEY, Oliver. From my perspective: A new methodology for anticipating STEEP surprises. Technological Forecasting \& Social Change, 78 , p. 1079-1097, 2011.

MENTZLER, John T.; KAHN, Kenneth B. Forecasting technique familiarity, satisfaction, usage, and application. Journal of Forecasting, Vol. 14, p. 465-476, 1995.

MILLER, Kent D.; WALLER, Gregory. Scenarios, Real Options and Integrated Risk Management. Long Range Planning, 36, p. 93-107, 2003.

MILLIKEN, Frances J. Three Types of Perceived Uncertainty about the Environment: State, Effect, and Response Uncertainty. The Academy of Management Review, Vol. 12, No. 1 (Jan., 1987), pp. 133-143, 1987.

MINTZBERG, Henry; RAISINGHANI, Duru; THÉORÊT, André. The structure of "unstructured" decision processes. Administrative Science Quarterly, Vol. 21, June 1976.

NEHME, Claudio C.; SANTOS, Marcio M.; FELlOWS F ${ }^{\circ}$, Lelio; COELHO, Gilda M. Challenges in communicating the outcomes of a foresight study to advise decision-makers on policy and strategy. Science and Public Policy, 39, pp. 245-257, 2012.

OKOLI, Chitu; PAWLOWSKI, Suzanne D. The Delphi method as a research tool: an example, design considerations and applications. Information \& Management, 42, p. 15-29, 2004.

PERMINOVA, Olga; GUSTAFSSON, Magnus; WIKSTRÖM, KIM. Defining uncertainty in projects $-a$ new perspective. International Journal of Project Management, 26, p. 73-79, 2008.

PORTER, Alan L.; ROPER, A. Thomas.; MASON, Thomas H.; ROSSINI, Frederick H.; BANKS, Jerry. Forecasting and Management of Technology. John Wiley \& Sons, 1991.

RAMIREZ, Rafael et al (Org.). Business planning for turbulent times: new methods for applying scenarios (The Earthscan Science in Society Series). Routledge, $2^{\text {nd }}$ edition, 2010.

RINGLAND, Gill. Scenario Planning - Managing for the future. $2^{\text {nd }}$ ed. John Wiley \& Sons, West Sussex, England, 2006.

ROHRBECK, René. Corporate Foresight: Towards a Maturity Model for the Future Orientation of a Firm. Springer, 2011.

ROHRBECK, René; BADE, Manuel. Environmental scanning, futures research, strategic foresight and organizational future orientation: a review, integration, and future research directions. ISPIM Annual Conference 2012, Barcelona, Spain, pg. 14. 
ROHRBECK, René; GEMÜNDEN, Hans G. Strategic Foresight in Multinational Enterprises: Building a Best-Practice Framework from Case Studies. R\&D Management Conference 2008 "Emerging methods in R\&D management", Ottawa, Canada, pg.10, 2008.

RONEY, Curtis W. Intersections of Strategic Planning and Futures Studies: Methodological Complementarities. Journal of Futures Studies, November 2010, 15(2): 71 - 100.

ROSSEL, Pierre. Early detection, warnings, weak signals and seeds of change: A turbulent domain of futures studies. Futures, 44, p. 229-239, 2012.

SAMPIERI, Roberto H. COLLADO, Carlos F. LUCIO, Pilar B. Metodologia de Pesquisa. 3. ed. São Paulo: McGraw-Hill, 2006.

SARDAR, Ziauddin. The Namesake: Futures; futures studies; futurology; futuristic; foresight-What's in a name? Futures 42 (2010) 177-184, 2010.

SCHOEMAKER, Paul J. H. Scenario Planning: A Tool for Strategic Thinking. Sloan Management Review; Winter 1995; 36, 2, 1995.

SLAUGHTER, Richard A. knowledge creation, futures methodologies and the integral agenda. Foresight, vol. 3, n 5, October, 2001.

STACEY, Ralph D. The chaos frontier: creative strategic control for business. Redwood Press Limited, 1991.

SCHWARZ, Jan O. Assessing the future of futures studies in management. Futures 40 (2008) 237-246, 2008.

SCHWARZ, Jan O. Business war gaming for teaching strategy making. Futures, 51, p. 59-66, 2013.

SCHWARTZ, Peter. Inevitable Surprises: thinking ahead in a time of turbulence. Gotham Books, ebook, 2003.

SCHWARTZ, Peter. The art of long view: paths to strategic insight for yourself and your company. Doubleday, 1996.

SIMON, Herbert A. Administrative behavior. A study of decision-making in administrative organizations $-4^{\text {th }}$ edition. The Free Press, New York, 1997.

TELLES, Renato. A efetividade da matriz de amarração de Mazzon nas pesquisas em Administração. Revista de Administração da Universidade de São Paulo, São Paulo v.36, n.4, p.64-72, outubro/dezembro 2001.

TOLICH, Martin. Internal Confidentiality: When Confidentiality Assurances Fail Relational Informants. Qualitative Sociology, Vol. 27, No. 1, Spring 2004. 
TVERSKY, Amos; KAHNEMAN, Daniel. Judgment under Uncertainty: Heuristics and Biases. Science, New Series, Vol. 185, No. 4157. (Sep. 27, 1974), pp. 1124-1131.

VAN DER DUIN, Patrick; HEGER, Tobias; SCHLESINGER, Maximilian D. Toward networked foresight? Exploring the use of futures research in innovation networks. Futures, 59, p. 62-78, 2014.

VAN DER HEIJDEN, Kees. Can internally generated futures accelerate organizational learning? Futures, 36, p. 145-159, 2004.

VECCHIATO, Ricardo. Environmental uncertainty, foresight and strategic decision making: An integrated study. Technological Forecasting \& Social Change, 79, p. 436-447, 2012.

VISSER, Maarten P.; CHERMACK, Thomas J. Perceptions of the relationship between scenario planning and firm performance: A qualitative study. Futures, 41, p. 581-592, 2009.

WALSH, Philip R. Dealing with the uncertainties of environmental change by adding scenario planning to the strategy reformulation equation. Management Decision Vol. 43 No. 1, p. 113-122, 2005.

WFS - World Future Society. WFS Facts\&Figures. Disponível em <https://www.wfs.org/Upload/WFS_Org\%20Overview_m4.pdf>. Acesso em: 11/01/2016.

WILSON, Ian. From Scenario Thinking to Strategic Action. Technological Forecasting and Social Change, 65, p. 23-29, 2000.

WOON, Wei L.; MADNICK, Stuart. Asymmetric information distances for automated taxonomy construction. Knowledge Information Systems, 21, p. 91-111, 2009.

WINKLHOFER, Heidi; DIAMANTOPOULOS, Adamantios; WITT, Stephen F. Forecasting practice: a review of the empirical literature and an agenda for future research. International Journal of Forecasting, 12, p. 193-221, 1996.

WRIGHT, George; GOODWIN, Paul. Decision making and planning under low levels of predictability: Enhancing the scenario method. International Journal of Forecasting, 25, p. 813-825, 2009.

WRIGHT, George; VAN DER HEIJDEN, Kees; BURT, George; BRADFIELD, Ron; CAIRNS, George. Scenario planning interventions in organizations: An analysis of the causes of success and failure. Futures, 40, p. 218-236, 2008).

WRIGHT, James T.C.; SPERS, Renata G. O país no futuro: aspectos metodológicos e cenários. Estudos Avançados, 20, (56), 2006.

ZHU, Donghua; PORTER, Alan L. Automated extraction and visualization of information for technological intelligence and forecasting. Technological Forecasting \& Social Change, 69, p. 495-506, 2002. 


\section{APÊNDICE 1 - Roteiro de entrevistas \\ Entrevistas abertas: Fase exploratória qualitativa}

\section{Roteiro de entrevista}

\section{Orientações para abertura e esclarecimentos dos objetivos da entrevista}

\section{Agradecimentos ao entrevistado:}

Antecipar a disposição em participar da pesquisa, enfatizando a contribuição oferecida pelo entrevistado.

Lembrar o entrevistado da previsão de tempo estimada para a entrevista: de 40 a 60 minutos por sessão.

\section{Dar segurança e liberdade ao entrevistado:}

A entrevista, bem como a pesquisa no geral, não visa à avaliação do gestor, do entrevistado ou da empresa em que trabalha. Ela tem foco nos fenômenos como eles ocorrem nas empresas, e partindo disso, pretende-se analisar relações com a teoria, desenvolver modelos para sistematizar e testar abordagens de aplicação. O entrevistado não está sendo avaliado ou julgado.

\section{Confidencialidade:}

Esclarecer que as respostas à entrevista são confidenciais e somente serão utilizados para propósitos acadêmicos.

O entrevistado poderá ter a confidencialidade preservada, assim como a empresa. Informar que setor de atuação da empresa, seu porte e região (ões) (país da matriz da empresa) de atuação poderão ser divulgados na pesquisa, mas que o princípio é preservar confidencialidade, e caso seja necessário alguma transparência sobre identificação das partes, entrevistado ou organização, será explicitamente solicitado, do contrário a confidencialidade é um pressuposto da pesquisa.

\section{Escopo:}

Informar que a entrevista se refere ao estudo das metodologias utilizadas para prospectar o futuro, mais especificamente o uso dos resultados prospectivos em projetos estratégicos. 
Esclarecer que o termo "prospecção do futuro" significa, nesta pesquisa, "estudar o futuro".

\section{Objetivos da entrevista:}

Está se desenvolvendo uma tese sobre a integração de prospecção do futuro com estratégia empresarial. A operacionalização da pesquisa foca na utilização dos resultados de estudos prospectivos (estudos do futuro) na tomada de decisões em projetos estratégicos. Pretende-se estudar como ocorre o fenômeno. Também se pretende estudar os fatores que influem no processo, se há limitações ou dificuldades nesse processo.

\section{Questões gerais da entrevista:}

Manter o entrevistado confortável para relatar suas experiências sobre prospecção e o uso dos resultados na estratégia empresarial. Caso seja necessário estimular os relatos, informar conforme o contexto do relato, as questões gerais da pesquisa:

A prospecção é praticada? Esse processo é estruturado?

Ela é considerada importante na organização?

Os projetos estratégicos da empresa refletem o que foi analisado na prospecção?

Que fatores facilitam ou dificultam a prática da prospecção?

Os resultados de estudos prospectivos contribuem nas decisões em projetos do âmbito da estratégia da organização?

A empresa tem alguma forma mais estruturada para utilizar os resultados de estudos prospectivos em decisões sobre projetos?

Qual o horizonte de tempo que é utilizado como referência para projetos envolvendo aspectos estratégicos?

Na empresa é considerado importante o uso de estudos prospectivos para suporte à decisões em projetos estratégicos? (Definir projetos estratégicos ao entrevistado)

Como o entrevistado avalia a atividade de prospecção do futuro na organização?

\section{Identificação do entrevistado e da empresa:}

Informar sobre aspectos gerais de disclosure pessoal e confidencialidade, enfatizando que o objetivo é adotar confidencialidade, tanto do entrevistado quanto da empresa. 


\section{APÊNDICE 2 - Questionário (survey)}

Prezado(a) respondente,

Esta pesquisa é parte do trabalho acadêmico de Doutorado em Administração que apresentarei à Faculdade de Economia, Administração e Contabilidade da Universidade de São Paulo FEA/USP.

Ela tem como objetivo estudar e aprimorar o uso de estudos prospectivos nos projetos estratégicos das organizações.

Sua participação é de fundamental importância para o desenvolvimento desta tese de doutorado. As respostas são consideradas confidenciais e a divulgação dos resultados será feita somente de forma agregada. Não serão divulgados nomes dos respondentes sem sua expressa autorização, nem tampouco das organizações na qual trabalhem ou tenham trabalhado.

São estimados aproximadamente 20 minutos como tempo para responder ao questionário. A tese final estará disponível na biblioteca digital da Universidade de São Paulo - USP.

Caso tenha dúvidas, favor entrar em contato por meio do endereço de e-mail nelson.yoshida@usp.br.

Muito obrigado pela sua participação.

Atenciosamente,

Nelson Daishiro Yoshida

\section{INTRODUÇÃO}

No processo de análise de projetos estratégicos, gestores têm que lidar com incertezas sobre o futuro. Por consequência disso, é realizada alguma forma de prospecção do futuro, uma atividade com foco em estudar o futuro, as incertezas relacionadas, as tendências e as mudanças que podem vir a acontecer.

A prospecção do futuro pode contribuir no processo de tomada de decisões nos projetos estratégicos.

Muitos temas, que são portadores de incertezas de futuro, estão presentes quando se analisam projetos estratégicos.

Adicionalmente, muitos processos podem ser necessários para o suporte à tomada de decisão nesses projetos.

A presente tese é desenvolvida para se estudar a prática da prospecção do futuro em projetos estratégicos.

Espera-se aprofundar a compreensão sobre esse fenômeno, bem como contribuir para a disseminação de metodologias que possam aumentar o potencial dos benefícios da prospecção do futuro. 


\section{Para as questões centrais da pesquisa, por favor considere as definições abaixo:}

Prospecção do futuro: É a atividade de estudar o futuro, analisar as incertezas relacionadas com ele, as tendências que podem se consolidar, as mudanças que podem vir a ocorrer, bem como os cenários que podem ser possíveis no futuro.

Projeto Estratégico: Projetos de médio e longo prazo, em diferentes áreas da organização, que envolvem muitos recursos físicos, humanos e econômicos, e que tipicamente são de difícil reversão após o início de sua implantação. Exemplos (não se restringindo a estes):

- Projetos de desenvolvimento e lançamento de novos produtos/serviços;

- Projetos de localização de novos pontos de presença para operação ou produção;

- Projetos de aquisição de novas plataformas tecnológicas para a produção ou suporte às operações da organização;

- Projetos sobre mudanças no portfólio de produtos/serviços;

- Projetos sobre mudanças nos modelos de negócios da organização.

Tema portador de incertezas de futuro: É o assunto (matéria, tópico) cujo futuro não pode ser descrito sem correr o risco de estar errado, uma vez que haja muitos fatores relacionados a ele que são de difícil previsibilidade.

Horizonte de tempo da prospecção: Trata-se do alcance de tempo para o futuro, ou o período de tempo para o qual é estudado o futuro, contado a partir da data em que se está fazendo a prospecção.

Frequência (percentual) da prática de prospecção: É o percentual dos casos de projetos estratégicos no qual a prospecção é praticada, por exemplo, se ela foi praticada em 5 projetos dentre 10 , então a frequência seria de $50 \%$.

\section{QUESTÕES CENTRAIS DA PESQUISA:}

1) Pense no último projeto estratégico de que tenha participado da análise ou da decisão, e cuja implantação tenha sido finalizada (concluída). Por favor, indique abaixo a satisfação quanto aos objetivos atingidos no projeto.

1. Totalmente insatisfeito

2. Parcialmente insatisfeito

3. Nem insatisfeito, nem satisfeito

4. Parcialmente satisfeito

5. Totalmente satisfeito

2) Quando se analisam projetos estratégicos em sua organização, qual a frequência (percentual) em que é praticada a prospecção do futuro? Preencha o campo abaixo com a porcentagem dos projetos estratégicos em que se pratica a prospecção: 
3) Pense na importância dos temas portadores de incertezas de futuro da lista abaixo. Indique o quanto gestores de sua empresa/organização avaliaram que era importante analisar e examinar, cada um deles, no último projeto estratégico do qual você tenha participado das análises ou das decisões, e cuja implantação tenha sido concluída.

Obs.: Note que a importância do tema não significa, necessariamente, que ele tenha sido analisado no projeto. Pode ser que fosse importante analisar o tema, mas ele não foi analisado.

\begin{tabular}{|c|c|c|c|c|c|}
\hline & $\begin{array}{l}\text { Nada } \\
\text { importante }\end{array}$ & $\begin{array}{l}\text { Pouco } \\
\text { importante }\end{array}$ & Important & $\begin{array}{l}\text { Muito } \\
\text { importante }\end{array}$ & $\begin{array}{l}\text { Extremam } \\
\text { ente } \\
\text { importante }\end{array}$ \\
\hline \multicolumn{6}{|l|}{ Ambiente Político e Governo } \\
\hline \multicolumn{6}{|l|}{ Economia } \\
\hline & $\square$ & 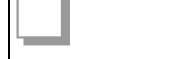 & $\square$ & $\square$ & $\square$ \\
\hline \multicolumn{6}{|l|}{ Sociedade } \\
\hline & 足 & $\square$ & 品 & 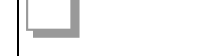 & $\square$ \\
\hline \multicolumn{6}{|l|}{ Tecnologia } \\
\hline & 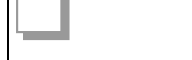 & 品 & $\square$ & $\square$ & $\square$ \\
\hline \multicolumn{6}{|l|}{ Meio-ambiente e sustentabilidade } \\
\hline & L & $\square$ & L & 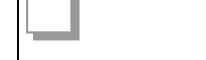 & $\square$ \\
\hline \multicolumn{6}{|l|}{ Legislação e regulação setorial } \\
\hline & 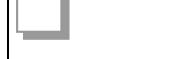 & 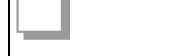 & $\square$ & $\square$ & 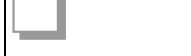 \\
\hline \multicolumn{6}{|l|}{ Mercado e demanda } \\
\hline & 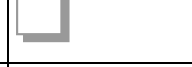 & $\square$ & 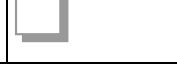 & 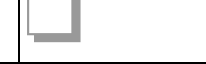 & $\square$ \\
\hline \multicolumn{6}{|l|}{ Insumos e recursos } \\
\hline & ب & 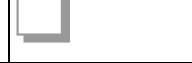 & 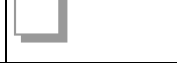 & ب & $\square$ \\
\hline \multicolumn{6}{|l|}{ Inovação em Produtos ou Serviços } \\
\hline & 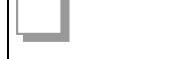 & 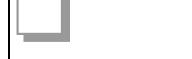 & 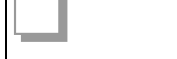 & 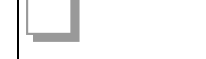 & $\square$ \\
\hline \multicolumn{6}{|l|}{ Outras oportunidades de negócios } \\
\hline & 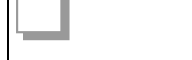 & $\square$ & 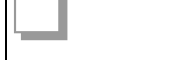 & 要 & $\square$ \\
\hline \multicolumn{6}{|l|}{ Competidores } \\
\hline & $\square$ & 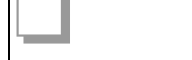 & 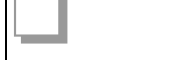 & 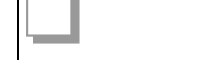 & 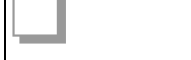 \\
\hline \multicolumn{6}{|l|}{ Fornecedores } \\
\hline & 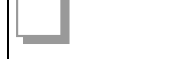 & 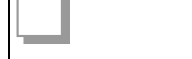 & $\square$ & $\square$ & $\square$ \\
\hline $\begin{array}{l}\text { Em geral, neste último projeto, qual foi a } \\
\text { importância de checar se os temas acima } \\
\text { foram analisados? }\end{array}$ & $\square$ & $\square$ & $\square$ & $\square$ & $\square$ \\
\hline
\end{tabular}

4) Considere o último projeto estratégico de que você tenha participado das análises ou das decisões. E que tenha tido a implantação concluída. Quanto os temas da lista abaixo foram analisados na prospecção do futuro?Para responder, observe a descrição dos diferentes níveis de escala:

Nada = não foi feita análise sobre este tema;

Muito pouco = foi feita uma análise superficial sobre este tema, que não contribuiu para se ter segurança nas decisões;

Mínimo suficiente $=$ o tema foi analisado com o menor investimento de recursos necessários, mas ainda assim, suficiente para fornecer elementos mínimos para apoiar decisões no projeto. 
Com alguma profundidade $=$ o tema foi analisado com aprofundamento maior do que o mínimo suficiente para apoiar decisões no projeto.

Com grande profundidade $=$ o tema foi analisado com elevado uso de recursos, possibilitando explorar com riqueza de detalhes e de alternativas possíveis para o futuro.

\begin{tabular}{|c|c|c|c|c|c|}
\hline & Nada & $\begin{array}{l}\text { Muito } \\
\text { pouco }\end{array}$ & $\begin{array}{l}\text { Mínimo } \\
\text { suficiente }\end{array}$ & $\begin{array}{l}\text { Com } \\
\text { alguma } \\
\text { profundida } \\
\text { de }\end{array}$ & $\begin{array}{l}\text { Com } \\
\text { grande } \\
\text { profundida } \\
\text { de }\end{array}$ \\
\hline Ambiente Político e Governo & & $\square$ & & & $\square$ \\
\hline Economia & & $\square$ & & & $\square$ \\
\hline Sociedade & $\square$ & $\square$ & $\square$ & $\square$ & $\square$ \\
\hline Tecnologia & $\square$ & $\square$ & $\square$ & $\square$ & $\square$ \\
\hline Meio-ambiente e sustentabilidade & $\square$ & $\square$ & $\square$ & $\square$ & $\square$ \\
\hline Legislação e regulação setorial & $\square$ & $\square$ & $\square$ & $\square$ & $\square$ \\
\hline Mercado e demanda & $\square$ & $\square$ & $\square$ & $\square$ & $\square$ \\
\hline Insumos e recursos & $\square$ & $\square$ & $\square$ & $\square$ & $\square$ \\
\hline Inovação em Produtos ou Serviços & $\square$ & $\square$ & $\square$ & $\square$ & $\square$ \\
\hline Outras oportunidades de negócios & $\square$ & $\square$ & \begin{tabular}{|l|} 
\\
\end{tabular} & $\square$ & $\square$ \\
\hline Competidores & $\square$ & $\square$ & $\square$ & $\square$ & $\square$ \\
\hline Fornecedores & $\square$ & $\square$ & $\square$ & $\square$ & $\square$ \\
\hline $\begin{array}{l}\text { Em geral, neste último projeto, quanto } \\
\text { prospecção foi praticada? }\end{array}$ & $\square$ & $\square$ & \begin{tabular}{|l|} 
\\
\end{tabular} & $\square$ & $\square$ \\
\hline
\end{tabular}

5) Agora, pensando nas análises desenvolvidas na prospecção do futuro, por favor, indique abaixo, para cada tema, o quanto elas contribuíram na tomada de decisão do último projeto estratégico de que tenha participado, e cuja implantação foi concluída.

Observe a descrição da escala a seguir:

Nada $=$ nenhuma contribuição.

Pouco $=$ ajudou um pouco, mas fez pouca diferença.

Moderado $=$ ajudou a esclarecer parte das incertezas, contribuindo para aumentar a segurança nas decisões, embora as incertezas cruciais continuassem a incomodar.

Muito $=$ algumas das incertezas cruciais do projeto foram analisadas, possibilitando boa segurança nas decisões.

Extremamente $=0$ projeto foi analisado com ampla gama de possibilidades, todas as 
incertezas cruciais puderam ser tratadas e foram analisadas com a profundidade necessária.

\begin{tabular}{|c|c|c|c|c|c|}
\hline & Nada & Pouco & Moderado & Muito & $\begin{array}{l}\text { Extremam } \\
\text { ente }\end{array}$ \\
\hline Ambiente Político e Governo & $\square$ & $\square$ & $\square$ & 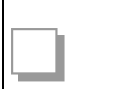 & $\square$ \\
\hline Economia & $\square$ & $\square$ & & & $\square$ \\
\hline Sociedade & & & & & \\
\hline Tecnologia & $\square$ & $\square$ & $\square$ & $\square$ & $\square$ \\
\hline Meio-ambiente e sustentabilidade & $\square$ & $\square$ & $\square$ & $\square$ & $\square$ \\
\hline Legislação e regulação setorial & $\square$ & $\square$ & $\square$ & $\square$ & $\square$ \\
\hline Mercado e demanda & $\square$ & $\square$ & $\square$ & $\square$ & $\square$ \\
\hline Insumos e recursos & $\square$ & $\square$ & $\square$ & $\square$ & $\square$ \\
\hline Inovação em Produtos ou Serviços & $\square$ & $\square$ & $\square$ & $\square$ & $\square$ \\
\hline Outras oportunidades de negócios & $\square$ & $\square$ & $\square$ & \begin{tabular}{|l|} 
\\
\end{tabular} & $\square$ \\
\hline Competidores & $\square$ & $\square$ & $\square$ & $\square$ & $\square$ \\
\hline Fornecedores & $\square$ & $\square$ & \begin{tabular}{|l|} 
\\
\end{tabular} & $\square$ & $\square$ \\
\hline $\begin{array}{l}\text { Em geral, neste último projeto, quanto a } \\
\text { prospecção, sobre os temas acima, } \\
\text { contribuiu nas decisões? }\end{array}$ & $\square$ & $\square$ & $\square$ & $\square$ & $\square$ \\
\hline
\end{tabular}

6) Pense agora em processos relacionados com a análise de projetos estratégicos. Indique, dentre os processos da lista abaixo, quanto eles foram praticados no último projeto estratégico do qual você tenha participado das análises ou das decisões, e que tenha tido a implantação concluída.

\begin{tabular}{|c|c|c|c|c|c|c|}
\hline & $\begin{array}{l}1 \text { - Não } \\
\text { foi } \\
\text { praticado }\end{array}$ & $\begin{array}{l}2 \text { - Pouco } \\
\text { praticado }\end{array}$ & $\begin{array}{l}3 \\
\text { Moderad } \\
\text { amente } \\
\text { praticado }\end{array}$ & praticado & $\begin{array}{l}5 \\
\text { Extrema } \\
\text { mente } \\
\text { praticado }\end{array}$ & $\begin{array}{l}-99 \text { - Não } \\
\text { sei } \\
\text { responder }\end{array}$ \\
\hline $\begin{array}{l}\text { Análise dos contextos futuros dos } \\
\text { negócios envolvidos no projeto }\end{array}$ & $\square$ & 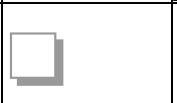 & 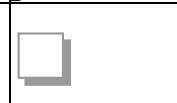 & 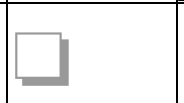 & 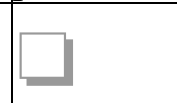 & 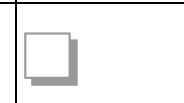 \\
\hline $\begin{array}{l}\text { Análise do alinhamento do projeto com } \\
\text { a estratégia da organização. }\end{array}$ & $\square$ & $\square$ & 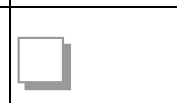 & 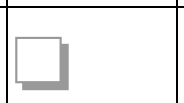 & 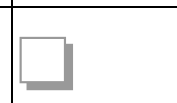 & 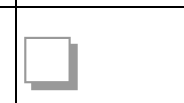 \\
\hline
\end{tabular}




$\begin{aligned} & \text { Calibração de premissas utilizadas no } \\ & \text { projeto }\end{aligned}$
$\begin{aligned} & \text { Definição de sinais ou indicadores que } \\ & \text { sirvam para monitorar o futuro }\end{aligned}$
acontecendo (ou começando
acontecer) no âmbito da implantação do
projeto

7) Agora observe a mesma lista de processos da questão anterior. Indique o quanto as análises e conclusões obtidas a partir da prospecção do futuro contribuíram nos processos da lista, no último projeto estratégico do qual você tenha participado das análises ou das decisões, e que tenha tido implantação concluída.

\begin{tabular}{|c|c|c|c|c|c|c|}
\hline & 1 - Nada & 2 - Pouco & $\begin{array}{l}3 \\
\text { Moderad } \\
\text { amente }\end{array}$ & 4- Muito & $\begin{array}{l}5 \\
\text { Extrema } \\
\text { mente }\end{array}$ & $\begin{array}{l}-99 \text { - Não } \\
\text { sei } \\
\text { responder }\end{array}$ \\
\hline $\begin{array}{l}\text { A prospecção contribuiu para: Análise } \\
\text { dos contextos futuros dos negócios } \\
\text { envolvidos no projeto }\end{array}$ & & & & & & \\
\hline $\begin{array}{l}\text { A prospecção contribuiu para: Análise } \\
\text { do alinhamento do projeto com a } \\
\text { estratégia da organização. }\end{array}$ & & & & & & \\
\hline $\begin{array}{l}\text { A prospecção contribuiu para: } \\
\text { Calibração de premissas utilizadas no } \\
\text { projeto }\end{array}$ & & 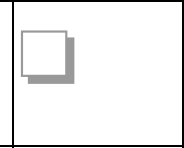 & 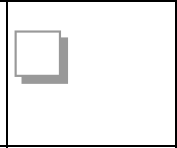 & 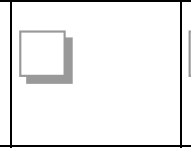 & 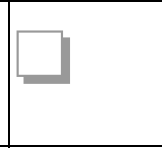 & 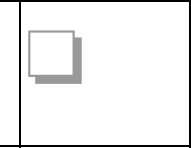 \\
\hline $\begin{array}{l}\text { A prospecção contribuiu para: Análise } \\
\text { de forças relevantes do futuro que } \\
\text { influenciem o projeto }\end{array}$ & 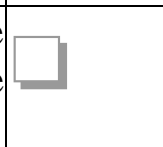 & & & $\square$ & $\square$ & $\square$ \\
\hline $\begin{array}{l}\text { A prospecção contribuiu para: } \\
\text { Definição de sinais ou indicadores que } \\
\text { sirvam para monitorar o futuro } \\
\text { acontecendo (ou começando a } \\
\text { acontecer) no âmbito da implantação do } \\
\text { projeto }\end{array}$ & $\square$ & 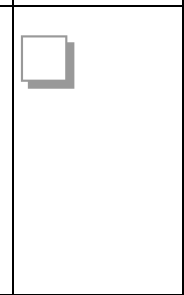 & 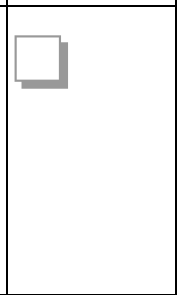 & $\square$ & $\square$ & $\square$ \\
\hline
\end{tabular}




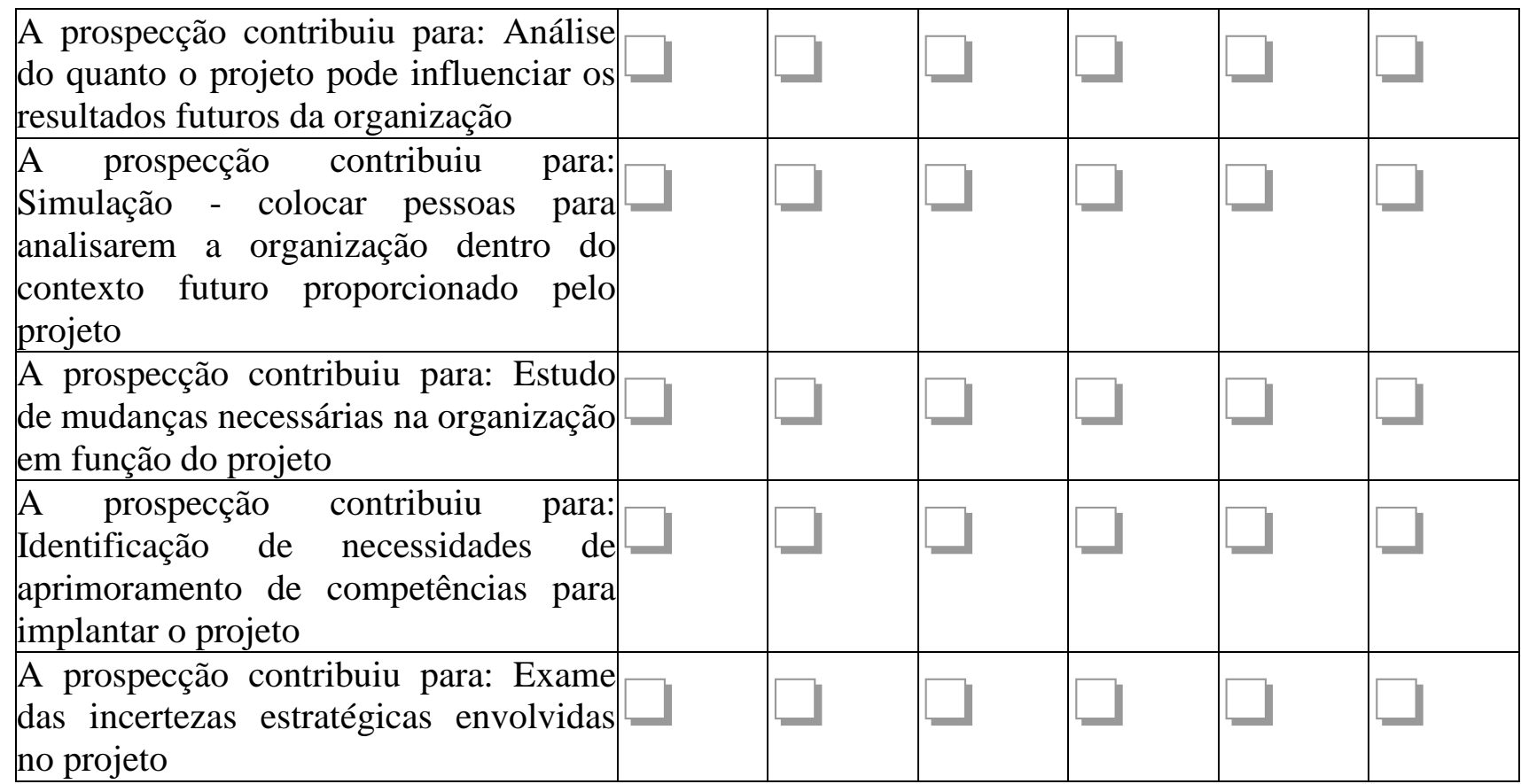

8) Indique o quanto a prática da prospecção do futuro, no último projeto estratégico, contribuiu para que os processos a seguir tenham sido praticados.

\begin{tabular}{|c|c|c|c|c|c|c|}
\hline & 1 - Nada & 2 - Pouco & $\begin{array}{l}3 \\
\text { Moderad } \\
\text { amente }\end{array}$ & -4 - Muito & $\begin{array}{l}5 \\
\text { Extrema } \\
\text { mente }\end{array}$ & $\begin{array}{l}-99-\text { Não } \\
\text { sei } \\
\text { responder }\end{array}$ \\
\hline $\begin{array}{l}\text { A prospecção contribuiu } \text { para: } \\
\text { Identificação dos temas que } \\
\text { representam lacunas de análise, } \\
\text { podendo provocar pontos cegos na } \\
\text { análise do projeto }\end{array}$ & & & & & $\square$ & 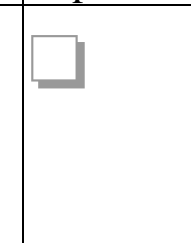 \\
\hline $\begin{array}{l}\text { A prospecção contribuiu para: } \\
\text { Aprimoramento do processo de tomada } \\
\text { de decisão no projeto, por meio da } \\
\text { análise das incertezas de futuro }\end{array}$ & & & 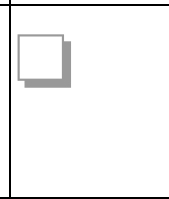 & 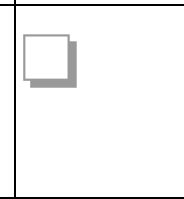 & 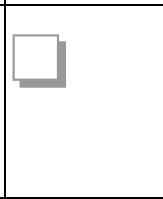 & $\square$ \\
\hline $\begin{array}{l}\text { A prospecção contribuiu para: } \\
\text { Identificação de quais os principais } \\
\text { temas que devem ser monitorados após } \\
\text { o início da implantação do projeto }\end{array}$ & & 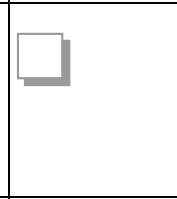 & $\square$ & $\square$ & $\square$ & 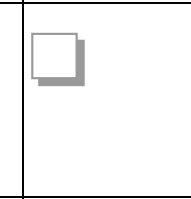 \\
\hline $\begin{array}{l}\text { A prospecção contribuiu para: } \\
\text { Identificação de quais as principais } \\
\text { tendências e eventos do ambiente } \\
\text { futuro, estimando as chances de suas } \\
\text { ocorrências. }\end{array}$ & & $\square$ & U & 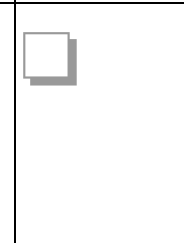 & $\square$ & 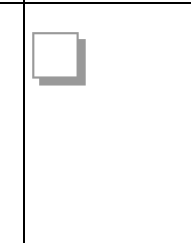 \\
\hline $\begin{array}{l}\text { A prospecção contribuiu para: Análise } \\
\text { de quais as possíveis consequências de } \\
\text { uma alternativa de decisão no projeto }\end{array}$ & 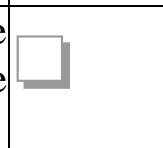 & L & 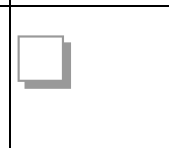 & 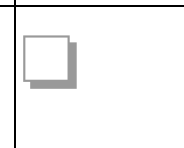 & $\square$ & $\square$ \\
\hline $\begin{array}{l}\text { De forma geral, no último projeto, } \\
\text { quanto a prospecção do futuro } \\
\text { contribuiu nos processos acima? }\end{array}$ & $\square$ & ـ & U & 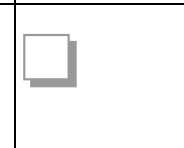 & $\square$ & $\square$ \\
\hline
\end{tabular}


9) As afirmações abaixo devem ser relacionadas com o último projeto estratégico de que tenha participado das análises ou das decisões, e cuja implantação tenha sido concluída. Indique o quanto você concorda com cada uma delas.

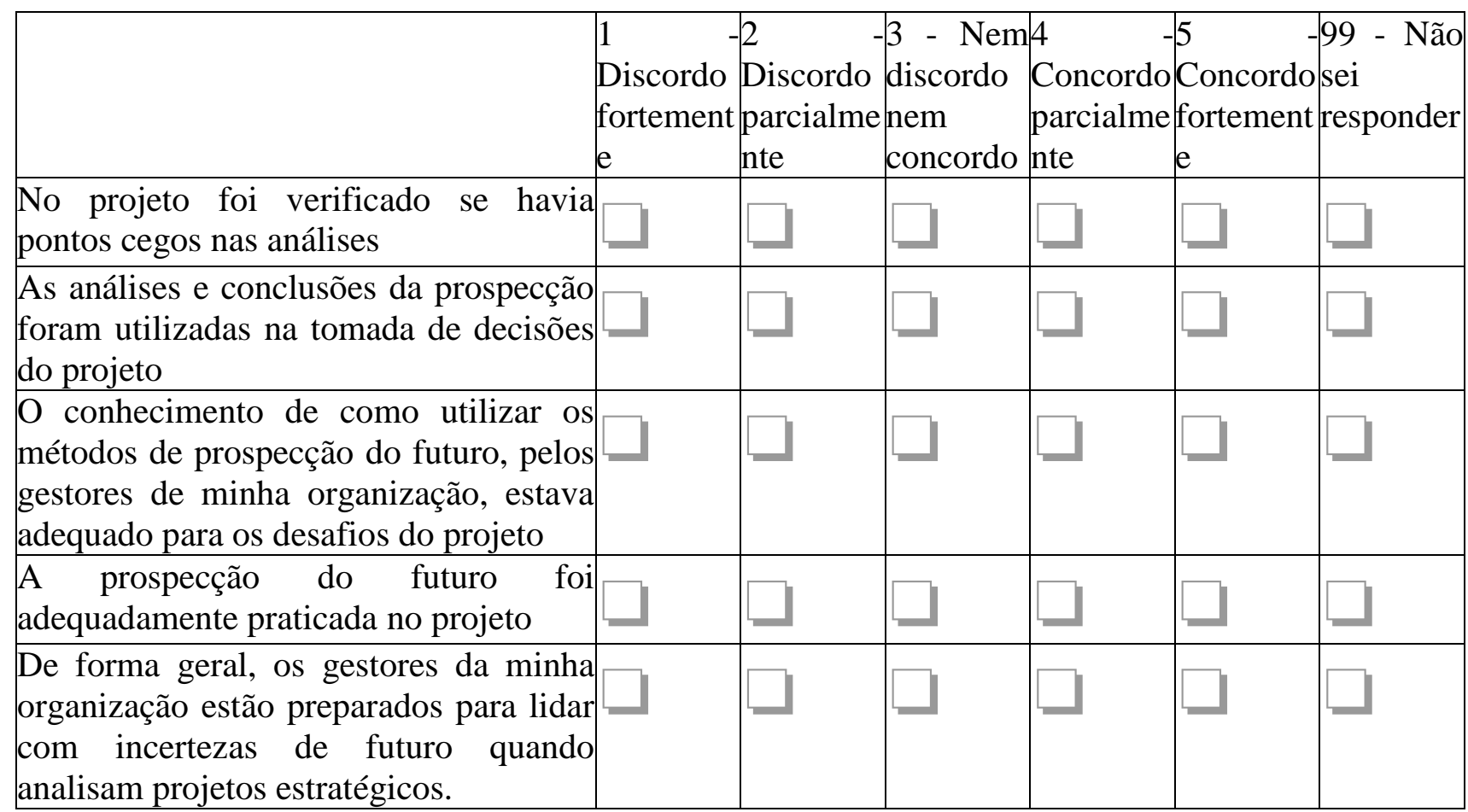

Caso deseje comentar suas respostas acima, por favor faça aqui:

10) Qual o horizonte de tempo da prospecção no último projeto estratégico de que você tenha participado da análise ou da decisão?

até 6 meses

de 6 meses a 1 ano

de 1 a 2 anos

de 2 a 3 anos

de 3 a 5 anos

de 5 a 10 anos

mais de 10 anos

não sei responder 


\section{Parte 2: Informações pessoais}

11) Qual o seu cargo na empresa/organização?

Conselheiro (de Administração, Fiscal)

Presidente (CEO)

Gerente Geral

Diretor

Gerente

Supervisor

Consultor

Analista

Proprietário / sócio proprietário

Outro (digitar ao lado)

12) Qual a sua formação acadêmica mais recente?

Ensino fundamental - primeiro grau

Ensino médio ou técnico

Ensino superior - graduação

Ensino superior - pós-graduação lato sensu (Especialização/MBA)

Ensino superior - pós-graduação stricto sensu (mestrado, doutorado)

Outro (digitar ao lado)

13) Qual o seu tempo de experiência profissional (tempo total)?

até 2 anos

entre de 2 a 5 anos

entre de 5 a 10 anos

entre de 10 a 15 anos

entre de 15 a 20 anos

entre de 20 a 25 anos

entre de 25 a 30 anos

mais de 30 anos

14) Qual a sua faixa etária?

Até 25 anos

de 25 a 35 anos

de 35 a 45 anos

de 45 a 55 anos

de 55 a 65 anos

de 65 a 75 anos

mais de 75 anos

15) Sexo

Feminino

Masculino

Informações sobre sua empresa/organização:

16) Qual a forma de controle de sua empresa/organização (no Brasil)?

Sociedade de capital aberto

Sociedade de capital fechado

Limitada 
Estatal de economia mista

Estatal de capital $100 \%$ público

Autarquia pública

Organização do terceiro setor (OSCIP - Organização da Sociedade Civil de Interesse Público)

Outro

(digitar

ao

lado)

17) Qual a predominância da origem do capital de sua empresa/organização?

brasileira

estrangeira

18) Qual a quantidade de funcionários de sua empresa/organização (no Brasil)?

Menos de 50

Entre 51 e 100

Entre 101 e 300

Entre 301 e 500

Entre 501 e 1.000

Entre 1.001 e 2.000

Entre 2.001 e 3.000

Entre 3.001 e 4.000

Entre 4.001 e 5.000

Entre 5.001 e 6.000

Entre 6.001 e 7.000

Entre 7.001 e 8.000

Entre 8.001 e 9.000

Entre 9.001 e 10.000

Entre 10.001 e 15.000

Entre 15.001 e 20.000

Acima de 20.000

19) Qual o faturamento anual de sua empresa no Brasil? Caso não seja uma empresa com fins lucrativos, considere o orçamento anual da organização.

menos de 10 milhões de reais

de 10 até 20 milhões de reais

de 20 até 50 milhões de reais

de 50 até 100 milhões de reais

de 100 até 300 milhões de reais

de 300 até 500 milhões de reais

de 500 milhões até 1 bilhão de reais

de 1 até 2 bilhões de reais

de 2 até 3 bilhões de reais

de 3 até 5 bilhões de reais

de 5 até 7 bilhões de reais

de 7 até 10 bilhões de reais

de 10 a 13 bilhões de reais 
de 13 a 16 bilhões de reais de 16 a 20 bilhões de reais de 20 a 25 bilhões de reais de 25 a 30 bilhões de reais acima de 30 bilhões de reais

20) Qual o setor de atuação de sua empresa/organização?

Açúcar e álcool

Administração do estado e da política econômica e social

Aeronáutico

Agricultura, pecuária, produção florestal, pesca e aqüicultura

Água, esgoto, atividades de gestão de resíduos e descontaminação

Alimentação - Catering, bufês e alimentos preparados

Alimentação - Restaurantes

Alimentos - fabricação de produtos alimentícios

Alojamento - Hotéis e similares

Artes, cultura, esportes, recreação e lazer

Atividades jurídicas, de contabilidade e de auditoria

Automóveis e Veículos - Fabricação de veículos automotores, reboques e carrocerias

Autopeças - fabricação de peças e componentes

Bebidas - fabricação

Calçados -fabricação

Comércio atacadista

Comércio varejista

Construção, engenharia, obras de infraestrutura

Consultoria

Cosméticos - fabricação de produtos cosméticos

Educação

Eletroeletrônica

Embalagens

Empreendimentos imobiliários e atividades imobiliárias

Energia elétrica

Farmacêutica - produção de produtos farmoquímicos e farmacêuticos

Financeiro - Atividades de serviços financeiros - Bancos, intermediação, captação, fundos de investimentos, arrendamento mercantil

Gás - distribuição

Higiene e limpeza - fabricação de produtos

Higiene pessoal - fabricação de produtos

Holding multi-atividades

Impressão gráfica e fotografia

Madeira - fabricação de produtos de madeira

Madeira - produção florestal

Máquinas e equipamentos - fabricação de bens de capital

Materiais de construção e decoração

Mecânica

Metalurgia e siderurgia

Mineração - extração de minerais

Organismos internacionais e outras instituições extraterritoriais 
Organização do terceiro setor (OSCIP - Organização da Sociedade Civil de Interesse Público)

Organizações associativas - Associações

Papel e celulose

Pesquisa e desenvolvimento científico

Petróleo e gás - extração, refino, distribuição

Plásticos e borrachas - fabricação

Química e petroquímica - fabricação de produtos

Rádio e televisão

Saúde - Atividades de atenção à saúde humana: hospitais, laboratórios, imagem

Saúde animal - atividades veterinárias

Seguros, resseguros, previdência complementar e planos de saúde

Tecnologia da informação

Telecomunicações

Têxtil, couro e vestuário - fabricação de produtos

Transportes - aéreo, terrestre, aquaviário - passageiros e logística

Transportes - Equipamentos de transporte

Outro

(digitar

ao

lado)

21) Nome de sua empresa/organização (opcional)

22) Seu email (opcional) 